\title{
Assessment of Zero Energy Prefabricated Accessory Dwelling Units in Support of New Zealand Housing Needs
}

\section{Milad Moradibistouni}

A Thesis Submitted to the Victoria University of Wellington in Fulfilment of the Requirements for the Degree of Doctor of Philosophy in Architecture 


\section{Abstract}

\section{Problem statement}

The demographics of New Zealand are changing and the country is getting older. The literature shows the housing needs of older people are different, and that many would prefer to stay in their existing neighbourhood and age in place. In addition to the shortage of houses, low residential densities, the fast growth of land and house costs over income, and an aging population are all current issues in New Zealand housing. Projections also show the shortage of energy resources and environmental pollution will affect the future of housing, as the housing industry is responsible for over one-third of global energy use and $\mathrm{CO}_{2}$ emissions.

\section{Aim of the research}

This thesis aims to design and evaluate the practicality and efficiency of a prefabricated Accessory Dwelling Units (ADU) as a partial response to New Zealand housing needs. Prefabrication was selected as the method of construction as it has been claimed to be more efficient in terms of energy and material use, as well as leading to a shorter construction time and lower environmental impacts. The use of ADUs could increase residential density and add to the housing stock by using existing developed land and infrastructure. ADUs also offer smaller houses within the existing social context, which the literature suggests is the main housing requirement of older people. As a result, the ADU in this research was designed to suit older residents, whilst recognising that it would also be suitable for small households of all ages.

\section{Methodology}

This research used design as a tool with which to explore the potential of prefabricated ADUs as a contribution to New Zealand housing needs. The design was then tested against housing needs by using Life Cycle Analysis (LCA). This part of the research was conducted in the three phases of life-cycle energy, life-cycle cost, and life cycle $\mathrm{CO}_{2}$ emissions of the ADU as designed.

\section{Results}

While the transport limitations pushed the design to be narrow (the maximum allowed load width was $2.55 \mathrm{~m}$ ), the Lifemark accessibility standard asked for doors, corridors, and spaces wide enough to ease the movement of disabled people. Despite these difficulties, it was possible to design an ADU which could be manufactured in New Zealand and transported 
anywhere in the country without any need for over-dimension load permissions. However, the analysis in the last phase, looking at the ADU during its life span, showed there was no substantial difference between its performance and that traditionally made houses. The results of the analysis suggest that, despite the importance of the construction method, the building energy efficiency, $\mathrm{CO}_{2}$ emissions and cost, the environmental impact of a house is more dependent on the choice of materials than the method of making it.

\section{Future research}

The results suggest the importance of further investigation into the choice of materials used to make residential buildings and the effect such choices have on life-cycle impact. There is also a need to seek feedback on the ADU as designed from both potential users and potential manufacturers. 


\section{Acknowledgements}

I would like to take this opportunity to extend my sincere gratitude and appreciation to all those who have supported me over the course of my PhD study.

First and foremost, I would like to extend my sincere gratitude to my supervisor, Professor Brenda Vale and say thank you for her dedicated advice, inspiration, encouragement and continuous support throughout my PhD. Her enthusiasm, integral approach to my research and her mission for achieving high-quality work, has made a deep impression on me. Working and learning from Professor Brenda Vale was the best thing that happened to me during my PhD. No matter whether it was weekend or holiday, Professor Brenda Vale was always on the other side of the line, ready to give me her unwavering and unlimited support and guidance. I owe her much gratitude for having shown me this way of doing research and more importantly the way to live as a better person.

I would also like to say thank you to my supervisor, Doctor Nigel Isaacs, for his constant guidance, availability, facilitating all the requirements and giving technical advice throughout my PhD, which has always kept me going ahead. Having Doctor Nigel Isaacs always ready to help, made me more confident in doing my PhD. I feel privileged to be associated with a person like him during my life.

A very special thanks to my family. Words cannot express how grateful I am to my mother, father, brother, and sister-in-law for all of the sacrifices that they have made for me. Having my family supporting me all the time made the journey far more pleasant.

I also would like to say thank you to my great friend and colleague, Doctor Iman Khajehzadeh who helped me at a very special time, when I needed help. It was impossible to do this without his help, support, and guidance.

Finally I acknowledge the financial assistance I have received through the John Fitzgerald Memorial Award, the technical help from Lifetime Design Ltd, and the support of members of the Faculty of Architecture and Design of Victoria University of Wellington, especially Professor Marc Aurel Schnabel, Anne Keogh, Sarah Wilson and Stewart Milne. 


\section{Contents}

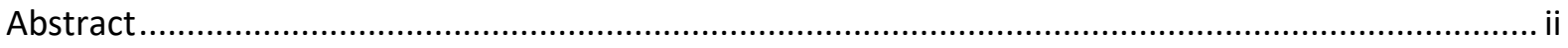

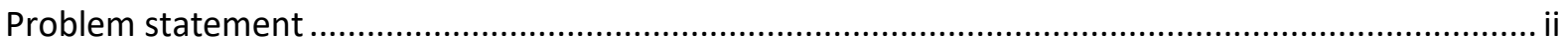

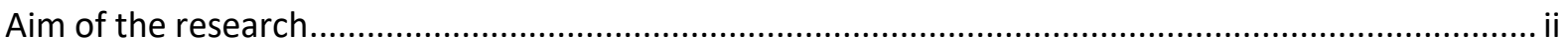

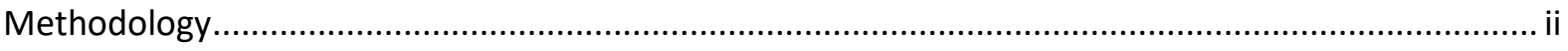

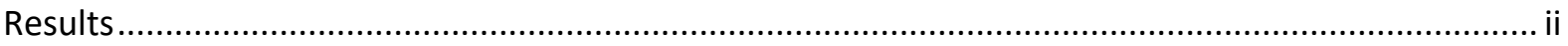

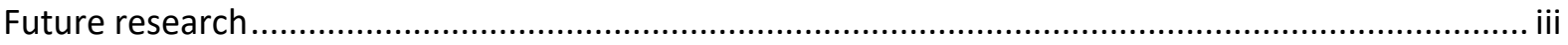

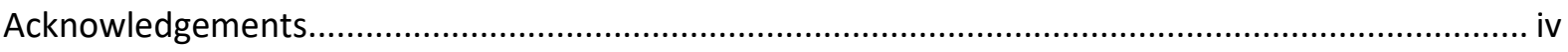

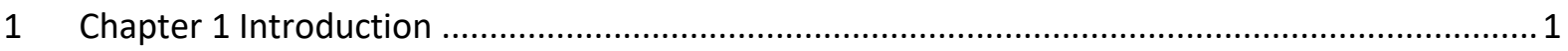

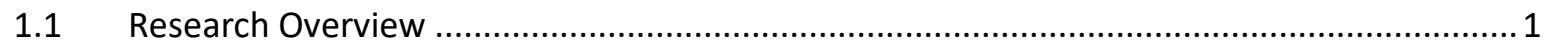

1.1.1 Shortage of Affordable Houses ..................................................................... 2

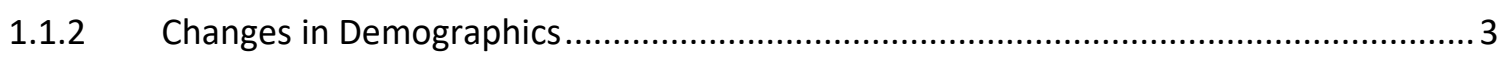

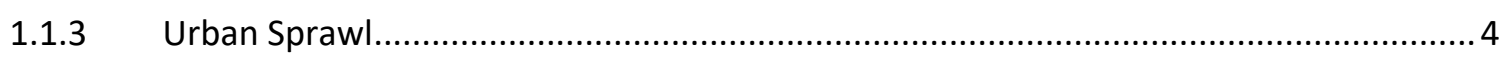

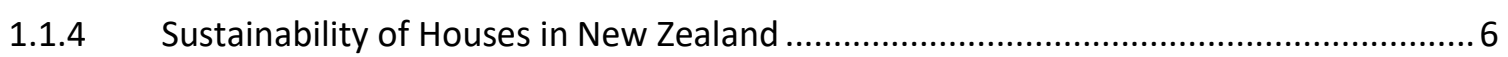

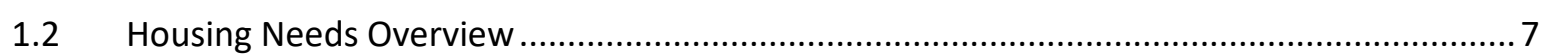

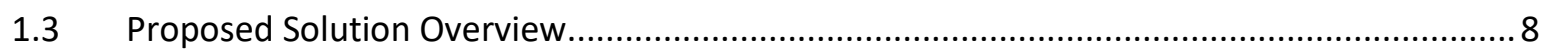

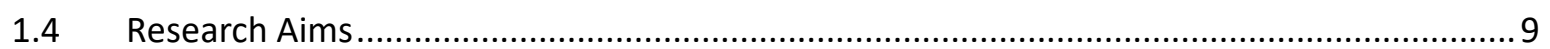

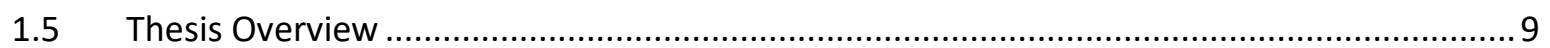

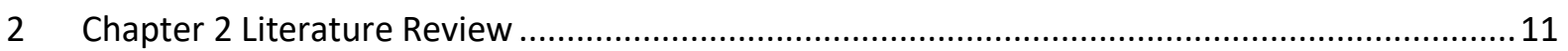

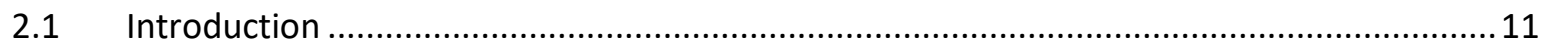

2.2 Prefabrication ............................................................................................. 11

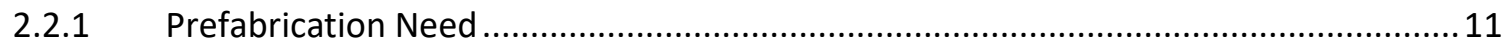

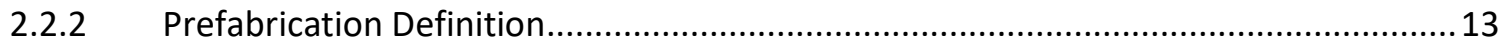

2.2.3 Different Types of Prefabrication.................................................................. 14

2.2.4 A Brief History of Prefabrication .................................................................... 21

2.2.5 Potential Benefits of Prefabrication................................................................... 41

2.2.6 Potential Weaknesses of Prefabrication........................................................... 42

2.2.7 Uptake of Prefabrication in New Zealand......................................................... 46

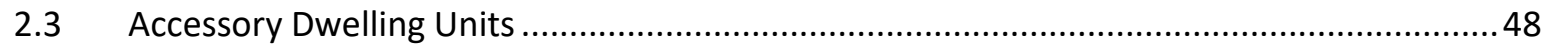

2.3.1 Accessory Dwelling Unit Definition................................................................ 49

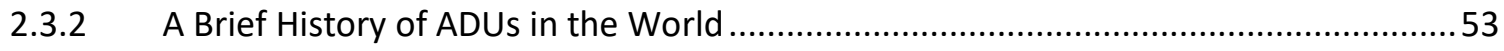

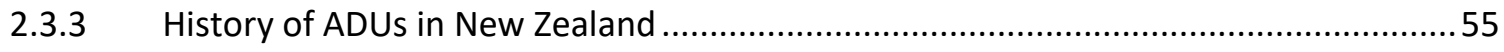

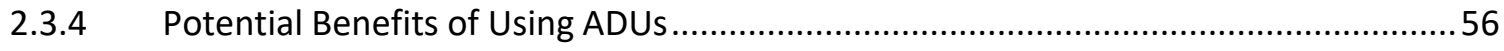

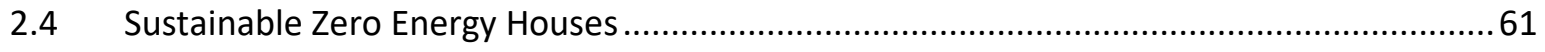

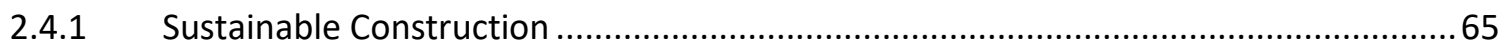




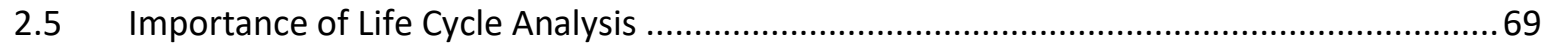

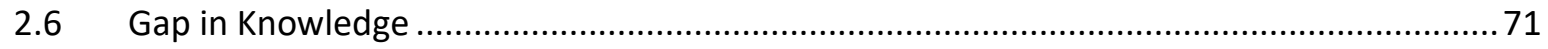

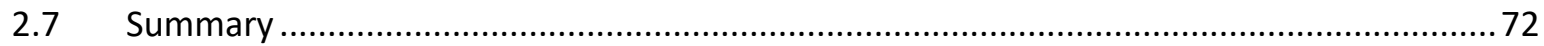

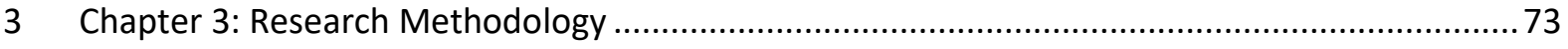

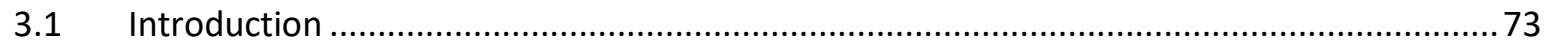

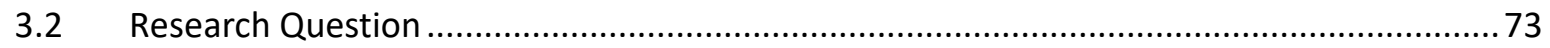

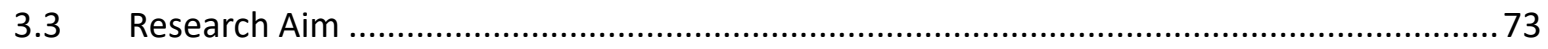

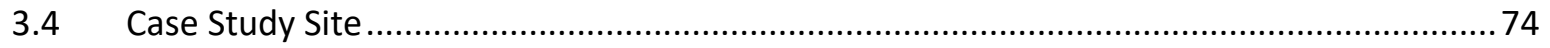

3.5 Methodology

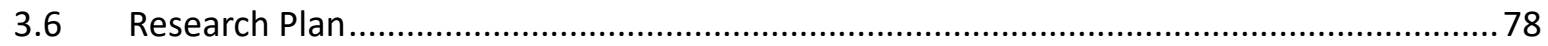

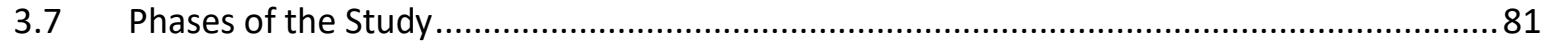

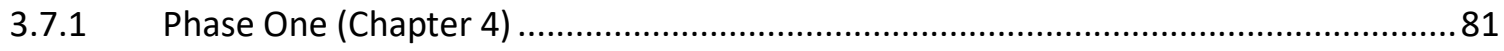

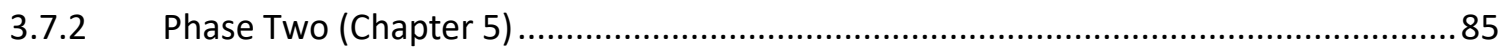

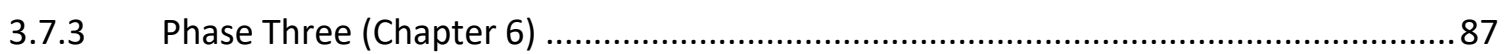

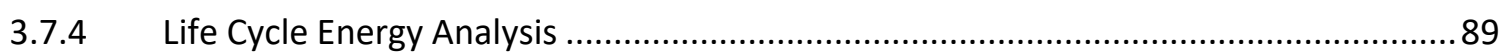

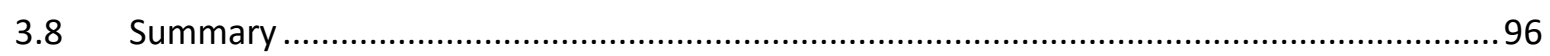

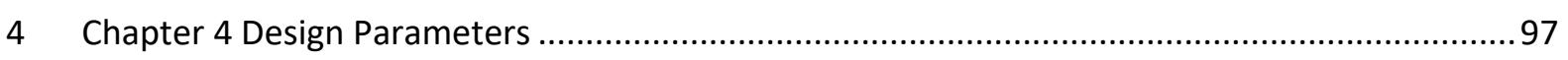

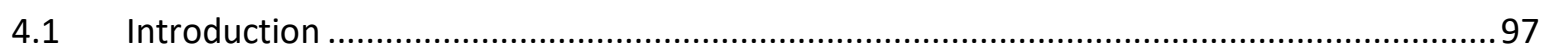

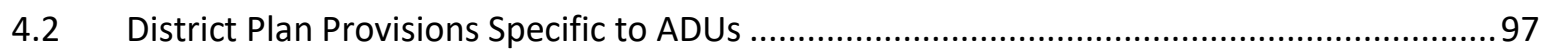

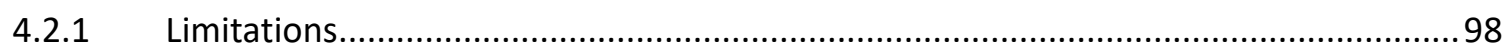

4.3 Review of Manufacturers of Prefabrication in New Zealand ............................................. 107

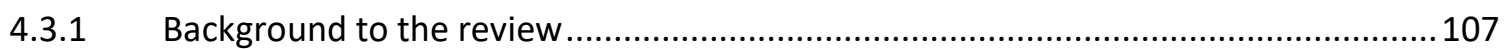

4.3.2 Location and Field of Expertise of Manufacturers ..................................................... 107

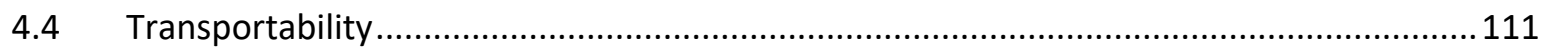

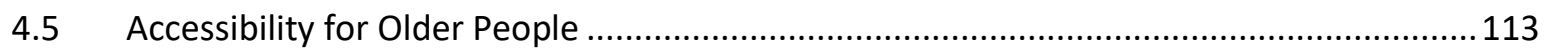

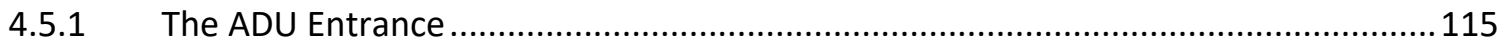

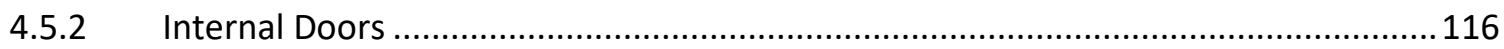

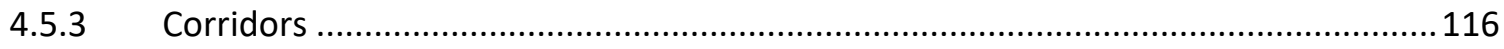

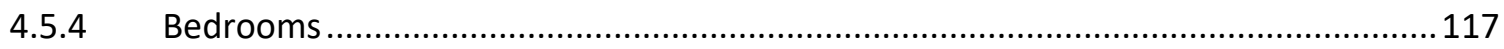

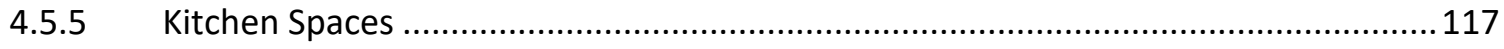

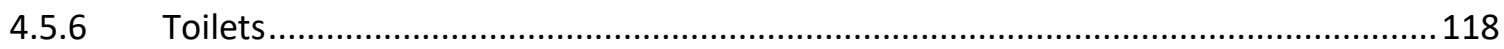

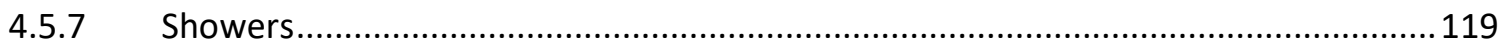

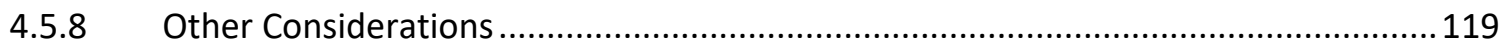

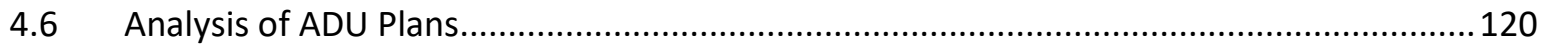

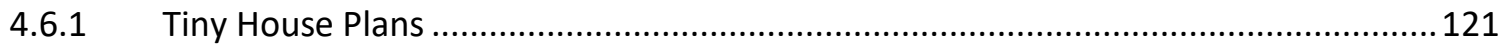

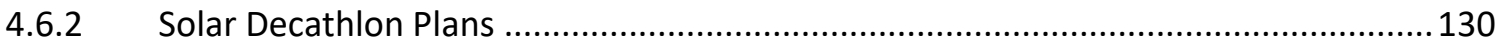




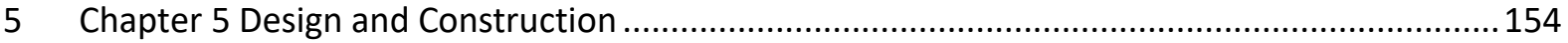

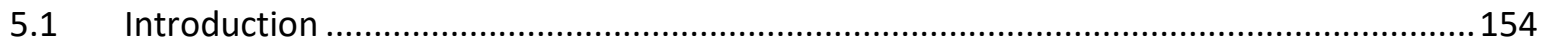

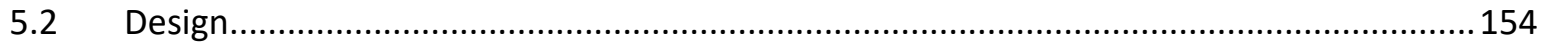

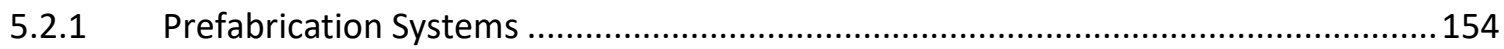

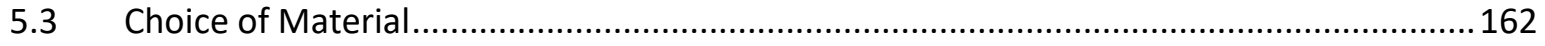

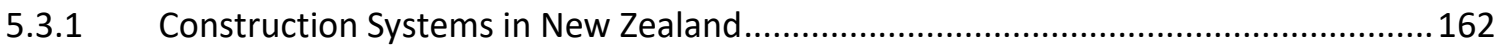

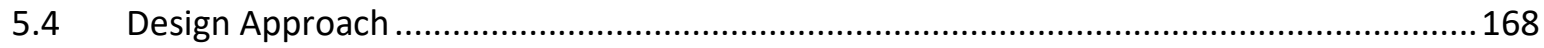

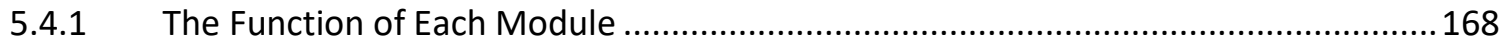

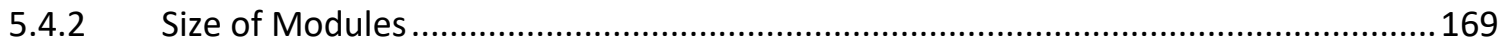

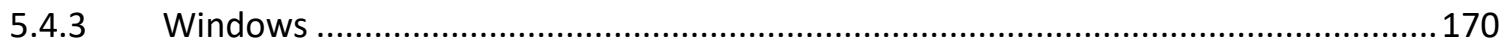

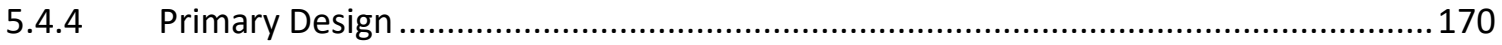

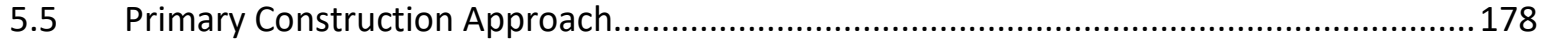

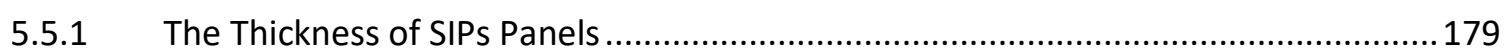

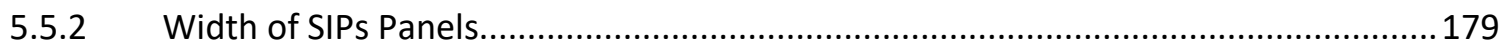

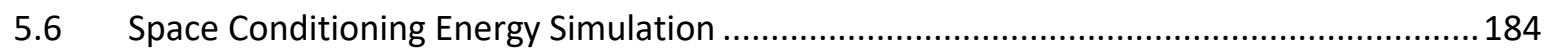

5.6.1 The First Round of Simulations (most energy efficient construction scenario)...........187

5.6.2 The Second Round of Simulation (most effective level of thermal mass) ..................189

5.6.3 The Third Round of Simulations (most effective size and placement of windows)....190

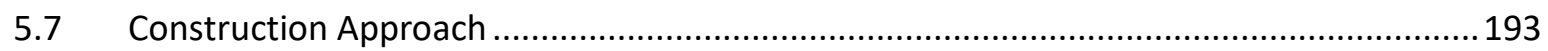

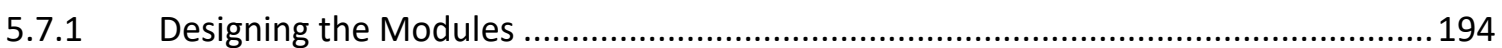

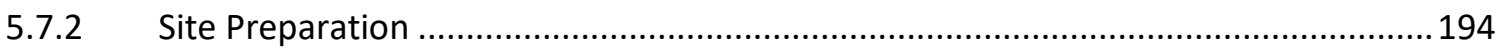

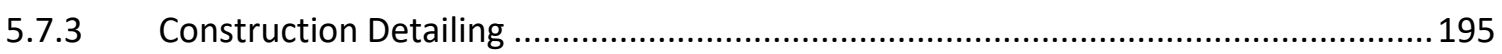

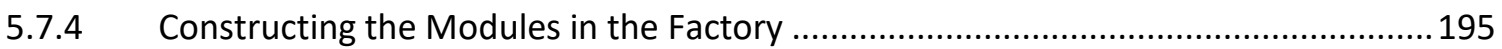

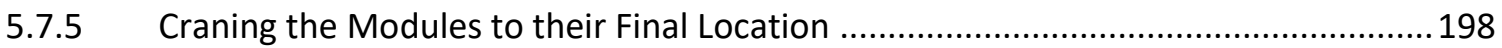

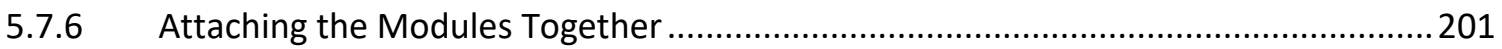

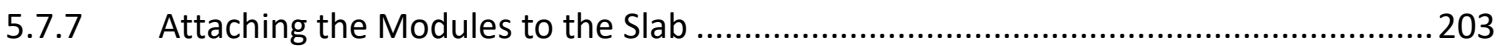

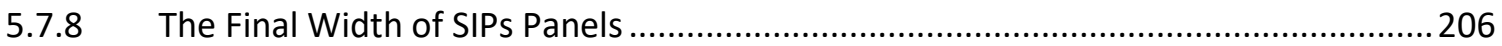

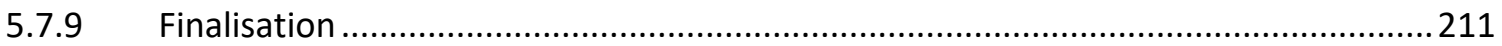

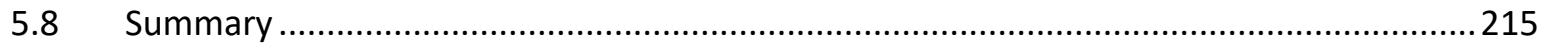

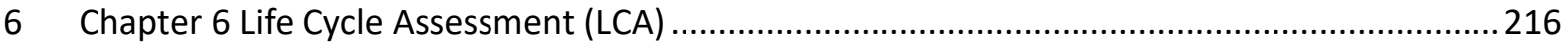

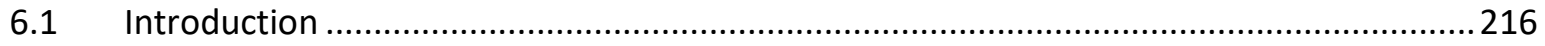

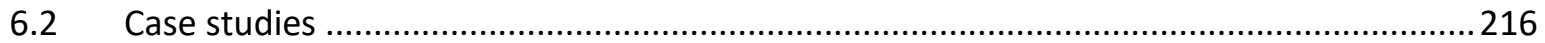

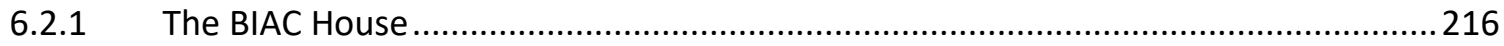

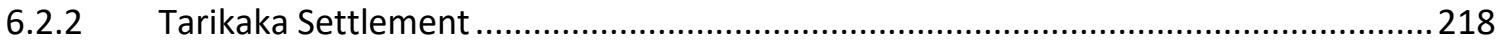

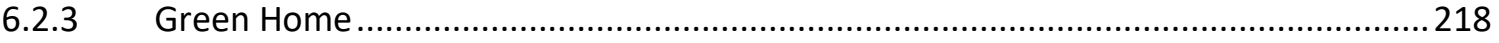


6.2.4 Hockerton House .............................................................................. 219

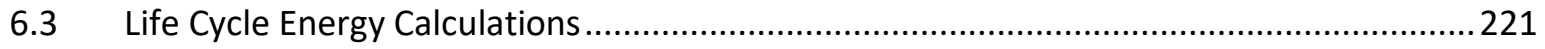

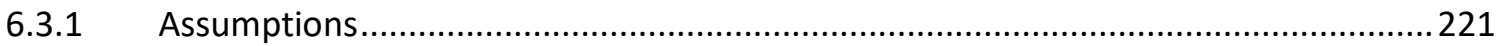

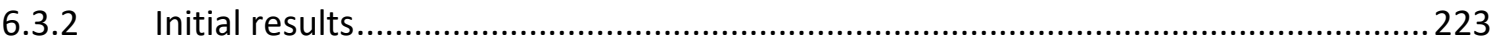

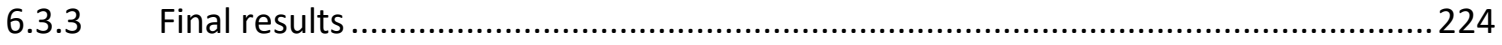

6.3.4 Life Cycle Energy Analysis of the ADU .............................................................231

6.3.5 Life Cycle Energy of the ADU Made of Different Insulating Materials......................232

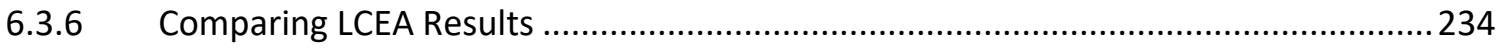

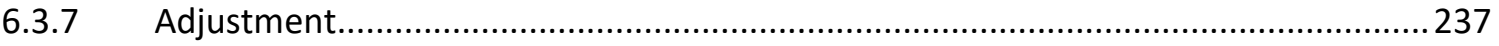

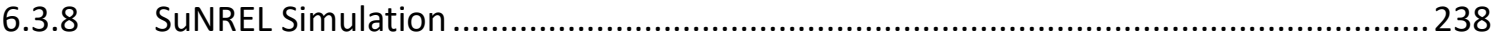

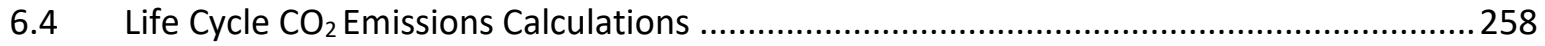

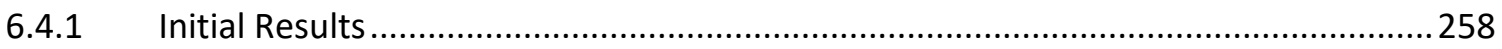

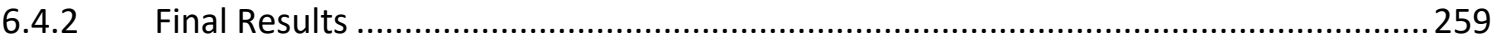

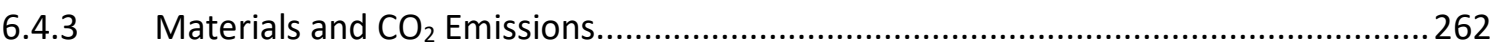

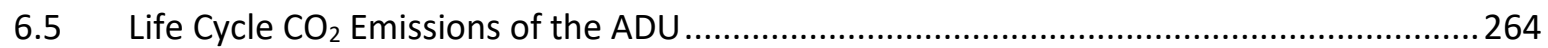

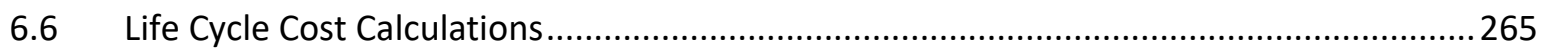

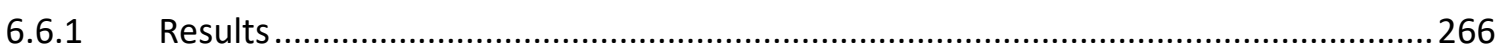

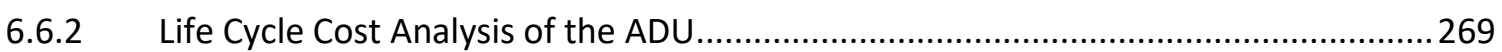

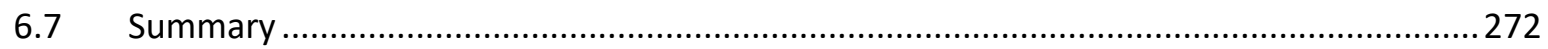

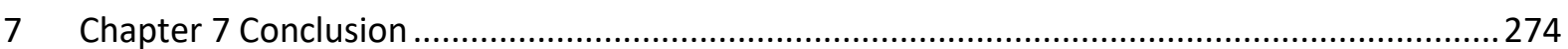

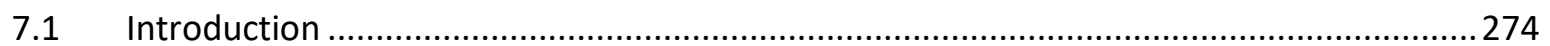

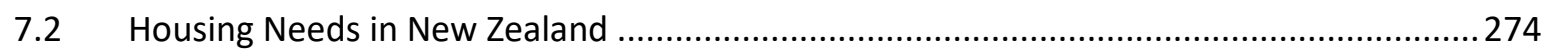

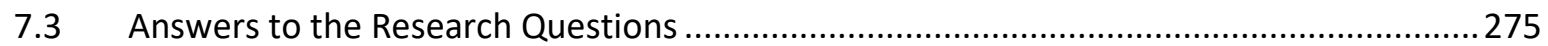

7.3.1 Factory Built, Transportable ADU ............................................................... 275

7.3.2 Is the Prefabricated ADU More Efficient than a Conventional House? ....................277

7.3.3 An Age-Friendly, Zero Energy Prefabricated ADU ................................................278

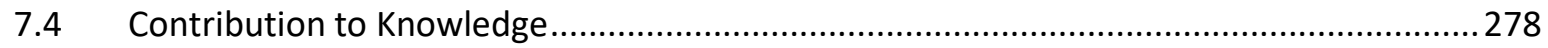

7.4.1 Research Implication .......................................................................... 278

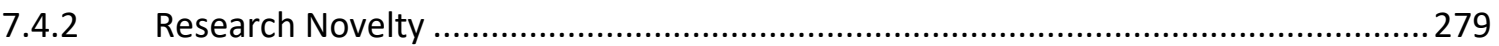

7.5 Limitations and Further Research .............................................................279

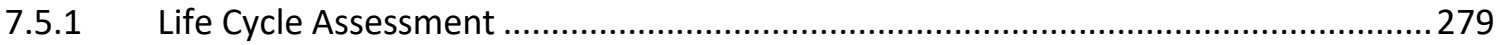

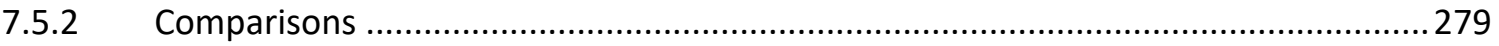

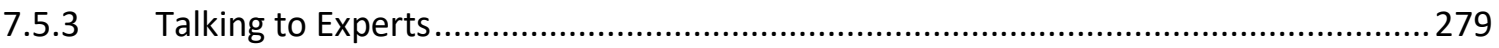

7.5.4 Potential Benefits of Prefabrication............................................................280

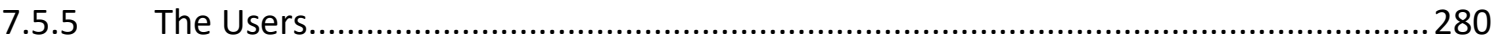

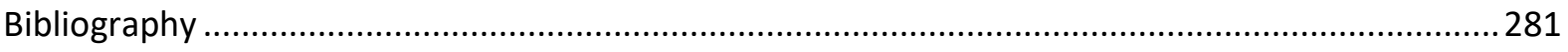


Appendix A: District Plan Provisions Specific to ADUs.... 310

Appendix B: Manufacturers of Prefabrication in New Zealand ... 317

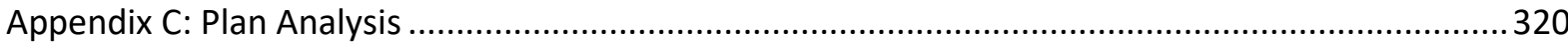

Appendix D: Construction Details. 


\section{Figures}

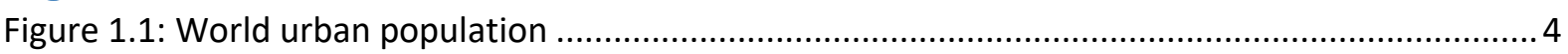

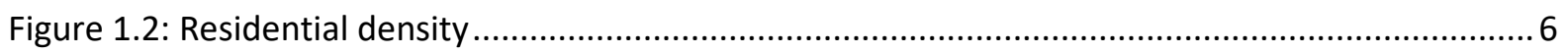

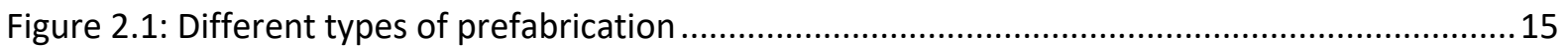

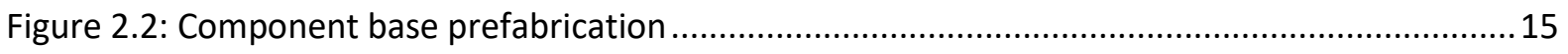

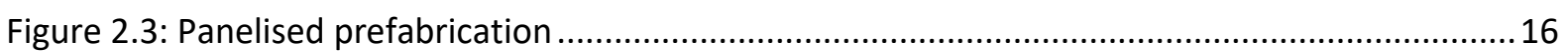

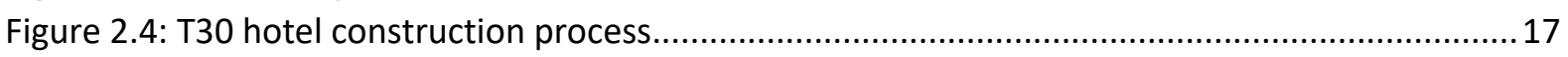

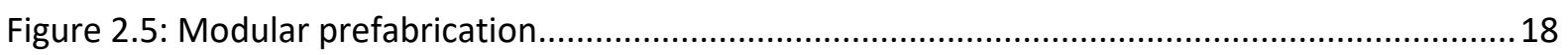

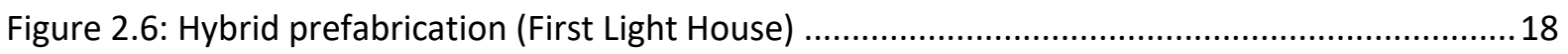

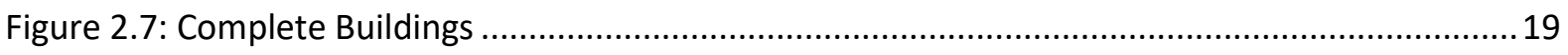

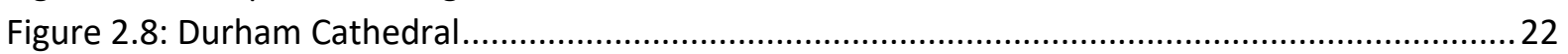

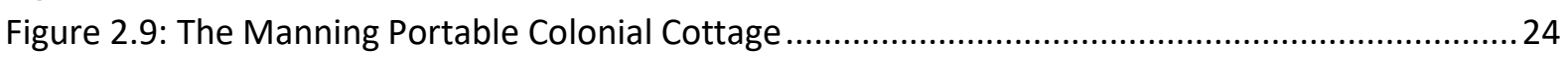

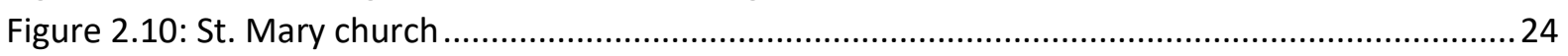

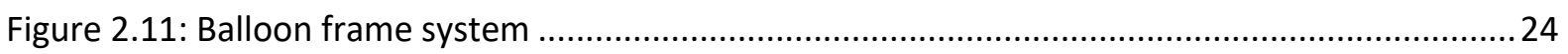

Figure 2.12: Naylor's advertisement in Sherwood's Emigrant's Guide ...........................................25

Figure 2.13: Aladdin Readi-Cut House and Sears, Roebuck \& Co catalogue ......................................... 26

Figure 2.14: Advertisement for model no.146. Sears, Roebuck \& Co ............................................... 27

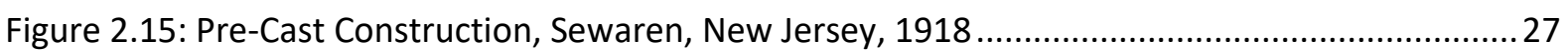

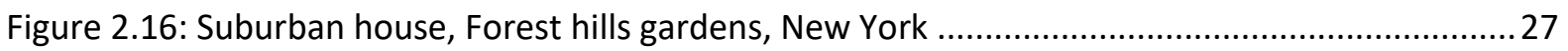

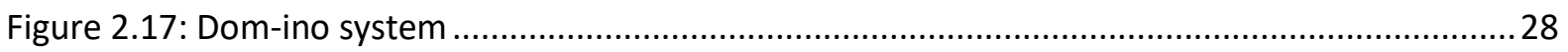

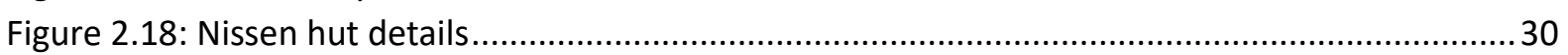

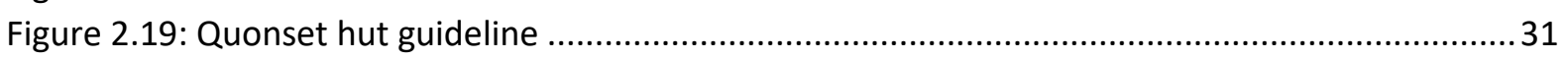

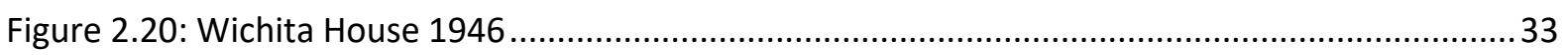

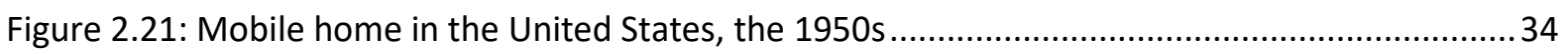

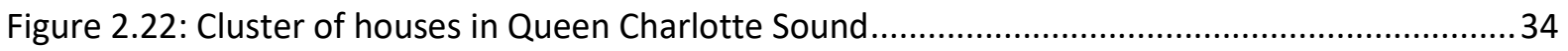

Figure 2.23: Typical railway house elevation, plan AB 1123, Factory Cut .......................................... 36

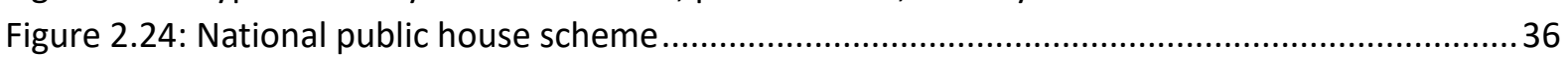

Figure 2.25: National Hydro scheme in Otematata .................................................................... 37

Figure 2.26: Jo La Grouw Senior's home being built in 1954 in Rotorua, New Zealand ......................... 38

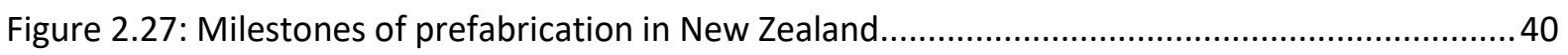

Figure 2.28: Importance of component choice (Customer rating - Germany) ...................................... 45

Figure 2.29: GHG emissions using four different construction approaches....................................... 46

Figure 2.30: Percentage of residential buildings using the prefabrication method ............................ 47

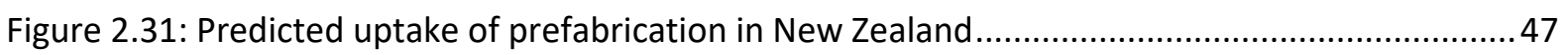

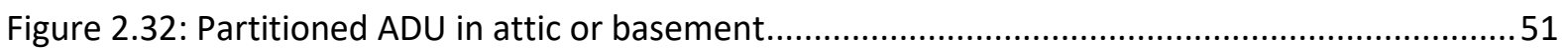

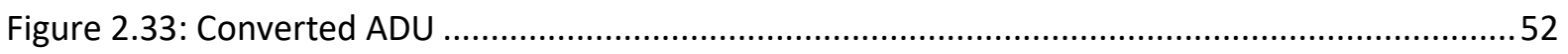

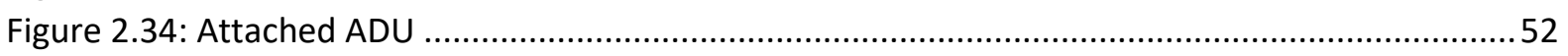

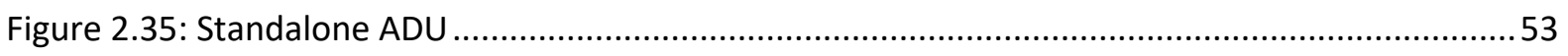

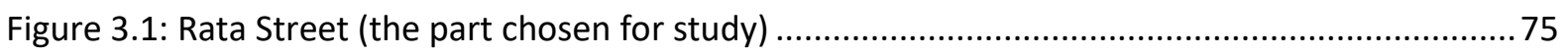

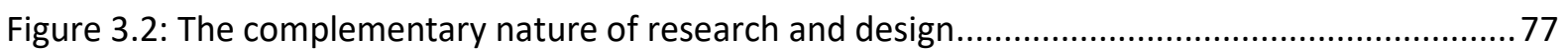

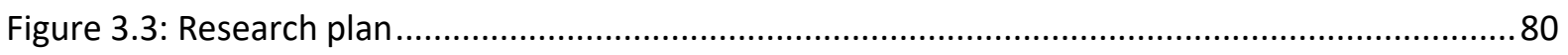

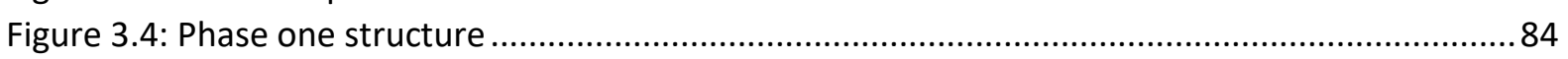

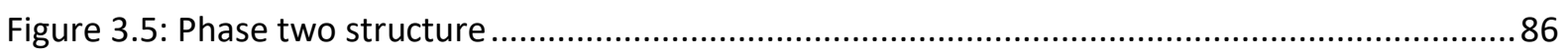

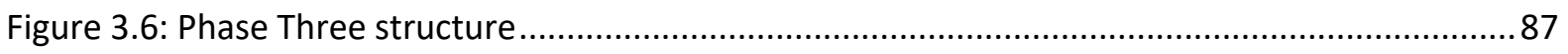

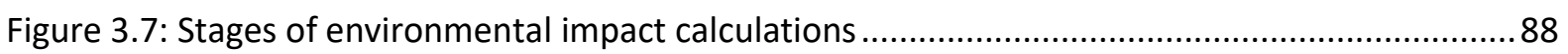

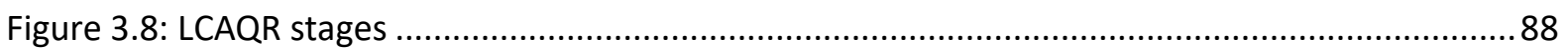


Figure 4.1: Manufacturers and type of prefabrication in each region .........................................110

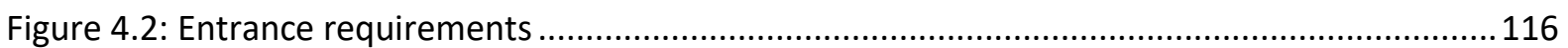

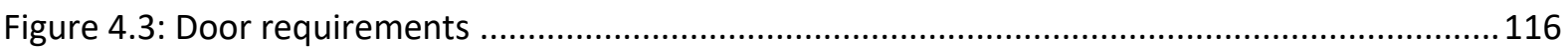

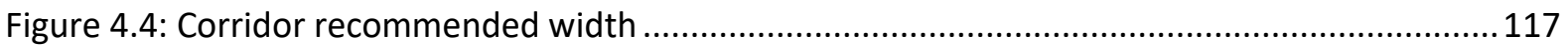

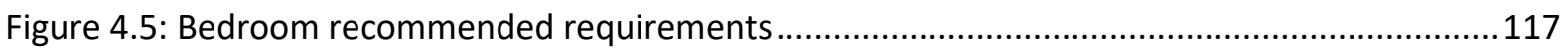

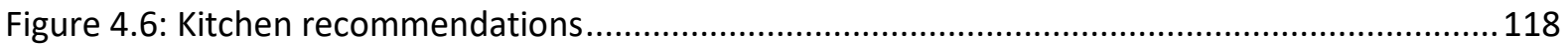

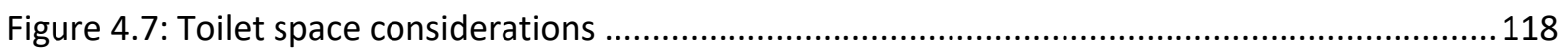

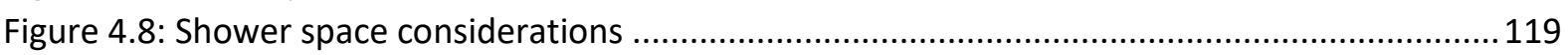

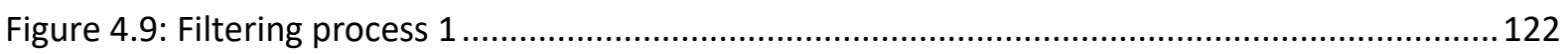

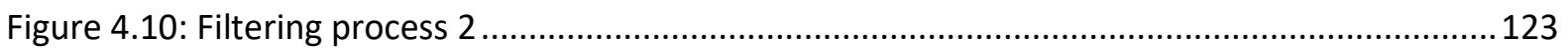

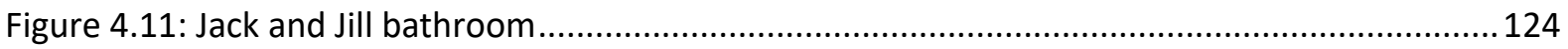

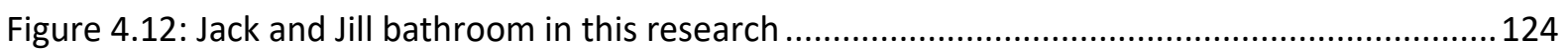

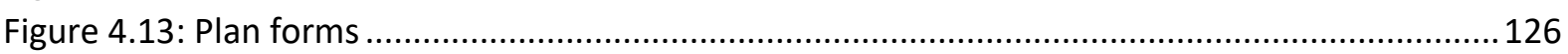

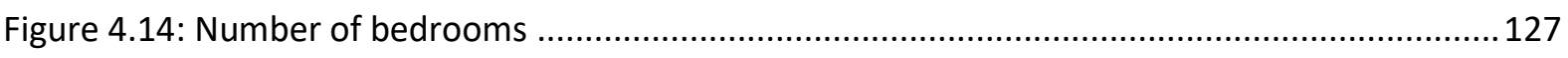

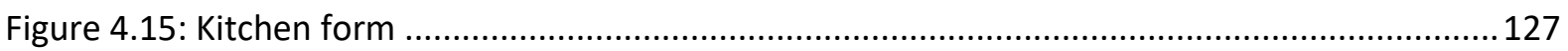

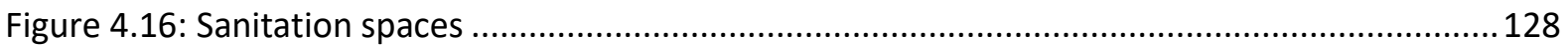

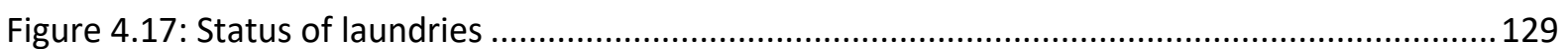

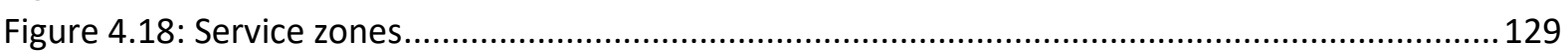

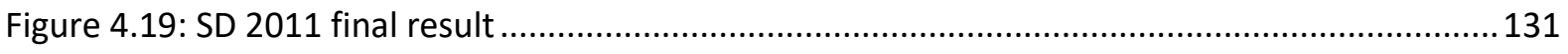

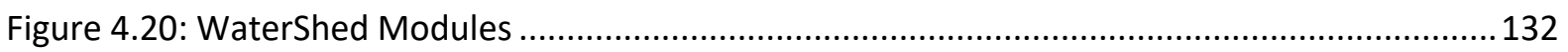

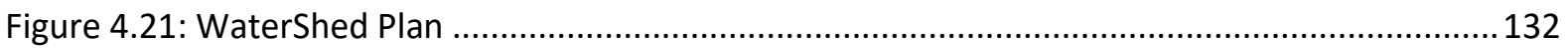

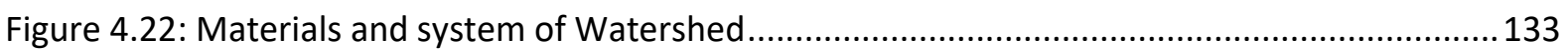

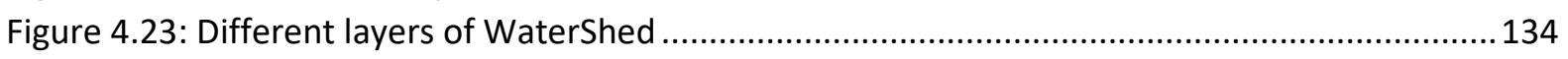

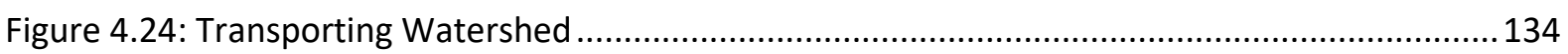

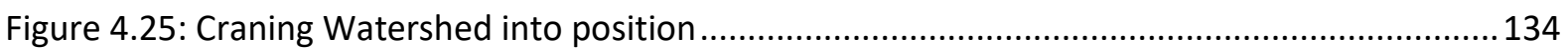

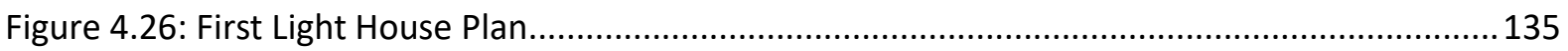

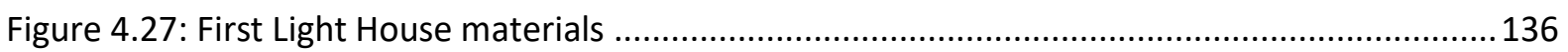

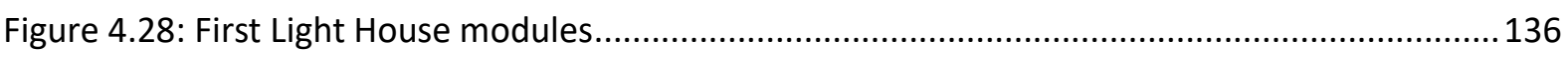

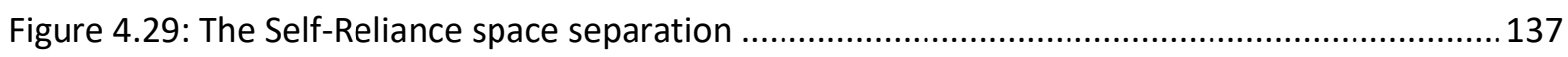

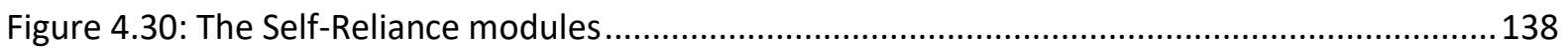

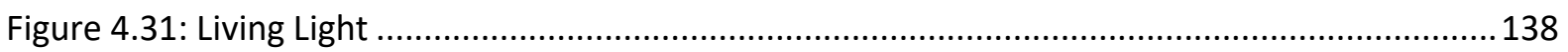

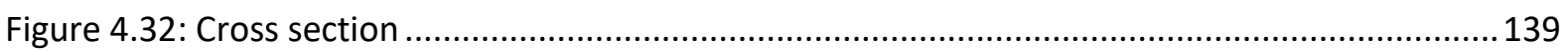

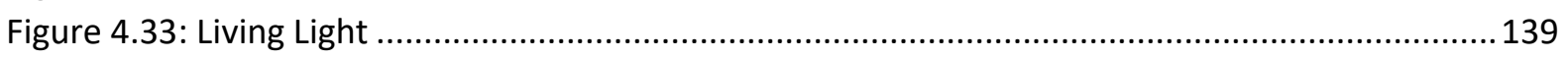

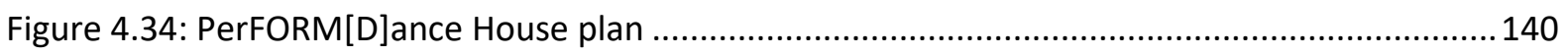

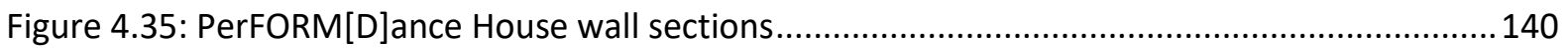

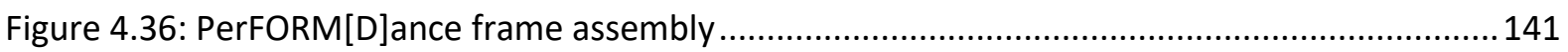

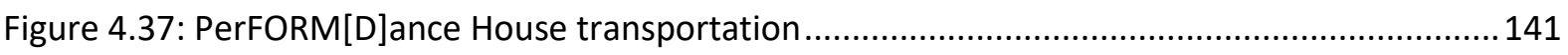

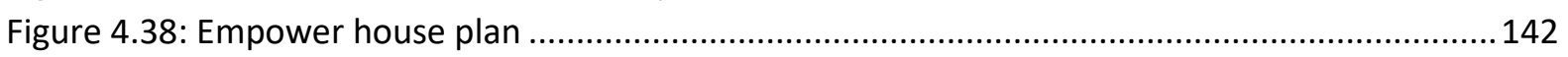

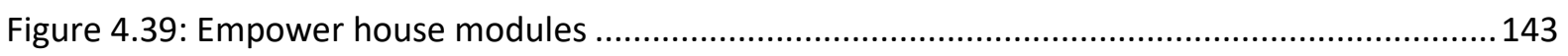

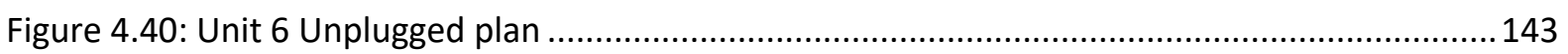

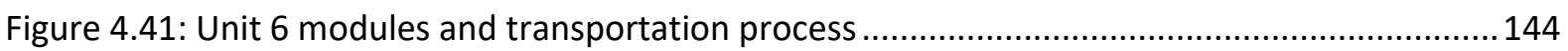

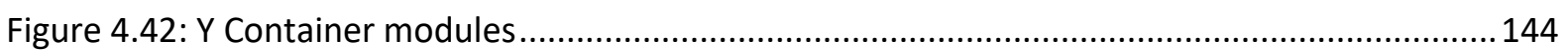

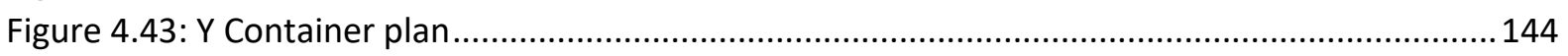

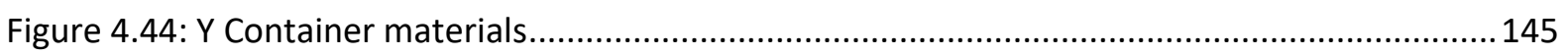

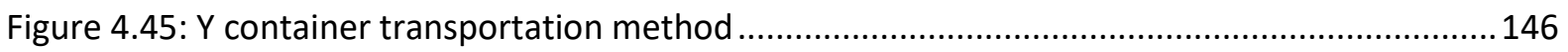

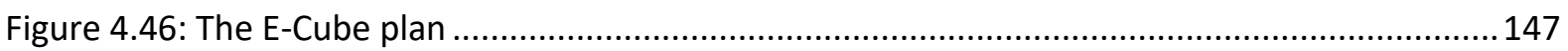

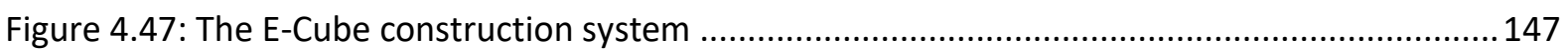

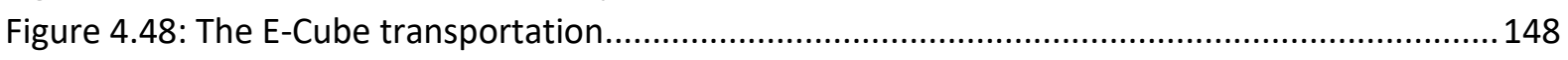


Figure 4.49: Solar Roof Pod plan

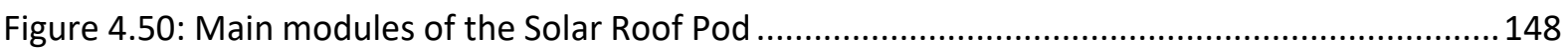

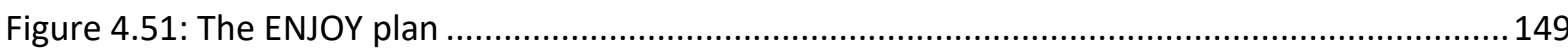

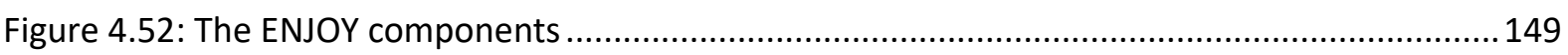

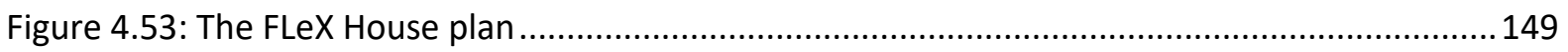

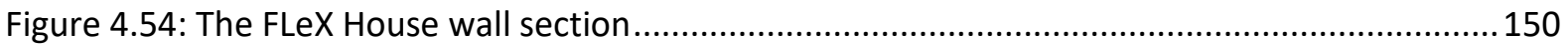

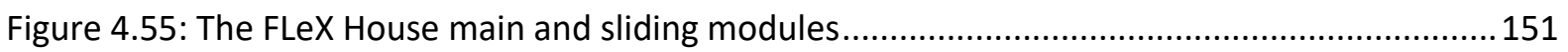

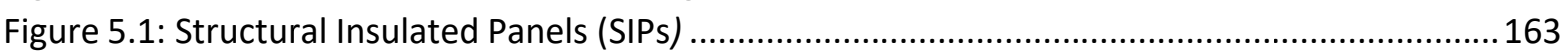

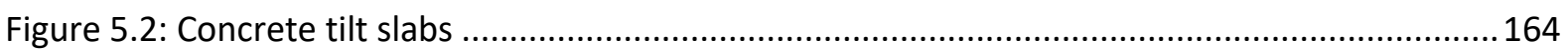

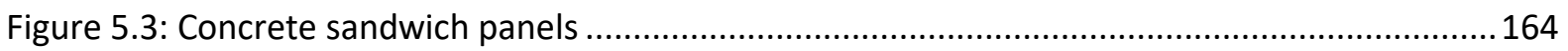

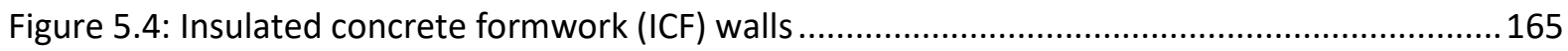

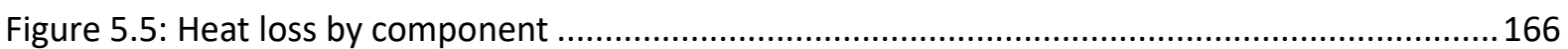

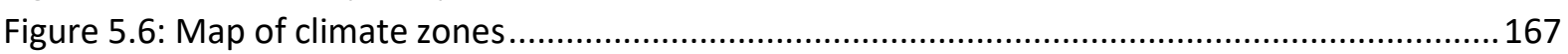

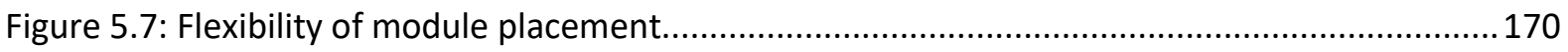

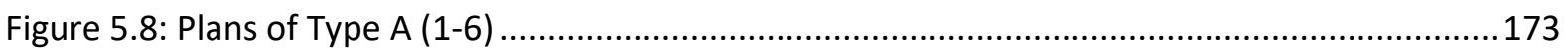

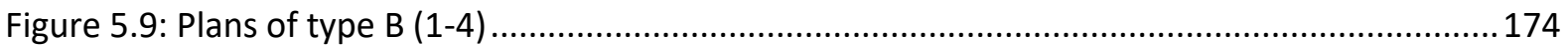

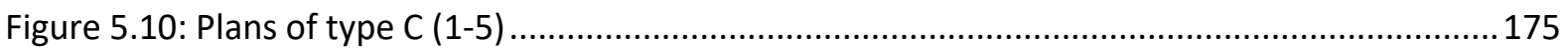

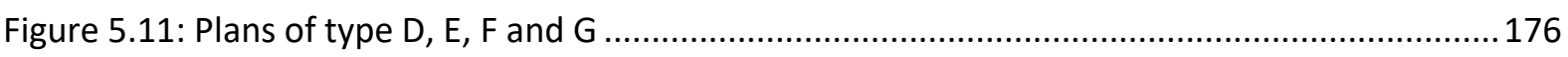

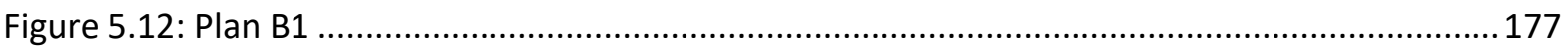

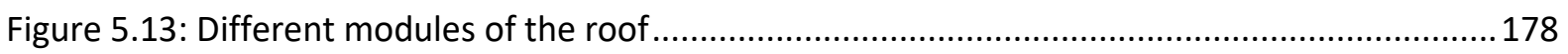

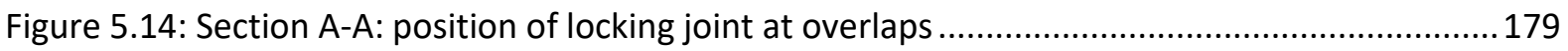

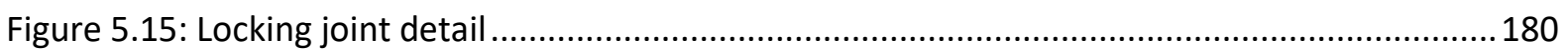

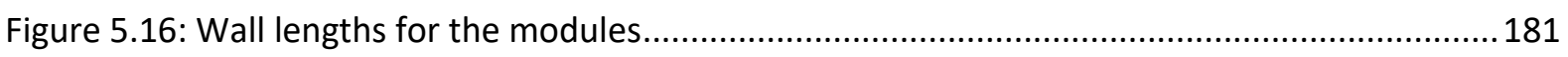

Figure 5.17: placement of panels in each module................................................................... 181

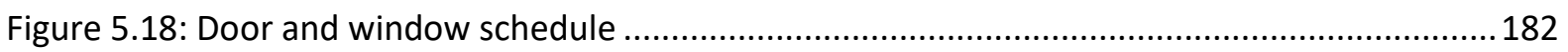

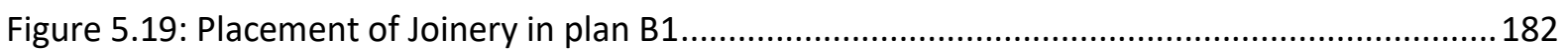

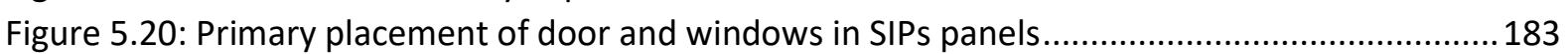

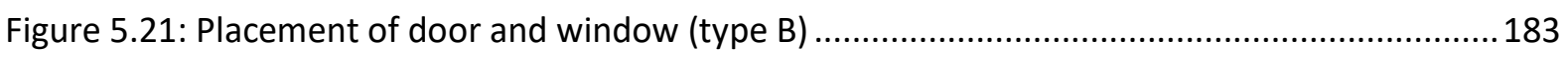

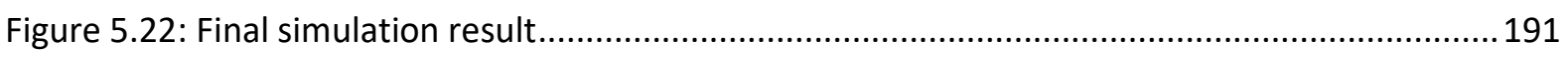

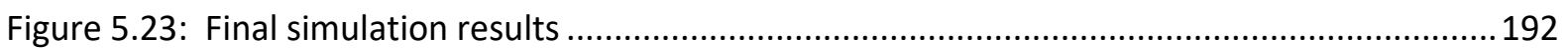

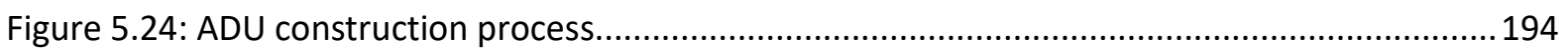

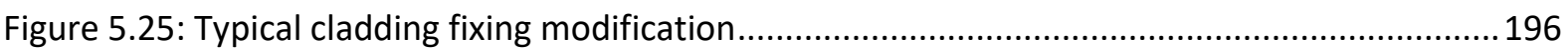

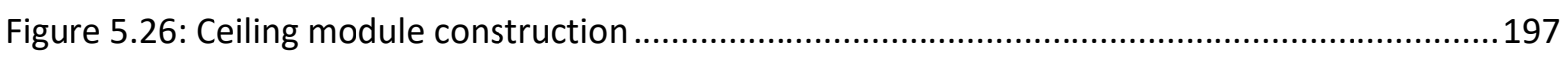

Figure 5.27: Ceiling modules arrangement............................................................................... 197

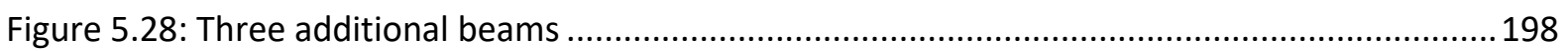

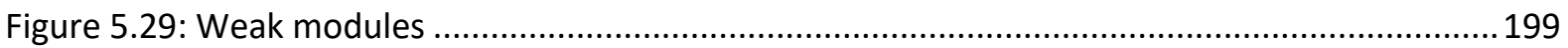

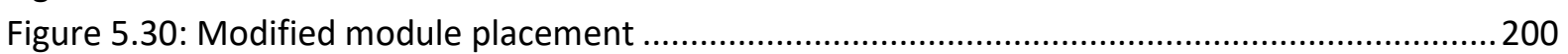

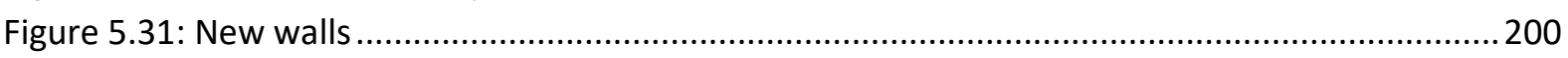

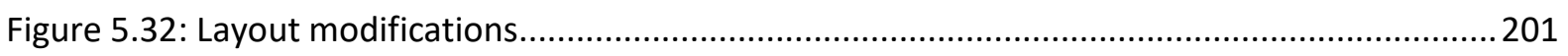

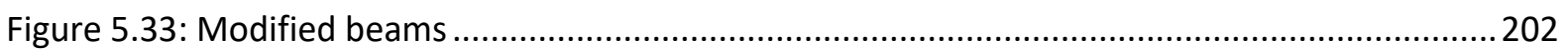

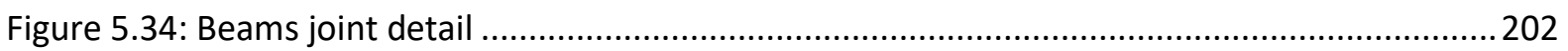

Figure 5.35: Bottom plate detail (detail does not show the external cladding-see Appendix D).......203

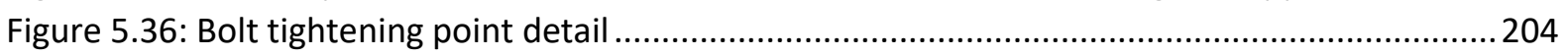

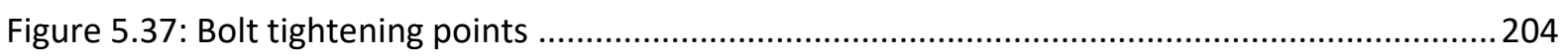

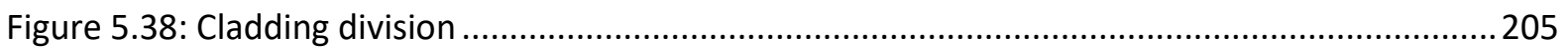

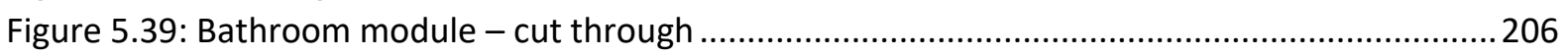

Figure 5.40: Concrete slab showing the detail in the shower area ..................................................206

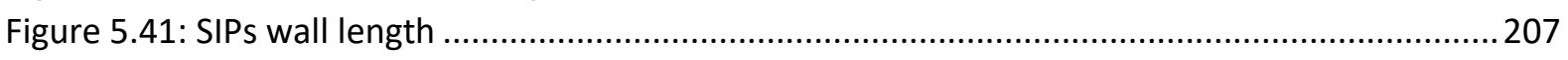


Figure 5.42: Openings placement.....

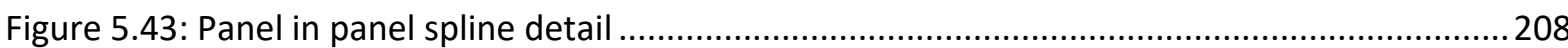

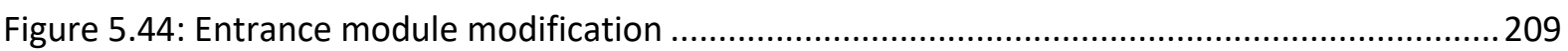

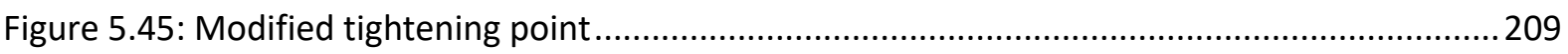

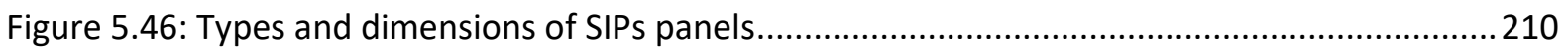

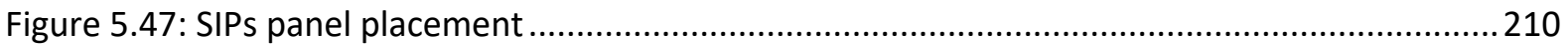

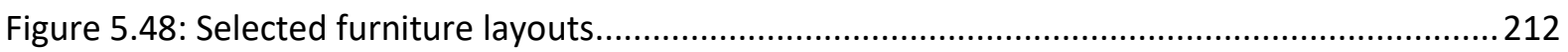

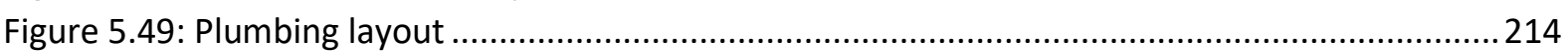

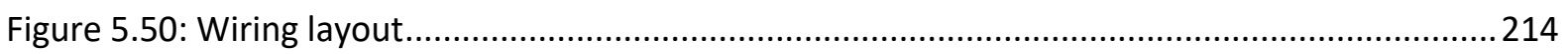

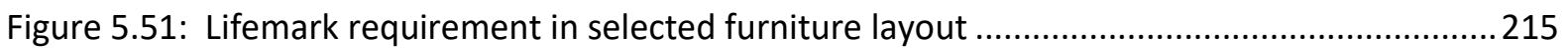

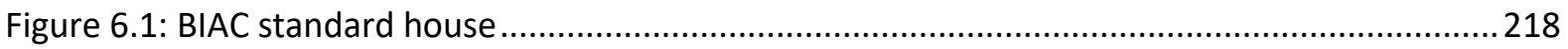

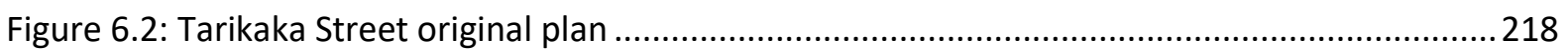

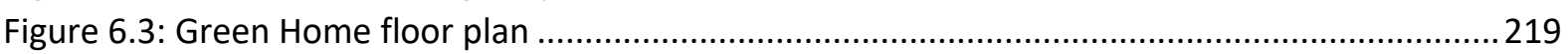

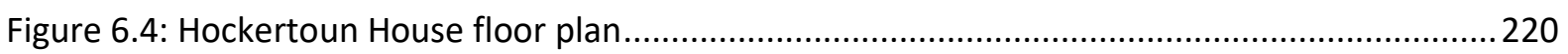

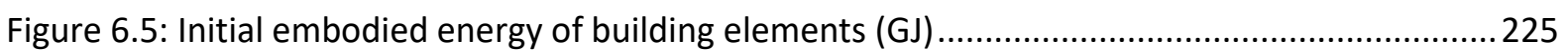

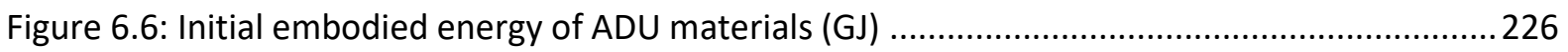

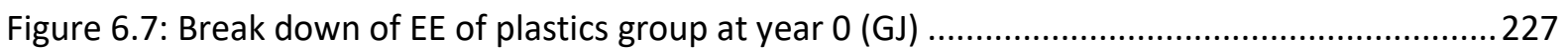

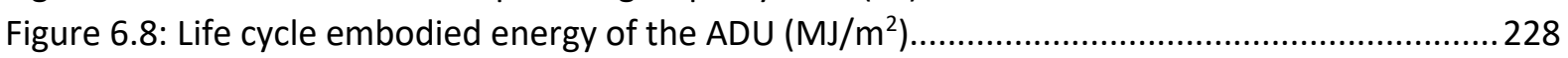

Figure 6.9: Breakdown of life cycle embodied energy for initial construction, repair and maintenance

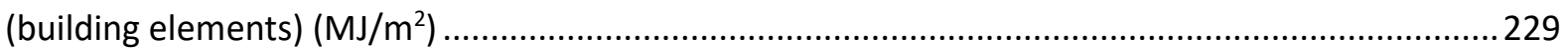

Figure 6.10: Breakdown of life cycle embodied energy for initial construction, repair and

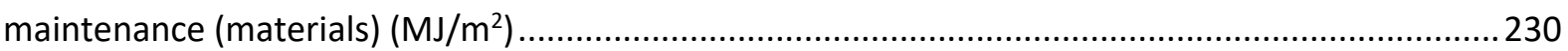

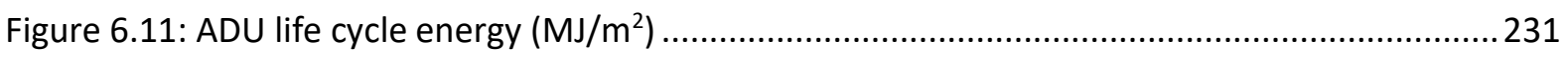

Figure 6.12: Life cycle energy of the ADU using different insulation materials $\left(\mathrm{MJ} / \mathrm{m}^{2}\right)$.................233

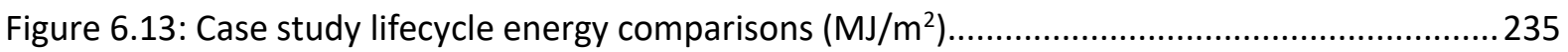

Figure 6.14: Differences between ambient temperature and internal temperature for the four

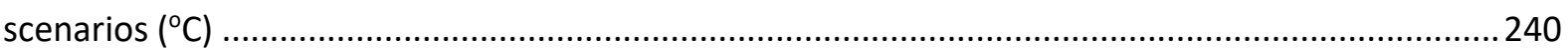

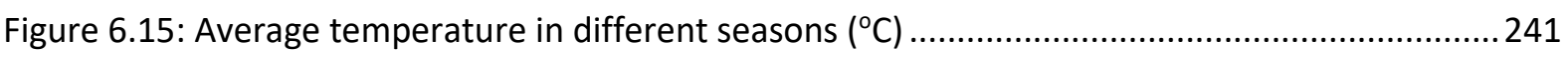

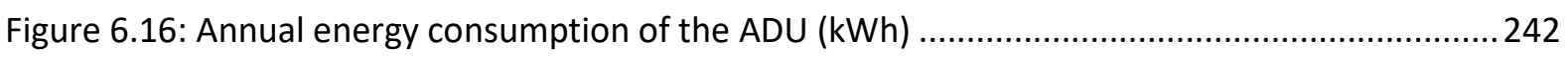

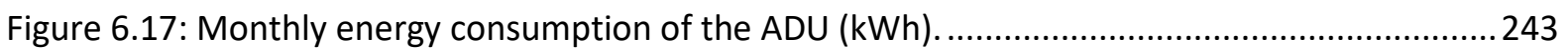

Figure 6.18: Differences between ambient temperature and internal temperature in different

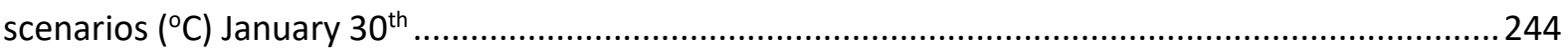

Figure 6.19: Differences between ambient temperature and internal temperature in different

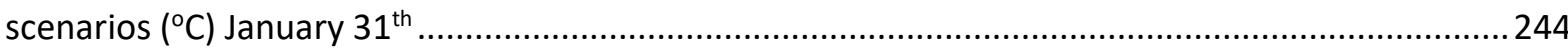

Figure 6.20: Differences between ambient temperature and internal temperature in different

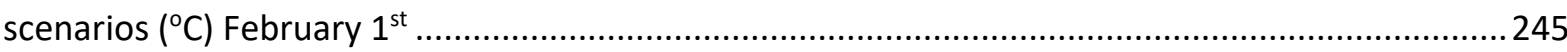

Figure 6.21: Differences between ambient temperature and internal temperature in different

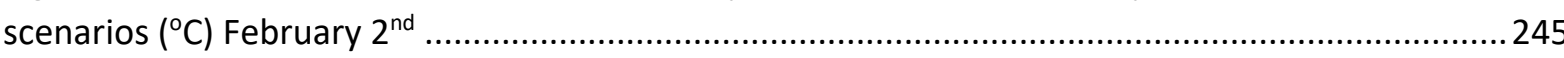

Figure 6.22: Differences between ambient temperature and internal temperature in different

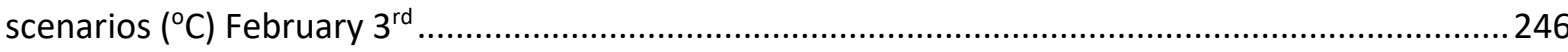

Figure 6.23: Differences between ambient temperature and internal temperature in different scenarios $\left({ }^{\circ} \mathrm{C}\right)$ February $4^{\text {th }}$

Figure 6.24: Differences between ambient temperature and internal temperature in different

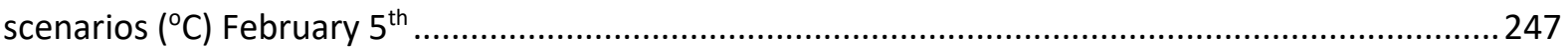

Figure 6.25: ADU internal monthly average temperatures in three New Zealand cities $\left({ }^{\circ} \mathrm{C}\right)$.............251

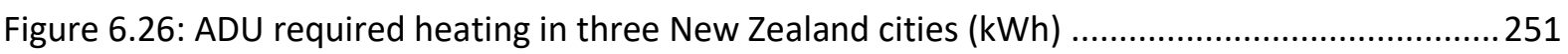

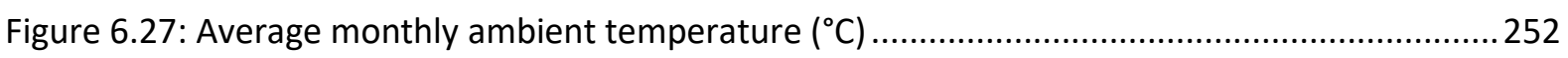

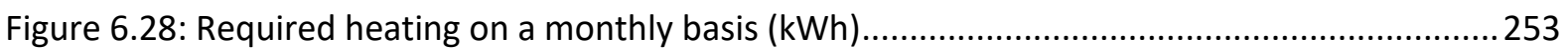


Figure 6.29: The ADU plan

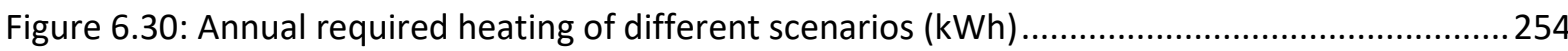

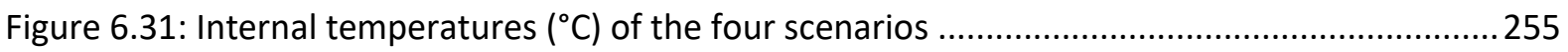

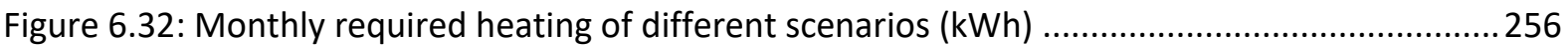

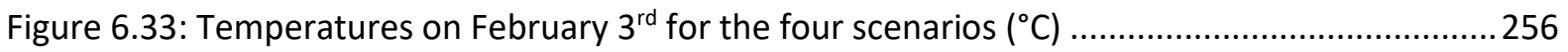

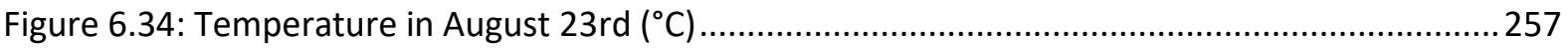

Figure 6.35: Elemental life cycle $\mathrm{CO}_{2}$ emissions of the ADU compared to the BIAC House ...............259

Figure 6.36: Breakdown of life cycle embodied $\mathrm{CO}_{2}$ emissions of the ADU ......................................263

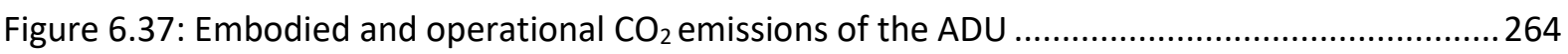

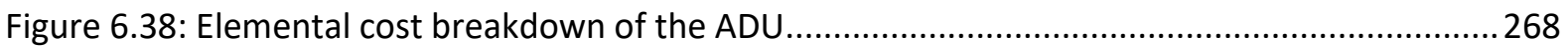

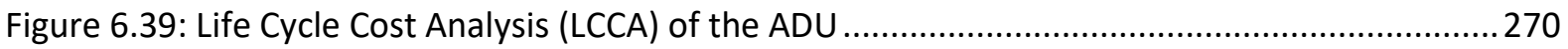




\section{Tables}

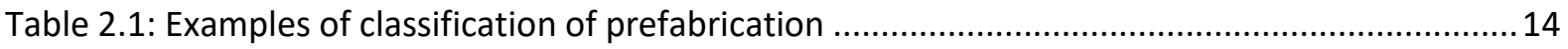

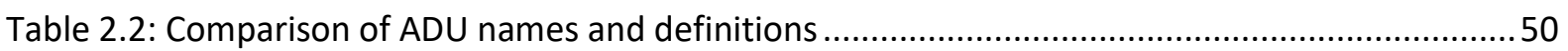

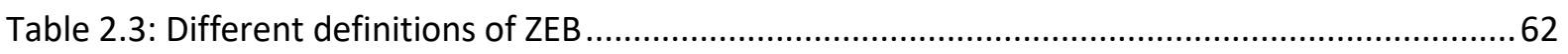

Table 2.4: Review of factors affecting the sustainability of construction ...........................................65

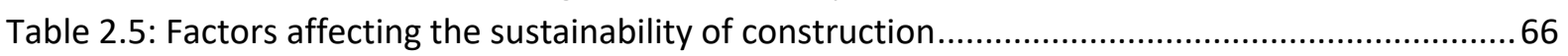

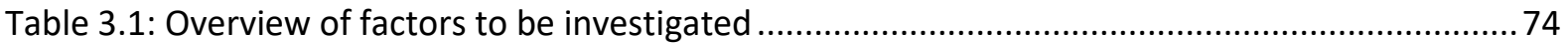

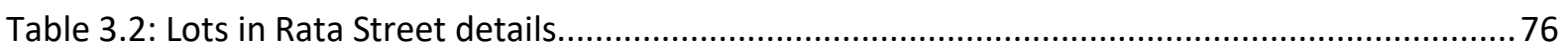

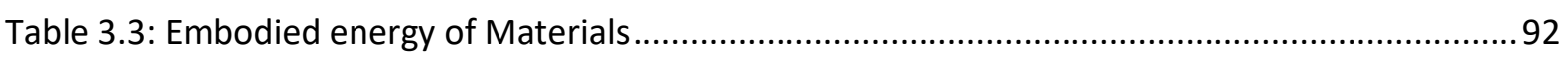

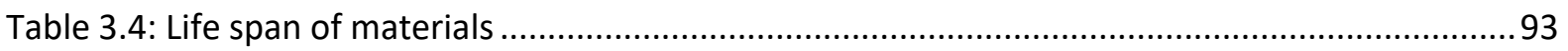

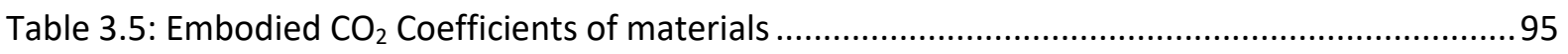

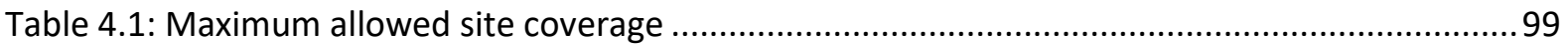

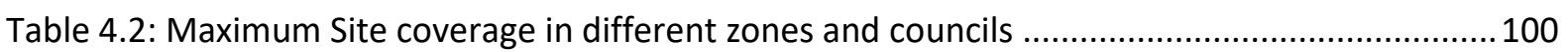

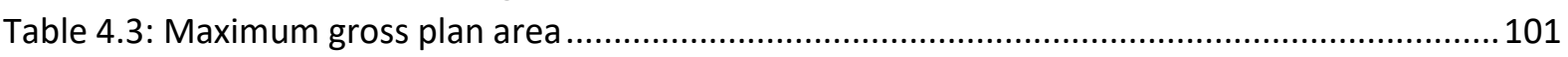

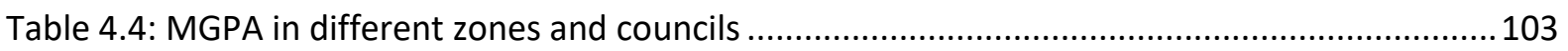

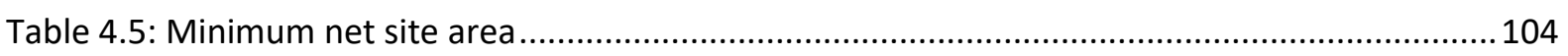

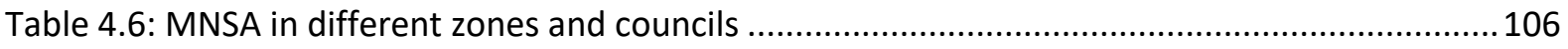

Table 4.7: Households and prefabrication manufacturers in the regions of New Zealand.................108

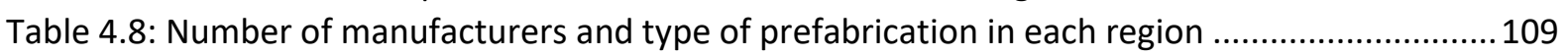

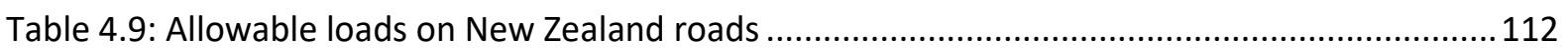

Table 4.10: Categories of overdimension loads on New Zealand roads (metres) ............................112

Table 4.11: secondary group recommendations for Lifemark ....................................................120

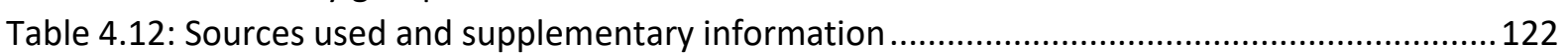

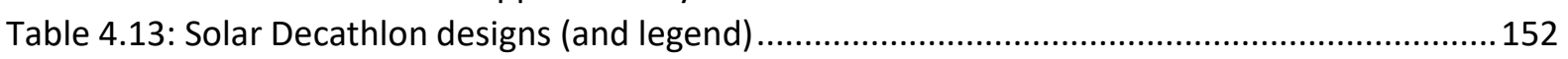

Table 5.1: Dimensions of a 20ft General Purpose Container (Royal Wolf, 2019)................................161

Table 5.2: R-values in different climate zones (Standard New Zealand, 2009) ..................................166

Table 5.3: R-value comparison of PUR and EPS made SIPs panels (NZSIPs, 2017; Formance, 2019). 167

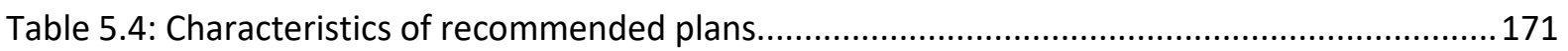

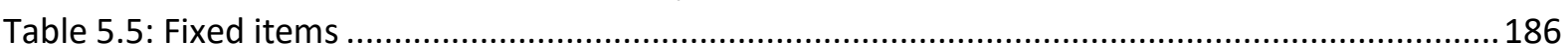

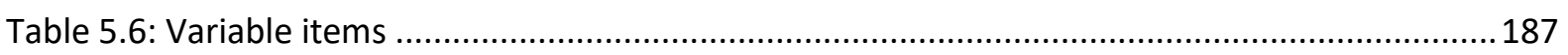

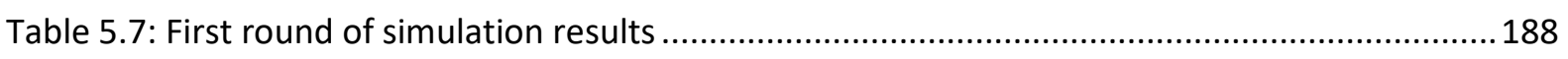

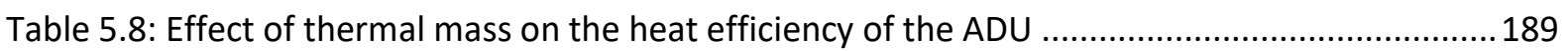

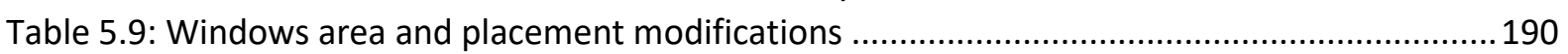

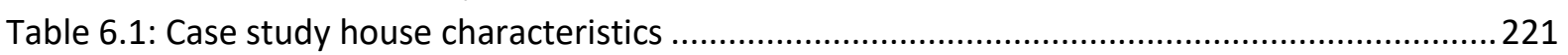

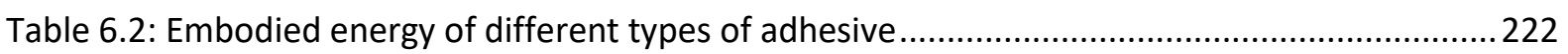

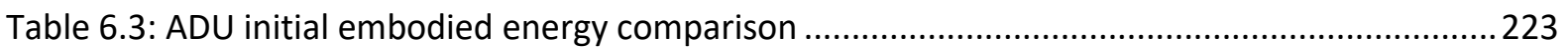

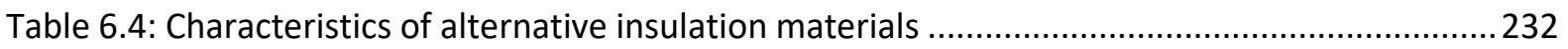

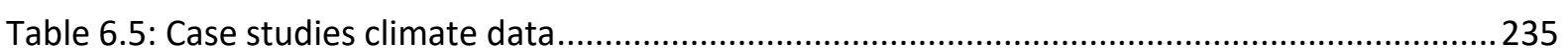

Table 6.6: Life cycle energy of different polystyrene core ADUs (100 years) using ALF 4..................237

Table 6.7: Specifications of different scenarios in SUNREL simulations .............................................239

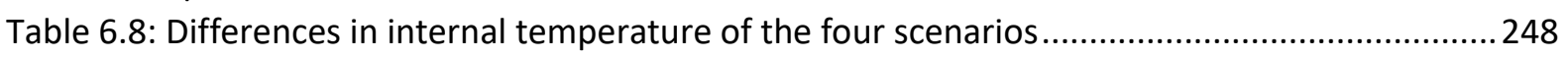

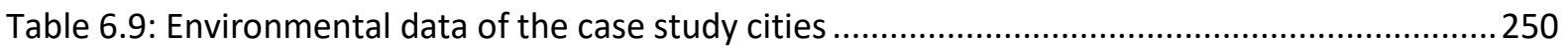

Table 6.10: Life cycle embodied $\mathrm{CO}_{2}$ emissions of the ADU based on the types of materials ............262

Table 6.11: Life cycle operational $\mathrm{CO}_{2}$ emissions of the ADU and BIAC house.....................................264

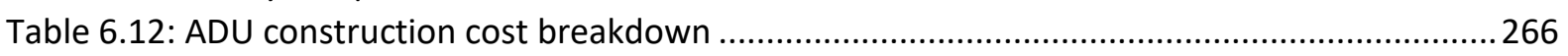

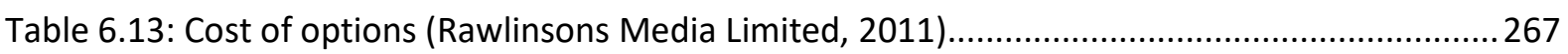

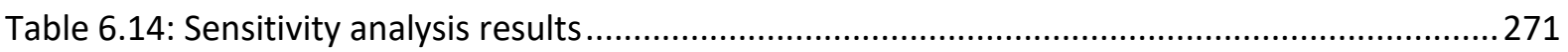


Table 6.15: ADU cost comparison. 


\section{$1 \quad$ Chapter 1 Introduction}

\subsection{Research Overview}

Providing enough sustainable houses is one of the most important indicators of any successful society (Schwartz, 2015; Henilane, 2016). A house is the first structure to surround people, protect them from exterior hazards, and provide them with a place to rest. The United Nations (1991) emphasised that everyone, especially woman, children and disabled people have the right to live in a safe and reasonable house. Despite this, close to one billion urban households in the world suffered from a lack of reasonable housing in 2010 (United Nations Human Settlements Programme, 2016).

"Close to 3 billion people, or about $40 \%$ of the world's population by 2030 , will need to have housing and basic infrastructure services. This translates into completing 96,150 housing units per day or 4000 per hour" (United Nations Human Settlements Programme, 2016).

The United Nations (2016) stated that urban sprawl, lack of attention to the special needs of vulnerable groups, such as migrants, disabled people and older persons, and a growing number of informal settlements including slums were some of reasons underlying the housing crisis. To this needs to be added population growth and the inevitable demand for more dwellings. The world population, which was 7.6 billion in 2017 was predicted to reach 8.6, 9.8 and 11.2 billion by 2030, 2050 and 2100 respectively. In 2018 over 55\% of the world population lived in urban areas and this percentage was predicted to reach $68 \%$ by 2050 (United Nations, 2018). One United Nations report (2018) shows many countries face housing, energy, infrastructure, and transportation issues as a result of population growth and urbanisation. An earlier report (United Nations, 2016) also insisted that confronting the housing crisis and expanding housing opportunities were necessities in achieving sustainable development.

Moving toward sustainable development is important as, currently, humanity is using the earth's resources at a rate equivalent to 1.6 planets and without change, this will be 2.0 planets by 2050 (Global Footprint Network, 2016). In 2016 over 81\% of world energy and more than $99 \%$ of world $\mathrm{CO}_{2}$ came from coal, oil and natural gas, which all are non-renewable 
fossil fuels (International Energy Agency, 2018). In 2015, the average concentration of $\mathrm{CO}_{2}$ (399 ppm) was a 40\% increase in comparison with that of the mid-1800s and was also the highest level in the last 800,000 years (Hong Kong Observatory, 2013). This $\mathrm{CO}_{2}$ concentration is one of the main reasons behind global warming, which has been predicted to rise by approximately $0.3^{\circ} \mathrm{C}$ per decade (with an uncertainty range of $0.2-0.5^{\circ} \mathrm{C}$ ) in the next century (Whitehouse, 2013). Significant improvements in the building sector could help overcome the shortage of non-renewable sources of energy and reduce greenhouse gas (GHG) emissions as buildings and the activities inside them (embodied and operating energy) are responsible for over one-third of global final energy demand (Global Energy Assessment, 2012). This implies that new houses should be economically, socially, and environmentally sustainable to guarantee the stability of natural resources for the next generations (Strange and Bayley, 2008; Giovannoni and Fabietti, 2013; Purvis et al, 2019). In New Zealand, building, including housing construction, is the fifth largest sector when it comes to employment. It employs over 175,000 workers, contributes to $40 \%$ of the landfill, and approximately $4.3 \%$ of GDP (Burgess et al., 2013). Looking at the literature, contemporary housing needs in New Zealand can be classified as, shortage of affordable houses, changes in demographic, urban sprawl and urbanisation, and sustainability of houses.

\subsubsection{Shortage of Affordable Houses}

In 2017 there was a shortage of over 71,000 houses in New Zealand, and half of these houses were needed in Auckland (Miller, 2017; Ministry of Business Innovation and Employment, 2017a). Wellington City Council (2019) has also announced a need for 21,400 new houses to be built by 2043. Part of this shortage is due to unbalanced population distribution. Since 1948 the population of New Zealand, 1.8 million, has been growing and this trend is predicted to continue at least through the second half of this century. In 2017 the population was 4.8 million and there is a 90\% probability of this increasing to 6.0 million by 2043 (Statistics New Zealand, 2016). In 2013 approximately 75\% of New Zealand households were located in the North Island, with an annual growth rate of $1.1 \%$ compared with $0.9 \%$ for the South Island (Statistics New Zealand, 2015a). Similarly, Statistics New Zealand (2017a) indicates that in 2017, 77\% of the New Zealand population lived in the North Island with an annual growth rate of $2.2 \%$, while that of the South Island was $1.8 \%$. This growth in the North Island population has put pressure on existing urban settlements to expand. 
While the population in New Zealand continues to grow, the number of completed houses has followed a different trend especially after 1970. The number of completed dwellings per decade, which reached a peak of 279,000 between 1960 and 1970, dropped to 155,000 in 2000 (Bassett and Malpass, 2013).

After 2000, there has also been a mismatch in supply and demand (Statistics New Zealand, 2017c). The Department of Building and Housing (2010) projection showed that at least until 2026 demand would be greater than supply by over 10,000 and 14,000 houses in the years 2016-2021 and 2021-2026 respectively. This shows the urgent need for more houses to be built quickly in New Zealand.

The differences between supply and demand, in addition to other factors such as availability and cost of land, have pushed up the price of houses. The land price, which until 2014 was less than $\$ 1,000,000$ per hectare in all regions except for Wellington City, has been growing continuously. Auckland and Wellington have had the sharpest growth of over $400 \%$, followed by Tauranga, Christchurch, Queenstown Lakes and Hamilton City, with grow rates of 200\%400\% (New Zealand Productivity Commission, 2015). This growth in land price has directly affected house prices in New Zealand, and especially in Auckland, where in 2014 the land value accounted for $60 \%$ of the price of a house compared with around $45 \%$ for the rest of New Zealand (New Zealand Productivity Commission, 2015).

It is argued that one of the reasons for land cost growth is council regulations that have limited the growth of residential land. Most of the time councils are reluctant to expand urban areas as these new urban areas need new infrastructure (Jiang et al., 2013). If expansion is not an option, then there is a need to use the existing urban land and infrastructure more efficiently (see Section 1.1.3).

\subsubsection{Changes in Demographics}

The demographics of New Zealand have been changing rapidly and the country is predicted to get older in the next 50 years (Statistics New Zealand, 2016). Demographic changes in New Zealand have been highly affected by the baby boomers, or those born post-WWII in a period when the number of births was considerably higher than the number of deaths. In New Zealand, this period covered the years 1946-1965, when the birth rate was 3.5 births per woman (Statistics New Zealand, 2019). This is the reason behind the rapid growth in the 
number of those aged 40-64 between1988-2008, and the projected growth in those aged 65+ as the baby boomers age (Statistics New Zealand, 2016). Understanding how demographics will change is essential as different age groups have different housing needs.

\subsubsection{Urban Sprawl}

By dividing the land in New Zealand into urban and rural, just $1.9 \%$ or 5,078 square kilometres are classified as urban, with over $80 \%$ of this being in the North Island (Statistics New Zealand, 2004). This has led to an unbalanced population distribution.

“New Zealand's population density at 30 June [2017] was 18 people per square kilometre, compared with 13 in 1991. However, there is considerable variation at the local level, ranging up to 18,000 people per square kilometre in Central Auckland" (Statistics New Zealand, 2017b).

After Auckland, the Wellington and Canterbury regions had the highest population densities in 2017 (Statistics New Zealand, 2017a). For the years 2006-2013 Auckland also had the fastest population growth rate of $8.5 \%$, with a rate of $2.6 \%$ alone in 2017 , the highest in the country, closely followed by Waikato and Northland both with a growth rate of $2.4 \%$ in the same year (Statistics New Zealand, 2013a; Statistics New Zealand, 2017a). Figure 1.1 compares the urban population of New Zealand with that of other countries as a percentage of total, with a projection to 2050 .

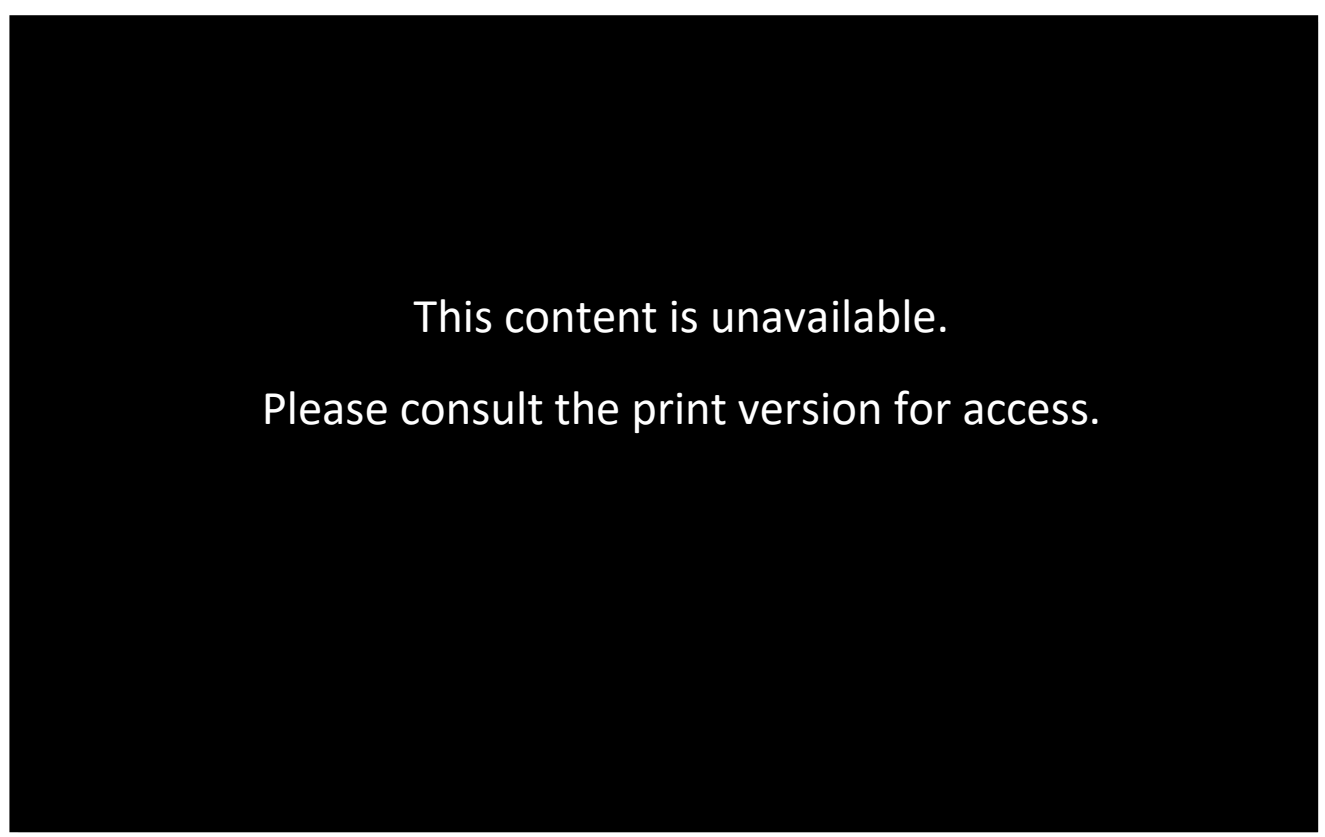

Figure 1.1: World urban population (World Bank, 2018) 
Figure 1.1 shows over $72 \%$ of New Zealanders lived in urban areas in 1950, which was far higher than the world average of $30 \%$ and just lower in the United Kingdom and Australia at $79 \%$ and $77 \%$ respectively. However, urbanisation has been growing faster in New Zealand than in both the United Kingdom and Australia and is predicted to reach over $91 \%$ by 2050 .

Knowing the population of New Zealand is growing fast, and the majority of people tend to live in urban areas, more houses are needed within the existing developed areas to avoid urban sprawl and loss of productive land, otherwise, a shortage of houses and an increase in house prices in urban areas is inevitable.

“Wellington City Council has identified Victoria Street in Wellington's CBD as an area where it would like to see more people living and working in future. The council expects that Victoria Street will accommodate another 1,100 new apartments housing at least 2,500 people along with $37,000 m^{2}$ of new commercial space. The council's preliminary estimates were that the infrastructure costs associated with accommodating this growth could be as much as \$20 million. However, more detailed analysis, making use of the council's asset management systems, showed that the planned level of development could be accommodated entirely with existing capacity" (New Zealand Productivity Commission, 2015, p.179).

Expanding the boundaries of urban areas can lead to urban sprawl, which is the low-density expansion of urban patterns by exceeding city boundaries using low-cost land far away from the city centre. These low-density areas can neither be classified as urban nor rural as they have lost their rural characteristics without having all the necessary characteristics of urban areas, and their residents are highly dependent on private transportation (Howard, 2002; Clawson, 1962; Karakayaci, 2016; Dieleman and Wegener, 2005). Low densities, separated land use, automobile dominance, few areas of public space, and leapfrog patterns of building on pieces of lands far away from each other, are some of the development characteristics of urban sprawl (Gillham, 2002; Ewing, 1997; Gordon, 1997; Heim, 2001; Osman et al., 2008; Noor et al., 2014). Leapfrog development is one form of urban sprawl and is a development where houses or buildings are built far away from each other and from the boundaries of the urban area (Barnes et al., 2012). Urban sprawl or low-density development puts more pressure on the government as they must expand the roads and infrastructure beyond the 
boundaries of existing urban areas to serve those of out of the boundaries. Evans (2012) compared the residential density of New Zealand's cities with other cities in Europe and Asia (Figure 1.2).

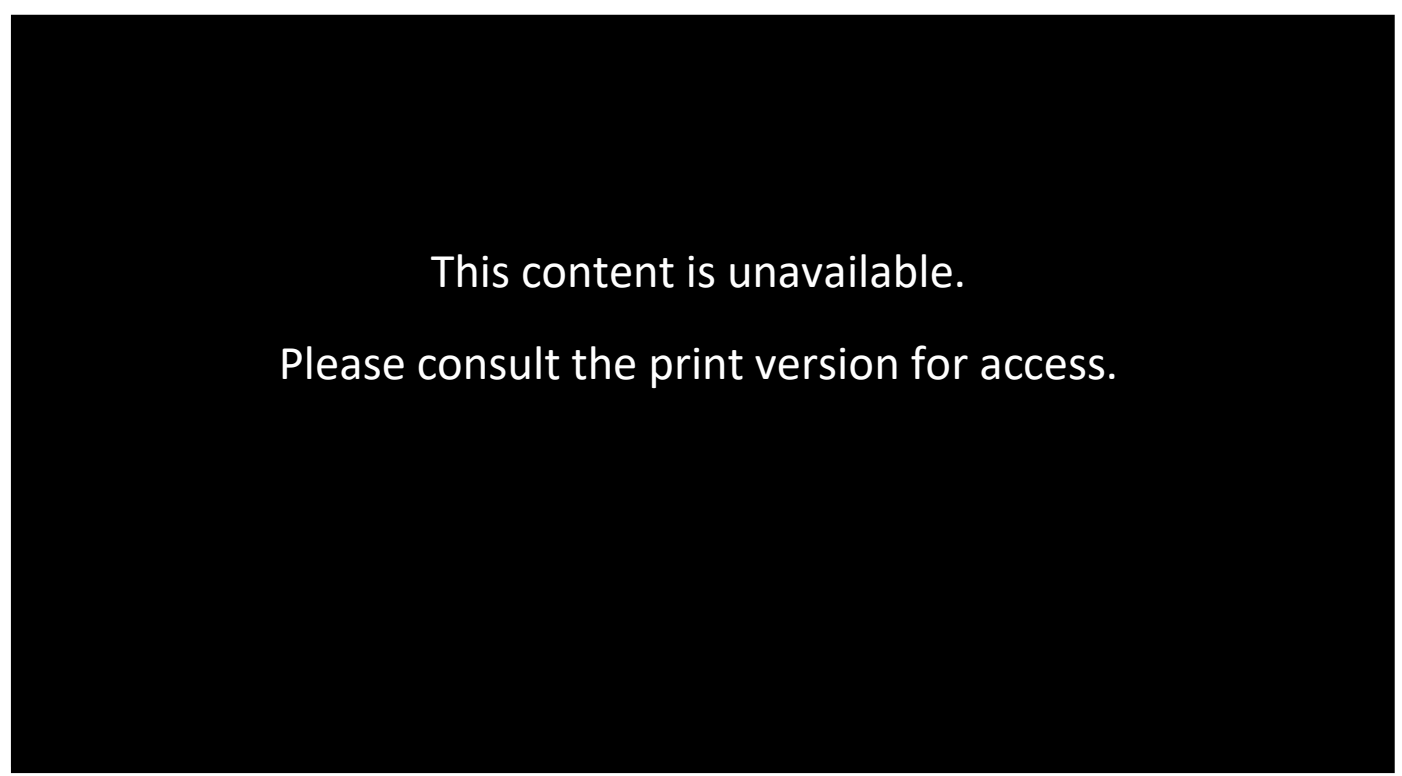

Figure 1.2: Residential density (Evans, 2012)

Figure 1.2 shows the considerable differences between the residential density of New Zealand and that of other cities in the world, suggesting there is the potential for infill growth. Sprawl has a considerable effect on horticulture and market gardening by consuming productive land for low-density urban development.

\subsubsection{Sustainability of Houses in New Zealand}

Sustainability, particularly the energy and $\mathrm{CO}_{2}$ emissions related to houses, also needs to be considered in this research. In 2017 the residential sector was responsible for the third highest energy demand of $11 \%$ after transport and industries at $39 \%$ and $37 \%$ respectively. The building and construction industry was responsible for $4 \%$ of the industrial sector demand, or just over 1\% of the total (Ministry of Business Innovation \& Employment, 2018). So, in 2017 the construction industry and residential sector in New Zealand was responsible for over $12 \%$ of total national delivered energy. The same report also showed that in the residential sector, electricity, fossil fuels, and renewable sources were responsible for $69 \%, 17 \%$ and $14 \%$ of sector energy respectively. However, just over $18 \%$ of this electricity was generated from fossil fuels, in this case, gas, coal and oil (Ministry of Business Innovation \& Employment, 2018). 
The Business New Zealand Energy Council developed two energy scenarios called Kayak and Waka. In both scenarios, the residential and commercial sectors were predicted to have the biggest growth in demand for electricity (Business New Zealand Energy Council, 2015). The Kayak scenario also predicted the thermal energy in the residential and commercial sectors would grow despite improvement in the efficiency of technologies, due to the growth of both the economy and population (Business New Zealand Energy Council, 2015). This show that the energy consumption and $\mathrm{CO}_{2}$ emissions in the housing sector could be a big concern in the future. As a result, new houses should be as energy efficient as possible.

\subsection{Housing Needs Overview}

The primary present need of the housing industry in New Zealand is mainly related to the shortage of houses. While there are not enough houses for the current population, the population is growing fast and based on projections this trend will not be reversed in the near future. This population growth makes the shortage of houses an issue that gets worse on a daily basis, and one which needs a quick reaction and a short term plan. So, houses that can be built faster than current construction systems are needed. Simultaneously, discussed in section 1.1.2 the demographic changes that are happening in New Zealand means the population is aging. This is important as different age groups have different housing needs and requirements. So, many of the houses that need to be built should align with the requirements of older people.

Another issue linked to the shortage of houses is the availability of urban land for new houses. Despite less than $2 \%$ of land in New Zealand being classified as urban, the residential density in this $2 \%$ is one of the lowest in the world. This suggests the urban population is dispersed, and there is need to see if it is possible to use existing developed land in a more efficient way to accommodate more people. If other countries can achieve higher urban densities, New Zealand should be able to as well. So, new houses need to be built inside existing urban boundaries.

The next issue is the use of energy and the consequent environmental impact of the residential sector. Although currently the residential sector is responsible for the third highest energy demand, the projections show the residential and commercial sectors are predicted to have the biggest growth in energy demand. Fossil fuels are still one of the main sources of 
energy in New Zealand, and these contribute to greenhouse gases (GHG). So, the houses that are needed should be built with higher energy efficiency and reduced GHG emissions.

\subsection{Proposed Solution Overview}

This thesis will use a design approach to explore whether prefabrication of Accessory Dwelling Units (ADUs) could be a way of fulfilling New Zealand housing needs. An ADU is defined as a dwelling that is added to an existing plot that already contains a dwelling (see Section 2.3). The potential solution which is investigated in this thesis is the manufacturing of houses, as the method of construction, and ADUs, as the type of houses to be built, due to the potential benefits they have. In other words this thesis aims to see whether combining the speed and quality of prefabrication with the ability of ADUs to benefit from the existing infrastructure can make a useful contribution to New Zealand housing needs. The following paragraphs briefly introduce these benefits while a detailed review is presented in Chapter 2.

Prefabrication is a method of construction where building elements are manufactured away from the final location and then transported to the site to be craned, assembled and attached to the foundation (Generalova et al., 2016; Baghchesaraei et al., 2015). The main reason this method of construction was selected to be investigated was its potential benefits over traditional methods, most importantly being faster (see Section 2.2.5). This could add to the New Zealand housing stock quickly. The house or its elements are made in a factory, which due to having more control over the production process, makes its construction faster, as well as being more energy and material efficient, with fewer defects in the final product than those made traditionally. There are different types of prefabrication (see Section 2.2) but this investigation focuses on modular prefabrication, as this best meets the aims of the research.

An ADU is a self-contained secondary unit, independent from the primary dwelling on the site that provides independent living facilities for its occupants (Cobb and Dvorak, 2000, p.17; Hulse, 2015, p.1). ADUs have the potential to add to the housing stock using existing infrastructure and can increase urban residential density with the least construction-related changes to the neighbourhood environment. ADUs could also provide new and smaller accommodation for those aging within their social group, thus letting them age in place. There are different types of ADUs (see Section 2.3.1) but the focus here is on the detached ADU as all that is required is a free area of land, thus making best use of the prefabrication approach. 


\subsection{Research Aims}

This thesis aims to design and evaluate the practicality and efficiency of a prefabricated ADU as a panacea to New Zealand housing needs. The tasks to be done are:

- Designing the ADU by abiding with local council rules, while making it is accessible for older people and testing its buildability and transportability; and

- Analyzing the cost and the energy efficiency of the $\mathrm{ADU}$, as well as its $\mathrm{CO}_{2}$ emissions; and

- Studying the factors affecting any excellence or weaknesses the prefabricated ADU has over conventionally made houses.

\subsection{Thesis Overview}

Having set out the housing needs in New Zealand in Chapter 1, and argued for the use of a prefabricated $A D U$ as a contribution to meeting these needs, Chapter 2 investigates the literature in the three different areas of: prefabrication; ADUs; and zero energy houses. The prefabrication section introduces the different types of prefabrication and the benefits and disadvantages of prefabrication compared with traditional building methods. Chapter 2 continues by reviewing the history of prefabrication in the world and New Zealand and ends with an extensive review of current manufacturers involved in prefabrication in New Zealand. The ADU section starts by defining the different types of ADU and how this type of dwelling might help to meet New Zealand housing needs. This section also investigates the district plan provisions specific to ADUs in New Zealand as well as existing plans of ADUs and tiny houses. The last section of Chapter 3 investigates the concept of zero energy houses and ends by analysing a number of energy-efficient designs from around the world and New Zealand.

Chapter 3 presents the methods to be used and the main research questions. This chapter explains the logic behind the research and how different chapters relate to each other and how they have been developed in relation to each other. Chapter 4 discusses factors affecting the design of the ADU including the district provisions specific to ADUs, reviewing the manufacturers of prefabrication in the country, road rules, and consideration of accessible design for older people. Chapter 5 describes the design and construction approach, and the choice of materials. The selected designs are presented in Chapter 5 and then used as the 
basis of the following chapters. Chapter 5 also simulates and explores the space conditioning energy of the ADU to see how the design and construction decisions affect energy use.

The Life Cycle Energy (LCE), $\mathrm{CO}_{2}$ emissions (LCCO) and Cost (LCC) of the ADU are analysed in Chapter 6. The LCE, LCCO and LCC of the ADU are compared with a conventional New Zealand house (the BIAC house) as well as with other examples. Finally, Chapter 7 brings the results of all chapters together and concludes the research by answering the research question. The last pages of the thesis consist of the bibliography and appendices. 


\section{Chapter 2 Literature Review}

\subsection{Introduction}

Chapter 1 discussed the considerable housing needs in New Zealand. These were summarised as the need to speed up the rate of housing construction, use existing developed land and infrastructure to avoid sprawl, consider the living needs of an ageing population, and using sources of energy more efficiently and emitting less $\mathrm{CO}_{2}$ in response to the government's policy of moving towards carbon neutrality (Young, 2017). There are many ways to tackle these issues, but this research evaluates the possibility of using a zero-energy prefabricated $A D U$ as a viable solution. This chapter is structured into three sections dealing separately with prefabrication, ADUs, and sustainable zero energy houses. In the first two sections, the reasons for selecting prefabrication and Accessory Dwelling Units (ADUs) are discussed. Then the background is discussed in each section as well as different definitions and types. In the last section, the concepts of zero energy buildings and sustainable construction are investigated in addition to a comparison of the sustainability of prefabrication with traditional methods. Later the benefits of using LCA are discussed. The chapter ends by discussing where the potential gap of knowledge is.

\subsection{Prefabrication}

\subsubsection{Prefabrication Need}

Whenever there was a housing issue in the last century it seems prefabrication was discussed as one of the potential solutions. The use of prefabrication after both World Wars when traditional materials and skills were in short supply is one of the most important examples, and is discussed later in this chapter. Given the housing crisis is a global phenomenon prefabrication has again emerged as a potential solution.

Mostafa et al., (2014) reviewed the housing crisis in 24 developing housing contexts and concluded that prefabrication could be an efficient solution to the shortage of houses. Davies (2018) studied modern methods of construction in the UK and pointed to off-site manufacturing as a reliable response to the growing population, shortage of houses, and lack of housing affordability. However, both these studies are theoretical and just focus on limited theoretical aspects of construction rather than being based on measured performance. These same issues can be found in cities with different characteristics such as San Francisco in the 
United States of America and Mumbai in India. San Francisco is coping with demand exceeding the housing supply, resulting in lowering the affordability of houses (Stein, 2016). In this situation, Stein (2016) also mentioned the higher speed of prefabrication compared to traditional methods as well as its lower costs could be the way to respond to that housing crisis. Mumbai, which has one of the highest residential population densities in the world, is struggling with rapid urbanisation, which has led to a shortage of houses and lack of affordability, as well as a growing number of slums (Villaitramani and Hirani, 2014). Again, prefabrication has been recommended to overcome these issues in Mumbai (Villaitramani and Hirani, 2014).

In Australia and New Zealand, prefabrication has also been cited as a potential response to housing needs. In Australia, the research focus has been on the speed and efficiency of prefabrication as the country needs more houses to be built in a shorter time than is possible with conventional construction methods (Navaratnam et al., 2019). There are also concerns over the environmental impact of housing in Australia, as this forms over $10 \%$ of the ecological footprint of the country, and this is where prefabrication could be a solution due to its higher efficiency and fewer emissions (Simpson et al., 2000; Steinhardt et al., 2013a). Prefabrication has been announced as one of the eight Australian construction industry "Vision 2020" due to its higher safety, its being more environmentally friendly, and its lower cost (Hampson and Brandon, 2004, p.24). The other visions are environmentally sustainable construction, meeting client needs, improved business environment, welfare and improvement of the labour force, information and communication technologies for the construction industry, virtual prototyping for design, manufacture and operation, and improving the process of manufacture of constructed products (Hampson and Brandon, 2004, p.1).The problem and the proposed solution are similar in New Zealand, where Mendoza (2018) says:

"NZ is not the first country that has experienced housing shortage problems. Countries like Japan, USA and Sweden have long experienced housing shortages and used different alternatives to overcome them. Prefabrication has been a key part of these offshore solutions...Manufactured houses can be built faster cheaper, and to higher quality standards due to controlled fabrication conditions than traditional onsite construction" (Mendoza, 2018, p.1). 
Roskruge (2011) has also mentioned the shortage of houses in New Zealand and the housing affordability issue which came after the economic recession. She investigated the potential use of a hybrid prefabrication system (see Section 2.2.3.4) and claims that this system can improve the New Zealand housing stock due to its flexibility and the shorter time it needs on site. This brief introduction about prefabrication shows why this method has been selected as a potential solution in this research as it has been promoted in different countries that have faced similar issues.

\subsubsection{Prefabrication Definition}

Prefabrication should be seen in the context of a time horizon, as the term is commonly misconstrued and has suffered from historical misperceptions. Over time prefabrication has variously been referred to as standardisation, off-site construction or manufacturing, and industrial or modular construction, which can lead to public confusion (Neelamkavil, 2009; Bell and Southcombe, 2012; Hamdy et al., 2018). Moardibistouni and Gjerde (2017) stated people's understanding of prefabrication has included a wide range of ideas, "From cheap and flimsy New Zealand classrooms from the 70s to 21st century modern luxurious and highly energy efficient prefabricated homes offered by some European prefabricators". Vale (1995, p.64) describes Le Corbusier's opinions on prefabrication, which he derived from a comparison with the automobile industry. Once manual car production was replaced with an assembly line process, cars were made more affordable. So, if house production followed a similar process and became streamlined like that of cars, then manufactured houses could be more affordable and practical than traditional ones.

Prefabrication can be defined in different ways, but the majority of the literature agree on following definition, which is the one used in this thesis (Seratts, 2012, p.i; Lu and Yuan, 2013; Abrantes et al., 2017, p.vii; Tam et al., 2006): Prefabrication is a method of construction, where elements from one component to a complete building are manufactured in a factory some distance away from the final location, the pieces are sold, purchased and carried to the final building location, and the end result coming from assembling the kits or attaching a complete building to the pre-made foundation. 


\subsubsection{Different Types of Prefabrication}

Prefabrication has been classified in different ways based on different criteria. Some researchers have classified prefabrication based on the type of materials used (e.g. Warszawski, 1999, p.16; Ngoenchuklin, 2014; Rahman and Omar, 2006), while others have based their categorisation on the degree of prefabrication encountered (Majzub, 1977; Gibb and Isack, 2003). Alternatively, Baghchesaraei et al. (2015) looked at the industry structurally and classified prefabricated buildings based on their structure Table 2.1 sets out selected classifications in detail.

Table 2.1: Examples of classification of prefabrication

\begin{tabular}{|c|c|c|c|}
\hline Classification type & Source & Classification type & Source \\
\hline $\begin{array}{l}\text { Panel system } \\
\text { Box system } \\
\text { Frame system }\end{array}$ & Majzub (1977) & $\begin{array}{l}\text { Wood framing } \\
\text { Steel framing } \\
\text { Concrete framing }\end{array}$ & $\begin{array}{l}\text { Ngoenchuklin } \\
\text { (2014) }\end{array}$ \\
\hline $\begin{array}{l}\text { Volumetric } \\
\text { Panellized } \\
\text { Hybrid } \\
\text { Subassemblies and } \\
\text { components } \\
\text { Non-off-site-Modern } \\
\text { Methods of Construction }\end{array}$ & $\begin{array}{l}\text { Gibb and } \\
\text { Pendlebury } \\
\text { (2005) }\end{array}$ & $\begin{array}{l}\text { Pre-cast concrete-framed building } \\
\text { Pre-cast concrete wall system } \\
\text { Reinforced concrete building with } \\
\text { pre-cast concrete slab } \\
\text { Steel formwork system } \\
\text { Steel-framed building and roof } \\
\text { trusses }\end{array}$ & $\begin{array}{l}\text { Rahman and } \\
\text { Omar(2006) }\end{array}$ \\
\hline $\begin{array}{l}\text { Component manufacture } \\
\text { and sub-assembly } \\
\text { Non-volumetric sub- } \\
\text { assembly } \\
\text { Volumetric pre-assembly } \\
\text { Modular system }\end{array}$ & $\begin{array}{l}\text { Gibb and Isack } \\
\text { (2003) }\end{array}$ & $\begin{array}{l}\text { Volumetric system } \\
\text { Panellized system } \\
\text { Hybrid system } \\
\text { Sub-assemblies and component } \\
\text { system } \\
\text { Modular system }\end{array}$ & $\begin{array}{l}\text { Abosad et al. } \\
\text { (2009) }\end{array}$ \\
\hline $\begin{array}{l}\text { Timber } \\
\text { Steel } \\
\text { Cast in situ concrete } \\
\text { Precast concrete }\end{array}$ & $\begin{array}{l}\text { Warszawski } \\
(1999, \text { p.16) }\end{array}$ & $\begin{array}{l}\text { Frame systems } \\
\text { Panel systems } \\
\text { Cells system }\end{array}$ & $\begin{array}{l}\text { Baghchesaraei } \\
\text { et al. (2015) }\end{array}$ \\
\hline
\end{tabular}

Obviously not all the types of prefabrication are appropriate for making an ADU in New Zealand, where timber framing is the most comment approach to single and two storey house building. Although in the UK post-WWII lightweight, prefabricated concrete panels were used for one of the temporary single storey house types, this was driven more by basing the prefabrication method on one already in use for wartime huts than the argument that prefabricated concrete panels were the best way of making a small house (Vale, 1995, p.14). A better way might be to look at what has been said about types of modern prefabrication in New Zealand. Bell (2009) classified the types based on the degree of prefabrication of component, panel, module or volume, hybrid, and complete buildings (Figure 2.1). 


\section{This content is unavailable.}

\section{Please consult the print version for access.}

Figure 2.1: Different types of prefabrication (Bell, 2009)

\subsubsection{Component Prefabrication}

This category comprises pieces and their sub-assembly (Figure 2.2). Pieces are simple parts that are cut and shaped into a specific size and form, transported to the site and then assembled, which in some cases could result in a puzzle, as many people find with flat packed furniture (Bell, 2009). Sub-assemblies are more complicated pieces, which are the combination of simple parts, such wall panels with openings left for windows and doors. The component system presents the highest level of flexibility and customization among all types of prefabrication (Boafo et al., 2016). The disadvantage is that this approach needs more labour and extra attention on site to ensure everything is correctly assembled. The majority of all prefabricated houses in New Zealand and Australia, including passive houses, use the component method (Moardibistouni and Gjerde, 2017).

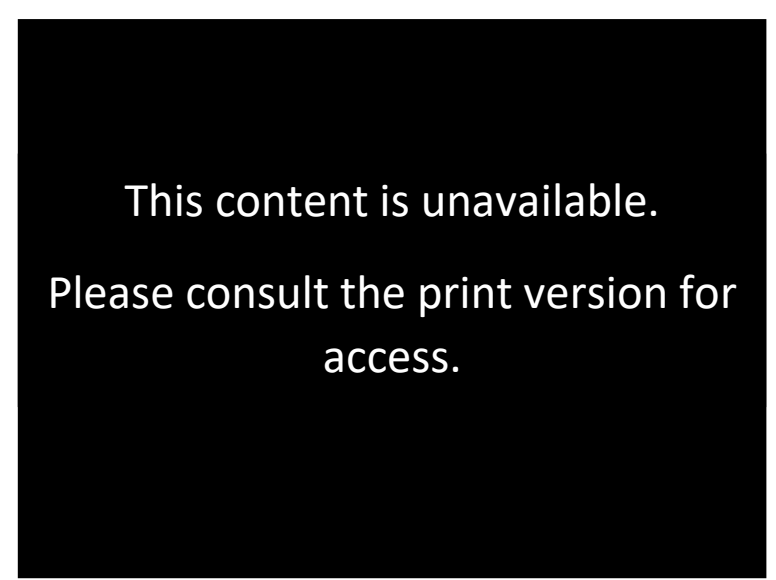

Figure 2.2: Component base prefabrication (Burgess et al., 2013)

\subsubsection{Panel}

Panelised or two-dimensional prefabrication describes the making of components which are joined together in some way in the factory (Bell, 2009). Panels normally need a crane on site so they can be lifted into position. The panels are classified as closed panels, which come complete with doors, windows, services, cladding, and linings, and open panels, which are transported to the site as a flat-pack and are assembled there (Figure 2.3). 


\section{This content is}

unavailable.

\section{Please consult the} print version for access.

Figure 2.3: Panelised prefabrication (Smith, 2016)

Panels are very useful for both residential and commercial buildings because, they are much cheaper to transport in comparison with modules, and allow designers the freedom to design wide, open spaces and high ceilings (Elitzer, 2015). The T30 hotel in Hunan province, China, is an example of panelised prefabrication that illustrates the usefulness of this method (Figure 2.4). This 30-storey hotel, which was built just in 15 days, is reportedly five times more earthquake resistant and five times more energy efficient in comparison with traditional buildings (Broad Sustainable Building, 2013), although some of these excellent attributes relate as much to the design as the prefabrication method of construction. 


\section{This content is unavailable.}

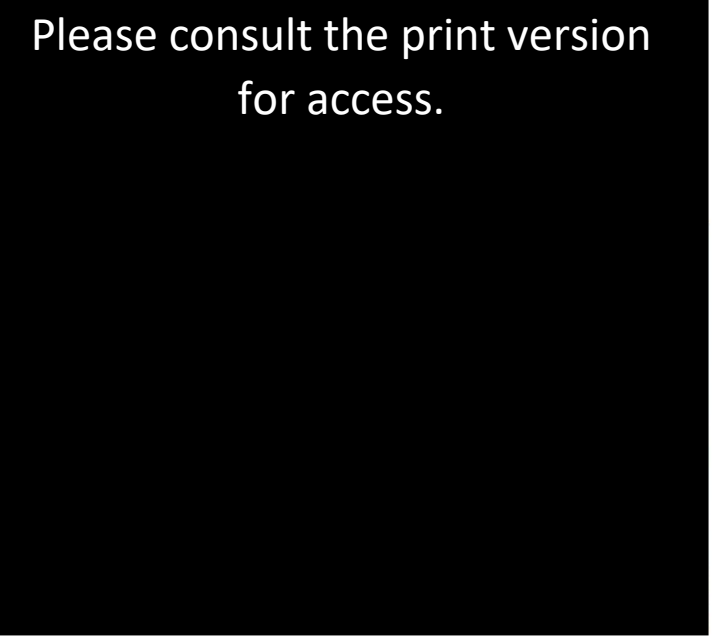

Figure 2.4: T30 hotel construction process (Williamson, 2014)

\subsubsection{Module or Volume}

Modular or volumetric prefabrication (Figure 2.5) refers to the creation of a threedimensional structural unit made up from panels in a factory, which is then fixed onto a permanent foundation at the site. Prefabricated modules are usually used for architecture that has a repetitive geometry and that can be mostly completed before being shipped to the job site (Kaufmann and Remick, 2009, p.21). Modular buildings come to the site as separate parts that are joined together to form a whole. In recent years this type of house has become more customised in comparison with 10 years ago when the scale of the parts, or rooms, was limited to truck size (Elitzer, 2015). Moreover, this form of prefabrication potentially has a higher quality end product in comparison with components and panels, as fewer joints have to be accessible and finished on site. However, modules need more space during transportation, which means more limitations on the design and building process. From now on this type is called modular prefabrication. 


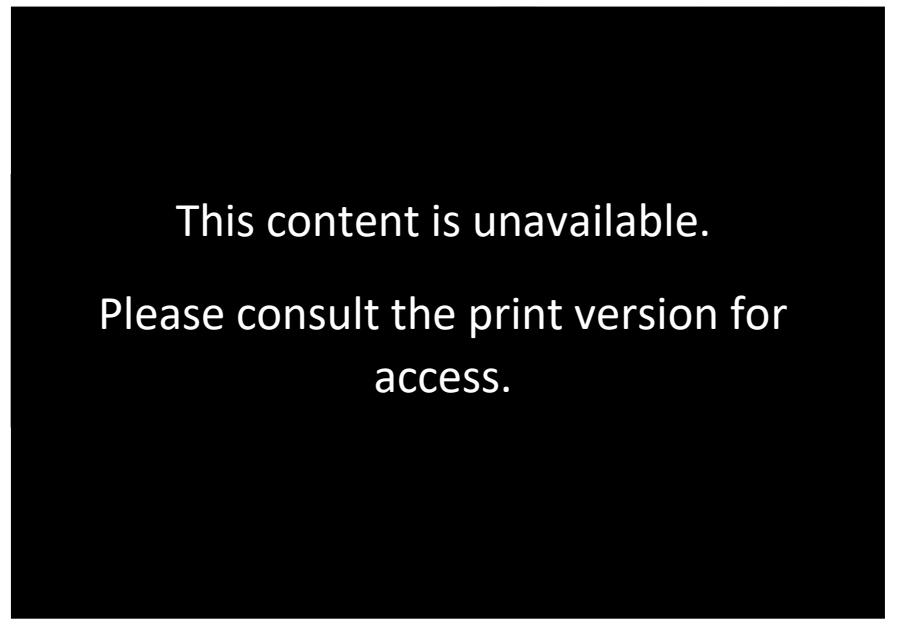

Figure 2.5: Modular prefabrication (Burgess et al., 2013)

\subsubsection{Hybrid Prefabrication}

Hybrid prefabrication, also called module-plus-panel or semi-volumetric, refers to the combination of the panelised system and modules (Burgess et al., 2013). This system (Figure 2.6) uses modular units for serviced zones such as a kitchen and bathroom, combined with panels for the construction of the other parts of the house. The hybrid method combines the advantages of off-site construction with the merits of on-site building methods to achieve an optimised way of building. This method uses local resources, including unskilled labour for some on-site jobs which do not need specialist skills, and materials, something not possible with other methods (Bell, 2009). An example of this method is the Meridian First Light House. The house was made of six independent prefabricated modules with wooden decking surrounding the house and linking the interior to the surrounding environment. It was made in New Zealand and shipped to the USA for the 2011 Solar Decathlon Completion (FirstLight Studio, 2017).

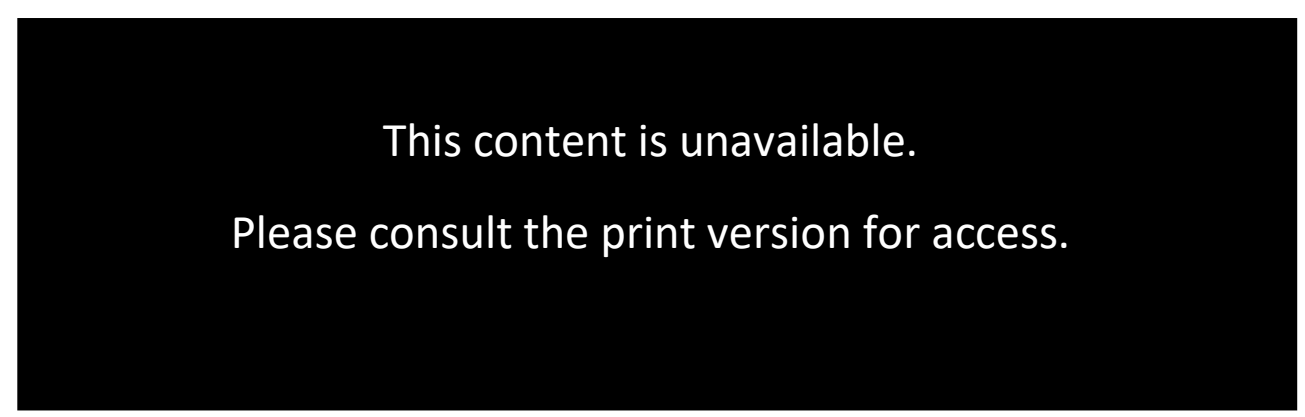

Figure 2.6: Hybrid prefabrication (First Light House) (First Light, 2011) 


\subsubsection{Complete Building}

The complete building, also known as portable, relocatable or transportable buildings, is a type of volumetric prefabrication (Figure 2.7) where the entire building is constructed in the factory and moved by a heavy haulage vehicle to the site where it is then attached to permanent foundations (Steinhardt et al., 2013b). Eglinton (2014) says the history of complete prefabricated buildings in New Zealand dates back to the 1950s when some homes were constructed for the government's hydro scheme. During that period, the government needed a method of construction which was easy, fast and cheap to assemble, disassemble and transport. The need came from the necessity of providing houses for workers who were moving from one scheme to another on a continuous basis. The Ministry of Works manufactured 250 houses on a production line and signed contracts with building firms such as Keith Hay Homes and Martin Homes for producing more prefabricated houses throughout the 1940s and 1950s for the North Island, and during the 1960s and 1970s for the South Island (Bell, 2009; Kinsella, 2012).

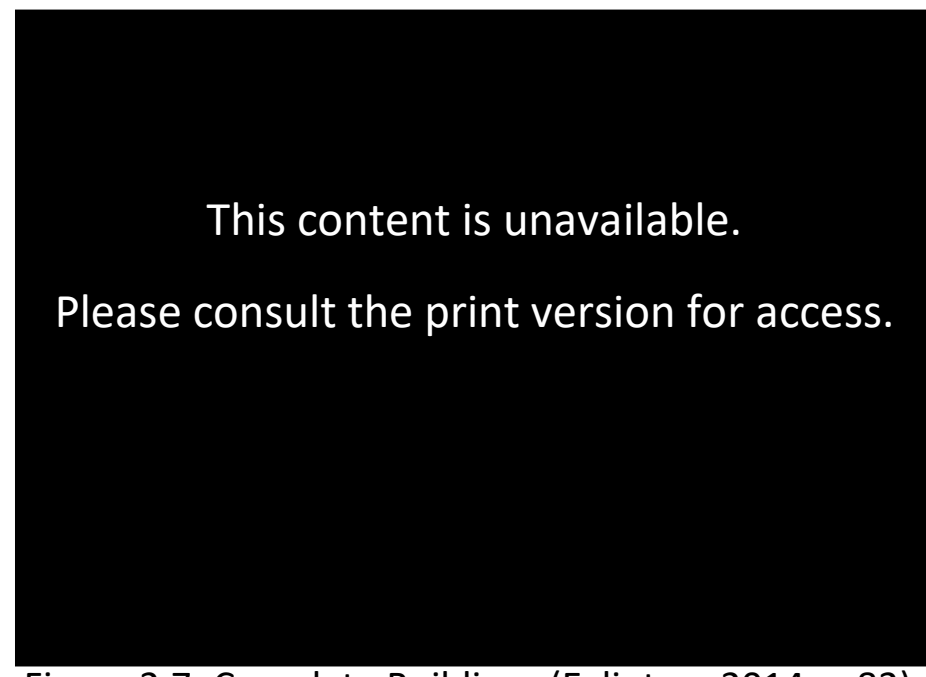

Figure 2.7: Complete Buildings (Eglinton, 2014, p.82)

\subsubsection{Thesis Definitions}

To make it clear, the following definitions will be used in this thesis.

\section{- Components}

Components are usually small three-dimensional elements cut in a factory to a special size and form and that are then attached together. A single piece of wood cut to length in a factory, a bath, or a vanity unit are not prefabricated components in this definition. Pre-cut and pre-nailed frames and trusses are a good example of this type of prefabrication. 
- Panels

Panels are more complicated components. If a premade timber frame is given cladding in the factory it becomes a panel. A panel could be a frame of studs and nogs or a completed wall that includes the cladding, door, window, and services such as wiring and pipes for later connection on site.

\section{- Modules}

Modules are a combination of more than two panels to make a three-dimensional form and which are more than $90 \%$ completed in the factory. This means modules will normally include the cladding, doors, windows, and services. Modules could be used alone as a small house or can be attached to other modules to form a bigger house or even a multi-storey complex. Container houses converted from shipping containers by adding services, bathroom, kitchen and other necessary parts of a house would fall into this category.

\section{- Hybrid}

Hybrid prefabrication is a combination of modules, usually, for serviced zones such as a kitchen and bathroom, and panels for other parts of the house.

\section{- Completed buildings}

As the name shows this group is of prefabricated houses that are completely manufactured in a factory and where the only work needed on site is attaching the building to the foundation and connecting to the services.

To illustrate the potential confusion in the use of the terms portable, transportable, mobile, and relocatable, the following definitions are given below. However, in this research, all of these types are considered to be prefabricated.

- Portable

This type usually consists of small buildings, designed for transportation to a site for shortterm or temporary use. Such buildings could be used as a temporary office, classroom, or even a sleep-out, but after use will then be moved to another site to be used again (Prefab NZ, 2016). 


\section{- Transportable}

Transportable buildings are those designed to be built in a factory or a yard and then moved to another place to be used. However, some manufacturers of prefabricated buildings such as Genius Homes use the word transportable in a different way (Prefab NZ, 2016). Genius Homes (2018) defines a transportable building as one designed to be moved to a site for longterm temporary use. This means it is designed to be moved easily later so it is not attached to the foundation permanently.

\section{- Mobile}

This type of building was used for the first time in the United States around 1920 by workers travelling around the country to find a job (TechLaw, 2011). Mobile houses are manufactured in a factory and transported to the site in a largely completed state. These buildings do not need to conform to building codes and are not necessarily fixed to permanent foundations.

\section{- Relocatable}

A relocatable building is one designed as a kitset, module of a complete unit. After manufacturing in a factory, it is then taken to the site (Prefab NZ, 2016).

\subsubsection{A Brief History of Prefabrication}

Much has been written about the prefabrication of buildings. The following paragraphs summarise a brief history of prefabrication from both a worldwide and New Zealand point of view. The aim is not to be comprehensive but to consider the milestones and most important events that have led to the contemporary prefabrication industry in New Zealand.

\subsubsection{Worldwide View}

Smith (2010, p.3) states "Prefabrication in architecture is a tale of necessity and desires." In the past it was probably more a case of necessity than desire. The history of prefabrication dates back to the beginning of nomadic life and times when people had to migrate due to external threats or environmental conditions. The main reason people looked to prefabrication was their need to have houses which were easy to assemble, disassemble, and transport (Herbers, 2004, p. 14). These early prefabricated shelters were made of a number of pre-cut structural elements, usually, timber, joined together using precut holes and/or ropes and covered by an envelope of leather, woollen fabric or other natural materials. 
Examples of these shelters can be found in the civilizations of the early Persians, North American Indians and Mongolians, where they are respectively called the Black Tent, Tipi, and Yurts (Giller, 2012).

The history of prefabricated permanent buildings also goes back a long way. Prasher (2016) tracked the history of prefabricated stone buildings to $3000 \mathrm{BC}$ when the Sinshalese Kings of ancient Sri Lanka decide to try a new method of construction and asked for the offsite manufacturing of components, which was done with considerable success. Similarly, Chiu $(2012$, p.8) pointed to how the stone blocks were shaped at one site and transported to another site for building the pyramids in Ancient Egypt around 2500-2600BC. Thus for very large structures, it was better to shape the stone off-site as the problem was moving such a heavy material. This practice continued into the medieval period with stones for the great cathedrals and churches being shaped off-site and then moved, as evidenced by the imperfections in the stones that form the piers of Durham Cathedral (Figure 2.8).

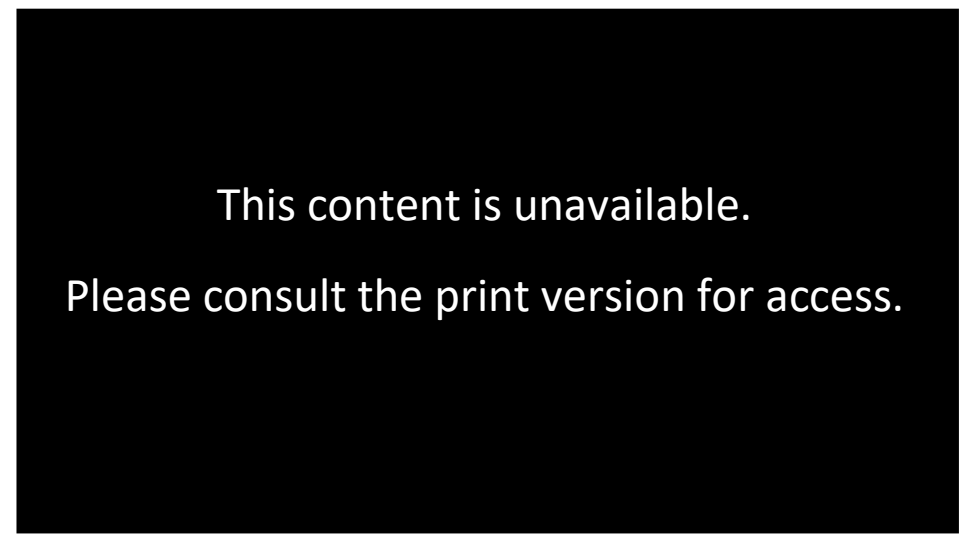

Figure 2.8: Durham Cathedral (Zucker, 2017)

In contrast, O'Neill (2016) claimed that timber was the first material used for prefabricating houses due to its availability, and ease for manufacturing and transportation. The use of timber for prefabricating the components of a house can be tracked to the 12th century in England and Wales (Gibb, 1999, p.8; Piroozfar and Farr, 2013; Marshall et al., 2014, p.227). Moreover, there are documents that show how by the 12th century the Japanese made their temples using pre-cut components of wood (Bergdoll et al., 2008, p.14). Schofield (1991) studied the domestic structures and materials of buildings in London during the medieval period and pointed to the fact that between the mid-14th century and 17th century the size of timber components reduced along with their variety, going from thirteen different cross- 
sections in 1369 to only five general thicknesses in 1602 due to ease of preassembly and transportation.

"Buildings were sometimes framed elsewhere, presumably near the source of the timber, and brought to London in a prefabricated state. For the large Bucklersbury house in 1405 St Paul's had the timber, including the arch-couple roof, framed at Hadleigh (Essex); in 1425 the new frame for Drapers' Hall came from Croydon, though other timber was bought at Hunton in Kent. A house 40ft x 22ft and 24ft to the eaves built in 1510 was to be framed at Kingston on Thames, and in 1515 the new Bridge storehouse was framed at Charlwood (Surrey), carried to Kingston and brought by boat in 225 loads" (Schofield, 1991, p.14).

Later emigration to the British colonies in the 17th to 19th centuries led to the development of transportable prefabricated houses and housing components (Smith, 2009). The reason behind these prefabricated buildings was again the need for houses which could be easily transported and assembled, often on an unknown site. Most of these houses were made of timber and were covered by canvas and later clad with weatherboarding (Smith, 2009). These houses could even be assembled by unskilled owners. The first example of a prefabricated house was shipped in 1624 by the British to Cape Ann, a city in Massachusetts. This was a panelised wooden house for a fisherman (Arieff and Burkhart, 2002, p.13). As the British Empire expanded for those who could afford it prefabricated houses and houses components were shipped to India, the Middle East, Africa, Australia, New Zealand, Canada, and the USA to guarantee that there would be no accommodation problem when the colonists arrived (Smith, 2009). Once the immediate need for housing was satisfied and sufficient building skills accrued in the new colonies, the need to ship prefabricated houses was less urgent.

The Manning Portable Colonial Cottage was an early example of such prefabricated houses (Figure 2.9). The first prototype had been manufactured for Manning's son who immigrated to Australia in 1830. In 1837 Manning advertised his cottages in South Australia, which led to the export to Australia of dozens of such cottages, which could be assembled in one day (Bergdoll et al., 2008, pp.14-40). 


\section{This content is unavailable.}

\section{Please consult the print}

version for access.

Figure 2.9: The Manning Portable Colonial Cottage (Bergdoll et al., 2008, p.40)

At the same time as Manning in London, in Chicago, an American builder named Augustine Taylor was developing a wood frame system to solve the shortage of housing in the city. The goal of Taylor's system was to change the building process from a time consuming, complicated endeavour needing many skilled labourers to a simplified industrial process which could be done by a few unskilled workers in a shorter time (Giedion, 1967, p.269; Bergdoll et al., 2008, p.41). St. Mary's church (Figure 2.10) was constructed in 1833 and is known as the first building to use Taylor's balloon frame system (Figure 2.11). The revolutionary system "Involves the substitution of thin plates and studs-running the entire height of the building and held together only by nails - for the ancient and expensive method of construction with mortised and tenoned joints" (Giedion, 1967, p.269).

\section{This content is unavailable. \\ Please consult the print version for access.}

Figure 2.10: St. Mary church

(Giedion, 1967, p.269)
Figure 2.11: Balloon frame system

(Bergdoll et al., 2008, p.41)

Later in 1849 , the California gold rush gave another spur to the prefabricated housing industry. The huge number of newcomers in California and the surrounding areas produced an urgent need for more houses (Peterson, 1965). This need and new findings in England in the early 1800s about the use of corrugated iron in prefabricated buildings resulted in an expansion of the prefabrication industry (Smith, 2009; Vale and Vale, 2013, pp.64-71). 
Corrugated iron was more dimensionally stable, easier to assemble and disassemble without damaging the material, and structurally more efficient in comparison with other materials. By 1849 the first California handbook entitled Sherwood's Emigrant's Guide, which was published in New York, carried advertisements for two dealers in prefabricated iron houses (Peterson, 1965, p.319) (Figure 2.12).

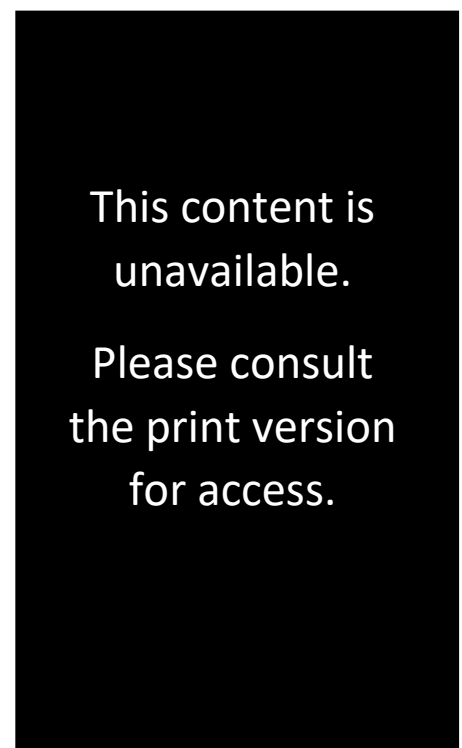

Figure 2.12: Naylor's advertisement in Sherwood's Emigrant's Guide (Peterson, 1965, p.320) In addition to early prefabricated wooden houses exported to the colonies, prefabricated metal houses were experimented with in the late 18th century, mostly in Britain. A lockkeeper's cottage, built the late 18th century at Tipton Green in Staffordshire, is believed to be the first prefabricated, metal building in Britain (Vale and Vale, 2013, p.64). The cottage, which was built for a canal lock keeper, consisted of flanged, bolted cast-iron wall panels and metal windows, and was based on bridge and ship construction technology. By 1860 some experts in the field of construction, mostly French, were investigating the possibility of using concrete to manufacturing panels to export to places with a tropical climate and a concrete house made of panels was shipped to the Caribbean island of St. Thomas (Bergdoll et al., 2008, p.15). The idea persisted and 18 years later a Queen Anne style house made of red painted concrete panels in a timber frame won first place at the Exposition Universelle in Paris (Bergdoll et al., 2008, p.15).

During the next 50 years, different companies and architects investigated new methods of building and marketing prefabricated houses (Figure 2.13). 
"Aladdin Readi-Cut Houses, founded in 1906, was the first company to offer a true "kit" house composed of pre-cut, numbered pieces. But the first and most notable company to offer houses by mail was Sears, Roebuck \& Co., which sold houses through its catalogue and sales offices to nearly 100,000 clients between 1908 and 1940. Priced from $\$ 650$ to $\$ 2,500$, each house by mail kit included lumber, nails, shingles, windows doors, hardware and house paint (and instructions too, of course)" (Arieff and Burkhart, 2002, p.13).

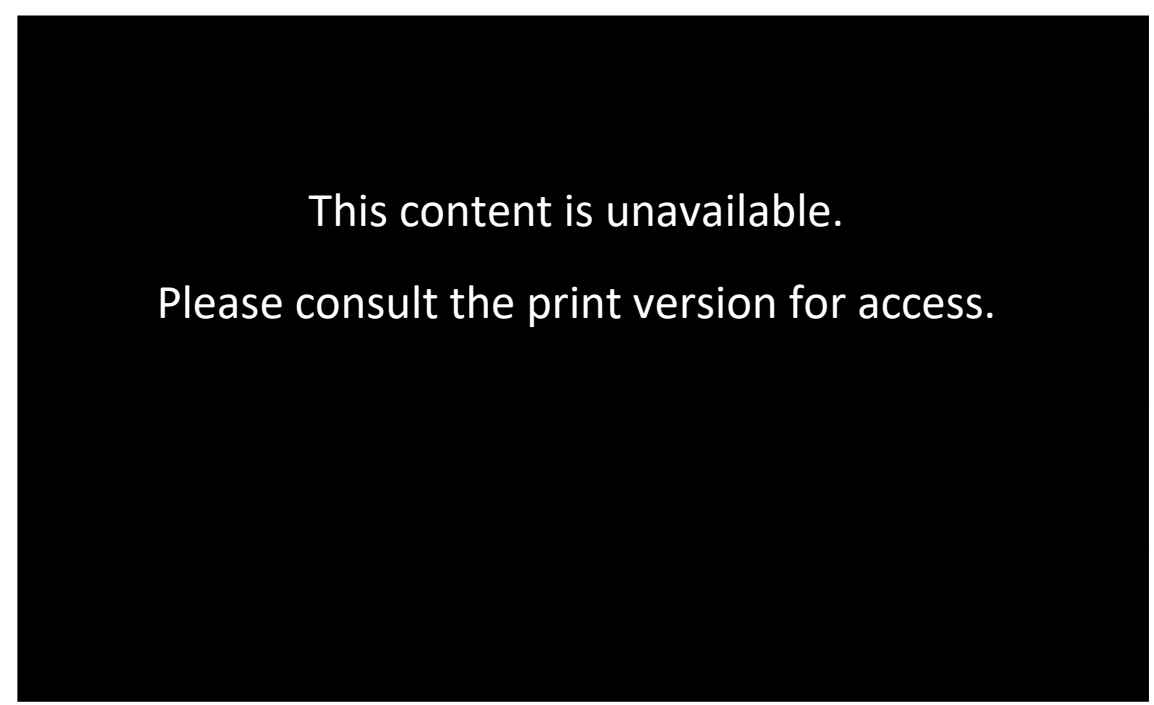

Figure 2.13: Aladdin Readi-Cut House and Sears, Roebuck \& Co catalogue (Arieff and Burkhart, 2002, p.14)

During the first 25 years of the 20th century, the prefabrication industry was highly influenced by the innovative designs of Frank Lloyd Wright and Grovsner Atterbury in the USA and Le Corbusier in Europe. Frank Lloyd Wright designed a series of pre-cut houses in timber and produced more than 900 drawings to provide a collection of ready-to-go houses for Americans, with the minimum need for onsite carpentry. Frank Lloyd Wright released his design just a few years after Sears (Figure 2.14), which was one of the most active promoters of prefabrication of houses in the early 20th century (Bergdoll et al., 2008, pp.48-50). 


\section{This content is unavailable.}

\section{Please consult the print}

version for access.

Figure 2.14: Advertisement for model no.146. Sears, Roebuck \& Co (Bergdoll et al., 2008, p.49)

Grosvenor Atterbury believed a change in technology to be the only way of providing affordable houses, and between 1902 and 1907 developed a cast concrete prefabricated panel system (Jara, 1996; Pennoyer et al., 2009) (Figure 2.15 and Figure 2.16).

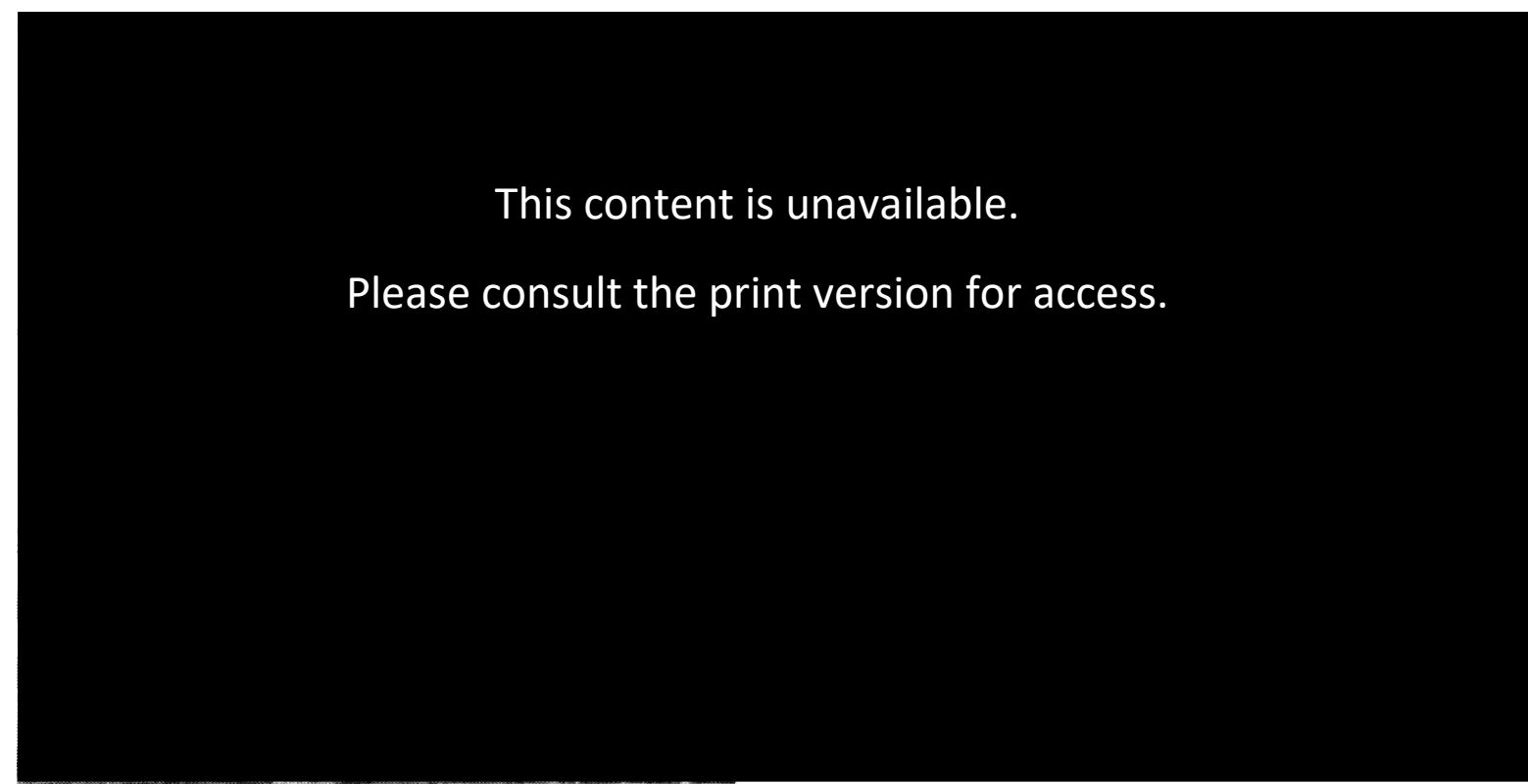

Figure 2.15: Pre-Cast Construction, Sewaren, New Jersey, 1918 (Jara, 1996, p.2)
Figure 2.16: Suburban house, New York

(Bergdoll et al., 2008, p.16)

In 1914 Le Corbusier introduced his innovative concrete structural building system that formed the Dom-ino house (Figure 2.17). The system comprised concrete slab floors and thin reinforced concrete columns which meant the elimination of load-bearing walls and divided the building into the two independent parts of structure and envelope. This division meant that the facade, interior parts, and windows could be designed freely without affecting the 
structure (Sendai, 2010). The system thus had elements of prefabrication in that a standardised structure could be customised in many different ways.

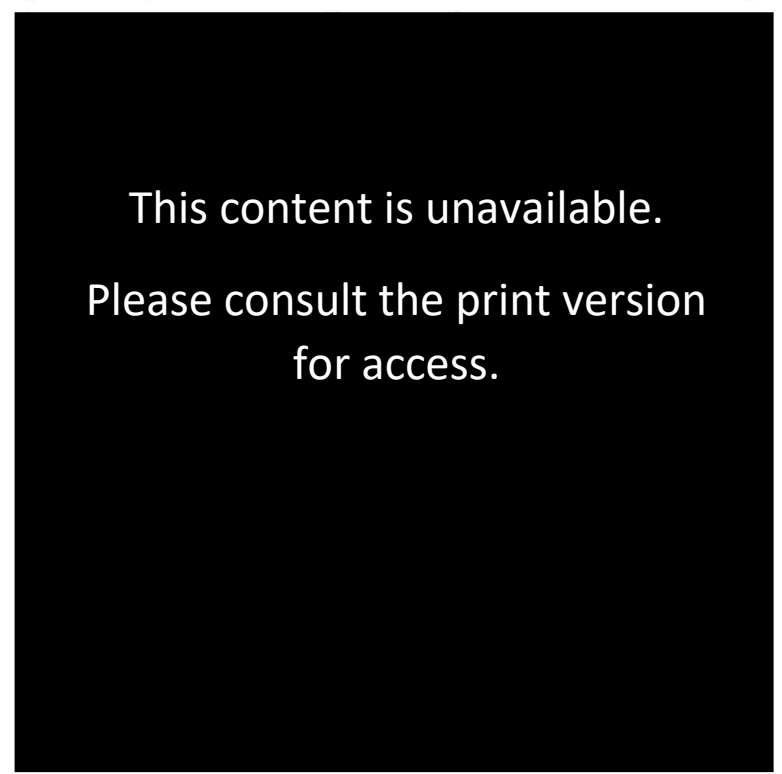

Figure 2.17: Dom-ino system (Anderson, 2017)

Both world wars can be labelled as one of the most important milestones in the expansion of prefabrication. During both World Wars, many factories changed their function to serve the war effort. In the UK and other countries, the draft reduced the availability of men to work in factories or build, leading to a significant shortage of houses, while the focus on the manufacture of war goods led to a shortage of building materials (Historic England, 2011). During the time, there was an urgent need for buildings for the armed services and these needed methods of construction with less on-site work which used materials more efficiently. This gave a spur to prefabrication as this method was potentially more efficient than traditional methods (see Section 2.2.5).

After WWI the shortage of both houses and materials gave a spur to prefabrication. In 1927 for the first time in Scotland more than 20,000 non-traditional houses with some type of prefabricated system were completed (O'Neill, 2016). Some, like the Atholl and Weir systems, had walls of steel plate, using the skills developed building ships for the war effort (Ministry of Works, 1944, pp. 80-84). However, the poor quality of joints and ventilation, and lack of sufficient thermal mass and resistance to the flow of heat meant these houses needed a lot of heating. There were other ventures in prefabrication in this period. The first was the many systems that used concrete, beginning with Atterbury's 1918 standardized prefabricated hollow concrete slab houses at Forest Hills Gardens (Pennover et al., 2009, pp. 255-265). 
Concrete was so used so often by house prefabricators in the USA that, in the 1934 review of 98 illustrated systems of prefabrication by Bemis and Burchard, and based on the major material in hybrid systems, $50 \%$ were of concrete, $38 \%$ of steel, $10 \%$ of wood and $1 \%$ of plastic (Vale and Skinner, 2018). These developments in concrete prefabrication were to lead to the many panel based systems developed for apartment housing because of the speed these offered, though many also suffered from poor indoor environments and lack of comfort.

Another boost to prefabrication between the wars came from the need to provide temporary accommodation for workers on big infrastructure projects, such as the dams built in the USA under the aegis of the Tennessee Valley Authority. These demountable houses were of wood and came in sections that could be transported on public highways (Huxley, 1943, p. 112; Herbert, 1984, pp.230-231). This, in turn, gave rise to associating prefabrication with temporary and trailer based housing. In 1933 just three months after becoming president of the United States, Roosevelt aimed to solve the poverty and flood-related issues along the Tennessee River by building dams across it, which led to building 18 dams in 10 years (Vale, 1995, p.44). The builders of these dams needed large numbers of houses in a short period, together with the ability to move them from one site to another every three to six years. To achieve this it was necessary to do as much work as possible in the factory to reduce the amount of onsite work (Vale, 1995, p.45). The scheme resulted in building more than 10,000 dwellings in 6 different types of prefabricated unit. There were innovations such as houses that could be finished or extended later by their occupants and extendable, portable trailer houses (Culvahouse, 2007, p.40; Vale, 1995, pp.45-49).

During WW II the armed services again needed buildings and one of the most recognized prefabricated constructions during this period was the Quonset hut. "Approximately 150,000 to 170,000 units of these funny half dome-shaped houses were built during the war" (Chiu, 2012, p.10). The Quonset hut project was begun in 1937 when President Roosevelt was trying to prepare the United States for the upcoming war. This preparation included the development of twenty-five additional air bases, both in the USA and overseas, including at Quonset Point. The construction was started on July 16, 1940, by George A. Fuller's company and the Scott Corporation under the NOy-4175 contract (Chiei and Decker, 2005, p.1). By 1941 the United States Government added a supplement to NOy-4175, 
"...to develop and produce a new prefabricated hut system to shelter troops abroad. These buildings would need to be designed for mass production, able to be portable, erected and knocked down quickly and easily, adaptable to any climate and geography, and provide soldiers with the most protection and comfort possible...the team was directed to use the British Nissen hut as the starting point for their design" (Chiei and Decker, 2005, pp.3-4).

The Quonset hut design team decided to use the Nissen hut as the basis of the design. The Nissen hut had been designed during WW I by the Canadian engineer Peter Nissen, as a cheap, portable shelter for the British Army (Figure 2.18). The Nissen hut, which was made of corrugated sheet metal pulled into a half cylinder and fixed on brick foundations, could be used for different functions such as a shelter, hospital, or armoury (Florian, 2013; Chiei and Decker, 2005, pp. 5-7). The Nissen hut has also been claimed as the first mass-produced prefabricated building (Mallory and Ottar, 1973. 81). It was easy and fast to transport and could be assembled by unskilled workers but it had weaknesses. The biggest was the lack of thermal insulation which made the hut cold in winter and hot in summer (George, 1937, p.63).

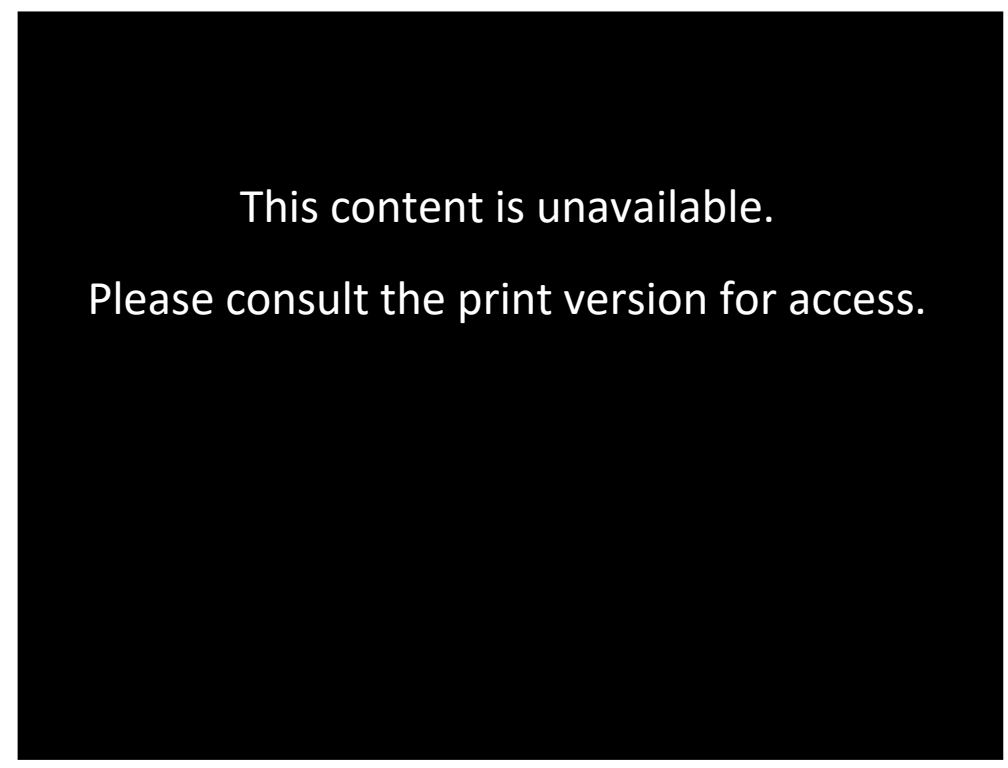

Figure 2.18: Nissen hut details (keywordbasket, 2019)

As soon as the Quonset team started working on Nissen's design they found problems, mostly related to lack of insulation, which made the huts hard to live in. The team modified the design and built prototypes (Figure 2.19). On April 4, 1941, the first version of the final drawings appeared under the title of " 16 ' $\times 36^{\prime}$ Hut" $(4.9 \mathrm{~m} \times 11.0 \mathrm{~m})$ and on May 15, 1941, the final drawings were submitted (Chiei and Decker, 2005, p.7). The design which included two sizes 
of a $20 \mathrm{ft}(6.0 \mathrm{~m})$ and $40 \mathrm{ft}(12.2 \mathrm{~m})$ span was accepted and the Davisville facility fabricated some 32,253 Quonsets and exported most of these (Garne, 1993, p.56). The smaller version $(20 \mathrm{ft} \times 48 \mathrm{ft})(6.0 \mathrm{~m} \times 4.7 \mathrm{~m})$ weighed about 6 tonnes and could be erected by eight men in one day. It could accommodate a squad (approximately 10 men) and could also be moved if required. The larger version could accommodate two squads and included a latrine. The hut was mainly made of metal, with headers, sills, hinged windows, bulkhead framing, and floor decking of wood (Garne, 1993, p. 56). Initially, the primary outputs of the assembly line were unpainted galvanized curved iron huts which reflected the sunlight and increased their visibility for the enemy, so later ones came out painted to reduce the reflection. By 1942 special export packaging was provided to make the transportation easier (Manning, 1947, p.161).

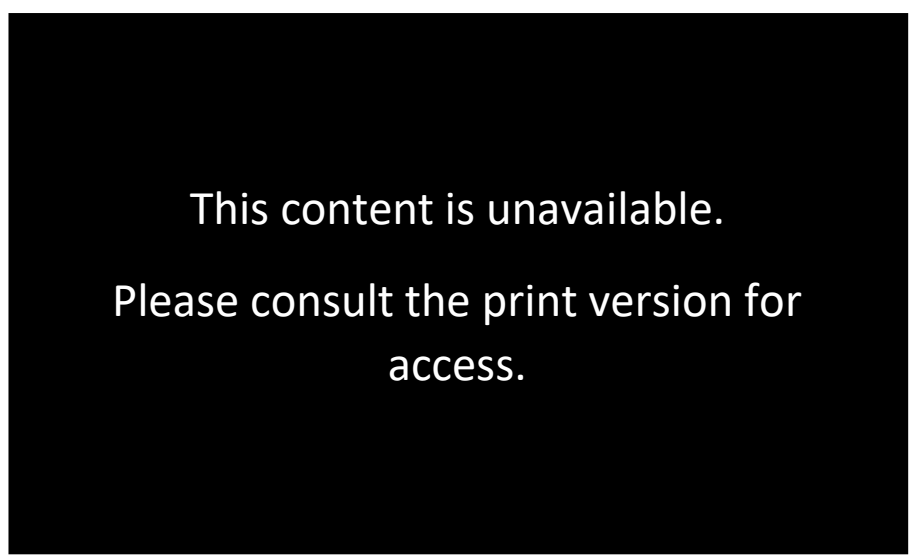

Figure 2.19: Quonset hut guideline (Chiei and Decker, 2005, pp.10-11)

By the last year of WWII, after six years of war, 475,000 houses in the UK were destroyed or uninhabitable (Barr, 1958). Again, the need for a new method of construction which was faster and more efficient continued in the face of a shortage of conventional building materials and labour (Turner and Partington, 2015; Waskett, 2001). In addition to the need for more houses in less time and using non-conventional materials and unskilled workers other reasons, especially in the UK, were a shortage of work and the need to find jobs for the demobilized troops (Gay, 1987). This ready market led to considerable further investigation into the prefabricated house industry in the post WWII years. During this period countries the USA and Japan overcame the barriers to such an industry and gained temporary success but others, including many European countries, failed to do this (Bell, 2009).

In 1944 UK Prime Minister Winston Churchill released his plan for constructing approximately 300,000 permanent and 500,000 temporary houses without increasing demand on 
conventional building resources and skilled labour (Historic England, 2011; Finnimore, 1989). The result was the development of non-traditional houses, many of which drew on the systems used for wartime huts and other buildings. This led to problems related to sound and thermal insulation, and fire resistance (Hayes, 1999, p. 54; McIntyre and Stevens, 2010; Nash et al., 1954). There were also serious concerns over the quality of these prefabricated houses as there was an attitude of valuing quantity over quality in their design and construction (Hashemi, 2013). More importantly, the 1944 temporary houses in the UK were designed to last approximately 10-15 years, but most were used for much more than this period of time, which led to defects and leaks (Harrison et al., 2012). In fact although "some 156,623 temporary bungalows were produced for rent under the aegis of the 1944 temporary housing program" (Vale, 1995, p. 1), the program was wound up because it was considered to be too expensive. The prefabricated temporary houses had cost more than expected.

From 1945 to 1947, the UK government gave a heavy subsidy to non-traditional construction methods so as to encourage their use (Hayes, 1999). However, once the subsidies were cut in 1947, prefabricated buildings failed to compete economically with traditional methods, in part because they needed the application of new technologies in different stages of manufacturing, transporting, and assembling. Prefabrication is most efficient when used for larger numbers of buildings, but it has higher start-up costs than conventional house construction. The costs of creating suitable designs, factories in which they can be made by a specially trained workforce under appropriate management systems, and systems to transport and place buildings on-site all have to be paid for before even one house has been completed. This capital investment continues to be a problem for prefabrication-based construction companies, which in turn can lead to financial institutions treating prefabrication companies as having a greater risk than conventional construction businesses.

Those promoting prefabrication continued to struggle with the post-war financial crisis and shortages of materials and manpower (Finnimore, 1989; Hayes, 1999). Moreover, in the 1950s off-site construction was hampered by site delays, the inability to stay with in expected costs, and the inability to estimate realistic on-site man-hours (Hayes, 1999). As Mckean (1995), and Piroozfar and Farr (2013) have noted, there was also a conflict between manufacture-based production of houses and the aesthetic side of architecture. Hashemi (2013) also pointed to a lack of policy post-WWII for monitoring buildings constructed using 
new technologies. These weaknesses combined to cause problems, such as the 1968 collapse of Ronan Point, a 21-storey prefabricated, panelised London tower block which collapsed following a gas explosion. These problems affected the success and acceptance of prefabrication (Pearson and Delatte, 2005).

After WWII, Richard Buckminster Fuller proposed turning the Beach Aircraft Company in Wichita into a company for the mass production of houses. His aim was to use the factory materials, tools and production line to prevent the closure of the factory and loss of jobs (Bock et al., 2012; Mrkonjic, 2007). The final design was a prototype called the "Wichita House" (Figure 2.20), which has been called one of the most important prefabricated house of the 20th century (Bell, 2009, p.46). The house had a circular shape based on a tensile frame cantilevered from a central column fixed to the ground, making the house appropriate for sloping sites (Mrkonjic, 2007; Bell, 2009). However, these houses were never put into production and the prototype was purchased by William Graham, who was one of the investors. Graham assembled the house and modified it to suit with his family needs. When Graham died his family donated the house to the Henry Ford Museum (Schnyder, 2016).

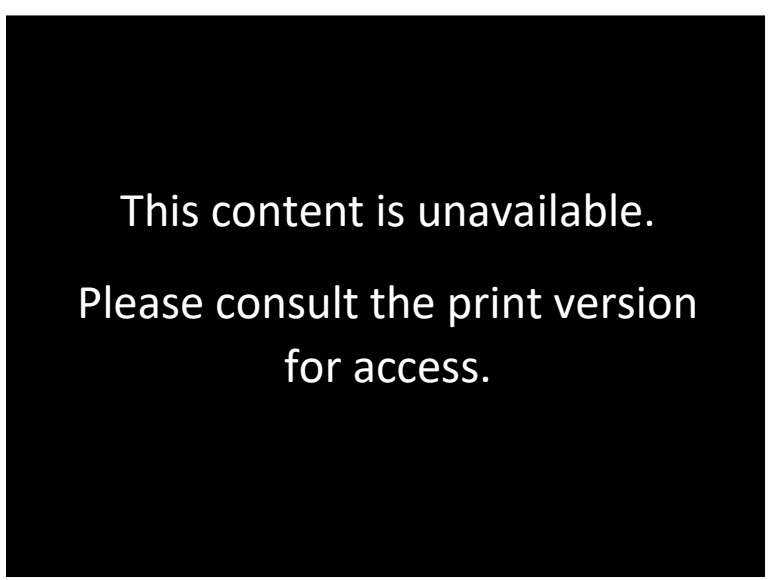

Figure 2.20: Wichita House 1946 (Prefab, 2009)

The contemporary prefabricated housing industry in the USA is believed to have grown not out of attempts like those of Fuller to make the house in the factory, but out of the manufacture of mobile houses in the 1950s (Xu and Zhao, 2010) (Figure 2.21). These houses were the first steps on which the industry developed in subsequent years. Mobile houses became accepted by a large number of Americans, and by 1960 around $15 \%$ of all houses in the United States were mobiles (Bell, 2009). The number of mobile homes increased by 10,000 between 1950 and 1960 in the USA and reached a total of 163,000, where the growth 
was even sharper in the next decade achieving 400,000 in 1970 (Bell and Southcombe, 2012, p.26).

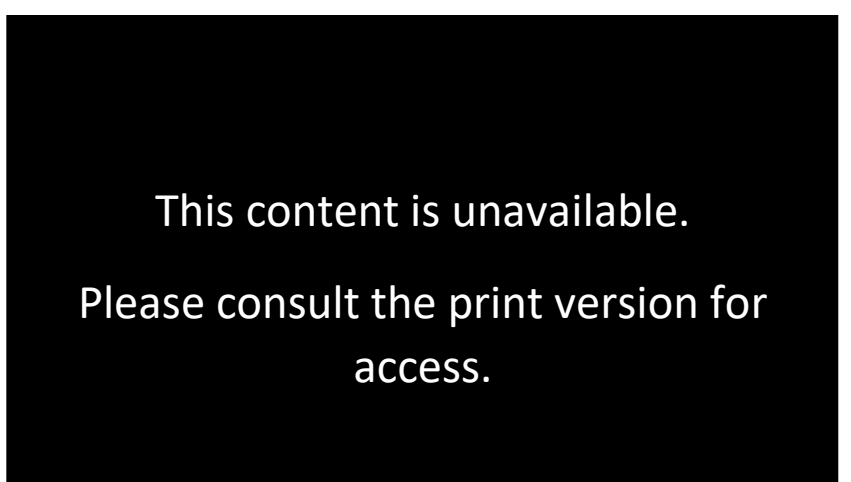

Figure 2.21: Mobile home in the United States, the 1950s (Airstream, 2019)

\subsubsection{Prefabrication in New Zealand}

The Maori people as the first settlers of contemporary New Zealand arrived around A.D 800. Their settlements usually consisted of separate houses, such as sleeping houses, cooking shelters (Kauta) most of which included an earth oven (Hangi), storage (Pataka or Whata), latrines and middens, and open spaces (Marae). Each of these with its particular function would work together as a unity to form a dwelling place (Salmond, 1986). These houses were simply built of on-site materials and used traditional construction techniques (Figure 2.22).

Pre-1800 Maori used traditional techniques for raupo house construction. These involved bundling of clumping of six to eight raupo (bulrush) stems into $300 \mathrm{~mm}$ wide vertical panels with flax strips. These were then bound prior to attaching to an independent timber-framed structure, which enable a very orderly and fast fixing technique and construction. This is an early application of the prefabricated process. (Bell and Southcombe, 2012, p.49)

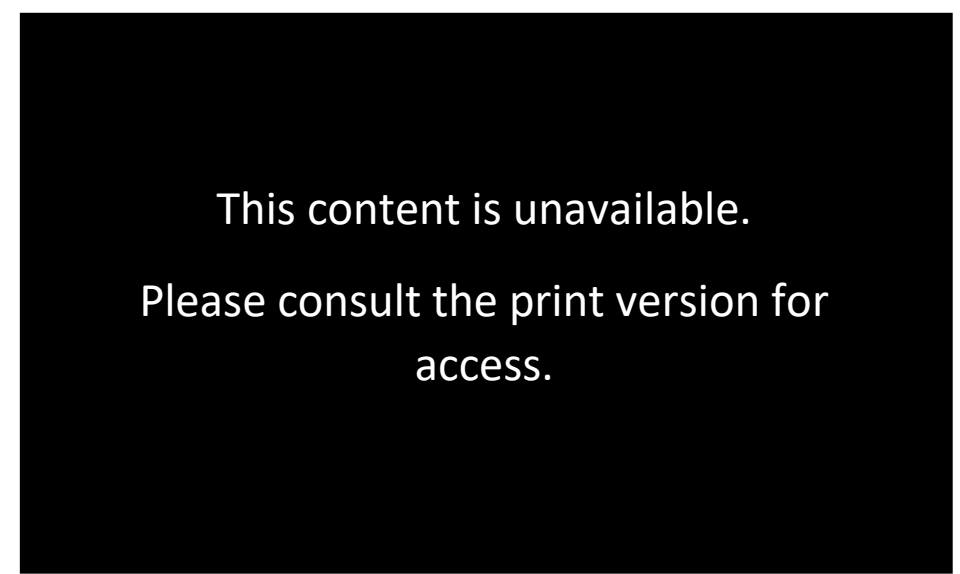

Figure 2.22: Cluster of houses in Queen Charlotte Sound (Salmond, 1986, p.19) 
The need for a new type of construction arose with the whalers and sealers, who arrived in New Zealand in the late 18th and early 19th centuries (Owen, 2007). These first arrivals did not have the time or tools to build houses so they had to spend their first days in temporary shelters. Later they brought tools and this affected the way the Maori people built their houses and lived in them.

The first prefabricated house in New Zealand has been reported as early as 1806 . This house had been imported as a gift from Governor King of New South Wales for Te Pahi, the Maori chief. The house was erected in the Bay of Islands and later burned down in a dispute with some whalers (Vale and Pooley, 2002).

The need for shelter for the first European arrivals and the economic benefits for carpenters and builders in Europe (mostly England) provided a good opportunity for exporting prefabricated houses to New Zealand, as these were easy and fast to assemble in large quantities (Salmond, 1986). The prefabrication industry in New Zealand started with the importation of prefabricated houses for individuals around 1833. These houses were imported from the United Kingdom, the United States, and Australia as kits and pre-cut frames (Bergdoll et al., 2008; Toomath, 1996). At that period the number of early European settlers who came to the country increased, so the industry rapidly extended in response to the progressive needs of migrants for a permanent dwelling (Isaacs, 2008).

Between 1840-1850 more than 26,000 Europeans, coming mostly from England, arrived in New Zealand and all with an urgent need for shelter. This huge number of migrants caused rapid growth in the industry and importing prefabricated houses to New Zealand became the starting point for manufacturing prefabricated houses in the country. In 1849 Kauri Houses exported some prefabricated houses to the United States during the Gold Rush (Salmond, 1986). The company had also exported at least seven houses to Australia by 1850 (Bell, 2009).

As early as the 1880s, the New Zealand Railways Department (NZRD) became the first mass producer of prefabricated housing in the country (Figure 2.23), eventually producing around 1,600 houses between 1920-1926 (Moardibistouni and Gjerde, 2017). The NZRD Frankton factory was established in 1920 and sent prefabricated houses to different parts of the North Island using the railway. These pre-cut houses, which were produced in less than two days in 
the factory, could be erected in less than two weeks by two men (Bell and Southcombe, 2012, p.50). Five years later in 1925, the railway scheme and the Hutt Valley Land Settlement Act provided a full housing package for house owners, including houses from the Railways Department, land serviced by the Lands Department, and a special loans scheme from the State Advances Corporation (Bell, 2009). Using prefabrication methods provided a context for using unskilled labourers to build houses and made the national public house scheme, which had been started in 1937, one of the best examples of its type around the world (Brookes, 2000, p.139) (Figure 2.24). Three years later in 1940 soldiers coming back from the war joined the construction body to erect prefabricated houses to save time and money in that critical period (Schrader, 2005, p.99).

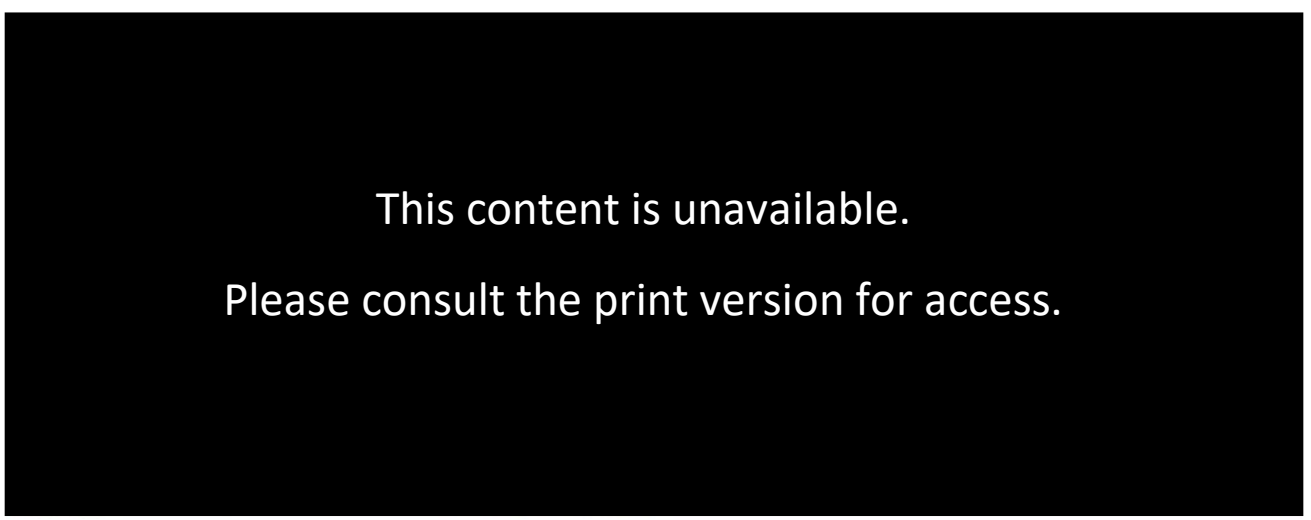

Figure 2.23: Typical railway house elevation, plan AB 1123, Factory Cut (Leah, 2015)

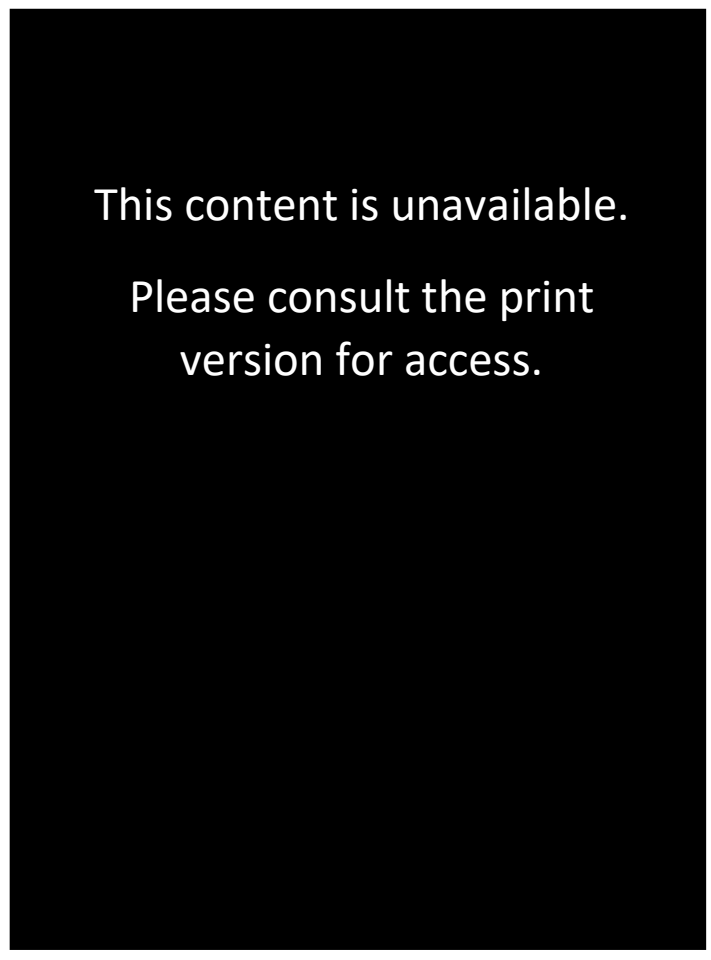

Figure 2.24: National public house scheme (Schrader, 2005, p.91) 
During WWII, most factories in New Zealand stopped their normal activities and aligned themselves with military needs, and more than 30,000 prefabricated huts for military camps around the country were produced (Bell and Southcombe, 2012, p.51). Around 1940, when the United States military was about to arrive in Paekakariki in the North Island, a manufacturing project was begun to provide shelters for them. The camps for these soldiers, which were manufactured in the South Island to provide a settlement for around 20,000 soldiers, were assembled in six weeks (Kinsella, 2012).

Between 1930 and 1950 when the TVA program in the United States was running, there was a similar project related to producing hydroelectricity in New Zealand. This project also needed houses for workers that could be assembled, disassembled and transported to remote areas. As a result, a number of prefabricated dwellings were built in the 1940s and 1950s for the Waikato Hydro Scheme in the north and in the 1960s and 1970s for similar schemes at Otematata and Twizel in the south (Bell and Southcombe, 2012, p.56) (Figure 2.25).

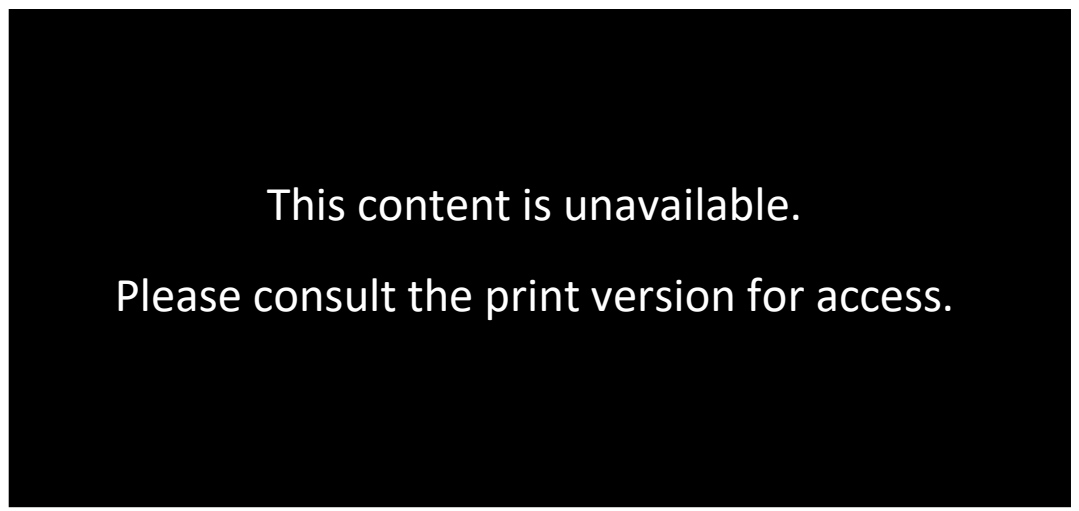

Figure 2.25: National Hydro scheme in Otematata (Kinsella, 2012, p.47)

Kinsella (2012) reported that at the time the idea was to build the same houses at both Otematata and Twizel, but later due to differences in the climate and site, recommendations included changes in size, adding insulation, having a shower and separate indoor toilet, and providing a stainless steel basin and wet-back stove (for water heating).

250 of these houses were built at Otematata, this was not going to be enough and so De Geest Brothers Construction Ltd of Oamaru was contracted to begin production of the prefabricated modules at their factory. De Geest were eventually to construct 467 houses for Twizel at Oamaru and transport them to site by truck through the Waitaki valley. The housing was predecorated, papered and painted, with kitchens, laundries and bathrooms decorated in warm 
tones. Each house had also been allocated a variety of trees, shrubs and grass seed for the section and garages were provided at the back of the section. (Kinsella, 2012, p.75)

As with other countries, New Zealand was faced with a critical shortage of houses after WWII. At that time the government imported 1,000 prefabricated houses from England and Austria with half going to each of Point England, in Auckland and Titahi Bay, near Wellington (Kellaway, 1994; Vale and Pooly, 2002). However, later the government decided to stop importing prefabricated houses due to high transportation costs (Bell and Southcombe, 2012, p.52). Houses constructed during those times include in 1943 in Naenae Wellington five houses made of prefabricated wall panels, and for the years 1947-1949, five blocks of residential buildings made of prefabricated concrete panels in Petone. In 1948 twocomponent based houses from England made of aluminium were temporarily erected in Wellington (Bowren, 2007, p.83; Bell and Southcombe, 2012, p.52). In 1953, the government decided to motivate builders to build more houses to overcome the post-war housing shortage. To do this they guaranteed to buy houses built in groups of six or more that were still unsold two months after their completion. This scheme continued until 1963 when the urgent need for more houses had passed (Bell and Southcombe, 2012, p.56).

In 1951 two Dutch immigrants, Johannes La Grouw and Johannes Van Loghem came to Wellington and started their business of engineered timber system houses, which became known as Lockwood. They first imported these houses from Holland until in 1953 they moved to Rotorua to start their construction business. They built their first prefabricated house as a fishing bach for Doctor Morrow of Auckland in 1954 (Isaacs, 2008; Lockwood, 2017) (Figure 2.26).

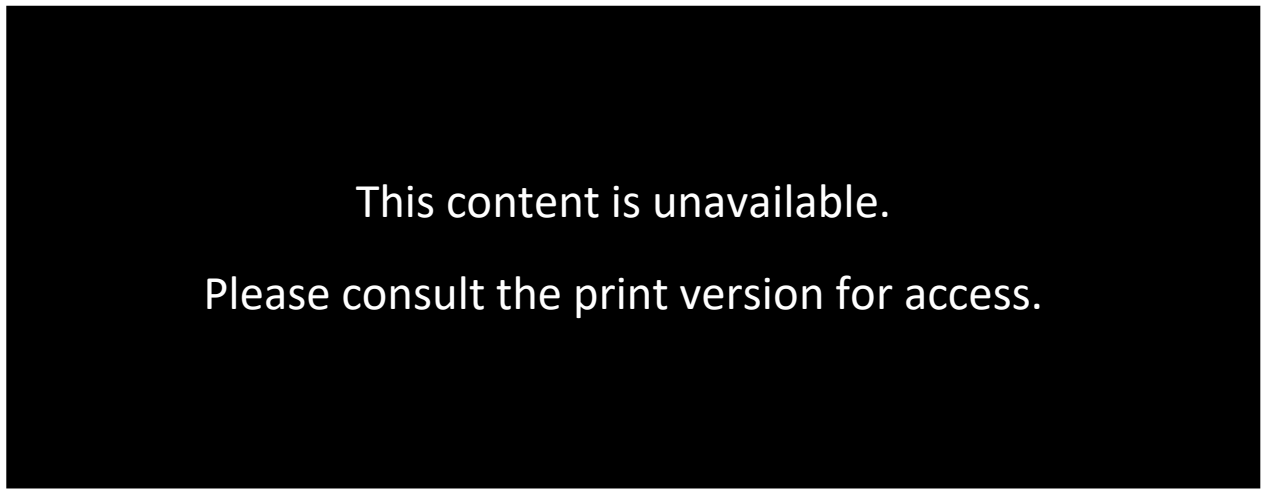

Figure 2.26: Jo La Grouw Senior's home being built in 1954 in Rotorua, New Zealand (Lockwood, 2017) 
In 1968 Keith Clark founded Industrialised Building Systems (IBS) with the ambitious aim of producing 1,000 houses per annum with at least $25 \%$ cost saving in comparison with conventional houses. However, this firm was to later collapse in the 1978 economic recession and after spending over $\$ 2.5$ million (Bell and Southcombe, 2012, p.26). It is not clear how many IBS homes were built during the time, but the main reason of the general unwillingness for buying them were firstly transport limitations. It was hard to carry them on New Zealand's narrow roads and also due to the transport rules, the houses had low steep pitched roof, make it different and unacceptable for buyers. Moreover, the market research showed only $12 \%$ cost saving, below the $25 \%$ target (Bell and Southcombe, 2012, pp.26-33).

Keith Hay Homes, which was relocating second hand houses and later making new relocatable houses, was one of the housing companies that managed to survive the economic recession in the late 1970s. Conecta and Lockwood, which were component-based prefabricated systems, also survived (Bell, 2009).

The number of manufacturers of prefabricated building components and whole buildings has grown during the 21st century in New Zealand. A web-based search (see Section 4.3) revealed that by 2018 there were more than 180 companies who felt they were part of the NZ prefabrication industry. This search found 51 companies which produced prefabricated houses or house elements. Based on this research, Figure 2.27 shows the timeline of the history of prefabrication in New Zealand. 
-The first prefabricated house in New Zealand was imported as a gift from Governor King of New South Wales for Te Pahi, the Maori chief.

- The prefabrication industry in New Zealand started with the importation of prefabricated houses for individuals.

- New Zealand Railways Department became the first and largest producer of prefabricated housing.

-Approximately 300 houses were produced by the Frankton factory, for railway housing around the North Island.

-The Dutch-born founders of Lockwood Buildings arrived in Wellington in January, and by April, the first Dutch-made, prefabricated steel framed house had been placed near Wellington.

- Lockwoods moved to Rotorua and started their own business designing, manufacturing and assembling prefabricated 'Lockwood' houses.

-Industrialised Building Systems (IBS) began under the leadership of Palmerston North
property developer Keith Clark with the aim of producing up to 1200 homes per annum,
or 25 per week.

Figure 2.27: Milestones of prefabrication in New Zealand 


\subsubsection{Potential Benefits of Prefabrication}

Prefabrication has potential benefits relating to the different parts of the act of commissioning a building. "Prefabrication can potentially offer 'more for less' and more quality for less time at the site, more known outcomes and fewer unknowns, and potentially more energy efficiency for less resource use" (Bell, 2009, p.35).

The construction sector and construction-related services are the fifth largest employer in New Zealand (after health care and social assistance, manufacturing, retail, and accommodation and food services), employing over 10\% of workers (Hunt, 2016). In 2017 the construction industry created $60 \%$ of the national GDP (Prefab NZ, 2018a). While the construction sector has a worker fatality rate almost triple that of any other sector, it has been shown that there are $75 \%$ fewer fatalities in factory-based construction compared to site-based processes (Hunt, 2016). This suggests there could be significant opportunities for cost savings for the government in subsidised medical services and other areas if more construction were to be factory based. Any move to prefabrication in the construction sector could potentially have a great effect on the economy, health, and quality of living in New Zealand.

Unfortunately, the construction sector is also responsible for creating $40 \%$ of landfill waste (Hunt, 2016). The literature shows prefabrication can reduce construction waste by $40-90 \%$ and $\mathrm{CO}_{2}$ emissions by 35\% (Gorgolewski, 2005, pp.125-126; Britto et al., 2008, p.14; Bell and Southcombe, 2012, p.16; Phillipson, 2001, p.3). Prefabrication is claimed to be $50 \%$ more efficient at using sources of energy, but it is not clear where this happens in the life of building (see Section 7.5.4), 30\% more efficient at using water, and $40 \%$ more efficient when it comes to using raw materials (Britto et al., 2008, p.14; Bell and Southcombe, 2012, p.16; Phillipson, 2001, p.3; Gorgolewski, 2005, pp.125-126).

Most of the environmental benefits of prefabrication come from having more control over the production process in the factory (Legmpelos, 2013). Design standardisation and tighter control over the production process in the factory can also reduce defects in the final product by up to 60\% (Phillipson, 2001, p.3; Gorgolewski, 2005, pp.125-126). Prefabrication is also more than $50 \%$ faster than traditional construction due to its repetitive nature. Being faster and based in the factory, materials and workers are less prone to natural hazards such as wind 
and rain, which also leads to higher safety. Faster construction is also important as a response to the growing demand for new houses (see Section 1.1.1). Moreover, factory-installed insulation can be better than that installed on site, leading to fewer cold bridges and fewer defects in the prefabricated building in comparison with a traditional building. Additionally, the construction site is less susceptible to damage caused by the construction process, which reduces local environmental impacts by 30-70\% (Gorgolewski, 2005, pp.125-126).

Prefabrication could be more economical in comparison with traditional methods of construction. A 2012 study by BRANZ shows that a reduction in house construction time can mean a saving of $\$ 1,000-\$ 1,600$ per week in New Zealand. Prefabrication also increases general productivity by around 10\% (Shahzad et al., 2013). Even a 1\% increase in labour productivity in the construction sector is worth $\$ 139 \mathrm{M}$ to the New Zealand economy (Hunt, 2016). This supports Nana's (2003) report in finding that a $10 \%$ increase in labour productivity would increase GDP by \$2B in the New Zealand economy. A Ministry of Business Innovation and Employment study (2013) showed that by 2020 in New Zealand potentially \$92M could be saved per annum on a total build value of $\$ 4.2 \mathrm{~B}$ by reducing the rental cost during construction, due to faster construction and also minimising the, changes during the work and site and weather based delays. These findings are similar to those of Taware and Taware (2017) who stated prefabrication is potentially much more economically efficient in comparison with traditional construction methods. The reasons given for this were a reduction in construction costs, reduction in construction time, and reduction in defects on completion. Additionally, prefabrication could decrease land holding costs, bank loan interest payment savings through time savings, and give increased profit by building more houses per year.

\subsubsection{Potential Weaknesses of Prefabrication}

Although prefabrication has many benefits, there must be perceived disadvantages that result in users still preferring traditional ways of building. There are also arguments that some claimed benefits of prefabrication need investigation. El_Abidi and Ghazali (2015) studied barriers to prefabrication in European countries, USA, Hong Kong, Malaysia and Australia. They pointed to the negative perceptions of prefabrication associated with past practices, shortage of skills, size/weight restrictions on truckloads, higher initial cost, monotone aesthetics, and inflexibility regarding design changes, project delivery, lack of comprehensive 
regulations and enough guarantees, and the supply chain. Fenner et al. (2017) also investigated the barriers to an extension of the prefabrication industry. Their results showed the negative perceptions were due to the higher initial cost, the time to establish the industry, greater emissions, design constraints, and the difficulty of making changes when product was being manufactured. Rippon pointed to transport limitations and constraints as the main issue, while Molavi and Barral (2016) cited craning and assembly limitations in addition to the transportation as the main drawbacks. Sanna (2018) also mentioned the negative perceptions of house owners and the construction industry toward prefabrication, mostly originating from their previous experiences of prefabricated buildings. Finally, Kelly $(1951$, p.87) pointed to the need sell prefabrication, stating "There can be no mass production without mass marketing."

Below the potential disadvantages of prefabrication have been classified into the five categories of negative perceptions, economic obstacles, weakness regarding regulation and guarantees, design capabilities, and transport limitations, for consideration in more detail.

\subsubsection{Negative Perceptions}

The public understanding of prefabrication must play an important role in the general acceptance of prefabricated buildings. Such understanding, however, is greatly influenced by historical views and especially the prefabricated buildings associated with WWI and WWII (see Section 2.2.4.1). At the time due to the urgent need for more houses, the focus was on quantity rather than quality and prefabricated houses were seen as temporary, usually having a shorter life span than traditionally made ones (Sanna, 2018). This means people's perceptions are based examples such as on mobile houses and manufactured homes which are light, loose, and often temporary without proper insulation, and these ideas have a long history (see Section 2.2.4).

"People have got the idea that it [prefabrication] means jerry-building, tumbledown shacks, caravans, shoddy work, ribbon development, draughts and leaks and everything that's bad in the building. The Government itself seems to hold the confused opinion that prefabrication means something temporary" (Vale, 1995, p.17).

Most householders believe prefabricated buildings are low-quality, and without aesthetic value, being the output of a repetitive, fully standardised, and non-creative mechanical process (Jabar, 2015). These negative perceptions, despite the fact the industry has changed 
considerably since the 1940s, are one of the main drawbacks against expansion of the prefabrication the industry.

\subsubsection{Financial Obstacles}

There are concerns about the depreciation of prefabricated houses, making them inappropriate as a rental investment (Phillipson, 2001). Financial institutions prefer to invest their money in more traditional projects which, they think, will have less depreciation. Given the high initial costs needed for buying parts from the factory, as usually the client needs to pay all the cost of the project at the beginning rather than in different stages, financial institutions have no interest in granting loans for these projects (Khatavkar and Joshi, 2015). Prefabricated buildings are not seen as a logical investment from the investor's point of view mostly due to misunderstandings of the prefabrication industry (Moardibistouni and Gjerde 2017). To buy a prefabricated house, more money should be paid at the first step to buy the house, than a conventional house that the money can be paid during the construction process, which is longer, so buyers are more dependent on financial institutions loans.

The other important economic point is the fact that prefabricated houses require a high level of system standardisation in factories and the final cost of each house produced is highly affected by the number of houses sold in a year. "Among manufacturers surveyed [Canada], only those producing an estimated 500 or more residential units a year were found to operate integrated and automated systems mainly for the production of the roof and floor trusses" (Lapointe et al., 2006, p.7). So, if the number of houses sold by each manufacturer does not meet the target, prices go up to cover the fixed costs and justify the production.

\subsubsection{The Weakness of Regulations (monitoring) and Guarantees}

Prefabricated buildings need extra monitoring during manufacturing, transporting and assembly in comparison with traditional buildings due to the fact that components are built in one place and joined together in another (Khatavkar and Joshi, 2015; Steinhardt et al., 2013a; Patel and Sharma, 2015). However, since the prefabrication industry is relatively new, no suitable rules yet exist to monitor such issues at these stages (Wilden, 2002). Despite the risk of damage especially during transportation, most manufacturers do not provide a reliable guarantee and a minority only guarantee their product for a limited time (Wilden, 2002). For example, the Queensland Home Warranty Scheme, which protects consumers and builders 
against a wide range of problems such as defects in construction during the contract, or even after moving into the building after construction, does not cover off-site prefabricated buildings (Queensland Building Services Authority, 2009). Consequently, the industry needs clear rules for monitoring the components during production, transportation and assembly, and needs to provide adequate guarantees to consumers.

\subsubsection{Design Capabilities}

Prefabricated houses are known to have less design variety than traditional buildings, and usually they can only be erected on a flattish site (Chiu, 2012). Besides the structural limitations, another important obstacle to creating variety in prefabricated buildings is the physical characteristics of the components. The size and weight of elements should be considered carefully during the design process because of transportation and logistics issues (Javanifard et al., 2013) and this often leads to optimum sizes for these, which limits design possibilities. Variety in design plays an important role in the acceptance of prefabrication. Schoenwitz (2014) studied customer's perceptions of prefabrication in Germany and found over $90 \%$ of respondents preferred to have some choice at the time of buying a prefabricated house (Figure 2.28).

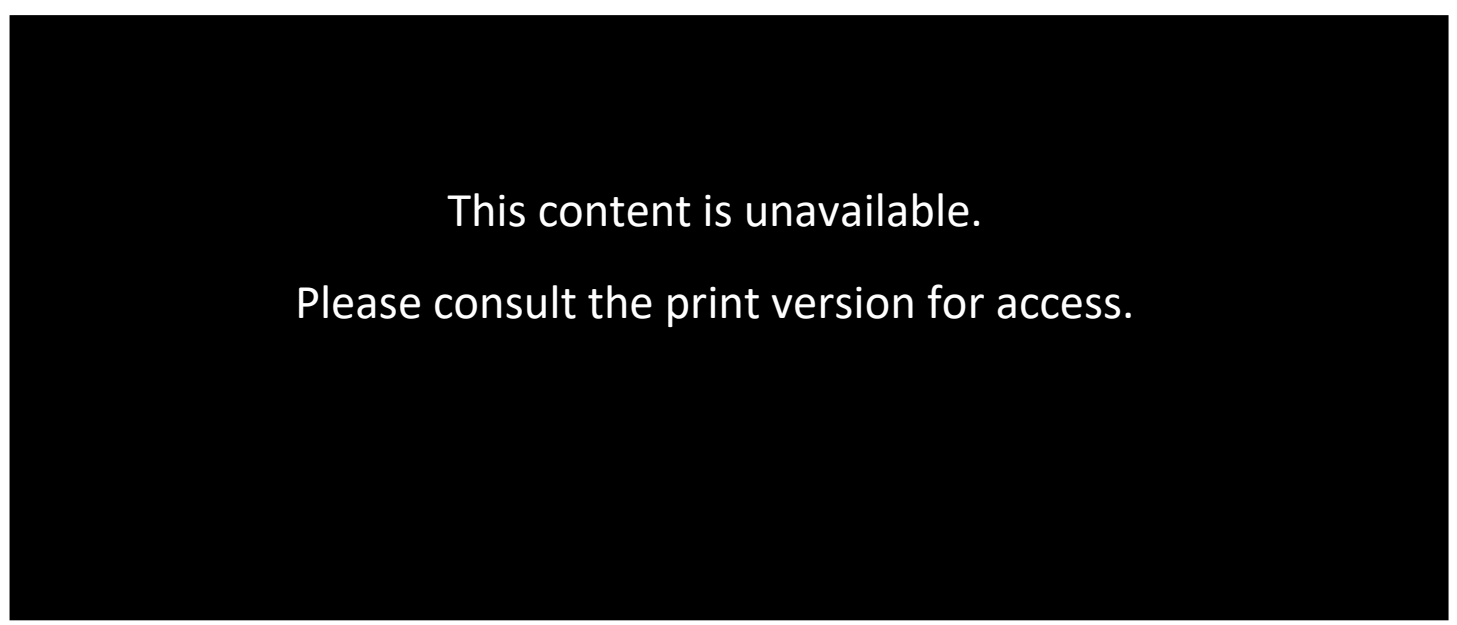

Figure 2.28: Importance of component choice (Customer rating - Germany) (Schoenwitz, 2014, p.162)

\subsubsection{Transport Limitations}

Transporting prefabricated houses of all types from the factory to the site is one of the most important obstacles to the expansion of the industry (Rippon, 2011). Transporting large and heavy prefabricated elements needs time in preparation to meet the legal requirements which adds cost to projects (Lu, 2007). Moreover, transporting prefabricated elements can 
lead to increased energy consumption and GHG emissions, which should be considered as a potential disadvantage of prefabrication. BRANZ conducted research to see how GHG emissions (excluding embodied emission) change based on the method of construction based on a $120 \mathrm{~m}^{2}$ transportable house (Burgess, 2013). The result (Figure 2.29) shows using transportable, panelised, and hybrid prefabrication systems can reduce total emissions, with the majority of the reduction occurring in the waste and construction categories. Looking just at transportation emissions, on-site construction releases more $\mathrm{CO}_{2}$ than all types of off-site construction.

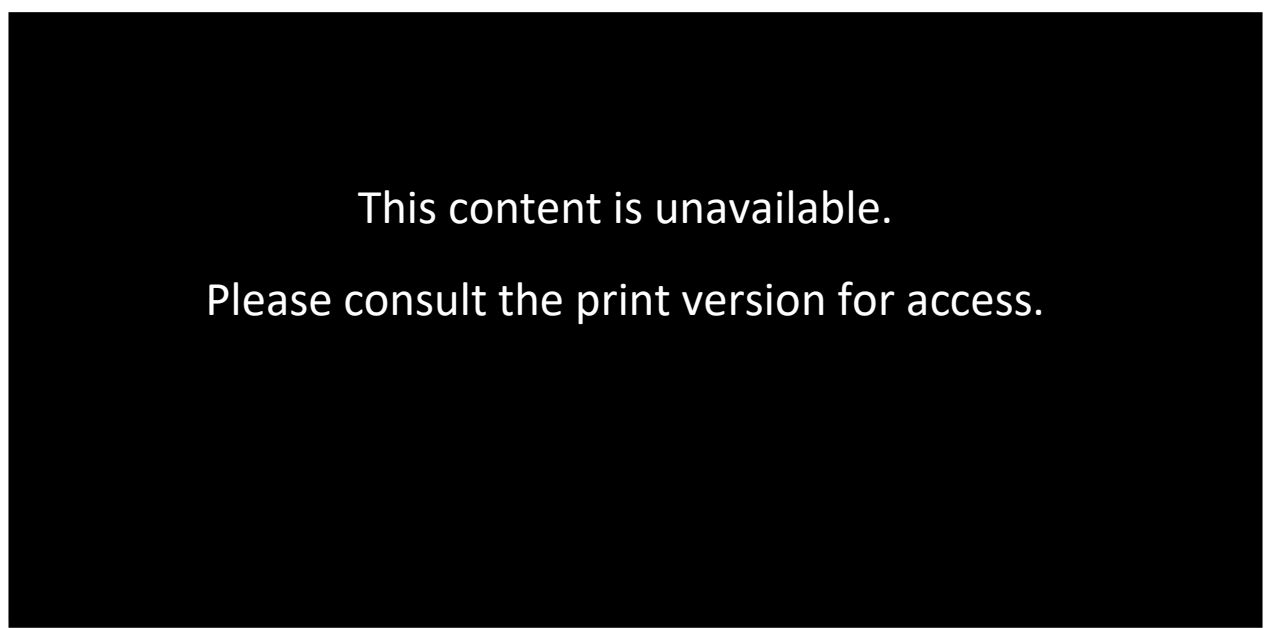

Figure 2.29: GHG emissions using four different construction approaches (Burgess, 2013)

\subsubsection{Uptake of Prefabrication in New Zealand}

This section gives a more detailed view of the prefabrication industry in New Zealand. It starts with a comparison of prefabrication uptake with other countries and continues with projections regarding how the use of different types of prefabrication are expected to grow. The results of an extensive online survey of the manufacturers of prefabrication elements in New Zealand are presented in Chapter 4.

Looking at the potential benefits of prefabrication it worth looking at the uptake of prefabrication in New Zealand compared with other countries (Figure 2.30). It is notable that uptake of prefabrication in New Zealand increased by $5 \%$ compared the previous year of 2012, reaching $32 \%$ of all residential buildings in 2013 . This is lower than Finland where $50 \%$ of houses are prefabricated and much lower than the $90 \%$ of houses in Sweden. The majority of houses that make use of prefabrication in New Zealand used prefabricated wall framing, roof trusses, windows and joinery, with less than $2 \%$ of all buildings being completely prefabricated. In 2013 over 91\% of all walls and 95\% of all roof trusses in New Zealand were 
prefabricated (Burgess et al., 2013). Burgess et al. (2013) also investigated the percentage of new prefabricated residential building in New Zealand by value finding this reached around 32\% in December 2013, compared with 23\% in 2012. The uptake in New Zealand is far higher than in Australia and the UK, but this could be due to the different classification system and data collection methods.

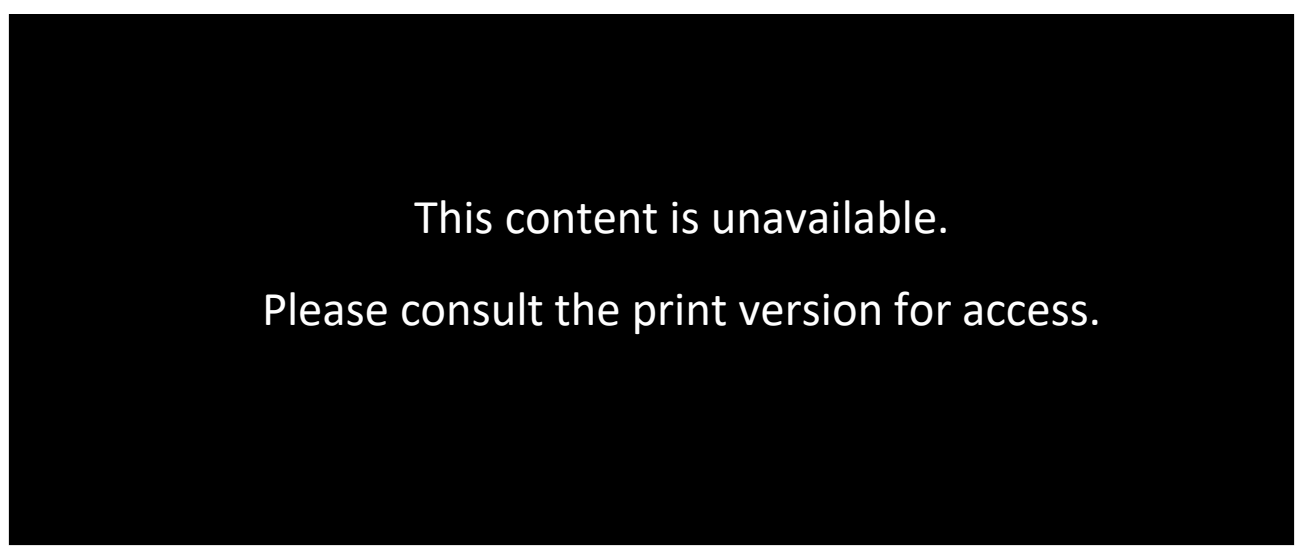

Figure 2.30: Percentage of residential buildings using the prefabrication method (Prefab NZ, 2015a) $)^{1}$

The uptake of prefabrication in New Zealand grew to $44 \%$ by 2015 (Figure 2.31). It would seem that the number of houses with at least one prefabricated element begins to approach 100\%. Figure 2.31 compares the uptake of each type of prefabrication in New Zealand in 2015 with the predicted uptakes by 2020 and 2025 .

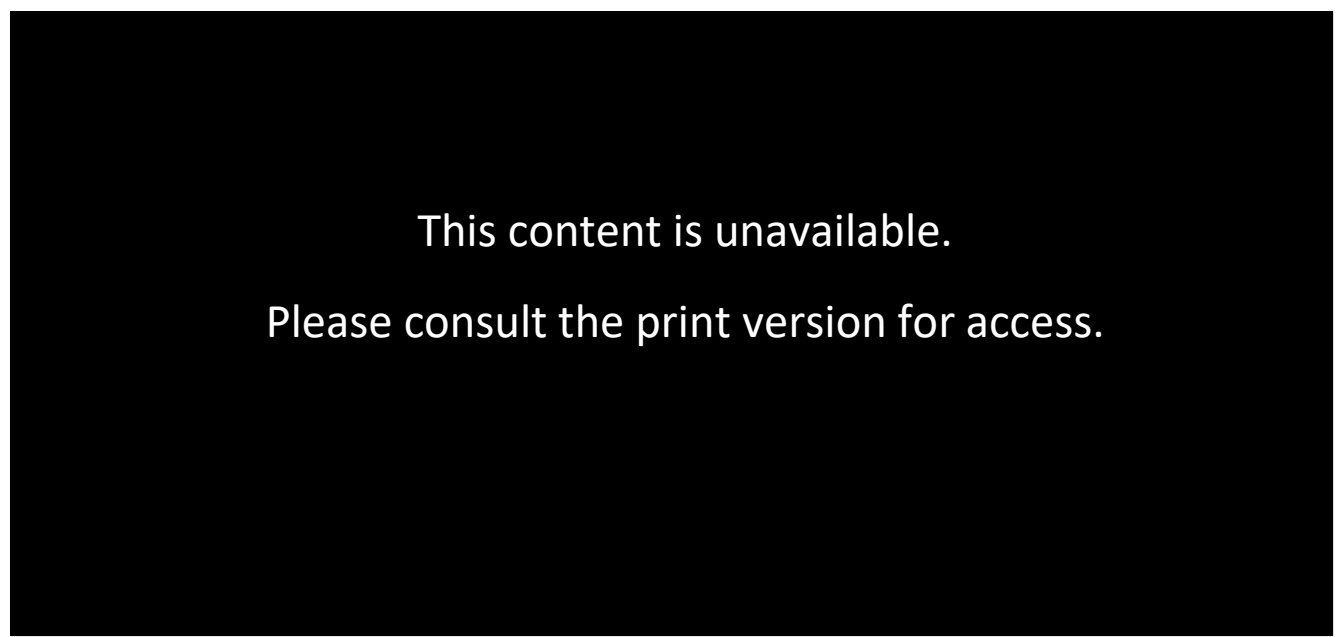

Figure 2.31: Predicted uptake of prefabrication in New Zealand (Prefab NZ, 2015b)

\footnotetext{
${ }^{1}$ Data was produced in different years: New Zealand 2013 and USA 2008. Some countries, like New Zealand, include all types of prefabrication, while others just include only one or two types, owing to lack of consistent data.
} 
Figure 2.31 shows the use of prefabricated components is the highest in both 2020 and 2025 with a $30 \%$ growth in each period. Panelised prefabrication uptake has tripled by 2020 and doubled again in the next five years. Uptake of modular, hybrid and complete buildings, grows even more sharply, as people become more interested in higher degrees of prefabrication.

\subsection{Accessory Dwelling Units}

Accessory Dwelling Units (ADUs) are additional dwellings placed on an existing plot (or 'section' in New Zealand or 'lot'). As such they could potentially respond to the multiple housing related needs of New Zealand. In the 21st-century, as discussed, the shortage of houses, along with amenity, overcrowding, and housing affordability, has become a worldwide crisis (Li, 2014, p.1). Financial difficulties and a shortage of urban land have made the crisis worse (see Section 1.2). Lack of new land for construction has pushed up the price of existing land and consequently the price of houses, which in turn has also raised rents for those who cannot afford to buy, making their ability to save for a deposit on a house even less viable (Wetzstein, 2017, p.14; Li, 2014, p. 1). Meanwhile homeowners have become richer on paper, and if they chose to move to a smaller and cheaper house can realise some of this 'money' as cash. In doing this they compete with people trying to buy a small, first house and this leads to a rise in the number of people who do not own a house, and hence those who become more financially vulnerable. The shortage of houses has also pushed the New Zealand government into deciding to build more houses, as from 1969 to 1993 the area of the urban regions has trebled in New Zealand (Taylor and Smith, 1997). These newly developed houses access to roads and infrastructure before they can be used, which can put more pressure on both national and local governments and lead to more environmental issues.

The other need in developed countries, especially in New Zealand, is providing suitable houses options for older people as, from 1951 to 2000 the population aged 65+ increased by over 100\% (Khawaja and Thomson, 2000). The group is also predicted to keep growing in the coming decades (see Section1.1.2).

In this situation people, in both developed and developing countries often find themselves having to choose to live in low-quality accommodation or having to cut other expenditures, such as food, healthcare and education, to afford liveable accommodation (Wetzstein, 2017). 
Having neighbourhoods with a variety of housing options for groups of people, such as older residents, single parents, young couples, and transient workers, means having affordable and acceptable accommodation that will allow these groups to live within the same community (Cobb and Dvorak, 2000, p.16). One potential solution to this problem is the use of ADUs. ADUs could make a neighbourhood more flexible in terms of housing types and provide affordable houses for different groups of people with different incomes and needs using existing infrastructure (Simafranca, 2017; Levering, 2017; King, 2012).

\subsubsection{Accessory Dwelling Unit Definition}

ADUs are known by several terms and work in different ways (Table 2.2). The following paragraphs consider the different definitions of other researchers and practitioners in order to reach a clear definition of what this thesis means by an ADU.

Cobb and Dvorak (2000, p.17) defined an ADU as a residential unit in the same lot with the main house, which can provide all the necessary dwelling needs of its residents in the form of an accessory apartment or accessory cottage. In this version an ADU would usually provide independent facilities for sleeping, eating, cooking and sanitation. The American Planning Association looked at ADUs from a wider point of view, defining ADUs as autonomous living areas that can be located within the main house or away from the main house in the same lot (Hulse, 2015, p.1).

Krass (2013) pointed to the different terms used to describe ADUs, including 'mother-in-law units', 'granny flats', and 'accessory apartments'. Krass goes on to say ADUs are distinguished from shops, garages, basements or other outbuildings. However, ADUs which usually include a kitchen and bathroom which could be a conversion of such spaces or a standalone unit. The standalone unit could be added to the main dwelling space later on or it could be constructed at the same time (Carswell, 2012, p.5).

Either attached or not, ADUs are independent units, providing the facilities for the basic needs of their inhabitants, such as sleeping, eating, cooking, and sanitation (Tyre, 2008, p.13). Ross (2016, p.17) stated ADUs, which are smaller and secondary to the primary residence, usually appear only where there is existing infrastructure to provide affordable housing by using predeveloped land. 
Recently, Saville-Smith et al. (2017) published a report, as a result of the National Science Challenge, Building Better Homes (BBH), which aims to design principles for overcoming present issues and consider the future needs of New Zealand's housing. The report focussed on ADUs to see if existing houses and built land could meet the rising needs of New Zealanders for housing, stating, “...perhaps the broadest and most universally applicable definition is that it [an ADU] is an independent dwelling but one created subsequent to the primary dwelling with which it is associated" (Saville-Smith et al., 2017, p.2). Thus, an ADU could be an internal subdivision of a dwelling, or an extension, or a separate unit on the same lot. Table 2.2 shows ADU definitions have many common points and some differences.

Table 2.2: Comparison of ADU names and definitions

\begin{tabular}{|l|l|l|}
\hline Name & Definition & Reference \\
\hline ADU & $\begin{array}{l}\text { A small, self-contained unit, subordinate to a primary unit } \\
\text { which could be made by partitioning, conversion, or be a } \\
\text { detached new construction. }\end{array}$ & $\begin{array}{l}\text { Saville-Smith et al., } \\
\text { (2017) } \\
\text { Carswell (2012) } \\
\text { Tyre (2008) }\end{array}$ \\
\hline Granny flat & $\begin{array}{l}\text { Separate smaller unit aimed at an older person to allow } \\
\text { for mutual support and independency. }\end{array}$ & $\begin{array}{l}\text { Saville-Smith et al., } \\
\text { (2017) } \\
\text { Krass (2013) }\end{array}$ \\
\hline Hidden Homes & $\begin{array}{l}\text { Partitioning of existing dwelling to accommodate more } \\
\text { than one household, with minor extension. }\end{array}$ & $\begin{array}{l}\text { Saville-Smith et al., } \\
\text { (2017) } \\
\text { Hulse (2015) }\end{array}$ \\
\hline Partitioning & $\begin{array}{l}\text { Subdivision of an existing dwelling to accommodate one } \\
\text { or more additional households independently }\end{array}$ & $\begin{array}{l}\text { Saville-Smith et al., } \\
\text { (2017) } \\
\text { Hulse (2015) }\end{array}$ \\
\hline $\begin{array}{l}\text { Secondary } \\
\text { Suites/Dwellings }\end{array}$ & $\begin{array}{l}\text { Units created from unutilised space within a primary } \\
\text { residence such as basement and attic. }\end{array}$ & $\begin{array}{l}\text { Saville-Smith et al., } \\
\text { (2017) } \\
\text { Krass (2013) }\end{array}$ \\
\hline $\begin{array}{l}\text { Secondary } \\
\text { dwelling }\end{array}$ & $\begin{array}{l}\text { Independent dwelling added to a lot already containing a } \\
\text { dwelling. }\end{array}$ & $\begin{array}{l}\text { Saville-Smith et al., } \\
\text { (2017) } \\
\text { Ross (2016) } \\
\text { Cobb and Dvorak } \\
\text { (2000) }\end{array}$ \\
\hline Laneway Homes & $\begin{array}{l}\text { Small, detached homes, built behind a primary residence } \\
\text { and facing a laneway. }\end{array}$ & $\begin{array}{l}\text { Saville-Smith et al., } \\
\text { (2017) }\end{array}$ \\
\hline $\begin{array}{l}\text { Carriage Houses } \\
\text { (Mews) }\end{array}$ & $\begin{array}{l}\text { Detached residence in the backyard of a dwelling with } \\
\text { entry off a rear lane. }\end{array}$ & $\begin{array}{l}\text { Saville-Smith et al., } \\
\text { (2017) } \\
\text { Antoninetti (2008) }\end{array}$ \\
\hline
\end{tabular}

\subsubsection{Thesis Definition}

ADUs are secondary units in the same lot as the primary building, which provide facilities for the basic needs of residents, such as sleeping, cooking, and sanitation, with no dependency 
on the primary unit, no need for new infrastructure, and with the least changes in the environment.

ADUs are usually made some years later than the primary house, when a new need such as the providing accommodation for family members or gaining income from rent arises. Reviewing the literature (Ramsey-Musolf, 2018; Saville-Smith et al., 2017; Brown and Taylor, 2012) ADUs as understood in this thesis include the following four types.

\section{- Partitioned ADUs}

These units are the result of dividing an existing dwelling into two or more units by using partitions inside the existing house envelope. Despite the fact that partitioned ADUs are independent units, they sometimes share areas, such as a laundry or sitting room, with the primary unit (Figure 2.32).

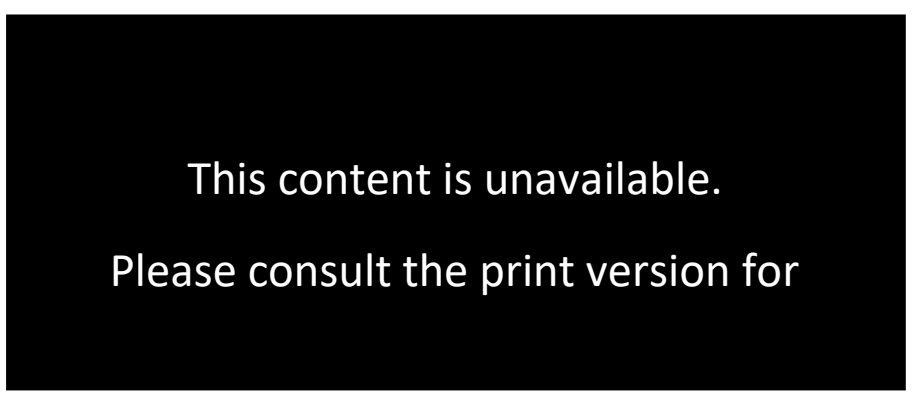

Figure 2.32: Partitioned ADU in attic or basement (Elrich, 2019)

\section{- Converted ADUs}

This group of ADUs are the result of converting an existing independent space, such as a garage or basement into a living unit by adding cooking facilities, a bathroom, and a living and sleeping space (Figure 2.33). As with partitioned units converted ADUs can be completely independent or share some minor spaces with the primary unit. 


\section{This content is unavailable.}

\section{Please consult the print version}

for access.

Figure 2.33: Converted ADU (Elrich, 2019)

\section{- Attached ADUs}

This group of ADUs are the result of constructing or attaching a unit to an existing house. This attachment would be made horizontally, such as adding a unit to the back of the house, or vertically, such as units obtained from adding an extra storey to a single storey house (Figure 2.34).

This content is unavailable.

Please consult the print version for access.

Figure 2.34: Attached ADU (Elrich, 2019)

\section{- Detached ADUs}

Detached ADUs are built from scratch as a separated residential unit on a lot, which already includes a house. Despite the fact that detached ADUs use the same infrastructure and services as the primary unit, they independently provide cooking, sleeping, sanitation and living facilities for their residents (Figure 2.35). 


\section{This content is unavailable.}

\section{Please consult the print version for access.}

Figure 2.35: Standalone ADU (Elrich, 2019)

All four types of ADU could be made of any material and constructed using any techniques or systems. However, the main focus of this research is on standalone detached ADUs in order to use the empty developed land in the most efficient way. The following sections describe a brief history of ADUs in the world and also New Zealand.

\subsubsection{A Brief History of ADUs in the World}

Stege (2009) said the idea of ADUs was first invented in the 18th century in Amish communities in North America, in the form of the 'Grossdaadi Haus'. These houses, which are now called granny flats, were small units for grandparents in the same lot as the family house. However, at a bigger scale, the idea of ADUs flourished in the alley-facing mews houses of the 1830s during a house building boom in London, as cheap accommodation for those working as servants in the main house (Antoninetti, 2008). "Mews houses were to serve as stables with upstairs living quarters for the staff working in the main Georgian terraced houses located at the other end of the lots" (Antoninetti, 2008, p.3).

The idea was then developed and exported to the United States of America and other British colonies, where they were called carriage or guesthouses. Stege, Reston $(2008$, p.1) disagree, believing that the history of ADUs dates back to the 12th century when these types of house were common in residential areas. However, it is not clear what types of ADUs Reston was talking about and they were certainly not then known as ADUs.

At the start of the 20th century, ADUs were built by wealthy families on their estates to accommodate their servants, chefs and other staff who worked for them (Hulse, 2015, p.10). These could range from the standalone gardener's cottage to the chauffeur's flat over the garage. The ADU concept changed progressively during the 20th century from accommodation for low-income workers to that for new or older members of the family, or 
as a source of rental income. These practices continued until the end of WWII and even beyond (Antoninetti, 2008; Gellen, 1985).

Ross (2016) pointed to this historical interpretation and stated that ADUs were a win-win situation. On one side ADUs, which are usually small residential units, provide a cheap rental dwelling for low-income persons, and on the other, this money could be an extra income for the original owners allowing them to stay in their original larger house. Ross (2016) even went further, stating that if the rules allowed, and based on the situation and needs of the owner(s), they could move to the smaller unit and rent out the primary residence for more income.

In the decades that followed the development of zoning restrictions in the USA, and increasing demand for single-family housing in the suburbs, led to a decreased interest in ADUs (Krass, 2013; Wright, 1983). The zoning regulations which began in 1916 in New York and divided the urban fabric into different functions and densities, were aimed at protecting cities from sudden changes and keeping them liveable (Jackson, 1985, p.241-242). Simultaneously, some structural changes in building methods, such as the use of precast concrete slabs for basements and garages that were attached to the house has reduced the potential for ADUs due to lack of appropriate spaces to convert (Antoninetti, 2008).

During WWII in the USA congestion in manning production lines in safe areas led to huge numbers of illegal ADUs for accommodating workers. After WWII, due to the huge number of soldiers that came back from the war and the subsequent baby boom, the suburban population increased dramatically (Reston, 2008, p.1). People wanted to be near their work in industries but also did not want the effect of living near these same industries. The other factors decreasing the use of ADUs and forwarding the movement to the suburbs in these years in the USA were mass factory based automobile production, cheap fuel, and improvement in infrastructure and roads that gave the people the option to work in crowded cities and live in the low-density suburbs (Jackson, 1985, p.191).

After the 1960s community leaders in the USA started advocating for a change in the urban development approach which supported ever increasing low-density suburbs. This decision was made in response to urban sprawl (see Section 2.3.4.2) and with the aim of providing different affordable housing options to limit car dependency and improve the quality of life. 
This led to permission from some municipalities for building ADUs in the period 1970-1990 (Reston, 2008, p.1).

\subsubsection{History of ADUs in New Zealand}

Surprisingly there is little written about ADUs in New Zealand, despite the evidence of their existence. One of the main reasons for this is the fact that, especially in the past, owners would convert their properties or add to the existing house without trying to get consent for this. This makes keeping a record of ADUs hard. In 2015 alone, over 700 landlords who converted their properties to rental accommodation without any consent were given notice to fix issues in these secondary accommodation units (Owen, 2016).

Antoninetti (2008) tracked the background of ADUs in New Zealand to granny flats in the 1980s. Chalmers and Hails (1991) also claimed granny flats were introduced into New Zealand in the 1980 s as a response to demographic changes and the need for different housing options. The chapter written by Chalmers and Hails (1991) is one of the few sources which have investigated the history of granny flats in New Zealand and is used as the main source in the next few paragraphs.

Despite the main building of granny flats that started in the 1980 s the plan for this began in the middle of the 20th century. The changing demographics of New Zealand in the 1970s, when conventional houses had three bedrooms and sat in $1000 \mathrm{~m}^{2}$ lots, accelerated the need for providing more rental housing and smaller living options for older people. In 1974 a central state agency was founded with the aim of providing, mostly rental, housing for the elderly. This movement peaked in 1978 as in that year 952 units were completed using \$8.4 million in subsidies. However, the concept of a granny flat on the land owned by the elderly or their families was borrowed from an Australian program in 1980. The idea at the time was providing autonomous residential units for elderly people and those of with special needs, a move that was given government financial support. In addition to a loan of $\$ 2,000$ for on-site assembly and construction, the fund for each granny flat was $\$ 17,000$ of which $63 \%$ was direct subsidy and the rest was a loan at a $3.5 \%$ interest rate. However, there were some eligibility criteria to be met. The recipient was supposed to be over 60 or close to this age for those with disabilities, with an upper single person (or combined) asset limit. However, the scheme was not that successful due to issues related to the funding, maintenance, and inspection costs, 
and the small size of the residential construction industry in New Zealand, which led to higher costs for these flats (Brookes, 2000). In 1986 to solve the financial issues, the government reviewed the process and decided to build some relocatable houses on its own account, rather than supporting individuals to build for themselves. This plan ended with the building of 239 relocatable units, which people were able to rent.

The history of ADUs shows that despite the persistence of the concept, these units were used to respond to different needs in each period. The use of ADUs which was started with the aim of accommodating low-income workers close to their work then continued as a residential option for older members of families to stay in their neighbourhood and close to their relatives. Later on, ADUs, while still being used for these reasons, were considered as a rental income option for homeowners and simultaneously cheap accommodation for younger people. ADUs are also used to increase urban densities with no need for new infrastructure. This suggests that considering the contemporary needs in New Zealand ADUs could potentially be helpful. However, this needs to be tested and this research aims to evaluate if there is any potential for using prefabricated ADUs as a contribution to the current housing needs in New Zealand.

\subsubsection{Potential Benefits of Using ADUs}

The growth in New Zealand's population and the needs of the country for more houses were discussed in Chapter 1 of this thesis. ADUs could be a reliable response to the need for more houses, with no need for new infrastructure, which can save money and time, while also minimising changes in the environment. In 2013 the Oregon Department of Environmental Quality's Green Building program sponsored a survey of the owners of permitted ADUs in the Oregon cities of Portland, receiving over 200 responses (Brown and Palmeri, 2014). Some of the results reveal how ADUs can positively affect the city as follows.

- Over $80 \%$ of ADUs were in use as long term residences and over $64 \%$ were occupied by their owners;

- ADUs are as attractive as apartments for rent.

- ADUs were more environmentally friendly, where "Their median area per resident is 44\% lower than newly constructed single-family residences, and some ADUs have a notable number of above-code green features" (Brown and Palmeri, 2014). 
- ADUs are associated with approximately $30 \%$ fewer cars on average, where over $50 \%$ of those lived in ADUs, parked their cars in the street, so as "ADUs may be as effective in reducing vehicles owned per household as transit-oriented developments" (Brown and Palmeri, 2014).

- "ADUs do serve older persons, both as places to live and assets to own, but not to a greater extent than other forms of housing. However, many Portland ADUs are owned by 55-64 year-olds, who will be 65+ in a decade. The beneficial effect of ADUs for older persons will likely be larger then" (Brown and Palmeri, 2014).

- ADUs were cheaper to build, and so were cheaper to rent.

However, the use of ADUs needs to be seen in the context of New Zealand. A recent study showed that over $12 \%$ of dwellings in New Zealand had the potential of being partitioned, which means approximately 180,000 new dwellings could be added to the stock just by partitioning (Saville-Smith et al., 2017).

\subsubsection{The Ageing Population in New Zealand}

Looking at the age of New Zealanders, the population aged 65+, which was less than 200,000 in 1951, exceeded 400,000 in 2000 and is predicted to exceed 900,000 by 2031 (Khawaja and Thomson, 2000). Considering this group of the population also consists of small households of one or two people this increase will exacerbate the current housing shortage.

Existing options for older people in New Zealand include living in the family home, living with family or friends, moving to a retirement village which could include full-time residential care, or more recently moving to co-housing such as Abbeyfield housing (Greenbrook, 2005; Yavari et al., 2018). However, few of these options are available to everyone. In 2017, despite considerable investment in retirement villages, $5.4 \%$ of those aged $65+$ lived in these compared to 4.2\% in 2012 (Saville-Smith and James, 2016; Lang LaSalle, 2017). One of the reasons behind this lack of success is the various expectations and needs of those older people, based on their socio-cultural context (Davey et al., 2004), which will be discussed in the next few paragraphs.

A study was conducted in New Zealand in order to define "ageing in place" which is a term that has appeared recently as an option for older members of families (Wiles et al., 2011). Ageing in place can be defined as the option of staying in their community and social group 
in order to have some level of independency while receiving social and health support from their community as well as national services (Wiles et al., 2011; Davey et al., 2004). As, aside from social benefits, which will be discussed later, providing health care for older people in their house can be potentially cheaper than institutional support (Chappell et al., 2004).

Wiles and colleagues (2011) recruited 121 New Zealanders 56 to 92 years old using 17 focus groups and 17 interviews, and asked them about their preferences when it came to a place to grow older. They found this group of people were not familiar with the term ageing in place as much as the policymakers and developers who use it. They also found that, while older peoples prefer to stay in smaller houses as they age, one of the most important factors is staying in their neighbourhood and social community. This does not necessarily mean they want to stay in their home, but means they want to stay in the area with which they are familiar (Wiles et al., 2011), as walking around familiar places and seeing familiar faces, shops and groups can give them the feeling of warmth and safety.

Davey et al. (2004) conducted 30 face to face interviews with socially and economically average New Zealanders aged over 60 in the Wellington, Hutt Valley and Kapiti/Horowhenua regions about how they viewed ageing in place. The respondents' answers to the question of where you would prefer to go if you were forced to move out of your house, showed the majority were reluctant to moving into a retirement village and would prefer to move into a smaller, independent house close to their family and social group. The following are some of the respondents' answers to this question, which helps in understanding what might make a suitable house for older people in New Zealand (Davey et al., 2004).

- "Retirement villages are too expensive and cliquey."

- "My wife would like a retirement village, but I have a bad impression of them, they are full of nosy old people."

- "A separate house in a similar location but smaller and with a small garden. But not an apartment or a retirement village."

- "An apartment with no garden and possibly no car.

- But if there was no workshop that could lead to a marked deterioration in my lifestyle."

- "Probably an apartment or granny flat at my daughter's place." 
- "My family would provide a home, but a retirement village complex would be better."

- "One could find a small flat near the children, but I would not want them to take us in."

Davey et al. (2004) classified the preferences of this group about their future house based on their responses as follows.

- No stairs - all on one level;

- Easy access from the street;

- Warm and sunny;

- A garden that is small and easy to manage;

- A modern bathroom and kitchen;

- Room for visitors and for an office/hobby space (many now need a space for a computer);

- Low maintenance (brick, aluminium windows, low-maintenance roofs);

- Safe steps that are not slippery and with rails; grab rails in the bathroom. (In this case it worth noting that, out of the 30,12 has modified their house and 7 had some kind of plan to do this.)

- Accessible for transport, health services, and social networks.

Given these preferences, with proper design ADUs could be an efficient response to the ageing population of New Zealand. ADUs would be smaller than the primary house and independent of it, while still being located in the same community as the primary house. Being smaller they would be easier to maintain and heat. The accessibility of the interior space of the ADU is also important, and this is discussed in Chapter 4 of this research.

\subsubsection{The Effect of ADUs on the Urban Status of the Neighbourhood}

From the urban viewpoint, changing the density is one of the main effects of ADUs on the neighbourhood. Having more ADUs on site can decrease urban sprawl with no need for new infrastructure (see Section 1.1.3).

Frey (2005, pp.36-37) looked at different but related studies and summarised the benefits and disadvantages of higher urban density, as below.

- Potential benefits of high urban density 
-Limiting urban development, using existing infrastructure and developed land;

-Increasing accessibility, with cycling and walking as the most energy-efficient ways of travelling;

-Reducing traffic congestion and car-related pollution and fatalities;

-Leading to sustainable development and a more healthy society by decreasing emissions and using non-renewable sources of energy more efficiently;

-Increasing the variety in a society by accommodating different groups of people in a neighbourhood;

-Greater safety; and

-Encouraging local activities.

- Potential disadvantages of high urban density

-Increasing congestion and use of energy and pollution;

-Reducing open space resulting in poor environmental quality;

-Threats to economic development especially in rural areas;

-Lowering of overall amenity and reducing privacy;

-Breaking the society down due to high differences in the cost of the city centre and other parts of the city; and

-Decrease in the possibility of using active and passive solar design.

Compactness, and as a result the shortening the distances between desired places, and providing more options in terms of routes and transit services is an important factor in increasing the sustainability of a city (Litman, 2017; Adams and Chapman, 2016; Ewing and Cervero, 2010). Litman (2017) said that the low-density extension of cities reduces the area of both farmland and natural areas, which can negatively affect the agriculture productivity and ecological sustainability of the region. He also mentioned that this type of development means people need to travel longer, there is a reduction in the possibility of walking and cycling, and an increase in energy use and consequent emissions, which means the need for more roads, with negative effects on the local ecosystem, and transport related infrastructure.

Holden (2004) conducted a 4 year survey of 537 households in Norway looking at different types of urban development with an eye to their impact as measured by the ecological 
footprint. He found car ownership, which usually increases in low-density areas, was the second most important factor affecting the ecological footprint of each household member, with the number of people per house being the most important factor, and income the least important factor.

"When it comes to types of housing, the single-family (detached) house is a poor alternative, at least with regard to the ecological footprint. On average, the ecological footprint per household member is almost $20 \%$ higher than for people living in more concentrated types of housing, i.e. semi-detached or terraced houses and multi-family residential buildings (blocks of flats)" (Holden, 2004, p.103).

Finally, it is hard to conclude that high-density neighbourhoods are better than low-density ones or vice versa. However, the effects of density on neighbourhoods should be considered because of the fact that New Zealand has one of the lowest population densities in the word. In June 2017 the population density in New Zealand was 18 people per square kilometre (Statistics New Zealand, 2018) compared with 268 PPSK in the UK and 420 people per square kilometre in England in 2015 (The Statistics Portal, 2018). Moreover, from 1969 to 1993 the area of urban regions trebled in New Zealand, with a further 10\% growth between 1996 and 2012 (Taylor and Smith, 1997; Ministry for the Environment and Statistics New Zealand, 2015b). This urban extension together with other human's activities has decreased the area of New Zealand's indigenous forest from $85 \%$ of the land area when Polynesian and European settlers arrived around 750 AD, to $23 \%$ in the late 20th century (Taylor and Smith, 1997).

Despite the benefits and disadvantages of high-density urban areas, and considering the density of New Zealand cities in comparison with others, it seems that increasing the density of cities in New Zealand is not only unavoidable but also necessary. This increase in density also needs to happen quickly due to the present shortage of houses and ageing population accommodation issues.

\subsection{Sustainable Zero Energy Houses}

The aim of this thesis is to evaluate the possibility of using near zero energy prefabricated ADUs as a contribution to housing needs in New Zealand. This requires discussion of what a zero energy house is in general, which factors affect the sustainability of its construction and how these factors should be tested. 
The concept of the Zero Energy Building (ZEB) as a type of energy efficient building is not new. In the past many houses relied only on renewable energy, for example being lit by tallow (animal fat) candles and heated by burning wood or other biomass. Such houses were effectively zero fossil fuel houses. The modern definition of a ZEB stems from the late 1970s and early 1980s when the over-use of non-renewable sources of energy and environmental issues became more of a public concern (Marszel et al., 2011). This led to a far greater investigation of the use of renewable sources of energy at both the large and small scales. In turn, this led to a number of definitions of ZEB, some of which have been collected together in Table 2.3.

Table 2.3: Different definitions of ZEB

\begin{tabular}{|c|c|}
\hline Definition & Source \\
\hline $\begin{array}{l}\text { ZEBs are extremely energy efficient buildings that produce enough renewable } \\
\text { energy onsite to meet annual consumption needs through a combination of } \\
\text { innovative design strategies, efficient technologies, and improvements in the } \\
\text { management of building operations. }\end{array}$ & $\begin{array}{l}\text { U.S. } \\
\text { Department of } \\
\text { Energy, } 2018 .\end{array}$ \\
\hline $\begin{array}{l}\text { A ZEB is an energy-efficient building where, on a source energy basis, the actual } \\
\text { annual delivered energy is less than or equal to the on-site renewable exported } \\
\text { energy. }\end{array}$ & Peterson, 2015. \\
\hline $\begin{array}{l}\text { - Net zero source energy building: the building produces at least as much } \\
\text { energy as it uses in a year when accounted for at the primary sources that } \\
\text { generate the building energy. } \\
\text { - Net zero site energy building: the building produces at least as much energy } \\
\text { as it uses in a year when considered at the scale of the site. } \\
\text { - Net zero energy cost building: in this building, the amount of money the } \\
\text { owner could earn from selling surplus building generated energy is at least } \\
\text { equal to what the owner should pay for energy when there is insufficient } \\
\text { energy generated by the building's systems. } \\
\text { - Net zero energy emissions building: the building produces the fewest possible } \\
\text { emissions to keep the environment clean and sustainable. }\end{array}$ & Torcellini, 2006 \\
\hline $\begin{array}{l}\text { A zero energy house is a house that at the very least produces the amount of } \\
\text { energy it uses during a year and where no } \mathrm{CO}_{2} \text { is generated by operating the } \\
\text { house. It is possible for the house to buy } \mathrm{CO}_{2} \text { credits on a carbon trading market } \\
\text { or renewable energy from others. }\end{array}$ & $\begin{array}{l}\text { Mertz et al., } \\
2007\end{array}$ \\
\hline $\begin{array}{l}\text { ZEBs are buildings that do not use fossil fuels but that get all their required } \\
\text { energy from solar energy and other renewable energy sources. }\end{array}$ & Lausten, 2008 \\
\hline $\begin{array}{l}\text { A ZEB is one that can generate enough electricity from renewable sources to } \\
\text { balance its energy demand over an average year }\end{array}$ & Jaques, 2013 \\
\hline
\end{tabular}

The overall conceptual understanding of a ZEB is an "energy efficient, grid-connected building enabled to generate energy from renewable sources to compensate its own energy demand. This agreed definition only deals with operating energy, and in recent years it has been suggested that zero-energy should not focus solely on the energy used in the building 
operation phase, but also include the energy embodied in the building construction and materials (Hernandez \& Kenny, 2010). Hernandez and Kenny (2010) defined a ZEB as a building "whose primary energy use in operation plus the energy embedded in materials and systems over the life of the building is equal to or less than the energy produced by renewable energy systems within the building." In this scenario, allowing for the energy embedded in materials and systems makes Net ZEB more demanding and the energy balance harder to achieve. This is especially so as the guaranteed lifetime of PV panels, the most common renewable energy system used on buildings is $20-25$ years, meaning they will potentially need replacing a number of times during the life of the building. Hernandez and Kenny (2010) also acknowledged the limitations in this method in terms of the selection of primary energy as an indicator, the calculation method, and the boundaries of the embodied energy calculations. On the other hand, embodied energy is not commonly considered in the calculations of energy use in a building and perhaps should be (Marszal et al., 2011).

Bahho (2017) studied different definitions of ZEB and came to the conclusion that a ZEB is a building "....with reduced energy requirements for building materials, services, and operation, with the objective of meeting all energy requirements from low-cost, locally available, nonpolluting, and renewable sources" (Bahho, 2017). One of the most important facts about a zero energy house $(\mathrm{ZEH})$ is that producing the equivalent of the energy the house uses by benefitting from on-site renewable sources of energy does not necessarily means that the house should not be connected to the public energy grid (Vale and Vale, 2000; Torcellini, 2006). The house can thus use imported energy any time the systems cannot generate enough energy to meet the demand, such as during the night or in winter. The house can also export any surplus energy produced, such as in summer. For being a ZEH, the annual energy balance of imported to exported energy should be zero or negative. The house could import another type of energy such as electricity from natural gas from the grid and export the equivalent amount of renewably generated electricity. However, the source of energy would affect the overall GHG emissions, so meeting the goal of zero emissions could be even more stringent.

From investigating the literature (Table 2.3) most ZEB definitions are similar and focus on the same areas of minimising the operating energy, on-site energy generation, minimising $\mathrm{CO}_{2}$ emissions, using renewable sources of energy, and using energy efficient materials. In this research, a Zero Energy House (ZEH) is thus defined as: 
A ZEH should be designed with the aim of minimising the operational (heating) and embodied energy and the environmental emissions, by making optimised design decisions and use of most efficient materials. This research tries to achieve a near-zero energy design for the ADU by reducing the annual operating energy use of the ADU, by using appropriate insulating materials and making design decisions related to energy efficiency.

Being zero energy is a complex concept with a number of calculation methods, each one highlighting a certain aspect. Marszel et al. (2011) made a survey of twelve calculation methods for zero-energy, most of which considered the balance between energy generated by the building and that consumed by its users. However, most rating systems for producing low energy and more sustainable buildings have yet to consider embodied energy and zero energy buildings. As an example, in 2009 the New Zealand Green Building Council (NZGBC) introduced Green Star as a rating tool with which to measure the environmental attributes and performance of office buildings (New Zealand Green Building Council, 2009). It was a modification of the Australian Green Star rating system with changes made because of the differences between the countries. The Green Star framework follows the same approach as international accepted rating tools, including BREEAM and LEED (New Zealand Green Building Council, 2009). The tool assesses the environmental impact of a building in relation to its site selection, design, construction, and maintenance. There are eight separate categories of management, indoor environment quality, energy production and use, transport, water use, materials selection, ecology and emissions, plus an additional one for innovation. Each contains credits where points are awarded for actions that prove a level of performance. The overall score out of 100 is then translated to a Green Star rating from 1 to 6 , where the latter is the highest (New Zealand Green Building Council, 2009).

In order to improve the performance of the housing stock in New Zealand, BRANZ, the New Zealand Green Building Council (NZGBC), and Beacon Pathway, collaborated to produce and operate a residential rating tool called Homestar. This is able to evaluate the environmental attributes of new and existing houses. The rating tool was compared to international standards such as LEED for homes in the USA and Canada and the Code for sustainable homes in the UK (New Zealand Green Building Council, 2014). Homestar, which is a 0-10-star rating system, assesses homes under categories of energy production and use, health and comfort, water use, and waste generation (New Zealand Green Building Council, 2014). These are 
considered to be the most important factors affecting the sustainability of construction and this is where prefabrication could potentially be more efficient than traditional methods (Moradibistouni et al., 2018). However, there is debate about this claim. The next section briefly evaluates the sustainability of prefabrication before explaining what sustainable construction is and the factors affecting this.

\subsubsection{Sustainable Construction}

Sustainable construction is defined as the process of constructing a building by maximizing the efficiency of using energy, water and raw materials, and also minimizing its environmental effects (Atombo et al., 2015). In sustainable construction, efficient use of materials and environmental impacts should ideally be considered at the stages of pre-use, use, and afteruse of the building (Bourdeau et al., 1998). The parameters to be considered include recycling and reducing the use of materials, as well as the efficient use of energy resources, land, and water, and the effect on ecosystems and the ability for the regeneration of the resources used (Kibert, 2016). A summary of the main factors affecting the sustainability of construction from the literature is presented in Table 2.4 .

Table 2.4: Review of factors affecting the sustainability of construction

\begin{tabular}{|l|l|}
\hline Factors affecting the sustainability of construction & Source \\
\hline $\begin{array}{l}\text { Energy consumption, dust and gas emissions, waste generation, water } \\
\text { resources, land misuse and pollution, and consumption of non- } \\
\text { renewable natural resources. }\end{array}$ & Kaatz et al., 2005 \\
\hline $\begin{array}{l}\text { Construction time, cost, quality, durability, architectural appearance, } \\
\text { health and safety, material conservation, waste, environmental } \\
\text { emissions, and energy and water consumption. }\end{array}$ & $\begin{array}{l}\text { Jaillon and Poon, 2008; } \\
\text { Chen et al., 2010; } \\
\text { Yu and Kim, 2011 }\end{array}$ \\
\hline $\begin{array}{l}\text { Environment protection, solid waste reduction, energy, water and } \\
\text { natural resource conservation, climate stabilization. }\end{array}$ & Landman, 1999 \\
\hline $\begin{array}{l}\text { Energy conservation, pollution prevention, resource efficiency, system } \\
\text { integration, and cost. }\end{array}$ & Zeng et al., 2003 \\
\hline $\begin{array}{l}\text { Reusable/recyclable elements, provision of services, energy } \\
\text { consumption, water cost, and water pollution assessment. }\end{array}$ & Enshassi et al., 2016 \\
\hline
\end{tabular}

In another study, Markelj et al. (2014) investigated international building sustainability assessment methods (BSAM) and standards in order to develop a simplified method for evaluating building sustainability. The method was based on twelve international examples and the evaluation system was also based on the frequency of appearance of different criteria. Markelj et al.'s (2014) research shows that environmental pollution, waste production, water use, and human wellbeing are the most important factors affecting the 
sustainability of construction which appear in eleven BSAM and standards. With the exception of water, this is in contrast with the investigation above (Table 2.4) where energy, materials and natural resources were seen to be the most important criteria. In Markelj's study (2014) of assessment methods, energy only appeared together with sustainable land use, functionality, and technical characteristics, with these appearing in nine standards. Finally material use and property value (cost), with eight appearances in BSAM and standards, were the next most important factors. Table 2.5 compares the findings.

Table 2.5: Factors affecting the sustainability of construction

\begin{tabular}{|c|c|c|c|}
\hline Factor & $\begin{array}{l}\text { Number of appearances in the } \\
\text { literature (Table 2.4)(out of 8) }\end{array}$ & $\begin{array}{l}\text { Number of appearances } \\
\text { in Markelj et al. (2014) } \\
\text { (out of 12) }\end{array}$ & Total \\
\hline Water consumption & 7 & 11 & 18 \\
\hline Waste generation & 6 & 11 & 17 \\
\hline Energy consumption & 8 & 9 & 17 \\
\hline $\begin{array}{l}\text { Environmental emissions } \\
\text { (pollution) }\end{array}$ & 6 & 11 & 17 \\
\hline $\begin{array}{l}\text { Material (natural } \\
\text { resources) consumption }\end{array}$ & 8 & 8 & 15 \\
\hline $\begin{array}{l}\text { Environmental impacts } \\
\text { (sustainable land use) }\end{array}$ & 6 & 9 & 15 \\
\hline $\begin{array}{l}\text { Durability, quality and } \\
\text { wellbeing }\end{array}$ & 4 & 11 & 15 \\
\hline Cost (property value) & 6 & 8 & 14 \\
\hline Other factors & Less than 10 & & \\
\hline
\end{tabular}

Taking all these factors together (Table 2.4 and Table 2.5) and based on the number of appearances in the literature, the top four factors of water and energy consumption, waste generation, and environmental pollution, which were pinpointed by over $85 \%$ of the studies, emerge as the most important factors. It is thus worth looking at the claimed advantages of prefabrication for these.

\section{- Water consumption}

Water consumption, which was mentioned in $90 \%$ of the 20 articles studied, emerged as the most important factor affecting the sustainability of a construction project. The construction industry is responsible for $16 \%$ of world annual water consumption (Arena and De Rosa, 2003). However, there is little evidence to support the claim that prefabrication will save water. 
"Internationally, it is suggested that prefabricated construction uses less water in construction [up to 50\%], although this is not well supported...Due to bulk water metering onsite, the lack of sufficient data for analysis has meant that it could not be established at this time whether there is a difference in water use between traditional onsite construction and offsite prefabrication in New Zealand" (Burgess et al., 2013).

The water used during the life of a building can be classified into the same three groups of construction, operation, and demolition. There are no big differences in the amount of water use during the building operation between prefabricated buildings and conventional ones since the use of water in this period is more dependent on occupant behaviour and habits rather than the building design and construction method (Waylen et al., 2011).

The use of water during the construction phase can be divided into the two groups of on and off-site use. The water used for construction on site is less than one-third of the water used in the whole construction process (McNab et al., 2011; Waidyasekara, 2016). Bardhan (2011) claim that $92 \%$ of the water used in a construction process is for the extraction and preparation of materials and just $8 \%$ is used on site (Bardhan, 2011). Initially, this suggests there is no difference in the use of water between onsite and offsite construction. However, prefabrication has been claimed to use materials over $50 \%$ more efficiently, which potentially means a substantial reduction in materials used and the water embedded in them (Gorgolewski, 2005, pp.125-126; Britto et al., 2008, p.14). This would have to be tested further by looking in detail at the types of materials chosen.

However, prefabrication tends to imply a dry construction method, such as the use of timber components, which would involve less water than, for example, a building made of concrete, although there have been many prefabricated concrete systems, and modern tilt-up panels are a common sight in New Zealand. Typically water forms $14-21 \%$ of the total ingredients in a concrete mix (Kosmatka and Wilson, 2016). The wood in a timber frame requires drying out rather than having water applied, although water will be used in making the steel for the nails. It is the choice of material type rather than being prefabricated which will affect the level of embedded water, so less water in a prefabricated building probably comes from it being made of lighter and more portable timber components. 
On a construction site, water is mainly used in any temporary accommodation of workers, for dust suppression, for preparing materials such as concrete, and in hydro-demolition and cleaning (Waylen et al., 2011; McNab et al., 2011; Burgess et al., 2013; Waidyasekara, 2016). Some of these water uses can be cut or decreased using prefabrication and others cannot. For example, the amount of water used in temporary accommodation can be reduced using prefabrication as this method can halve construction time, which means less or no need for onsite accommodation. Moreover, toilets and showers used in factories are more efficient than those in temporary use on site (Burgess et al., 2013). So, using off-site methods can slightly reduce the on-site water consumption of construction process, but there is a greater potential reduction from the choice of materials, which tend to be dry construction for ease of transportability. However, further research is needed into the use of water in prefabricated and on-site construction

\section{- Waste generation}

Unlike water consumption related to construction projects, which suffers from a lack of data, there have been more studies on the waste generation of prefabricated buildings. The majority of researchers agree that prefabrication can reduce the amount of waste created during construction and demolition, and the only differences are in the level of this reduction, which range from 52\% to 87\% (Jaillon et al., 2009; Begum et al., 2010; Bell and Southcombe, 2012; Lu and Yuan, 2013; Tam and Hao, 2014).

Reducing waste generation is an important component of sustainable construction as it is far easier to not produce waste at the beginning, rather than manage it after it has been generated (Gavilan and Bernold, 1994). Tam and Hao (2014) investigated the main sources of waste generation in a construction process and found these were from cutting materials, over ordering, damage during transportation, loss during installation, poor workmanship, and design changes (Tam and Hao, 2014). Of these factors prefabrication should aid in reducing waste from cutting, over ordering, poor workmanship, and design changes. Also, due to the modular concept of off-site construction, prefabricated elements could be reused in another project, when a change is needed in one project. 


\section{- Energy consumption and GHG emissions}

Energy consumption and environmental emissions are the last two factors to be discussed in this section. These two factors have a cause and effect relationship, so can be studied together. Over $99 \%$ of world $\mathrm{CO}_{2}$ emissions come from oil, natural gas and coal, which all are non-renewable sources of energy (Jaillon et al., 2009), so using more energy in a construction project is equal to creating more emissions and vice versa.

Previous studies suggest prefabrication is over $50 \%$ more energy efficient than traditional methods with 35\% fewer CO2 emissions (see Section 2.2.5), which seems substantially more sustainable. However, there is no clarity in the literature whether this $50 \%$ is just for the construction stage, or to the whole lifetime energy use of the building, or just relates to the embodied energy of materials. There should be no major difference in operating energy for a building using the same materials and techniques constructed on-site or off-site. However, prefabricated buildings have fewer defects and energy leaks on completion, so their operating energy use could potentially be slightly less than conventionally made buildings. As a result, it can be concluded that energy reduction from prefabrication comes mainly from the reduction in embodied energy through less wastage of materials.

\subsection{Importance of Life Cycle Analysis}

LCA was used in this research to see how sustainable the ADU is compared with conventionally made houses in terms of energy consumption, $\mathrm{CO}_{2}$ emissions and cost. The early use of LCA as an environmental management tool dates back to the period 1960-1970, when the Midwest Research Institute (MRI) assessed the use of resources, emission loadings, and waste flows for different beverage containers for Coca Cola (Khasreen et al., 2009; Buyle et al., 2013).

"LCA is a technique for assessing the environmental aspects and potential impacts associated with a product, by

- compiling an inventory of relevant inputs and outputs of a product system;

- evaluating the potential environmental impacts associated with those inputs and outputs;

- interpreting the results of the inventory analysis and impact assessment phases in relation to the objectives of the study" (ISO 14040, 1997). 
The International Organization for Standardization (ISO) standard ISO 14040 (1997) pointed to three important uses of LCA;

- To improve the environmental aspects of a product during its life span; and/or

- Make the best decisions in small, medium, and big scale projects including marketing; and/or

- Find the most relevant criteria for environmental performance and measurement techniques (ISO 14040, 1997).

Vale looks at LCA in the construction industry from another point of view and says "LCA is a much simplified model of reality and as such, it should never be used to predict final outcomes" (Vale, p.113 in Petrovic et al. 2017). Usually an LCA consists of estimating the energy embodied in making the building materials (including extraction, transportation and processing), the energy used for transporting materials and labour to the site, the energy used for constructing the building, the energy used for maintaining the building, and for demolishing it and disposing of the waste. It also includes the energy consumed by the building and its occupants for its operation during the life of building (Vale, pp.113-114 in Petrovic et al. 2017). Thus, assumptions need to be made in any LCA and some aspects will be hard to predict, such as the efficiency of appliances used in the building in the next 50 years. This implies that the main use of LCA “...is in comparing alternatives, whether these be choosing between different materials for a wall, or choosing between making a building that can gain at least some of its energy for running from renewable resources such as the sun" (Vale, p.114 in Petrovic et al. 2017). This research a must, therefore, also based on assumptions which are given in section 6.3.1. An LCA can be conducted using data from three methods, as described by Khajehzadeh (2017).

- Input-Output analysis: This analysis is based on national economic input-output tables which are then combined with the known energy used by various industries for each $\$$ value of their products.

- Process analysis: This analysis is based on energy and material data taken from a manufacturer for the production processes plus other upstream data that have an effect on the overall process. 
- Hybrid analysis: This analysis is a combination of Input-Output and Process analyses. The hybrid analysis is based on either Input-Output or process analysis and each is supplemented by the other.

\subsection{Gap in Knowledge}

Chapter 1 of this research suggested a need for a change in the construction approach to housing in New Zealand. This has arisen as contemporary methods and approaches are no longer able to respond to the growing housing needs of the country. The new method(s) should be able to add to the existing housing stock quickly with the least changes in the environment and ideally with no need for new infrastructure. There is also a need to give specific attention to the ageing population. The chosen method needs to be more efficient in the use of sources of materials and energy with fewer environmental emissions than existing methods to help guarantee the chance of a sustainable future for New Zealand.

This literature review suggests a prefabricated ADU may have the potential to answer these needs. This is because prefabrication is faster, has higher efficiency in the use of resources, and has fewer emissions than traditional methods. ADUs are also a flexible type of accommodation that can add to the housing stock within existing urban areas with no need for new infrastructure. ADUs potentially also have most of the criteria older people expect from the place they want to age in, such as being small and easy to heat and maintain, while still being located within their social context.

Similar studies in the literature have usually focused on one aspect of the housing crisis, for example, providing more houses in a shorter time or providing suitable houses for the ageing population. One of the latest examples is Yavari's (2019) research focusing on the ageing population of New Zealand, but partitioning or subdividing existing houses rather than using detached ADUs and without considering the method of construction as a part of the solution. Given the importance and urgency of the housing crisis in the world and New Zealand, there is a need for a solution that deals with different aspects of the issue simultaneously rather than focusing on just one aspect.

Moreover, there has been no research looking to meet the housing needs using both prefabrication as the method of construction and ADUs as the type of house. This needs to be done to see if it is possible to manufacture an ADU and how efficient the final design would 
be. Despite the literature suggesting prefabrication is highly efficient, no explanations are given about where this benefit comes from and when, during the life of the building, it accrues. This could be investigated through the design of a prefabricated ADU and running LCA analysis of energy consumption, $\mathrm{CO}_{2}$ emissions and the cost of the ADU.

\subsection{Summary}

This chapter looked at the literature around prefabrication as the method of construction, ADUs as the type of house, sustainable construction as a response to the environmental concerns and LCA as the analysis method, which was used later in Chapter 6. Prefabrication has been claimed to be a method of construction, which is faster and more energy-efficient than conventionally made houses, with higher quality due to its factory based nature. This method also uses sources of energy and materials more efficiently than traditional methods, needing fewer hours of labour on site. On the other side, there is some concern around this method mostly originating from the past experiences of those involved, including consumers. ADUs are a type of house that can add to the variety of accommodation options and also increase the residential density of urban areas, using existing infrastructures. ADUs give older people the chance to age in place by moving to an ADU in their existing neighbourhood.

The prefabricated ADU should meet sustainable construction requirements, including reducing waste, and using water and sources of energy more efficiently with less environmental impact. To test this, in this LCA will be used to evaluate the energy consumption, $\mathrm{CO}_{2}$ emissions and cost of constructing and maintaining the ADU during its life span. An LCA should also reveal the areas where the ADU could be improved. 


\section{Chapter 3: Research Methodology}

\subsection{Introduction}

This chapter describes the methods used to answer the research questions, which emerged based on the gap in the knowledge. In turn the gap in knowledge was based on the literature review (see Section2.6). The aim and scope of the research are also discussed. It worth noting that this research uses design as a tool to explore the potential of using prefabricated ADUs in New Zealand as a contribution to housing needs. The design will be modified continuously based on the results of each stage of the research. This chapter presents a general view of the main approach and how the stages are organized.

\subsection{Research Question}

Given the literature review and the current housing needs in New Zealand leads to the main research question:

How could an age-friendly zero energy prefabricated ADU be developed as a contribution to contemporary housing needs in New Zealand?

To answer the main question, required answering the following sub-questions:

How could a zero energy ADU be made in a factory, and transported to site and erected on site while abiding by the existing rules?

How would such an ADU compare with conventional houses in terms of energy consumption, cost, and environmental impacts?

\subsection{Research Aim}

This research aims to design a prefabricated house in the form of an Accessory Dwelling Unit (ADU), which is buildable and transportable as a contribution to housing needs. As described in sections 2.2 and 2.3 there are many approaches to both prefabrication and the design of an ADU. This research will be limited to designing a prefabricated, detached ADU that could be placed on an existing section. Detached houses accounts for four out of five residential buildings in New Zealand (Johnstone, 2001). At this stage the assumption is that such a section is flat and is located at Hutt City in Wellington (see Section 3.4). A further aim is to analyse the cost and the energy efficiency of the $\mathrm{ADU}$, as well as its $\mathrm{CO}_{2}$ emissions, to see how efficient 
it is in comparison with traditionally made houses over the life of the ADU. The accessibility of the ADU for older people will also be considered. Table 3.1 summarises the factors which will be investigated in chapters four, five and six. These factors then will be returned to in Chapter 7 to see how successful the design is as a contribution to housing needs in New Zealand.

Table 3.1: Overview of factors to be investigated

\begin{tabular}{|c|c|}
\hline \multirow{6}{*}{$\begin{array}{l}\text { Design and construction } \\
\text { (chapters } 4 \text { and } 5 \text { ) }\end{array}$} & Design should abide by district provisions for ADUs \\
\hline & Design should be accessible for older people \\
\hline & $\begin{array}{l}\text { Design should be transportable around New Zealand on } \\
\text { existing roads }\end{array}$ \\
\hline & Design should be energy efficient \\
\hline & Design should be able to be manufactured in New Zealand \\
\hline & Design should be technically and structurally stable \\
\hline \multirow[t]{3}{*}{$\begin{array}{l}\text { Life Cycle analysis } \\
\text { (Chapter 6) }\end{array}$} & $\begin{array}{l}\text { Energy needed for building, maintaining and operating the } \\
\text { ADU should be equal to or less than conventionally made } \\
\text { houses. }\end{array}$ \\
\hline & $\begin{array}{l}\mathrm{CO}_{2} \text { emitted during building, maintaining and operating the } \\
\mathrm{ADU} \text { should be equal to or less than conventionally made } \\
\text { houses. }\end{array}$ \\
\hline & $\begin{array}{l}\text { The ADU should be financially acceptable in comparison with } \\
\text { conventionally made houses. }\end{array}$ \\
\hline
\end{tabular}

\subsection{Case Study Site}

Given the huge effect the site can have on the ADU, this section aims to study different sites and pick one as a case study. As the research was done in Wellington, different regions and suburbs in Wellington were considered, so it would be easy to make a site visit. After an online search using "Google maps" and council websites, the Hutt City region was chosen for further investigation. The reason behind this was the geographical characteristics of Wellington city, with its many settlements on slopes, whereas Hutt City is mostly flat or with a very gentle slope. Another assumption was that the existing house on the site should be a single storey residential building. To choose a single lot as the case study, different streets and blocks in Hutt City were investigated using the Hutt City council website (Hutt City Council, 2018). Factors considered were the slope of the street, size of the lots, site coverage of existing houses, and type of placement of the existing house on the site. The idea behind this filtering was choosing a street which had various types of lots and houses to cover many possible 
situations. As a result, lots in Rata Street located between Fleet Street and Waddington Drive were chosen for further investigation (Figure 3.1). The width of Rata Street, which is an important factor when it comes to using a crane, is $11 \mathrm{~m}$ and could be increased to $20 \mathrm{~m}$ by including the sidewalks as an extension of the street.

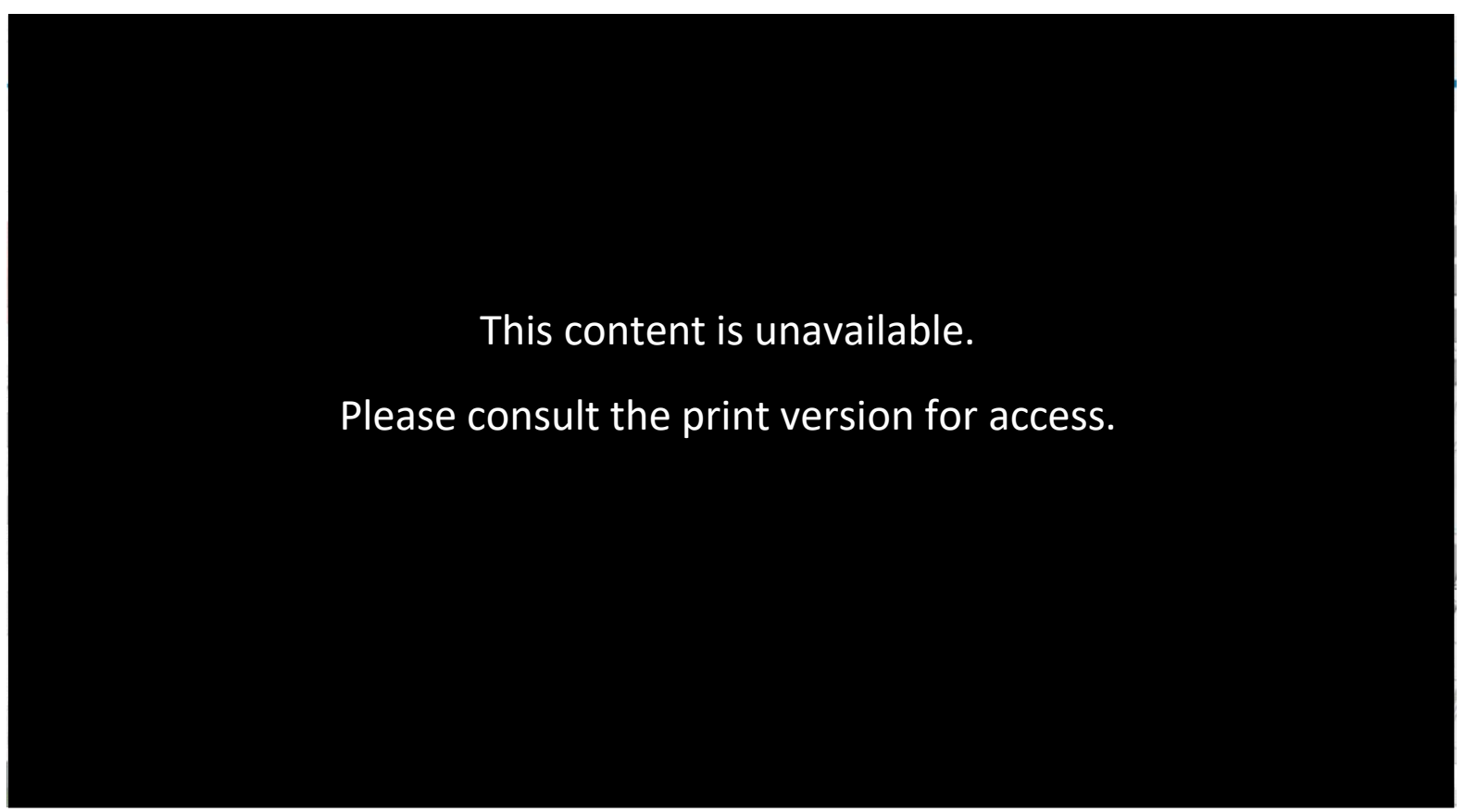

Figure 3.1: Rata Street (the part chosen for study) (Hutt City Council, 2018)

Table 3.2 shows the different characteristics of lots in the street and information about the existing houses. There are 38 lots in the chosen street, 6 are commercial buildings (lots 83, $85,87,89,91$ and 93$)$, and lot 99 is two storeys. These seven lots were removed from the list as they did not meet the research requirements as the ADU is planned to be placed in a lot with a single story existing residential building. Eight lots $(90,97,101,102,103,115,117$ and 118) are already subdivided, with no more land to host an ADU, so they were also removed from the list. The next factors used for filtering were minimum net site area and maximum site coverage based on the results of studying the $71 \mathrm{New}$ Zealand council ADU related rules (see Section 4.2.1). The investigation showed the average minimum net site area for having an ADU in a residential zone is $613 \mathrm{~m}^{2}$ and the average maximum allowed site coverage is $38 \%$. This set boundaries and led to removing two more lots ( 84 and 88 ) from the list as their minimum net site area was less than $613 \mathrm{~m}^{2}$. Considering all these factors 20 lots located in Rata Street remained on the list of further analysis. Lots 109 and 111 had been combined, probably by the owner to form a bigger lot and counted as one lot. 
Table 3.2: Lots in Rata Street details

\begin{tabular}{|c|c|c|c|c|c|c|c|c|}
\hline \multirow[t]{2}{*}{ Lot } & \multirow{2}{*}{$\begin{array}{l}\text { Area } \\
\left(\mathrm{m}^{2}\right)\end{array}$} & \multirow[t]{2}{*}{ HF* } & \multirow[t]{2}{*}{ SC* } & \multirow[t]{2}{*}{ ABW* } & \multirow[t]{2}{*}{ OBS* } & \multicolumn{3}{|c|}{ Existing building location on the site } \\
\hline & & & & & & Roadside half & Middle & Rear half \\
\hline 86 & 1005 & 109 & 10 & 4.6 & $\mathrm{v}$ & & $\mathrm{V}$ & \\
\hline 92 & 660 & 108 & 16 & 2.5 & $\mathrm{~V}$ & $\mathrm{~V}$ & & \\
\hline 94 & 650 & 120 & 18 & 3.5 & $\mathrm{~V}$ & $\sqrt{ }$ & & \\
\hline 95 & 683 & 117 & 17 & 7.2 & $\mathrm{v}$ & & $\mathrm{V}$ & $\mathrm{V}$ \\
\hline 96 & 650 & 109 & 17 & 2.6 & $\mathrm{~V}$ & $\mathrm{~V}$ & & \\
\hline 98 & 650 & 129 & 20 & 2.4 & $\mathrm{v}$ & $\sqrt{ }$ & & \\
\hline 100 & 717 & 162 & 23 & 0.5 & $\mathrm{~V}$ & $\mathrm{~V}$ & & \\
\hline 104 & 717 & 146 & 20 & 3.7 & $v$ & $\mathrm{~V}$ & & \\
\hline 105 & 748 & 125 & 17 & 4.2 & $\mathrm{v}$ & V & & \\
\hline 106 & 717 & 172 & 24 & 3.2 & $\mathrm{~V}$ & $\mathrm{~V}$ & $\mathrm{~V}$ & \\
\hline 107 & 748 & 120 & 16 & 2.5 & $\mathrm{v}$ & $\mathrm{V}$ & & \\
\hline 108 & 797 & 142 & 18 & 1.7 & $\mathrm{~V}$ & $\mathrm{~V}$ & & \\
\hline $109-111$ & 1108 & 182 & 16 & 3.7 & $\mathrm{~V}$ & $\mathrm{v}$ & & \\
\hline 110 & 797 & 121 & 15 & 4.2 & $\mathrm{~V}$ & $\mathrm{~V}$ & & \\
\hline 112 & 812 & 153 & 19 & 4.6 & $\mathrm{~V}$ & $\mathrm{~V}$ & $\mathrm{~V}$ & \\
\hline 113 & 748 & 120 & 16 & 2.6 & & $\mathrm{~V}$ & & \\
\hline 114 & 797 & 229 & 29 & 2.9 & $\mathrm{~V}$ & $\mathrm{~V}$ & $\mathrm{~V}$ & \\
\hline 116 & 828 & 150 & 18 & 4.6 & $\mathrm{~V}$ & V & & \\
\hline 213 & 714 & 182 & 25 & 6.8 & $\mathrm{~V}$ & & $\mathrm{~V}$ & \\
\hline 1 & 825 & 150 & 18 & 6.7 & $\mathrm{v}$ & $\mathrm{V}$ & $\mathrm{V}$ & \\
\hline Average & 769 & 142 & 19 & 3.7 & - & - & - & - \\
\hline
\end{tabular}

*HF=House Footprint $\left(\mathrm{m}^{2}\right), \mathrm{SC}=$ Site Coverage (\%), ABW=Access to Backyard Width (m), OBS=Other Buildings on Site

The area of these 20 lots varied from $650 \mathrm{~m}^{2}$ to $1108 \mathrm{~m}^{2}$ with an average area of $769 \mathrm{~m}^{2}$. The house footprint area or GPA is between $108 \mathrm{~m}^{2}-229 \mathrm{~m}^{2}$ with an average of $142 \mathrm{~m}^{2}$ and site coverage varied from $10 \%$ to $29 \%$ with an average of $19 \%$. This footprint is just the main house and does not cover other existing structures on the site like sheds or garages. Most of these secondary structures may need to be moved or even removed, and all of these lots have some kind of additional building or structure. Allowing for this all of these lots could potentially be selected as a case study in this thesis.

The width of the access to the backyard is also important as this will affect the size of the prefabricated elements and the methods of moving them into the backyard, noting that in some cases where the existing house is in the rear half of the lot the ADU could be positioned in the front yard. Table 3.2 shows the access width in Rata Street varies from $0.5 \mathrm{~m}$ to $7.20 \mathrm{~m}$ with an average of $3.70 \mathrm{~m}$, compared with the width of modules of $2.55 \mathrm{~m}$ (see Section 5.4.2). Out of the 20 lots, numbers 92, 98, 100, 107 and 108 have access to the backyard less than 
$2.55 \mathrm{~m}$ wide. The two options for these lots are designing the ADU elements to smaller dimensions, which does not seem efficient, or craning the ADU elements over the existing houses, which could be practical but needs consideration regarding the weight of elements and crane limitations.

The existing building located on the site is also important as the existing house can be located within the roadside half of the land, and in the middle or to the rear of the lot (Table 3.2 ) If the house is placed on the rear of the land the ADU should be sited in front of the house which is the easiest situation for transporting the ADU elements from the truck to the final location. Lot 95 in Rata Street could be an example of this situation. Where the house is placed in the middle of the lot it could be hard to find sufficient space for an ADU with satisfactory private open space (lot 115). The last and most common situation (Table 3.2) is when the existing house is located in the front half of the lot. In this situation, the ADU should be transported to the backyard for assembly.

\subsection{Methodology}

The interplay of research and design in order to answer a question or to fill a gap in knowledge can happen in different ways. These have overlaps and this can sometimes lead to misunderstandings about the nature of design-based research. The interplay can be different based on the topic or even the level of research. Groat and Wang $(2013$, p.6) believe that as the level of the study grows, the research can overwhelm the design (Figure 3.2)

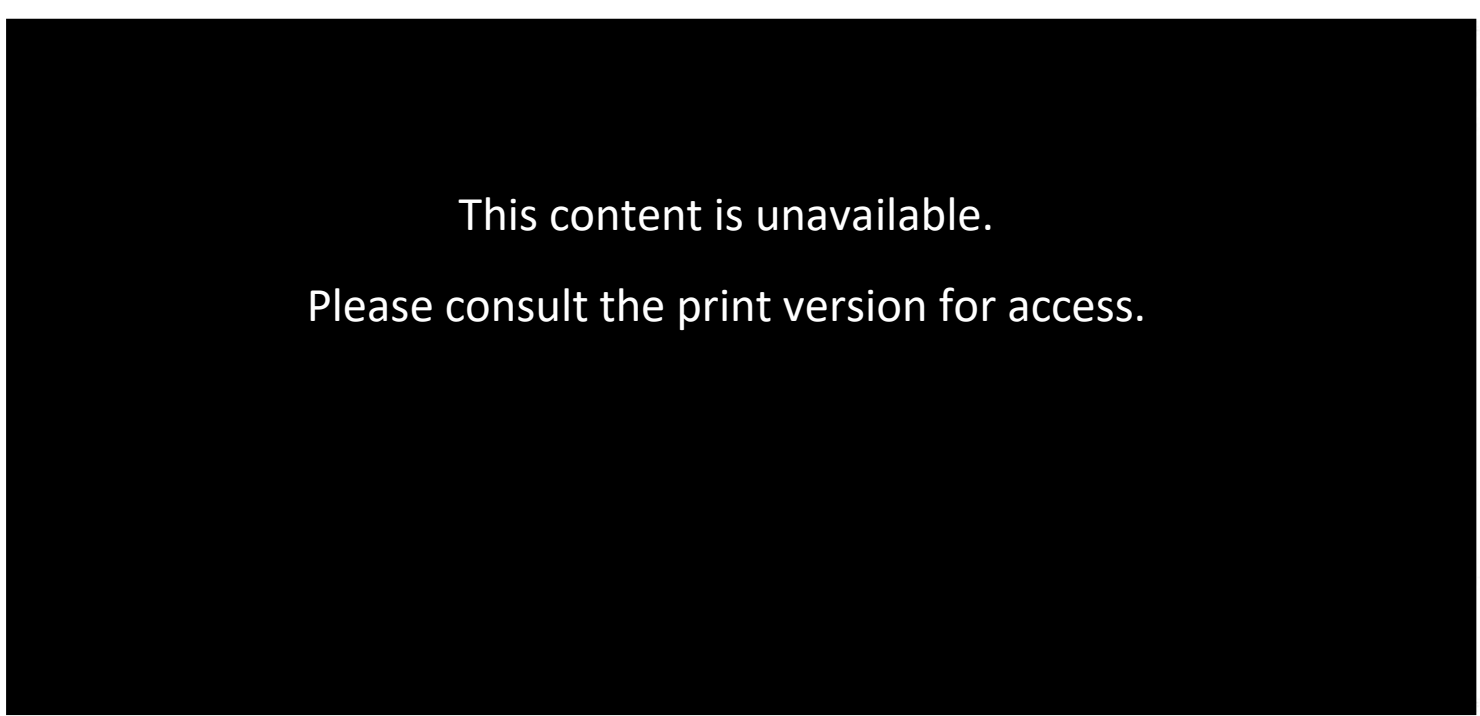

Figure 3.2: The complementary nature of research and design (Groat and Wang, 2013, p.6) 
The relationship between research and design can be generalised into the three groups of research for design, research on design(ing) and research by design, and research as design or research through design (Lenzholzer et al., 2013).

"In the first group, 'research for design' research informs design to improve the quality of the designed artefact and to increase its reliability...In the second group that can be circumscribed by 'research-on-design(ing)', research is carried out on finished design products (substantial) or on the design process (procedural)...In the third and last group that received various names such as research-by-design/research as design/research through design, the designing activity is employed as a research method" (Lenzholzer et al., 2013, p.121).

Looking at the Lenzholzer et al's (2013) definitions, the closest one to this research is the third group. The European Association for Architectural Education (EAAE) (2012) defines this as a strategy where design is the main constituent of the research. Research by design is an investigation where "design is explored as a method of inquiry, by the development of a project and also exploring the different materials by which a design is carried out - sketches, mapping, among others" (Barbosa et al., 2014). Roggema (2016) stated research by design accrues when "...designing is used as a means of exploring the spatial possibilities of and developing a new programmatic infill for a given site". This definition is similar to that of Hauberg (2011), who said "Research by design intends to bring in expressive and systematic tools in the research process and concerns the direct relationship between analysing and the proposing [sic]".

In this research, design is a tool, which is used for exploring the possibility and practicality of using prefabricated ADUs as a contribution to the accommodation of older people and the housing needs in New Zealand. This is not linear research and is based on iteration, which means the tool or design will be modified continuously based on the research outputs of the different stages.

\subsection{Research Plan}

Figure 3.3 illustrates the research plan with the three main phases of investigating the design parameters, the design and construction of the ADU, and its analysis and evaluation. The plan 
shows how design is used here to answer the research questions, where phase one and two form the design and phase three tests it. Whenever during the test or even in the later stages of design, there was a need for any change in layout or structure, the modified design was sent back to the beginning of the line and checked against the critical factors it needed to satisfy. These were revealed and discussed in phases one and two, examples being the district provisions specific to ADUs, so as to make sure the modified ADU still abided by the rules. 


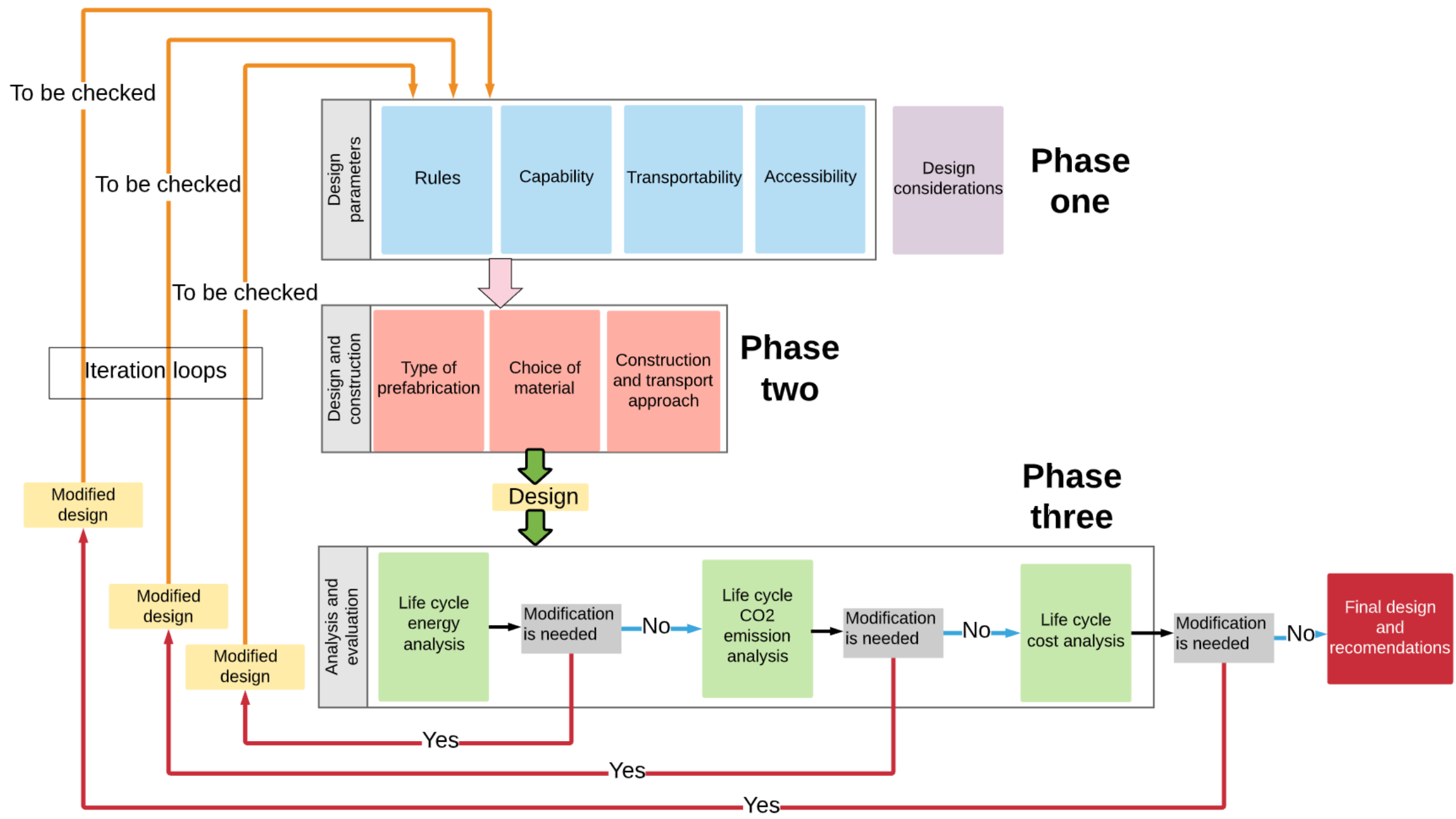

Figure 3.3: Research plan 


\subsection{Phases of the Study}

In this research, which is based on using design as a tool, the first step is to design the prefabricated ADU so as to use it for the next steps. This research is designed in three phases. The first phase is a prerequisite to the initial design and involves research into the parameters that will shape it. The second phase investigates the shape of the ADU, and the different materials and types of prefabrication to determine which is most appropriate given the investigation in phase one. There is a supplementary section between phases one and two which looks at designs with similar aims to help in choosing the best design strategy. These two phases are presented in Chapter 4 and Chapter 5 . The third phase aims to modify the design based on the quantitative results of the various simulations. Phase three also compares the modified design with similar projects in New Zealand and other countries (Chapter 6). The following paragraphs explain each phase in more detail.

\subsubsection{Phase One (Chapter 4)}

The first phase of determining the design parameters looks at the rules and requirements which must be included in the design (

Figure 3.4). This phase is divided into four sections: the rules for ADUs, the capability of the prefabrication industry, the transport rules for moving the ADU from factory to site, and the Lifemark rules for creating accessible homes. The rules section looks at New Zealand district provisions and plans specific to ADUs. Prefabrication has to be a generalised solution so the aim is to find how to design an ADU that would be acceptable in the places it is most needed. There is thus a focus on the three aspects of the maximum allowed site coverage and gross plan area, as well as the minimum required site area (see Section 4.2.1). The capability section investigates the existing manufacturers of prefabrication in New Zealand, looking at what type of prefabrication they are involved with and where they are located, as this can affect the construction approach in phase two.

In order to better understand the potential of prefabrication, data was collected on the 182 manufacturers of different types of domestic scale prefabrication available on the web. The main source of company information was Prefab NZ (2018b) a non-profit membership organization that informs, educates and advocates for innovation and excellence in offsite design and construction in New Zealand. From the Prefab NZ database, a list of 85 
manufacturers of prefabricated buildings was compiled. A further 72 manufacturers of frames and trusses were taken from the Frame and Truss Manufacturers' Association of New Zealand (FTAM NZ) (2016). Another 25 companies emerged as a result of a web-based search using keywords related to prefabrication. At the end of this process, 102 companies out of the 182 were selected based on the relevance of their services to manufacturing a prefabricated domestic scale building. This process removed duplications and companies that did not have the specified criteria needed for the research, as explained below.

- The list includes only companies directly manufacturing or building one or more types of prefabrication. This excluded companies who simply cut or shape elements (such as timber or steel) without factory assembly or those on-site builders with the ability to construct a prefabricated home.

- The list excludes companies which produce general products for prefabricated buildings, as well as other types of buildings, or those who produce machines or software for prefabricated manufacturers.

- The kitchen category only includes those companies which manufacture whole or some part of a kitchen (e.g. a sink fitted into a cabinet) and send it to site as a module.

- The bathroom category only includes manufacturers that assemble the whole bathroom at their factory and send it to the site as a module.

After filtering manufacturers of prefabrication, 51 remained the list. Apart from the type of prefabrication, other factors, such as additional services and guarantees, the types of standard they follow, and the level of flexibility offered to their customers needed to be investigated to gain a better understanding of manufacturers of building prefabrication.

Before looking at the result of the survey in Chapter 4 there is a need to deal with issues that arose during the online web-based search, which could affect the willingness of potential customers to pursue the prefabrication route. Notable issues included:

- Most company's websites are not straightforward when it comes to communicating with customers. Technical terms are often used without a clear explanation. For example, some of these companies stated they could provide prefabricated buildings, but they did not discuss the type of prefabrication on the home page. This would 
require customers to check all the links on the websites in order to understand exactly what the company could provide, and the time to do this could deter people.

- Some company's websites are very brief, lacking critical, basic information.

The terms used by manufacturers are not consistent. Some use different terms for a specific type of prefabrication. This is a critical point as each type of prefabrication has its own benefits and disadvantages and is often best used for a specific situation.

Transportation is one of the main constraints in any prefabricated house project (see Section 2.2), so the transportability section looks at New Zealand road rules. Given the importance of the housing needs of older people in this research, the last section of this part looks at an existing standard for delivering accessible dwellings for the ageing population. The New Zealand Lifemark standard will be used with the aim of achieving certification of at least three stars (see Section 4.5).

There is also a need to look at appropriate existing plans for small houses, and this is presented at the end of phase one. Designs were selected based on the plan area range (derived from council rules with respect to ADU) to see how other designers have arranged a small dwelling of this size. The plans to be analysed in this section included tiny house and ADU plans from New Zealand and other countries. The main source were plans from ADU handbooks, published by councils. Other plans came from a systematic online review of related websites using the terms ADU, accessory dwelling units, tiny houses, granny flats, and small houses.

The other need is to look at prefabricated zero energy house examples to see what approaches have been used to make the design energy efficient and also transportable. Plans to be investigated in this section were selected from the Solar Decathlon (SD) competition, which is about designing energy efficient houses that are able to shipped to the competition site (see Section 4.6.2). 


\section{Phase one: Pre-design preliminaries}
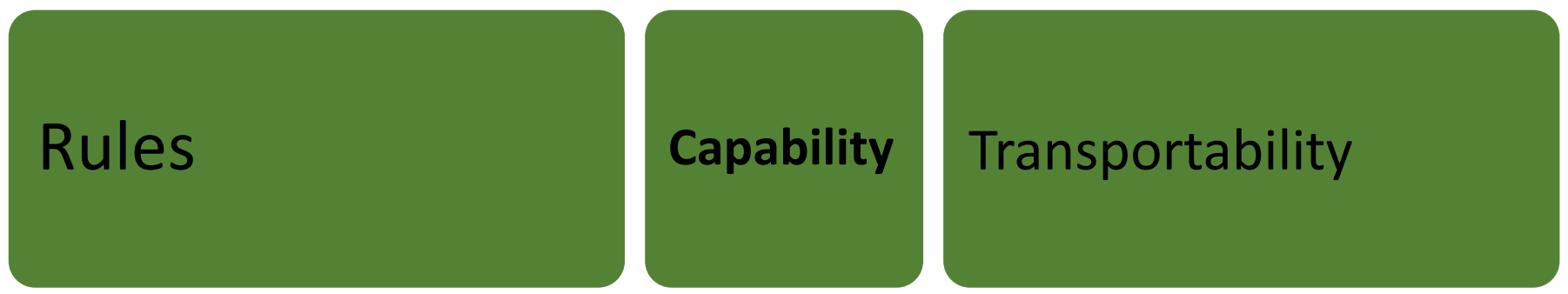

Accessab

ility for

older

people

District provisions specific to ADUs

\section{Minimum \\ Number and}

Maximum allowed

site

Maximum allowed gross plan area

required

site area
Prefabrication manufacturers

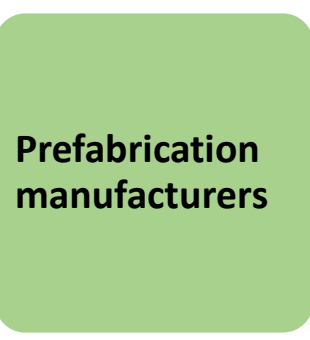

location of each type of

prefabrication

manufacturer
New Zealand road rules

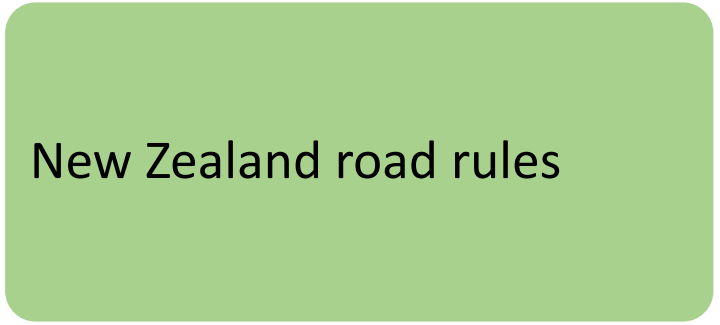

Maximum
allowed
loads
height

\section{Maximum} allowed

loads

width
Maximum allowed

loads

weight
Lifemark

standards

Minimum

sizes and

requirement

Figure 3.4: Phase one structure 


\subsubsection{Phase Two (Chapter 5)}

The second phase looks at different methods of prefabrication, leading on to the choice of materials. The aim here is to select the design and construction approach which aligns best with the needs and requirements that have emerged from phase one (Figure 3.5).

The first section of this phase evaluated the benefits and disadvantages of each type of prefabrication in relation to the research aims, to see which suit the best. The second section looked at the different materials, especially the different available types of insulation. At this stage based on the possible type and thickness of the floor, as well as the available thicknesses of walls and roof, 18 different construction scenarios were possible for each of the 21 different designed layouts. However, it was impossible to investigate the construction approach of all scenarios. In order to narrow the available options, the third section simulated the design using ALF 3.2 software in order to find the most energy efficient scenario in terms of space heating (BRANZ, 2018). In addition to the investigating the effects of adding different layers of thermal mass on the energy efficiency of the ADU, the area of windows was also modified at this stage to achieve the best ratio of heat gain and loss (see Section 5.6.3). The last part gives a detailed account of how the selected ADU would be constructed in the factory and the way it would be transported to site for assembly there. It is worth noting that while the type of prefabrication and materials to be used were decided in the preliminary design, the design was modified in this phase whenever this is needed. Changes needed at this stage were adding structural beams to ease the placement of ceiling panels, changing the size of the entrance module and making decisions about how to crane and attach the modules in place (Chapter 5). 


\section{Phase two: Design and construction}

\section{Design}

\section{Different}

types of prefabric ation
Different constructio n system and materials
Other design considerations

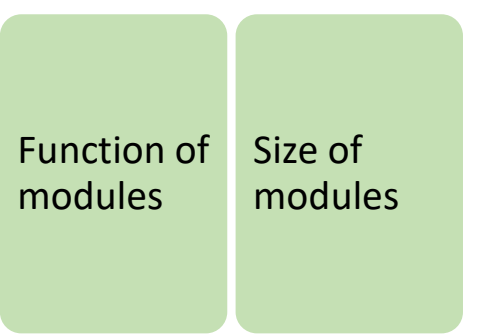

\section{Construction}

\section{Thickness} and width of panels

\section{Space conditioning energy}

Construction approach

Most

\section{Most}

energy

efficient

constructio

n scenario

Most
efficient
level of
thermal
mass

efficien

size and

placement

of

windows
Attaching modules together and to the slab

Figure 3.5: Phase two structure 


\subsubsection{Phase Three (Chapter 6)}

While the first two phases of this research concerned the design and construction of the ADU, the third phase evaluated its efficiency. This phase included three sections, each of which evaluated a specific aspect of the ADU as designed; life cycle energy, $\mathrm{CO}_{2}$ emissions and cost (Figure 3.6).

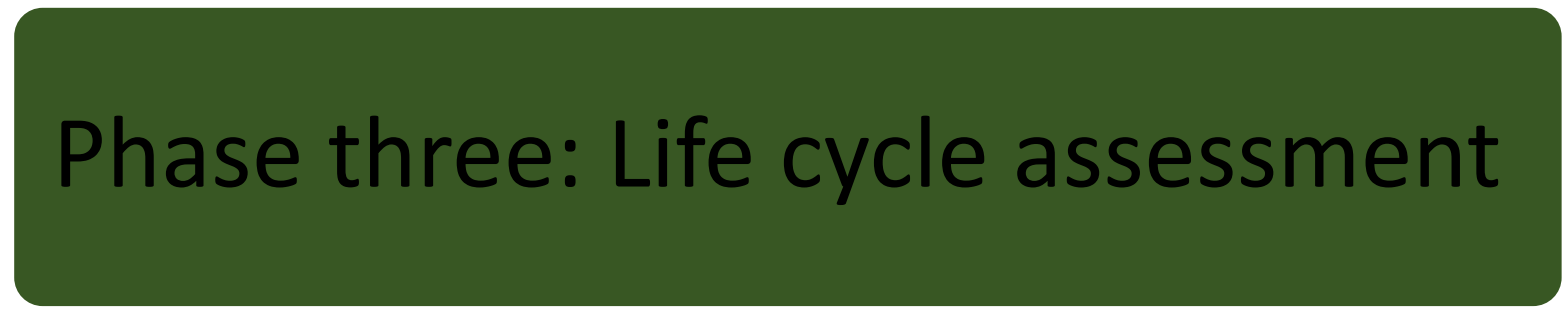

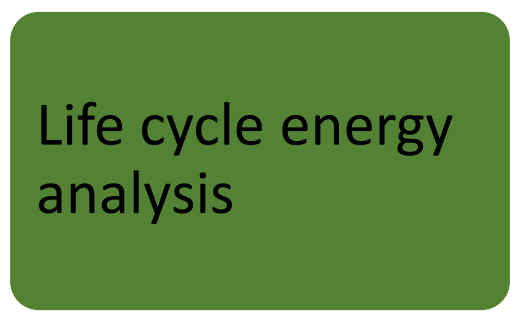
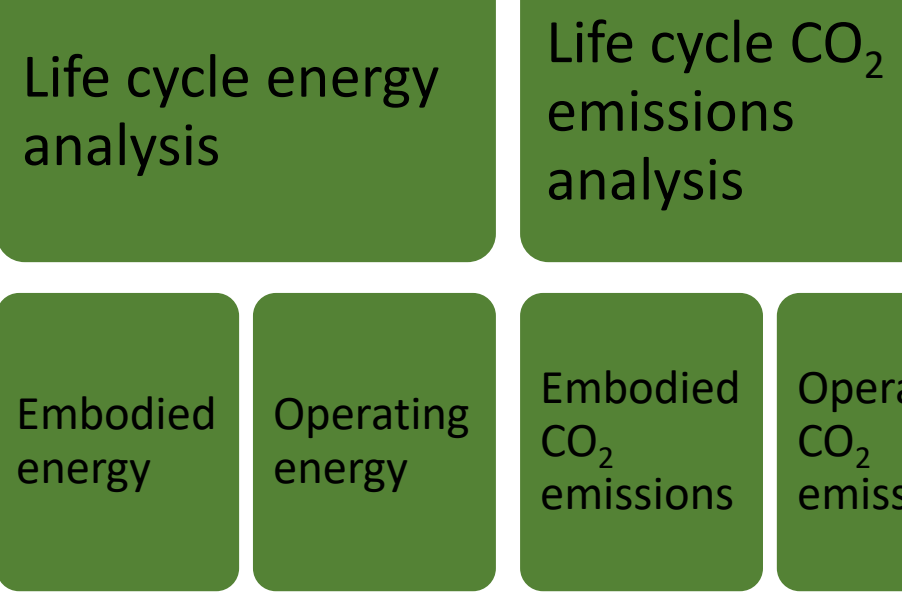

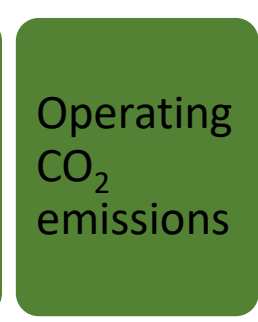

Life cycle cost analysis

Constructi

on and

maintena

ce cost
Operating energy cost

Figure 3.6: Phase Three structure

The design was continuously modified, based on the results of each Life Cycle Analysis (LCA) stage, so the efficiency of the ADU is gradually improved. In the other words, this research was based on iteration and a non-linear process, which meant that if a considerable change was needed based on the results of phase three, the modified ADU was sent back through phases one and two to make sure all parameters were still being met. Some of the modifications that happened in this phase were changing the thickness of ceiling panels and also the use of polystyrene made SIPs instead of those of with polyurethane core. The results of the LCA calculations were compared with similar buildings from New Zealand, Australia and the UK in order to compare the efficiency of the ADU with conventionally built houses.

\subsubsection{LCA Tools}

Two different tools were available for this LCA study. These were the Building Research Association of New Zealand (BRANZ) have developed software called LCA-Quick Residential 
(LCAQR) that provided a standardised approach, or a spreadsheet developed by the researcher.

In this research, an initial estimate of the Operating Energy (OE) was calculated using ALF3.2 (see Section 5.6). To calculate the Embodied Energy (EE) of the ADU, the initial thought was to use LCA-Quick Residential, which was a tool newly developed by BRANZ for calculating the Life Cycle Assessment (LCA) of a domestic building in New Zealand. At the time of this research, the only available version of the tool was LCA-Quick Office for commercial buildings and the residential version was under development. Following communication with BRANZ, the researcher was granted access to a pre-release residential version. LCA-Quick Residential calculates the environmental impact of the ADU over its lifetime in the four main stages of production, construction, use including maintenance, and end of lifetime. Figure 3.7 and Figure 3.8 illustrate each stage in more detail.

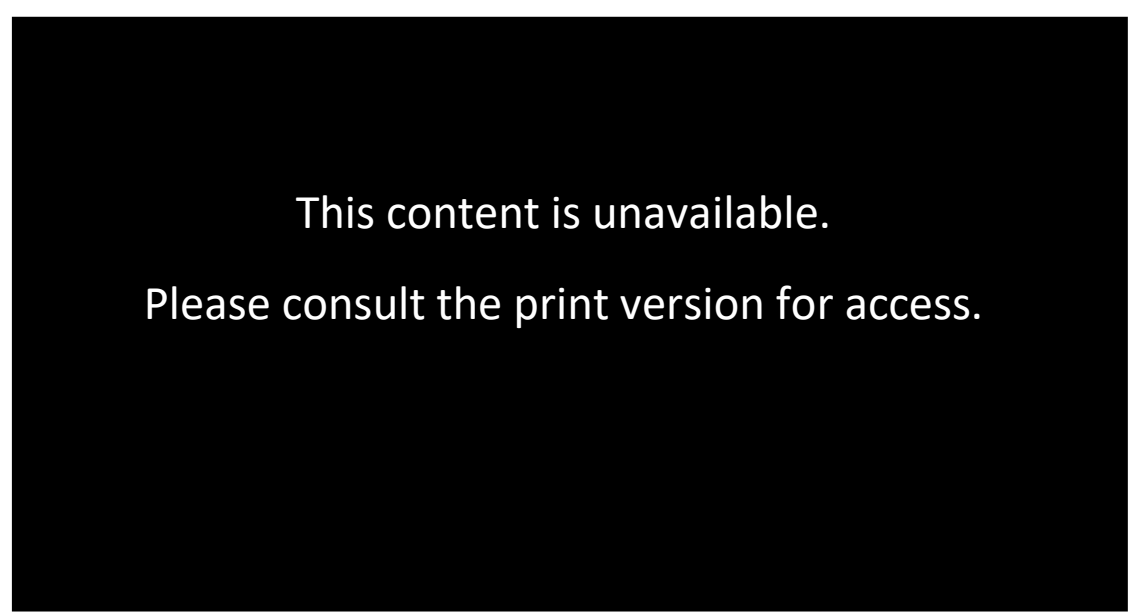

Figure 3.7: Stages of environmental impact calculations (BRANZ, 2018)

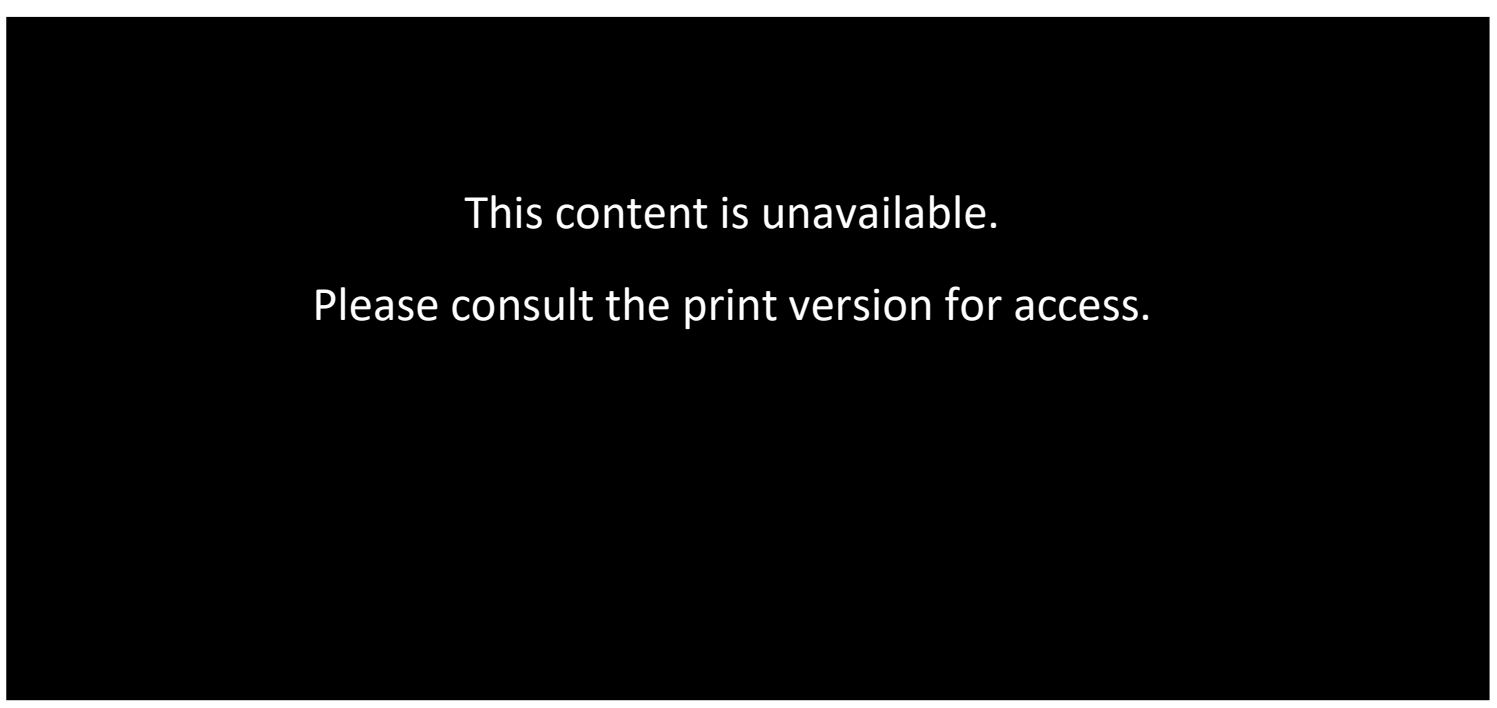

Figure 3.8: LCAQR stages (BRANZ, 2018) 
LCA-Quick Residential has a library of the EE and environmental impacts of materials and asks the user to insert the quantity used (normally volume $\left(\mathrm{m}^{3}\right)$ ). It then calculates the total EE and ecological footprint of the house using its library database. This stage required the creation of an inventory of materials and the amounts be used for constructing the redesigned ADU. However, issues came up after inserting the quantity of materials into LCAQuick Residential. The first was related to the limited variety of materials in the LCA-Quick library making it hard to rely on the output. The other issue was the fact that the lifetime of the materials was not visible, which makes it was hard to make a detailed lifetime analysis. The last issue could be due to the fact that the version used for this research was still under development. Given these issues and the time available for this research, it was decided to use a spreadsheet to calculate the LCA of the ADU. The spreadsheet consisted of type, quantity, and life span of materials (Table 3.4), and EE coefficients (Table 3.3), and $\mathrm{CO}_{2}$ coefficients (Table 3.5) of materials used in the construction process.

Although the construction of the ADU was determined (see Section 5.7) different material options were considered during the LCA, to see if there was a better choice when it comes to energy consumption or environmental impacts during the life span of the ADU. The LCA in this research consisted of the three sections of Life Cycle Energy Analysis (LCEA), Life Cycle $\mathrm{CO}_{2}$ Analysis, and Life Cycle Cost Analysis.

\subsubsection{Life Cycle Energy Analysis}

The first section of this phase included a Life Cycle Energy Analysis (LCEA) of the ADU. At the end of this section the selected design was then simulated again using SUNREL (U.S. Department of Energy, 2018), as the software produces a more detailed analysis compared with ALF 3.2. The goal was to make sure the selected design scenario had acceptable comfort during all hours of a year (see Section 6.3.8).

The LCEA included the EE as well as the Operating Energy (OE) of the ADU, so calculating the OE was the first step, but noting the EE was also important in the LCEA, especially as the OE was reduced with the goal of making a zero heating energy ADU. The OE is normally the energy used by the occupants and includes heating, cooling, and lighting as well as electrical devices (Mithraratne et al., 2007). However, it must be noted that hot water generation, lighting and the operation energy of appliances do not have much to do with design decisions 
or materials selection. Operating energy can also be affected by the number of occupants and their living habits, although the energy needed for space conditioning is highly affected by the house design and selection of materials. Space conditioning is approximately equal to $34 \%$ of household energy use in New Zealand, being the highest proportion amongst space conditioning energy, hot water, and all other energy uses (French et al. 2006). Because usually there is no need for cooling in New Zealand houses, heating was the only operating energy considered in this thesis.

The EE includes all the energy consumed for extracting and manufacturing building materials, transporting them to the site, and constructing the building, in addition to the energy needed to maintain the building and demolish it at the end of its life (Dixit et al., 2015). In conventional houses, the largest components of an LCEA are normally OE and then EE. Boafo et al. (2016) showed in their research that OE was responsible for 70\%-98\% of a building's life cycle energy use. Similarly, Ramesh et al. (2010) studied the life cycle energy of 46 residential buildings, and 27 office buildings made of wood, steel, concrete, steel frame and concrete, brick veneer, clay bricks, cement, and reinforced concrete, coming to the conclusion that during the life span of these buildings $80 \%-90 \%$ of all energy was consumed during operation and just $10 \%$ $20 \%$ was EE. However, this could be different for the ADU as it was designed to be zero heating energy.

\subsubsection{Embodied Energy Calculations:}

To calculate the EE of the ADU manually, all construction details of the ADU were designed (see 5.7.3) using the New Zealand standards, including NZS 3604. Putting the type and quantity of materials together a spreadsheet was created, which was also used for calculations in sections two and three of the third phase. There was also a need for a reliable database of material coefficients appropriate for New Zealand. This is due to the facts that the EE coefficients of materials vary in different countries, based on the technology used for extracting materials, the distance from the source of raw materials to the site of their manufacture and processing, as well as the energy mix used for their extraction and manufacture (Vale, p.114 in Petrovic et al. 2017). As a result, it was decided to collect the EE of materials in New Zealand from the four well-known sources of Alcorn (1996); Alcorn and Wood (1998); Alcorn (2003) and Alcorn (2010) (Table 3.3). 
"He [Alcorn] developed an input-output method (Baird \&Chan, 1983) into a process analysis method (Alcorn, 1996) and finally a hybrid analysis (Alcorn, 2003). The results culminated in his PhD thesis (Alcorn, 2010) in which he aimed to develop a method for measuring the sustainability of samples of New Zealand houses from the 1970s, 2000s, 2010s, and 2020s" (Khajehzadeh, 2017).

Because of the date, Alcorn (2010) was selected as the primary source of data. However, if data for a specific material was not available the other sources were consulted in reverse date order. All of these reports are New Zealand based, but if there was data missing, or a suspect figure that needed to be investigated further the report of Hammond and Jones (2011) was used. This report, which was published for the first time in 2005 and then updated in 6 other stages, collected the EE of over 200 materials from all available resources from 1968-2007. The priority for selecting sources was based on their focus being relevant for the UK. However, whenever data was not available from UK studies, data from other European countries was used as well as worldwide averages (Hammond and Jones, 2008). When it came to sanitary and electrical fittings, despite minor differences in sizes, the quantity of material for each item was extracted from Mithraratne et al (2007, pp.155-156), while the EE was calculated as for the other materials. Any LCA involves the expected life span of the building, so the life of each material or element was a critical value to be specified. Table 3.4 shows the expected life span of materials used in the ADU. The ADU was then assessed for a life span of 100 years. This was selected as being close to the economic life of a house in New Zealand (Johnstone, 2001). 
Table 3.3: Embodied energy of Materials

\begin{tabular}{|c|c|c|c|c|c|c|}
\hline Material & Unit & $\begin{array}{l}\text { Alcorn, } \\
1996\end{array}$ & $\begin{array}{l}\text { Alcorn and } \\
\text { Wood, } \\
1998\end{array}$ & $\begin{array}{l}\text { Alcorn, } \\
2003\end{array}$ & $\begin{array}{l}\text { Alcorn, } \\
2010\end{array}$ & $\begin{array}{l}\text { Hammond } \\
\text { and Jones, } \\
2011\end{array}$ \\
\hline $\begin{array}{l}\text { Timber, air dried, rough } \\
\text { sawn, treated }\end{array}$ & $\mathrm{MJ} / \mathrm{m}^{3}$ & - & - & 1,252 & 1,261 & - \\
\hline $\begin{array}{l}\text { Timber, air dried, rough } \\
\text { sawn }\end{array}$ & $\mathrm{MJ} / \mathrm{m}^{3}$ & 165 & 170 & 1,179 & & - \\
\hline Plywood & $\mathrm{MJ} / \mathrm{m}^{3}$ & 5,720 & 5,200 & - & - & 9,300 \\
\hline OSB & $\mathrm{MJ} / \mathrm{m}^{3}$ & - & - & - & - & 9,600 \\
\hline $\begin{array}{l}\text { Laminated Veneer } \\
\text { Lumber (LVL) }\end{array}$ & $\mathrm{MJ} / \mathrm{m}^{3}$ & - & - & - & - & $5,852^{*}$ \\
\hline Steel, galvanised & $\mathrm{MJ} / \mathrm{m}^{3}$ & 273,180 & 273,180 & - & 454,545 & 445,095 \\
\hline $\begin{array}{l}\text { Steel roofing } 0.4 \mathrm{~mm} \text {, } \\
\text { factory painted }\end{array}$ & $\mathrm{MJ} / \mathrm{m}^{2}$ & - & - & - & 204 & - \\
\hline $\begin{array}{l}\text { Steel, reinforcing } \\
\text { sections }\end{array}$ & $\mathrm{MJ} / \mathrm{m}^{3}$ & 69,790 & 69,790 & 67,144 & 67,420 & - \\
\hline Copper (rod, wire) & $\mathrm{MJ} / \mathrm{m}^{3}$ & - & - & 827,316 & - & 361,200 \\
\hline Copper (virgin) & $\mathrm{MJ} / \mathrm{m}^{3}$ & 631,164 & 631,164 & 21,217 & - & - \\
\hline Polyurethane* & $\mathrm{MJ} / \mathrm{m}^{3}$ & 44,400 & 44,400 & - & - & 3,045 \\
\hline Extruded polystyrene & $\mathrm{MJ} / \mathrm{m}^{3}$ & - & - & - & 2,450 & - \\
\hline Expanded polystyrene & $\mathrm{MJ} / \mathrm{m}^{3}$ & 2,340 & 2,340 & 1,401 & 1,400 & 1,993 \\
\hline Glass fibre (Fibre glass) & $\mathrm{MJ} / \mathrm{m}^{3}$ & 970 & 970 & 1026 & - & 336 \\
\hline $\begin{array}{l}\text { High Density } \\
\text { Polyethylene (HDPE) }\end{array}$ & $\mathrm{MJ} / \mathrm{m}^{3}$ & 97,340 & 97,340 & 48,166 & - & - \\
\hline PVC & $\mathrm{MJ} / \mathrm{m}^{3}$ & 93,620 & 93,620 & 80,944 & - & 94,500 \\
\hline $\begin{array}{l}\text { Reinforced concrete } \\
\text { (concrete } 17.5 \mathrm{MPa} \text { ) }\end{array}$ & $\mathrm{MJ} / \mathrm{m}^{3}$ & 2,350 & 2,350 & 2,019 & 2,020 & - \\
\hline Float glass & $\mathrm{MJ} / \mathrm{m}^{3}$ & 40,060 & 40,060 & 40,039 & 40,040 & 37,500 \\
\hline Tile & $\mathrm{MJ} / \mathrm{m}^{3}$ & 5,250 & 5,250 & - & - & 2,450 \\
\hline $\begin{array}{l}\text { Ceramics, sanitary } \\
\text { products }\end{array}$ & $\mathrm{MJ} / \mathrm{kg}$ & - & - & - & - & 29 \\
\hline Paint & $\mathrm{MJ} / \mathrm{m}^{3}$ & 115,000 & 115,000 & - & 89,500 & - \\
\hline$A B S$ & $\mathrm{MJ} / \mathrm{m}^{3}$ & 125,430 & 125,430 & - & - & \\
\hline Polycarbonate & $\mathrm{MJ} / \mathrm{kg}$ & - & - & - & - & 112.9 \\
\hline
\end{tabular}

* See Section 6.3.2. 
Table 3.4: Life span of materials

\begin{tabular}{|c|c|c|}
\hline Material & Life span (years) & Source \\
\hline Concrete in floors & 150 & Alcorn, 2010 \\
\hline DPM (Damp Proof Membrane) & 150 & Alcorn, 2010 \\
\hline Insulation EPS & 50 & Bennet, 2008 \\
\hline Insulation XPS & 150 & Alcorn, 2010 \\
\hline Nails, framing & 90 & Alcorn, 2010 \\
\hline Nails, galvanised, cladding & 40 & Page, 2005 \\
\hline Nails, lining fixing & 50 & Alcorn, 2010 \\
\hline Paint, normal & 8 & Page, 2005 \\
\hline Paint, factory applied & 15 & Page, 2005 \\
\hline Steel reinforcing & 150 & Alcorn, 2010 \\
\hline Steel sheet, factory painted \& repainted & 50 & Page, 2005 \\
\hline Timber, roof framing & 90 & Page, 2005 \\
\hline Timber, external windows and doors & 90 & Alcorn, 2010 \\
\hline Timber, internal doors & 150 & Alcorn, 2010 \\
\hline Timber, exterior wall framing & 90 & Page, 2005 \\
\hline Timber, $\mathrm{H} 1.2$ treated & 90 & Page, 2005 \\
\hline Timber, interior wall framing & 150 & Alcorn, 2010 \\
\hline Timber, External cladding & 30 & Bunnings, 2018 \\
\hline Tile (interior) & $75-100$ & Jackson, 2007 \\
\hline Glass & 100 & Bennet, 2008 \\
\hline PVC pipes & $50-100$ & Folkman (2014) \\
\hline LVL beams & 50 & Jackson, 2007 \\
\hline Copper (pipes) & 50 & Asadi et al., 2016 \\
\hline Copper (wires) & $100+$ & Jackson, 2007 \\
\hline Wiring, switchboard \& power outlets & 50 & Fay, 1999 \\
\hline WC pan, vanity basin & $100+$ & Jackson, 2007 \\
\hline ABS pipes & 50 & Lu et al.2003 \\
\hline Glass fibre insulation & 100 & Jackson, 2007 \\
\hline SIP panels & 50 & NZSIPs, 2018 \\
\hline Sink unit & 50 & Bunnings, 2018 \\
\hline Toilet double flap seat & 150 & Bunnings, 2018 \\
\hline Hot water cylinder & 40 & Smart homes, 2019 \\
\hline Taps and valves & 50 & Smart homes, 2019 \\
\hline Towel rail & 50 & Smart homes, 2019 \\
\hline Toilet paper holder & 50 & Smart homes, 2019 \\
\hline Grab bar & 50 & Smart homes, 2019 \\
\hline Switchboard & 50 & Mihraratne et al., 2007 \\
\hline Light fitting & 50 & Mihraratne et al., 2007 \\
\hline Power outlets & 50 & Mihraratne et al., 2007 \\
\hline Gutters and downpipes & 20 & Mihraratne et al., 2007 \\
\hline
\end{tabular}

After all data was inserted into the spreadsheet to calculate the LCE, the results were analysed using two different approaches. The first was classifying the results based on the elements of the ADU and the second was based on the type of material. The first approach used the seven elements of the gable roof, SIPs ceiling, SIPs walls, internal walls, doors and windows, 
plumbing and electrical (including fittings), and foundations (excluding drainage as this is too site dependent). In the second approach, the results were classified into the five material types of timber, metal (steel and copper), plastics (polyurethane, paint, slab insulation, wire coating and electrical fittings, SIPs adhesive and membranes), concrete, and ceramics and glass (tiles, sanitary fittings and window glass). Ceramics and glass were combined into one group as their share of the total EE was very small.

\subsubsection{2 $\mathrm{CO}_{2}$ Emissions Calculations:}

The same spreadsheets generated for the LCE calculations were used for calculating the $\mathrm{CO}_{2}$ emissions of materials, and the ALF 4, which had just been released at this stage of the research, outputs were used for the heating energy calculations. It is worth noting that $\mathrm{CO}_{2}$ calculations in this section followed the same assumptions as for the LCE calculations (see Section 6.3.1)

\subsection{Embodied $\mathrm{CO}_{2}$ Emissions}

As for the LCE calculations the first step was to list the $\mathrm{CO}_{2}$ coefficients of materials. These coefficients can differ based on the location of where the materials were made. In this research three New Zealand based studies by Alcorn (2003 and 2010) and Mithraratne et al. (2007) were used, with Alcorn (2010) selected as the primary source of data as it was the most recent. However, if data for a specific material was not available the other sources were consulted in reverse date order. Where data was missing the report of Hammond and Jones (2011) was used, while the New Zealand based report of Love (2010) was used for the $\mathrm{CO}_{2}$ coefficient of Laminated Veneer Lumber (LVL). Different units were found in these sources, and the one which aligned best with the calculated quantities in the spreadsheet was selected (Table 3.5). 
Table 3.5: Embodied $\mathrm{CO}_{2}$ Coefficients of materials

\begin{tabular}{|l|l|r|l|}
\hline Material & Unit & \multicolumn{1}{l|}{$\begin{array}{l}\mathrm{CO}_{2} \\
\text { coefficient }\end{array}$} & Source \\
\hline Timber, air dried, rough sawn, treated CCA & $\mathrm{kg} / \mathrm{m}^{3}$ & -695.0 & Alcorn, 2010 \\
\hline Timber, air dried, rough sawn & $\mathrm{kg} / \mathrm{m}^{3}$ & -907.0 & Mithraratne et al, 2007 \\
\hline Plywood & $\mathrm{kg} / \mathrm{m}^{3}$ & -619.0 & Mithraratne et al, 2007 \\
\hline Laminated Veneer Lumber (LVL) & $\mathrm{kg} / \mathrm{m}^{3}$ & -611.0 & Love, 2010 \\
\hline Steel, galvanised & $\mathrm{g} / \mathrm{kg}$ & $1,750.0$ & Alcorn, 2010 \\
\hline Steel roofing 0.4mm, factory painted & $\mathrm{g} / \mathrm{m}^{2}$ & $8,785.0$ & Alcorn, 2010 \\
\hline Steel reinforcing (Recycled) & $\mathrm{g} / \mathrm{kg}$ & 575.0 & Alcorn, 2010 \\
\hline Copper (rod, wire) & $\mathrm{g} / \mathrm{kg}$ & $66,844.0$ & Alcorn, 2003 \\
\hline Copper (tube) & $\mathrm{kg} / \mathrm{m}^{3}$ & $1,340.0$ & Alcorn, 2010 \\
\hline Copper (virgin, recycled) & $\mathrm{kg} / \mathrm{kg}$ & 7.7 & Alcorn, 2010 \\
\hline Polyurethane & $\mathrm{kg} / \mathrm{m}^{3}$ & $2,540.0$ & Mithraratne et al, 2007 \\
\hline Extruded polystyrene & $\mathrm{kg} / \mathrm{m}^{3}$ & 105.0 & Alcorn, 2010 \\
\hline Expanded polystyrene & $\mathrm{kg} / \mathrm{m}^{3}$ & 60.0 & Alcorn, 2010 \\
\hline Glass fibre (Fibreglass) & $\mathrm{kg} / \mathrm{m}^{3}$ & 37.0 & Alcorn, 2010 \\
\hline High-Density Polyethylene (HDPE) & $\mathrm{kg} / \mathrm{m}^{3}$ & $5,568.0$ & Mithraratne et al, 2007 \\
\hline PVC & $\mathrm{kg} / \mathrm{m}^{3}$ & $5,355.0$ & Mithraratne et al, 2007 \\
\hline Reinforced concrete (concrete $17.5 \mathrm{MPa})$ & $\mathrm{kg} / \mathrm{m}^{3}$ & 280.0 & Alcorn, 2010 \\
\hline Float glass & $\mathrm{kg} / \mathrm{m}^{3}$ & $4,370.0$ & Alcorn, 2010 \\
\hline Ceramic tile & $\mathrm{kg} / \mathrm{m}^{3}$ & 300.0 & Mithraratne et al, 2007 \\
\hline Ceramics, sanitary products & $\mathrm{kg} / \mathrm{kg}$ & 1.5 & Hammond and Jones, 2011 \\
\hline Paint & $\mathrm{kg} / \mathrm{m}^{3}$ & $2,130.0$ & Alcorn, 2010 \\
\hline ABS & $\mathrm{kg} / \mathrm{m}^{3}$ & $7,175.0$ & Mithraratne et al, 2007 \\
\hline Polycarbonate & $\mathrm{kg} / \mathrm{kg}$ & 6.0 & Hammond and Jones, 2011 \\
\hline
\end{tabular}

\subsection{Operating $\mathrm{CO}_{2}$ Emissions}

The OE of the ADU was extracted from ALF 4 simulation results and converted to delivered energy (see Section 6.3.7). The $\mathrm{CO}_{2}$ coefficient of $1 \mathrm{kWh}$ of electricity was taken as $0.1 \mathrm{~kg} \mathrm{CO}_{2}$, which is the national average factor for purchased electricity (Hargreaves, 2003; Ministry for the Environment, 2016).

\subsubsection{Cost Calculation:}

As with the LCE and life cycle $\mathrm{CO}_{2}$ emissions, there should be a balance between different types of cost in order to reach the best result over the ADU life cycle. This is the reason for undertaking a Life Cycle Cost Assessment (LCCA) of the ADU to see how the design decisions which have been made affect the cost. This section, therefore, set out to calculate the cost of the ADU and see how it compared with the average cost of conventionally made houses in New Zealand over a 100 year period, using the spreadsheet and assumptions developed in LCEA section (see Section 6.3.1) 


\subsection{Summary}

This research was developed in three main phases, each of which included different sections. The most important point worth recalling in this chapter is the fact this research used design as a tool with which to answer the research questions. Moreover, the design process was based on iteration, which meant the design was modified and developed based on the results of each section, with this mainly happening in phase three. This gives a realistic view, based on existing rules and requirements, of whether prefabricated ADUs have the potential to contribute to housing needs in New Zealand. 


\section{Chapter 4 Design Parameters}

\subsection{Introduction}

This chapter investigates the rules and requirements related to the design, construction and use of the ADU. The chapter first reviews the district plan provisions specific to ADUs in order to decide on the legal requirements to be considered at the design stage. Then it reviews the manufacturers of prefabrication to test the capability of prefabricating ADUs in New Zealand. It also investigates the road transport rules and the guidelines to be accessible for people with disabilities. The last part analyses plans regarding their size, level and type of prefabrication, and those designed to be zero energy. These stages end with some preliminary designs for the prefabricated ADU, to be used as the basis of the research in the next chapters. This chapter is phase one of the research (see Section 3.7.1).

\subsection{District Plan Provisions Specific to ADUs}

This section aims to give a better understanding of the existing rules set down by New Zealand councils to see the potential and barriers related to ADUs. Data extracted from Saville-Smith et al. (2017) has been collected and organised in Appendix A. Due to the size of the table, it has been broken down into smaller parts (Table 4.1 to Table 4.6) to be used in this section.

The table in Appendix A includes 55 New Zealand councils, but excludes 14 councils which do not specify any provisions for ADUs, and the Hauraki District Franklin Area and Tasman area for small subsidiary units as these do not allow cooking facility in ADUs. Each council has been divided into the three zones of residential, rural, and others, resulting in over 180 subgroups. The table further narrows the data by explaining the types of ADU to which the rules relate. Although the types are varied, they can be classified into the nine groups of attached, detached, conversion, partitioning, construction, minor dwelling, accessory building, workers' accommodation, and family flats. Next, there are the four sub-groups of permitted, discretionary, restricted discretionary, and controlled activity, which describe the kind of permission required by each council based on the zone and type of ADU.

ADUs are permitted in 80 subgroups out of the 180 (see Appendix A). ADUs are discretionary in 9 and restricted discretionary in 10 groups, and 11 consider ADUs as a controlled activity. This means 70 subgroups did not mention the type of permission required by the relevant council. Only one subgroup, which is Nelson, pointed out that conversion is not allowed in 
certain areas. Moreover, it should be noted that Tauranga, Opotiki, Tararua, Christchurch, New Plymouth, Masterton \& Carterton \& South Wairarapa, and Westland councils have various specific conditions for permitting ADUs in their district (see Appendix A). The table then sets out the area limitations posed by each council, and is classified into the three categories of Maximum Site Coverage (MSC), Maximum Gross Plan Area (MGPA) and Minimum Net Site Area Required (MNSA). The last is included for comments and points that are not apparent in any of the previous groups. This generally includes the status of the ADU (whether permanent or relocatable), extra needs for being granted permission, people who are allowed to use the ADUs, and the consent needs of ADUs in each sub-group. While data in Appendix A are extensive and can be analysed in different ways and for different purposes, given the aim of this research only the limitations will be discussed in this chapter.

\subsubsection{Limitations}

In the process of designing an ADU, understanding the rules or limitations is one of the early and most important stages. One of the main obstacles to the acceptance and expansion of ADUs is the fact the legal limitations differ from one council to another. In this situation, due to the differences in rules, one ADU which may work in one jurisdiction is not allowed in another or needs considerable modification. This limits some types of prefabrication, especially manufacture of whole buildings. Making a prefabricated system very flexible to meet all situations can also add to the cost of tooling up. The following sub-sections analyse the ADU limitations of each council to arrive at a suitable size that might be prefabricated for New Zealand.

\subsubsection{Maximum Site Coverage (MSC)}

When it comes to council limitations the first item to be studied is MSC. For this aspect, 40 out of the 180 sub-groups deal with MSC, with an average of $34.5 \%$ over all zone types (Table 4.1). 
Table 4.1: Maximum allowed site coverage

\begin{tabular}{|c|c|c|c|}
\hline Council & Zone & Type of ADU & MSC (\%) \\
\hline \multirow[t]{2}{*}{ Far North } & Residential & Alteration/addition & $55\left(\right.$ or $\left.550 m^{2}\right)$ \\
\hline & Rural & Alteration/addition & 10 (or $\left.2400 \mathrm{~m}^{2}\right)$ \\
\hline \multirow{7}{*}{$\begin{array}{l}\text { Thames- } \\
\text { Coromandel }\end{array}$} & Coastal & & 30 \\
\hline & Residential & & 35 \\
\hline & Extra Density Residential & & 45 \\
\hline & Low-Density Residential & & 15 \\
\hline & Rural Lifestyle & & 10 \\
\hline & Village & & 35 \\
\hline & Waterfront & & 50 \\
\hline \multirow[t]{4}{*}{ Rotorua } & Residential Zone 1 & Buildings and alterations & 40 \\
\hline & Residential Zone 3 & Buildings and alterations & 50 \\
\hline & Residential Zone 4 & Buildings and alterations & 40 \\
\hline & Residential Zone 5 & Buildings and alterations & 25 \\
\hline Opotiki & $\mathrm{N} / \mathrm{A}$ & Accessory dwellings & 40 \\
\hline Gisborne & & & 35 \\
\hline \multirow[t]{2}{*}{ New Plymouth } & Residential A\&C & 1 habitable & 35 \\
\hline & Residential B & 1 habitable & 50 \\
\hline South Taranaki & & & 40 \\
\hline Manawatu & Residential & Family flats & 35 \\
\hline \multirow[t]{6}{*}{ Napier } & Main residential & $\begin{array}{l}\text { Development of only one } \\
\text { supplementary unit }\end{array}$ & 50 \\
\hline & General Residential Zone & $\begin{array}{l}\text { One residential building and } \\
\text { one supplementary dwelling }\end{array}$ & 45 \\
\hline & Rural Residential & & 20 \\
\hline & Tuki Tuki Special Character & & 20 \\
\hline & City Living & & 45 \\
\hline & Character Residential & & 35 \\
\hline $\begin{array}{l}\text { Palmerston } \\
\text { North }\end{array}$ & & Minor dwellings & 35 \\
\hline \multirow[t]{2}{*}{ Horowhenua } & Residential & Family flats & 35 \\
\hline & & Detached Residential units & 35 \\
\hline Kapiti Coast & & & 40 \\
\hline Porirua & & $\begin{array}{l}\text { A second or any subsequent } \\
\text { detached dwelling }\end{array}$ & 35 \\
\hline \multirow[t]{2}{*}{ Upper Hutt City } & Residential Zones & & 35 \\
\hline & $\begin{array}{l}\text { Residential Conservation } \\
\text { and Residential Hill }\end{array}$ & & 30 \\
\hline \multirow[t]{3}{*}{ Hutt City } & $\begin{array}{l}\text { Landscape Protection } \\
\text { Residential }\end{array}$ & Dwelling Houses & 15 \\
\hline & Special Residential Activity & Dwelling Houses & 30 \\
\hline & Hill Residential Activity & Dwelling Houses & 30 \\
\hline \multirow[t]{4}{*}{ Mackenzie } & Residential 1 & Minor units & 40 \\
\hline & Residential 2 & Minor units & 85 \\
\hline & Residential 3 & & 20 \\
\hline & Residential 4 & Minor units & 10 \\
\hline Queenstown & & $\begin{array}{l}\text { Addition, alteration or } \\
\text { construction }\end{array}$ & 15 \\
\hline
\end{tabular}


Table 4.1 shows that for the 24 residential zones the average MSC is $38.1 \%$. The highest allowed MSC of $85 \%$ is for the Residential zone 2 of the Mackenzie Council and the lowest is $10 \%$ is from the same council for Residential zone 4 . Of the sub-groups, four are in rural zones with an average MSC of $18.7 \%$. The highest allowed MSC for a rural area is $35 \%$ by the ThamesCoromandel Council and the lowest $10 \%$ is from the same council but for the Rural Lifestyle zone. Eight councils have rules about MSC without mentioning the related zone, with an average of $34.3 \%$. It is worth noting that Hamilton and Hasting councils are not included in this analysis as they did not mention site coverage as a percentage but only as an area, making it hard to compare these two councils with the others. Table 4.2 shows the counts of MSC for different zones and councils.

Table 4.2: Maximum Site coverage in different zones and councils

\begin{tabular}{|l|l|l|l|l|l|l|}
\hline \multirow{2}{*}{ MSC (\%) } & \multicolumn{5}{l}{ Number of councils } & \multicolumn{2}{l|}{ Total } \\
\cline { 2 - 8 } & Residential & Rural & Other & General & Number & Percentage \\
\hline 10 & 1 & 2 & 0 & 0 & 3 & 7.5 \\
\hline 15 & 1 & 0 & 1 & 1 & 3 & 7.5 \\
\hline 20 & 1 & 1 & 1 & 0 & 3 & 7.5 \\
\hline 25 & 1 & 0 & 0 & 0 & 1 & 2.5 \\
\hline 30 & 3 & 0 & 1 & 0 & 4 & 10 \\
\hline 35 & 6 & 1 & 1 & 4 & 12 & 30 \\
\hline 40 & 3 & 0 & 0 & 3 & 6 & 15 \\
\hline 45 & 3 & 0 & 0 & 0 & 3 & 7.5 \\
\hline 50 & 3 & 0 & 0 & 0 & 3 & 7.5 \\
\hline 55 & 1 & 0 & 0 & 0 & 1 & 2.5 \\
\hline 60 & 0 & 0 & 0 & 0 & 0 & 0.0 \\
\hline 65 & 0 & 0 & 0 & 0 & 0 & 0.0 \\
\hline 70 & 0 & 0 & 0 & 0 & 0 & 0.0 \\
\hline 75 & 0 & 0 & 0 & 0 & 0 & 0.0 \\
\hline 80 & 0 & 0 & 0 & 0 & 0 & 0.0 \\
\hline 85 & 1 & 0 & 0 & 0 & 1 & 2.5 \\
\hline Total number & 24 & 4 & 4 & 8 & 40 & 100 \\
\hline
\end{tabular}

* The general column shows data for councils which did not mention the type of zone

Table 4.2 shows that of the 40 sub-groups that imposed a limit for MSC when inserting an ADU, 12 sub-groups (30\%) limited the coverage to 35\%, 6 sub-groups (15\%) allowed $40 \%$ coverage, and 4 councils (10\%) limited MSC to $30 \%$. Overall $55 \%$ of all sub-groups had a MSC within a range of $30-40 \%$. Table 4.2 shows that in residential zones, the focus of this research, councils are following a similar approach to that of the limits imposed for all zones. Of 24 subgroups in the residential zone, $6(24 \%)$ limited the site coverage to $35 \%$. The next popular 
limits were $30 \%, 40 \%, 45 \%$ and $50 \%$ each being mentioned by three councils ( $13 \%)$. So, overall 18 councils (76\%) limited the site coverage to $30-50 \%$.

\subsubsection{The Maximum Gross Plan Area (MGPA)}

The maximum allowed gross plan area is one of the most important factors affecting the design of the ADU as it should be in a range allowed by the majority of councils. The plan area of the ADU also affects its affordability and design appeal. Table 4.3 shows that 52 out of 180 sub-groups pose a limitation on the MGPA of ADUs.

Table 4.3: Maximum gross plan area

\begin{tabular}{|c|c|c|c|}
\hline Council & Zone & Type of ADU & $\begin{array}{l}\text { MGPA } \\
\left(\mathrm{m}^{2}\right)\end{array}$ \\
\hline Far North & $\mathrm{N} / \mathrm{A}$ & Detached & 45 \\
\hline Whangarei & $\mathrm{N} / \mathrm{A}$ & $\mathrm{N} / \mathrm{A}$ & 70 \\
\hline $\begin{array}{l}\text { Thames- } \\
\text { Coromandel }\end{array}$ & All & One minor Unit & 50 or $60^{*}$ \\
\hline \multirow[t]{4}{*}{ Waikato } & Country Living Zone & Construction or alteration & 80 \\
\hline & N/A & $\begin{array}{l}\text { Dependent person dwelling } \\
\text { (attached or detached) }\end{array}$ & 70 \\
\hline & $\mathrm{N} / \mathrm{A}$ & Second subsequent & 70 \\
\hline & $\mathrm{N} / \mathrm{A}$ & Subsidiary dwelling & 65 or 120 \\
\hline \multirow[t]{3}{*}{ Hamilton } & General Residential & One ancillary residential unit & 60 \\
\hline & Large Lot Residential & One ancillary residential unit & 60 \\
\hline & Medium density residential & One ancillary residential unit & 60 \\
\hline Otorohanga & N/A & $\begin{array}{l}\text { Small, habitable buildings, } \\
\text { additions and alterations }\end{array}$ & 30 \\
\hline Waipa & Residential & One secondary dwelling & 70 \\
\hline \multirow[t]{6}{*}{$\begin{array}{l}\text { Western Bay of } \\
\text { Plenty }\end{array}$} & $\begin{array}{l}\text { Residential areas, Future } \\
\text { Urban, Rural Residential and } \\
\text { Lifestyle. }\end{array}$ & One minor dwelling & 60 \\
\hline & $\begin{array}{l}\text { Katikati, Te Puke, Waihi Beach } \\
\text { (including Athenree, } \\
\text { Bowentown and Pios Beach) }\end{array}$ & $\mathrm{N} / \mathrm{A}$ & 60 \\
\hline & Omokoroa Stage 1 & $\mathrm{~N} / \mathrm{A}$ & 60 \\
\hline & Omokoroa Stage 2 & $\mathrm{~N} / \mathrm{A}$ & 60 \\
\hline & Existing Village & $\mathrm{N} / \mathrm{A}$ & 60 \\
\hline & Other areas & $\mathrm{N} / \mathrm{A}$ & 60 \\
\hline Rotorua & Residential Zone 1 & $\begin{array}{l}\text { Buildings and alterations } \\
\text { One additional household } \\
\text { unit }\end{array}$ & $70 * *$ \\
\hline \multirow[t]{4}{*}{ Whakatane } & $\begin{array}{l}\text { Deferred Residential, Mixed } \\
\text { Use, Commercial, Rural Plains, } \\
\text { Rural Foothills and Community } \\
\text { and Culture }\end{array}$ & One accessory building & 65 \\
\hline & Residential Zone & One accessory building & 65 \\
\hline & Urban Living & One accessory building & 65 \\
\hline & Rural Coastal & One accessory building & 65 \\
\hline
\end{tabular}




\begin{tabular}{|c|c|c|c|}
\hline & Rural Ōwhiwa & One accessory building & 65 \\
\hline Gisborne & N/A & $\mathrm{N} / \mathrm{A}$ & 60 \\
\hline South Taranaki & $\mathrm{N} / \mathrm{A}$ & $\mathrm{N} / \mathrm{A}$ & 60 \\
\hline Whanganui & $\mathrm{N} / \mathrm{A}$ & $\begin{array}{l}\text { One minor dwelling/granny } \\
\text { flat }\end{array}$ & 60 \\
\hline \multirow{2}{*}{ Manawatu } & Residential & Family flats & 70 \\
\hline & Rural & Family flats & 70 \\
\hline Napier & Main residential & $\begin{array}{l}\text { Development of a } \\
\text { supplementary unit (one) }\end{array}$ & 80 \\
\hline \multirow[t]{4}{*}{ Hastings } & Most residential & $\begin{array}{l}\text { One supplementary } \\
\text { residential building }\end{array}$ & 80 \\
\hline & Rural Residential & $\mathrm{N} / \mathrm{A}$ & 100 \\
\hline & Nature Preservation & $\mathrm{N} / \mathrm{A}$ & 100 \\
\hline & Tuki Tuki Special Character & $\mathrm{N} / \mathrm{A}$ & 100 \\
\hline $\begin{array}{l}\text { Palmerston } \\
\text { North }\end{array}$ & N/A & Minor dwellings & 80 \\
\hline Horowhenua & Residential & Family flats & 50 \\
\hline Kapiti Coast & $\mathrm{N} / \mathrm{A}$ & $\mathrm{N} / \mathrm{A}$ & 50 \\
\hline $\begin{array}{l}\text { Masterton } \\
\text { \&Carterton \& } \\
\text { South } \\
\text { Wairarapa }\end{array}$ & Rural & One minor dwelling & 60 \\
\hline Upper Hutt City & $\mathrm{N} / \mathrm{A}$ & Family flats & 55 \\
\hline $\begin{array}{l}\text { Marlborough } \\
\text { Marlborough } \\
\text { Sounds }\end{array}$ & $\begin{array}{l}\text { Urban Residential and Sounds } \\
\text { Residential }\end{array}$ & Family flats & 80 \\
\hline Grey & $\mathrm{N} / \mathrm{A}$ & Family flats & 65 \\
\hline Waimakiriri & $\mathrm{N} / \mathrm{A}$ & $\begin{array}{l}\text { One additional physically } \\
\text { separated dwelling-house }\end{array}$ & 75 \\
\hline Selwyn & $\mathrm{N} / \mathrm{A}$ & Family flats & 70 \\
\hline \multirow[t]{4}{*}{ Christchurch } & $\begin{array}{l}\text { Residential Suburban, } \\
\text { Residential Suburban Density } \\
\text { Transition, Residential Banks } \\
\text { Peninsula, Residential New } \\
\text { Neighbourhood. }\end{array}$ & Minor residential & $35-80$ \\
\hline & Residential Hills & Minor residential & $35-80$ \\
\hline & Residential Large Lot & Minor residential & $35-80$ \\
\hline & Residential Small Settlement & Minor residential & $35-80$ \\
\hline \multirow[t]{3}{*}{ Mackenzie } & Residential 1 & Minor units & 50 \\
\hline & Residential 2 & Minor units & 50 \\
\hline & Residential 4 & Minor units & 50 \\
\hline \multirow[t]{2}{*}{ Queenstown } & $\begin{array}{l}\text { Low Density and High-Density } \\
\text { Residential }\end{array}$ & Residential flats & 70 \\
\hline & $\begin{array}{l}\text { Mount Cardrona Station } \\
\text { Special Zone }\end{array}$ & Secondary units & 60 \\
\hline
\end{tabular}

* Thames-Coromandel and Waikato Councils gave two values based on situation (see Appendix A), so both numbers are included here.

** The maximum allowed GPA of Rotorua council was $72 \mathrm{~m}^{2}$ but here it has been rounded down to $70 \mathrm{~m}^{2}$ for ease of analysis. 
Using Table 4.3 the average MGPA which is allowed by councils is $63.5 \mathrm{~m}^{2}$. The highest gross plan area of $120 \mathrm{~m}^{2}$ is allowed by Waikato council is and the lowest of only $30 \mathrm{~m}^{2}$ by Otorohanga council. Table 4.4 gives the count of allowed MGPAs by councils classified by zone types.

Table 4.4: MGPA in different zones and councils

\begin{tabular}{|l|l|l|l|l|l|l|}
\hline \multirow{2}{*}{ MGPA $\left(\mathbf{m}^{2}\right)$} & \multicolumn{3}{|l|}{ Number of councils } & \multicolumn{2}{l|}{ Total } \\
\cline { 2 - 7 } & Residential & Rural & Other & General & Number & Percentage \\
\hline 30 & 0 & 0 & 0 & 0 & 0 & 0 \\
\hline 35 & 0 & 0 & 1 & 0 & 1 & 2 \\
\hline 40 & 0 & 0 & 0 & 0 & 0 & 0 \\
\hline 45 & 0 & 0 & 0 & 1 & 1 & 2 \\
\hline 50 & 4 & 0 & 1 & 1 & 6 & 11 \\
\hline 55 & 4 & 0 & 0 & 1 & 5 & 9 \\
\hline 60 & 4 & 2 & 6 & 4 & 16 & 32 \\
\hline 65 & 3 & 3 & 0 & 2 & 8 & 14 \\
\hline 70 & 4 & 1 & 0 & 4 & 9 & 17 \\
\hline 75 & 0 & 0 & 0 & 1 & 1 & 2 \\
\hline 80 & 4 & 0 & 0 & 1 & 5 & 9 \\
\hline 85 & 0 & 0 & 0 & 0 & 0 & 0 \\
\hline 90 & 0 & 0 & 0 & 0 & 0 & 0 \\
\hline 95 & 0 & 0 & 0 & 0 & 0 & 0 \\
\hline 100 & 0 & 1 & 2 & 0 & 3 & 0 \\
\hline 105 & 0 & 0 & 0 & 0 & 0 & 0 \\
\hline 110 & 0 & 0 & 0 & 0 & 0 & 0 \\
\hline 115 & 0 & 0 & 0 & 0 & 0 & 0 \\
\hline 120 & 0 & 0 & 0 & 1 & 1 & 2 \\
\hline Total number & 23 & 7 & 10 & 16 & 56 & 100 \\
\hline
\end{tabular}

Table 4.4 shows councils prescribe $60 \mathrm{~m}^{2}$ as the MGPA more than any other size. After $60 \mathrm{~m}^{2}$ mentioned by 16 sub-groups (32\%), 9 and 8 sub-groups (17\% and $14 \%$ ) allow ADUs of $70 \mathrm{~m}^{2}$ and $65 \mathrm{~m}^{2}$ respectively. The range of $60-70 \mathrm{~m}^{2}$ covers $63 \%$ of all MGPAs. By adding councils that allowed $50 \mathrm{~m}^{2}$ and $55 \mathrm{~m}^{2}$ (6 and 4 sub-groups (11\%-9\%)), the range of $50 \mathrm{~m}^{2}-70 \mathrm{~m}^{2}$ covers $83 \%$ of all councils. In residential zones, the range of $50 \mathrm{~m}^{2}-70 \mathrm{~m}^{2}$ includes 19 sub-groups (out of 23 ) or over $82 \%$ of all. The average MGPA which is allowed by councils in residential zones is $63.2 \mathrm{~m}^{2}$.

\subsubsection{Minimum Net Site Area (MNSA)}

From the 180 sub-groups, only 37 mentioned a specific MNSA as a compulsory factor for granting permission to build an ADU (Table 4.5). In this table whenever councils specify a range, the average area has been taken. The MNSA mentioned by these 37 sub-groups can be best studied in the four different groups of residential, rural, those who talked about MNSA 
generally, and others. Of these, 21 sub-groups stated residential sites should have a MNSA of an average $613 \mathrm{~m}^{2}$ for an ADU to be allowed. Within this, the highest site area of at least $1750 \mathrm{~m}^{2}$ was required by Christchurch council in the Residential Large Lot zone, and the minimum size of $200 \mathrm{~m}^{2}$ was required by Tauranga council in the City Living Residential zone and Whakatane council for the Urban Living zone. Whangarei, Tauranga, Western Bay of Plenty, Upper Hutt City and Hutt City talk about zones that could not be allocated to either residential or rural or talk about MNSAs generally.

Table 4.5: Minimum net site area

\begin{tabular}{|c|c|c|c|}
\hline Council & Zone & Type of ADU & MNSA $\left(\mathrm{m}^{2}\right)$ \\
\hline Kaipara & Residential & Detached & 800 \\
\hline \multirow[t]{3}{*}{ Whangarei } & Living Environments 1 & Construction or alteration & 500 \\
\hline & Living Environments 2 & Construction or alteration & 350 \\
\hline & Living Environments 3 & Construction or alteration & 2,000 \\
\hline Waipa & Residential & One secondary dwelling & 850 \\
\hline \multirow[t]{5}{*}{ Tauranga } & Suburban Residential & $\begin{array}{l}\text { Secondary independent } \\
\text { dwelling }\end{array}$ & 325 \\
\hline & Large Lot Residential & $\begin{array}{l}\text { Secondary independent } \\
\text { dwelling }\end{array}$ & 1,000 \\
\hline & City Living Residential & $\begin{array}{l}\text { Secondary independent } \\
\text { dwelling }\end{array}$ & 200 \\
\hline & $\begin{array}{l}\text { Urban Marae Community } \\
1\end{array}$ & N/A & 325 \\
\hline & Wairakei Residential & $\mathrm{N} / \mathrm{A}$ & 500 \\
\hline \multirow[t]{3}{*}{$\begin{array}{l}\text { Western Bay } \\
\text { of Plenty }\end{array}$} & $\begin{array}{l}\text { Katikati, Te Puke, Waihi } \\
\text { Beach (including } \\
\text { Athenree, Bowentown } \\
\text { and Pios Beach) }\end{array}$ & $\mathrm{N} / \mathrm{A}$ & 350 \\
\hline & Omokoroa Existing Village & $\mathrm{N} / \mathrm{A}$ & 600 \\
\hline & Other areas & $\mathrm{N} / \mathrm{A}$ & 800 \\
\hline $\begin{array}{l}\text { Rotorua } \\
\text { District }\end{array}$ & Residential Zone 1 & $\begin{array}{l}\text { Buildings and alterations } \\
\text { One additional household unit }\end{array}$ & 600 \\
\hline \multirow[t]{2}{*}{ Whakatane } & Residential Zone & One accessory building & 350 \\
\hline & Urban Living & One accessory building & 200 \\
\hline South Taranaki & $\mathrm{N} / \mathrm{A}$ & $\mathrm{N} / \mathrm{A}$ & 400 \\
\hline Manawatu & Residential & Family flats & 350 \\
\hline Wairoa & Residential (Mahia) & One dwelling per & 800 \\
\hline Hastings & General Residential Zone & $\begin{array}{l}\text { One residential building and } \\
\text { one supplementary dwelling } \\
\end{array}$ & 350 \\
\hline \multirow{3}{*}{$\begin{array}{l}\text { Upper Hutt } \\
\text { City }\end{array}$} & Residential Zones & $\mathrm{N} / \mathrm{A}$ & 425 \\
\hline & $\begin{array}{l}\text { Residential A (Centres } \\
\text { Overlay) }\end{array}$ & $\mathrm{N} / \mathrm{A}$ & 325 \\
\hline & Conservation and Hills & $\mathrm{N} / \mathrm{A}$ & 825 \\
\hline Hutt City & $\begin{array}{l}\text { Landscape Protection } \\
\text { Residential Area }\end{array}$ & Dwelling Houses & 2,000 \\
\hline
\end{tabular}




\begin{tabular}{|c|c|c|c|}
\hline & $\begin{array}{l}\text { Special Residential } \\
\text { Activity Area }\end{array}$ & Dwelling Houses & 700 \\
\hline & $\begin{array}{l}\text { Hill Residential Activity } \\
\text { Area }\end{array}$ & Dwelling Houses & 1,000 \\
\hline \multirow[t]{3}{*}{ Tasman } & Rural 1 & Workers' accommodation & 120,000 \\
\hline & Rural 2 & Workers' accommodation & 500,000 \\
\hline & Rural 3 & Workers' accommodation & 500,000 \\
\hline \multirow[t]{4}{*}{ Christchurch } & $\begin{array}{l}\text { Residential: Suburban, } \\
\text { Suburban Density } \\
\text { Transition, Banks } \\
\text { Peninsula, New } \\
\text { Neighbourhood, }\end{array}$ & Minor residential & 450 \\
\hline & Residential Hills, & Minor residential & 650 \\
\hline & Residential Large Lot, & Minor residential & 1,750 \\
\hline & $\begin{array}{l}\text { Residential Small } \\
\text { Settlement }\end{array}$ & Minor residential & 1,000 \\
\hline \multirow[t]{3}{*}{ Mackenzie } & Residential 2 & Minor units & 20 \\
\hline & Rural-Residential Zone1 & $\begin{array}{l}\text { One dwelling and one minor } \\
\text { dwelling per lot. }\end{array}$ & 10,000 \\
\hline & Rural-Residential Zone2 & $\begin{array}{l}\text { One dwelling and one minor } \\
\text { dwelling per lot. }\end{array}$ & 40,000 \\
\hline Clutha & N/A & Detached dwellings & 100 \\
\hline
\end{tabular}

Table 4.6 shows the MNSAs mentioned by councils for building an ADU and the number of sub-groups in each zone and that have mentioned each size. 
Table 4.6: MNSA in different zones and councils

\begin{tabular}{|c|c|c|c|c|c|c|}
\hline \multirow[t]{2}{*}{ MNSA $\left(m^{2}\right)$} & \multicolumn{4}{|c|}{ Number of councils } & \multicolumn{2}{|l|}{ Total } \\
\hline & Residential & Rural & Other & General & Number & Percentage \\
\hline 100 & 0 & 0 & 0 & 1 & 1 & 3 \\
\hline 200 & 2 & 0 & 0 & 0 & 2 & 5 \\
\hline 250 & 1 & 0 & 0 & 0 & 1 & 3 \\
\hline 325 & 2 & 0 & 1 & 0 & 3 & 8 \\
\hline 350 & 3 & 0 & 2 & 0 & 5 & 14 \\
\hline 400 & 0 & 0 & 0 & 1 & 1 & 3 \\
\hline 425 & 1 & 0 & 0 & 0 & 1 & 3 \\
\hline 450 & 1 & 0 & 0 & 0 & 1 & 3 \\
\hline 500 & 1 & 0 & 1 & 0 & 2 & 5 \\
\hline 600 & 1 & 0 & 1 & 0 & 2 & 5 \\
\hline 650 & 1 & 0 & 0 & 0 & 1 & 3 \\
\hline 700 & 1 & 0 & 0 & 0 & 1 & 3 \\
\hline 800 & 2 & 0 & 1 & 0 & 3 & 8 \\
\hline 825 & 0 & 0 & 1 & 0 & 1 & 3 \\
\hline 850 & 1 & 0 & 0 & 0 & 1 & 3 \\
\hline 1,000 & 3 & 0 & 0 & 0 & 3 & 8 \\
\hline 1,750 & 1 & 0 & 0 & 0 & 1 & 3 \\
\hline 2,000 & 0 & 0 & 2 & 0 & 2 & 5 \\
\hline 10,000 & 0 & 1 & 0 & 0 & 1 & 3 \\
\hline 40,000 & 0 & 1 & 0 & 0 & 1 & 3 \\
\hline 120,000 & 0 & 1 & 0 & 0 & 1 & 3 \\
\hline 500,000 & 0 & 2 & 0 & 0 & 2 & 5 \\
\hline Total number & 21 & 5 & 9 & 2 & 37 & 100 \\
\hline
\end{tabular}

Table 4.6 shows the size mentioned most by councils is $350 \mathrm{~m}^{2}$ being noted by $5(14 \%)$ subgroups. Next are $325 \mathrm{~m}^{2}, 800 \mathrm{~m}^{2}$ and $1000 \mathrm{~m}^{2}$ each mentioned by $3(8 \%)$ sub-groups. Table 4.6 shows of those residential zones sub-groups that asked for a MNSA, there were three that mentioned $350 \mathrm{~m}^{2}$ and another three $1,000 \mathrm{~m}^{2}$ with an average of $613 \mathrm{~m}^{2}$.

Finally, in their report Saville-Smith et al. (2017) stated the complicated prescriptions for ADUs may be a deterrent for both users and builders. However, the analysis above shows it is not impossible to find design parameters that would work for the majority of councils. In residential zones, the golden ranges for MSC, MGPA and MNSA are respectively 30-50\%, $50 m^{2}-70 m^{2}$ and $325 m^{2}-800 m^{2}$. In residential zones, $76 \%$ and $62 \%$ of sub-groups limited the maximum site coverage of the ADU and minimum net area of the site to respectively $30-50 \%$ and $325 m^{2}-800 m^{2}$. Regarding the MGPA, which has the most effect on the design of the ADU, the limit which is posed by over $82 \%$ of sub-groups in the residential zone is in the $50 \mathrm{~m}^{2}-70 \mathrm{~m}^{2}$ range. Obviously the range is not the whole story as the final size of the prefabricated ADU 
will determine how many council's requirements it will meet. However, having a range of sizes maybe helpful in designing a prefabricated ADU that can be rearranged in a variety of ways. In view of trying to achieve this level of flexibility the range of sizes is much more important. The range of $50 \mathrm{~m}^{2}-70 \mathrm{~m}^{2} \mathrm{MGPA}$ will thus be used as a starting point in the planning process (see Section 5.4).

\subsection{Review of Manufacturers of Prefabrication in New Zealand}

\subsubsection{Background to the review}

As part of evaluating the possibility of using prefabricated ADUs, there is a need to map the manufacturers and calculate their distance to the main population centres. This is important as any prefabricated ADU would ideally be made close to where there is a need for housing. Statistics New Zealand (2017d) shows in 2016 there were 333 companies engaged in prefabrication in the country based on the Australian and New Zealand Standard Industrial Classification system (ANZSIC). Of these 51 were directly related to this research topic (see Section 4.3). The following paragraphs show where these 51 were located and what they offered.

\subsubsection{Location and Field of Expertise of Manufacturers}

New Zealand can be divided to 16 regions (Figure 4.1), which can be combined into the bigger groups of the North and South Islands (Stewart Island, the third island, lies to the south of the South Island). In 2017 , approximately $77 \%$ of the total population lived in the North Island, compared to $23 \%$ lived in the South Island (Statistics NZ, 2017b).

The market of new houses is more related to number of households than number of people. Table 4.7 shows the existing and projected number of households in 2013 and 2018 and a projection for 2038 for each region (Statistics NZ, 2015), as well as the presence of prefabrication manufacturers identified in this research. 
Table 4.7: Households and prefabrication manufacturers in the regions of New Zealand

\begin{tabular}{|c|c|c|c|c|c|c|c|}
\hline \multirow{3}{*}{$\begin{array}{l}\text { Regional } \\
\text { Council area }\end{array}$} & \multicolumn{4}{|c|}{ Households at 30 June } & \multirow{2}{*}{\multicolumn{2}{|c|}{ Change 2013-38 }} & \multirow{3}{*}{$\begin{array}{l}\begin{array}{l}\text { Number of } \\
\text { factories }\end{array} \\
\end{array}$} \\
\hline & \multicolumn{3}{|c|}{ Number (000) } & \multirow{2}{*}{$\begin{array}{l}\%) \\
2018\end{array}$} & & & \\
\hline & 2013 & 2018 & 2038 & & $\begin{array}{l}\text { Count } \\
\text { ('000) }\end{array}$ & $\begin{array}{l}\text { Average } \\
\text { annual } \\
(\%)\end{array}$ & \\
\hline Northland & 65.2 & 69.2 & 774.0 & 4 & 12.1 & 0.7 & 3 \\
\hline Auckland & $4,98.0$ & 558.7 & 752.1 & 31 & 254.1 & 1.7 & 13 \\
\hline Waikato & 160.9 & 173.2 & 205.0 & 10 & 44.1 & 1.0 & 3 \\
\hline Bay of Plenty & 109.1 & 115.4 & 133.7 & 7 & 24.6 & 0.8 & 3 \\
\hline Gisborne & 17.5 & 18.1 & 19.4 & 1 & 1.9 & 0.4 & - \\
\hline Hawke's Bay & 61.4 & 64.2 & 68.6 & 4 & 7.2 & 0.4 & - \\
\hline Taranaki & 45.7 & 48.4 & 54.3 & 3 & 8.6 & 0.7 & 2 \\
\hline $\begin{array}{l}\text { Manawatu- } \\
\text { Wanganui }\end{array}$ & 92.4 & 95.4 & 100.3 & 5 & 7.9 & 0.3 & 2 \\
\hline Wellington & 185.4 & 195.8 & 220.0 & 10 & 34.6 & 0.7 & 9 \\
\hline North Island & $1,235.5$ & $1,338.3$ & $1,630.8$ & 75 & 395.3 & 1.1 & 35 \\
\hline Tasman & 19.3 & 20.6 & 23.3 & 1 & 4.0 & 0.8 & - \\
\hline Nelson & 19.8 & 21.3 & 24.3 & 1 & 4.5 & 0.8 & - \\
\hline Marlborough & 18.6 & 19.3 & 20.6 & 1 & 2.0 & 0.4 & 1 \\
\hline West Coast & 14.0 & 14.6 & 15.3 & 1 & 1.2 & 0.3 & - \\
\hline Canterbury & 218.2 & 239.4 & 288.0 & 13 & 69.9 & 1.1 & 13 \\
\hline Otago & 83.3 & 87.8 & 98.8 & 6 & 15.5 & 0.7 & 2 \\
\hline Southland & 39.4 & 41.0 & 42.7 & 2 & 3.3 & 0.3 & - \\
\hline South Island & 412.7 & 444.1 & 513.0 & 25 & 100.3 & 0.9 & 16 \\
\hline New Zealand & $1,648.5$ & 1782.7 & $2,144.0$ & 100 & 495.6 & 1.1 & 51 \\
\hline
\end{tabular}

Source: Statistics NZ, 2015

Table 4.7 shows that in 2018 the Auckland region has the highest number of households (31\% of total), followed by the Canterbury region with $17 \%$, and Waikato and Wellington regions each having $10 \%$ of all households. Table 4.7 also shows the Auckland, Canterbury and Waikato regions will have the highest predicted average growth in the number of households from 2013 to 2038 , this being by $1.7 \%, 1.1 \%$ and $1.0 \%$ respectively, compared with the average predicted annual growth of $1.1 \%$ for all New Zealand. Moreover, the table shows that 6 regions out of 16 have no factory producing any type of prefabricated building or building component. Based on Table 4.7, the need for houses in the Auckland, Canterbury, Waikato, and Wellington regions is higher than for the other regions. In order to have a better understanding of how manufacturers are distributed in the country, Table 4.8 and Figure 4.1 show the number of manufacturers based on the type of prefabrication in each region. 
Table 4.8: Number of manufacturers and type of prefabrication in each region

\begin{tabular}{|l|l|l|l|l|l|l|l|l|l|}
\hline Region & CT & PA & MO & CO & CG & KI & BA & OT & Total \\
\hline Northland & 1 & 2 & - & - & - & - & - & - & 3 \\
\hline Auckland & 6 & - & 1 & 1 & 2 & 2 & 1 & - & 13 \\
\hline Waikato & 1 & 1 & 1 & - & - & - & - & - & 3 \\
\hline Bay of Plenty & 2 & - & - & - & 1 & - & - & - & 3 \\
\hline Taranaki & 1 & 1 & - & - & - & - & - & - & 2 \\
\hline Manawatu-Wanganui & 1 & 1 & - & - & - & - & - & - & 2 \\
\hline Wellington & 5 & 2 & 1 & - & - & 1 & - & - & 9 \\
\hline Marlborough & - & 1 & - & - & - & - & - & - & 1 \\
\hline Canterbury & 5 & 4 & - & 1 & 1 & - & 1 & 1 & 13 \\
\hline Otago & - & - & - & - & - & - & 2 & - & 2 \\
\hline Total & 22 & 12 & 3 & 2 & 4 & 3 & 4 & 1 & 51 \\
\hline
\end{tabular}

\begin{tabular}{|l|l|}
\hline Feature & Abbreviation \\
\hline Component & CT \\
\hline Panel & PA \\
\hline Module & MO \\
\hline Container & CO \\
\hline Completed building & CG \\
\hline Kitchen & KI \\
\hline Bathroom & BA \\
\hline Other & OT \\
\hline
\end{tabular}




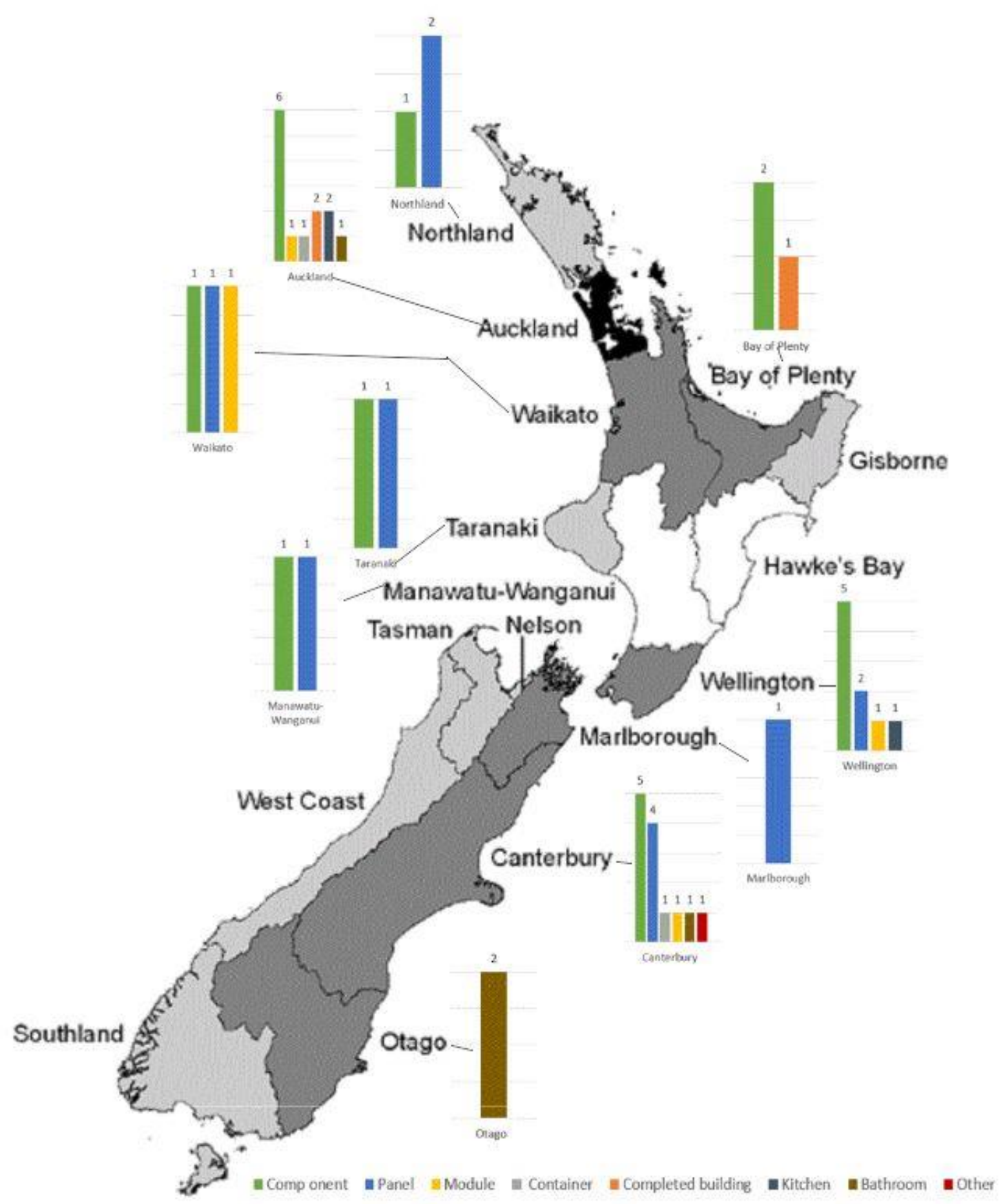

Figure 4.1: Manufacturers and type of prefabrication in each region

Table 4.8 and Figure 4.1 show the Auckland and Canterbury regions each have 13 factories undertaking prefabrication ( $26 \%$ of the total), which is more than any other region. The Wellington region has 9 manufacturers (18\%). The Waikato region, which based on Table 4.7 will need more houses than any other region except Auckland and Canterbury, has only 3 factories (6\%), which is the same as in the Northland and Bay of Plenty regions. Considering 
the type of prefabrication each factory produces, those in the Auckland and Canterbury region can offer six options to their customers, which is more than any other region. On the other hand, the only manufacturer in the Marlborough region produces panels while both manufacturers in the Otago region produce modular bathrooms. Table 4.8 also shows there is no manufacturer of complete prefabricated buildings in both the Wellington and Waikato regions. This is important as such buildings are larger than any of the other prefabrication types and harder to transport.

Looking at the services of each manufacturer, all of those making modules and completed buildings provide installation services, as well as 15 factories making other types of prefabrication. The majority of the products of the 21-panel manufacturers, as well as those from 8 other manufacturers state they can be assembled by an unskilled buyer on a DIY basis. However, only 9 manufacturers provide some kind of guarantee, and 13 have geographical limitations for the area to which they can send their products. Finally, 22 manufacturers give the buyers some options in terms of issues such as colour, size, plan, or the material of the prefabricated elements. Detailed information related to this investigation can be found in Appendix B.

Finally, it seems that except for the Waikato region, the regions with the highest number of households currently have a relatively acceptable number of manufacturers, although obviously this may change if prefabricated ADUs are made in significant numbers.

\subsection{Transportability}

There are many constraints when a house is to be prefabricated compared with conventional building, and the two most important are transportation and method of assembly or craning on to site, although which is used will depend on the size of the prefabricated element, and hence on the type of prefabrication to be used (see Section 5.2.1). For transportation, the most logical start is to consider how big loads can be on New Zealand roads.

Table 4.9 shows the maximum allowed size of loads in New Zealand, as if the dimensions and/or the weight of a load exceed these numbers, that load will be oversized and need to abide by the oversize load rules and get the necessary permissions as follows. 
"Overdimension vehicles or loads are only allowed to operate on an overdimension permit if they are indivisible. An indivisible load is a load that without an unreasonable amount of effort or expense, or the risk of damage to the load can't be divided into two or more sections for road transport" (New Zealand Transport Agency, 2017a).

Table 4.9: Allowable loads on New Zealand roads

\begin{tabular}{|l|l|l|l|}
\hline & Limit & Comments & Source \\
\hline $\begin{array}{l}\text { Weight } \\
\text { (tonne) }\end{array}$ & $45-50$ & $\begin{array}{l}\text { Based on number of trailer } \\
\text { axles (8 or 9) }\end{array}$ & $\begin{array}{l}\text { Stockdale, 2016; Petterson, 2016; } \\
\text { Road Transport Forum New } \\
\text { Zealand, 2018 }\end{array}$ \\
\hline Width (m) & 2.55 & & $\begin{array}{l}\text { Stockdale, 2016; Petterson, 2016; } \\
\text { New Zealand Transport Agency, } \\
\text { 2017b }\end{array}$ \\
\hline Height (m) & 4.30 & Includes the truck height & $\begin{array}{l}\text { Stockdale, 2016; Petterson, 2016 } \\
\text { Road Transport Forum New } \\
\text { Zealand, 2018; New Zealand } \\
\text { Transport Agency, 2017c \& 2017d }\end{array}$ \\
\hline Length (m) & 20 & & $\begin{array}{l}\text { New Zealand Transport Agency, } \\
\text { 2017a \& New Zealand Transport } \\
\text { Agency, 2018 }\end{array}$ \\
\hline $\begin{array}{l}\text { Forward } \\
\text { distance }\end{array}$ & 8.5 & $\begin{array}{l}\text { The distance from the rear } \\
\text { axis to the front of the vehicle } \\
\text { or its load }\end{array}$ & $\begin{array}{l}\text { New Zealand Transport Agency, } \\
\text { 2017a }\end{array}$ \\
\hline $\begin{array}{l}\text { Front and rear } \\
\text { overhang }\end{array}$ & \multicolumn{2}{|l|}{$\begin{array}{l}\text { Less than the maximum allowed for a } \\
\text { standard vehicle }\end{array}$} \\
\hline
\end{tabular}

If any size of a load exceeds the parameters given in Table 4.9, the resulting overdimension load would be classified in one of four different categories (Table 4.10).

Table 4.10: Categories of overdimension loads on New Zealand roads (metres)

\begin{tabular}{|l|l|l|l|l|}
\hline & $\begin{array}{l}\text { Category 1 } \\
\text { (up to } \mathbf{( m ) )}\end{array}$ & $\begin{array}{l}\text { Category 2 } \\
\text { (up to }(\mathbf{m}) \text { ) }\end{array}$ & $\begin{array}{l}\text { Category 3 } \\
\text { (up to } \mathbf{( m ) )}\end{array}$ & $\begin{array}{l}\text { Category 4 } \\
\text { (up to }(\mathbf{m}) \text { ) }\end{array}$ \\
\hline Width & 3.7 & 4.5 & 5 & More than 5 \\
\hline Forward distance & 11.4 & 13.3 & 20 & More than 20 \\
\hline Length & 25 & 35 & More than 35 & More than 35 \\
\hline Front overhang & 7 & 10 & More than 10 & More than 10 \\
\hline Rear overhang & 7 & 10 & More than 10 & More than 10 \\
\hline
\end{tabular}

Based on the category of each load, it would need a different permit, as summarised below. These limitations are given here to show technically and economically complicated transporting overdimension loads can be.

- Checking safety and clearance by the operator;

- Fluorescent yellow flags (at least $400 \mathrm{~mm}$ long and $300 \mathrm{~mm}$ wide) and hazard panel must be attached;

- Pilot escort is needed (3 escorts in category 4);

- Travel time is restricted based on day time and also environmental conditions; 
- Application to the Overdimension Permit Issuing Agency (OPIA) is needed for categories 3 and 4;

- Prior communication with emergency services is required in categories 3 and 4;

- Complying with different route specific requirement in categories 3 and 4 . For example, if the load width is more than $3.1 \mathrm{~m}$, it can travel through Auckland on the motorway but travel across the Auckland Harbour Bridge needs to be confirmed with Police Communications Centre and Bridge Control Officer. The maximum width on the Wellington motorway is $3.7 \mathrm{~m}$. The maximum height is $4.25 \mathrm{~m}$ on the Auckland motorway and $4.8 \mathrm{~m}$ on the Wellington motorway.

Considering the allowed length and width, the maximum area of a house that could be carried on one trailer without applying for oversized permissions is approximately $51 \mathrm{~m}^{2}(2.55 \mathrm{~m}$ by $20 \mathrm{~m})$. However, this would be if the ADU design was just one module, or in other words, it is made as a complete prefabricated building. This fits within the $50-70 \mathrm{~m}^{2} \mathrm{GPA}$ range, which is the thesis target for the ADU design. However, this will lead to a long narrow house as the width should be less than $2.55 \mathrm{~m}$, and in terms of size it would be like a house made from a converted shipping container.

Another important factor affecting the ADU design is the way it could be located or assembled on the site, probably in a backyard behind an existing and potentially occupied house. This is highly affected by the weight of the house and the method of prefabrication. The maximum weight, as a single module, that can be craned is 400 tonne using the latest technology. This would involve a Grove GMK6400 hydraulic all terrain mobile 400-tonne crane as the largest mobile, hydraulic crane in the southern hemisphere (Pollock Cranes, 2015). It is worth noting that, in craning, the weight and the radius which could be achieved have a reverse relationship, as the heavier the load the less the distance it can be craned. In deciding how to prefabricate the ADU both issues of transportability and craning will need to be considered.

\subsection{Accessibility for Older People}

Given to the changing demographics of New Zealand, the needs of older people should be considered when it comes to the usability of the space (see Section 1.2). Due to the possible disabilities this group could have (or develop) while living in the ADU, it should be designed in a way that makes all its spaces accessible and useable. Thus, the internal and external 
physical characteristics should be designed with the aim of making "tasks easier, reduce accidents and support independence" (De Jonge et al., 2006). There are different standards and rules related to age-friendly space design in New Zealand and the world. In New Zealand, one of the early attempts dates back to NZS 4121 (2011) (Design for accessibility and mobility-Buildings and Associated Facilities). However, the access requirements in the Building Act do not apply to private residential buildings, as built, when altered, or there is a change in use (Standard New Zealand, 2001). BRANZ published a supplementary guidance to NZS 4221 in 2001 (Homes without barriers: a guide to accessible houses), in order to include residential buildings in the standard.

The NZ building code includes some requirements for disabled access and use in clauses D1Access Routes; D2- Mechanical Installations for Access, F8- Signs, G1- Personal Hygiene, G2Laundering, G3- Food Preparation and Prevention of Contamination, G5- Interior Environment, G9- Electricity, and G12- Water Supplies. However, the disabled access requirements are not applicable to private residential buildings (Yavari, 2019).

Lifemark is the other standard in New Zealand that aims to make sure houses are designed so as to accommodate older people and those with disabilities (Lifemark, 2016). Lifemark uses a rating system of 3-stars to 5 -stars, where a 3-star house means the minimum requirements are met but with opportunities for some additional considerations, and 5-star means the house is fully accessible (Lifemark, 2016).

Yavari (2019) compared the Lifemark 3-star standard of New Zealand with Lifetime Homes (LTH) from the UK and Universal Design (UD) principles from the USA, in order to see which was applicable to her research into converting existing houses for older people. Her key findings are given below.

- LTH makes the house adaptable and useable but does not provide a fully accessible guide for dwellings.

- UD lacks a number of essential specifications which are seen in both LTH and LM. These include minimum clear opening widths for the main entrance and associated car parking and pathway widths. 
- UD has just one level of standard of requirement, while LTH has two (requirement and recommendations). Lifemark has the three levels of 3-star to 5-star, where 4-star and 5-star level could be seen as equating to the recommendations in LTH.

Yavari (2019) concluded that despite the fact the 3-star Lifemark requirement does not include all features of UD and LTH, it has the most conformity with the nature of New Zealand houses. It therefore seems sensible for this research to select Lifemark as the main accessibility standard with the aim of achieving at least 3 stars.

At this stage of the design, seven categories were investigated to see what considerations were needed to achieve at least 3 Lifemark stars. The requirements of 3-star Lifemark are classified into two main groups. The first group are those that affect the structural design of the $A D U$, such as the minimum spaces need in the bedroom as it affects the size of the bedroom and finally the size of the house. The second group are more related to materials or the installation of fixings, which have less effect on the schematic design. An example of this group would be the door handle, which is required to be $900 \mathrm{~mm}-1,200 \mathrm{~mm}$ above the finished floor level. While the width of the doors is discussed in the first group as it is a structural decision, the height of door handle is placed in the second group as it is a detail for the designer. Moreover, some requirements are not applicable to the ADU, such as multi-story access or are not applicable to its design, such as parking requirements. These considerations are also placed in the second group. The first group thus includes the entrance, internal doors, corridors, bedrooms, kitchen spaces, bathrooms and showers. Car parking, pathways, light switches, power points, windows, door hardware, tap fixing, alarms, laundry spaces and multi-story access are placed in the second group. The items in the first group are discussed in the next sections by focusing on the requirements and recommendations needed while the requirements of the second group are summarised in Table 4.11.

\subsubsection{The ADU Entrance}

The optimum entrance in Lifemark is one which is level and easy to access with proper landing areas both inside and outside the door made of slip resistance material with a minimum coefficient rating of 0.4 . The threshold should be less than $20 \mathrm{~mm}$. The door leaf width needs to be at least $860 \mathrm{~mm}$ with a clear opening of $810 \mathrm{~mm}$ (Figure 4.2 ). 


\section{This content is unavailable.}

Please consult the print version for access.

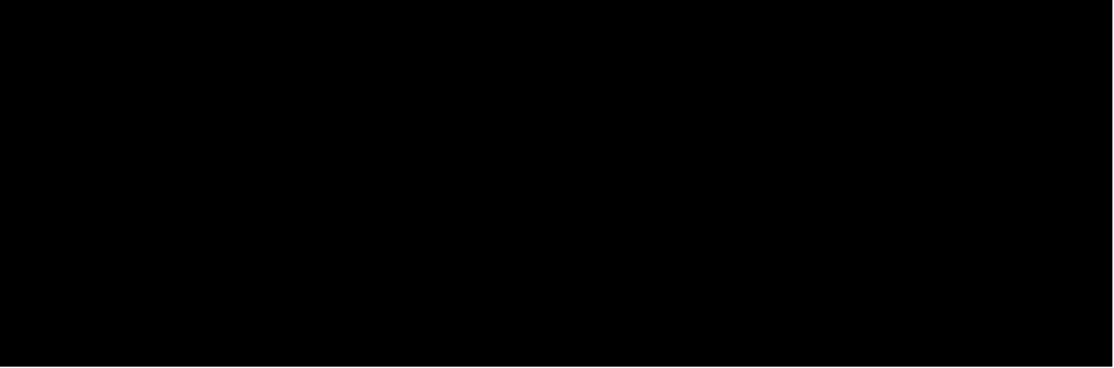

Figure 4.2: Entrance requirements (Lifemark, 2016, p.12)

\subsubsection{Internal Doors}

The requirements for internal doors are similar to those of the entrance and include the minimum clear opening of $810 \mathrm{~mm}$ and $860 \mathrm{~mm}$ door leaf. All doorways should have a level threshold, but Lifemark accepts a change of up to $20 \mathrm{~mm}$ either side of the doorway, provided the lip is bevelled. Doors should be able to be opened at least 90 degrees, with the protrusion of the door into rooms. Doors should have enough space to swing without interrupting the circulation (Figure 4.3).

This content is unavailable.

Please consult the print version for access.

\subsubsection{Corridors}

All internal corridors or passageways, need a minimum clear, finished width of $1,050 \mathrm{~mm}$ as shown in Figure 4.4. This is less than LH and UD, which ask for at least 1,200mm and $1,067 \mathrm{~mm}$ clear width respectively (Yavari, 2019). Light switches at both ends of a corridor and sensors 
to turn the lights on at night automatically are recommended by Lifemark. Given the importance of a smooth flow around the dwelling for all residents, it is also recommended to consider turning spaces in corridors and doorways, as well as enough space for use of both wheelchair users and others at the same time.

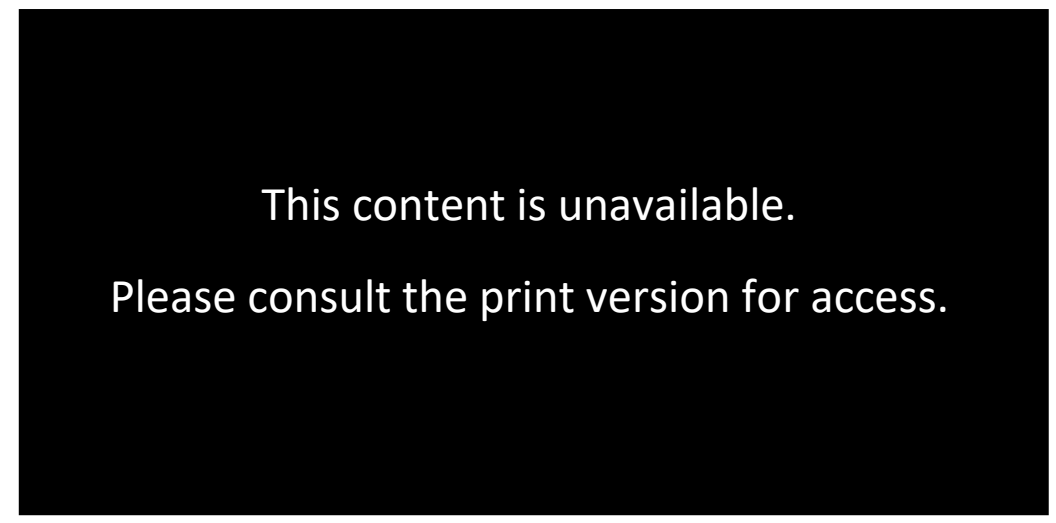

Figure 4.4: Corridor recommended width (Lifemark, 2016, p. 17)

\subsubsection{Bedrooms}

Bedrooms need enough space for a standard bed $(900 \mathrm{~mm}$ by $1,900 \mathrm{~mm}$ for a single bed and $1,350 \mathrm{~mm}$ by $1,900 \mathrm{~mm}$ for a double bed) with a minimum $800 \mathrm{~mm}$ of clear space available on three sides, at the sides and foot. There also needs to be a minimum $800 \mathrm{~mm}$ path from the door to the side of the bed (Figure 4.5). Bedrooms shall be on the same level as the main entrance to the dwelling with a level entry, and a 1,500 $\mathrm{mm}$ turning circle is recommended in the bedroom, as well as light switches at the entry door, linked to both sides of the bed.

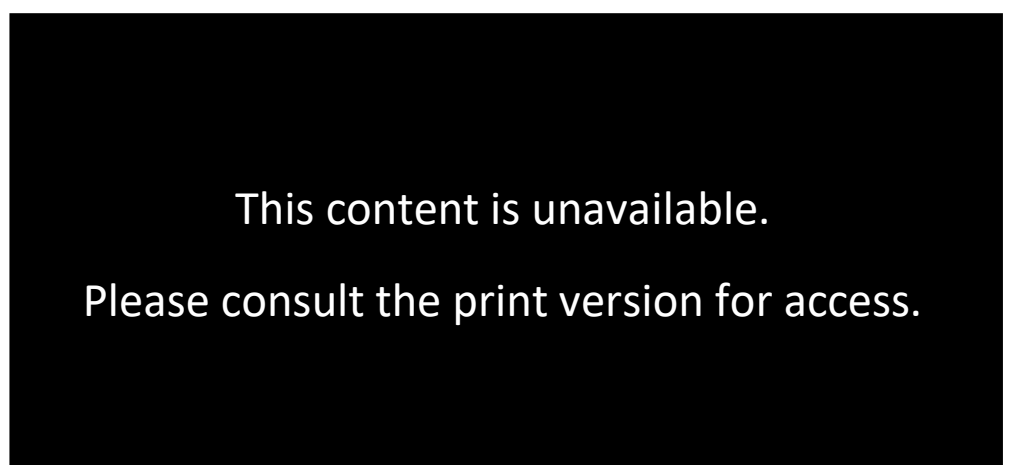

Figure 4.5: Bedroom recommended requirements (Lifemark, 2016, p. 31)

\subsubsection{Kitchen Spaces}

The kitchen needs to be on the same level as the main entrance to the dwelling, and a clearance of at least $1,200 \mathrm{~mm}$ is recommended in front of fixed benches, major appliances and fittings, with a $250 \mathrm{~mm}$ toe space under all kitchen fittings (Figure 4.6). The kitchen needs a slip-resistant floor with a minimum coefficient rating of 0.4 . The kitchen should have lighting 
over all workspaces, with the bottom edge of the lowest drawer to be at least $250 \mathrm{~mm}$ above the finished floor level. It is also recommended appliances should be installed at least $300 \mathrm{~mm}$ away from each corner (see Lifemark, 2016, pp 34-35 for further recommendations).

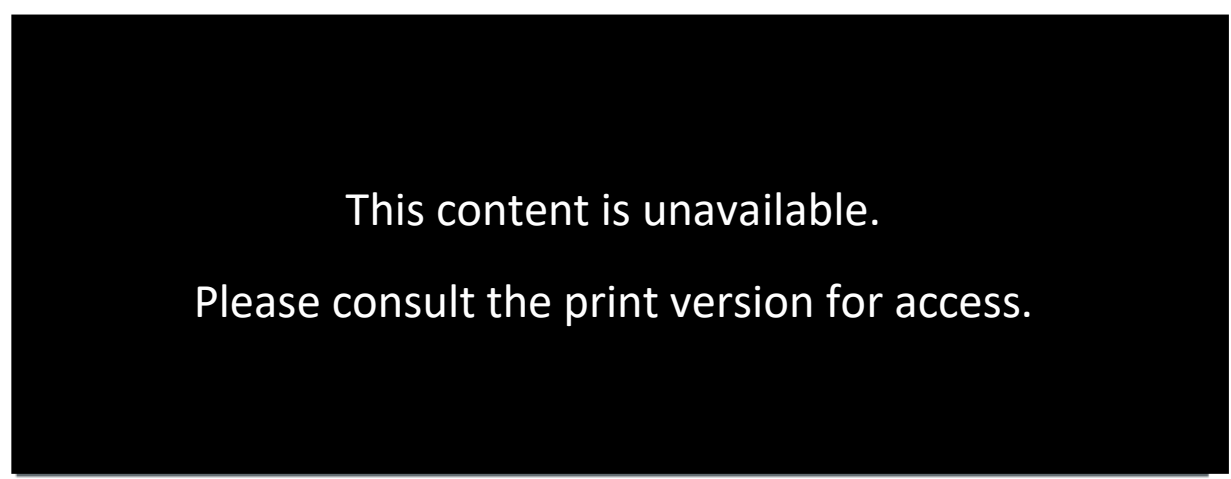

Figure 4.6: Kitchen recommendations (Lifemark, 2016, p. 35)

\subsubsection{Toilets}

Dwellings must have at least one toilet which extends $700-750 \mathrm{~mm}$ from the back wall. The centre line of the toilet pan should be $450-460 \mathrm{~mm}$ from side walls with minimum $800 \mathrm{~mm}$ clear transfer space beside and/or in front of the toilet (Figure 4.7). The top surface of the toilet is recommended to be $450 \mathrm{~mm}-480 \mathrm{~mm}$ above the finished floor level. The basin should be installed with the minimum knee clearance of $675 \mathrm{~mm}$ from the finished floor level, and its front edge be no more than $400 \mathrm{~mm}$ from the back wall. It should be at least $300 \mathrm{~mm}$ from the front of the toilet pan. Bathroom walls need to be reinforced to provide a fixing surface for $750 \mathrm{~mm}$ by $750 \mathrm{~mm}$ L-shaped grab rails to be installed with the horizontal leg being $700 \mathrm{~mm}$ above finished floor level and the vertical leg $150 \mathrm{~mm}-250 \mathrm{~mm}$ in front of the toilet pan.

This content is unavailable.

Please consult the print version for access.

Figure 4.7: Toilet space considerations (Lifemark, 2016, pp. 36-37) 


\subsubsection{Showers}

A Lifemark dwelling needs a step-free shower with minimum dimensions of $900 \mathrm{~mm}$ by $900 \mathrm{~mm}$ located in the corner of the room, with reinforced walls in order to facilitate the installation of a shower seat and grab rail. The shower door width needs be at least $810 \mathrm{~mm}$. A $750 \mathrm{~mm}$ by $750 \mathrm{~mm}$ L-shaped grab rail should be installed with the horizontal leg being $1,000 \mathrm{~mm}$ above the finished floor level. The shower floor should be made of slip-resistant material with a minimum coefficient rating of 0.4 . A hand-held shower head, attached to a $1,500 \mathrm{~mm}$ long hose which is attached to an adjustable side rail is recommended (Figure 4.8).

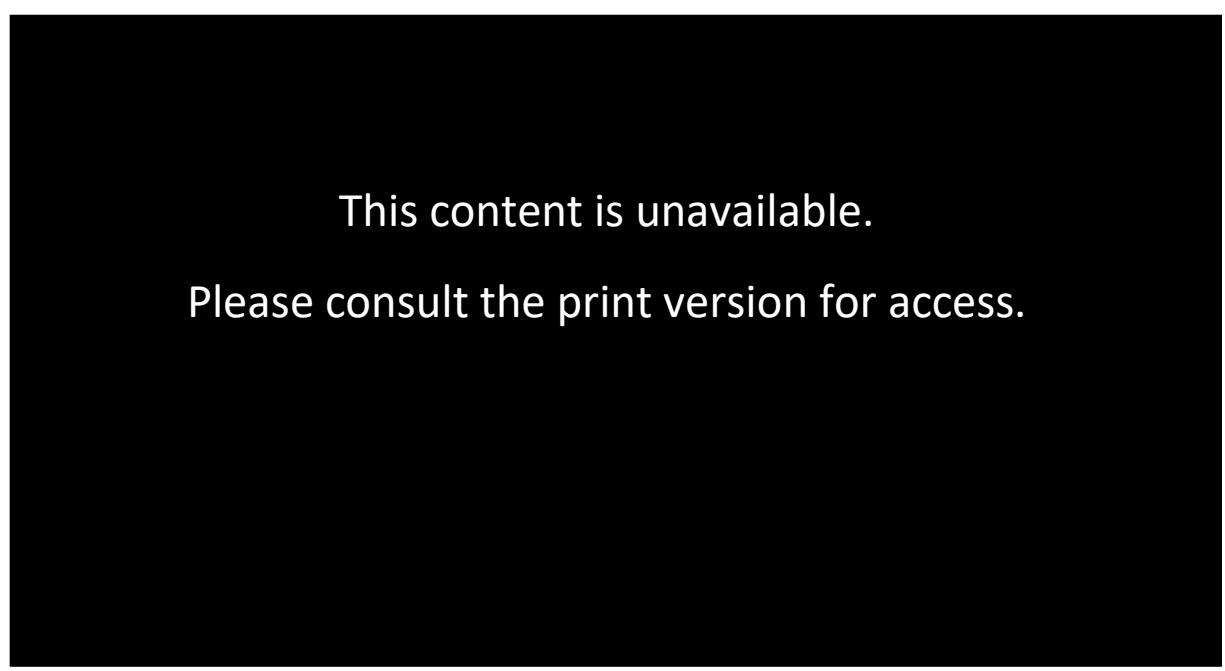

Figure 4.8: Shower space considerations (Lifemark, 2016, p.39)

\subsubsection{Other Considerations}

Table 4.11 summarises the Lifemark rating considerations that are more related to materials or the installation of fixings and less with the general design. 
Table 4.11: secondary group recommendations for Lifemark

\begin{tabular}{|c|c|}
\hline Category & Considerations \\
\hline Car parking & $\begin{array}{l}\text { At least one car park is needed with a minimum size of } 4800 \mathrm{~mm} \text {. A level firm, } \\
\text { slip resistance flat surface with a maximum slope of } 1: 40 \text { is recommended. }\end{array}$ \\
\hline Pathway & $\begin{array}{l}\text { The minimum width of a level firm, slip resistance pathway from either the } \\
\text { boundary of the property or car park is } 1,200 \mathrm{~mm} \text {. } \\
\text { The maximum slope and cross fall are respectively, } 1: 16 \text { and } 1: 50 \text {. } \\
\text { If the gradient is over } 1: 20 \text {, an approved handrail and } 1,200 \mathrm{~mm} \text { by } 1,200 \mathrm{~mm} \\
\text { flat rest area every } 8 \mathrm{~m} \text { are needed. }\end{array}$ \\
\hline Light switches & $\begin{array}{l}\text { Light switches and all other service controls shall be horizontally aligned with } \\
\text { door handles at } 900 \mathrm{~mm}-1,200 \mathrm{~mm}(1,000 \mathrm{~mm} \text { is preferred) above finished } \\
\text { floor level. }\end{array}$ \\
\hline Power points & $\begin{array}{l}\text { It is recommended that power points and outlets be installed between } \\
500 \mathrm{~mm} \text { and } 1,200 \mathrm{~mm} \text { above finished floor level and } 500 \mathrm{~mm} \text { from all internal } \\
\text { corners. }\end{array}$ \\
\hline Windows & $\begin{array}{l}\text { Windows controls are recommended to be lever handles that can be } \\
\text { operated with one hand and that are no higher than } 1,200 \mathrm{~mm} \text { above finished } \\
\text { floor level. }\end{array}$ \\
\hline Door hardware & $\begin{array}{l}\text { All door handles should be horizontally aligned with light switches at } 900 \mathrm{~mm}- \\
1,200 \mathrm{~mm}(1,000 \mathrm{~mm} \text { is preferred) above finished floor level. All hinged doors } \\
\text { should be fitted with lever action handles. }\end{array}$ \\
\hline Tap fixing & It is recommended all taps have a single spout. \\
\hline Alarms & $\begin{array}{l}\text { A hard-wired smoke alarm with both audible and visual warnings is } \\
\text { recommended to be installed in all primary living areas, including the master } \\
\text { bedroom. }\end{array}$ \\
\hline Laundry Spaces & $\begin{array}{l}\text { The laundry space should to be big enough to accommodate a washing } \\
\text { machine and a dryer (preferably front loading) side by side. There needs to be } \\
1,050 \mathrm{~mm}-1,200 \mathrm{~mm} \text { clearance in front of fixed benches and appliances and } \\
\text { also a } 1,500 \mathrm{~mm} \text { turning circle at least } 250 \mathrm{~mm} \text { above the floor. }\end{array}$ \\
\hline $\begin{array}{l}\text { Multi-storey } \\
\text { access }\end{array}$ & $\begin{array}{l}\text { The stair treads need to be slip resistance with a minimum coefficient rating } \\
\text { of } 0.4 \text {. A multi-story dwelling is recommended to have a stair lift, platform lift } \\
\text { or the space for future installation of these. } \\
\text { The tread depth (minimum } 310 \mathrm{~mm} \text { ) and riser height (maximum } 180 \mathrm{~mm} \text { ) } \\
\text { must be consistent. The stair clear width should be at least } 900 \mathrm{~mm} \text {. } \\
\text { Stairways are recommended to be straight or with a maximum of one winder } \\
\text { tread at } 90 \text { degrees or two with a } 180 \text {-degree change in direction. } \\
\text { The handrails are recommended to be on at least one side as well as round a } \\
1,200 \mathrm{~mm} \text { by } 1,200 \mathrm{~mm} \text { unobstructed landing and light switches need to be } \\
\text { fixd at top and bottom of the stairs. }\end{array}$ \\
\hline
\end{tabular}

\subsection{Analysis of ADU Plans}

As part of the investigation of parameters that will affect the design of the prefabricated ADU, this section looks at plans for existing ADUs and small houses to prepare an appropriate brief. This section starts with an investigation of tiny houses having a plan area of between $50 \mathrm{~m}^{2}$ to $70 \mathrm{~m}^{2}$ (see Section 4.2.1.2). This is followed by an examination of zero energy prefabricated 
house examples. While the main focus in the first (tiny house) group analysis is on plan arrangements, in the second group the main focus is on how to make a house be zero energy in use. Because of the need to transport the ADU, the examples are prefabricated, transportable, and are designed to be zero energy in use.

\subsubsection{Tiny House Plans}

The goal here is to explore how other designers have arranged all the necessary functions in a small plan area, mostly between $50 \mathrm{~m}^{2}$ to $70 \mathrm{~m}^{2}$. This could help in deciding what might be the best choice from the available options for each function, for example whether an Lshaped kitchen might be preferable to a U-shaped one, and also to see how functions should be arranged to work in the most efficient way. As discussed in Section 3.7.1, the tiny house plans collected for this section were drawn from two main area. In the first group the focus of an online search was based on ADUs. The goal here was to find ADU plans even where these had been consented in other countries. Key search terms used included ADU plan, ADU handbooks, granny flat plans, and secondary houses. The second group focused on small size houses without considering whether they were secondary dwellings. "Google" was used as the main search engine and key search terms included tiny houses, small dwelling, family houses, and compact residential buildings. Table 4.12 shows the original number of selected plans, the number after filtering, and the final number of plans chosen for the first stage of the analysis. The criteria for the filtering process are discussed after Table 4.12. 
Table 4.12: Sources used and supplementary information

\begin{tabular}{|l|l|l|l|l|}
\hline Context & $\begin{array}{l}\text { Total number of } \\
\text { plans }\end{array}$ & $\begin{array}{l}\text { Number of } \\
\text { plans after the } \\
\text { first filter }\end{array}$ & $\begin{array}{l}\text { Number of } \\
\text { plans } \\
\text { chosen }\end{array}$ & Source \\
\hline Los Angeles & 3 & 1 & 1 & Cuff and Blumenfeld, 2017 \\
\hline Australia & 30 & 17 & 17 & Granny flat Australia, 2013 \\
\hline Portland, Oregon & 18 & 6 & 4 & Accessory Dwellings, 2018 \\
\hline $\begin{array}{l}\text { The USA and } \\
\text { others }\end{array}$ & 17 & 0 & 0 & House plans.pro, 2018 \\
\hline New York & $1,000+$ & 341 & 42 & House plan, 2018 \\
\hline Kansas & $1,000+$ & 140 & 15 & Family home plans, 2018 \\
\hline USA & $200+$ & 5 & 0 & The house designers, 2018 \\
\hline Auckland & 16 & 3 & 1 & $\begin{array}{l}\text { Auckland design manual, } \\
\text { 2018 }\end{array}$ \\
\hline Hawaii & 2 & 0 & 0 & Hawaii Appleseed, 2016 \\
\hline San Francisco & 7 & 0 & 0 & Openscope studio, 2015 \\
\hline Others & $100+$ & 19 & 5 & Online search \\
\hline Total & $2,400+$ & 533 & 85 & \\
\hline
\end{tabular}

As Table 4.12 shows, initially, more than 2,400 plans were found that matched the keywords.

To narrow this number down to those most aligned with this research, plans were filtered in two stages. The first process was based on the Gross Plan Area (GPA) and the number of storeys. At this stage, all plans with a GPA outside the range of $50 \mathrm{~m}^{2}-70 \mathrm{~m}^{2}$ and those with more than one storey were removed from the list (see Section 4.2.1.2). This was undertaken manually for the handbooks and guidebooks by considering each plan individually. For the websites, the filtration was done using the website filtering facilities where possible (Figure 4.9 and Figure 4.10).

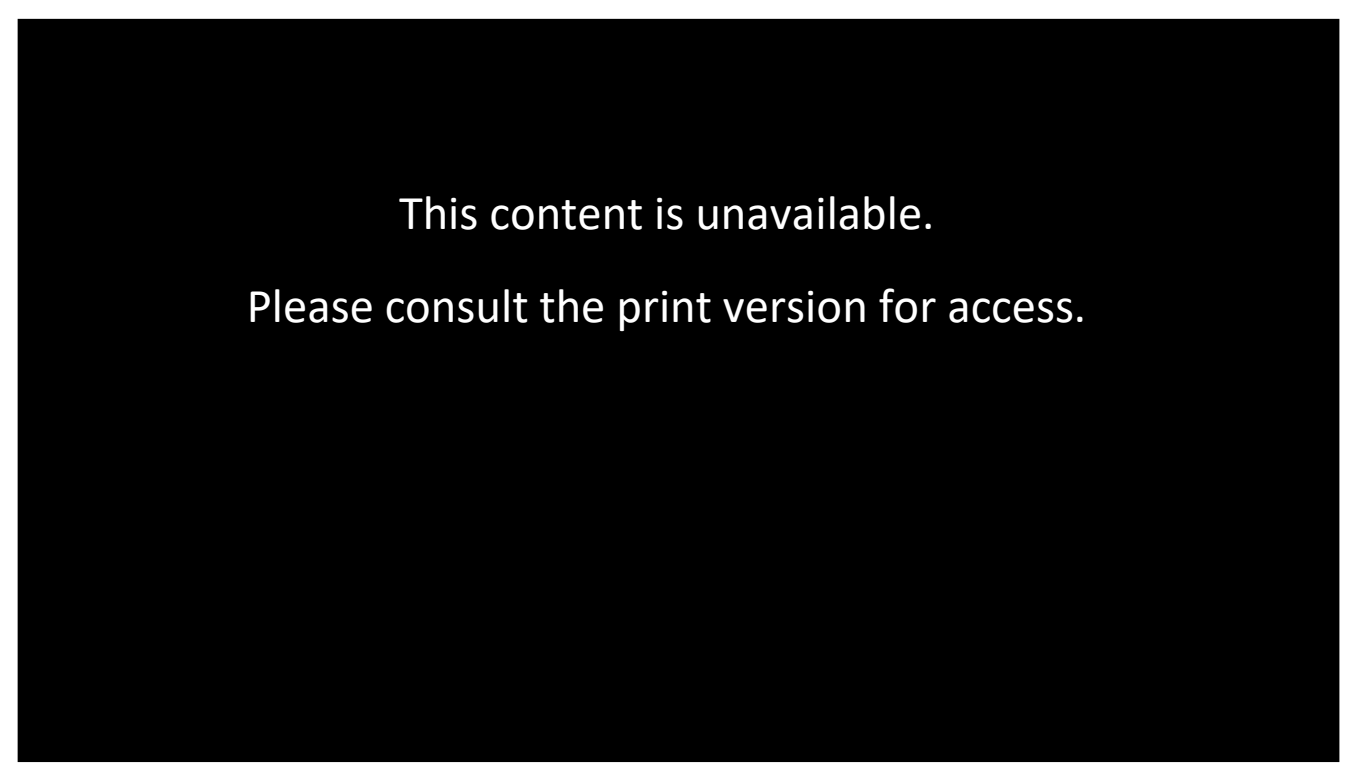

Figure 4.9: Filtering process 1 (House plan, 2018) 


\section{This content is unavailable.}

\section{Please consult the print version for access.}

Figure 4.10: Filtering process 2 (Family home plans, 2018)

Table 4.12 shows 533 plans passed the first filtering stage. These then underwent the second filtering process, by looking at the plans one-by-one in more detail. At this stage, more than 100 garages which were not filtered by the websites filtering facilities were removed. Moreover, houses located in a basement or on top of an existing building, or those including a mezzanine were removed from the list. This was due to the fact that in these types of houses some area was allocated to the stairwell, which did not align with the research goal of designing a single storey ADU. The other factor considered during the second filtering process was the type of space in each plan. All selected plans has to have at least one bedroom, one kitchen, one bathroom, and a living space. All plans without a separating wall between the living area and bedroom were also removed. The search for new plans ran in parallel to the fileting processes until the point that all new plans discovered were the same or very similar to previous plans. At the end of the second filtering stage, out of the 533 original plans 85 were selected for final analysis. These are described in detail in Appendix C.

\subsubsection{Analysis Results}

The final 85 plans were firstly classified based on their GPA into four groups: (1) $50 \mathrm{~m}^{2}-55 \mathrm{~m}^{2}$, (2) $55.01 \mathrm{~m}^{2}-60 \mathrm{~m}^{2}$, (3) $60.01 \mathrm{~m}^{2}-55 \mathrm{~m}^{2}$ and (4) $65 \mathrm{~m}^{2}-70 \mathrm{~m}^{2}$. The number of plans in each group were respectively 18 (21\%), 28 (33\%), 16 (19\%) and 23 (27\%). These plans were further analysed looking for nine main factors. These were the number of bedrooms, type of bathroom (ensuite, Jack and Jill, shower room, and separate WC); kitchen form (line, L-shaped and U-shaped); number of wardrobes; type of laundry (separate or shared); number of 
attached decks whether covered or uncovered; form of the plan (square, rectangle, L-shaped, or other), and whether there is a serviced or wet area core. Having a wet zone or service core was the last factor investigated as this emerged as a feature from the zero energy house plan analysis.

For more clarification regarding types of sanitation spaces, the definitions used follow:

- Ensuite: An ensuite is a bathroom that can only be accessed from a bedroom

- Jack and Jill: A Jack and Jill bathroom is normally only accessed from two bedrooms (a shared ensuite) (Figure 4.11). However, in this research, it also means a bathroom that can be entered from a bedroom and another room or circulation space (Figure 4.12).

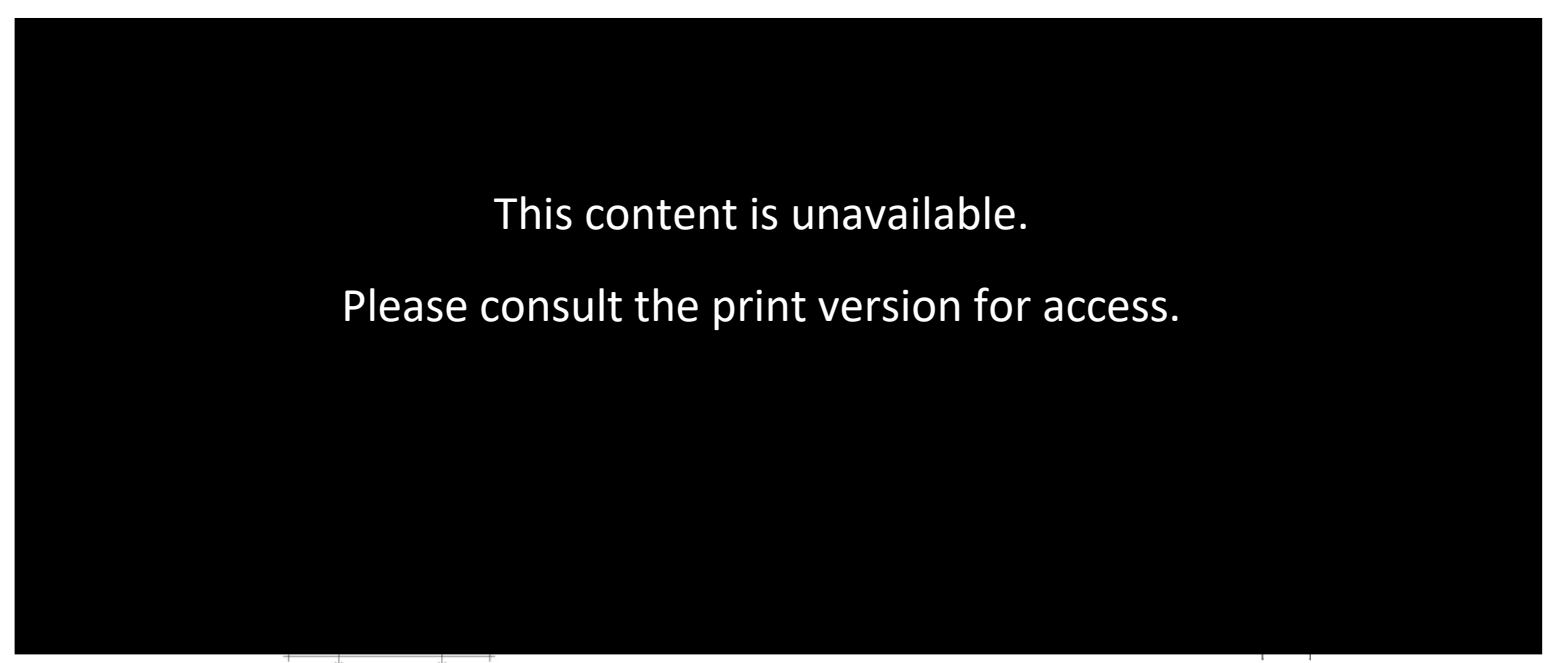

Figure 4.11: Jack and Jill bathroom (Family home plans, 2018)
Figure 4.12: Jack and Jill bathroom in this research (House plan, 2018)

- Bathroom: A bathroom is defined as a room that opens off a circulation space or a room that is not a bedroom and that includes a tub.

- Shower room: A shower is defined as a room that opens off a circulation space or a room that is not a bedroom and includes a shower but has no tub.

- WC: A WC is a space which only includes a WC and no shower or bath

In the plan analysis, the count of houses for some items (e.g. bathroom fittings) the total will be more than 85 as some plans include more than one bathroom. For example, plan \#504-8 includes an ensuite and another bathroom off the living area (see Appendix C). The percentage for these items was calculated based on the total number in each category rather than the number of plans. Out of the 85 plans, the majority of 49 (57\%) had two bedrooms, 
33 (39\%) had one, and just 3 plans (4\%) had 3 bedrooms. The 85 plans included 90 sanitation spaces, of which shower rooms and bathrooms were the most popular forming respectively $43(48 \%)$ and 32 (35\%) of total. Ensuite and "Jack and Jill" bathrooms each appeared 7 times (8\%) but only one design with a separate WC (1\%).

For kitchens, out of the 85 selected, 29 plans (34\%) had a linear form, 44 (52\%) had an L-shape and the U-shaped kitchen appeared in only 12 plans (14\%). Moreover, except for the 8 plans that did not include a wardrobe or where the wardrobe was not shown in the plan, all others had at least one wardrobe for each bedroom. A separate laundry occurred in 49 out of 85 plans (57\%), while 16 plans (19\%) had a washing machine/dryer in another space (11 in a bathroom and 5 in a mudroom), and 20 plans (24\%) did not show a laundry. This is similar to the number of decks, as 28 plans did not show a deck while rest had at least one.

Another important factor that needs to be considered in analysing small house plans is the general form based on the insulated envelope. Out of 85 plans, $3(4 \%)$ were designed as a square, $28(33 \%)$ were designed as a rectangle, 19 (22\%) had an L-shape, and 35 (41\%) were in a form which could not be classified as one of these. Finally, out of 85 plans studied, 34 (40\%) had two entrances and 6 (7\%) had three, resulting in a total of 128 entrances. Of these $64(53 \%)$ had entrances that opened into the living room, $16(13 \%)$ into the kitchen, 11(9\%) into the dining room, $15(12 \%)$ into a hall and another $10(8 \%)$ into a bedroom, and $4(3 \%)$ into a mudroom (a space to remove (muddy) boots, coats and wet clothing before entering the main house). Finally, 46 plans (54\%) had a service core.

Based on the analysis, it can be concluded that the most common design for an ADU between $50 m^{2}-70 m^{2}$ is an irregular-shape building with an entrance and 2 bedrooms each with 1 wardrobe. It has one sanitation space of some type, a separate laundry, an L-shaped kitchen, and a deck. However, to see how the GPA affects the design of small houses, the following paragraphs look at each group based on the GPA range to see if there are any differences between groups. The percentages were calculated based on the number of plans in that group.

Figure 4.13 shows that in the first (44\%), third (67\%) and fourth (44\%) groups most plans have an irregular form, followed by rectangular design for the first (7 plans or $39 \%$ ) and third groups 
(3 plans or 19\%) and by an L-shaped design for the last group (9 plans or $39 \%$ ). This order is a little different for the second group, where more rectangular (14 or 50\%) than L-shaped (8 or $29 \%$ ) plans occur and where other plans (6 or $21 \%$ ) are not so popular. There is also no square plan in this group.

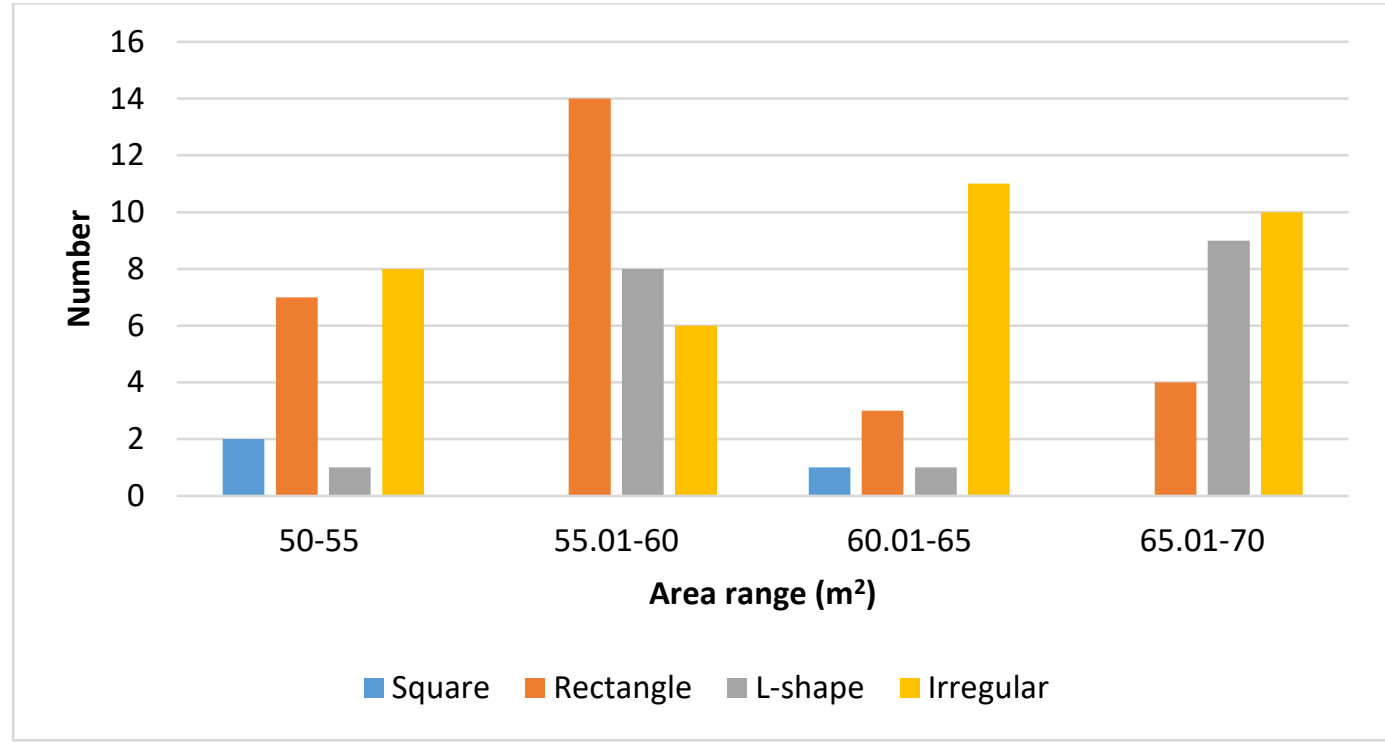

Figure 4.13: Plan forms

Figure 4.14, which compares the number of bedrooms for the four groups, shows that 10 (56\%) plans in the first and smallest plan area group $\left(50-55 \mathrm{~m}^{2}\right)$ had 1 bedroom and the remaining 8 (44\%) 2 bedrooms. In this group, 83\% of plans (15) had at least 1 wardrobe for each bedroom. Unlike the first group, in the second group $\left(55.01-60 \mathrm{~m}^{2}\right)$ the majority of plans, 17 or 59\% had 2 bedrooms and 9 plans (34\%) had 1 bedroom, while 2 plans (7\%) had 3 bedrooms. In this group, all plans (28) had a wardrobe in each bedroom. In the third group $\left(60.01-65 \mathrm{~m}^{2}\right)$ the highest count is 1 bedroom plans with 8 plans (50\%), 7 plans (43\%) had 2 bedrooms and just 1 plan (7\%) had 3 bedrooms. In this group, 13 plans (81\%) had at least 1 wardrobe in each bedroom. In the last group $\left(65.01-70 \mathrm{~m}^{2}\right)$ the majority of plans, 17 or $74 \%$ had 2 bedrooms and 6 plans (26\%) had 1 bedroom. As in the other groups, the majority of plans, 20 or $87 \%$ had at least one wardrobe in each bedroom. 


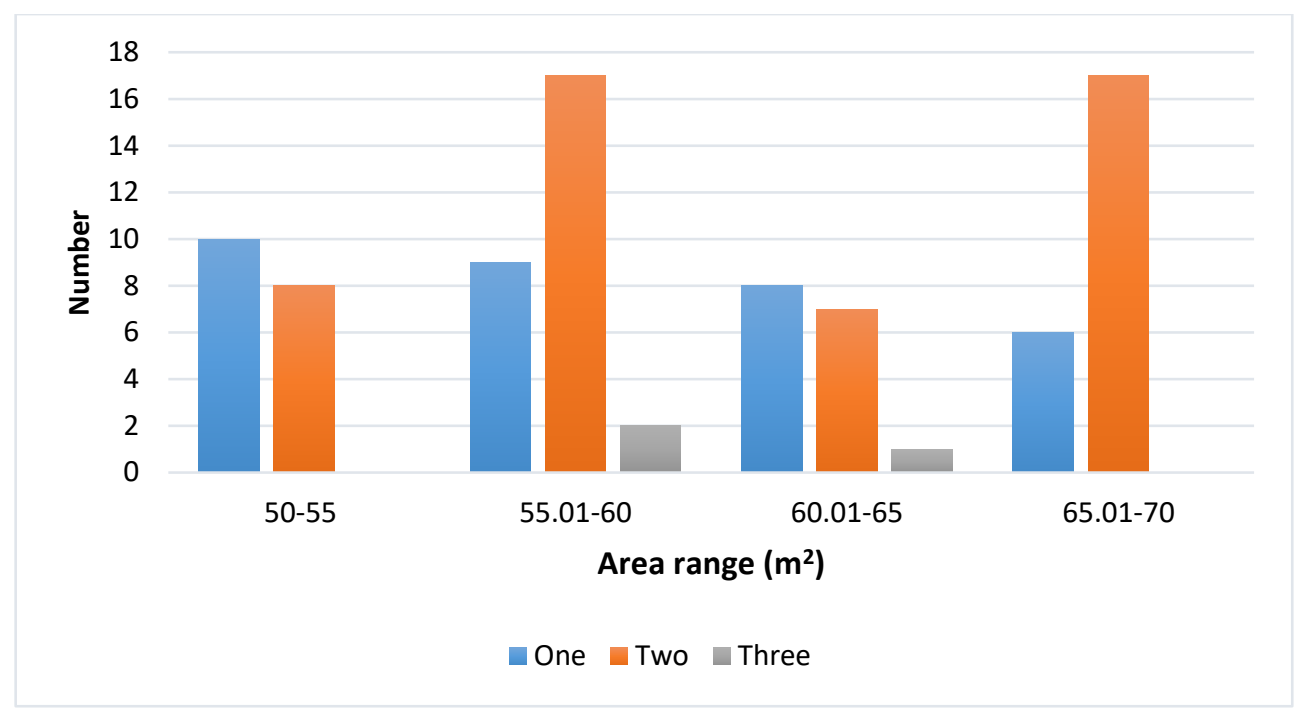

Figure 4.14: Number of bedrooms

Figure 4.14 shows the number of one bedroom houses decreased as the floor plan area increased. Curiously there were no 3 bedroom plans in the largest size range. This might be because people prefer to have a bigger kitchen or bigger living/dining areas when they have more space rather than having more bedrooms.

Figure 4.15 gives the different forms of kitchens in each group, showing that the first, second and fourth groups of plans followed a similar approach. In these groups, the L-shaped kitchen is the most common being respectively $11(61 \%), 12(43 \%)$ and $14(61 \%)$, followed by the linear design, and with the U-shape being the least common. Although the U-shaped kitchen is again the least popular form in the third group, the linear design and the L-shaped kitchen are equally popular at 7 (44\%) in this group.

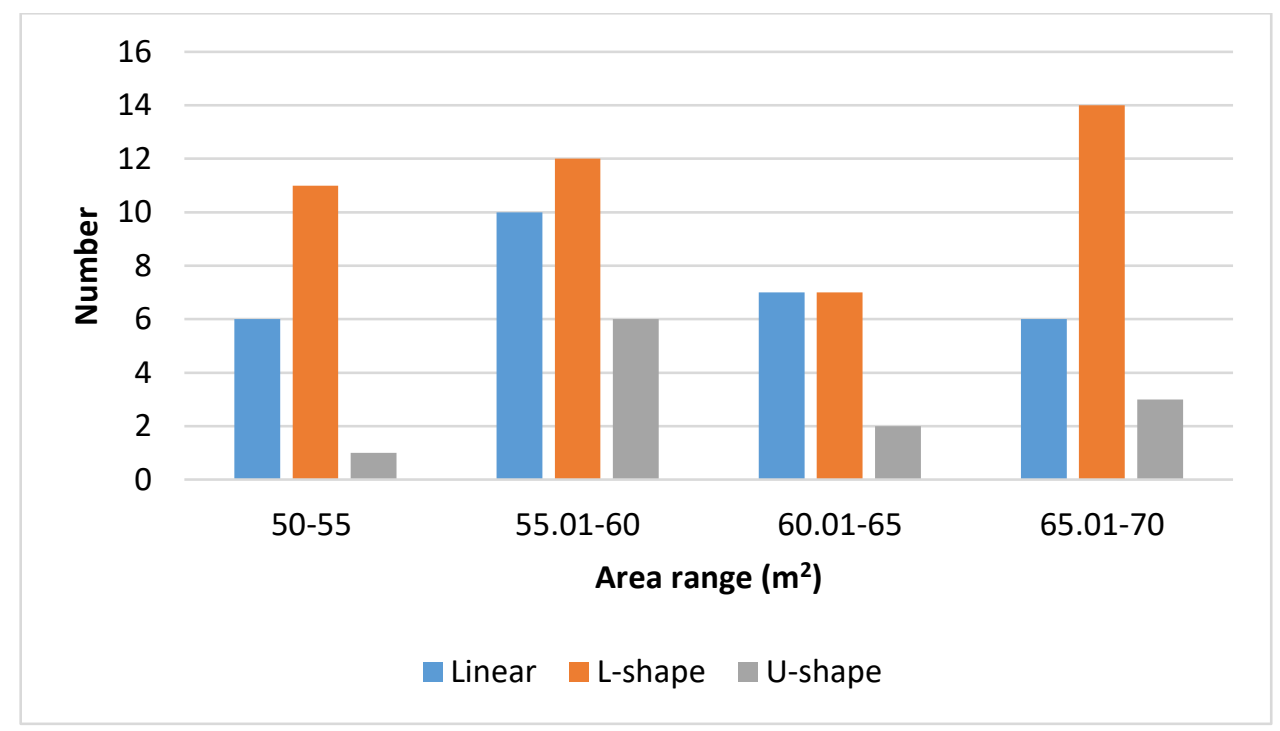

Figure 4.15: Kitchen form 
The type of sanitation space follows a similar pattern in the first three groups, as most designs include a room with a shower, or a bath and shower (Figure 4.16). In the first three groups, most plans (10 (43\%), 20 (69\%) and $8(40 \%))$ include a shower room, while in the fourth group the majority of plans $(18(62 \%))$ had a bathroom. It seems that when people have more space, having a bath is desirable. There is no pattern to the ensuites as there are four in the last group, in three plans, and three in the first group, in three plans. The only separate WC occurs once in the last group, so is not shown in Figure 4-16.

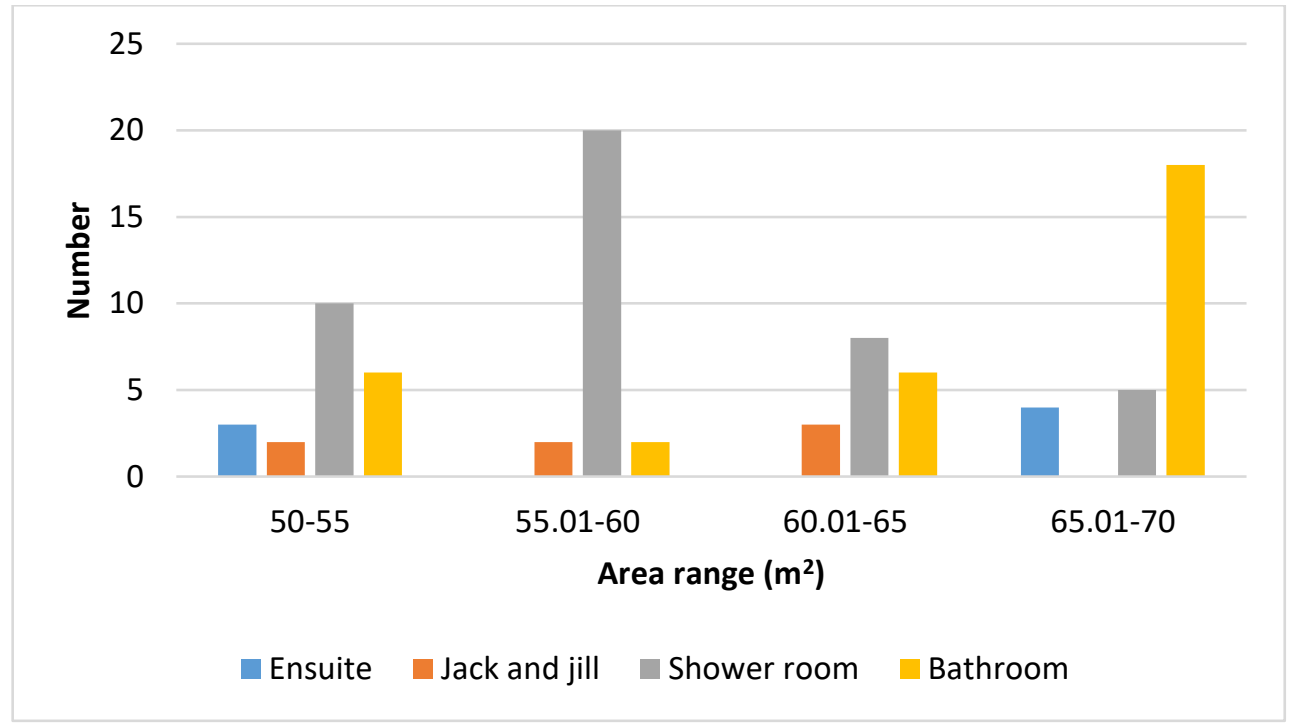

Figure 4.16: Sanitation spaces

Figure 4.17 illustrates the status of laundries showing that having a separated space is the first priority in all four groups as this occurred $8(44 \%), 14(50 \%), 8(50 \%)$ and 19 (83\%) times. Aside from the $20(24 \%)$ plans that did not show the laundry, 3 plans (17\%) in group one put the washing machine/dryer in a shared space ( 1 in the mudroom and 2 in the bathroom), 10 plans showed the laundry in a shared space in the second group (36\%) plans (7 in a bathroom and 3 in a mud room) and 2 in the third group (13\%) (1 in a bathroom and 1 in a mudroom). In the last and largest group, only 1 plan (4\%) had the washing machine/laundry in a bathroom. 


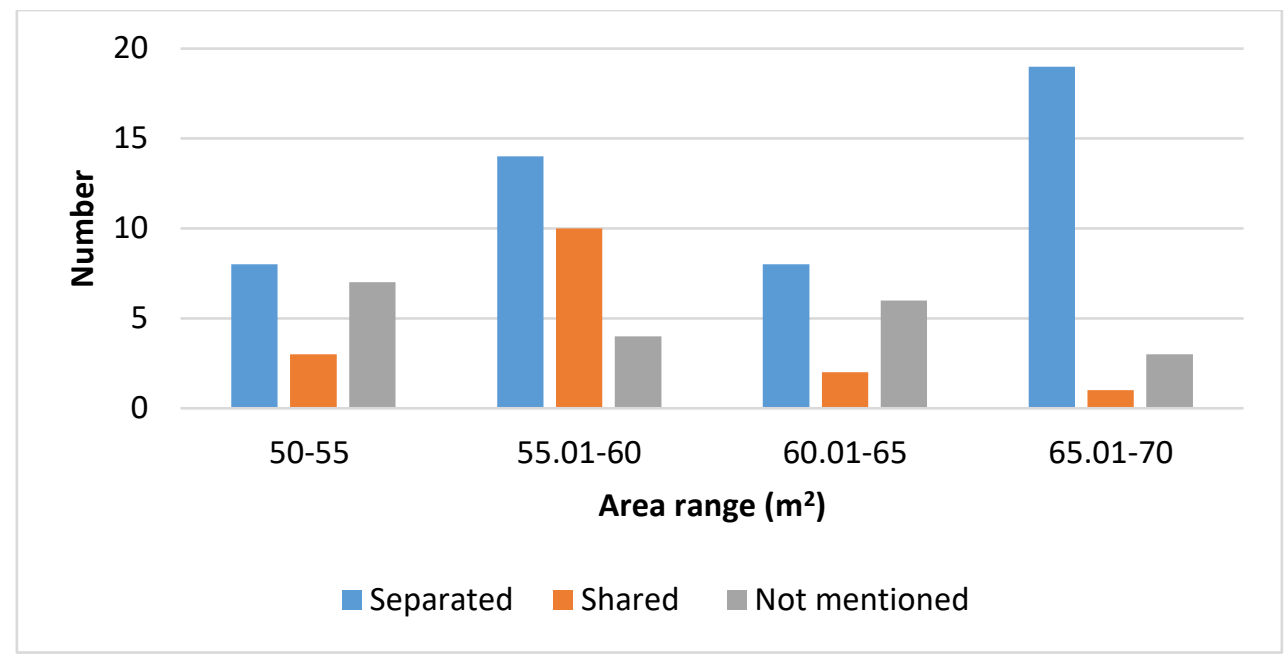

Figure 4.17: Status of laundries

When it comes to an attached deck, all groups had more plans than not with at least one deck. It is worth noting that of the $28(33 \%)$ of plans which did not show deck, this might not indicate that there would be no deck once the building was constructed. Figure 4.18 shows the number of plans that include a services zone in each GPA range. The figure shows that despite the equal number of plans with this feature in the first and smallest group, in the range of $55 \mathrm{~m}^{2}$ to $65 \mathrm{~m}^{2}$ more plans have a services zone, while in the last and largest group 14 plans or $61 \%$ did not have a services zone.

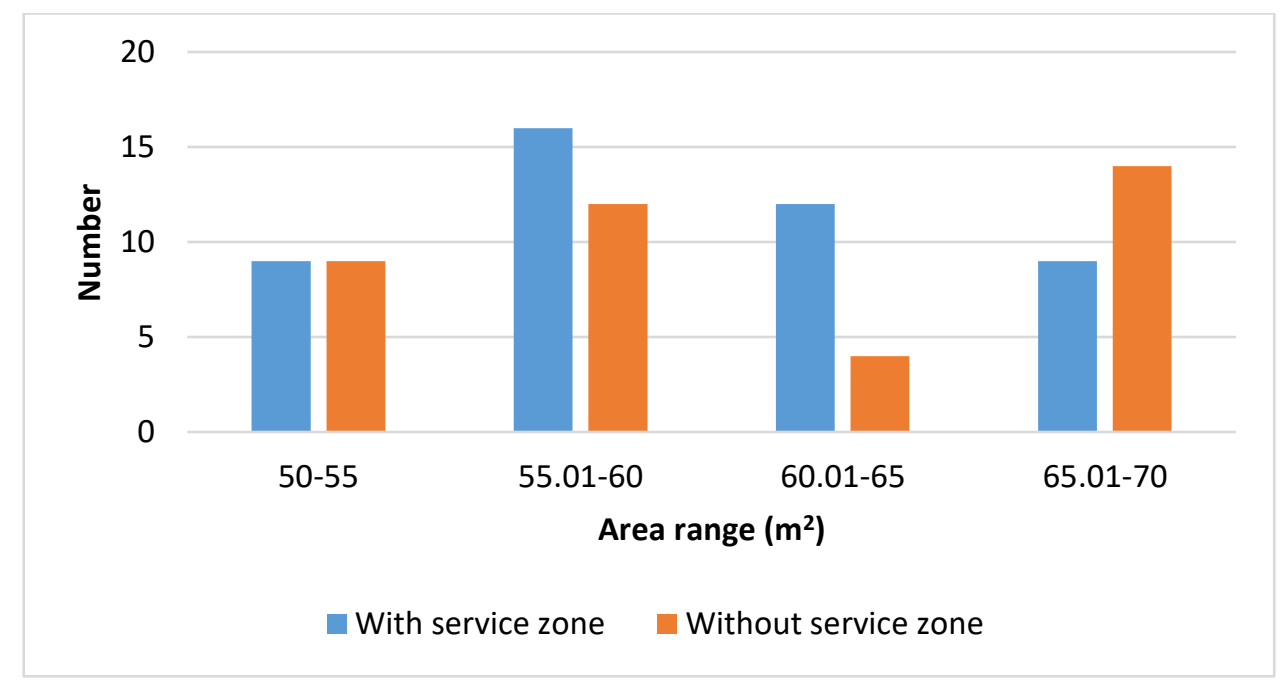

Figure 4.18: Service zones

From this analysis it seems that the first three groups by plan size follow a similar approach, with some small differences, while for the last and largest group the plan arrangement is different. This suggests that when people have more space their preferences for how they want their internal spaces arranged change. Figure 4.14 showed that in the last group, instead of having more bedrooms there are more plans with a bigger living/dining, bigger bedrooms 
and also a bigger bathroom with a tub in it. Moreover, despite a separated laundry appearing in all groups, the percentage occurrence in the last group is higher than in the others, as $95 \%$ of plans had a separated laundry. Also, Figure 4.18 showed that the last group is the only one in which majority of plans do not have a services core.

\subsubsection{Solar Decathlon Plans}

The aim of this research was to investigate the use of prefabrication as a contribution to the housing needs in New Zealand by designing a zero energy ADU. Considering this aim the ADU had to be autonomous, accessible for older people, transportable, and be as close to zero energy as possible.

Since the subject of designing a zero energy prefabricated ADU is relatively new, to study similar projects the designs from the Solar Decathlon (SD) competition seemed appropriate as investigating these should reveal how other designers have dealt with similar challenges. Despite the fact that the SD designs are not ADUs, based on the competition rules they should be residential, transportable to competition site for assembly, and highly energy efficient solar-powered houses (U.S. Department of Energy Solar Decathlon, 2018). These similarities between SD designs rules and the thesis goal made the competition designs highly useful in this review, even accepting that there are climatic differences between New Zealand and the SD competition sites. The main focus of this section was on the way different teams had designed their house to be simultaneously energy efficient and transportable.

The SD was first held by the U.S. Department of Energy in 2002, becoming the start of a chain of USA based competitions to be held every two years. After 2005, which was the second competition, the idea was also taken up by other countries and resulted in having SD competitions in Europe $(2010,2012,2014)$, China $(2013,2017)$ and Colombia (2015) (U.S. Department of Energy Solar Decathlon, 2018).

"It's [SD competition] an intensive learning experience for consumers and homeowners as they experience the latest technologies and materials in energy-efficient design, clean energy technologies, smart home solutions, water conservation measures, electric vehicles, and sustainable buildings" (U.S. Department of Energy Solar Decathlon, 2018). 
For this review the 2011 competition was chosen as Victoria University of Wellington (VUW) was one of the participants, winning third place. This could have eased the process of achieving detailed data as there were colleagues in the school who worked on the VUW entry. In 2011, 20 teams participated in the competition. Teams were responsible for making, transporting and assembling their houses in 1 week, with a GPA of between $55.7 \mathrm{~m}^{2}-92.9 \mathrm{~m}^{2}$. The competition was made up of ten sub-contests of architecture, market appeal, engineering, communication, affordability, comfort zone, hot water, appliances, home entertainment and energy balance (U.S. Department of Energy Solar Decathlon, 2018).

Figure 4.19 shows the overall results and points gained by each team in each contest. The following discussion looks briefly at each team's design. Of the 20 teams, detailed information about types of materials used, prefabrication system, and method of transportation could not be found for 7 teams, so these were removed from the list. These were Purdue University, The Ohio State University, The Southern California Institute of Architecture and California Institute of Technology, University of Illinois at Urbana-Champaign, Massachusetts College of Art and Design and University of Massachusetts at Lowell, University of Calgary and Appalachian State University. Sources reviewed for each team consisted of construction drawings, project manuals, the solar decathlon website, university websites, team websites (if existing), official videos of teams, and team members' interviews based on searching for the team and their house name using Google.

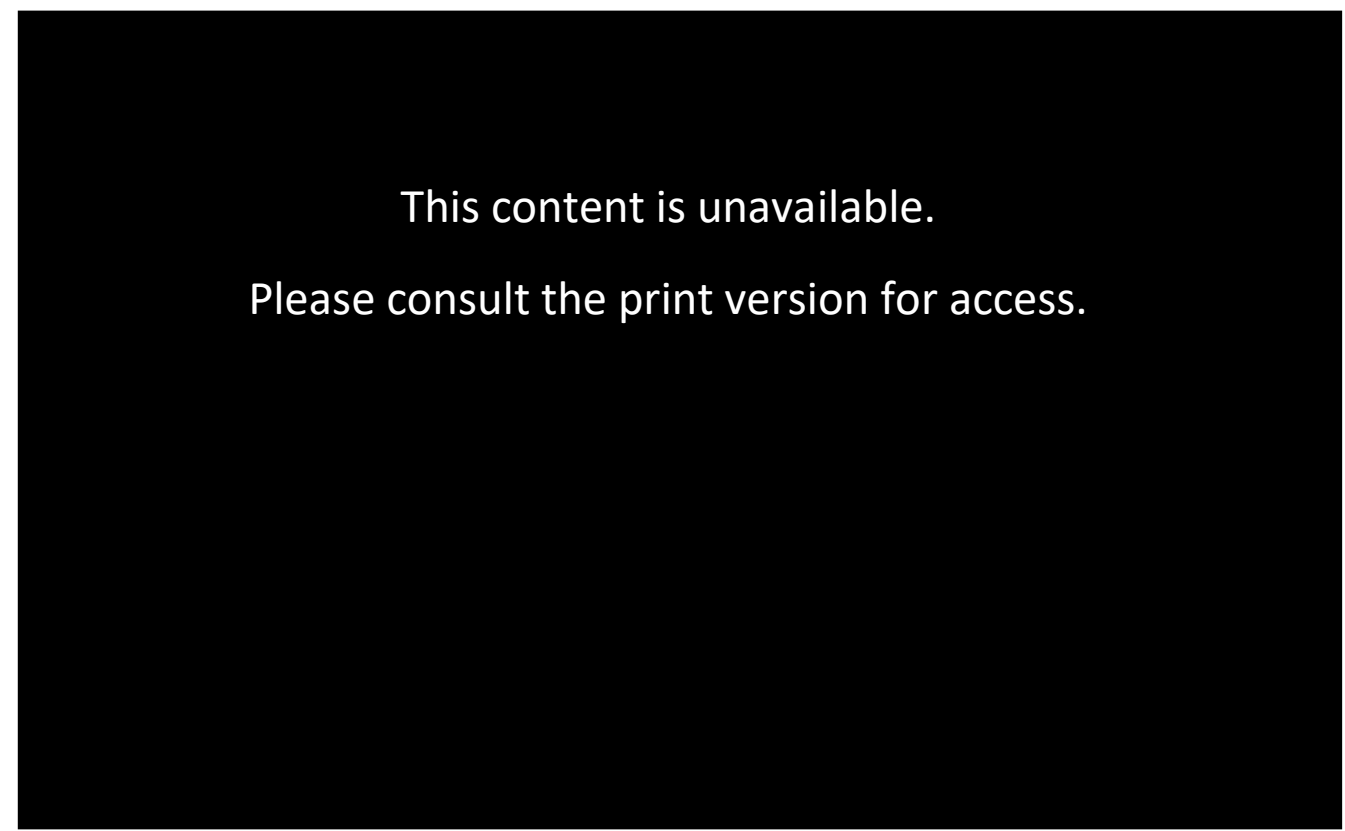

Figure 4.19: SD 2011 final result (U.S. Department of Energy Solar Decathlon, 2018) 


\subsubsection{University of Maryland (WaterShed)}

The University of Maryland team, which won the first place in the competition, designed their $81.38 \mathrm{~m}^{2}$ one-bedroom house using solar power production and focusing on recycling, water collecting, filtering, and reuse. This led to integrating water with other house systems such as humidity control. WaterShed used passive and active energy systems to provide a comfortable house for one person (WaterShed, 2011a). The house was designed in three modules with the aim of providing separated private and general spaces (Figure 4.20). Figure 4.21 shows Module $A$ included a living room and kitchen, Module $B$, which is the connection between Modules $\mathrm{A}$ and $\mathrm{C}$ included hall and bathroom, and Module $\mathrm{C}$ a bedroom and office (WaterShed, 2011b).

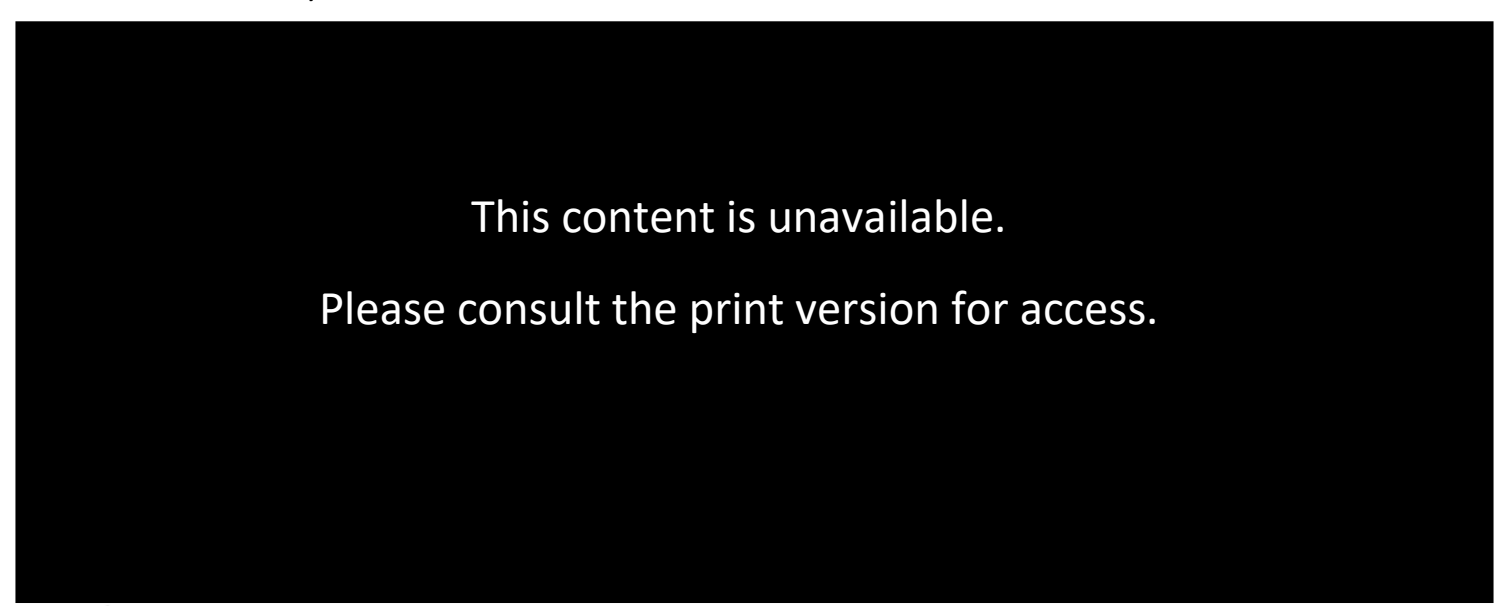

Figure 4.20: WaterShed Modules (WaterShed, 2011b)
Figure 4.21: WaterShed Plan

(WaterShed, 2011b)

\subsection{Materials and System}

Figure 4.22 shows the house had a multi-layer system including thermo-treated wood siding, rigid polyester insulation, a liquid applied waterproof membrane, open-cell spray foam cavity insulation, and metal flashings (WaterShed, 2011a, p. 28). 


\section{This content is unavailable.}

Please consult the print version for access.

Figure 4.22: Materials and system of Watershed (WaterShed, 2011a, p. 29)

\subsection{Construction and Transportation}

The Maryland team claimed, "Modularity and transportation were central considerations in building WaterShed" (WaterShed, 2011c). Figure 4.23 shows the different layers, which were assembled together in different stages. The structure of the modules was built and assembled in a factory in just three days. The structures were then moved by trailers to College Park, Maryland where students, in collaboration with professionals, added the insulation, cladding, electrical, mechanical and plumbing (WaterShed, 2011c). 
This content is unavailable.

Please consult the print version for access.

Figure 4.23: Different layers of WaterShed (WaterShed, 2011a, p. 30)

The completed modules were then transported to West Potomac Park in Washington, DC. by heavy trucks (Figure 4.24) and craned into position on the competition site (Figure 4.25).

This content is unavailable.

Please consult the print version for access.

Figure 4.24: Transporting Watershed

Figure 4.25: Craning Watershed into position

(WaterShed, 2011a, p. 75) 


\subsubsection{Victoria University of Wellington (First Light House)}

The First Light House was a prefabricated $71.9 \mathrm{~m}^{2}$ one-bedroom house that travelled over $14,081 \mathrm{~km}$ from Wellington, New Zealand's capital, to Washington D.C. (the longest journey of all 2011 competitors) (Figure 4.26). The scheme was based on a socialising and entertaining area at the centre to separate personal and general areas and increase the flow between inside and out (First Light, 2011).

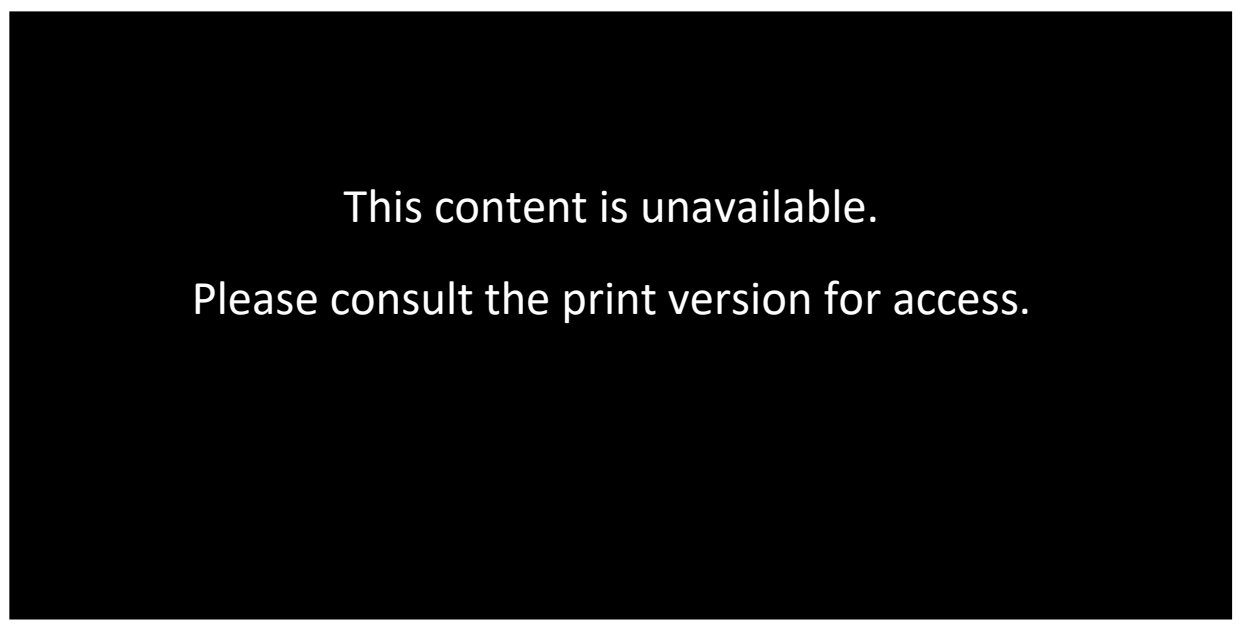

Figure 4.26: First Light House Plan (U.S. Department of Energy Solar Decathlon, 2018)

\subsection{Materials and System}

The First Light House designers were looking for materials which were recyclable, natural, locally made, cheap, and with low embodied energy. As a result, they came to the use of wood, concrete, wool, and glass as the main elements during the construction process (First Light, 2011) (Figure 4.27). The use of wood for houses is common in New Zealand as it is resilient, cheap, and acceptable in the New Zealand climate. Wood was used in First Light House for construction of the deck, in the Glulam posts and beams, for walls and floors, window and door frames, interior walls, and the exterior cladding. A 50mm fibre-reinforced concrete slab, which was crack resistant and easy to transport, was used for thermal mass to stabilize the internal temperature. Moreover, Marriage (a senior lecturer in the School of Architecture), who was involved in the project in 2011, said the design team decided to make the dining table in the middle of the house of concrete to absorb as much sun as possible from the sunroof (Marriage, 2018). A minimum of $250 \mathrm{~mm}$ of New Zealand recycled wool was used to insulate the entire house due to its thermal performance and natural resistance to slumping once installed. Triple glazed windows were installed to let in natural light and simultaneously keep the warmth inside (First Light, 2011). 


\section{This content is unavailable.}

\section{Please consult the print version for access.}

Figure 4.27: First Light House materials (U.S. Department of Energy Solar Decathlon, 2018)

\subsection{Construction and Transportation}

Being prefabricated and modular, the First Light House was designed to be easily transported. The house was made up of six independent modules that could be quickly assembled using a crane (Figure 4.28). This level of prefabrication allowed the team to fit out the modules with finishes, fixtures, plumbing, electrical, and mechanical equipment which made for simple and fast connections on-site. Wooden decking surrounded the house linking the interior to the surrounding environment. The decking was also constructed in modules which were carried into place for quick assembly. The concrete slab was made in Auckland and shipped to Wellington in 5 parts. The timber frame of the house was built in Wellington and the concrete dining table was built at the Victoria University of Wellington, (Marriage, 2018). The house was first assembled in Wellington to make sure everything was working well and then disassembled and put into six containers for transportation to Washington.

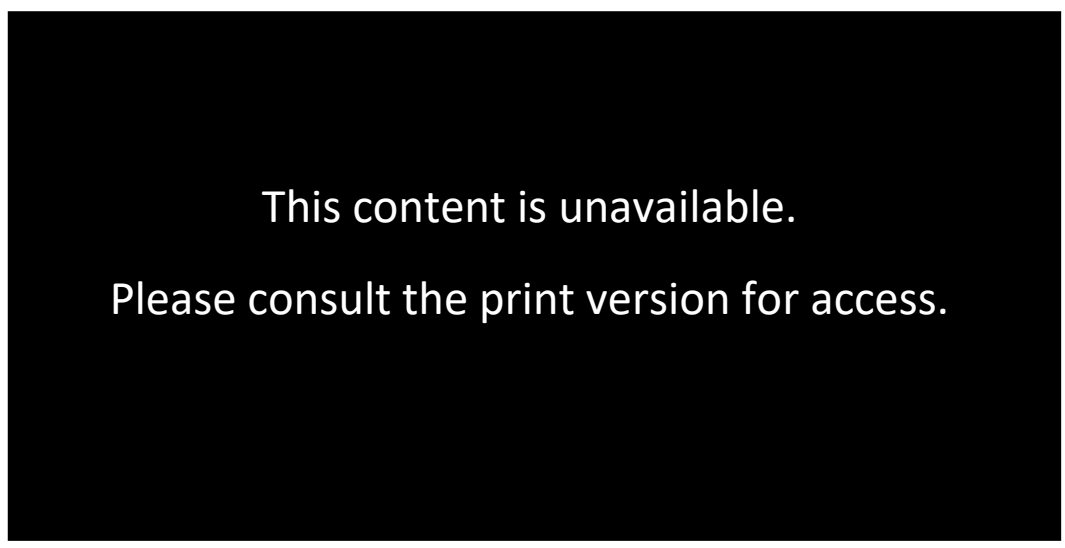

Figure 4.28: First Light House modules

Source: Marriage, 2018 


\subsubsection{Middlebury College (Self-Reliance)}

The Self-Reliance house of Middlebury College was a two-bedroom, $91.97 \mathrm{~m}^{2}$ house designed to produce all of its own energy (U.S. Department of Energy Solar Decathlon, 2012; Fendik, 2011). The design of the house was based on the idea of separating private space (bedrooms) and other spaces using a central bathroom and closet for mechanical equipment (Figure 4.29).

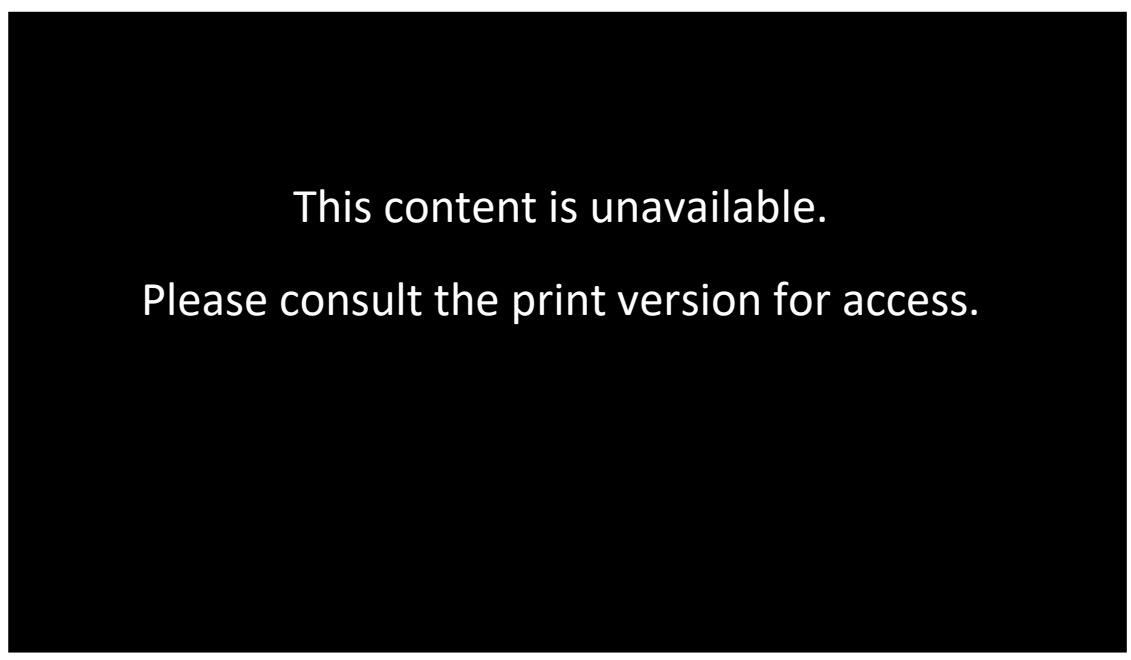

Figure 4.29: The Self-Reliance space separation (Fendik, 2011)

\subsection{Materials and System}

The idea of using local materials was maximised in the house, as most of the materials were grown on the College lands or in Vermont. These materials included sugar maple hardwood for floors, White oak, which is known for its natural rot-resistant properties and longevity, for outdoor decking, and naturally finished slate for kitchen countertop and flooring in kitchen, bathroom, and mudroom (Fendik, 2011). Frames of the triple-paned windows were insulated with cork as a natural insulation material (U.S. Department of Energy Solar Decathlon, 2012).

\subsection{Construction and Transportation}

Knowing that the Self-Reliance house needed to be moved from Middlebury, Vermont to Washington D.C. modularity was the main idea behind the design. The house was designed in eight modules consisting of two main modules and six roof modules (Figure 4.30). The team decided to design each module to be structurally independent, to decrease the disassembly and reassembly risks and defects (Fendik, 2011). 


\section{This content is unavailable.}

\section{Please consult the print version for}

access.

Figure 4.30: The Self-Reliance modules (Fendik, 2011)

\subsubsection{The University of Tennessee (Living Light)}

The Living Light is a $68.65 \mathrm{~m}^{2}$ one story detached single family house (Figure 4.31), developed as a module, and based on prefabricated components for better energy efficiency and sustainability (Siegel, 2011).

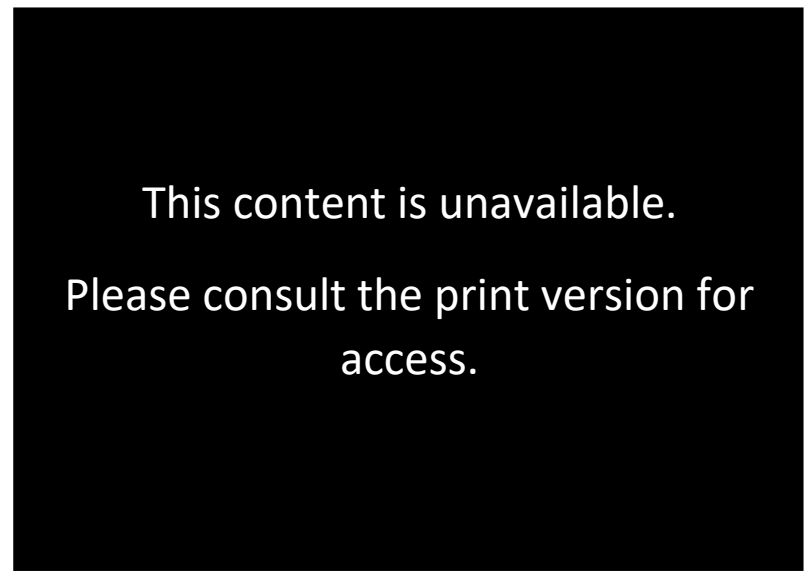

Figure 4.31: Living Light (U.S. Department of Energy Solar Decathlon, 2018)

\subsection{Materials and System}

As sustainability was one of the main goals and considering the importance of choosing local materials in sustainable development, the team decided to use materials that originated from within a 500 -mile $(804 \mathrm{~km})$ radius. The other factors considered when choosing materials were impact on environmental quality across the lifecycle, recycling, coatings, and adhesives (Fenwick, 2011). This led to wood, steel, and glass becoming the main materials (Figure 4.32). 


\section{This content is}

unavailable.

\section{Please consult the print} version for access.

Figure 4.32: Cross section (Rose, 2010)

\subsection{Construction and Transportation}

The Living Light was designed to be transported in one module by a truck (Figure 4.33). However, additional parts such as the deck modules were transported by another truck (AIGA, 2011; Siegel, 2011). Fenwick (2011) explained the shipment innovation of The Living Light as follows:

"The UT Solar Decathlon house will be built on two low-boy double-drop trailers that have wheels that lie outboard of the heavy load to keep the cargo as low as possible on the highway. A special chassis serving as the house floor and foundation structure will be designed to receive a detachable gooseneck and rear axles for transport" (Fenwick, 2011).

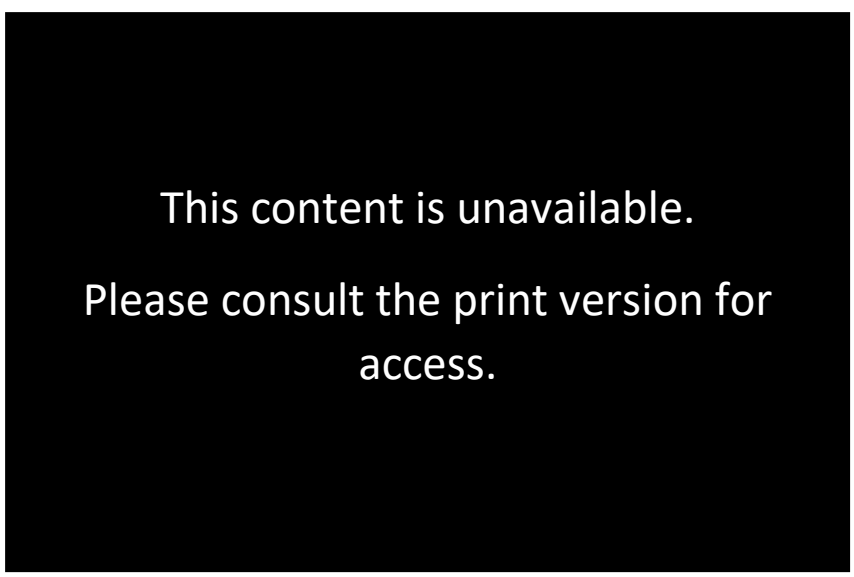

Figure 4.33: Living Light (U.S. Department of Energy Solar Decathlon, 2018) 


\subsubsection{Florida International University (PerFORM[D]ance House)}

PerFORM[D]ance House was a $74.32 \mathrm{~m}^{2}$ one-bedroom house designed in a U-shape around a central services zone with the aim of the house being mass-produced and portable (Perez, 2011) (Figure 4.34).

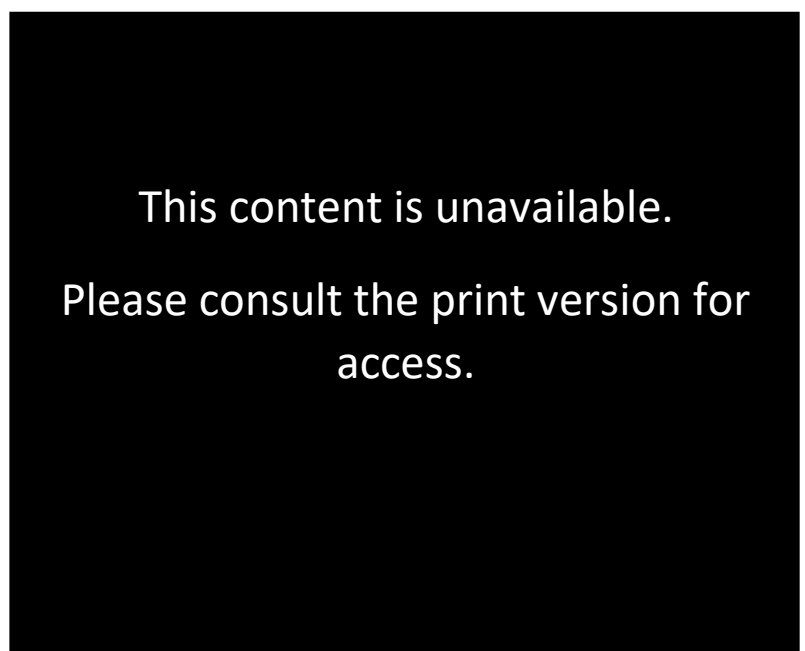

Figure 4.34: PerFORM[D]ance House plan (Perez, 2011)

\subsection{Materials and System}

Materials of the PerFORM[D]ance House were chosen based on how renewable, recyclable, and regenerative they were. It was also important for the team to choose materials with low life-cycle costs and that were locally available. The potential for being used in a modular construction and having low levels of chemical ingredients were other important factors affecting the types of material used by the team (Nepomechie, 2017, p.76) (Figure 4.35).

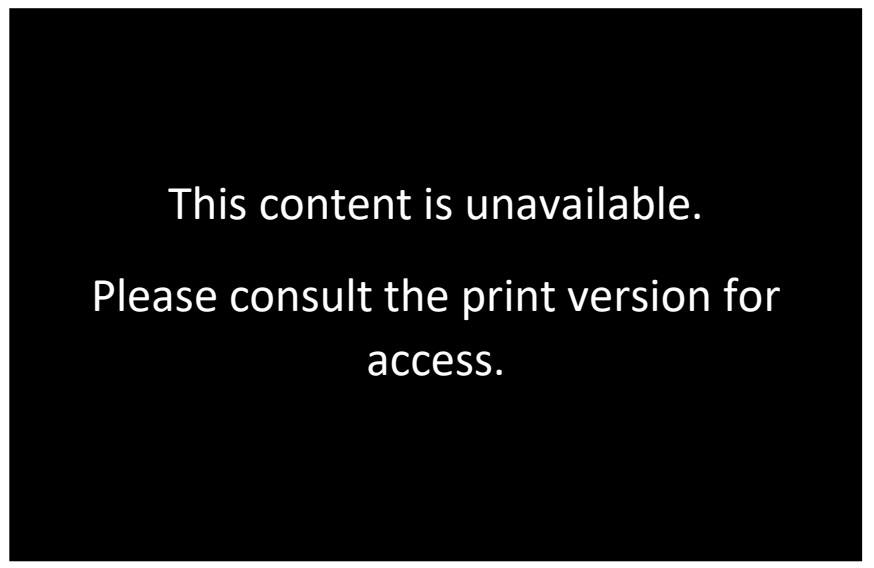

Figure 4.35: PerFORM[D]ance House wall sections (Perez, 2011)

\subsection{Construction and Transportation}

The construction process was started by assembling the steel frame of the house on the northernmost edge of the campus of Florida International University (Figure 4.36). Then the 
whole building was assembled by student and professionals on the campus. The completed building was then disassembled for transportation to the competition site.

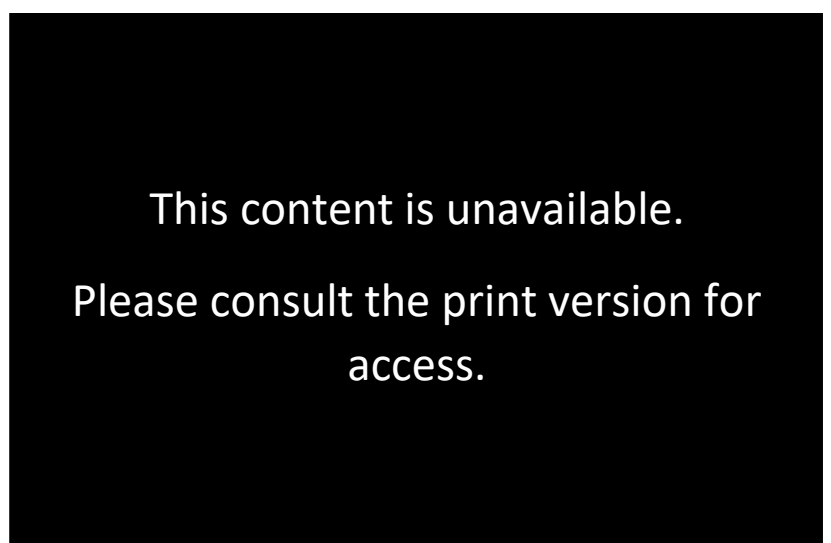

Figure 4.36: PerFORM[D]ance frame assembly (Nepomechie, 2017, p. 245)

The steel structure was designed to be divided into two parts for ease of transportation. The wooden deck and ramps were designed as a puzzle in 56 pieces to fit on a flatbed truck (Nepomechie, 2017, p. 370). Finally, the house, deck, furnishings and equipment, were packed and transported to the competition site over 1,700 km by seven trucks (Nepomechie, 2017, p. 74) (Figure 4.37).

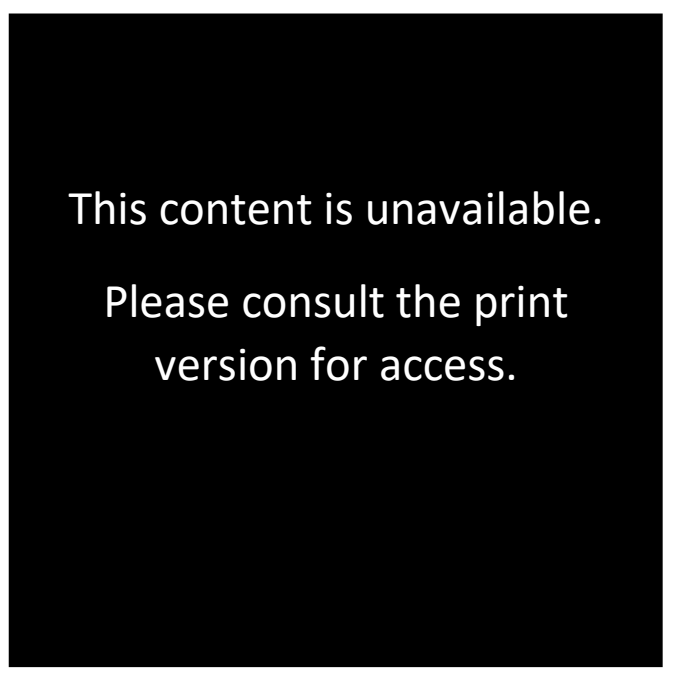

Figure 4.37: PerFORM[D]ance House transportation (Nepomechie, 2017, p. 309)

\subsubsection{Parsons: The New School for Design and Stevens Institute of Technology (Empower House)}

Empower House was a $92.90 \mathrm{~m}^{2}$ one-bedroom house constructed of prefabricated modules with the ability to produce its own energy, reduce potable water use, and grow food (Stevens, 2011) (Figure 4.38). 


\section{This content is unavailable.}

\section{Please consult the print version for}

access.

Figure 4.38: Empower house plan (U.S. Department of Energy Solar Decathlon, 2018)

\subsection{Materials and System}

The design team tried to choose materials based on affordability and being local, low embodied energy, low environmental impact, and non-toxicity. Materials were chosen to align with the goals of the design team for each part of the house, such as the thick insulation envelope which wrapped the house (Stevens, 2011).

\subsection{Construction and Transportation}

The general idea of the Empower House design was simplifying the transportation and replicability of the house while thinking about ease of construction. The house was made of three main modules as described below (Figure 4.39),

"A service "wet" module, containing the mechanical equipment, bathroom, and kitchen, anchors the house on the east, while the living "dry" module, containing the living area, office, light-loft, and bedroom, is open and airy. The west wall of the home, accentuated by the thick envelope required to meet passive house standards, wraps the house to become both floors, roof and porch as it extends beyond the front and rear of the house to embrace the neighbourhood beyond" (Stevens, 2011, p. 4). 
This content is unavailable.

Please consult the print version for access.

Figure 4.39: Empower house modules (U.S. Department of Energy Solar Decathlon, 2018)

\subsubsection{Tidewater Virginia: Old Dominion University and Hampton University (Unit 6 Unplugged)}

Unit 6 Unplugged was a $90.20 \mathrm{~m}^{2}$ one-bedroom house (Figure 4.40 ), which conceived as part of a six-unit multi-family building sharing infrastructure costs (Tidewater, 2011).

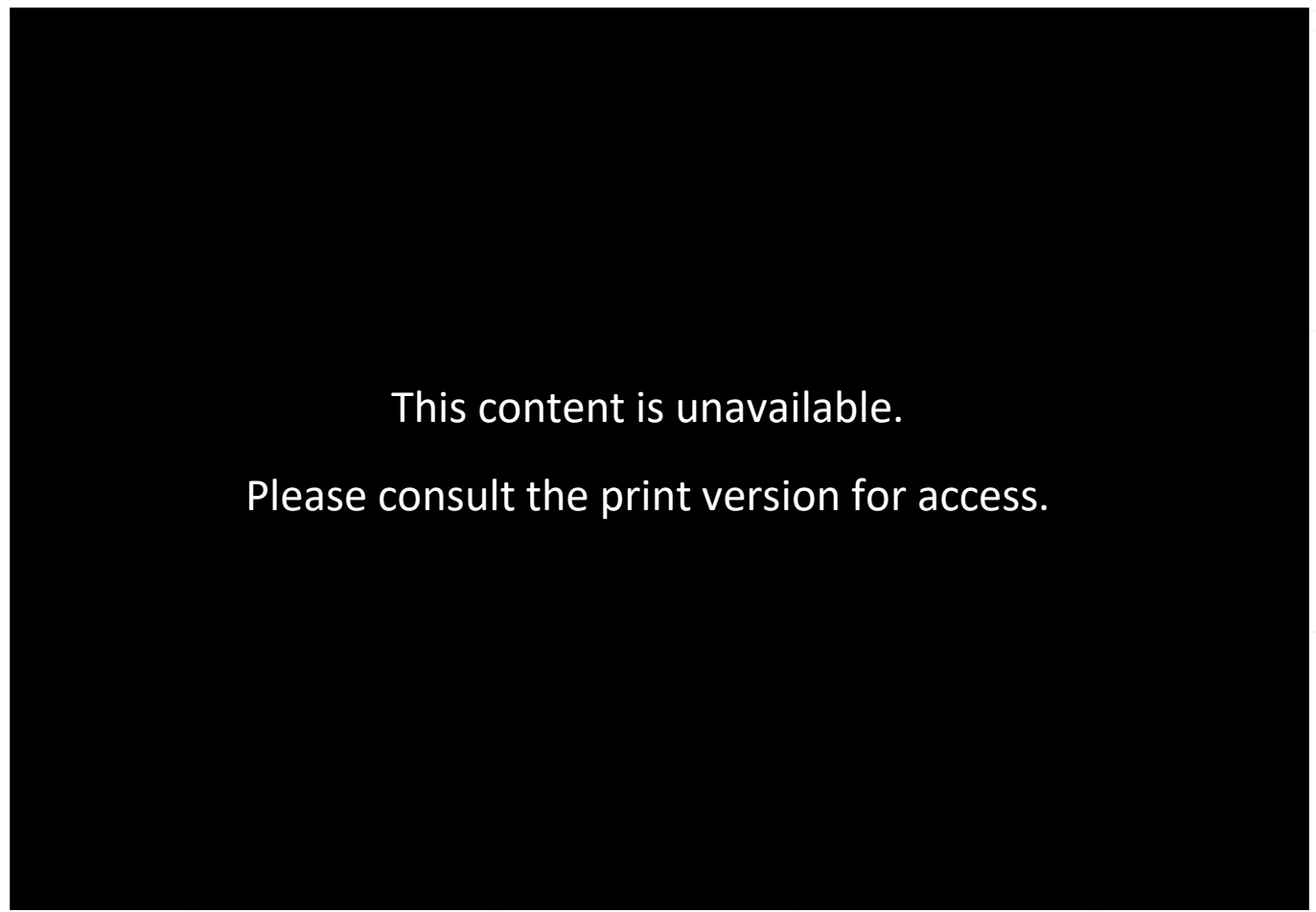

Figure 4.40: Unit 6 Unplugged plan (U.S. Department of Energy Solar Decathlon, 2018)

Unit 6 was built up from four main modules each having a specific function. In addition there were also utility, planters, deck modules, and a ramp. These were transported to the competition site by flat back trailers (Figure 4.41). Module A was the bedroom and this was joined to module B which included the living room. Module C consisted of the sunroom, kitchen, and all plumbing elements, and module D was a sloped roof that contained the solar panels and solar water heater (Bernard, 2011).

"The exterior walls will be constructed with the Zip System, a structural panel product with built-in overlays, eliminating the need for house wrap. The home will be clad with 
exterior-grade plywood, which functions as a rain screen. Wood battens and trim will camouflage the seams in a nod to the siding used for the mid-century homes in the neighbourhood" (Bernard, 2011).

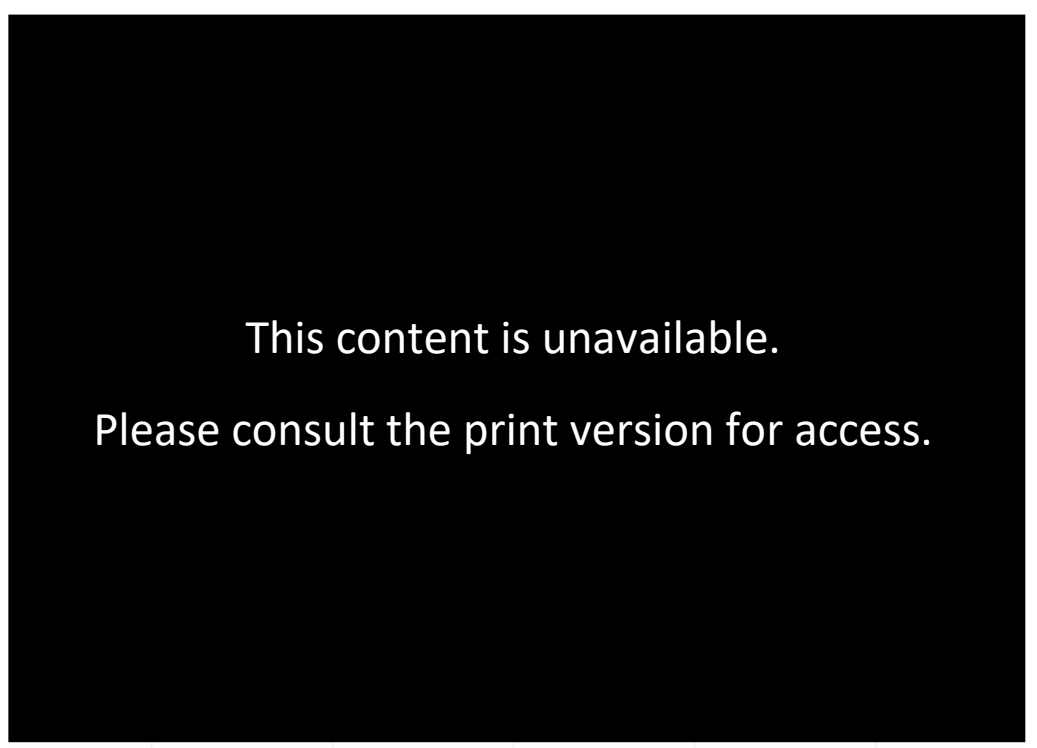

Figure 4.41: Unit 6 modules and transportation process (U.S. Department of Energy Solar Decathlon, 2018)

\subsubsection{Team China: Tongji University (Y Container)}

Team China put cost, modularity and ease of transportation as the first priorities during the design of the $Y$ Container which was an $80.91 \mathrm{~m}^{2}$ two-bedroom house. They combined 6 recycled shipping containers that cost only US\$600 into a " " shape (two containers side by side in each wing) (Figure 4.42). By folding the beds the space could be transformed into an open plan house (Techling, 2011) (Figure 4.43).

This content is unavailable.

Please consult the print version for access.

Figure 4.42: Y Container modules

Figure 4.43: Y Container plan

(U.S. Department of Energy Solar Decathlon, 2018) 


\subsection{Materials and System}

The nature of shipping containers is resistance to harsh natural circumstances during shipping. These containers are normally waterproofed by polymers and zinc-coated steel. In the $Y$ Container vacuum insulation and phase-change materials were both used to decrease and delay heat transfer. Figure 4.44 shows the materials and changes made to the containers for the $Y$ house.

This content is unavailable.

Please consult the print version for access.

Figure 4.44: Y Container materials (U.S. Department of Energy Solar Decathlon, 2018) 


\subsection{Construction and Transportation}

Using shipping containers as the base of the house made assembly, disassembly and transportation a lot easier as these containers were designed to seat together quickly and easily with high stability. It was also fast and easy to collect and ship them long distances. The Y container was designed to be shipped by 6 flat back trailers to the ship and from the ship to the site (Tongji University, 2011) (Figure 4.45).

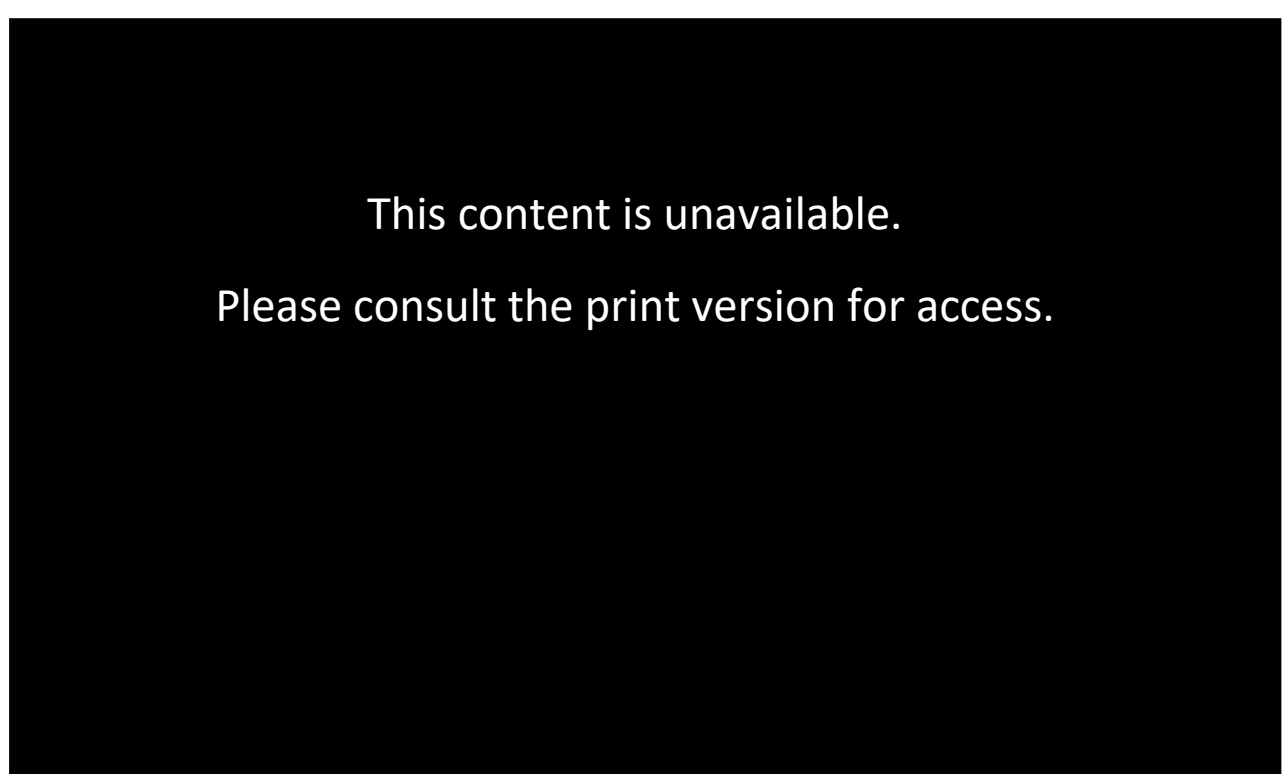

Figure 4.45: Y container transportation method (Tongji University, 2011)

\subsubsection{Ghent University (E-Cube)}

The Belgium team focussed on decreasing the cost and ease of construction during the ECube design of the $87.51 \mathrm{~m}^{2}$ two-bedroom house and presented an innovative idea of using a shelving system as the structural system. The E-Cube was the only two-storey building in SD 2011 (Figure 4.46). 
This content is unavailable.

Please consult the print version for access.

Figure 4.46: The E-Cube plan (U.S. Department of Energy Solar Decathlon, 2018)

\subsection{Material and System}

The E-Cube was designed as a modular Do It Yourself (DIY) building to cut the cost and get rid of the need for heavy machinery during the assembly and disassembly process. The steel structure of the house was based on a regular shelving system and the wooden wall panels and windows were designed on the same module to give the house the ability to be extended and modified (Sharlot, 2011) (Figure 4.47).

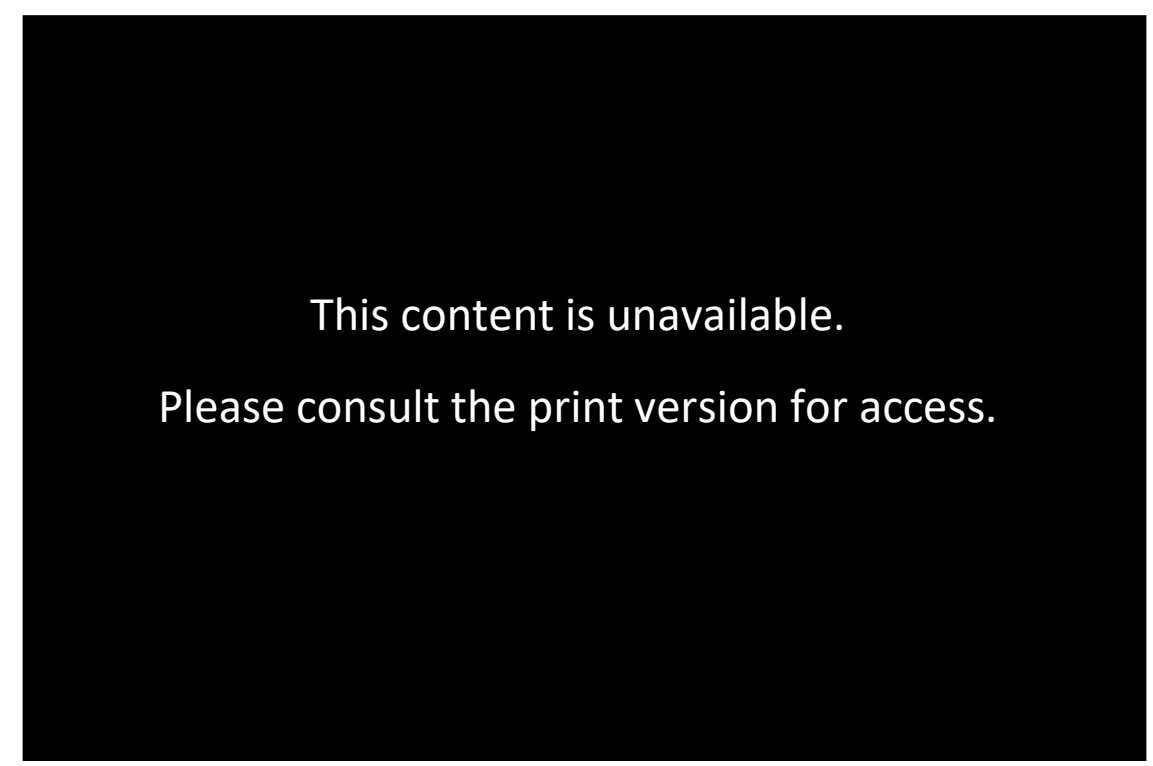

Figure 4.47: The E-Cube construction system (Inhabitat, 2011) 


\subsection{Construction and Transportation}

Due to the use of a shelving system and the DIY basis of the E-Cube, the house could be assembled, disassembled and transported easily and without the need for heavy cranes. The house was shipped to the competition site as a set of components (with a manual for DIY assembly) in three containers and assembled in around 24 hours on the site (Figure 4.48).

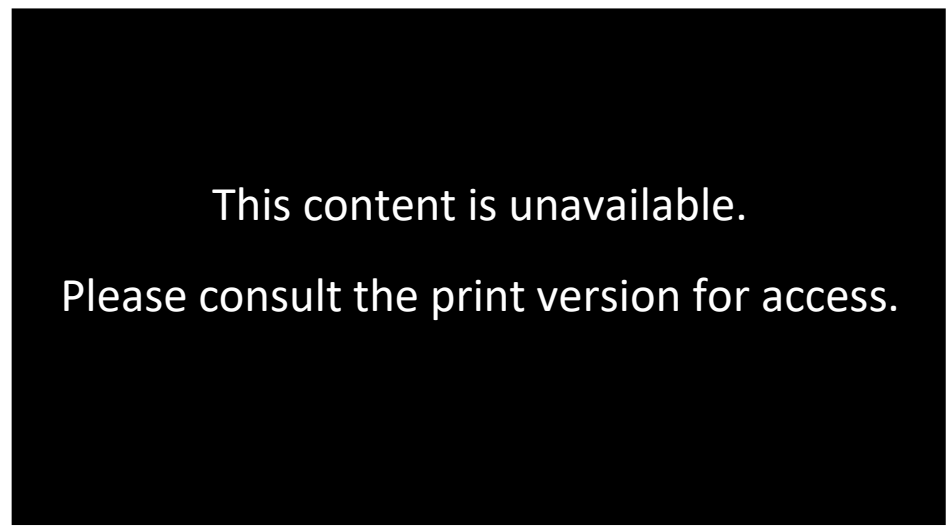

Figure 4.48: The E-Cube transportation (Inhabitat, 2011)

\subsubsection{The City College of New York (Solar Roofpod)}

The Solar Roof Pod was a $71.81 \mathrm{~m}^{2}$ one-bedroom, designed to be placed on the roof of an existing building (especially in New York) to use solar energy and increase the density of urban areas (Figure 4.49). It thus came closest to an ADU. The house consisted of three modules, these being the garden, the main module, and the trellis (Figure 4.50). The main module included the core, which included the kitchen, bathroom, and mechanical equipment. It had a steel frame, with cladding on the 64 poplar wood-framed envelope elements, and doors and windows (Team New York, 2011; U.S. Department of Energy Solar Decathlon, 2011).

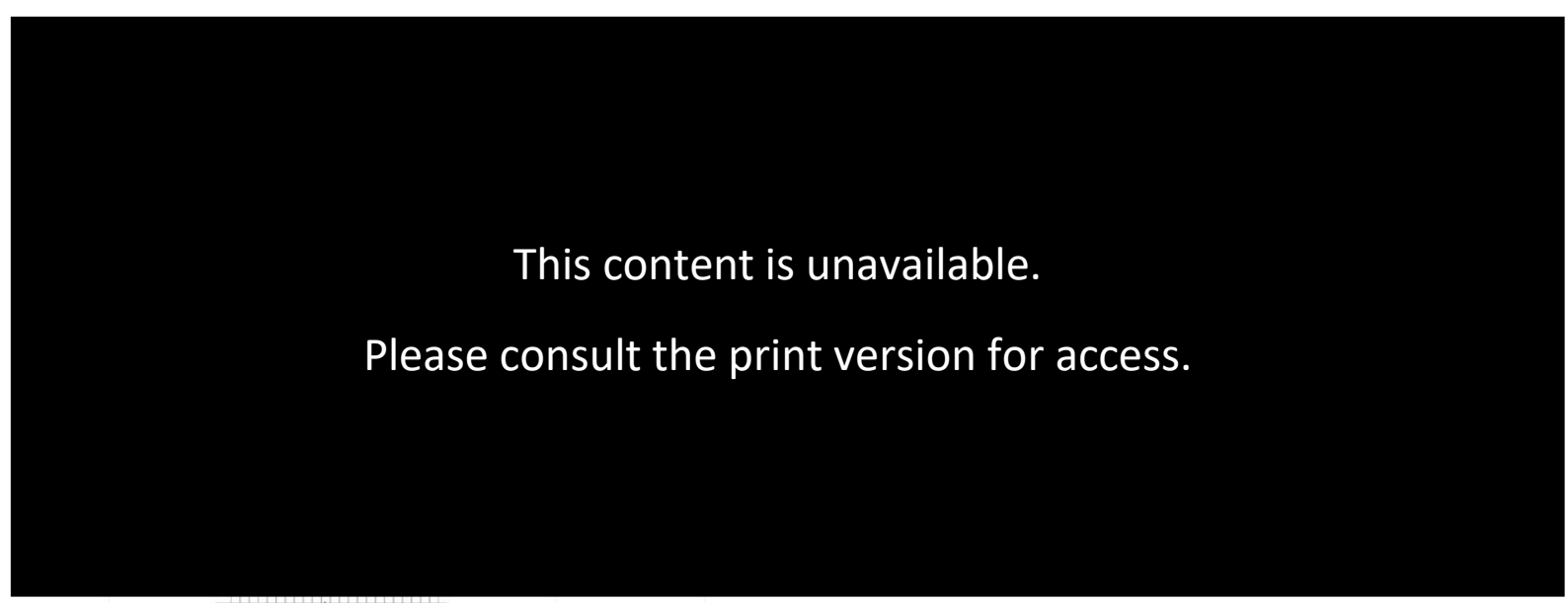

Figure 4.49: Solar Roof Pod plan Figure 4.50: Main modules of the Solar Roof Pod ( U.S. Department of Energy Solar Decathlon, 2018) 


\subsubsection{Team New Jersey (ENJOY)}

The ENJOY (Figure 4.51) $85.65 \mathrm{~m}^{2}$ one-bedroom house, was the first ever SD participant made of prefabricated precast concrete panels for walls, floor, and ramp as the primary construction material (Figure 4.52). The main reasons for using concrete were first its high thermal mass and then its durability (Cilento, 2011). However, there is no information about the methods used for transporting the house to the competition site.

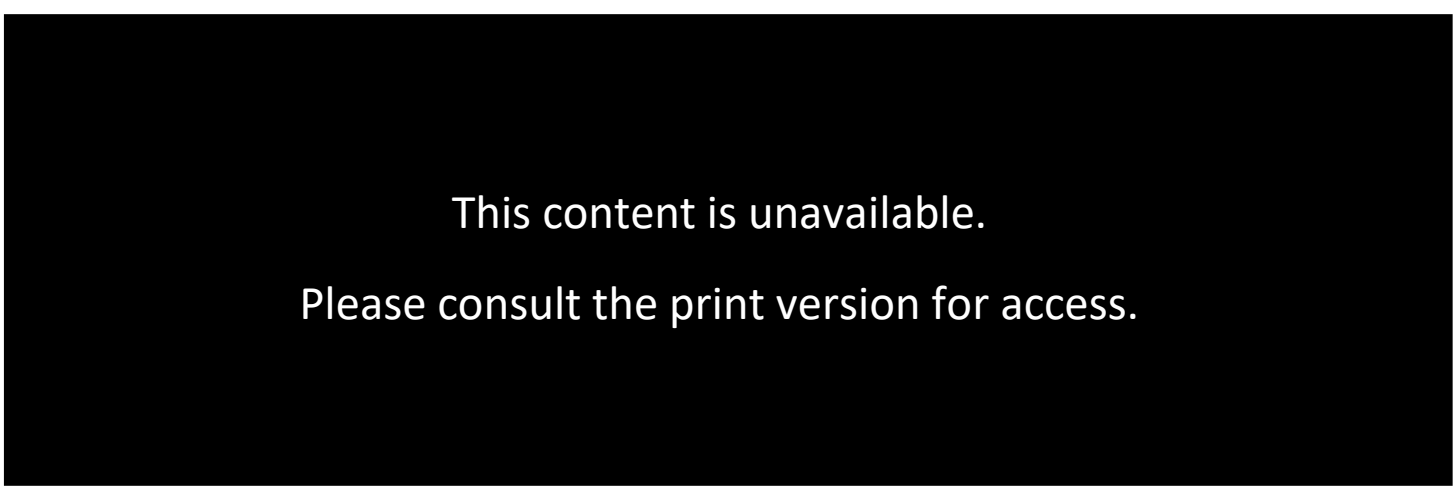

Figure 4.51: The ENJOY plan

Figure 4.52: The ENJOY components

(Cilento, 2011)

\subsubsection{The University of South Florida, Florida State University, the University of Central Florida, and the University of Florida (FLeX House)}

The FLeX House was an $83.51 \mathrm{~m}^{2}$ one-bedroom prefabricated house designed to be adjustable and easily transportable (Figure 4.53). The house could be adjusted by moving its internal partitions (Nepomechie, 2011).

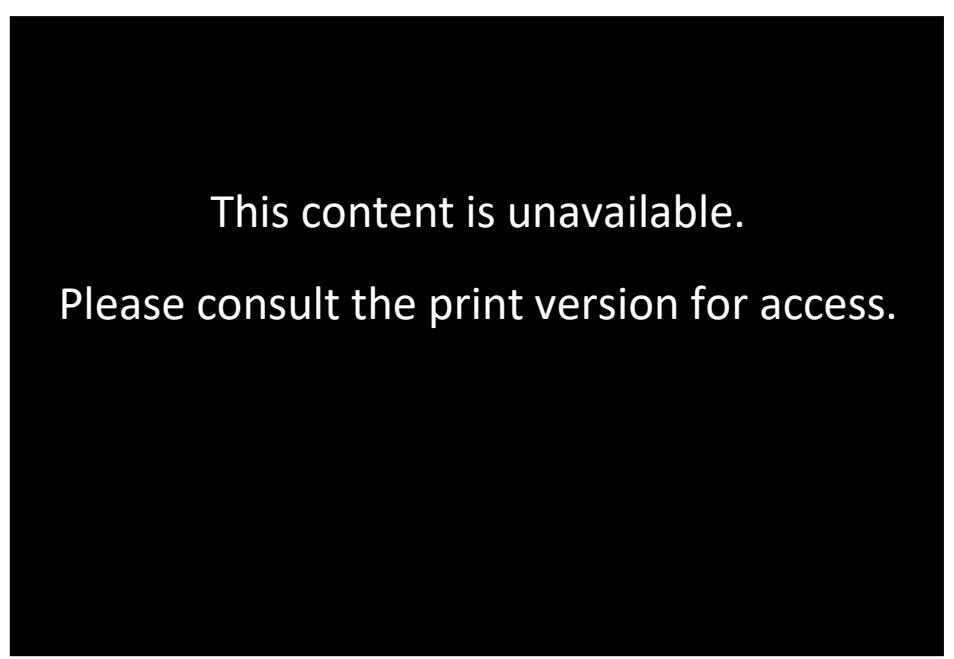

Figure 4.53: The FLeX House plan (U.S. Department of Energy Solar Decathlon, 2018) 4.6.2.12.1 Materials and System

The FLeX House was designed for the hot humid climate of Florida, so the structure was a little different from previous examples (Figure 4.54). It had a shading structure with cypress 
louvres covering the exterior of the house, with corrugated metal to decrease the thermal mass of the house and increase the reflectivity (Nepomechie, 2011; Russell, 2011).

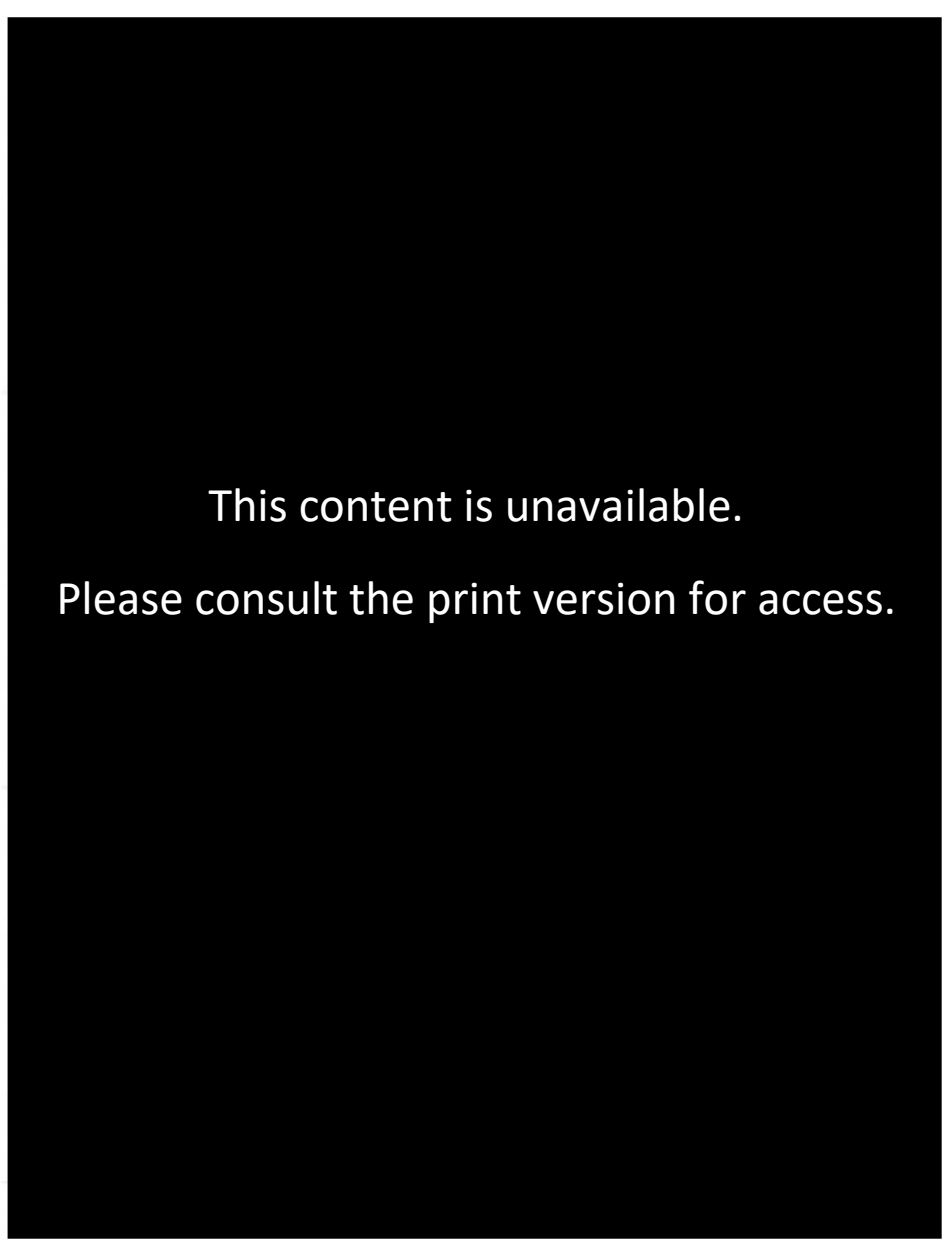

Figure 4.54: The FLeX House wall section (U.S. Department of Energy Solar Decathlon, 2018)

\subsection{Construction and Transportation}

Due to the needs for a type of house that could be transported easily and quickly, the team designed the house so that it could be prefabricated and transported as a single module on the back of one flat back trailer (Nepomechie, 2011; Russell, 2011). Figure 4.55 shows that the house consisted of one main module and two sliding modules that could be part of the main module during transportation and then pulled out at the site. 


\section{This content is unavailable.}

\section{Please consult the print version for access.}

Figure 4.55: The FLeX House main and sliding modules (U.S. Department of Energy Solar Decathlon, 2018)

\subsubsection{Discussion of SD 2011 houses}

Despite differences between designs, there were some considerations followed by most teams that might prove useful as factors to be considered during the design of the ADU (Table 4.13). Seven teams (58\%) divided the general areas of the house from the private areas. This, in turn, could break the plan down into separate modules for easier transportation and potentially higher efficiency in energy use than in an open plan configuration, as the owner could heat or cool one of these spaces without the need for heating/cooling the whole house. The majority of SD 2011 entries ( 9 houses or 75\%) had one bedroom and just 3 (25\%) houses had two bedrooms. Moreover, 11 (92\%) teams included a deck in their design, but this was in part often to do with circulation through the houses whilst being exhibited, which is not applicable to the ADU design.

Another prominent idea in most designs (10 or $83 \%$ ) was considering the kitchen, laundry (if it existed) and bathroom as a unit, making a wet services core. This could help the ADU design by cutting costs as less plumbing and waterproofing would be needed as all wet areas would be close together. From the manufacturing point of view, such a design would let a builder completely manufacture this unit in the factory under controlled conditions. Out of the 12 SD houses, 8 used the modular system, while 2 used a panelised system and 2 a hybrid system. Houses could be carried in 1-7 containers to the site and assembled in less than 1 week.

All teams used passive solar principles in the form of choosing materials with some thermal mass, despite the need to transport the house, and also wide windows or even sunrooms 
facing the sun during winter to absorb as much heat as possible. The idea of letting the sun in during winter needs to be complemented by having canopies to block out the sun during the summer.

Collecting and reusing rainwater was another idea used by eight (67\%) projects. In the case of materials, most designers decided to use local materials as these were easy and cheaper to obtain. Moreover, the materials specific to a region are usually the best ones to use in that region as they are most likely to have consistency with the region's climate.

Table 4.13: Solar Decathlon designs (and legend)

\begin{tabular}{|l|l|l|l|l|l|l|l|l|l|}
\hline & Area & NB & PSD & Wet core & SBPP & WCS & NC & Deck & PS \\
\hline WaterShed & 81.4 & 1 & $\mathrm{~V}$ & $\mathrm{~V}$ & $\mathrm{~V}$ & $\mathrm{~V}$ & 3 & $\mathrm{~V}$ & Module \\
\hline First Light & 71.9 & 1 & $\mathrm{~V}$ & $\mathrm{~V}$ & $\mathrm{~V}$ & $\mathrm{X}$ & 6 & $\mathrm{~V}$ & Module \\
\hline Self-Reliance & 92.0 & 2 & $\mathrm{~V}$ & $\mathrm{~V}$ & $\mathrm{~V}$ & NA & NA & $\mathrm{V}$ & Module \\
\hline Living Light & 68.7 & 1 & $\mathrm{~V}$ & $\mathrm{X}$ & $\mathrm{X}$ & NA & 2 & $\mathrm{~V}$ & Module \\
\hline PerFORM[D]ance House & 74.3 & 1 & $\mathrm{~V}$ & $\mathrm{~V}$ & $\mathrm{X}$ & $\mathrm{V}$ & 7 & $\mathrm{~V}$ & Panel \\
\hline Empower House & 92.9 & 1 & $\mathrm{~V}$ & $\mathrm{~V}$ & $\mathrm{~V}$ & $\mathrm{~V}$ & $\mathrm{NA}$ & $\mathrm{V}$ & Module \\
\hline Unit 6 Unplugged & 90.2 & 1 & $\mathrm{~V}$ & $\mathrm{~V}$ & $\mathrm{X}$ & $\mathrm{V}$ & 6 & $\mathrm{~V}$ & Module \\
\hline Y Container & 80.9 & 2 & $\mathrm{~V}$ & $\mathrm{~V}$ & $\mathrm{X}$ & $\mathrm{V}$ & 6 & $\mathrm{~V}$ & Module \\
\hline The E-Cube & 87.5 & 2 & $\mathrm{~V}$ & $\mathrm{~V}$ & $\mathrm{~V}$ & $\mathrm{NA}$ & 3 & $\mathrm{X}$ & Panel \\
\hline Solar Roofpod & 71.8 & 1 & $\mathrm{~V}$ & $\mathrm{~V}$ & $\mathrm{X}$ & $\mathrm{V}$ & NA & $\mathrm{V}$ & Hybrid \\
\hline ENJOY & 85.7 & 1 & $\mathrm{~V}$ & $\mathrm{~V}$ & $\mathrm{~V}$ & $\mathrm{~V}$ & NA & $\mathrm{V}$ & Hybrid \\
\hline FLeX House & 83.5 & 1 & $\mathrm{~V}$ & $\mathrm{X}$ & $\mathrm{V}$ & $\mathrm{V}$ & 1 & $\mathrm{~V}$ & Module \\
\hline Total & 81.7 & - & 12 & 10 & 7 & 8 & - & 11 & - \\
\hline
\end{tabular}

\begin{tabular}{|l|l|}
\hline Feature & Abbreviation \\
\hline Number of Bedroom/s & NB \\
\hline Passive Solar Design & PSD \\
\hline Separation Between Public and Privet area & SBPP \\
\hline Water Collection System & WCS \\
\hline Number of Containers need for transport & NC \\
\hline Prefabrication System & PS \\
\hline
\end{tabular}

\subsection{Summary}

This chapter investigated the design parameters, rules and requirements to be considered at the early design stage of the ADU. The first section of looking at the district provisions specific to ADUs, by focusing on MCS, MPPA and MNSA. The analysis of different council's rules showed that for consent by the majority of councils in New Zealand, the MSC, MGPA and MNSA of prefabricated ADU should respectively be in the ranges of $30-50 \%, 50 \mathrm{~m}^{2}-70 \mathrm{~m}^{2}$ and $325 m^{2}-800 m^{2}$. 
The second section investigated the capability of prefabrication manufacturers in building the ADU. The result of reviewing the manufacturers of types of prefabrication showed that despite the existing potential in the Auckland, Canterbury and Wellington regions, other regions of New Zealand suffer from lack of enough manufacturers, including Waikato despite the region's need for more houses based on the number of households there. Moreover, all regions suffer from the lack of an acceptable variety of manufacturers, and a general lack of completed building manufacturers.

The third and fourth sections of this chapter looked at transportability and the accessibility needs of older people. These two sections have a competing impact on the design as the perfect parcel to transport is a small, narrow one, while the fully accessible house needs wide spaces. The New Zealand road rules ask for a parcel to be less than $2,550 \mathrm{~mm}, 4,300 \mathrm{~mm}$ and $20,000 \mathrm{~mm}$ respectively in width, height and length, in order to be transportable without extra permissions. On the other hand, Lifemark asked for a minimum of 1,050 for corridors and $800 \mathrm{~mm}$ free space around furniture and recommends a $1,500 \mathrm{~mm}$ turning a circle in some spaces. As a result, there will be challenges to balance the design in order to make the ADU accessible, while still being transportable.

The last section of this chapter studied tiny houses and energy efficient prefabricated houses plans, in order to see how other designers have approached the different challenges the ADU design needs to overcome. Looking at the arrangements of small plans, the analysis showed the ADU should ideally have two bedrooms, a shower, an L-shaped kitchen and a separate laundry. The ADU should also have at least one wardrobe for each bedroom and potentially have a deck. Reviewing the prefabricated energy efficient houses revealed the fact that most of the designs divided the public and private spaces and serviced and wet areas were treated as a services core, often in one module. The presence of a services core was also clear in the tiny house plans. There was also an attempt in most of the energy efficient designs to use local and natural materials, and also have materials with some thermal mass to absorb solar heat. 


\section{Chapter 5 Design and Construction}

\subsection{Introduction}

This chapter develops the design of the ADU plan, and its factory construction with particular regard to transportation and craning. However, to decide on the construction details it is also necessary to investigate whether the designs achieve zero space heating energy. As a result, this chapter starts with three design-related sections. These are the design of the ADU, its space conditioning energy simulation, and finalisation of the construction details. By the end of the first stage there are 21 possible plans, with 18 different construction scenarios. The differences in the latter are mainly regarding the possible thicknesses of floor, wall, and roof, as well as the type of floor (see Section 5.6). As the technical details can change based on the selected construction scenario, to reduce the number of choices the best plan layout is selected for further testing at the end of the first section. This layout is then is simulated for all 18 construction scenarios at two different heating levels using ALF3.2. At the end of section two, the most energy efficient scenario is selected, and the construction details for this design are worked out in the third section. This detailed design then will be used in the next chapter to calculate the LCE, LCC and life-cycle cost of the ADU.

\subsection{Design}

The aim of this section was to design the ADU by first looking at different types of prefabrication to see which best aligned with the goals of this research. Finding a modular system as the best match (see Section 5.2.1.3), the next part investigated the size, function and materials for the modules. At this stage there were 21 possible layouts, each responding to different needs but made of same size module, in addition to an entrance module.

\subsubsection{Prefabrication Systems}

As discussed in Section 2.2.3 there are five different types of prefabrication but not all are suitable for use in this research. The following discussion addresses the suitability of each type, in order to choose the most appropriate for the ADU.

\section{- Component}

This prefabricated system is easy to load, transport, and deploy due to the size and weight of the elements. This is because a component-based house includes many small light elements, like wall frames, windows, and sections of floor, so the number of elements is high but the 
size and weight are low. Components are easy to transfer from a trailer to a backyard by light machines or even manpower with no need for a wide pathway. However, when it comes to assembly more on-site work is needed, and as a result, the house may be finished with more defects in comparison with other more factory based prefabricated systems. The componentbased ADU should still be faster with higher quality in comparison with on-site construction.

\section{- Panel}

Panels, which are a combination of some components assembled in a factory, are larger and heavier in comparison with components. This leads to a lower number of parcels needing to be loaded, transported and deployed on the site, making for faster construction and potentially fewer defects. Despite their bigger size and weight, panels are still easy to transport and transfer to a backyard using light machines and even by manpower in some circumstances. Panels can be considered as two-dimensional elements that can be laid on top of each other and loaded on to a forklift or the back of a flatbed trailer and transferred from the road to the site via a drive.

\section{- Module}

Modular construction is more efficient in comparison with the two previous types in terms of time and quality. However, modules are bigger and heavier than panelised or componentbased methods. This means they need more consideration during transportation. As noted in the previous chapter, an ADU made using the modular system should include more than one module. The biggest size a module should be, so as not to be an oversize load, is approximately $51 \mathrm{~m}^{2}$ with a maximum allowed width of $2.55 \mathrm{~m}$. Moreover, modules need semiheavy cranes for deployment and cannot be carried using manpower.

\section{- Hybrid}

This system is a combination of the two previous systems and tries to include the benefits of both and avoid their weaknesses. A hybrid system might consist of a services core in the form of a module around which prefabricated panels are attached to form the finished ADU.

\section{- Complete building}

This system is the heaviest, largest and the most difficult for transportation and deployment. Complete buildings need the heaviest cranes and trailers in comparison with other types of prefabrication. However, this type of building should have the least defects as it is completely 
assembled in a factory in a controlled condition. The only possible problem is breakage or damage during transportation.

To decide how a prefabricated ADU should be designed it is necessary to consider different factors, as each system has its own benefits and disadvantages. Generally speaking, more work completed in the factory means better quality and less time and work onsite, but more transport and craning constraints. If the aim is to design a house for an empty lot, it is probably worth finding a way to overcome these transport and craning constraints. However, in this research, the aim is designing an ADU for a lot with an existing house on it. This means, there is less control over the site conditions, where the ADU can be placed, and the potential access, as all are affected by the existing house, and each site will probably differ from the next. However, the aim is not to design a different ADU for each site but rather to find a system that could adapt itself to different sites without any change in the factory's production line. This requires a prefabricated system which has the quality of prefabrication and the flexibility of on-site construction.

As a start, it was noted there could be problems with the two approaches of components and completed buildings. Component systems have the least degree of prefabrication and do not benefit as much from the advantages of factory construction. Completed buildings, which are very good systems for empty lots, do not have the level of flexibility required for existing house situations, and also need more stringent transport and assembly considerations. There are also only four manufacturers of completed prefabricated buildings in New Zealand making transportation more critical (see Section 4.3). From the other three systems, a modular ADU would be harder to transport and crane, but has a higher quality in comparison with panelised and hybrid systems. However, considering the transport, craning and site limitations with an existing house, if the modular system is selected the ADU should be designed in smaller rather than larger modules. Having more, smaller modules will be easier for transportation and assembly and could give flexibility from having different arrangements of modules. The panelised system is also a good method for designing the ADU as it gives very good flexibility and is easy to transport and assemble. However, it needs more on-site work and this could lead to more defects in the final ADU. Given that the aim is to create a zero energy ADU this could be problematic, as the system will have to be assembled so as to form an airtight envelope. It seems a hybrid system might offer advantages. Wet areas, which are probably 
less than $2.55 \mathrm{~m}$ in width, could be manufactured in the factory as a plug-in service core that would be small and light to crane in. Other parts like walls or floors could be manufactured as panels to give the flexibility to adapt the ADU design to the different sites with their existing houses, and with design to achieve the zero energy goal.

The other factor affecting the prefabrication type is weight. The weight of the ADU needs to be considered during the design process due to its effect on transportation and assembly. A heavier ADU needs a heavier crane for deploying and moving it to the backyard. A heavier crane is also a bigger crane that needs more consideration during transport and operation, especially in conditions where the crane may block the street. Blocking the street needs additional permission and traffic considerations which can put pressure on the assembly team to finish the work faster. Overall it seems hybrid and modular systems have the most uniformity with a target of this research and New Zealand road rules. The panelised system is less good, as there are many joints to be made on-site, where each can be a potential source of defect or heat energy leakage.

\subsubsection{Hybrid}

The two main groups of elements that need to be considered in a hybrid ADU consist of the services core and the panels forming the walls, floors, ceiling and other parts of the house. In a services core, the most important and heaviest part is the bathroom if it comes to the site as a complete module. Kitchen fittings are normally prefabricated, and kitchen and laundry appliances, such as oven, washing machine and dryer, could come to site separately and do not weigh much in comparison with a complete bathroom.

The weights of bathroom units vary based on the materials and methods, but generally, a bathroom unit weighs between $500-2,500 \mathrm{~kg}$. While a $4.08 \mathrm{~m}^{2}$ precast concrete bathroom would weigh approximately 2,500kg, a fibre-reinforced panelised bathroom module weighs less than 2,000kg (Kryzhanovsky, 2012; Chong, 2014). Bathsystem, which is a manufacturer of prefabricated bathrooms, suggested the weight of $1 \mathrm{~m}^{2}$ of a concrete bathroom unit would be 300-625kg (Bathsystem, 2017). PUDA (2017), which is another bathroom manufacturer, gave $500 \mathrm{~kg}-920 \mathrm{~kg}$ as the range for a $3.2 \mathrm{~m}^{2}$ prefabricated bathroom made of glass reinforced plastic. 
When it comes to panelised prefabrication there are various options with different weights. As an example Structural Insulated Panels (SIPs) (see Section 5.3.1.3) made by New Zealand Smart Structural Insulation Panels (NZSIP) weigh $20.0-27.9 \mathrm{~kg} / \mathrm{m}^{2}$ based on their thickness which varies from $115 \mathrm{~mm}$ to $215 \mathrm{~mm}$ (NZSIP, 2017). The common size of panels in New Zealand is $1.2 \mathrm{~m}$ wide by $2.4 \mathrm{~m}$ high, so each panel weighs $57.6-80.3 \mathrm{~kg}$. This weight can be carried by 2-3 people without any mechanical assistance. This is because despite considerations, such as how the loads are lifted, how close to the body they are held, and how high or low the weights are, a man can carry up to $25 \mathrm{~kg}$ and a woman up to $16 \mathrm{~kg}$ (Health and Safety Executive, 2012; The University of Waikato, 2015). This safe weight limit could be increased using manual lifters, but in this research, $25 \mathrm{~kg}$ is considered the heaviest load that can be carried by a man. A SIPs panel $1.2 \mathrm{~m} \times 2.4 \mathrm{~m}$ could be carried by $2-3$ men through narrow pathways between an existing house and the site boundary. However, the biggest weakness of SIPs is that they come to the site as raw panels, without cladding, doors and windows, wiring or plumbing. This is one of the main reason why SIPs are light, but this also means a lot of onsite work with the opportunity for more defects. It is worth noting that precast concrete structural panels would weigh at least double the weight of SIPS and cannot be carried by manpower (Archer, 2017). Moreover, sometimes panels could weight more.

The Durapanel, which is a panel manufacturer in New Zealand, team's response to questions about their panels was "Costs approx. $\$ 60-\$ 80 \mathrm{~m}^{2}$ for our panels but that does not include the doors or windows or insulation as we do not supply those components as part of our package. Panels weigh $220 \mathrm{~kg}$ at the most so usually a standard Hiab (a road based lifting system) is sufficient for installation" (Garton, 2018).

The weights of panels for inserting in a frame vary based on the company and the way they are constructed. For example, Kingspan architectural insulated panels weigh $11.2 \mathrm{~kg} / \mathrm{m}^{2}$ to $14.8 \mathrm{~kg} / \mathrm{m}^{2}$ and Sto panels weigh $39 \mathrm{~kg} / \mathrm{m}^{2}$ to $122 \mathrm{~kg} / \mathrm{m}^{2}$ (Kingspan, 2018; Sto Panel Technology, 2016). In the same way, Easybuild panels, which are not structural and exclude windows and insulation, weigh $28 \mathrm{~kg} / \mathrm{m}^{2}-35 \mathrm{~kg} / \mathrm{m}^{2}$ for standard panels which are $1.2 \mathrm{mx} 2.4 \mathrm{~m}$ (Lee, 2018). These groups of panels are not considered for the ADU design in this research, as they are not structural and need a separate structure or frame, leading to more onsite work. 


\subsubsection{Module}

The ADU can be made of modules based on sizes less than the oversized load legislation. However, considering that the ADU will be designed to be usable in all New Zealand, and potentially overseas, and is supposed to be an easy and fast solution to the shortage of houses, an oversized load will negatively affect the practicality of the ADU. Given the weight of modules, Matrix Homes modules which are between $53 \mathrm{~m}^{2}-140 \mathrm{~m}^{2}$ weigh between 8,000 $15,000 \mathrm{~kg}$ and can usually be assembled by a Hiab or crane up to 350 tonnes (Bokkerink, 2018). Thus a $50 \mathrm{~m}^{2}-70 \mathrm{~m}^{2} \mathrm{ADU}$ will weigh approximately $7,500 \mathrm{~kg}$ and could be placed in a backyard using a semi-heavy mobile crane.

The next option is manufacturing the ADU in more than one module that can be carried to the site without the need for considering the oversized load regulations. This approach also results in having several light modules instead of one heavy one, which will let the builder use a lighter crane during assembly. This can be an efficient way of benefitting from the advantages of prefabrication with a good level of flexibility without struggling with road rules. In comparison with a single module, this type needs more work on site as the different modules need to be joined together, but it is still an effective way of constructing the ADU. This is the system the Victoria University of Wellington team used in the First Light House for Solar Decathlon 2011 (see Section 4.6.2.2). Marriage (2018) said each of the six modules of the First Light House weighed approximately $2,500 \mathrm{~kg}$. This weight related to "an area of $2.4 \mathrm{~m}$ $\times 5.0 \mathrm{~m} \times 50 \mathrm{~mm}$ thick equals $0.6 \mathrm{~m}^{3} \times 2500 \mathrm{~kg} / \mathrm{m}^{3}$ equals $1,500 \mathrm{~kg}$ for each module's concrete lid" (Marriage, 2018). This means the weight of each module excluding the concrete part could be around $1,000 \mathrm{~kg}$. The team used a 25 -tonne boom truck for equipment and small lifts, and for heavier lifts a 50-tonne mobile crane that was able to handle 2,000kg at maximum extension (Marriage, 2018).

\subsubsection{Final selection}

Considering transport regulations in New Zealand, crane capacities and limitations and the benefits and weaknesses of each type of prefabrication, prefabrication based on components, panels, and completed buildings were removed from the options for the ADU. The reasons for removing these were the low degree of prefabrication and the need for a high level of on- 
site work for the first two system, and the oversize road rules, as well as the need for heavy cranes at the site. This leaves the hybrid and module systems.

The hybrid system is an efficient method of construction which can give a combination of a high degree of prefabrication, through creating a service zone as a complete module and flexibility from using prefabricated panels which could be assembled in different ways. The only potential weakness of the hybrid system is the amount of on-site work. Benefiting from the advantages of both systems also means suffering from some of their disadvantages. This means while there is a need for a crane on site to place the service core, even if it is a light crane, there is also a need for considerable on-site assembly. The alternative is to create a system of modules that can be craned in and linked together on site. This would avoid road transportation constraints but offers the benefit of reasonably complete factory construction, including all finishes. Careful design could produce a system of modules that could be assembled in different ways to suit both the site and the client. Comparing these systems, hybrid is more flexible but modules have a higher degree of prefabrication which means less onsite work. Both systems need some form of cranage.

The ADU design for this research will be based on the modular approach as it has fewer joins to be made on site. Given that there are probably people living in the existing house on site during the time the ADU is to be assembled, a quicker assembly time will be less disruptive for them. The design approach will, therefore, be to create a series of prefabricated room modules that can ideally be joined in different ways to create different ADU sizes and different plan layouts.

\subsubsection{Is this a container home?}

Deciding to build the ADU using modules led to the question of whether using shipping containers could be an option instead of building the modules using SIPs panels from scratch. Botes (2013) the advantages of contained homes as their durability, ease of transport, availability, and being cheaper than conventional houses, and their disadvantages as the lack of thermal comfort due to the steel shell, condensation due to high moisture in uninsulated containers, presence of solvents and toxic contaminants, and their price instability due to changes in the international price of steel. In addition to these, Hamilton (2017) pointed to cost of containers, which can start from $\$ 1,200$ USD for used ones to $\$ 6,000$ USD for new ones, 
as a benefit as this can lead to a container home being $30 \%$ cheaper than a conventionally made house not least because of the speed of construction, as well as being eco-friendly, especially in case of repurposing used containers. Hamilton (2017) also mentioned similar weaknesses to Botes (2013), mainly the lack of proper insulation and less control over the internal temperature of the house, and toxic concerns. Container houses also need a concrete foundation made on site like the prefabricated ADU. However, as neither are conventionally made houses, a more detailed comparison of the three main aspects of this research of transportability, accessibility for older people, and energy efficiency, can be useful.

The closest sized container to the modules of the ADU is a 20ft container as specified below (Table 5.1), although the size of a $20 \mathrm{ft}$ container can vary a little based on where it has been manufactured.

Table 5.1: Dimensions of a 20ft General Purpose Container (Royal Wolf, 2019)

\begin{tabular}{|l|l|l|}
\hline & External & Internal \\
\hline Length & $6.06 \mathrm{~m}$ & $5.90 \mathrm{~m}$ \\
\hline Width & $2.44 \mathrm{~m}$ & $2.35 \mathrm{~m}$ \\
\hline Height & $2.59 \mathrm{~m}$ & $2.39 \mathrm{~m}$ \\
\hline Weight & $2,220 \mathrm{~kg}$ & \\
\hline
\end{tabular}

Table 5.1 shows the containers are easy to transport, especially due to their smaller width compared to the modules of the ADU. The height and length of the containers are also suitable for transportation as expected. Looking at the weight, containers are heavier than the ADU modules (see Section 5.7.5.1) but still easy to transport. However, Table 5.1 shows the wall thicknesses of the container are $80 \mathrm{~mm}$ for the long walls, $45 \mathrm{~mm}$ for the short end walls, and $100 \mathrm{~mm}$ for both roof and floor including the top and bottom zones for stacking and lifting (numbers are extracted from comparing the internal and external dimensions and divided by two). These numbers show there is little space for insulating materials inside the walls, floor and ceiling. To make the container more energy efficient it would be necessary to add insulation layers inside it, which would reduce the internal space thus going against the ideal of having wider spaces for easy accessibility. Despite easier transportation, when it comes to energy efficiency and accessibility, containers homes have less flexibility than the prefabricated ADU as designed. The reason is the dimensions of the module have been modified to get the best combination of internal size and transportability, while containers have fixed dimensions with no possibility of change. 


\subsection{Choice of Material}

Regarding the choice of materials for the ADU, first there is a need to look at conventional construction systems. Given the research aim of designing an energy efficient prefabricated $A D U$, there is also a need to consider the thermal performance of different materials. This section first looks at different construction systems and materials, with an eye on the required R-values that will meet the Building Code.

\subsubsection{Construction Systems in New Zealand}

Construction systems in New Zealand can be broadly classified into the two groups of lightweight (or low mass) and heavyweight (or high mass) construction (The Authority on Sustainable Building, 2013). Each of these if prefabricated would need a different approach, but generally buildings made of heavyweight construction are more durable, need less maintenance, and have thermal mass that could be part of a zero energy solution. However, lightweight buildings are better for remote sites due to lower weight, and if of timber would have reduced embodied energy and environmental impacts (The Authority on Sustainable Building, 2013).

\subsubsection{Lightweight/low Mass Construction}

Building elements, especially walls, in lightweight construction are generally made with a timber or steel frame, and clad on both sides. To meet the New Zealand Building Code (NZBC), there also needs to be a cavity between the structure and cladding to let the air flow so that moisture is not absorbed into the structure (Smarter Homes, 2018). Inward of this cavity, which is backed with building wrap, the structural frame will be filled with an insulation material. Lightweight construction in New Zealand is mostly timber frame, as the country has a plentiful supply of Pinus radiata (n.d.). There is some use of Structural Insulated Panels (SIPs), and straw bale walls are also found but not commonly in urban areas (Smarter Homes, 2018), but the latter are not appropriate for a transportable ADU.

\section{- Structural Insulated Panels (SIPs)}

SIPs are structural elements that include insulation, usually polystyrene or polyurethane, sandwiched between two boards, usually plywood, Oriented Strand Board (OSB), or metal. Panels can be used as a wall, roof, or floor (Panjehpour, 2013) (Figure 5.1). 


\section{This content is unavailable.}

\section{Please consult the print version}

for access.

Figure 5.1: Structural Insulated Panels (SIPs) (NZSIP, 2017)

Compared with conventional wood framed house, a SIPs system house has twice the bracing capacity and is also more energy efficient with less waste (NZSIPs, 2017). Meis (2015) compared the SIPs system with a framed system and stated that the SIPs was $18-24 \%$ more energy efficient, $5 \%$ faster, and provides $20-30 \%$ better air tightness.

Kosny et al. (1999) compared the R-value of a SIPs wall with that of a conventional wood framed wall and found the R-value of a $8.9 \mathrm{~cm}$ core SIPs wall was approximately $50 \%$ more than that of $50 \times 100 \mathrm{~mm}$ insulated wood frame walls and slightly less than that of a $50 \times 150 \mathrm{~mm}$ insulated wood frame wall. NZSIPs (2017) also claimed an R-value of $4.5 \mathrm{~m}^{2 \circ} \mathrm{C} / \mathrm{W}$ for a $155 \mathrm{~mm}$ SIPs wall compared with $2.7 \mathrm{~m}^{2 \circ} \mathrm{C} / \mathrm{W}$ for a $147 \mathrm{~mm}$ timber-framed wall with a rigid air barrier. Petrie and Christian (2002) ran a comparison test to see how SIPs made rooms and conventional rooms of $50 \times 150 \mathrm{~mm}$ wood framing behaved in the case of air leakage. Their work showed that SIPs made rooms can potentially be 10 times less leaky.

However, there are some potential weaknesses that need to be considered. Meis (2015) noted SIPs can cost 5-15\% more than conventional building systems. Also, there are environmental, health, and flame resistance concerns about the use of SIPS, as the panels are usually made using a polystyrene core (Meis, 2015).

\subsubsection{Heavyweight/high Mass Construction}

Heavy construction mainly uses concrete which tends to have better sound insulation compared with light weight construction. A building made from concrete blocks or precast concrete panels will have high thermal mass but concrete is a poor insulator, though good fire and vermin resistance. Heavy construction includes concrete tilt slabs and concrete sandwich panels. Insulated concrete formwork (ICF) and even rammed earth walls are also 
examples of heavy construction (Smarter Homes, 2018), but both can have thermal performance issues.

\section{- Concrete tilt slabs}

Concrete tilt slabs (Figure 5.2) are panels of concrete cast horizontally, on-site or off-site, that could include some insulation. They can be finished with an externally insulated plaster or internal insulated lining, in the latter case decoupling the thermal mass from the inside (Smarter Homes, 2018; Chisholm, 2004).

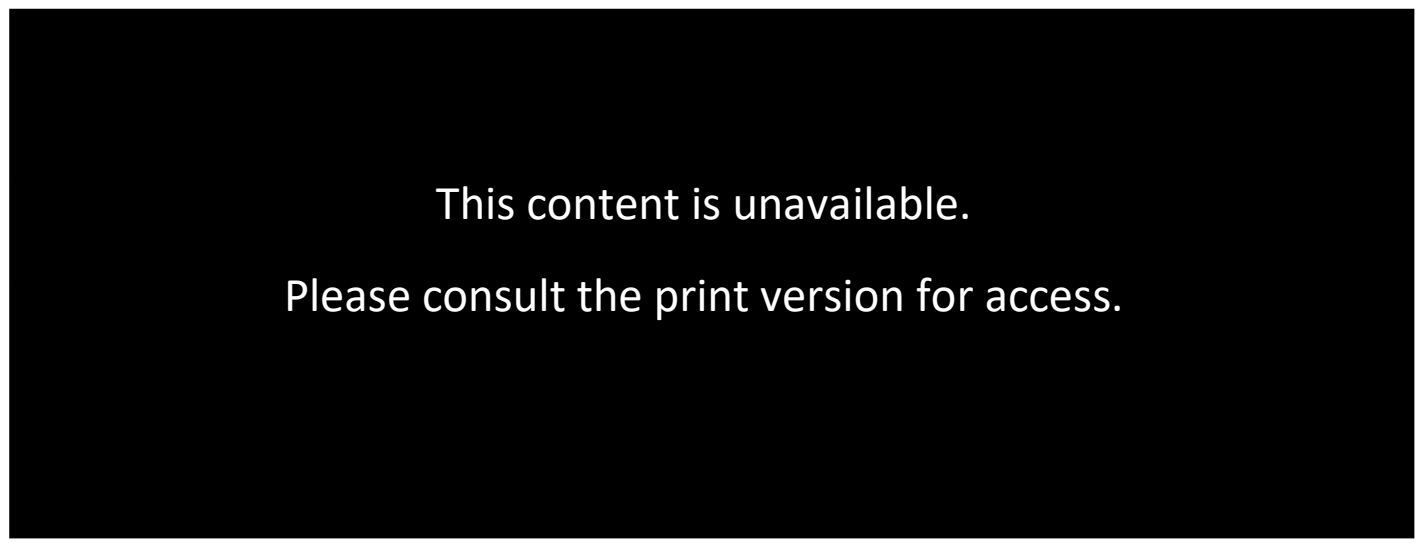

Figure 5.2: Concrete tilt slabs (HDW builders, 2016)

\section{- Concrete sandwich panels}

Concrete sandwich panels (Figure 5.3) consist of an insulation layer, sandwiched between two layers of concrete, and most of the time the external layer is load bearing (Pečur et al., 2014). This is similar to SIPs panels but using concrete instead of timber or steel to encase the insulated core. This means the room-side thermal mass is useful.

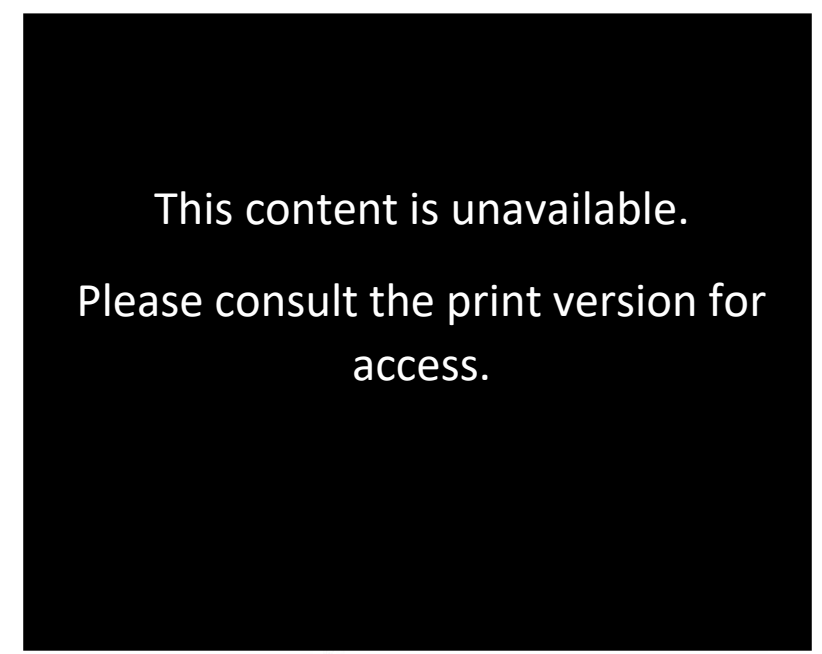

Figure 5.3: Concrete sandwich panels (Tilt Wall, 2017) 


\section{- Insulated concrete formwork (ICF)}

Insulated Concrete Formwork (ICF) walls (Figure 5.4) are made of hollow expandedpolystyrene blocks, which stay in place as a layer of insulation, working as a casing for the reinforcing and concrete which is poured into the voids (Smarter Homes, 2018). If the internal insulation remains in place, it again decouples the thermal mass of the concrete so that it plays no part in the energy regulation of the house.

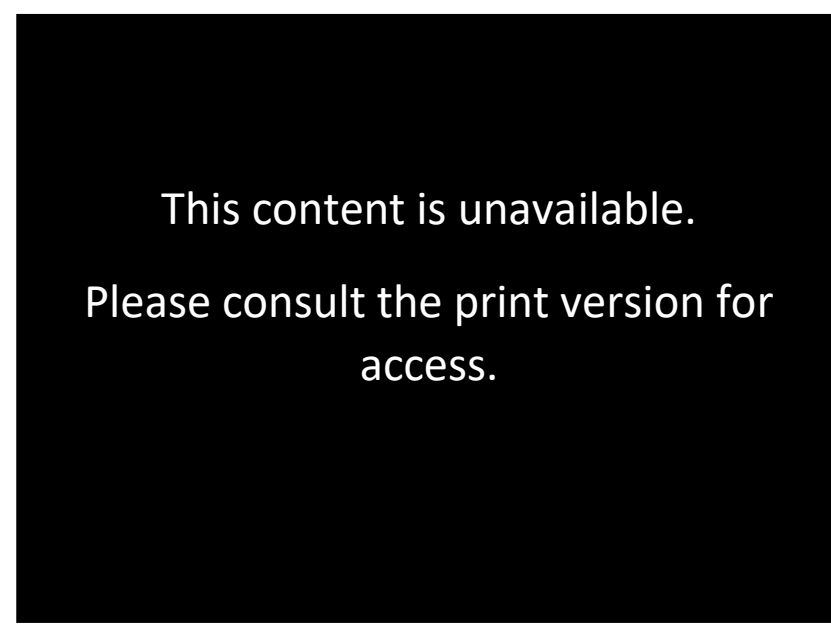

Figure 5.4: Insulated concrete formwork (ICF) walls (Rowley, 2014)

The floor and roof options for all these systems depend on the designer and other conditions such as the site characteristics. Most of these common construction systems can be prefabricated. For example, framed walls with their insulation could be shop assembled and transported to the site. SIPs and concrete sandwich panels are prefabricated and the former would be hard to build on site. Concrete blocks and concrete tilt slabs could be built on-site or offsite based on the site conditions and requirements.

Considering transport and craning limitations, as well as the manufacture of an ADU, a lightweight system could be preferable, such as using SIPs panels. These panels are structural and the internal OSB layer could be used as the internal lining. Moreover, the panels are highly insulated and airtight compared with a conventional timber frame system. Section 5.3.1.3 records that SIPs panels can come to site as raw panels, but in this research the raw panels would be transported to the prefabrication factory to be completed by adding doors and windows, membranes and cladding, and finishes.

It was decided to use SIPs panels for the walls and ceiling, noting the latter would need a waterproof roof, but the issue of the floor was not obvious as it could be made of SIPs panel 
or concrete. Using SIPs panels would lead to a lighter house (see Section 5.7.5.1) probably with better insulation, while using insulated concrete with its thermal mass could increase the thermal efficiency and comfort. So, both a slab and SIPs floor were simulated to see which best suited the goal of being close to zero heating energy use (see Section 5.6).

\subsubsection{SIPs Panels}

There were four different companies offering SIPs panels in New Zealand. Investigating the different SIPs producers was important as they used different materials for their insulation core and this results in different R-values. SIPs panels are also produced in different thicknesses for the different building elements of floor, walls and roof. These elements each have their own impact on the energy performance of the ADU. Figure 5.5 shows in a conventional house the roof, windows, walls and floors are responsible for approximately $30 \%-35 \%, 21 \%-31 \%, 18 \%-25 \%$ and $12 \%-14 \%$ of the heat loss of a house respectively (White and Jones, 2017).

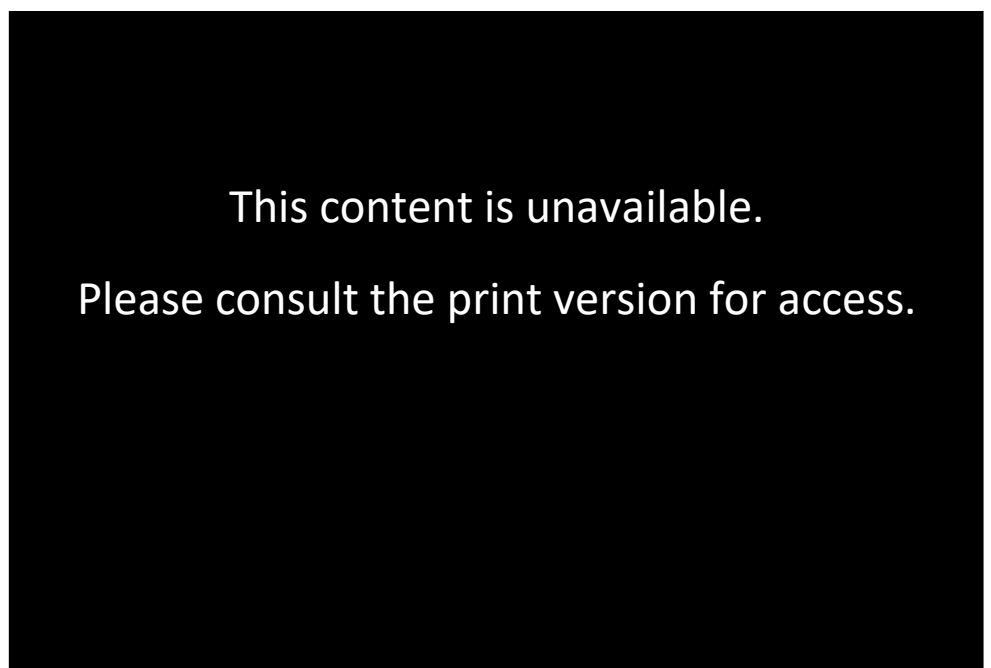

Figure 5.5: Heat loss by component (White and Jones, 2017)

There are also minimum R-value requirements for the different elements, which vary based on climate zone (Table 5.2 and Figure 5.6).

Table 5.2: R-values in different climate zones (Standard New Zealand, 2009)

\begin{tabular}{|l|l|l|}
\hline Element & Climate Zones 1 and 2 & Climate Zones 3 \\
\hline Roof & 2.9 & 3.3 \\
\hline Wall & 1.9 & 2.0 \\
\hline Floor & 1.3 & 1.3 \\
\hline Heated floors & 1.9 & 1.9 \\
\hline Windows (glazing) & 0.26 & 0.26 \\
\hline Skylights & 0.26 & 0.31 \\
\hline
\end{tabular}




\section{This content is unavailable.}

\section{Please consult the print}

version for access.

Figure 5.6: Map of climate zones (Ministry of Business Innovation and Employment, 2017c)

The four producers of SIPs panels (Formance, Premier Building Systems (PBS), Kingspan and NZSIPs) were investigated. Despite some differences, these companies can be classified into the two groups based on the insulation core: expanded polystyrene (EPS) and polyurethane (PUR). Only NZSIPS uses PUR and the rest use EPS due to its availability, being easier to work with, better stability and lower cost compared with PUR (Formance, 2019). However, the thermal efficiency of PUR panels can be better than EPS ones, so in Table 5.3 data for NZSIP panels are compared with that of panels made by Formance.

Table 5.3: R-value comparison of PUR and EPS made SIPs panels (NZSIPs, 2017; Formance, 2019)

\begin{tabular}{|l|l|l|}
\hline Thickness of panel & Type of insulation core & R-value $\left(\mathbf{m}^{\mathbf{2}} \mathbf{C} / \mathbf{W}\right)$ \\
\hline \multirow{3}{*}{115} & EPS & 2.8 \\
\cline { 2 - 3 } & PUR & 4.5 \\
\hline \multirow{2}{*}{2155} & EPS & 4.3 \\
\cline { 2 - 3 } & PUR & 5.2 \\
\hline \multirow{2}{*}{265} & EPS & 5.7 \\
\cline { 2 - 3 } & PUR & 6.9 \\
\hline \multirow{3}{*}{315} & EPS & 7.2 \\
\cline { 2 - 3 } & PUR & NA \\
\hline & EPS & 8.6 \\
\cline { 2 - 3 } & PUR & NA \\
\hline
\end{tabular}

Table 5.3 shows the R-value of NZSIPs panels made with a PUR core is higher than those made by EPS core. Given the goal of being zero energy for heating, and also because they are locally produced, the SIPs panels made by NZSIPs using PUR were selected for this research. NZSIPS panels are normally made of $12 \mathrm{~mm}$ OSB on each side of the PUR core. The panels come in three different final thicknesses of $155 \mathrm{~mm}, 165 \mathrm{~mm}$ and $215 \mathrm{~mm}$. Wall panels are available in two thickness of $115 \mathrm{~mm}$ or $165 \mathrm{~mm}$ weighing $20.0 \mathrm{~kg} / \mathrm{m}^{2}$ and $22.0 \mathrm{~kg} / \mathrm{m}^{2}$ respectively. Roof 
panels have more variety being $115 \mathrm{~mm}, 165 \mathrm{~mm}$ and $215 \mathrm{~mm}$ thick and weighing $20.0 \mathrm{~kg} / \mathrm{m}^{2}$, $24.7 \mathrm{~kg} / \mathrm{m}^{2}$ and $27.9 \mathrm{~kg} / \mathrm{m}^{2}$ respectively. Finally, floor panels only come in a thickness of $165 \mathrm{~mm}$ weighing between $22.0 \mathrm{~kg} / \mathrm{m}^{2}$ and $24.7 \mathrm{~kg} / \mathrm{m}^{2}$. The standard panel width is $1,205 \mathrm{~mm}$, while the length can be $2,400 \mathrm{~mm}, 2,700 \mathrm{~mm}$ or $3,000 \mathrm{~mm}$. However, panels can be ordered in customised sizes (NZSIPs, 2017). These different panel thicknesses will become the variable items in the energy simulation section (see Section 5.6).

\subsection{Design Approach}

The ADU design process was predicated on creating a series of prefabricated room modules that could be joined in different ways to create different ADU sizes and plan layouts. In the beginning, three important areas that needed attention were identified based on prefabricated house design criteria and the idea of creating a zero energy ADU. These were the function(s) of each module, the size of modules, and the size and placement of windows. Other factors to be considered from reviewing tiny houses plan (see Section 4.6.1) and analysis of the 2011 Solar Decathlon projects (see Section 4.6.2) were;

- Accessibility for older people;

- Floor area between $50 \mathrm{~m}^{2}-70 \mathrm{~m}^{2}$;

- Having an L-shaped kitchen;

- Separate laundry;

- Two bedrooms;

- Separating private and public areas;

- The importance of considering a services zone;

- Combining the WC and shower in the same space;

- Sufficient storage (at least one wardrobe in each bedroom).

\subsubsection{The Function of Each Module}

The functions allocated to each module also affect other module specifications such as size. Based on the literature and similar projects, the design was started based on the idea of allocating one module to each function. In this approach, each module or function is independent and can be matched to others in different ways, resulting in different layouts. To avoid unnecessary on-site work, especially plumbing, it was decided to have a kitchen, bathroom and all other functions needing plumbing, such as the laundry, in one services module. This would decrease the on-site work and potential defects, and make waterproofing 
easier but would also result in having fewer design options and potentially make the modules bigger. To see if this approach was feasible, an ADU was designed using the following modules;

- A services module (kitchen, bathroom and laundry);

- Bedroom module/s; and a

- A living module that could be furnished as a lounge, and include a small dining table and entrance area.

The design was modified as it progressed. For example combining the entrance and living area reduced the available space for living and dining so it was decided to remove the entrance space from the living module and design it as a smaller, independent module. A separated entrance area would then be a transition space between the outside and the space conditioned area which would improve the energy efficiency.

\subsubsection{Size of Modules}

Given the New Zealand transport limitations, probably the most important factor to be determined is the size of modules. The width of modules became $2.55 \mathrm{~m}$, the maximum allowed without oversized load permissions. The length of a load can be up to $20 \mathrm{~m}$ but based on the site analysis not using the maximum allowed length seemed desirable so the ADU could be fitted on as many sites as possible. Moreover, to benefit from the advantages of a modular system it was decided to start by designing all modules the same size, regardless of function. The length of modules is affected by;

- The minimum required space for each module based on its function and what it needs to contain;

- Having a balance between the length and width of modules to make the dimensions work for all functions; and

- Meeting the target area of $50-70 \mathrm{~m}^{2}$ when combining modules;

- Accessibility of modules for older people.

Considering all these factors and listing with their sizes the appliances and furniture that needed to be accommodated led to $5.1 \mathrm{~m}$ as the primary length of modules. Having the modules with length twice the width, means modules can be placed together either side by side or head to the side to provide more flexibility in layouts (Figure 5.7). Moreover, due to 
the efficiency of rectangular forms and also the need for assembling the ADU on different unknown sites, having rectangular modules should allow them to be put together in different ways. However, small modules will also be tried in case this increases the variety possible.
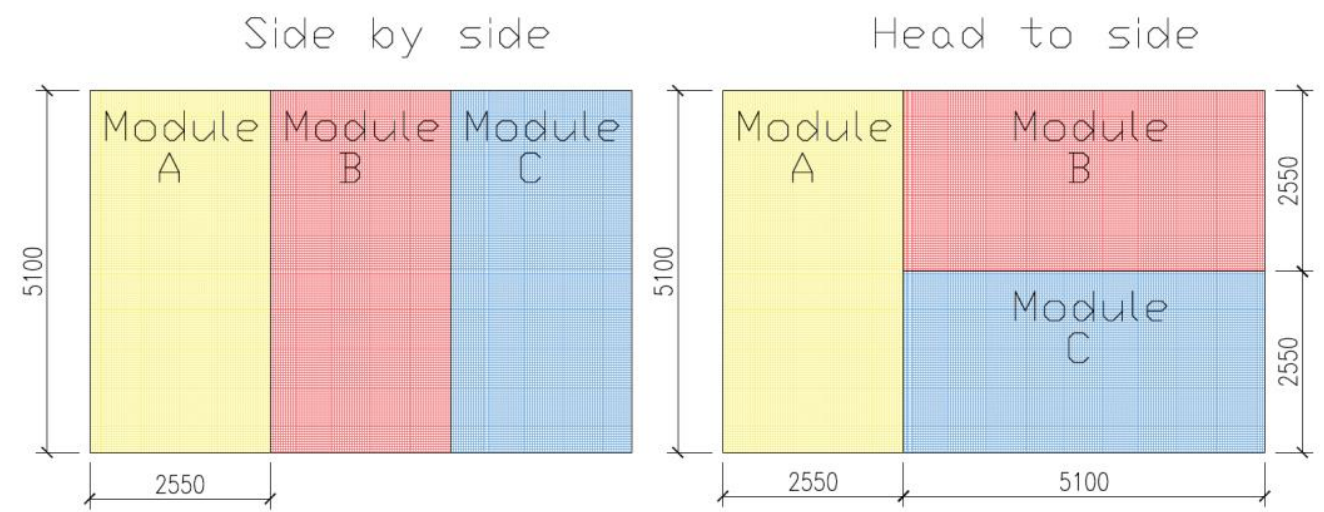

Figure 5.7: Flexibility of module placement

\subsubsection{Windows}

The size and placement of windows affect the energy efficiency of the ADU. Factors to be considered and the outcomes include;

- The fact that the ADU needs to be placed in different orientations based on the unique characteristics of each site. This led to having at least one window in all possible sides of the assembled ADU;

- The Window to Wall Ratio (WWR). The initial idea was to keep the WWR to $20 \%$. Obviously where passive solar design is the goal, the WWR could be bigger (Smith, 2005).

\subsubsection{Primary Design}

The next stage in the design process was based on designing each module such that all designs were both accessible for older people and transportable. The result of this approach was the design of six different types of bedroom module, one services module that includes the kitchen, bathroom, and laundry, and one living module, all of the same size of $5.1 \mathrm{mx} 2.55 \mathrm{~m}$. There is also an entrance module $2.1 \mathrm{~m} \times 2.1 \mathrm{~m}$. These modules can potentially be combined together in different ways to give a rectangular, square or $L$ shape ADU. In this thesis, the main focus was on the rectangular form, which resulted in three main types of $A D U$ ( $A, B$ and C, Figures 5-8 to 5-10) and four supplementary types (D, E, F and G, Figure 5-11). The overwhelming idea in the design of the ADU was to offer different plans with different 
characteristics, from which the purchaser/users could choose based on their priorities. These priorities could be:

- Accommodating as many people as possible regardless of disabilities (Lifemark requirements may not apply to all spaces);

- Accommodating as many people with accessibility issues as possible (3 Lifemark stars);

- Having more living space rather than more bedrooms;

- A balance of all of the above.

Table 5.4 shows the characteristics of the recommended plans, each of which is illustrated in plan in the following sections. Comparing the primary area of types of ADU with recommended council MGPA (see Section 4.2.1.2), type A can be consented in over $82 \%$ of councils, while close to one-third of councils would consent types B and C.

Table 5.4: Characteristics of recommended plans

\begin{tabular}{|c|c|c|c|c|c|c|c|c|c|}
\hline \multicolumn{2}{|c|}{ Plan* } & \multirow[t]{2}{*}{ Area $\left(m^{2}\right)$} & \multirow[t]{2}{*}{ NB } & \multirow[t]{2}{*}{ NP } & \multirow[t]{2}{*}{ NDP } & \multirow[t]{2}{*}{ NM } & \multirow{2}{*}{$\begin{array}{l}\text { Dimensions } \\
((\mathbf{x} \text { w }(\mathrm{m}))\end{array}$} & \multirow{2}{*}{$\begin{array}{l}\text { WWR } \\
(\%)\end{array}$} & \multirow[t]{2}{*}{ NW } \\
\hline $\begin{array}{l}\text { Typ } \\
\mathrm{e}\end{array}$ & Version & & & & & & & & \\
\hline \multirow{6}{*}{ A } & 1 & 55 & 2 & 3 & 3 & 5 & $10.1 \times 5.1$ & 16.9 & 4 \\
\hline & 2 & 55 & 2 & 3 & 3 & 5 & $10.1 \times 5.1$ & 16.9 & 4 \\
\hline & 3 & 55 & 2 & 4 & 2 & 5 & $10.1 \times 5.1$ & 15.8 & 4 \\
\hline & 4 & 55 & 2 & 4 & 2 & 5 & $10.1 \times 5.1$ & 15.8 & 4 \\
\hline & 5 & 55 & 1 & 1 & 1 & 5 & $10.1 \times 5.1$ & 15.8 & 5 \\
\hline & 6 & 55 & 1 & 2 & 0 & 5 & $10.1 \times 5.1$ & 15.8 & 5 \\
\hline \multirow{4}{*}{ B } & 1 & 68 & 2 & 3 & 3 & 6 & $12.55 \times 5.1$ & 15.9 & 5 \\
\hline & 2 & 68 & 2 & 3 & 3 & 6 & $12.55 \times 5.1$ & 15.9 & 4 \\
\hline & 3 & 68 & 2 & 4 & 2 & 6 & $12.55 \times 5.1$ & 13.5 & 4 \\
\hline & 4 & 68 & 2 & 4 & 2 & 6 & $12.55 \times 5.1$ & 13.5 & 5 \\
\hline \multirow{5}{*}{ C } & 1 & 68 & 3 & 5 & 3 & 6 & $12.55 \times 5.1$ & 14.5 & 6 \\
\hline & 2 & 68 & 3 & 5 & 3 & 6 & $12.55 \times 5.1$ & 14.5 & 5 \\
\hline & 3 & 68 & 3 & 6 & 2 & 6 & $12.55 \times 5.1$ & 12.8 & 5 \\
\hline & 4 & 68 & 3 & 6 & 2 & 6 & $12.55 \times 5.1$ & 12.8 & 6 \\
\hline & 5 & 68 & 3 & 4 & 4 & 6 & $12.55 \times 5.1$ & 14.5 & 4 \\
\hline \multirow[t]{2}{*}{ D } & 1 & 43 & 1 & 2 & 0 & 4 & $7.65 \times 5.1$ & 13.0 & 2 \\
\hline & 2 & 43 & 1 & 1 & 1 & 4 & $7.65 \times 5.1$ & 13.0 & 2 \\
\hline \multirow[t]{2}{*}{$E$} & 1 & 80 & 3 & 5 & 3 & 7 & $15 \times 5.1$ & 14.2 & 5 \\
\hline & 2 & 80 & 3 & 4 & 4 & 7 & $15 \times 5.1$ & 14.2 & 5 \\
\hline \multicolumn{2}{|l|}{$\mathrm{F}$} & 81 & 3 & 5 & 3 & 7 & - & 13.9 & 5 \\
\hline \multicolumn{2}{|l|}{ G } & 57 & 2 & 3 & 3 & 5 & $10.1 \times 5.1$ & 12.1 & 3 \\
\hline
\end{tabular}

*NB $=$ Number of bedrooms, NP = Number of people, NDP = Number of disabled people, $\mathrm{NM}=$ Number of modules, $\mathrm{WWR}=$ Window to wall ratio, $\mathrm{NW}=$ Number of wardrobes.

Area values are rounded 


\subsubsection{Laundry}

Following the discussion in chapter 4 (see Section 4.7) the primary idea was to have a separated laundry space at the ADU. However, due to the two following reasons it was decided to abandon this idea. The first reason was the lack of enough space. The ADU is a secondary unit, the size of which is affected both by the existing house and the council rules. Any additional space made available in the ADU required other spaces to be smaller, and this was not possible as the ADU was designed based on the minimum requirements of Lifemark and the maximum size allowed on the roads. The other reason was the idea of minimising the length of pipes and putting all functions needing water as close together as possible, leading to the laundry being inside the bathrooms in all plans.

\subsubsection{Plans of Type A}

Type $A$ is the smallest ADU with a floor area of $55 \mathrm{~m}^{2}$, with either one bedroom (A 5\&6) or two bedrooms (A 1-4) (Figure 5.8). Type A can accommodate one to four persons, with a maximum of three disabled persons (A1\&2). This type of ADU consists of five modules with a WWR of between $15.8-16.9 \%$. In $A 5$ and $A 6$ the priority was more living space rather than more bedrooms. 

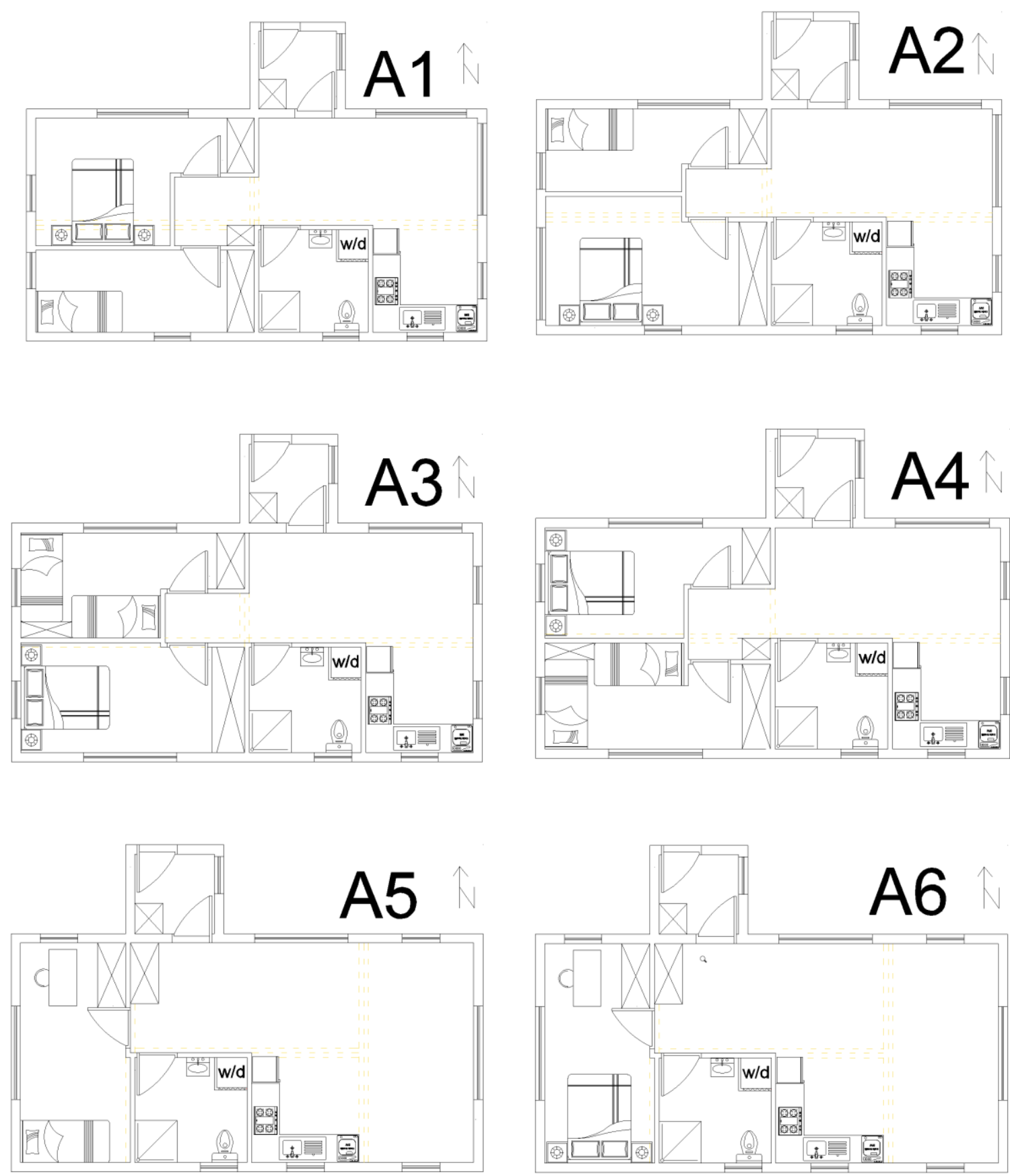

Figure 5.8: Plans of Type A (1-6) 


\subsubsection{Plans of Type B}

Type $B$, with a floor area of $68 \mathrm{~m}^{2}$ was designed based on having a balance between the number of bedrooms and living space area (Figure 5.9). Different layouts of this type have two bedrooms, in different sizes and forms, and a living area of more than $20 \mathrm{~m}^{2}$.
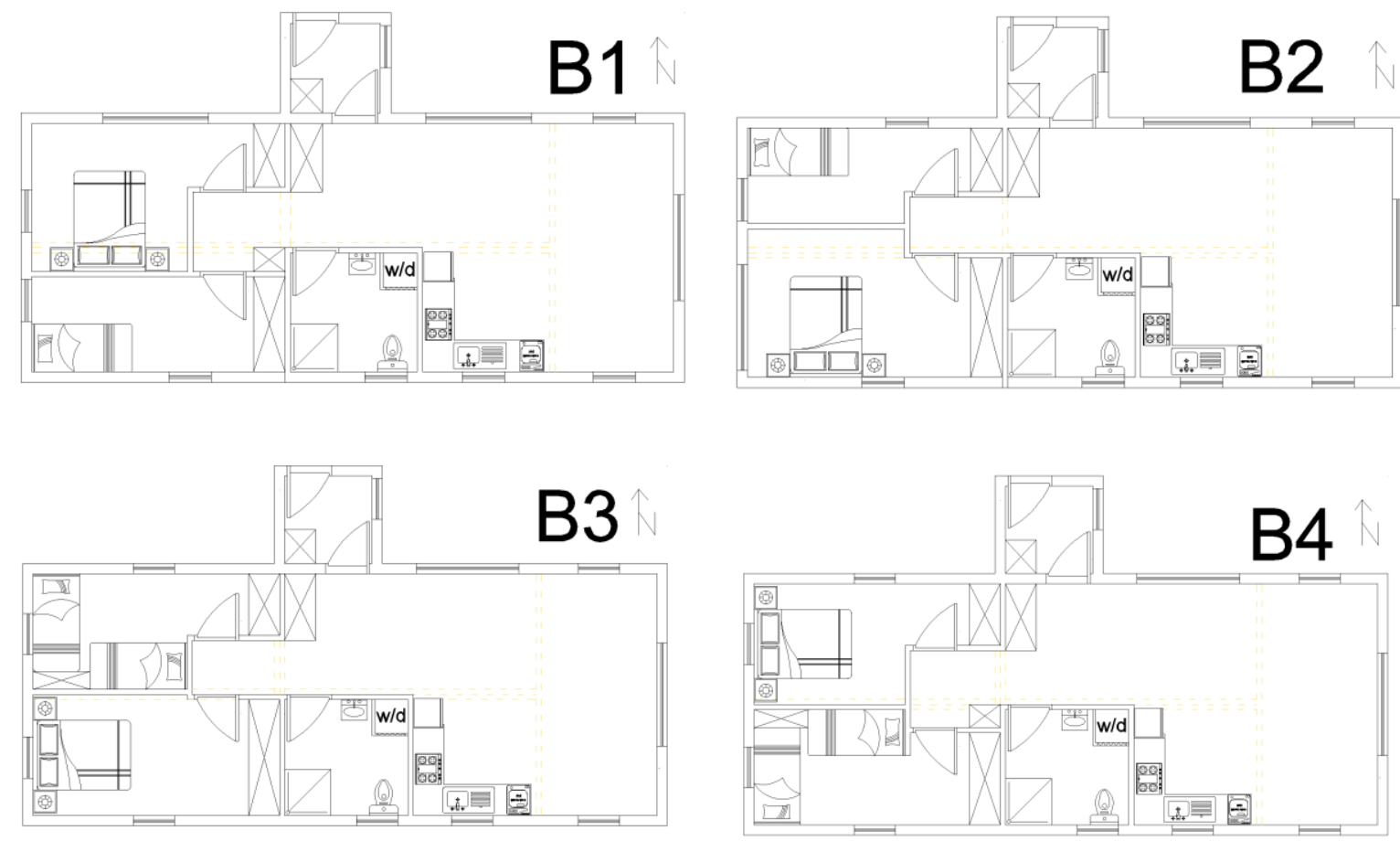

Figure 5.9: Plans of type B (1-4)

\subsubsection{Plans of Type C}

In type $C$, which is similar to type B in terms of area and general design, having more bedrooms was prioritised over more living area (Figure 5.10). Plans in this type have 3 bedrooms, meaning the living area is halved in comparison with type B plans. This might be more suitable for young people flatting. 

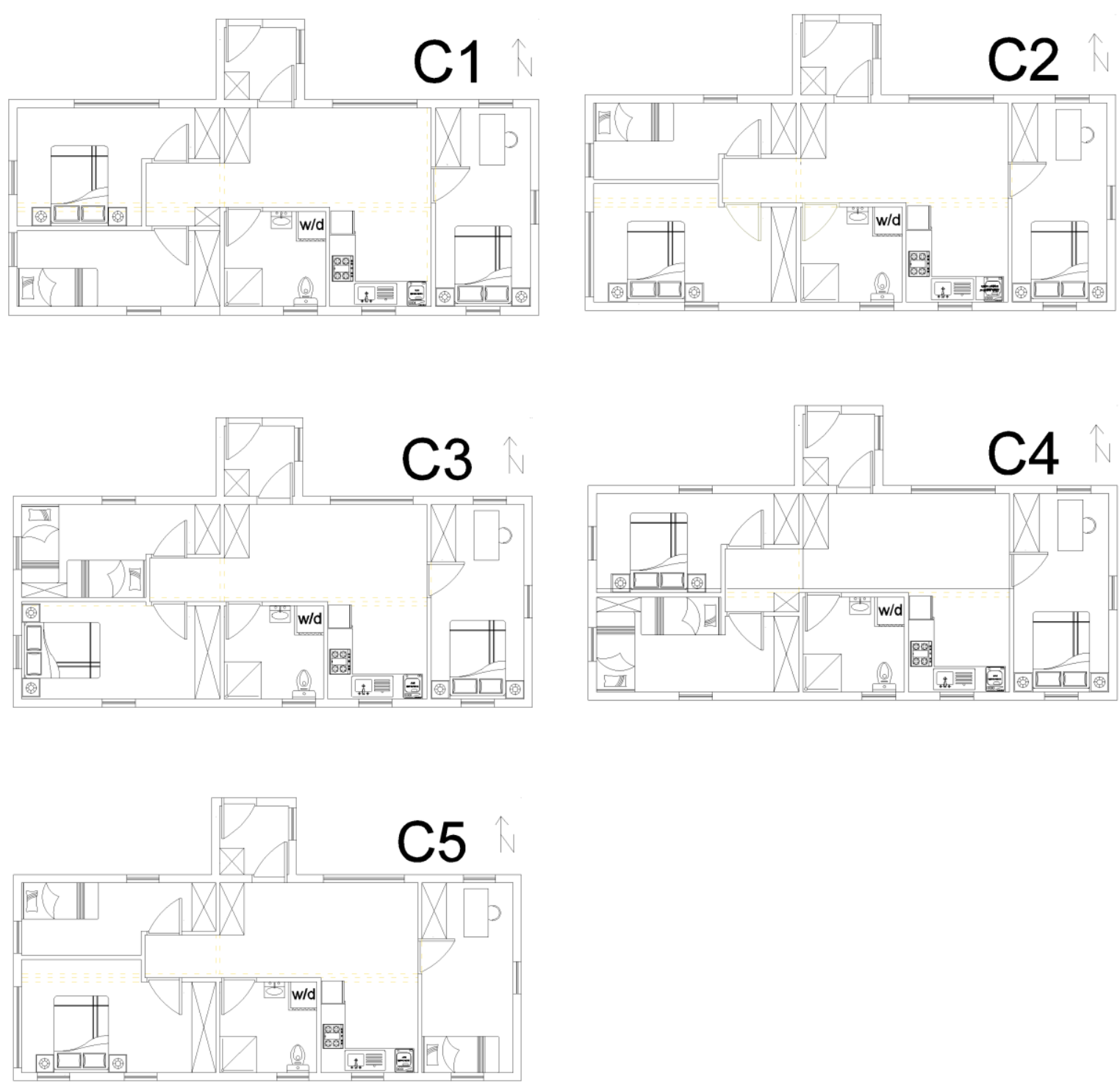

Figure 5.10: Plans of type C (1-5)

\subsubsection{Plans of Types D, E, F and G}

The total floor areas of types A, B and C are in the target range of 50-70 $\mathrm{m}^{2}$. After designing these types, it was decided to test whether it is possible to design both smaller and bigger ADUs using the same modules, as the $50 \mathrm{~m}^{2}-70 \mathrm{~m}^{2}$ range is not the minimum or the maximum allowed GPA. This led to type D with an area of $43 \mathrm{~m}^{2}$, which includes the services module, one bedroom, one living room module and an entrance module.

Type E was designed to show the expandability of the ADU. This has three bedrooms and an area of $80 \mathrm{~m}^{2}$. Type $\mathrm{F}$ showed the modules can be assembled in an L-shape. Finally, type $\mathrm{G}$ is 
an example of how the modules can be rotated based on site considerations or owner preferences. Plans of other types can be found in Figure 5.11.
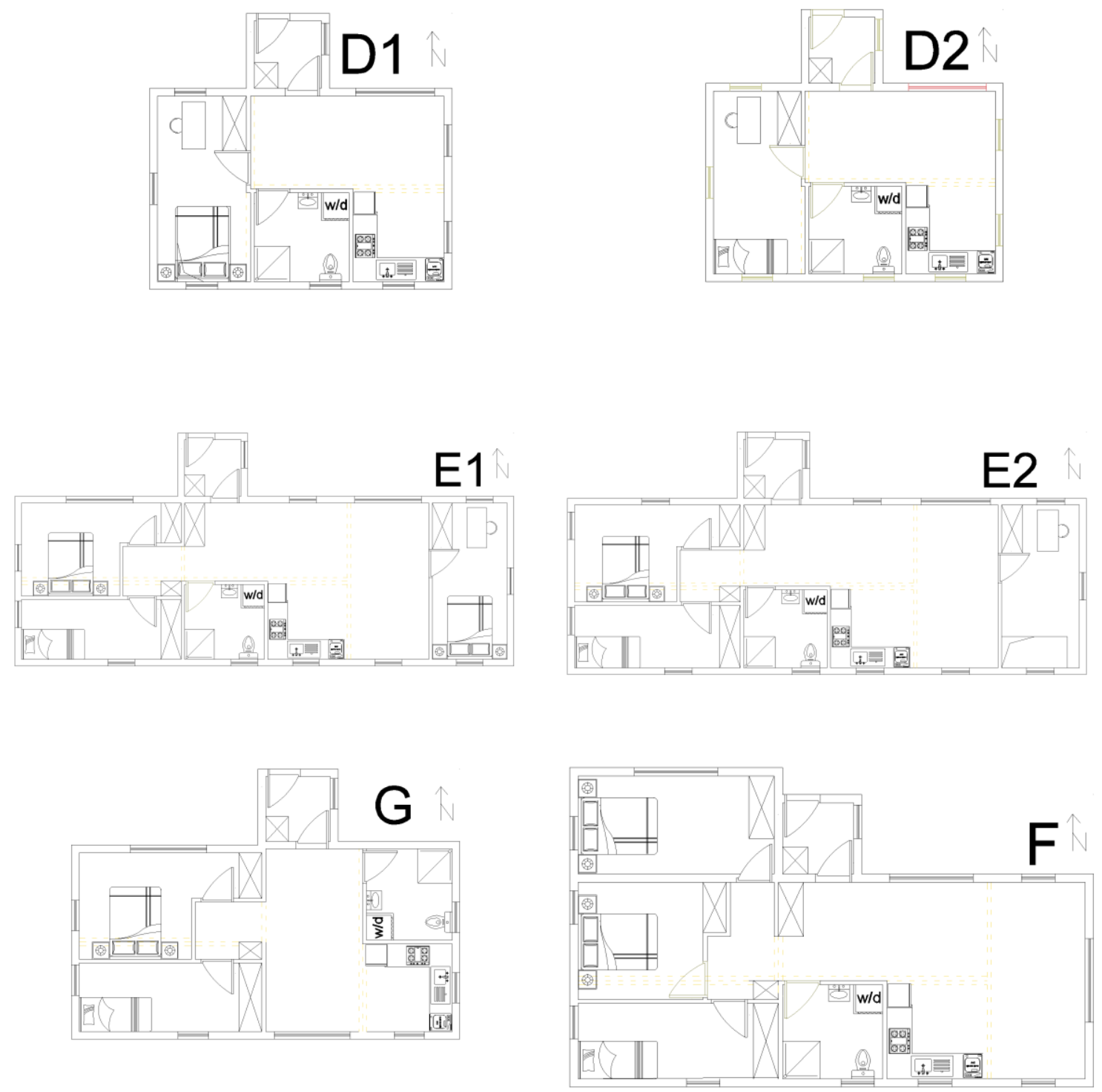

Figure 5.11: Plans of type D, E, F and G

Due to small differences in layouts plan B1 (Figure 5.12), which perhaps represents the best mid-range ADU that can be made from the modules, has been used for illustration (see Section 5.5.2.2). 


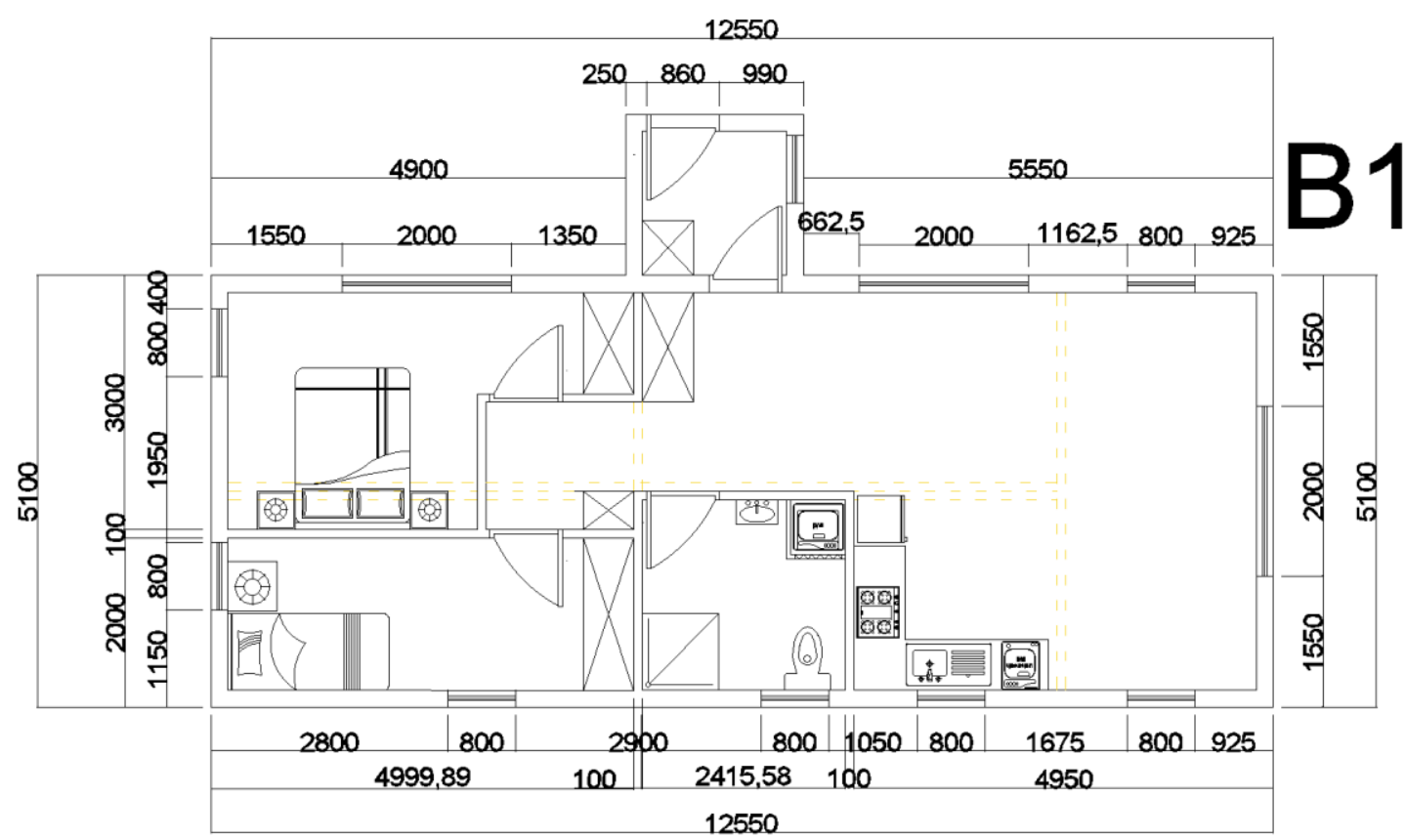

Figure 5.12: Plan B1

\subsubsection{The Roof}

The other point to be considered is the roof of the ADU. During the design it was decided to have a SIPs ceiling to be attached to the walls in the factory, but this means there is a need for a roof to keep out the rain. The roof of the ADU also had to be designed considering transportation and assembly limitations. The most common internal room height in New Zealand is $2.4 \mathrm{~m}$. The floor and ceiling thickness can vary based on the thickness of selected SIPs panels or the slab. Adding these together, the module heights could reach approximately $2.8 \mathrm{~m}$. The maximum allowed road load height is $4.3 \mathrm{~m}$, including the trailer height which is approximately $1.5 \mathrm{~m}$, leaving $2.8 \mathrm{~m}$ for the load itself. So it seems it is not possible for the modules to have the roof in place when they leave the factory, as the height will exceed the limits. The only option would be to assemble the roof separately in the factory and transport it to the site for fixing to the assembled modules.

To decide on the type of roof, the benefits and limitations of three different roof types (hip, gable and mono pitch) were investigated. The gable roof emerged as the best option for the $A D U$, due to the fact that a hip roof has more joints for completion on-site. The roof is also modular but separated from the room modules. Given the roof cannot be designed and transported in one module, the way it should be divided was the next factor to investigate. Different approaches such as designing a separate roof for each module or every two modules 
were tested. Based on this, it was decided to design the roof as two identical modules. Figure 5.13 shows these roof modules for the different recommended plan types. The insulation layer is within the SIPs panel ceiling, which allows the wall and ceiling insulation to be continuous to avoid thermal bridging.

Type E Type B\&C Type A\&G Type D

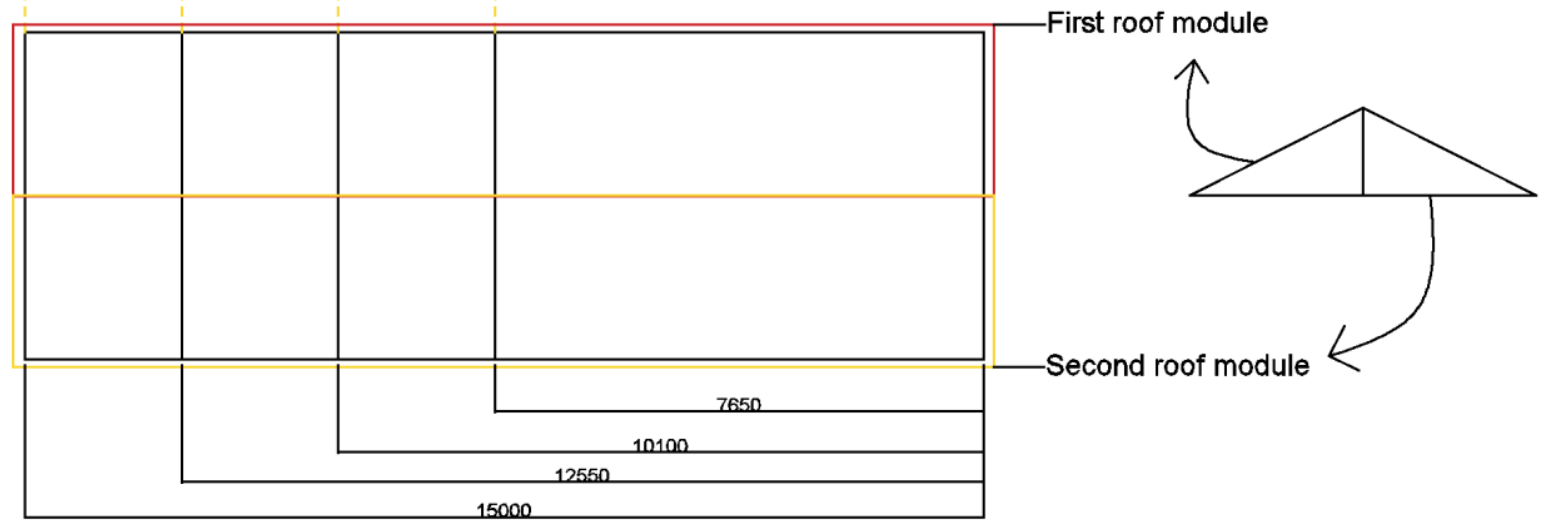

Figure 5.13: Different modules of the roof

\subsection{Primary Construction Approach}

Investigating the different options (see Section 5.3) SIPs panels, which comply with the NZBC (B1.3.1-4, B2.3.1, F2.3.1 and H1.3.1) were selected for making the ADU in the factory. Although the panels come in standard sizes, sometimes it is more efficient to use other sizes due to the unique characteristics of each project. However, the main idea in this research is minimising the amount of cutting in panels and hence waste. All of the developed ADU types are designed to be built using multiples of just five modules, which are the same size, and one entrance module, and which can be joined together in different ways to form the various layouts.

At this point, there was a need to decide the size of SIPs panels, and the size and placement of windows. Some dimensions were based on the rules and common requirements like the $2.4 \mathrm{~m}$ internal height of walls. Other dimensions needed to be decided after analysing their effect on the energy efficiency of the ADU (see Section 5.6). However, some primary decisions had to be made in order to create the initial thermal models. These characteristics were then modified based on the results. The following are the primary decisions that had been made before undertaking the thermal analysis (see Section 5.6). 


\subsubsection{The Thickness of SIPs Panels}

The thickness of SIPs panels is the main thermal variable in ALF 3.2 simulations, as all possible factory combinations are simulated (Table 5.7). But at this stage $200 \mathrm{~mm}$ was assumed as the wall thickness, made up of $165 \mathrm{~mm}$ for the SIPs panels and $35 \mathrm{~mm}$ for the cladding and its supporting elements, including the air gap.

\subsubsection{Width of SIPs Panels}

The idea here was building the modules with a minimum variety of panel sizes to use the advantages of modular mass production.

\subsubsection{The Overlap}

The entrance module is a square with sides of $2.1 \mathrm{~m}$, whereas the width of the main modules is $2.55 \mathrm{~m}$, and the length is $5.1 \mathrm{~m}$. However, at the early design stages, it was decided to consider two $100 \mathrm{~mm}$ overlaps along the length of the modules. The idea behind the overlaps was to make a locking joint to make the junction point stronger (Figure 5.14 and Figure 5.15). This led to a final length of $12.55 \mathrm{~m}$ (see Section 5.7.6).

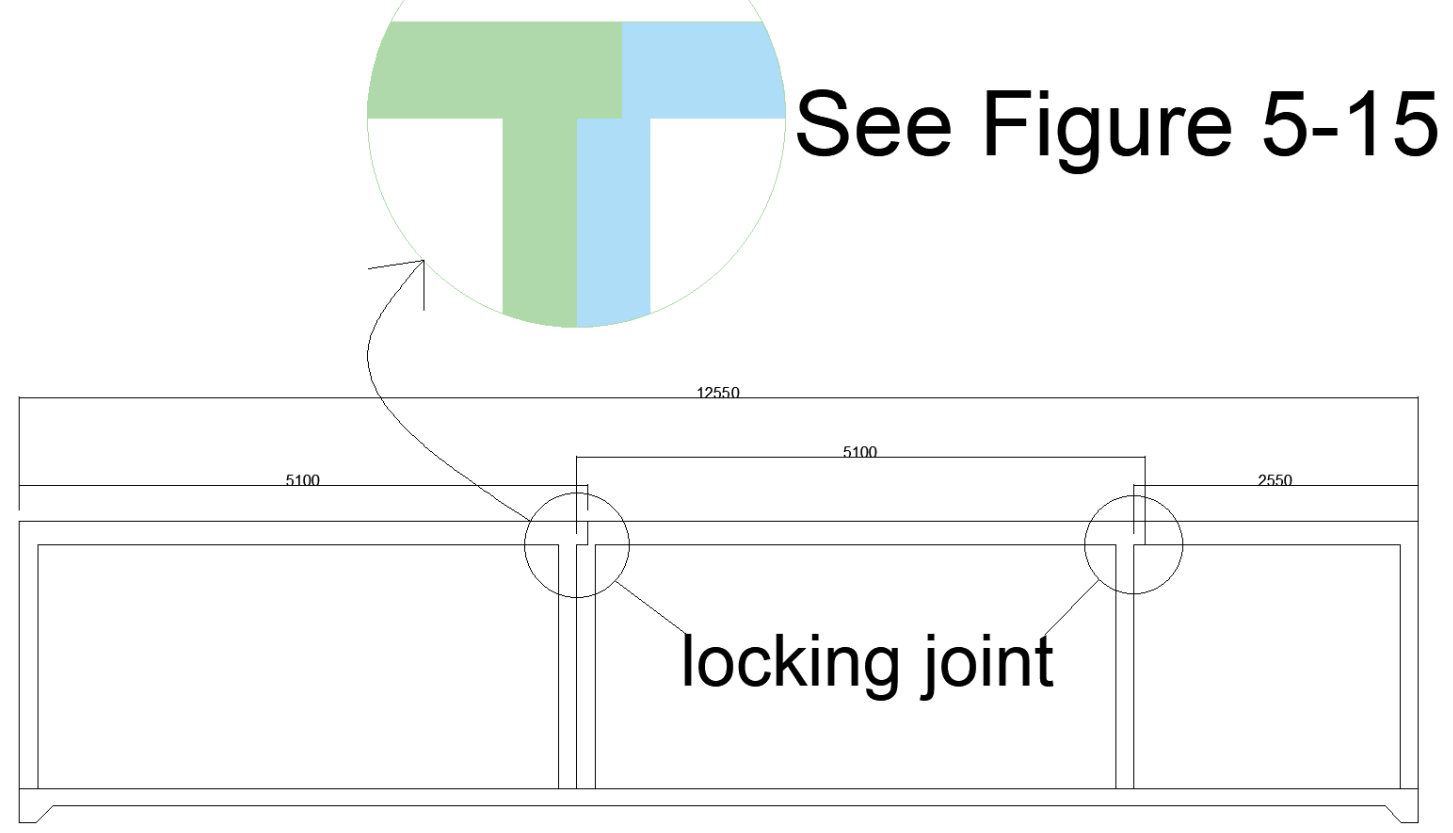

Figure 5.14: Section A-A: position of locking joint at overlaps 


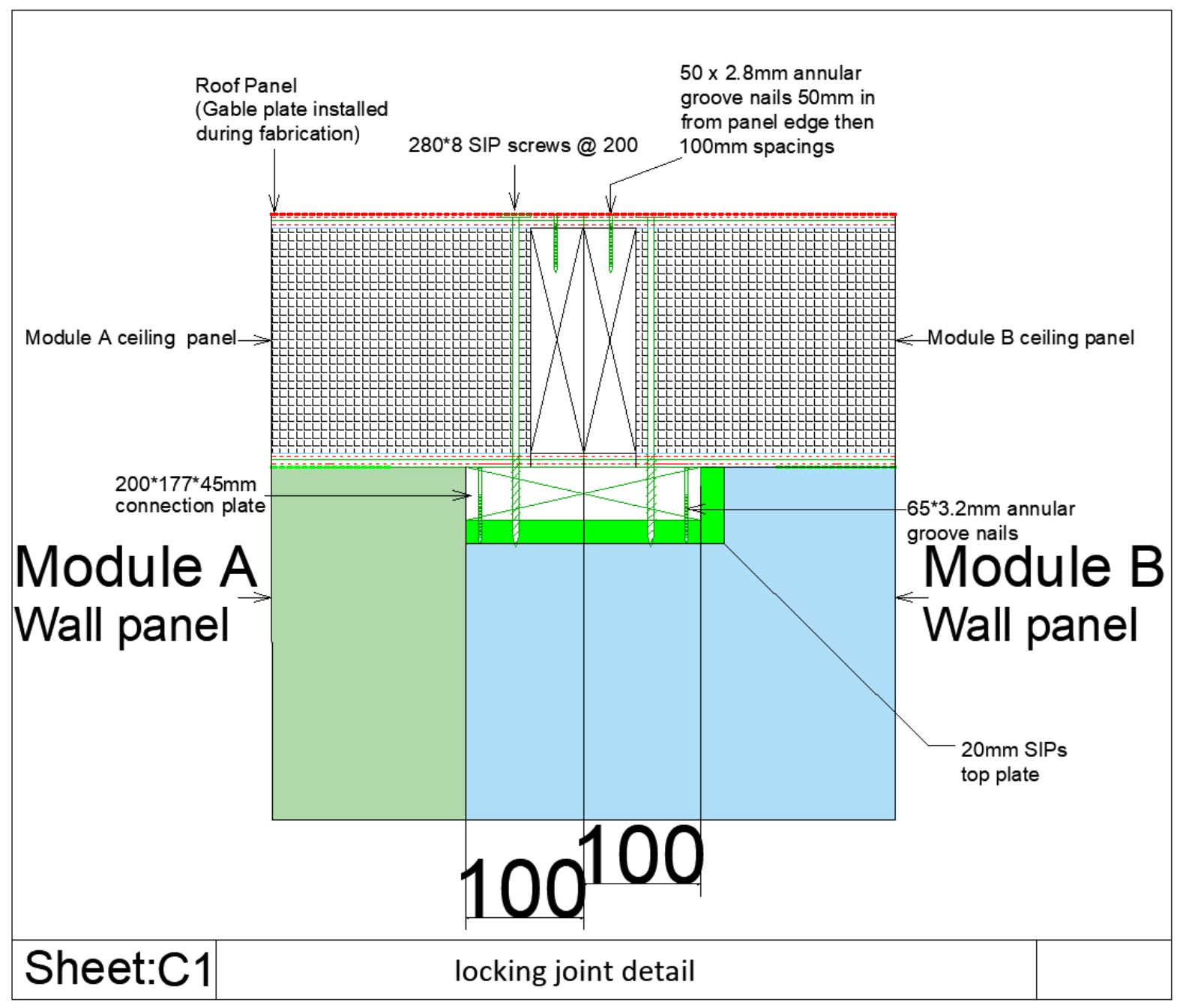

Figure 5.15: Locking joint detail

It was also important to be aware of the thickness of the walls and the way each module or wall connects to the others. So, using $200 \mathrm{~mm}$ for the wall thickness and based on the following wall arrangement and two overlaps, each of $100 \mathrm{~mm}$, there would be two SIPs panel wall lengths of $4.9 \mathrm{~m}$ and $2.35 \mathrm{~m}$ for the main modules and a $1.9 \mathrm{~m}$ wall panel for the entrance module (Figure 5.16). 

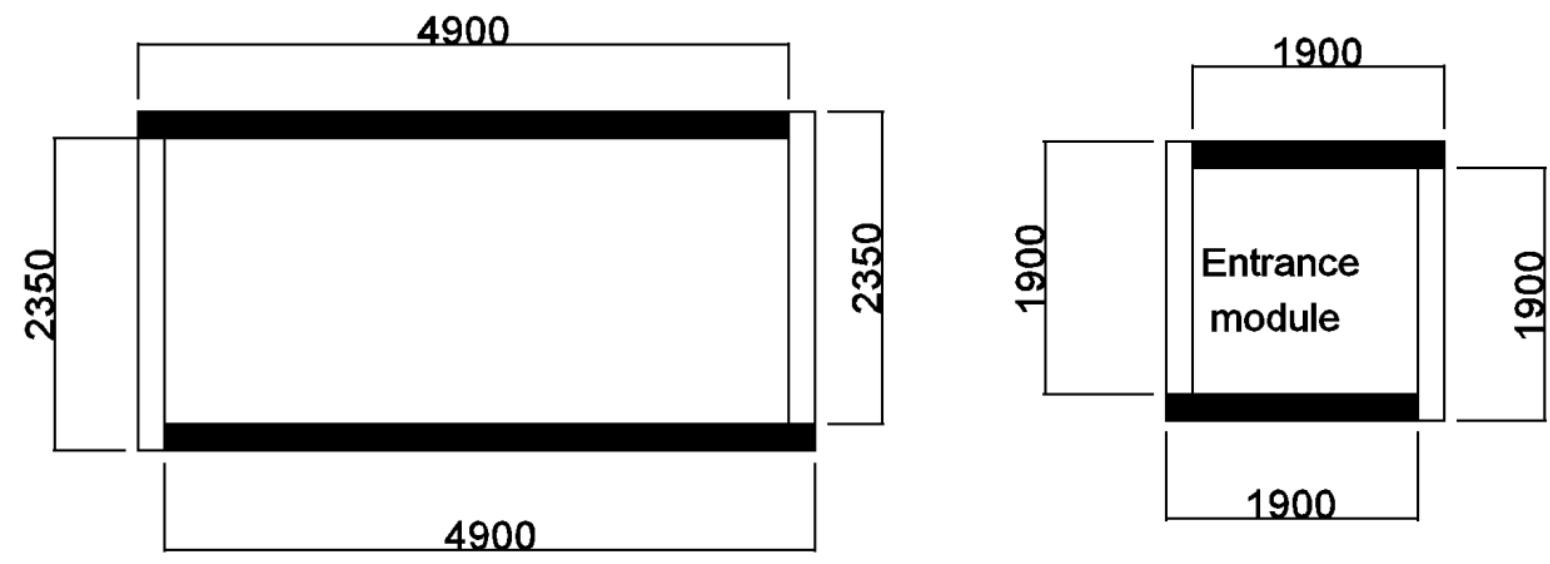

Figure 5.16: Wall lengths for the modules (Not to scale)

Testing the different options, led to three panel widths of $1200 \mathrm{~mm}, 1150 \mathrm{~mm}$, and $750 \mathrm{~mm}$. Figure 5.17 shows how all three modules can be constructed using these three types of panel (windows are not included (see Section 5.7.8)). The main module length would be adjusted to add the extra $100 \mathrm{~mm}$ using two panel splines (Figure 5.43). Moreover, each main module has its own SIPs ceiling module of $1,020 \mathrm{~mm} \times 2,550 \mathrm{~mm}$, and the entrance ceiling would be made of two SIPs panels each of $1,100 \mathrm{~mm} \times 1,100 \mathrm{~mm}$.
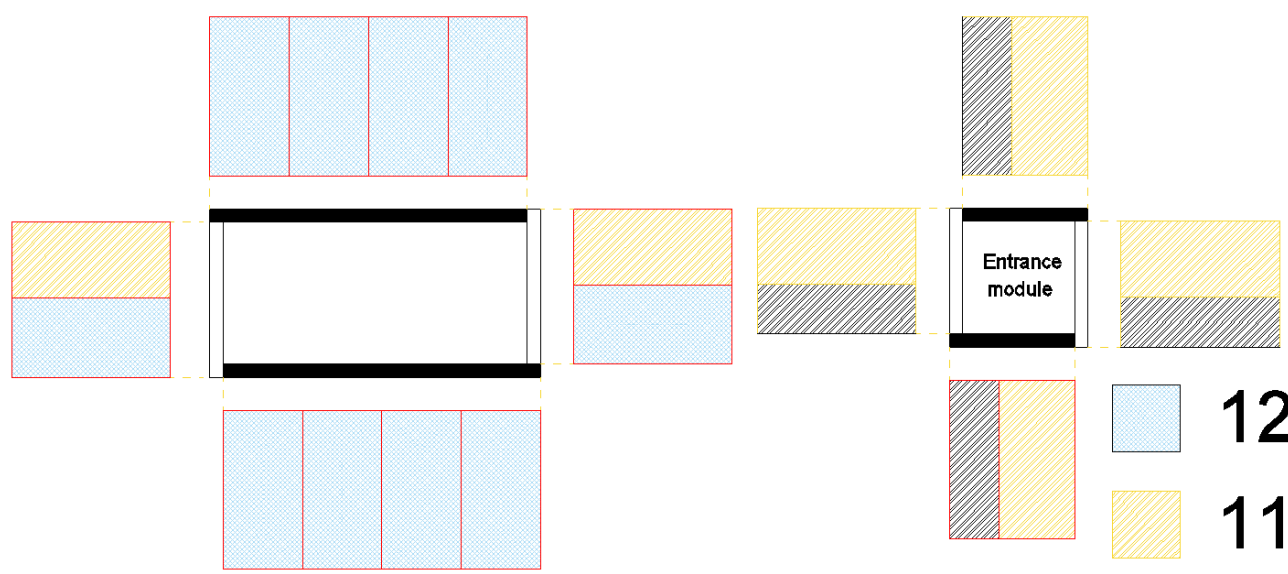

Figure 5.17: placement of panels in each module (Not to scale)

\section{$1200 \times 2400$ $1150 \times 2400$ $750 \times 2400$}

\subsubsection{Doors and Windows in the SIPs Panels}

The placement of doors and windows in the SIPs panels was the next step. There was no literature on the effects of the size and placement of openings in the behaviour of SIPs panels and their energy efficiency, so again this would be a focus of the energy simulation. Most SIPS 
related studies have focused on the materials which can be used for panels and their advantages and disadvantages in comparison with other construction systems (Little, 2002; Miller et al., 2010; Pardue, 2011). Figure 5.18 shows the door and window types which would be used in the ADU. There were two types of window Type $A(1,200 \mathrm{~mm} \times 800 \mathrm{~mm})$, and Type $B(1,200 \mathrm{~mm} \times 2,000 \mathrm{~mm})$, and an external door of $1,000 \mathrm{~m} \times 2,100 \mathrm{~mm}$. The internal doors were $860 \mathrm{~mm} \times 2,100 \mathrm{~mm}$.

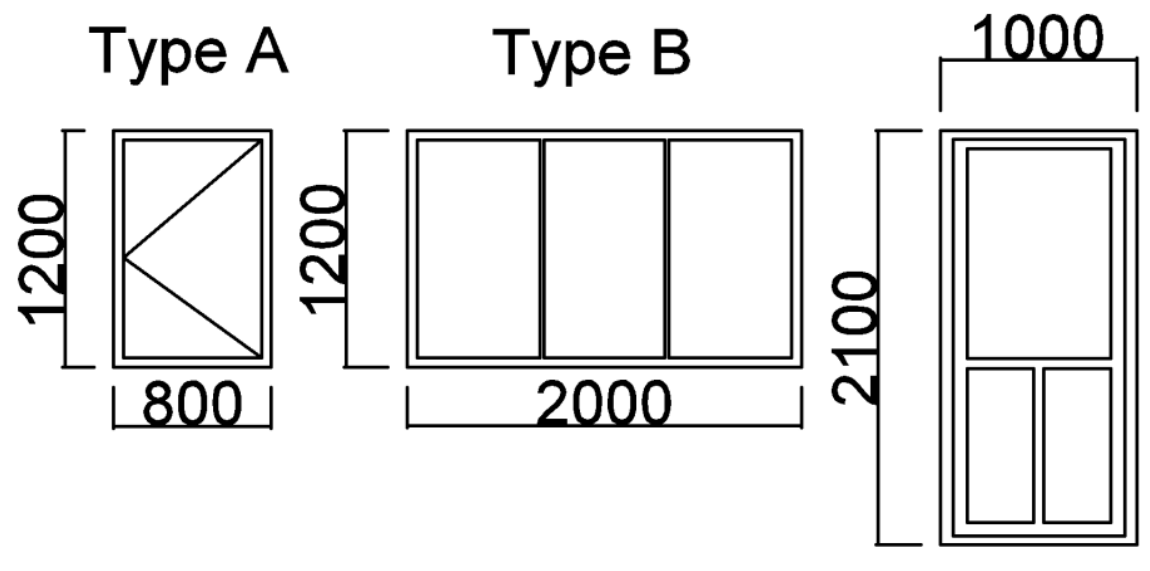

Figure 5.18: Door and window schedule (Not to scale)

Figure 5.19 shows the placement of joinery in plan B1.

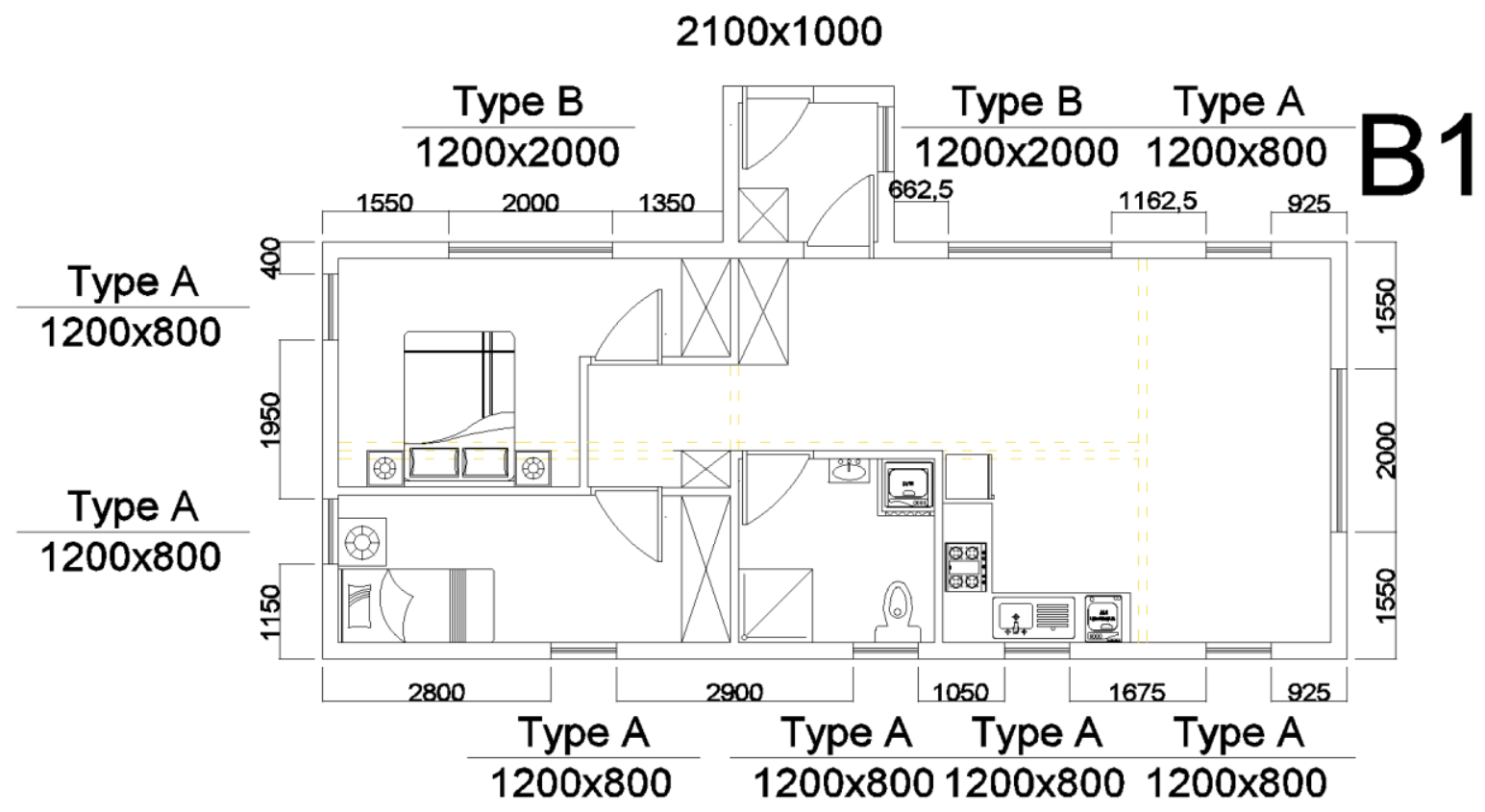

Figure 5.19: Placement of Joinery in plan B1 (Not to scale)

The goal was to minimise the cutting of the SIPs panels, especially horizontal cuts where panels join together and share a vertical edge, as this can negatively affect their performance. The primary idea was to keep doors and type A windows in one panel and type B windows 
between two panels as shown in Figure 5.20. The other possibility was ordering custom sized panels to avoid any cutting, but it was felt the focus should be on mass production rather than customisation.
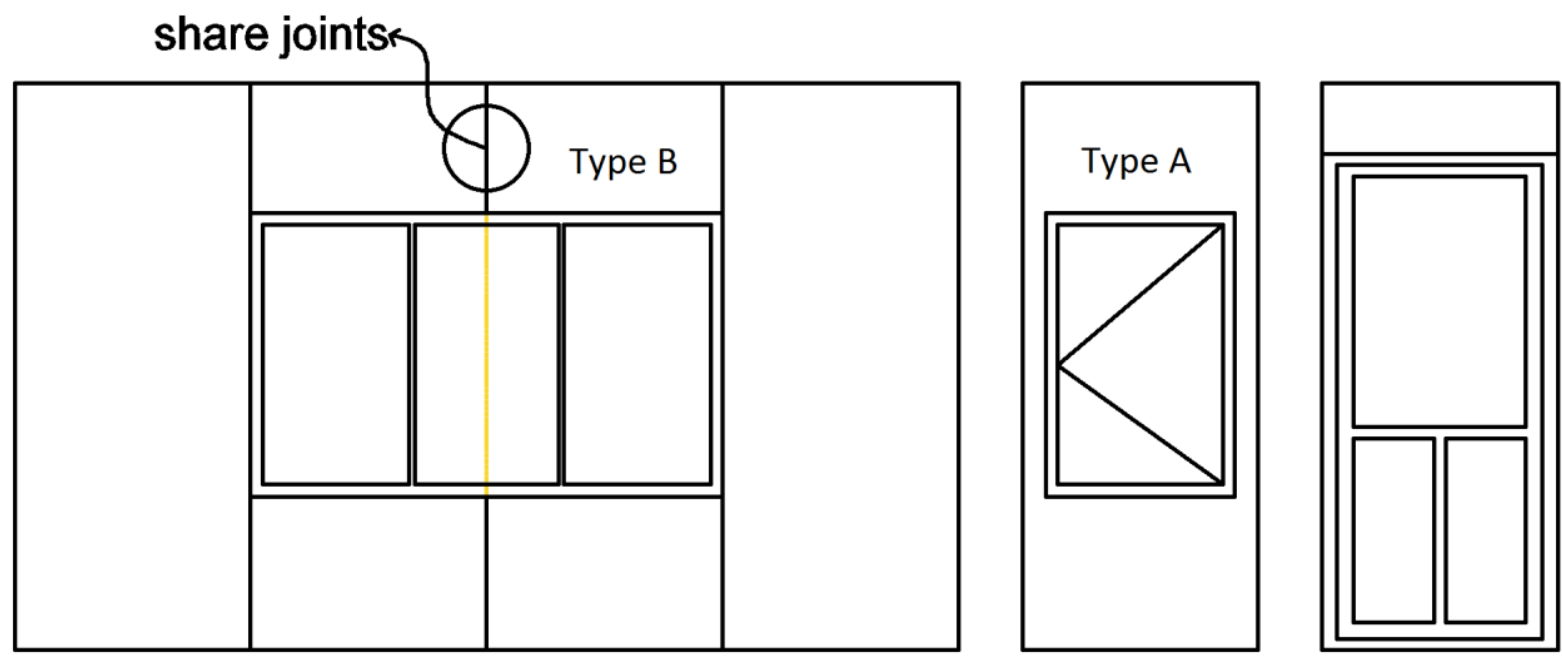

Figure 5.20: Primary placement of door and windows in SIPs panels (Not to scale)

Keeping the joinery in one SIPs panel could potentially decrease the number of cuts needed especially at the joints. However, working on details of this idea revealed technical issues that would make it hard or even impossible to place a door in just one panel in some cases due to the overlap between perpendicular SIPs. During the preliminary sketches, the idea emerged of rearranging the order of panels for type B windows to reduce waste and cutting. It was decided that instead of having four vertical panels beside each other and cutting them to place the window (Figure 5.20), the window would be placed between two vertical SIPs panels and two horizontal panels each of $600 \mathrm{~mm} \times 2,000 \mathrm{~mm}$ added at the top and bottom of the window to fill the gaps (Figure 5.21).

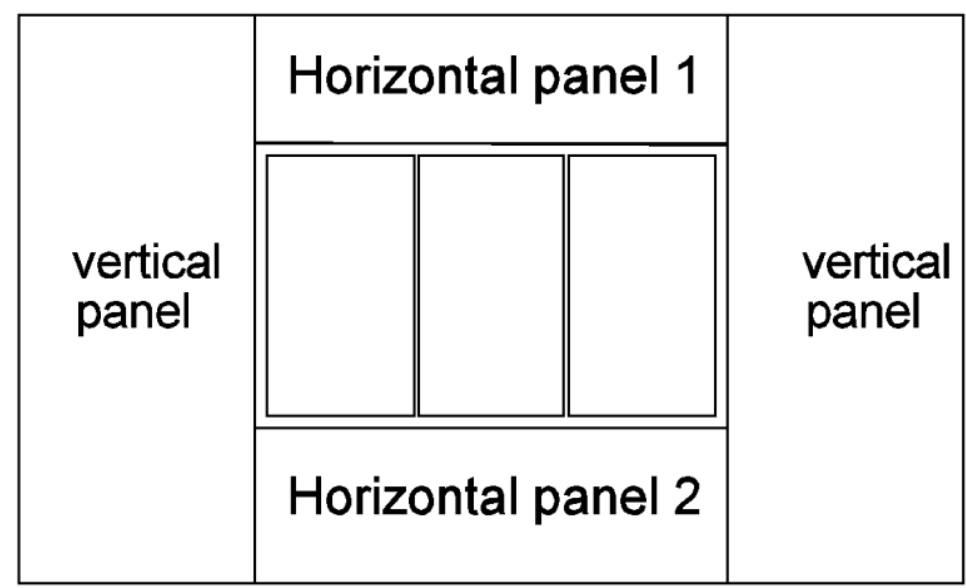

Placement of type B window

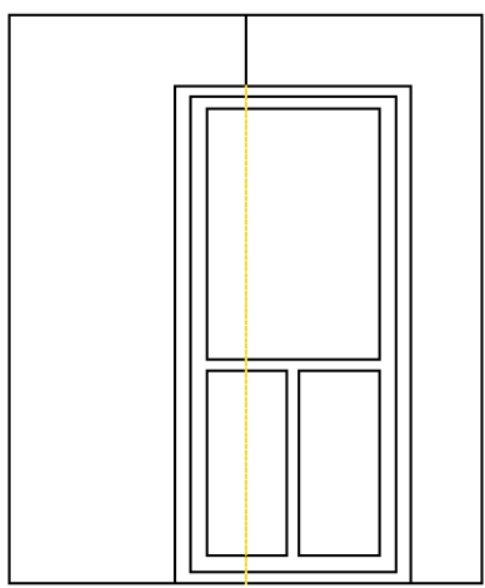

Door placement

Figure 5.21: Placement of door and window (type B) (Not to scale) 


\subsection{Space Conditioning Energy Simulation}

Before looking into the construction process of the ADU and explaining any changes required due to technical, transportation or craning constraints, it was first necessary to narrow the design options. At this stage based on the possible type and thickness of the floor, as well as the available thicknesses of panels for walls and roof, 18 different construction combinations were possible for each of the 21 different layouts (Table 5.4 and Table 5.7). As a result, it was decided to simulate the conditioning energy of the ADU using the B1 layout in order to find the best combination, which would then be used as the basis for the construction details. The simulation was conducted in three consecutive rounds. The first round investigated all 36 different construction scenarios, made of different thickness of SIPs, different type of floors and with different heating level assumptions to find the most energy efficient one. The second round evaluated the effect of adding different layers of mass to the best two scenarios (one on a slab and one with a suspended floor). The last round modified the placement and size of windows for the most energy efficient scenario to find the most efficient ratio of window to wall area.

To run the simulations, the first step was choosing appropriate software. The two primary options were SUNREL from the U.S. Department of Energy and ALF (Annual Loss Factor) version 3.2 by BRANZ. At this early stage, ALF 3.2 was chosen for two reasons. The first was the New Zealand basis of the software, and the second it ability to compare different designs. ALF is designed for calculating the energy performance of conventional New Zealand houses and determining the BPI or Building Performance Index as used in NZBC Clause H1. Clause H1 requires under defined temperature, humidity and uncontrollable airflow (infiltration) the thermal performance using approved software has a BPI below 1.55. ALF provides a context for comparing the heating energy efficiency of different designs (up to 30) to see the effects of different insulation levels, window types, building orientations, levels of thermal mass and other design options on the energy efficiency of the house. Aside from the project details, ALF collects information about different designs under the six main categories of climate and heating level (temperature), floors, roof/skylights, walls and windows, mass, ventilation, and moisture. 
Each category in these six groups has different items to be determined. These items can be classified into fixed and variable items. Fixed items are those which are not changed during the different simulations and so their values stand, while variable items can be changed in each simulation. This allows the effect of a specific variable on the thermal efficiency of the ADU to be seen. At each stage of the simulation only one variable was changed to see its effect on the design. Table 5.5 and Table 5.6 show the fixed items and their values and also the variable items in each category and their options. Given the importance of the consistency of fixed items, it was decided to use the B1 design (Figure 5.12). The thicknesses of the SIPS panels were chosen based on the options offered by NZSIPS. The entrance module is not part of the simulations as it is assumed it is not heated. 
Table 5.5: Fixed items

\begin{tabular}{|c|c|c|c|}
\hline \multicolumn{2}{|c|}{ Category } & Fixed items & Fixed values \\
\hline \multirow{3}{*}{\multicolumn{2}{|c|}{ Climate and heating }} & Region & Lower North Island \\
\hline & & Town/city & Wellington \\
\hline & & Heating Schedule & 24-hour heating \\
\hline \multirow[t]{12}{*}{ Floors } & \multirow{8}{*}{$\begin{array}{l}\text { In case of } \\
\text { suspended floor }\end{array}$} & Suspended floor area $\left(\mathrm{m}^{2}\right)$ & 64.01 \\
\hline & & Perimeter length $(\mathrm{m})$ & 35.3 \\
\hline & & Perimeter height $(\mathrm{m})$ & 0.15 \\
\hline & & Perimeter wall type & $\begin{array}{l}\text { Continuous perimeter wall, } \\
\text { sheltered from the wind }\end{array}$ \\
\hline & & Number of occupants & 2 \\
\hline & & Total floor area (all levels, $\mathrm{m}^{2}$ ) & 64 \\
\hline & & Average room height (m) & 2.4 \\
\hline & & $\begin{array}{l}\text { Floor covering R-value } \\
\left(\mathrm{m}^{2 \circ} \mathrm{C} / \mathrm{W}\right)\end{array}$ & 0 \\
\hline & \multirow{4}{*}{$\begin{array}{l}\text { In case of slab on } \\
\text { ground floor }\end{array}$} & Slab floor area $\left(\mathrm{m}^{2}\right)$ & 64.01 \\
\hline & & Perimeter length $(\mathrm{m})$ & 35.3 \\
\hline & & Soil conductivity $\left(\mathrm{W} / \mathrm{m} \cdot{ }^{\circ} \mathrm{C}\right)$ & 1.2 \\
\hline & & Type of slab & $\begin{array}{l}150 \mathrm{~mm} \text { concrete slab with } 150 \\
\mathrm{~mm} \text { polystyrene underneath } \\
\text { with R-value of } 5.2\left(\mathrm{~m}^{2 \circ} \mathrm{C} / \mathrm{W}\right)\end{array}$ \\
\hline \multirow{3}{*}{\multicolumn{2}{|c|}{ Roof }} & Width & 5.1 \\
\hline & & Length & 12.55 \\
\hline & & Area & 64.01 \\
\hline \multirow{3}{*}{\multicolumn{2}{|c|}{ Wall and windows }} & Orientation of walls & \multirow{2}{*}{$\begin{array}{l}\text { The internal height of walls is } \\
2.4 \mathrm{~m} \\
\text { For other information about } \\
\text { walls see Figure } 5.12\end{array}$} \\
\hline & & Length and height of walls & \\
\hline & & Window type & $\begin{array}{l}\text { PVC or wooden frame with } \\
\text { IGU clear / Low E + Argon gas }\end{array}$ \\
\hline Mass & & Wall area & None \\
\hline \multirow{9}{*}{\multicolumn{2}{|c|}{ Ventilation }} & Air tightness classification & $\begin{array}{l}\text { Airtight - Post-1960 simple } \\
\text { shape and the single-storey } \\
\text { less than } 120 \mathrm{~m}^{2}\end{array}$ \\
\hline & & Chimneys for open fires & \multirow[t]{5}{*}{ None } \\
\hline & & Metal flued heaters & \\
\hline & & Window passive vents & \\
\hline & & Windows cracked open & \\
\hline & & Retrofit air tightening & \\
\hline & & Kitchen vents over the hob & $\begin{array}{l}\text { Window mounted extract used } \\
1 \text { hour/day }\end{array}$ \\
\hline & & Mechanical bathroom vents & $\begin{array}{l}\text { Bathroom extract humidistat } \\
\text { or light controlled }\end{array}$ \\
\hline & & Building wind exposure & Medium sheltered \\
\hline \multicolumn{2}{|c|}{ Moisture } & \multicolumn{2}{|l|}{ NA } \\
\hline
\end{tabular}

* For BPI calculations three occupants for buildings under $120 \mathrm{~m}^{2}$, four occupants for buildings between $120 \mathrm{~m}^{2}$ and $180 \mathrm{~m}^{2}$ and five occupants for buildings larger than $180 \mathrm{~m}^{2}$ are assumed by the software. 
Table 5.6: Variable items

\begin{tabular}{|c|c|c|}
\hline Category & Variables & Variable values \\
\hline \multirow[t]{2}{*}{ Climate and heating } & \multirow[t]{2}{*}{ Heating Level } & $16^{\circ} \mathrm{C}$ \\
\hline & & $18^{\circ} \mathrm{C}$ \\
\hline \multirow[t]{2}{*}{ Suspended floor } & \multirow[t]{2}{*}{$\begin{array}{l}\text { Construction type and } \mathrm{R}- \\
\text { values }\left(\mathrm{m}^{2 \circ} \mathrm{C} / \mathrm{W}\right)\end{array}$} & $\begin{array}{l}115 \mathrm{~mm} \text { thick SIPs panel with R- } \\
\text { value of } 4.5\end{array}$ \\
\hline & & $\begin{array}{l}165 \mathrm{~mm} \text { thick SIPs panel with R- } \\
\text { value of } 5.2\end{array}$ \\
\hline \multirow[t]{3}{*}{ Roof } & \multirow[t]{3}{*}{$\begin{array}{l}\text { Construction type and } R- \\
\text { values }\left(m^{2 \circ} \mathrm{C} / \mathrm{W}\right)\end{array}$} & $\begin{array}{l}115 \mathrm{~mm} \text { thick SIPs panel with R- } \\
\text { value of } 4.5\end{array}$ \\
\hline & & $\begin{array}{l}165 \mathrm{~mm} \text { thick SIPs panel with R- } \\
\text { value of } 5.2\end{array}$ \\
\hline & & $\begin{array}{l}215 \mathrm{~mm} \text { thick SIPs panel with R- } \\
\text { value of } 6.9\end{array}$ \\
\hline \multirow[t]{3}{*}{ Wall and windows } & \multirow[t]{2}{*}{$\begin{array}{l}\text { Construction type and } \mathrm{R}- \\
\text { values of the wall }\left(\mathrm{m}^{2 \circ} \mathrm{C} / \mathrm{W}\right)\end{array}$} & $\begin{array}{l}115 \mathrm{~mm} \text { thick SIPs panel with R- } \\
\text { value of } 4.5\end{array}$ \\
\hline & & $\begin{array}{l}165 \mathrm{~mm} \text { thick SIPs panel with R- } \\
\text { value of } 5.2\end{array}$ \\
\hline & Size of windows & See Table 5.9 \\
\hline \multirow[t]{4}{*}{ Mass } & \multirow[t]{3}{*}{ Slab on the ground } & $50 \mathrm{~mm}$ slab with full insulation \\
\hline & & $100 \mathrm{~mm}$ slab with full insulation \\
\hline & & 150mm slab with full insulation \\
\hline & Suspended floor & $50 \mathrm{~mm}$ slab with full insulation \\
\hline
\end{tabular}

\subsubsection{The First Round of Simulations (most energy efficient construction scenario)}

Analysing the efficiency of the ADU was started by using values from Table 5.5 and Figure 5.12 which shows the orientation of the house, and the placement and size of windows. A 24-hour heating schedule was chosen as if the ADU is used for accommodating older people they could spend most of their time at home and need heating all day. In the first round of simulations the four series of variables includes heating level, type and thickness of the floor, and the thickness of walls and roof, which are changed one by one, ending with 36 different scenarios (Table 5.6). The aim was finding the most efficient ADU in terms of space heating to narrow down the number of scenarios for the next round of simulations. Table 5.7 shows the variables changed and the required annual heating for each scenario. 
Table 5.7: First round of simulation results

\begin{tabular}{|c|c|c|c|c|c|c|c|c|c|c|c|}
\hline \multirow[t]{3}{*}{ scenario } & \multicolumn{2}{|c|}{$\begin{array}{l}\text { Heating } \\
\text { level } \\
\left({ }^{\circ} \mathrm{C}\right)\end{array}$} & \multicolumn{3}{|c|}{$\begin{array}{l}\text { Type and thickness of the } \\
\text { floor }\end{array}$} & \multicolumn{2}{|c|}{$\begin{array}{l}\text { Thickness } \\
\text { of walls } \\
\text { (mm) }\end{array}$} & \multicolumn{3}{|c|}{$\begin{array}{l}\text { Thickness of } \\
\text { ceiling }(\mathrm{mm})\end{array}$} & \multirow{3}{*}{$\begin{array}{l}\text { Required } \\
\text { heating } \\
\text { (kWh/ann } \\
\text { um) }\end{array}$} \\
\hline & \multirow[t]{2}{*}{16} & \multirow[t]{2}{*}{18} & \multicolumn{2}{|c|}{$\begin{array}{l}\text { SIPs } \\
\text { suspended } \\
\text { floor }(\mathrm{mm})\end{array}$} & \multirow[t]{2}{*}{$\begin{array}{l}\text { Concrete } \\
\text { slab } \\
(150 \mathrm{~mm})\end{array}$} & \multirow[t]{2}{*}{115} & \multirow[t]{2}{*}{165} & \multirow[t]{2}{*}{115} & \multirow[t]{2}{*}{165} & \multirow[t]{2}{*}{215} & \\
\hline & & & 115 & 165 & & & & & & & \\
\hline 1 & $*$ & & $*$ & & & $*$ & & $*$ & & & $1,759.03$ \\
\hline 2 & & $*$ & $*$ & & & $*$ & & $*$ & & & $2,254.74$ \\
\hline 3 & $*$ & & $*$ & & & & $*$ & $*$ & & & $1,640.60$ \\
\hline 4 & & $*$ & $*$ & & & 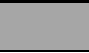 & $*$ & $*$ & & & $2,070.63$ \\
\hline 5 & $*$ & & & & $*$ & $*$ & & $*$ & & & $1,591.61$ \\
\hline 6 & & $*$ & & & $*$ & * & & * & & & $1,992.17$ \\
\hline 7 & $*$ & & & & $*$ & & $*$ & $*$ & & & $1,489.89$ \\
\hline 8 & & $*$ & & & $*$ & 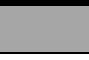 & $*$ & $*$ & & & $1,822.75$ \\
\hline 9 & $*$ & & & $*$ & & $*$ & & $*$ & & & $1,639.52$ \\
\hline 10 & & $*$ & & $*$ & & $*$ & & $*$ & & & $2,068.91$ \\
\hline 11 & $*$ & & & $*$ & & & $*$ & $*$ & & & $1,532.24$ \\
\hline 12 & & $*$ & & $*$ & & & $*$ & $*$ & & & $1,894.59$ \\
\hline 13 & $*$ & & $*$ & & & $*$ & & & $*$ & & $1,614.17$ \\
\hline 14 & & $*$ & $*$ & & & $*$ & ( & & $*$ & & $2,028.50$ \\
\hline 15 & $*$ & & $*$ & & & & $*$ & & $*$ & & $1,509.73$ \\
\hline 16 & & $*$ & $*$ & & & & $*$ & & $*$ & & $1,856.68$ \\
\hline 17 & $*$ & & & & $*$ & $*$ & & & $*$ & & $1,467.96$ \\
\hline 18 & & $*$ & & & $*$ & $*$ & 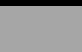 & & $*$ & & $1,784.59$ \\
\hline 19 & $*$ & & & & $*$ & & $*$ & & $*$ & & $1,385.67$ \\
\hline 20 & & $*$ & & & $*$ & & $*$ & & $*$ & & $1,632.25$ \\
\hline 21 & $*$ & & & $*$ & & $*$ & & & $*$ & & $1,508.79$ \\
\hline 22 & & $*$ & & $*$ & & $*$ & & & $*$ & & $1,855.10$ \\
\hline 23 & $*$ & & & $*$ & & & $*$ & & $*$ & & $1,419.03$ \\
\hline 24 & & $*$ & & $*$ & & & $*$ & & $*$ & & $1,696.18$ \\
\hline 25 & $*$ & & $*$ & & & $*$ & & & & $*$ & $1,575.60$ \\
\hline 26 & & $*$ & $*$ & & & $*$ & & & & $*$ & $1,966.17$ \\
\hline 27 & $*$ & & $*$ & & & & $*$ & & & $*$ & $1,475.94$ \\
\hline 28 & & $*$ & $*$ & & & & $*$ & & & $*$ & $1,798.55$ \\
\hline 29 & $*$ & & & & $*$ & $*$ & & & & $*$ & $1,436.67$ \\
\hline 30 & & $*$ & & & $*$ & $*$ & & & & $*$ & $1,728.65$ \\
\hline 31 & $*$ & & & & $*$ & & $*$ & & & $*$ & $1,361.16$ \\
\hline 32 & & $*$ & & & $*$ & & $*$ & & & $*$ & $1,582.28$ \\
\hline 33 & $*$ & & & $*$ & & $*$ & & & & $*$ & $1,475.05$ \\
\hline 34 & & $*$ & & $*$ & & $*$ & & & & $*$ & $1,797.01$ \\
\hline 35 & $*$ & & & $*$ & & & $*$ & & & $*$ & $1,391.36$ \\
\hline 36 & & $*$ & & $*$ & & & $*$ & & & $*$ & $1,643.44$ \\
\hline
\end{tabular}

Given the results from Table 5.7, as was predictable, the higher the R-value the less was the annual heating required. Generally, scenarios which included a concrete slab were more heat efficient as the slab adds thermal mass to absorb any solar gain. However, for this round of 
simulations the specific tab in ALF 3.2 for adding layers of mass, was turned off, so the software did not consider it as thermal mass (see Section 5.6.2). The polystyrene underneath the concrete slab had an $\mathrm{R}$ value of $5.2 \mathrm{~m}^{2 \circ} \mathrm{C} / \mathrm{W}$, whereas the R-values of the suspended floors made of $115 \mathrm{~mm}$ and $165 \mathrm{~mm}$ SIPs panels were respectively $4.5 \mathrm{~m}^{2 \circ} \mathrm{C} / \mathrm{W}$ and $5.2 \mathrm{~m}^{2 \circ} \mathrm{C} / \mathrm{W}$. Scenario 31 was the closest zero heating energy by requiring just $1361.16 \mathrm{kWh}$ a year. However, for the next round of simulations looking at the effects of adding thermal mass, the most efficient suspended floor ADU (scenario 35) was chosen in addition to scenario 31 with its concrete slab.

\subsubsection{The Second Round of Simulation (most effective level of thermal mass)}

The second round of simulations tested the effect of adding different thicknesses of thermal mass to scenarios 31 and 35 . The area of mass for most simulations was $64 \mathrm{~m}^{2}$ thus equal to floor area (excludes the entrance), with no added mass in the walls. Table 5.8 shows the effect of adding mass to these scenarios.

Table 5.8: Effect of thermal mass on the heat efficiency of the ADU

\begin{tabular}{|c|c|c|c|}
\hline scenarios & $\begin{array}{l}\text { Required heating } \\
\text { without mass } \\
\text { (kWh) }\end{array}$ & Type of mass & $\begin{array}{l}\text { Required heating with } \\
\text { mass(kWh) }\end{array}$ \\
\hline \multirow[t]{4}{*}{31} & \multirow[t]{4}{*}{1361.16} & 50mm slab with full insulation & 597.71 \\
\hline & & $100 \mathrm{~mm}$ slab with full insulation & 464.66 \\
\hline & & $150 \mathrm{~mm}$ slab with full insulation & 448.09 \\
\hline & & $\begin{array}{l}150 \mathrm{~mm} \text { slab with full insulation } \\
\text { and } 50 \mathrm{~mm} \text { concrete block lining } \\
\text { to the internal face of external } \\
\text { walls }\end{array}$ & 445.76 \\
\hline 35 & 1391.36 & $\begin{array}{l}50 \mathrm{~mm} \text { concrete block on the } \\
\text { floor }\end{array}$ & 629.56 \\
\hline
\end{tabular}

Table 5.8 shows how effective having a layer of mass can be on the heat efficiency of the ADU. The required heating is reduced by over $50 \%$ after adding the mass in the different scenarios. The other positive effect of having some thermal mass is balancing the internal temperature of the house and providing a comfortable living situation by absorbing the surplus heat in summer and also afternoon hours and giving it back to the space when there is no sun outside (Balaras, 1996). Table 5.8 shows having a $150 \mathrm{~mm}$ slab as thermal mass can decrease the required heating of scenario 31 from $1361.16 \mathrm{kWh} /$ annum to $448.09 \mathrm{kWh} / a n n u m$ which means cutting over $66 \%$ of the heating needs of the ADU. Adding $50 \mathrm{~mm}$ of concrete block to scenario 35 decreases the heat needed from $1391.36 \mathrm{kWh}$ to $629.56 \mathrm{kWh}$. However, Table 5.8 shows that where the mass is added is critical. Adding concrete blocks to the walls, as a 
layer of mass, in scenario 31 with $150 \mathrm{~mm}$ of floor mass, only decreases the heating energy by just over $2 \mathrm{kWh} /$ annum. Given the extra energy needed for transporting and assembling them, having these blocks in the walls would have a negative effect overall.

At the end of the second round of simulations scenario 31, which from now on will be called the ADU, was chosen as the most efficient option and picked for the third round of simulations. The ADU is made of $165 \mathrm{~mm}$ SIPs panel walls and $215 \mathrm{~mm}$ SIPs ceiling panels seating on a $150 \mathrm{~mm}$ concrete slab with $150 \mathrm{~mm}$ polystyrene insulation underneath it.

\subsubsection{The Third Round of Simulations (most effective size and placement of windows)}

The aim of the third round of simulations was changing the assumptions made about the placement and size of windows to test their effects on the heating efficiency of the ADU. The orientation of the ADU was consistent as the idea was having the main bedroom and living room facing the north, where solar gain is maximised. The effects of changes in the orientation of the ADU on the required heating are discussed in Chapter 6 (see Section 6.3.8.7). Modifying the placement and size of windows to find the most efficient scenario ending with having smaller windows in all directions and as a result reducing the required heating of the ADU from $448.09 \mathrm{kWh} /$ annum to $405.74 \mathrm{kWh} / \mathrm{annum}$.

In order to better understand the changes to the windows, Table 5.9 shows the previous and present number and area of windows in the different sides of the ADU, excluding the unheated entrance module. There is also a little shading on the north face wall windows. In the table, BF stands for "Before Modification" and AF for "After Modification". There is no window in the east wall either before or after modification. This is different from the original idea of having at least one window in each exterior wall (see Section 5.4.3) as the east side of the ADU is one wall of the living area and there is already a window in its north facing exterior wall.

Table 5.9: Windows area and placement modifications

\begin{tabular}{|c|c|c|c|c|c|c|c|c|c|c|c|}
\hline \multirow[t]{2}{*}{ Design } & \multicolumn{3}{|c|}{$\begin{array}{l}\text { North facing wall } \\
\text { windows }\end{array}$} & \multicolumn{3}{|c|}{$\begin{array}{l}\text { South facing wall } \\
\text { windows }\end{array}$} & \multicolumn{3}{|c|}{$\begin{array}{l}\text { West facing wall } \\
\text { windows }\end{array}$} & \multirow[t]{2}{*}{$\begin{array}{l}\text { Total } \\
\left(\mathrm{m}^{2}\right)\end{array}$} & \multirow[t]{2}{*}{$\begin{array}{l}\text { WWR } \\
\text { (\%) }\end{array}$} \\
\hline & $\mathrm{N}$ & $\begin{array}{l}\text { Size } \\
(\mathrm{m})\end{array}$ & $\begin{array}{l}\text { Total } \\
\text { area }\left(\mathrm{m}^{2}\right)\end{array}$ & $\mathrm{N}$ & $\operatorname{Size}(\mathrm{m})$ & $\begin{array}{l}\text { Total } \\
\text { area }\left(\mathrm{m}^{2}\right)\end{array}$ & $\mathrm{N}$ & Size $(m)$ & $\begin{array}{l}\text { Total } \\
\text { area }\left(\mathrm{m}^{2}\right)\end{array}$ & & \\
\hline $\mathrm{BF}$ & 3 & $2 \times 1.2$ & 7.2 & 2 & $0.8 \times 1.2$ & 1.92 & 1 & $0.8 \times 1.2$ & 0.96 & 10.1 & 15.74 \\
\hline \multirow[t]{2}{*}{$\mathrm{AF}$} & 1 & $1 \times 1.2$ & 1.2 & \multirow[t]{2}{*}{1} & \multirow[t]{2}{*}{$1 \times 1.2$} & \multirow[t]{2}{*}{1.2} & \multirow[t]{2}{*}{1} & \multirow[t]{2}{*}{$1 \times 1.2$} & \multirow[t]{2}{*}{1.2} & \multirow[t]{2}{*}{7.2} & \multirow[t]{2}{*}{8.57} \\
\hline & 2 & $1.5 \times 1.2$ & 3.6 & & & & & & & & \\
\hline
\end{tabular}

$* \mathrm{~N}=$ Number 
The reason for needing less heating with smaller windows was the fact that, despite the positive effects of bigger windows on the solar gains especially for those facing north, bigger windows also increase the amount of air leakage and decrease the usefulness of the gains. However, the effects of different window sizes could be different for other climates, and different heating schedules and levels.

Figure 5.22 illustrates the result of the ALF 3.2 ADU heat efficiency simulation after modifying the placement and area of windows, where the charts illustrate the total gains without considering their usefulness.

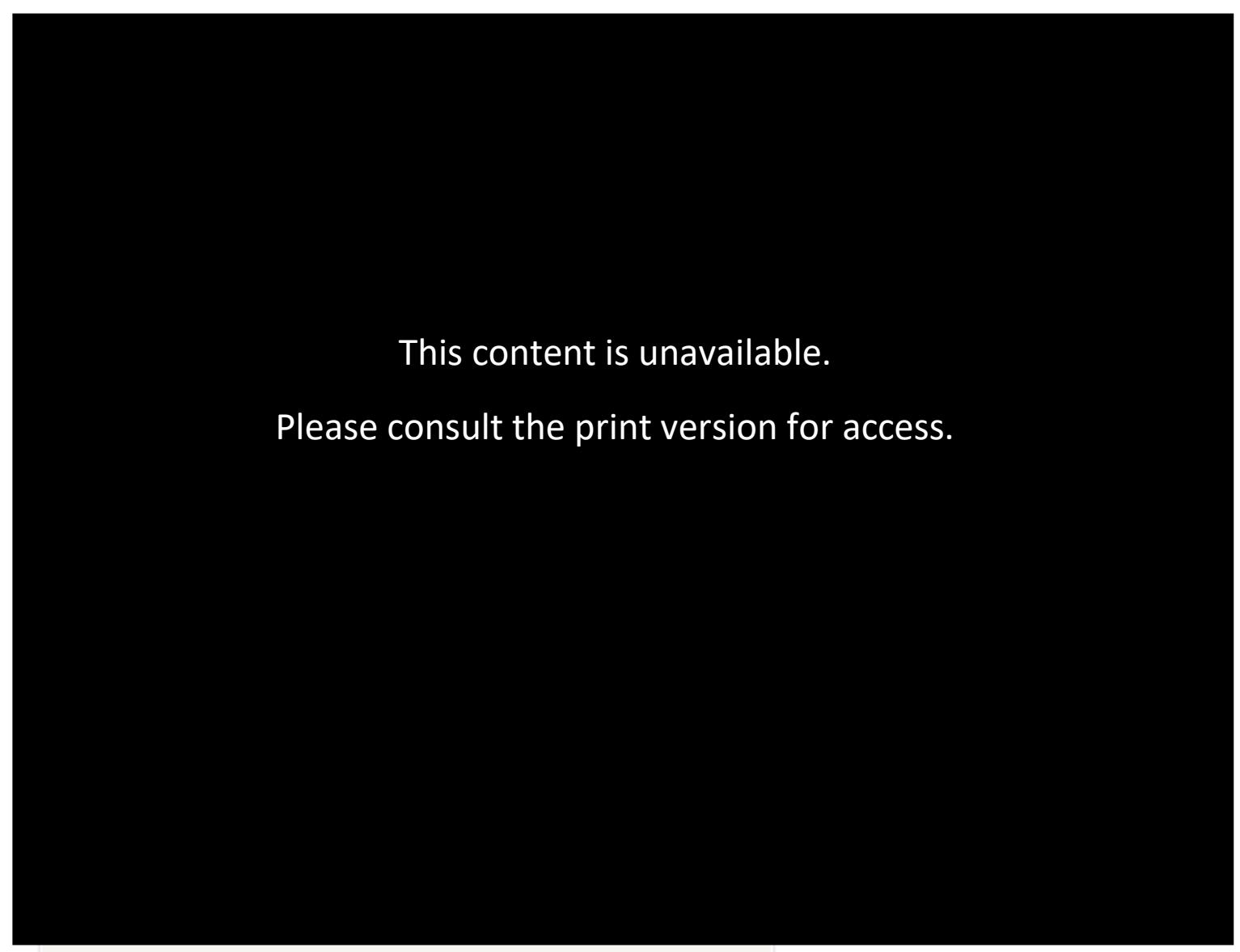

Figure 5.22: Final simulation result

Figure 5-17 also shows that the current BPI is 0.59 , which means the ADU meets the requirements of Clause $\mathrm{H} 1$ as it is less than 1.55 (Figure 5.22). Figure 5.23, an output from ALF 3.2 , shows the results of the scenario 31 simulation more in detail. 
This content is unavailable.

Please consult the print version for access.

Figure 5.23: Final simulation results

Figure 5.23 shows the total useful gain is $1130.88 \mathrm{kWh} /$ annum (Usefulness of Gains $(0.4427) *($ Solar Gains $(940.32 \mathrm{kWh})+$ Internal Gains $(1614.22 \mathrm{kWh})))$, which is $405.74 \mathrm{kWh}$ less than the total load. It also shows over $75 \%$ of the solar gains come from the three windows facing north, proving the importance of the correct orientation of windows. This is a potential weaknesses of the ADU as there is little design control over the direction of the house on the site as it is affected by the existing house (see Section 6.3.8.7). Figure 5.23 also shows that air leakage is the largest source of energy loss in the ADU amounting to $27 \%$ of total. This is the reason behind the better efficiency of the ADU with smaller windows. After air leakage, walls which are responsible for $21 \%$ of all energy losses, windows, slab floor, and roof are respectively responsible for $20 \%, 17 \%$ and $13 \%$ of all losses. However, this share of losses is a little different from Figure 5.5, which could be due to use of different materials and using concrete slab instead of a suspended timber floor. 
Considering that SIPs panels are up to $30 \%$ more air tight than the conventional methods of construction assumed by ALF, the air leakage could potentially be less than the calculated $420.9 \mathrm{kWh}$ /year (see Section 5.3.1.1). However, given air leakage is the main source of energy loss there is need for more investigation into ways of decreasing it. One of the most reliable ways of controlling air leakage in buildings is the use of a heat recovery system. This system relies on having a sealed building, something that could be achieved with an ADU using SIPs, and recovering the heat from the exhaust air and using it to warm the incoming fresh air (Binamu, 2000; Younes, 2012). The efficiency of different types of heat recovery system can be from $50-95 \%$, but most of the researchers agree on $80 \%$ in a situation similar to that of the ADU (Hansen, 2017; Kamendere, 2014; Roulet; 2001). Installing an 80\% efficient heat recovery system would decrease the energy lost through air leakage by $80 \%$ or $336.72 \mathrm{kWh} /$ year. Deducting this from the total heat required $(405.74 \mathrm{kWh} /$ year) would leave $81.89 \mathrm{kWh} /$ year, which is close to being zero for heating energy. However, this reduction should be seen in relation with the capital and installation costs plus maintenance of heat recovery system. To reduce this further by having smaller windows, or thicker panels did not seem feasible, so at this stage of analysis, it was decided to accept the existing design as a nearly zero energy ADU. However, it should be noted that the ALF outputs are a yearly analysis of the energy efficiency of the house. ALF does not provide a detailed picture of the thermal behaviour of the ADU. Based on ALF outputs it seems the ADU is working sufficiently well during winter, as the internal air temperature would feel warmer than $16^{\circ} \mathrm{C}$ because of the insulated natures of the interior walls, ceiling and floor and the effect on the Mean Radiant Temperature on the feeling of comfort. However, there is as yet no information about the internal temperature of the ADU in summer, and whether being a well-insulated box will cause overheating. It was therefore decided to simulate the best scenario from ALF using SUNREL (see Section 6.3.8).

\subsection{Construction Approach}

The ADU is made of the four individual parts of the foundation, walls, ceiling, and roof. The foundation is the only part which has to be made on-site, while the others will be made in the factory and transported to the site for joining to the foundation. Figure 5.24 illustrates the construction process of the ADU broken into the three stages of primary design, construction detailing, and finalising. This figure also is used as the structure for this section, where the red 
arrows show iteration loops. The design is also constantly monitored for it being accessible for disabled people, regardless of any changes.

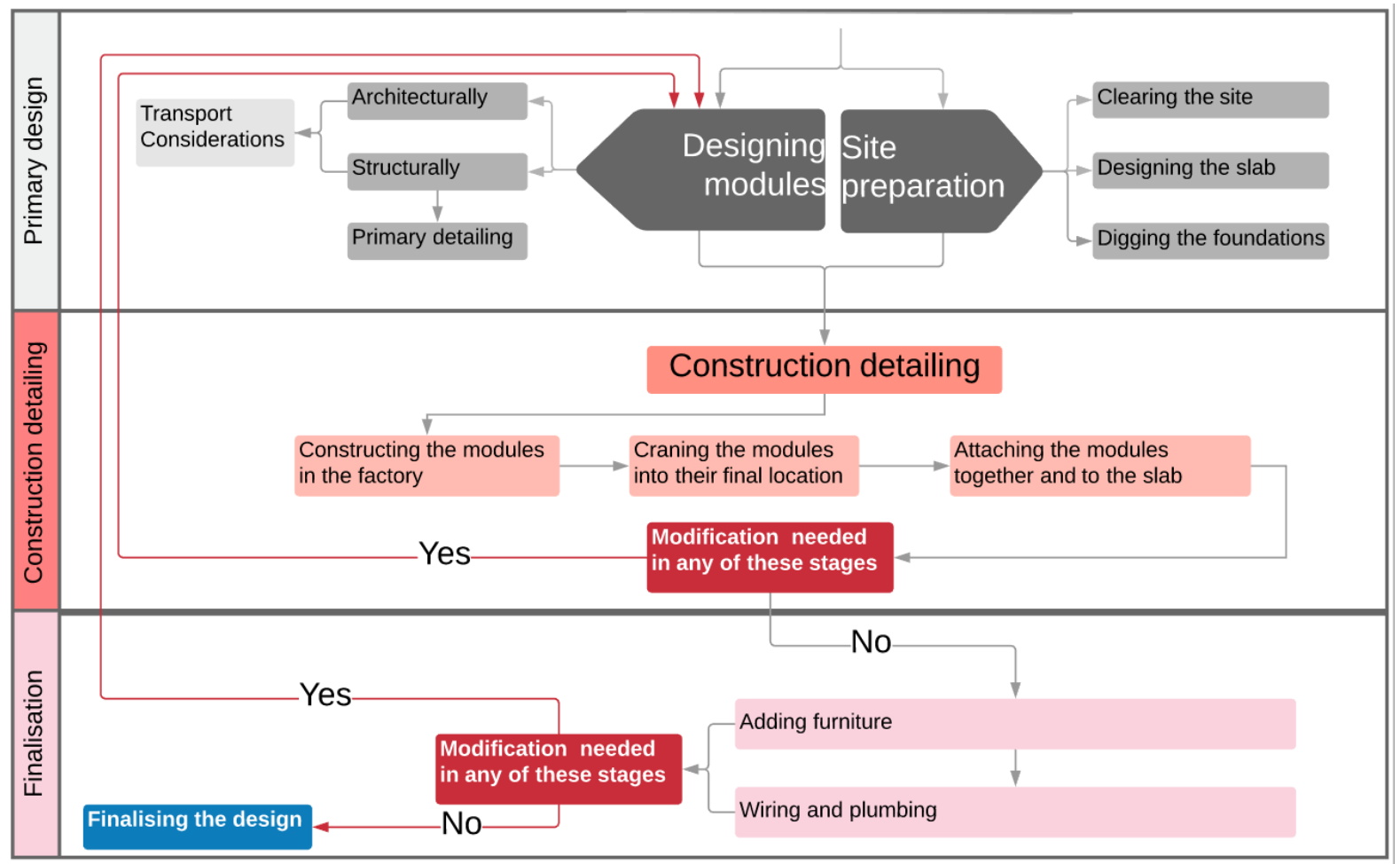

Figure 5.24: ADU construction process

\subsubsection{Designing the Modules}

The primary design was a $64 \mathrm{~m}^{2} \mathrm{ADU}$ plus a $4 \mathrm{~m}^{2}$ entrance (Figure 5.12). The ADU was designed with the aim of achieving at least three Lifemark stars. The master bedroom was placed to the north to get the best sun and wardrobes and cupboards were designed to provide as much storage as possible. The structure of the ADU consisted of normal internal stud walls joined to the SIPs external walls, ceiling, and floor with a timber trussed rafter roof on top of the ceiling of the assembled modules.

\subsubsection{Site Preparation}

Given the available options for the foundations based on the results from the energy simulations (see Section 5.6) it was decided to build the ADU on a $150 \mathrm{~mm}$ slab with $150 \mathrm{~m}$ polystyrene on top of a damp proof membrane as the insulation. The slab could be built either on-site or off-site. Building the slab in the factory as an attached element to each module would decrease the amount of on-site work substantially. However, doing this would mean each module would be approximately $4,500 \mathrm{~kg}$ heavier, as each cubic metre of concrete weighs $2,400 \mathrm{~kg}$, and the module would be $150 \mathrm{~mm}$ taller. Considering the transport 
limitations, it would still be possible to transport the modules with the slab attached. However, when it comes to craning the modules into the backyard, this extra weight means there is a need for a larger crane. Considering all the advantages and disadvantages it was decided the best strategy would be to build the slab on the site, as drainage would have to be dug on site, and so digging for the slab and drainage would be done together.

\subsubsection{Construction Detailing}

This stage tested the constructability of the ADU based on the existing design. It investigated the construction details in the following three categories of: constructing the modules in the factory; craning the modules to their final location; and attaching the modules together and to the slab. All construction details from the SIPs manufacturer were modified using NZS 3604:2018. NZS 3604 sets out the construction requirements of one to three storey timber frame buildings in New Zealand to comply with Building Code clause B1, Structure and Building Code clause E2 External Moisture, E2/AS1 (Ministry of Business and Employment, 2018). It is worth noting that in considering different possible types of sites (see Section 3.4) it is assumed that the ADU walls are far enough from the site boundaries so there is no need for fire proofing layers in external walls. At the end of this stage over 20 construction details were produced for the ADU (see Appendix D). This is the prerequisite to the next chapter which analyses the environmental impacts of the final design of the ADU during its life cycle.

\subsubsection{Constructing the Modules in the Factory}

At this stage, the technical details needed for construction of the ADU in the factory were worked through with the aim of modifying the design if needed. The documentation of the construction was done using the existing details from the SIPs panel manufacturer and NZS 3604 and other related New Zealand requirements in order to modify the design wherever needed. It is worth noting that:

- Based on communication with the New Zealand access was granted to the manufacturer's Google drive files including all construction details and tests results;

- If needed, details were then modified based on the specific ADU requirements;

- The specification of nails, hangers and other fixings were selected from well-known companies and knowing they were readily available in New Zealand. 


\subsubsection{Justifications}

At this stage, it became apparent that the wall cladding and roof panel connections needed modification and reconsideration.

\subsection{Wall Cladding}

At the primary design stage, the idea was to clad both sides of the external walls. However, after detailing the final width of the external walls became $229 \mathrm{~mm}$. Going back to the transport limitations and also the importance of keeping the internal areas accessible by meeting Lifemark standards, there was the need to adjust the thickness of the walls. Had the internal space been reduced Lifemark turning circles would not have been possible. It was decided to remove the internal cladding of the walls and finish the interior with a layer of paint on the SIPs panel, which led to a wall width of $200 \mathrm{~mm}$. Given the size of each module is fixed $(5.1 \mathrm{~m} \times 2.55 \mathrm{~m})$, this allowed an extra $29 \mathrm{~mm}$ or $58 \mathrm{~mm}$ in each direction to the internal spaces of each module. Figure 5.25 shows the wall cladding detail before and after modification.
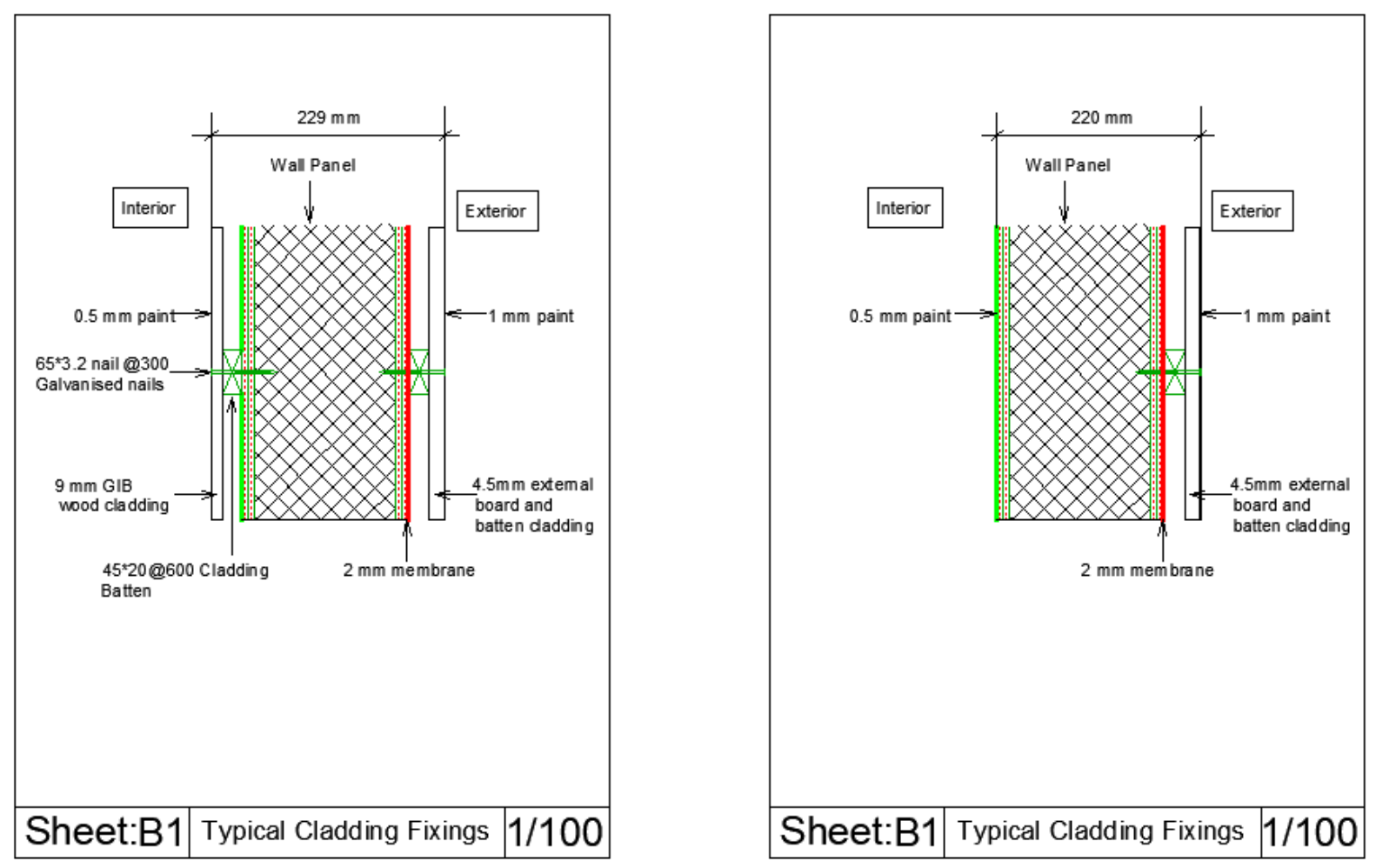

Figure 5.25: Typical cladding fixing modification (Not to scale)

\subsection{Ceiling Panel Connections}

The initial design of the ceiling was based on the idea of attaching the SIPs panels together to build a ceiling module and then attaching the module to the external walls. Each ceiling 
module consists of five SIPs panel of $1,020 \mathrm{~mm} \times 2,515 \mathrm{~mm}$ (the length is $2,515 \mathrm{~mm}$ as $35 \mathrm{~mm}$ is deducted for the cladding thickness) (Figure 5.26).

\section{Ceiling module}

\section{5mm SIPs ceiling panel}
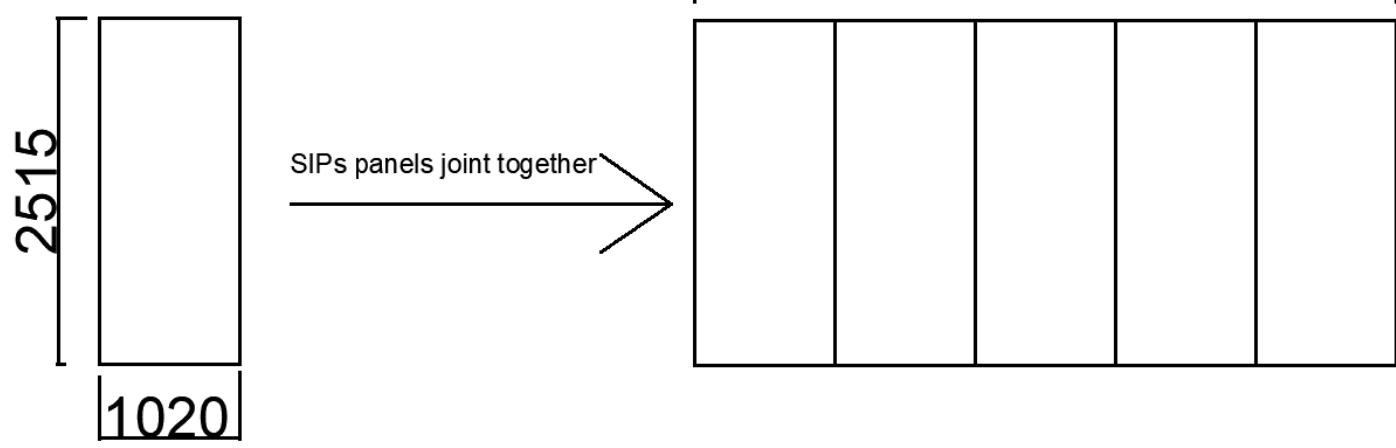

Figure 5.26: Ceiling module construction (Not to scale)

As the sizes of the main modules are the same, there is only one type of ceiling module attached to the different main modules, regardless of the internal design. Figure 5.27 shows the placement of the ceiling modules on the selected layout.

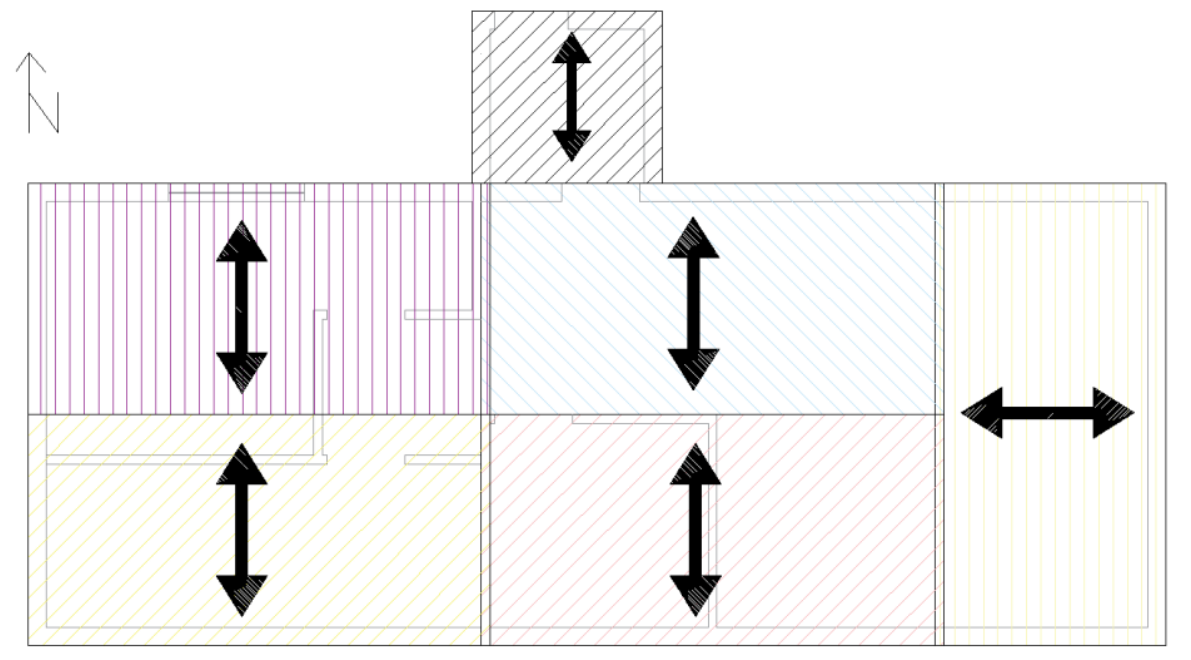

Ceiling module a Ceiling module $b$ Ceiling module $\mathrm{C}$ Ceiling module $d$ Ceiling module e Ceiling module $f$

Figure 5.27: Ceiling modules arrangement (Not to scale)

The manufacturer's details and structural considerations showed that there should be support on both sides of the ceiling module. Considering the external walls as the support on one side, there is a need for another support on the other. To provide the support, three structural beams were added to the design (see Section 5.7.6). Figure 5.28 shows these as 1 , 2 and 3, Laminated veneer lumber (LVL) beams. 


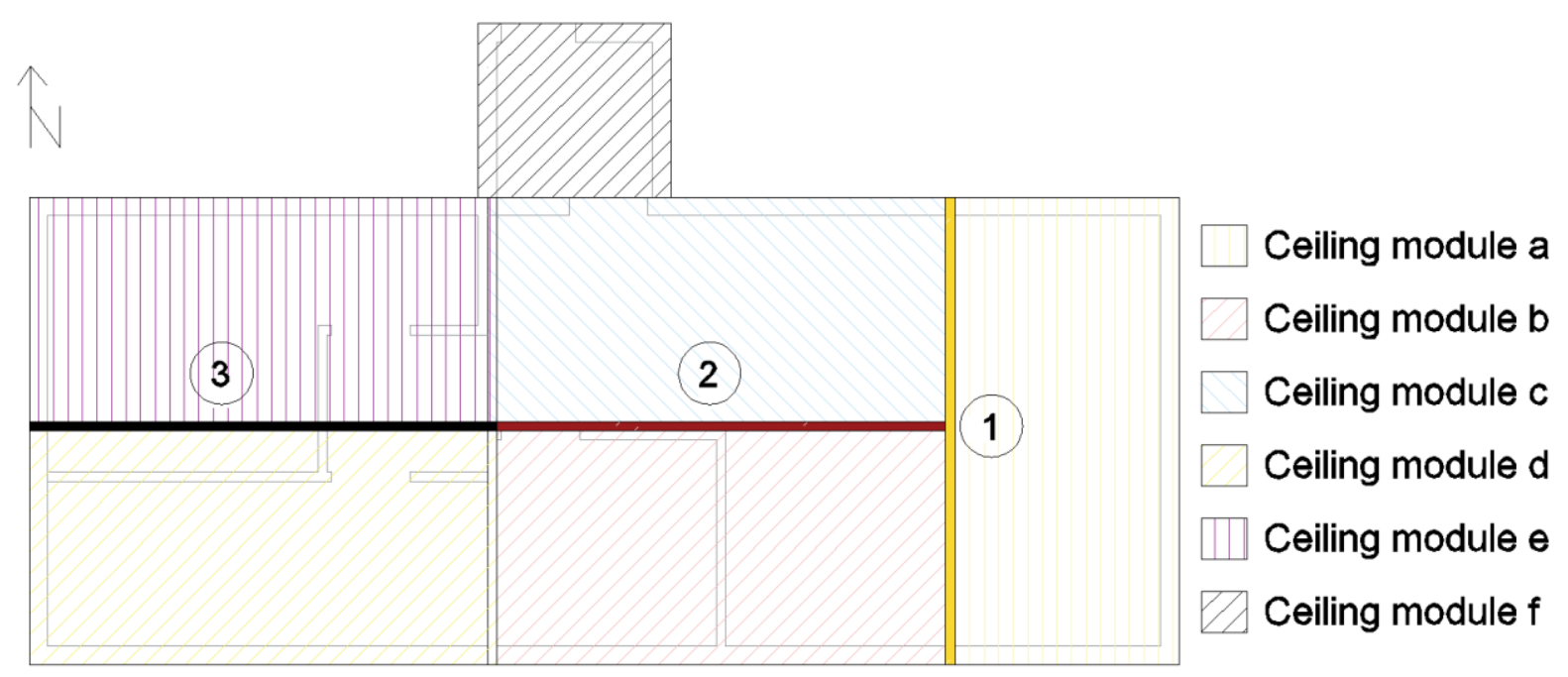

Figure 5.28: Three additional beams (Not at scale)

\subsubsection{Craning the Modules to their Final Location}

At this stage, the modules were investigated to ensure they could be craned into the backyard with no damage to the joints. A draft 1/100 scale maquette of each module was made to see whether there was a potential structural weakness when the modules were lifted. The criteria here was, to have a supporting structure, at least in the three vertical sides of each module. Investigating the maquette and the drawings showed that two modules of the serviced area (kitchen and bathroom) and the living area did not have enough support for being craned into their final location. The reason for these weak areas was the idea of having a shared wall between modules which would only be present in one of the modules for transport. For example, the bathroom and the bedroom, which are in two separate modules, share a wall (Figure 5.29). In the factory this wall would be built into one of the modules making the other one weak. 


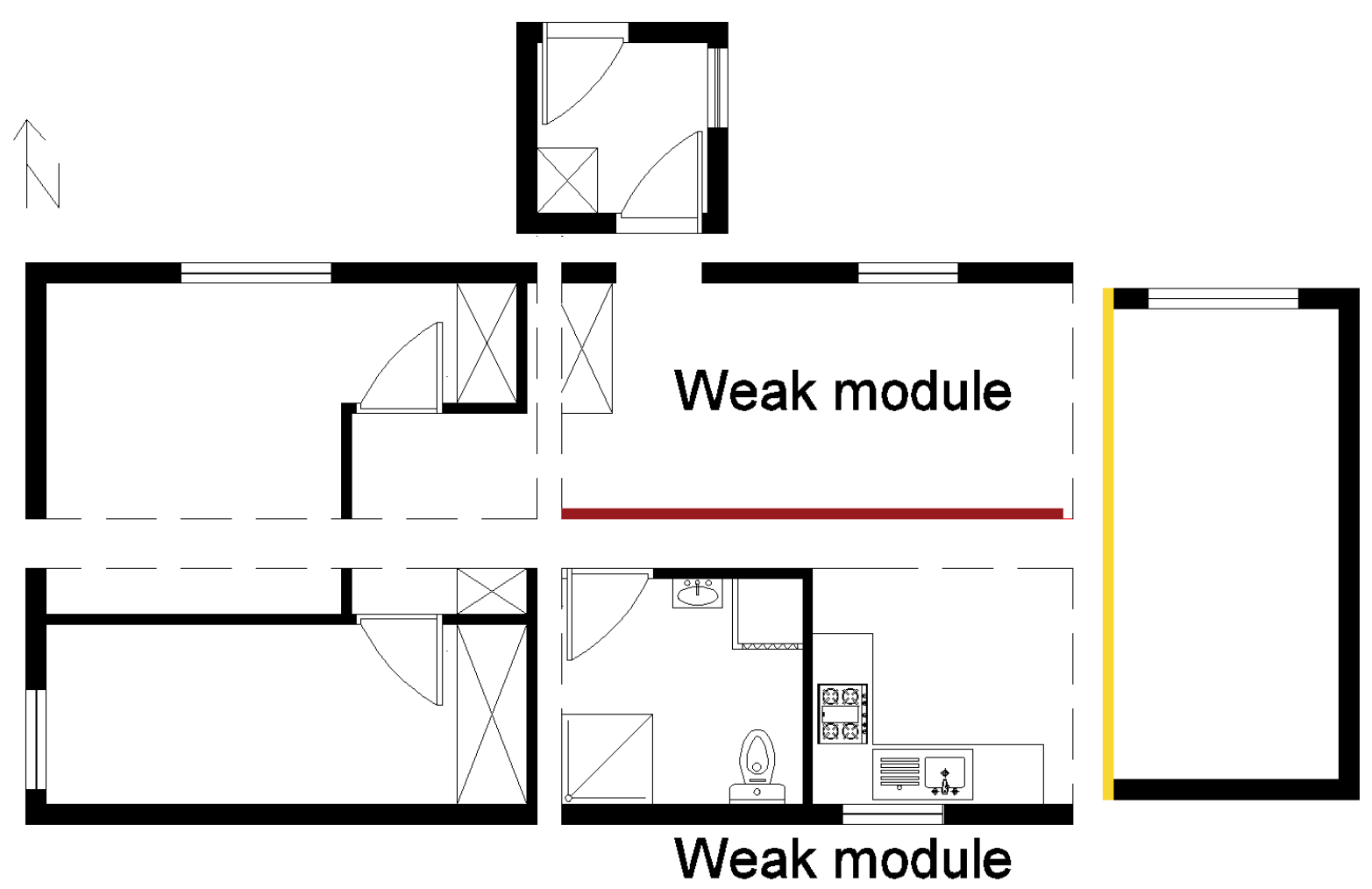

Figure 5.29: Weak modules (Not at scale)

In order to add a supporting structure to the weak modules, different approaches were investigated such as use of temporary bracing in weak modules. Finally, the decision was made to add two walls to the living module and one to the serviced module (Figure 5.31). However, adding these walls could potentially affect the accessibility of the ADU. In order to keep the internal area but provide enough space for these new walls, it was decided to put the modules together edge to edge with no fixing overlap. This gives the modules an extra $200 \mathrm{~mm}$ in length which can be used for the new walls. Removing the overlaps resulted in a slightly bigger $A D U$ of $65 \mathrm{~m}^{2}\left(0.025 \mathrm{~m}^{2}\right)$ plus the entrance module (Figure 5.30$)$. 


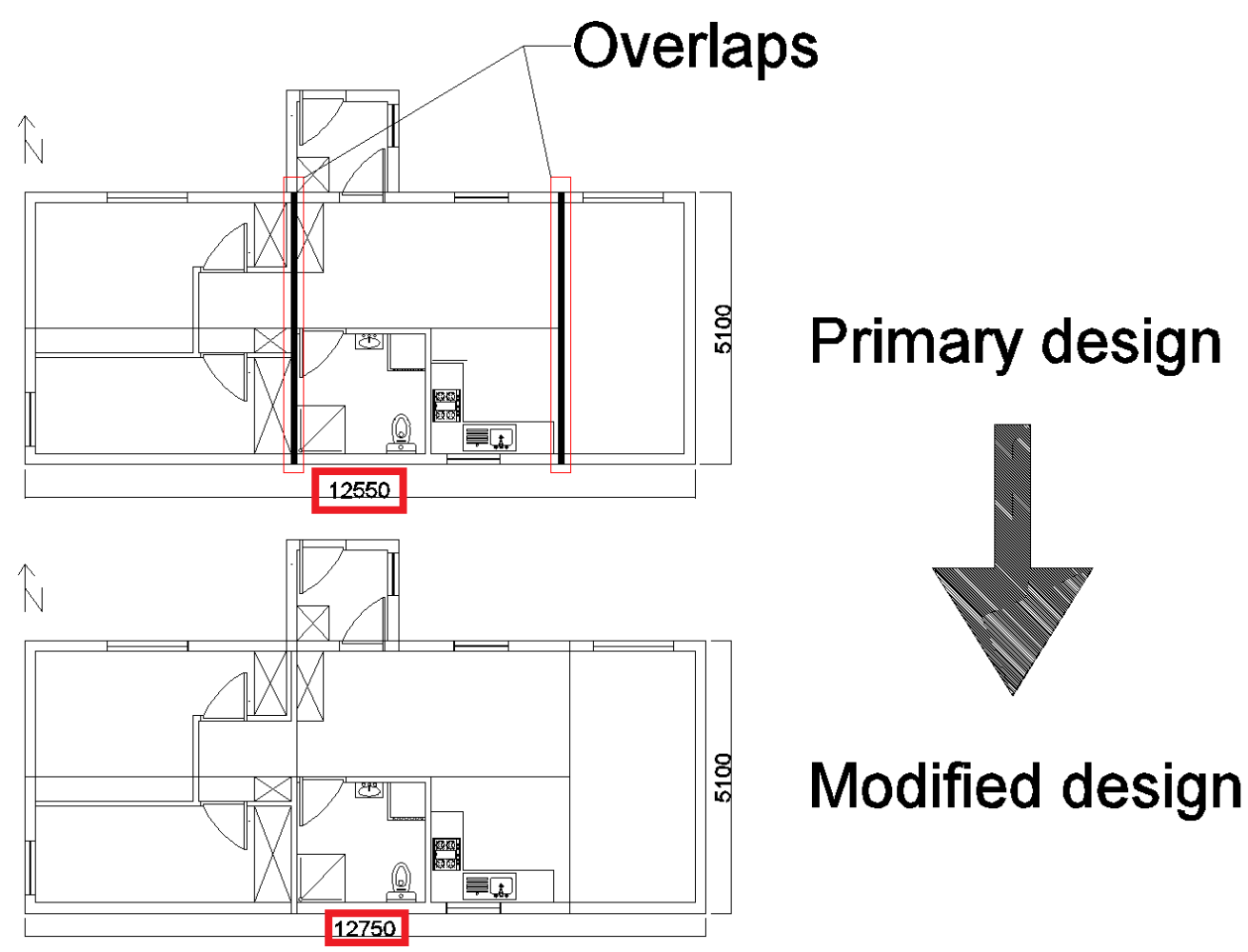

Figure 5.30: Modified module placement (Not at scale)

This change provided enough space for the new walls, as illustrated in Figure 5.31. It worth noting that the open side of each module would be temporarily braced (using timber or steel bracing) in order to make sure no damaged accrues during transportation, craning or assembly. Bracings can be reused for future transportation of prefabricated ADUs.

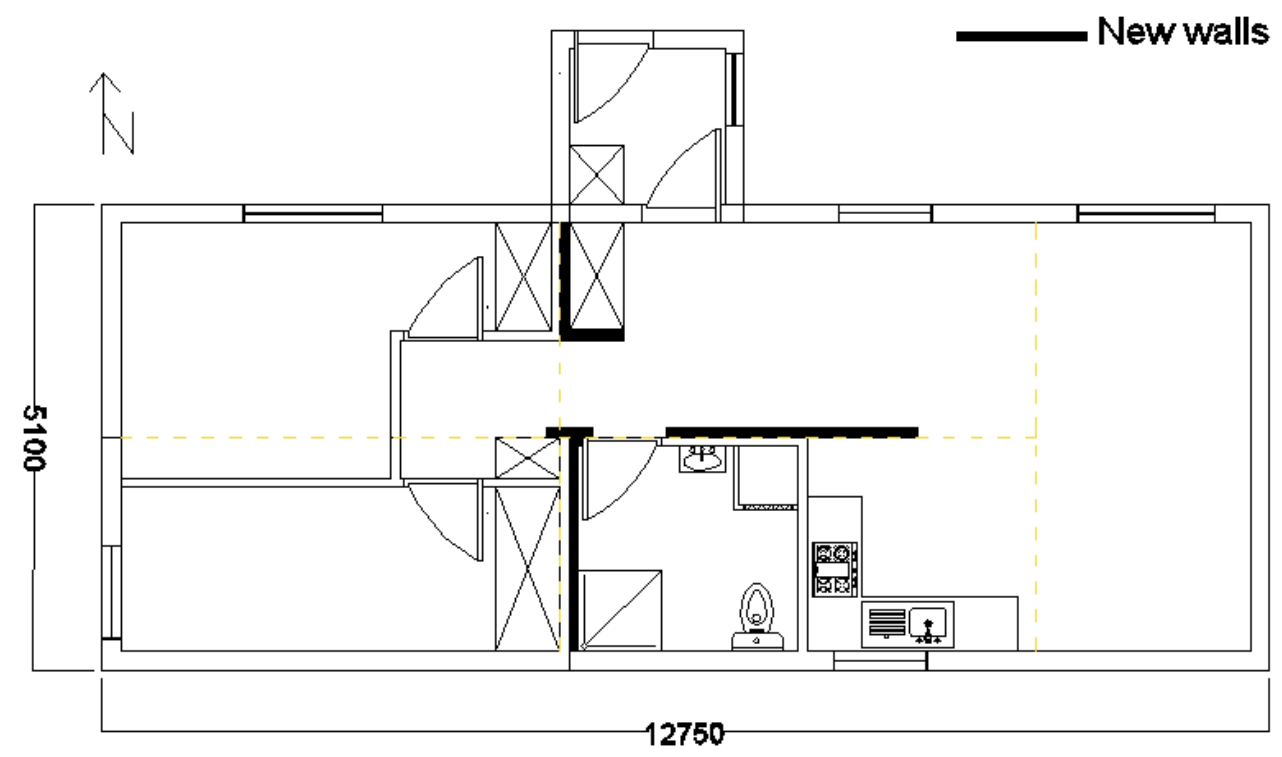

Figure 5.31: New walls (Not at scale) 
Adding these new walls at this stage meant architectural changes were made to the design with the aim of increasing the efficiency of use of the space, providing more storage especially in the master bedroom, and also providing more working space in the kitchen. This led to layout changes in the two bedroom modules as well as adding some working space to the kitchen. Also, it was decided to change the dimensions of the entrance module and make it one-third of the area of the standard modules in order to make the manufacturing process easier and provide more storage. (Figure 5.32).

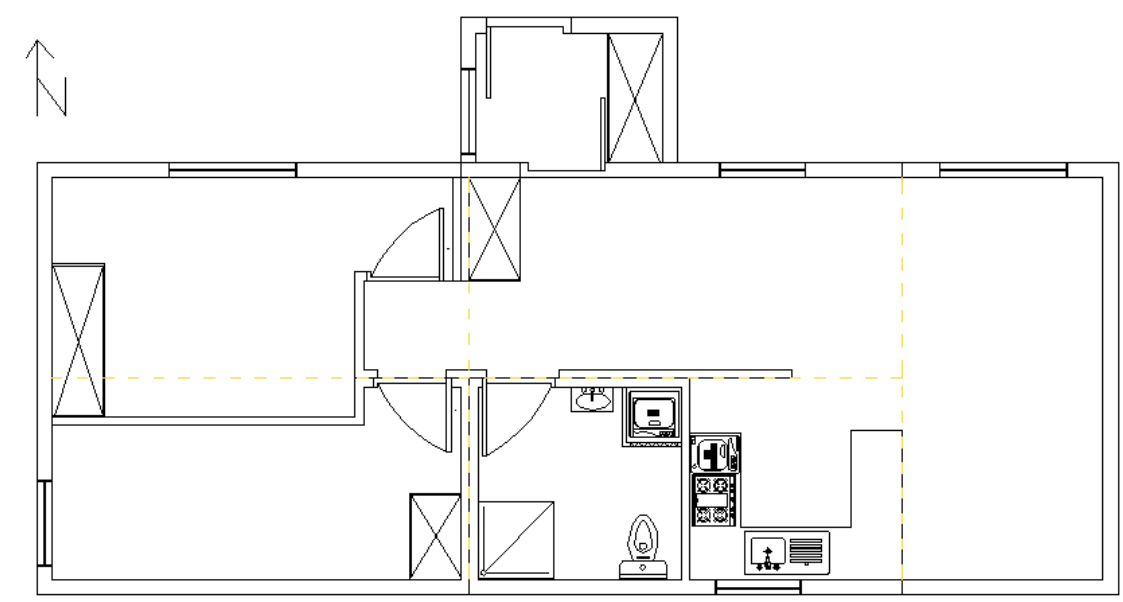

Figure 5.32: Layout modifications (Not at scale)

\subsubsection{Weight of Modules}

The weight of modules is critical when it comes to craning them to their place. Based on manufacturers' data, $165 \mathrm{~mm}$ and $2015 \mathrm{~mm}$ SIPs wall and ceiling panels weigh $22 \mathrm{~kg} / \mathrm{m}^{2}$ and $27.9 \mathrm{~kg} / \mathrm{m}^{2}$ respectively (NZSIPs, 2017). Lightweight cladding weighs a maximum of $30.0 \mathrm{~kg} / \mathrm{m}^{2}$ (Edhouse, 2014). As a result, inclusive of SIPs walls and ceiling, cladding and windows, modules A-F weigh $904 \mathrm{~kg}, 612 \mathrm{~kg}, 571 \mathrm{~kg}, 777 \mathrm{~kg}, 780 \mathrm{~kg}$ and $352 \mathrm{~kg}$ respectively. None of these modules are heavy and each can be moved using a light crane. The total weight of the ADU would be higher than the sum of these numbers $(3996 \mathrm{~kg})$ but still lighter than similar prefabricated modular houses (see Section 5.2.1.2).

\subsubsection{Attaching the Modules Together}

Despite the changes described above, the majority of details designed at the construction stage (see Section 5.7.3), were still applicable. The only detail that changed at this stage was the beam connection to the SIPs panels and to other beams (Figure 5.28). In Figure 5.28 both beams 2 and 3 were intended to support two ceiling modules, respectively b \& c and d \& e. 
This meant there were the two options of having a shared beam between modules or having a beam in each module. The first option was not possible as having a beam shared between modules means the beam should be located between the two modules. Considering the fact that the width of each module is $2.55 \mathrm{~m}$, which is the maximum allowed road width, the beam could not be attached to the modules in the factory, as half of it would project beyond the $2.55 \mathrm{~m}$. It also increases the possibility of defects during transportation and the amount of onsite work. The other option was using two thinner beams (one in each module) and joining the beams together on site. This seemed the easier option. It is worth noting that "beam 1" is supposed to carry half the load of "ceiling module a" and half the load of "beam 2". As a result, this beam should be stronger than the other beams and can be a single beam placed inside "module a" in the factory. In this approach, ceiling modules sit on five beams (Figure 5.33).

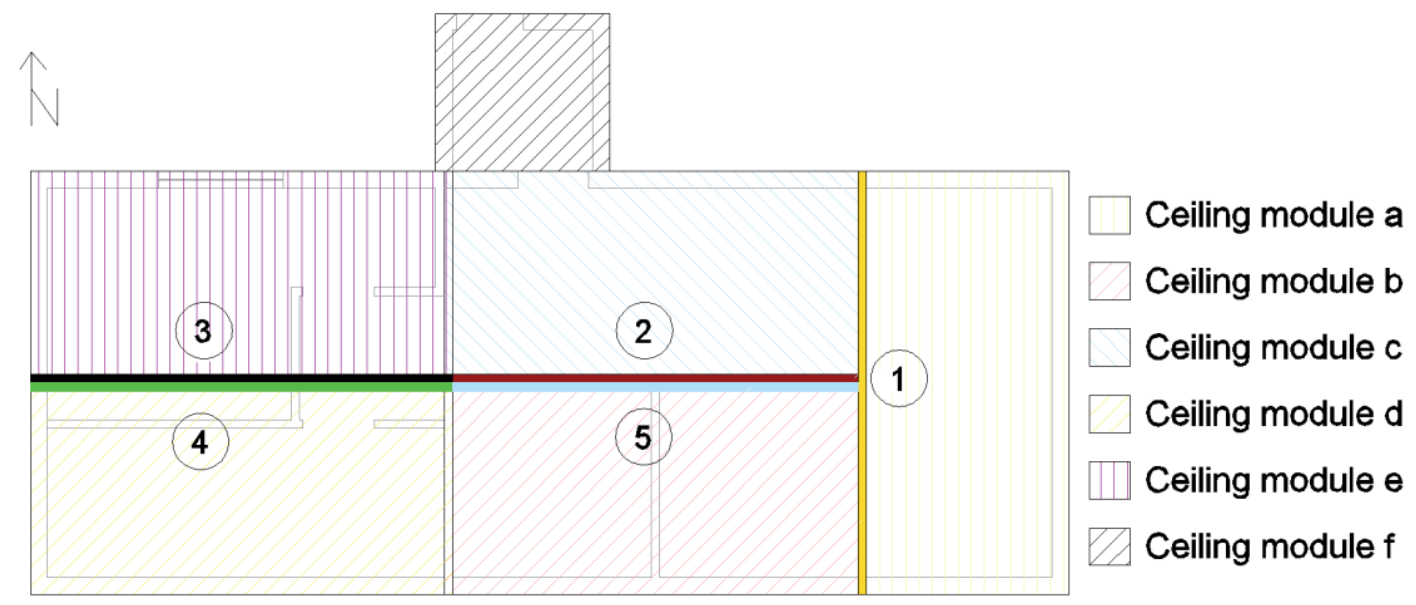

Figure 5.33: Modified beams (Not at scale)

The details for how the beams are attached together are found in Figure 5.34.

\section{Beam 1}

Simpson SDE Split Face Mount Joist Hanger

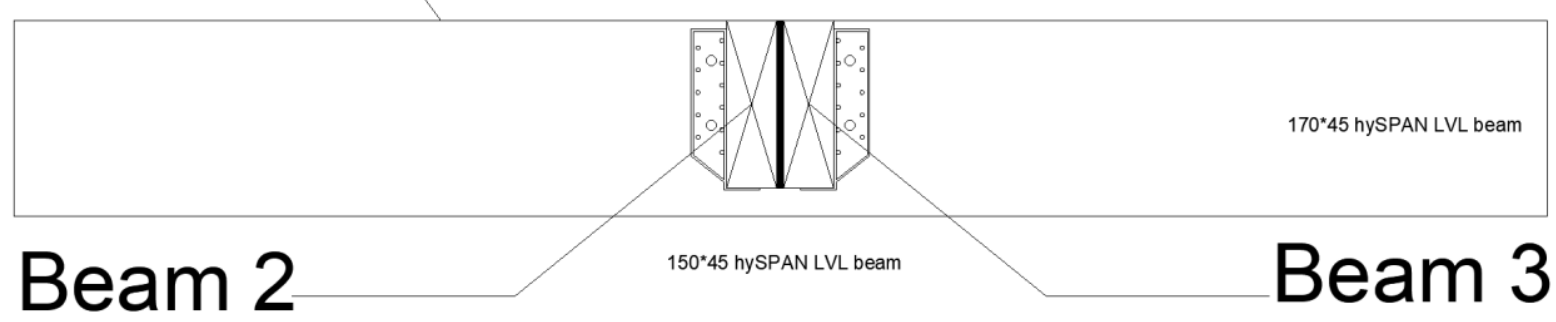

Figure 5.34: Beams joint detail (Not at scale) 


\subsubsection{Attaching the Modules to the Slab}

The structural details for attaching the modules to the slab were designed at the construction detailing stage, using a bottom plate (Figure 5.35). The continuous bottom plate would be attached to the slab on site and the modules would sit on this. In this approach, the bottom plate of the whole ADU would be continuous, while if the bottom plate was attached to the modules in the factory, each module would have its own separate bottom plate. This decision was based on the idea of minimising the joints.

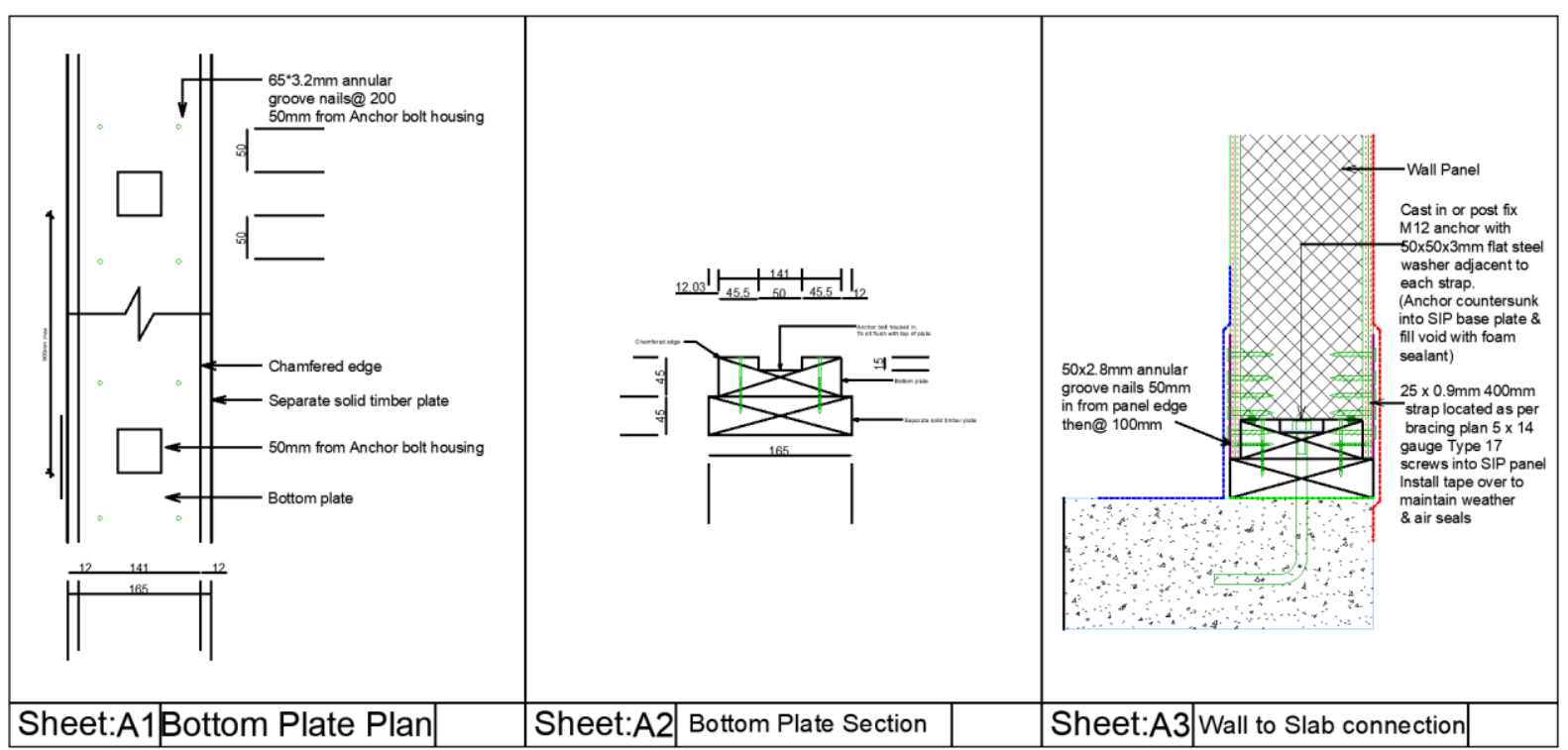

Figure 5.35: Bottom plate detail (detail does not show the external cladding-see Appendix D) (Not to scale)

At this point, the issue emerged of how the nut attached to the bolts in the middle of the wall section should be tightened. Different approaches were investigated to best solve the issue. Finally, it was decided to cut out a section of the SIPs panels at the factory at the points where the bolts are located, to provide the access for a socket spanner to tighten the nuts on-site. The cut sections of $107.5 \mathrm{~mm} \times 100 \mathrm{~mm} \times 100 \mathrm{~mm}$ would then put back in their place, and sealed with foam and extra layers of waterproof membrane (Figure 5.36) in order to maintain a continuous thermal insulation layer. Considering there is no interior cladding, it was decided to cut these holes in the exterior sides of the wall panels as the extra sealants would be hidden under the exterior cladding. 


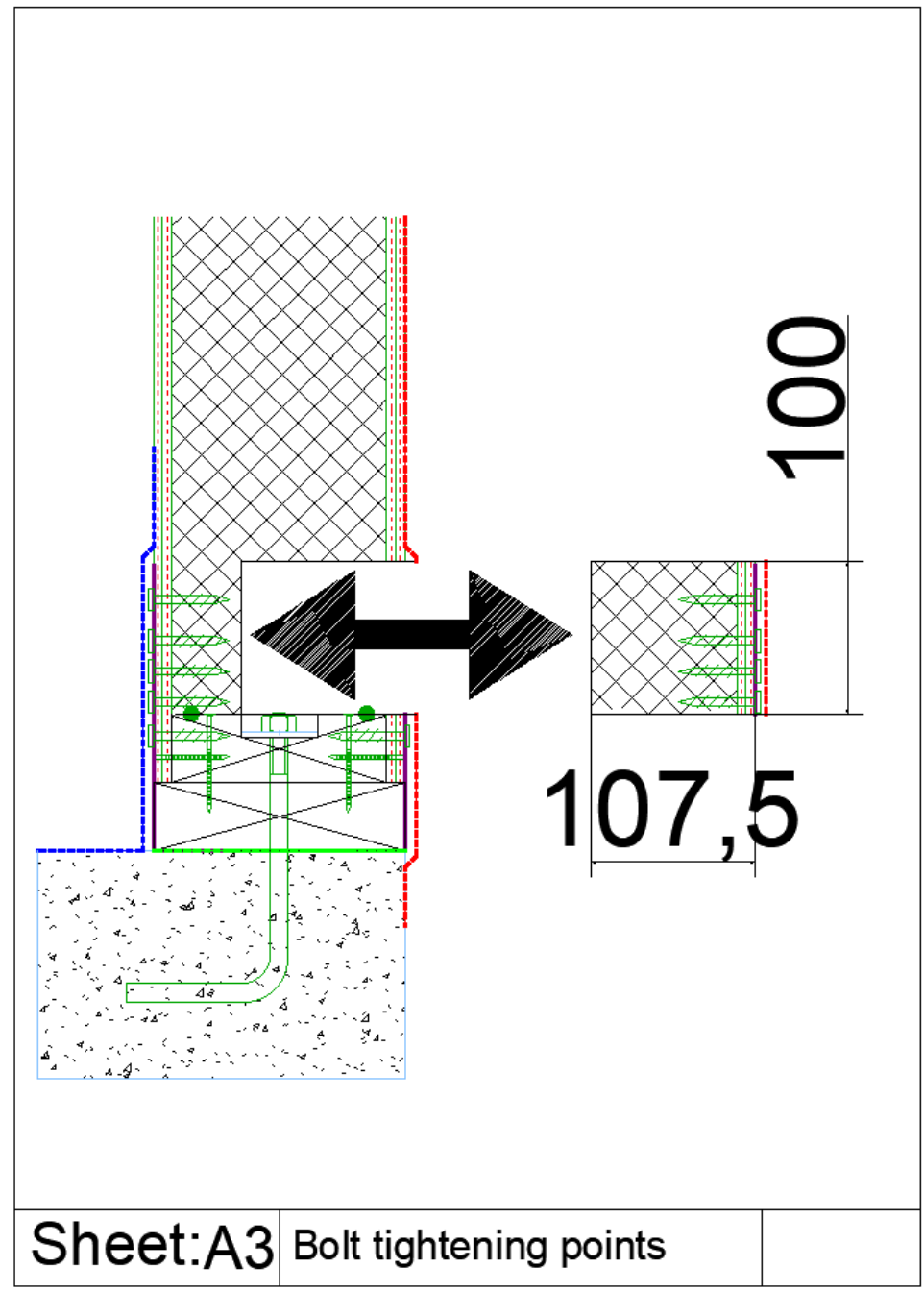

Figure 5.36: Bolt tightening point detail (Not at scale)

Figure 5.37 shows the 56 bolt points needed for attaching the modules to the slab.

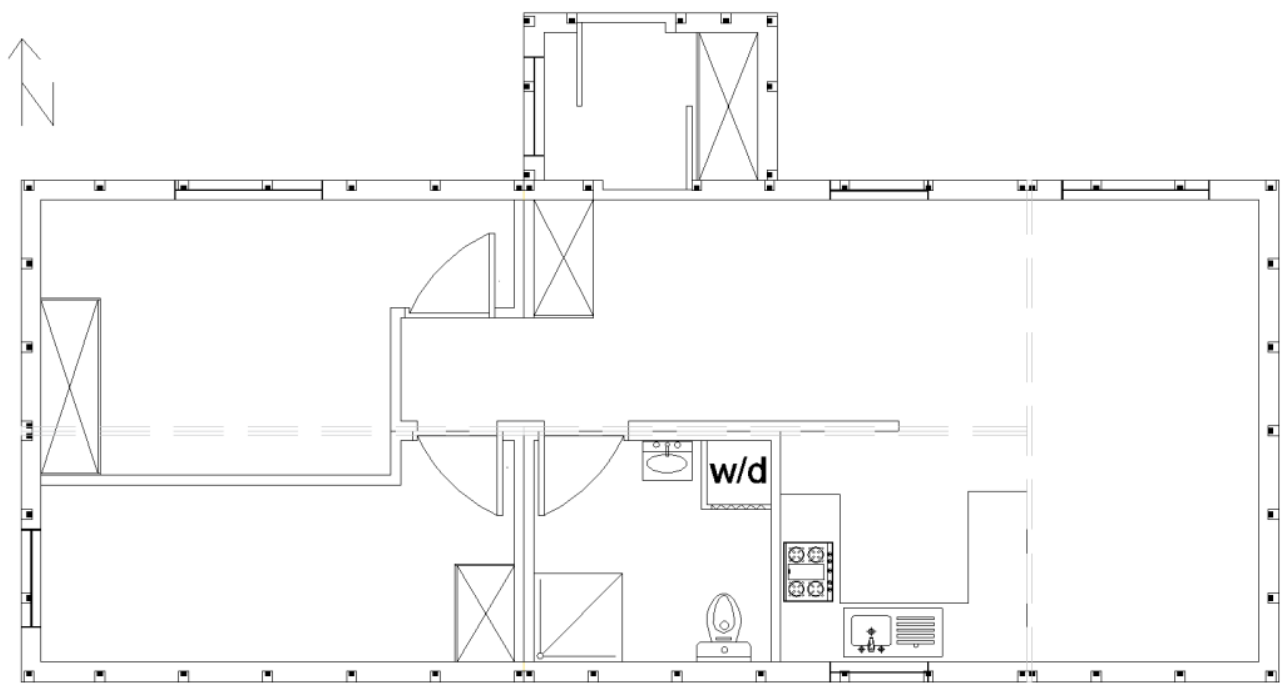

Figure 5.37: Bolt tightening points (Not at scale) 
The same idea was needed for the internal walls, so it was decided to design the cladding of the internal walls in two pieces (Figure 5.38), where the first piece was attached to the internal walls in the factory and the second piece would be attached on site to provide enough space for tightening the bolts. This additional cladding only occurs on one side of the internal walls and on the other side the cladding can be attached to the wall as one piece in the factory.

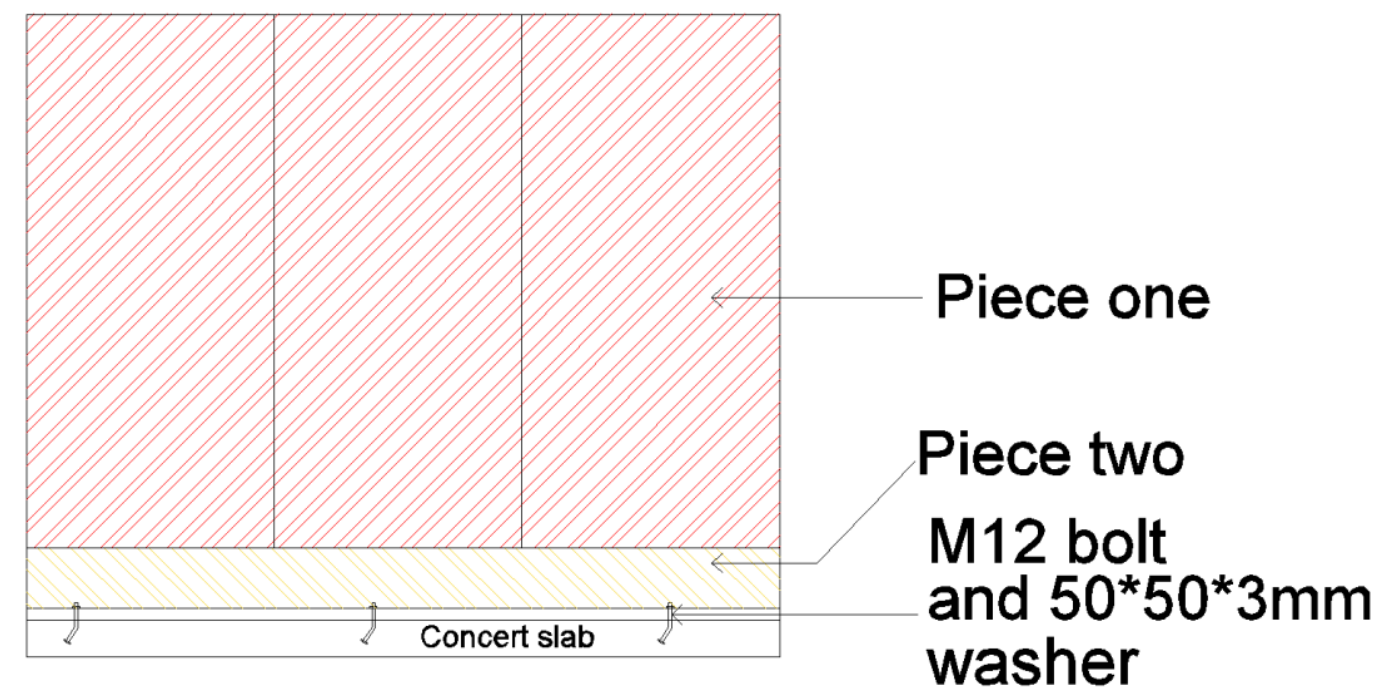

Figure 5.38: Cladding division (Not at scale)

\subsubsection{Attaching the Bathroom to the Slab}

Although the bathroom is built in the factory there are two factors to be considered. The first is that the shower should be step free and fully insulated, and the second is the different approaches to craning in this level entry shower and how this would fit with the slab. Different approaches have different advantages and disadvantages. For example, firstly it was decided to use a shower pod and make the slab thinner in the pod location, thus making it level. But eventually, it was concluded that the best approach would be building the bathroom on an insulated timber floor in the factory and sending it to the site as a fully closed module (Figure 5.39). The module can then be seated on the slab which is thinner beneath it (Figure 5.40). In this approach the bathroom will be fully insulated in the factory leading to minimum defects and the only on-site work will be attaching the module to the concrete slab. 


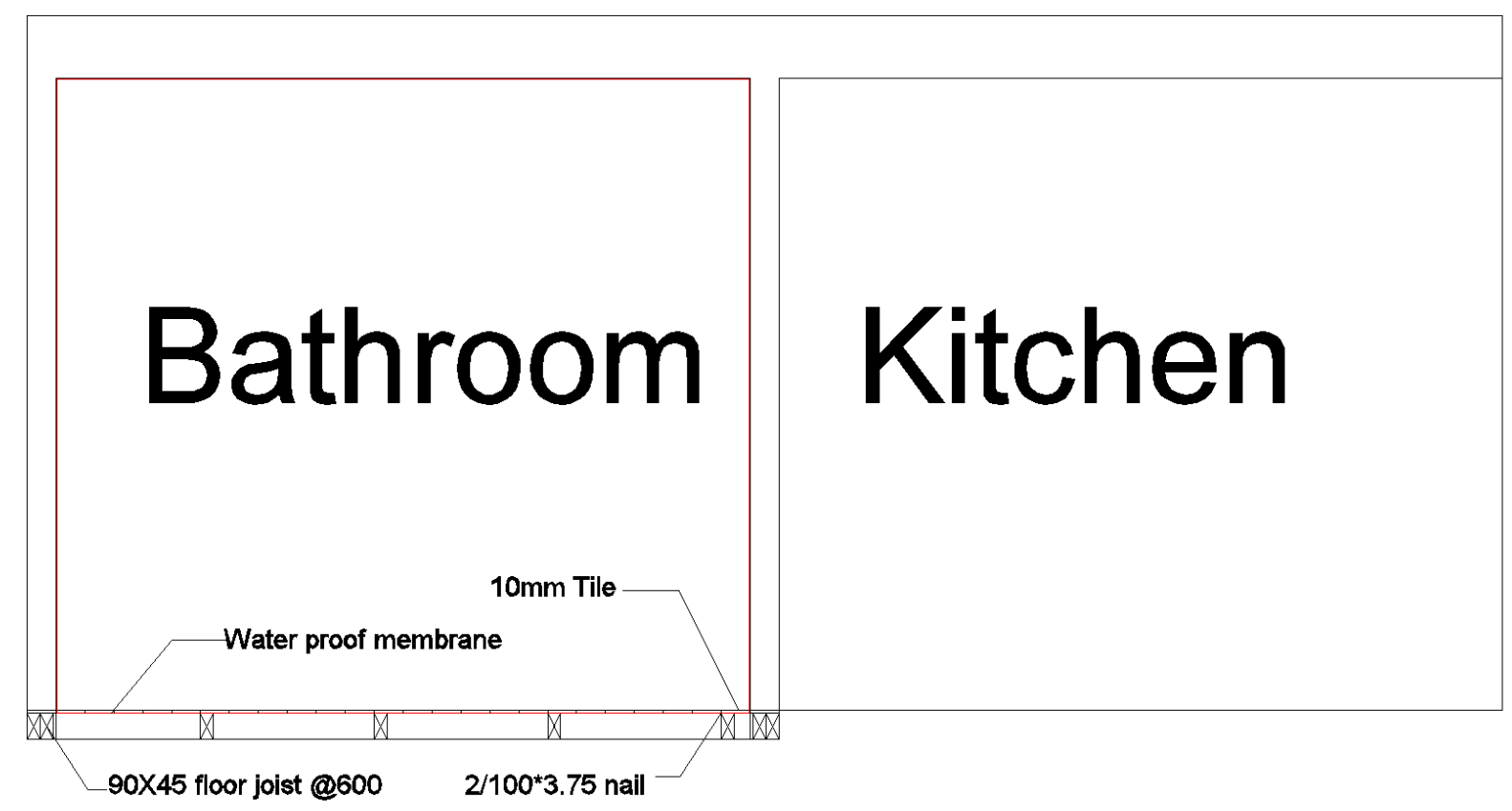

Figure 5.39: Bathroom module - cut through (Not at scale)
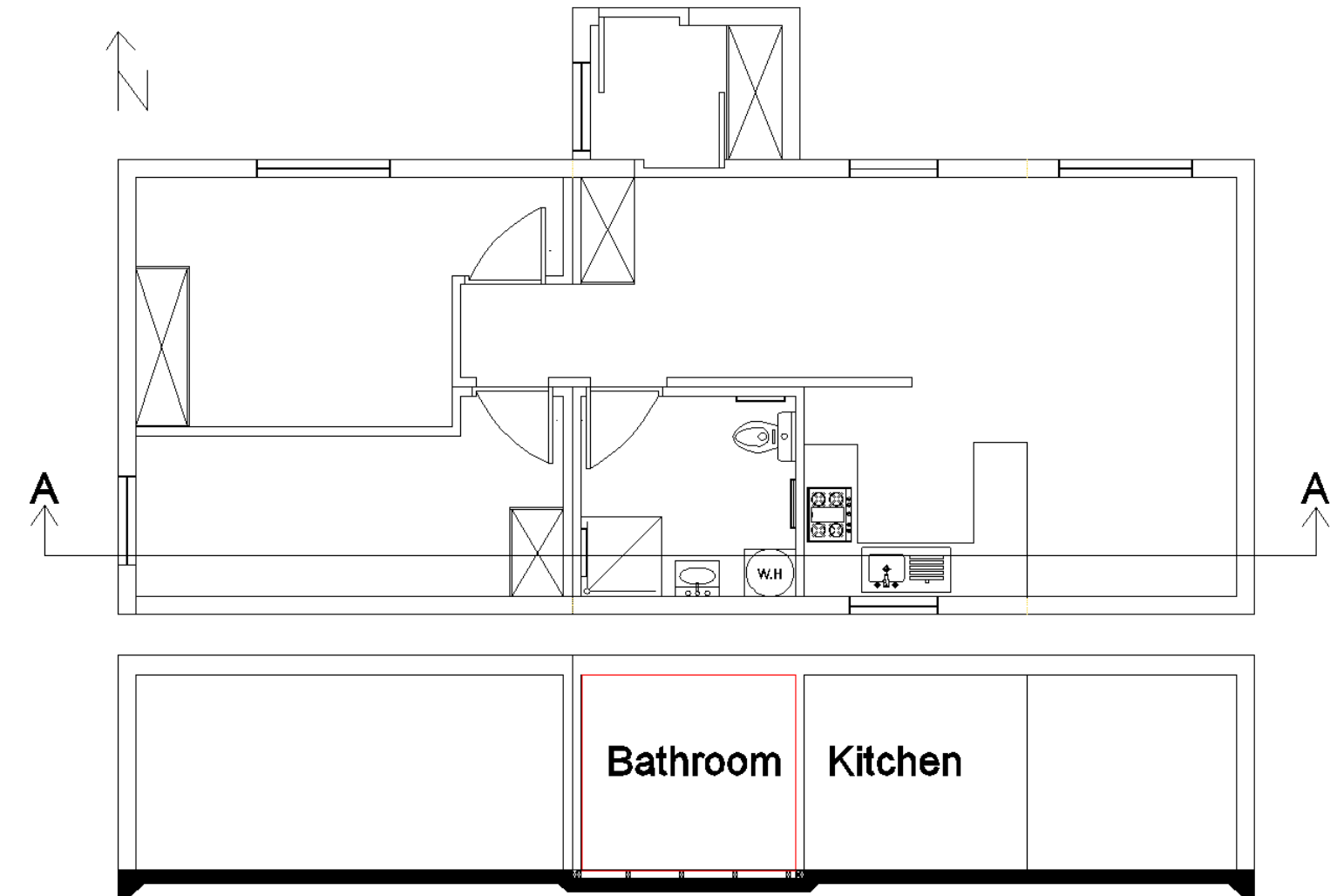

\section{$\operatorname{Sec} A-A$}

Figure 5.40: Concrete slab showing the detail in the shower area (Not at scale)

\subsubsection{The Final Width of SIPs Panels}

Having completed the investigation into the construction, transportation and assembly details, and having a final design, the last stage was to see what width of SIPs panels should be used for constructing the modules in the factory, as this might be different from the 
selected width discussed in Section 5.5. Figure 5.41 shows the SIPs walls in each module noting that these dimensions are the net length of SIPs walls, excluding $35 \mathrm{~mm}$ of membrane, cavity, cladding and paint (Figure 5.25).

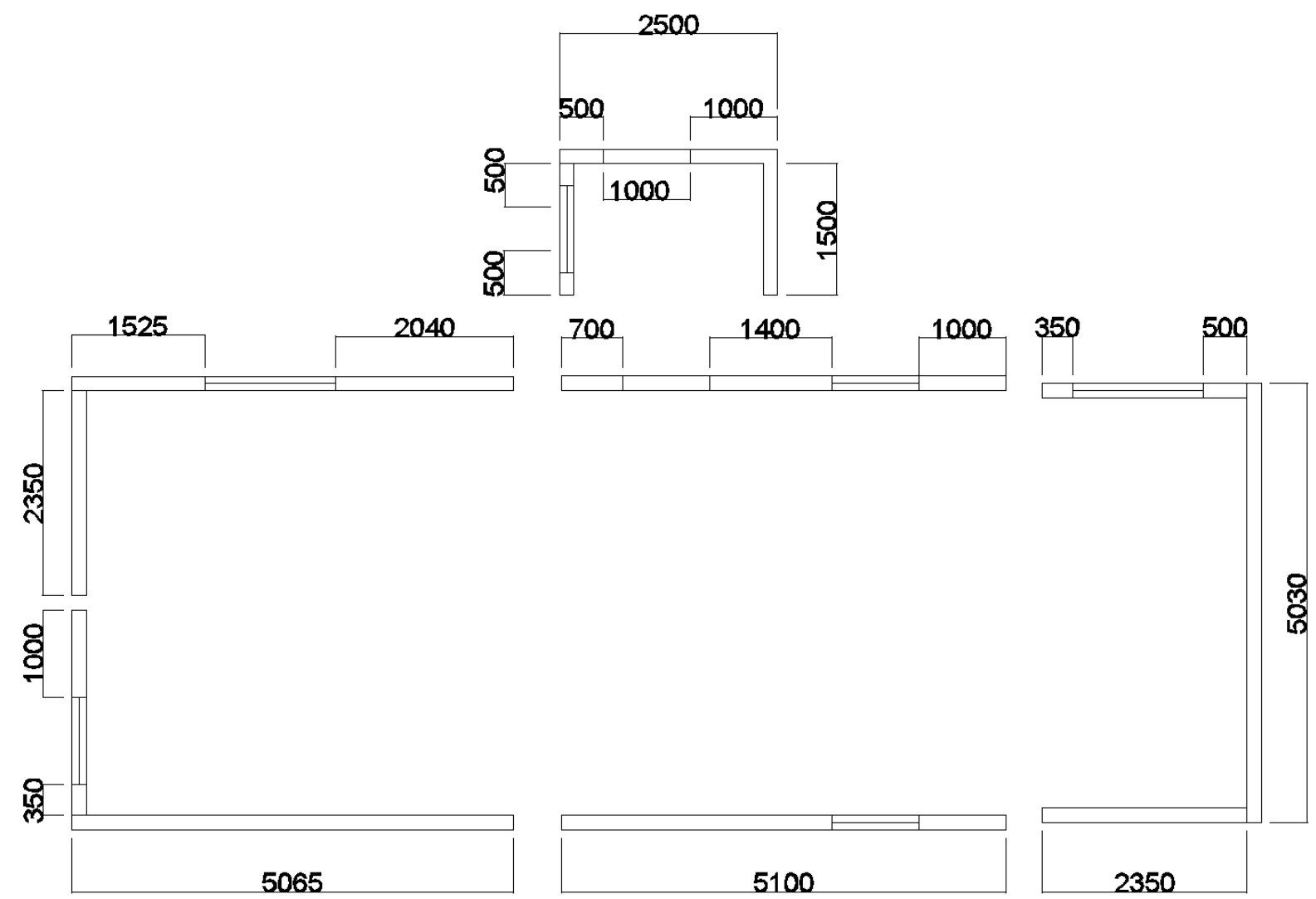

Figure 5.41: SIPs wall length (Not at scale)

Despite the fact that the final dimensions of all main modules are the same, $5.1 \mathrm{~m} \times 2.55 \mathrm{~m}$, the length of SIPs made walls in each module can be different based on where they sit. This idea was based on using the least variety of SIPs panel widths, while the openings were to be placed between panels, to make the manufacturing process easier (Figure 5.42).
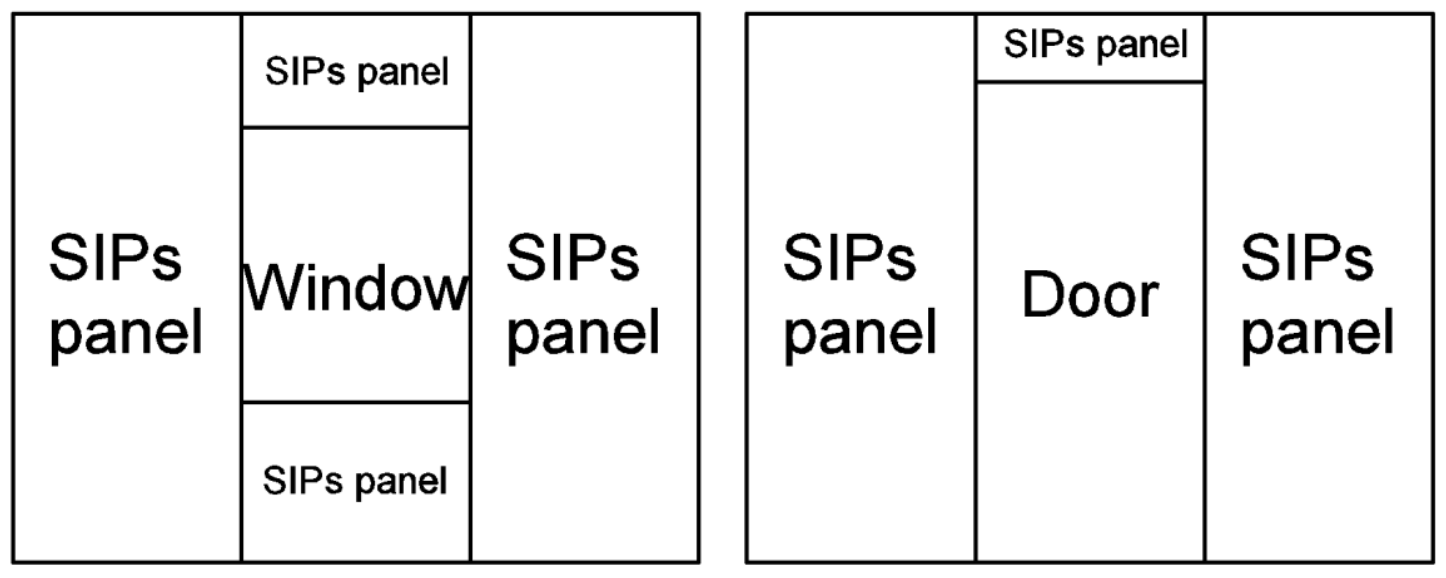

Figure 5.42: Openings placement (Not at scale) 
Considering Figure 5.41 and also testing different options, it was decided to build the SIPs walls using three different widths of SIPs panels of $1,000 \mathrm{~mm}, 500 \mathrm{~mm}$ and $350 \mathrm{~mm}$ as well as four secondary panels for completing the openings. The length of the wall can be adjusted using the panel-in-panel spline (Figure 5.43).

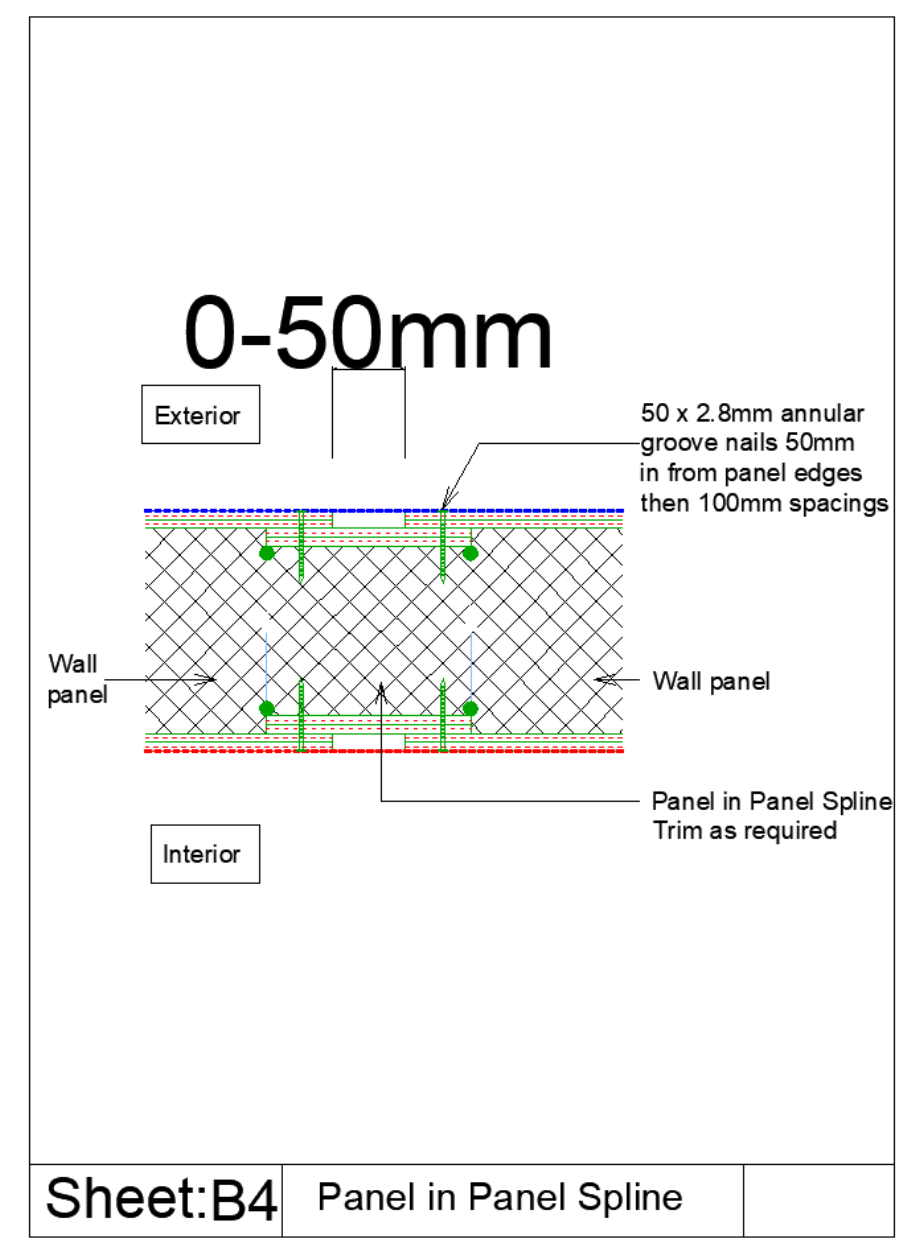

Figure 5.43: Panel in panel spline detail (Not at scale)

At this stage, the only module which could not be made of these three sizes of SIPs panel was the entrance. In order to avoid introducing a new width of SIPs panel, it was decided to modify the dimensions of the entrance to ease the manufacturing process. Two changes were made to the entrance module - increasing the net length of the SIPs wall from $2,480 \mathrm{~mm}$ to $2,500 \mathrm{~mm}$ and reducing the width of the entrance window from 1,000 $\mathrm{mm}$ to $500 \mathrm{~mm}$ (Figure 5.44). 

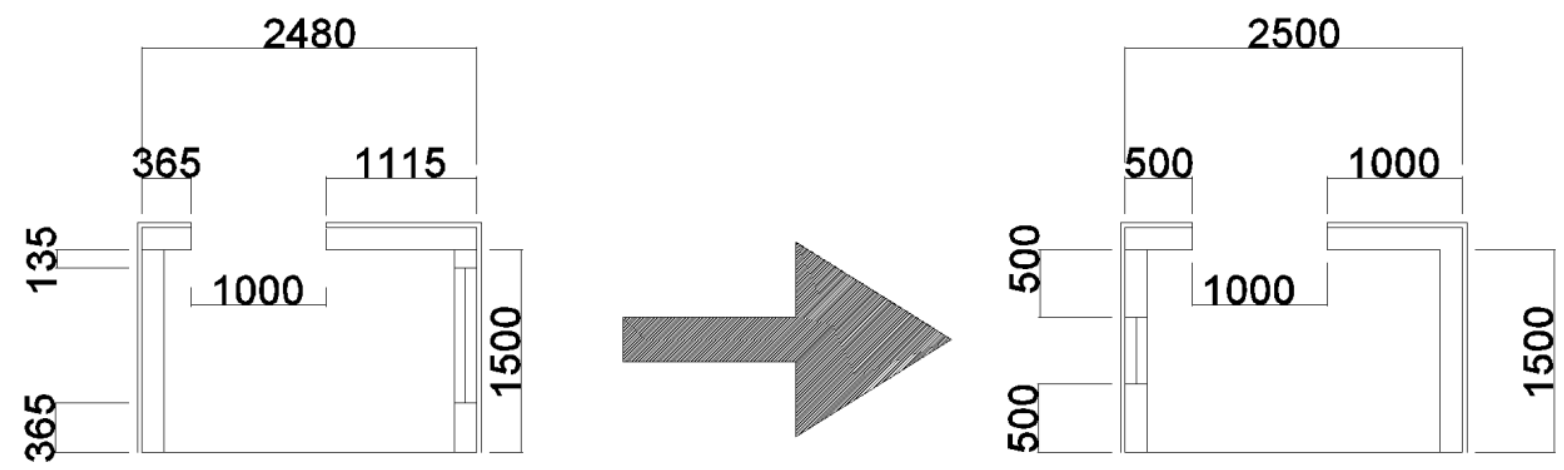

Figure 5.44: Entrance module modification (Not at scale)

These changes to the entrance module led to some minor modification in the bolt tightening layout by shifting the tightening point $20 \mathrm{~mm}$ to the right (Figure 5.45 ).

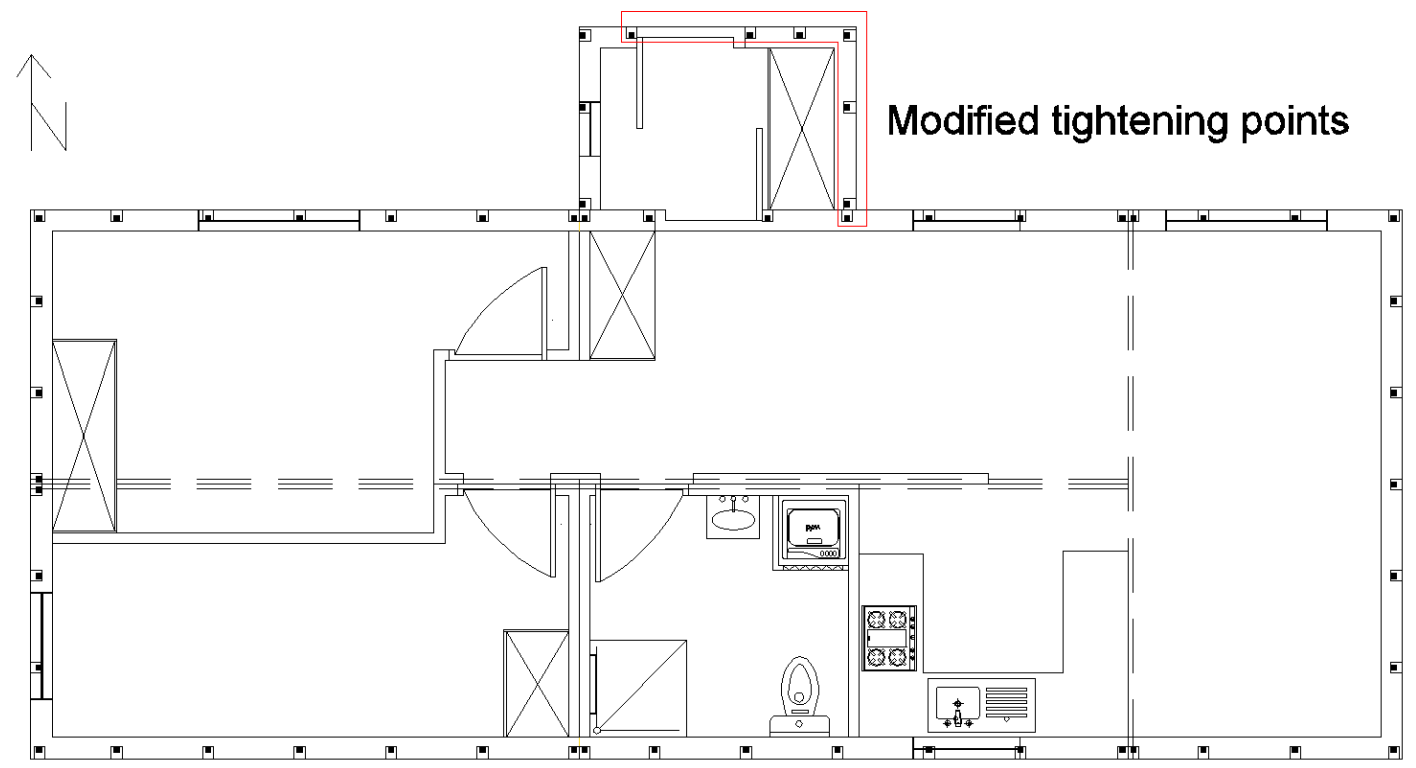

Figure 5.45: Modified tightening point (Not at scale)

Based on this information, Figure 5.46 shows the seven types of SIPs panels to be used to build the ADU in the factory. 


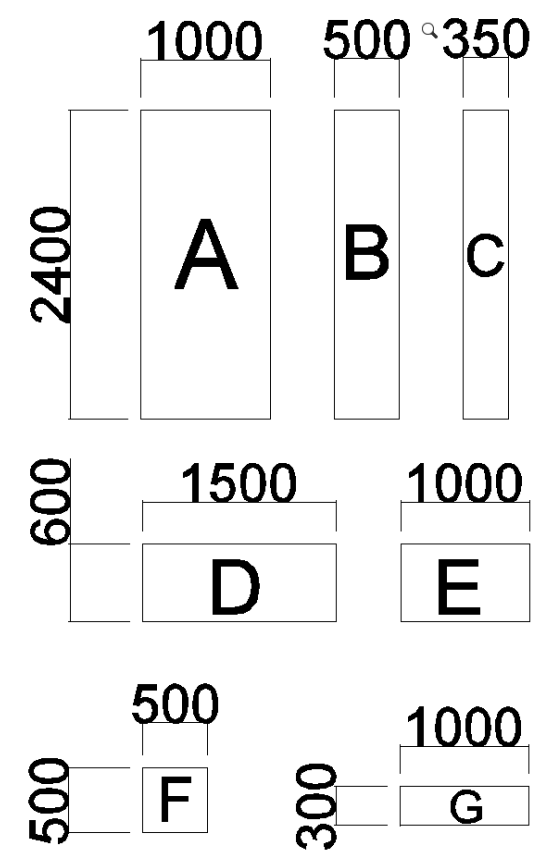

Figure 5.46: Types and dimensions of SIPs panels (Not at scale)

Figure 5.47 shows how the ADU is made of the seven types of panel in Figure 5.46, where the red rectangles indicate spline joints of between $25 \mathrm{~mm}-50 \mathrm{~mm}$.
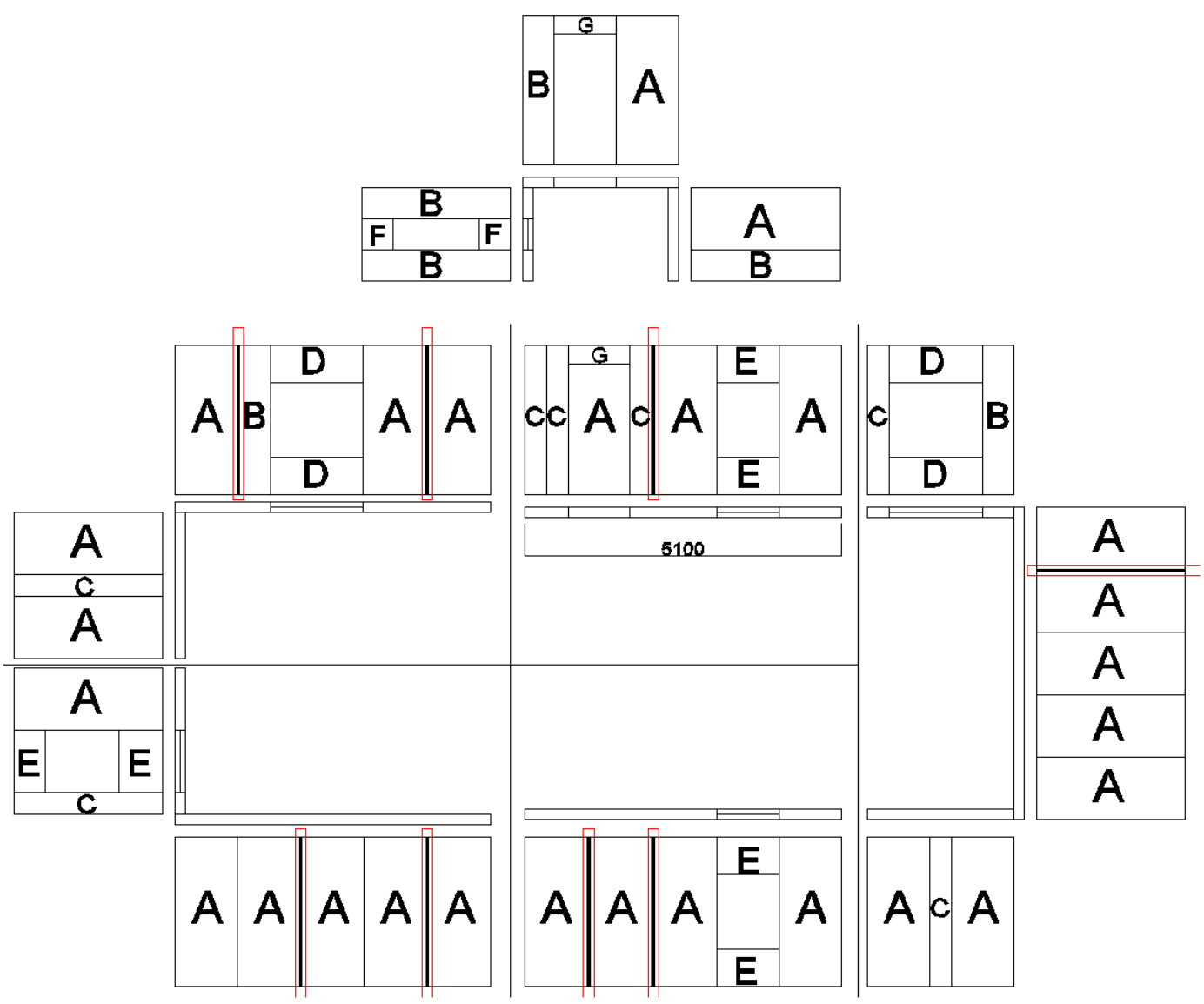

Figure 5.47: SIPs panel placement (Not at scale) 
Figure 5.47 shows the ADU can be made in a factory using 27 "Type A" sips panel, 6 each of "Type B", "Type C", and "Type E", 4 of "Type D", and 2 each of "Type F" and "Type G". There are also eight spline joints, which are marked using red rectangles in Figure 5.47. These adjust the length of the walls and avoid the need for further types of SIPs panel. The ceiling of each main module is made of five $1,020 \mathrm{~mm} \times 1,515 \mathrm{~mm}$ panels (Figure 5.26 ). The entrance module ceiling also is made of two SIPs panels of $2500 \mathrm{~mm} \times 750 \mathrm{~mm}$.

\subsubsection{Finalisation}

The aim of this stage was finalising the architectural and structural design of the ADU.

\subsubsection{Adding Furniture}

At this stage, furniture was added to the ADU plan in order to:

- See if the ADU has enough internal space for furniture based on Lifemark requirements;

- See if there is a need for any architectural/structural changes based on different possible furniture layouts;

- Have a better idea where the electrical sockets, lights and pipe runs should be placed to be able to serve different possible layouts.

In order to do this, different furniture layouts were designed, and Figure 5-50 shows two furniture layouts for Type B1. It is worth noting that at this stage there was no need for any architectural/structural change. 

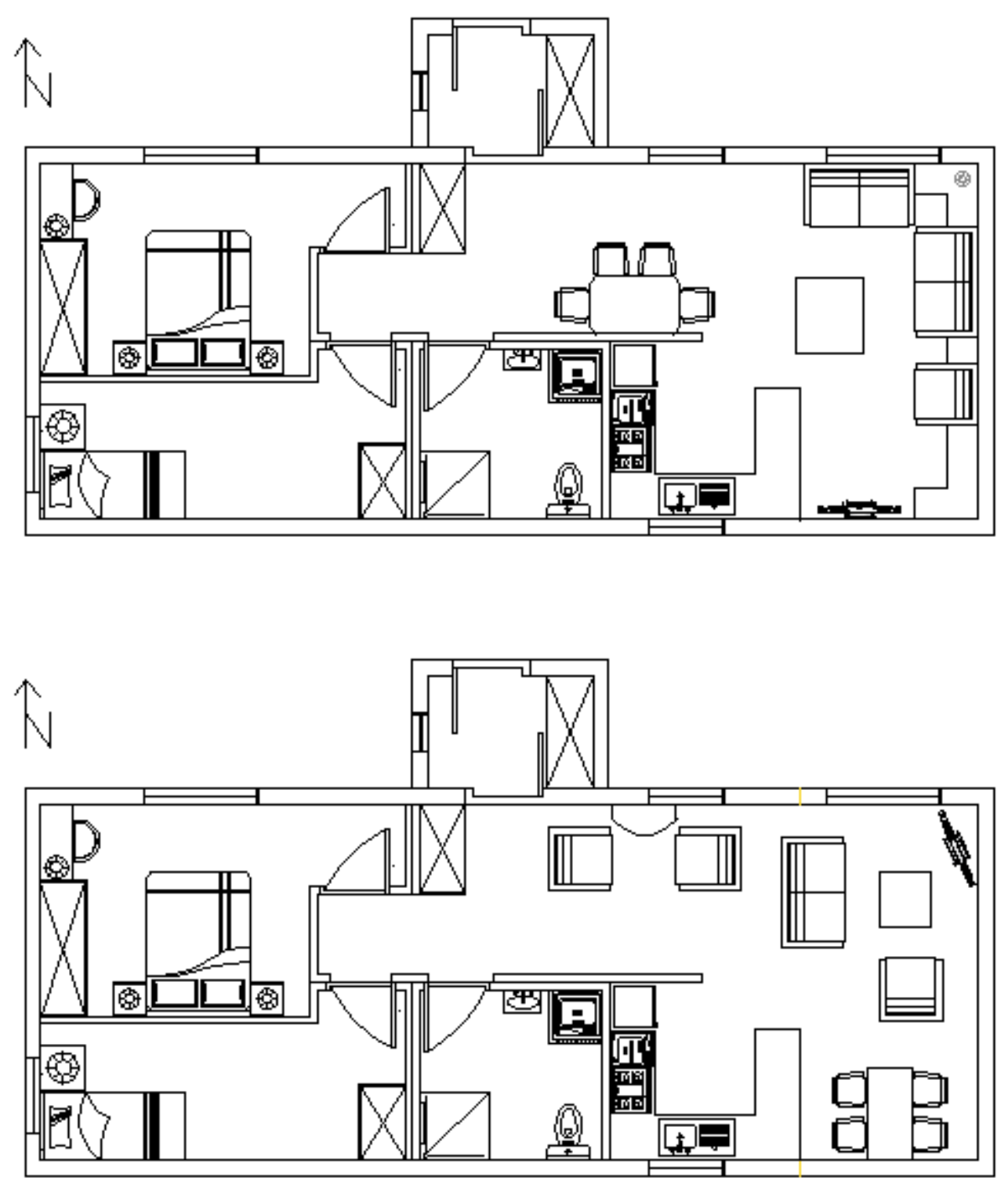

Figure 5.48: Selected furniture layouts (Not at scale)

Checking the bathroom layout with the Lifemark standards revealed that placing the WC on the outside wall to make the plumbing simpler would not give the required space around the WC so that those with accessibility issues could use it safely. This resulted in moving the WC to an internal wall (Figure 5-50). 


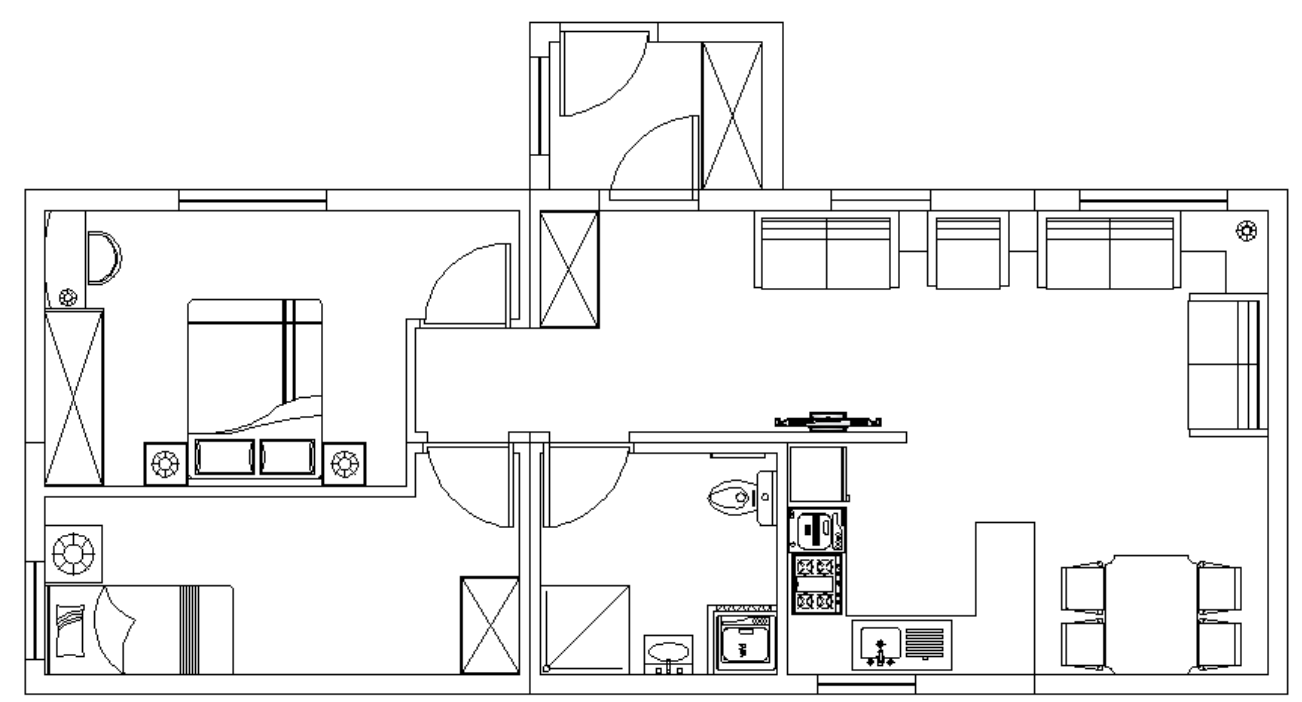

Figure 5-50: Furniture layout with WC moved (Not at scale)

At this point other possibilities were considered regarding the use of sliding doors and foldable furniture to use the space more efficiently. While use of sliding doors could improve the flow inside the ADU, they could not be used here. The main reason was the fact that sliding doors need space to slide into when the door is open. However due to the small size of the ADU and characteristics of SIPs panels there is no such space inside the ADU walls. The use of foldable furniture, as a common way of using tiny spaces, was considered but if was felt the priority should be for fixed furniture. The reason was considering older people as one of the main potential users of the ADU, this meant they would probably have furniture they would want to reuse in their new home. However, if the ADU was able to function with fixed furniture the use of foldable furniture would only create more interior space.

\subsubsection{Wiring and Plumbing}

\subsection{Plumbing}

From the beginning of the design, the idea was to put all appliances and services needing water into one module in order to make the waterproofing and plumbing of the ADU easier and reduce the length of the pipes. As the existing bathroom design meant that pipes needed to run along three walls (Figure 5-50) it was decided to redesign the bathroom to look for a more efficient layout. The result was Figure 5.49, where the water heater is located above the washing machine to increase the efficiency of the plumbing system. In the new bathroom, pipes run along with two walls rather than three. 


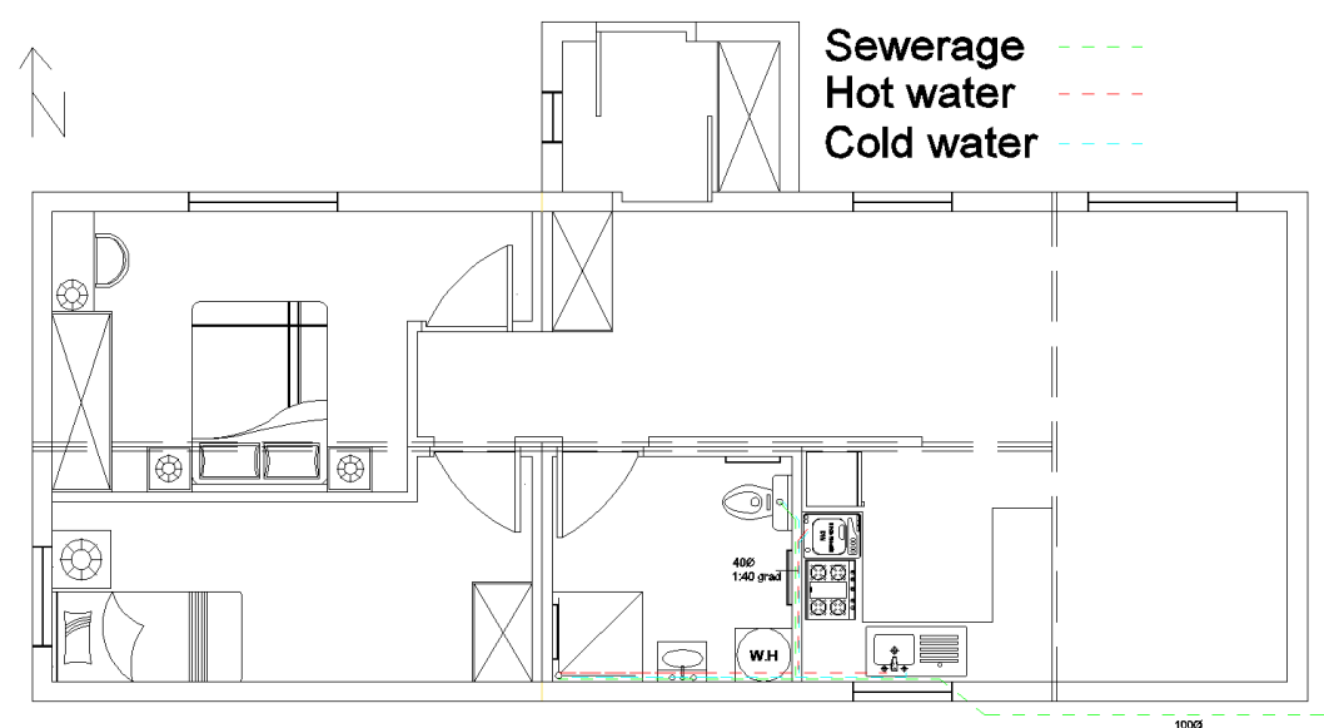

Figure 5.49: Plumbing layout (Not at scale)

\subsection{Wiring}

The wiring layout was designed in a flexible way to be able to provide an acceptable level of access to power points and light switches regardless of the furniture layout (Figure 5.50). Due to the flammability of the SIPs panel's insulation core, especially those made of polystyrene, it was decided to avoid putting electrical cables inside the external walls. As a result, the majority of wires were placed inside the internal walls. Whenever it was impossible to do this, cabling was attached to the internal surface of the SIPs panels and covered by trunking.

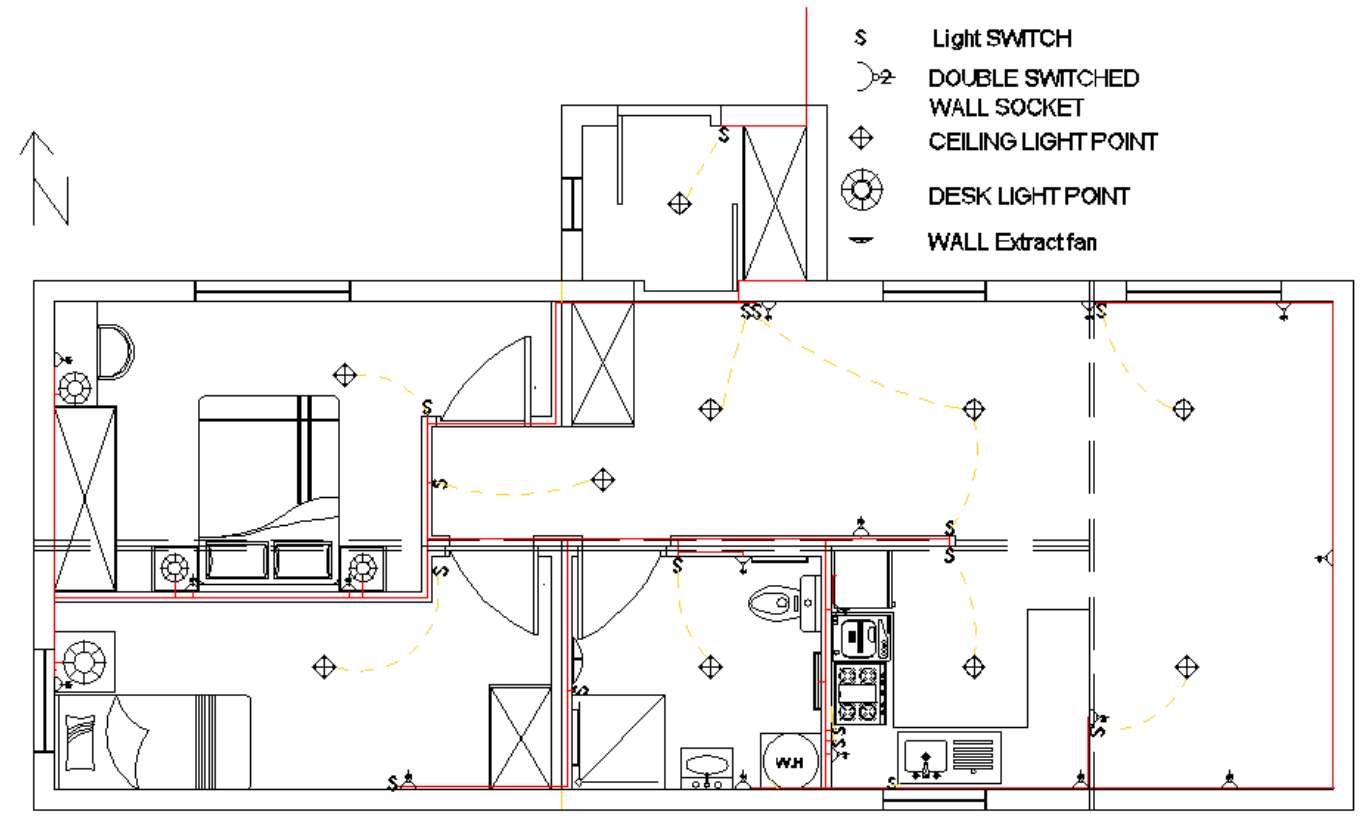

Figure 5.50: Wiring layout (Not at scale) 


\subsubsection{Accessibility for Older People}

Finally, one of the main aspects of the design is accessibility. This aspect was continuously tested again Lifemark requirements to make sure that the ADU would accessible. Figure 5.51 shows the $1050 \mathrm{~mm}$ corridor, and minimum of $800 \mathrm{~mm}$ space beside the beds required by Lifemark. This space guarantees the easy travel inside the ADU for people with disabilities, but on the other side puts pressure on the layout design.

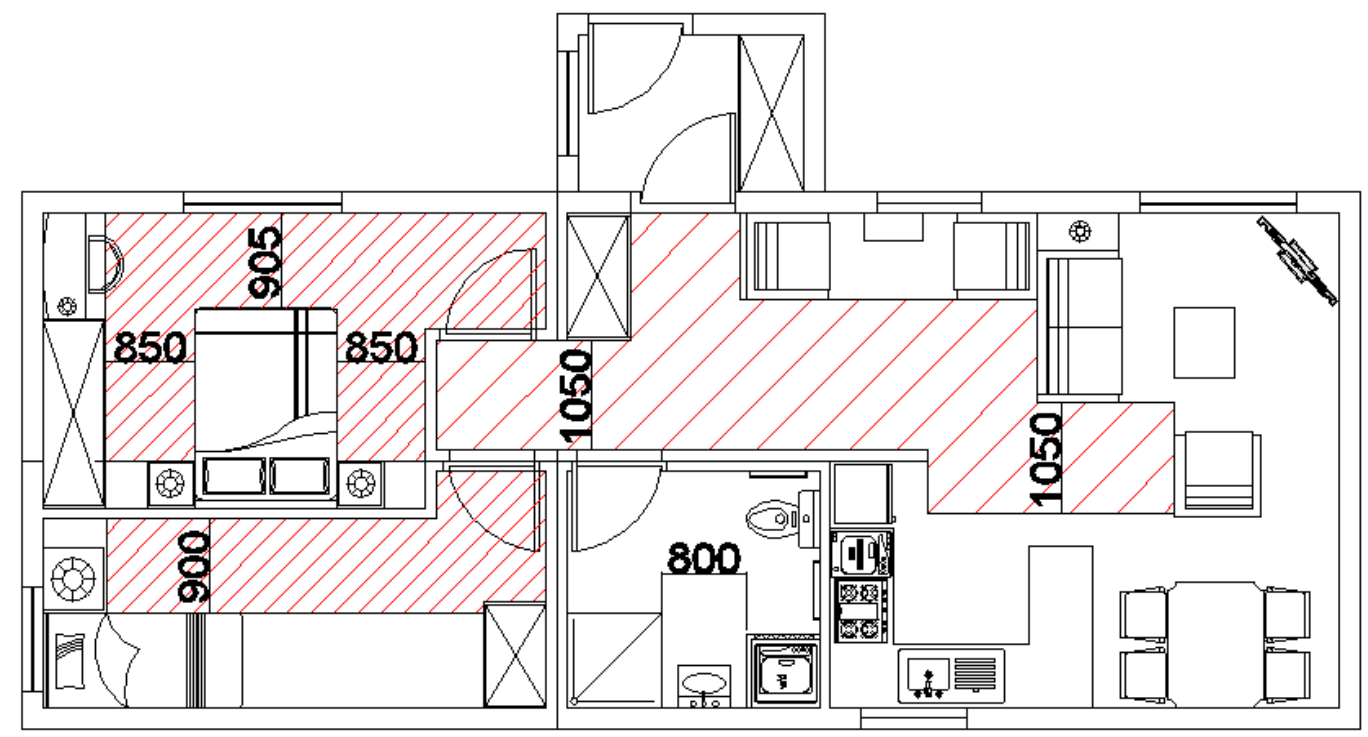

Figure 5.51: Lifemark requirement in selected furniture layout (Not at scale)

\subsection{Summary}

This chapter presented different layouts for the ADU and investigated the way it could be built, transported and assembled on the site. Based on this investigation a typical twobedroom ADU is made of five modules, each with its own function and all of the same size, and a smaller entrance module. These modules can sit together in different ways to make different layouts (see Section 5.4.4). Based on the construction approaches and the materials available, and the three series of space conditioning energy simulations, a typical twobedroom ADU is made of $165 \mathrm{~mm}$ and $215 \mathrm{~mm}$ SIPs wall and ceiling panels, with a separate trussed rafter gable roof. The energy simulations showed the best floor option is a $150 \mathrm{~mm}$ concrete slab, insulated with $150 \mathrm{~mm}$ polystyrene underneath. The construction details and assembly process were then designed and discussed based on these decisions. Part Three of the thesis presents a detailed analysis of the typical two-bedroom ADU. 


\section{Chapter 6 Life Cycle Assessment (LCA)}

\subsection{Introduction}

This chapter evaluates the energy consumption, $\mathrm{CO}_{2}$ emissions and cost of the ADU construction and its maintenance during its life span. Chapter 6 is in three sections. The first section focuses on Life Cycle Energy Assessment (LCEA) and includes calculations of the energy embodied in building materials and also the energy needed for operating the ADU, which here is just heating. At the end of this section, the results of the SuNREL space conditioning energy simulation are presented in two parts. The first part looks at the ADU with different layers of thermal mass to see how efficient it is, and also to check if there is any risk of its overheating. The second part simulates the space conditioning energy consumption of the ADU, based on modifications made as a result of the LCEA. The performance of the ADU in different climates and different orientations in the Wellington case study is investigated.

The second part of this chapter evaluates the $\mathrm{CO}_{2}$ emissions of the ADU during its life. As with LCEA, the Life Cycle $\mathrm{CO}_{2}$ emissions (LCCO) of the ADU include the $\mathrm{CO}_{2}$ emitted during producing and manufacturing the materials and also those released during the conditioning energy production and use. The third section investigates the cost of building, maintaining and operating the ADU over a 100 -year period.

The LCA gives extensive data about how the ADU behaves in terms of its energy consumption, $\mathrm{CO}_{2}$ emissions and cost. In order to have a more realistic idea of the value of the ADU these results are compared with some conventionally made houses. These houses were all designed to be energy efficient but not prefabricated. The houses are the BIAC house (New Zealand), the Green Home (Australia) and the Hockerton Houses (UK). A normal New Zealand house located in the Tarikaka Settlement in Wellington was used for a life cycle embodied energy comparison. The LCCO and Life Cycle Cost (LCC) of the ADU are also compared with the BIAC house. The availability of LCA data was the reason for choosing these case studies.

\subsection{Case studies}

\subsubsection{The BIAC House}

The BIAC House was a $94 \mathrm{~m}^{2}$ timber house on a flat site, with concrete steps and precast piles and corrugated steel clad gable roof, and with 12 electrical lights and 16 power points (Baird 
et al., 1984, p.113) (Figure 6.1). While Baird et al. (1984) calculated the life cycle energy of the original house, Mithraratne et al. (2007, pp. 124-125) investigated the life cycle energy of the house over 100 years for the three different scenarios of light, heavy, and super-insulated construction as follows (Mithraratne et al., 2007, p.152-154):

\section{Light construction}

- Softwood framing to walls and roof;

- Fibre cement weather boarding as external cladding and plasterboard internal lining;

- Corrugated steel roofing with plasterboard ceiling;

- $94 \mathrm{~mm}$ glass fibre insulation to walls and $75 \mathrm{~mm}$ glass fibre to sloping and flat ceilings;

- Raised timber floor with draped foil insulation;

- Aluminium framed windows with single clear glass.

\section{Heavy construction}

- Softwood framing to walls with external brick veneer and plasterboard internal lining;

- $94 \mathrm{~mm}$ glass fibre insulation to walls and $75 \mathrm{~mm}$ glass fibre to sloping and flat ceilings;

- Softwood framing to roof with concrete tile covering and plasterboard ceiling;

- Concrete slab floor with $25 \mathrm{~mm}$ expanded polystyrene perimeter insulation to depth of $500 \mathrm{~mm}$;

- Aluminium framed windows with single clear glass.

\section{Super-insulated construction}

- Particleboard finished timber floor and softwood framed walls both with $200 \mathrm{~mm}$ glass fibre insulation;

- Pitched roof with corrugated steel cladding and a flat ceiling with $200 \mathrm{~mm}$ glass fibre insulation;

- Aluminium double-glazed windows.

Considering the different characteristics of each scenario, the super-insulated scenario is the closest to the ADU and was used for comparison. 
This content is unavailable.

Please consult the print version for access.

Figure 6.1: BIAC standard house (Baird, et al., 1984, P.113)

\subsubsection{Tarikaka Settlement}

Tarikaka Settlement house in Wellington, New Zealand was a timber-framed and clad house of approximately $86.5 \mathrm{~m}^{2}$ built by the Department of Railways in $1928-29$ and rented to its workers (Leah, 2015) (Figure 6.2).

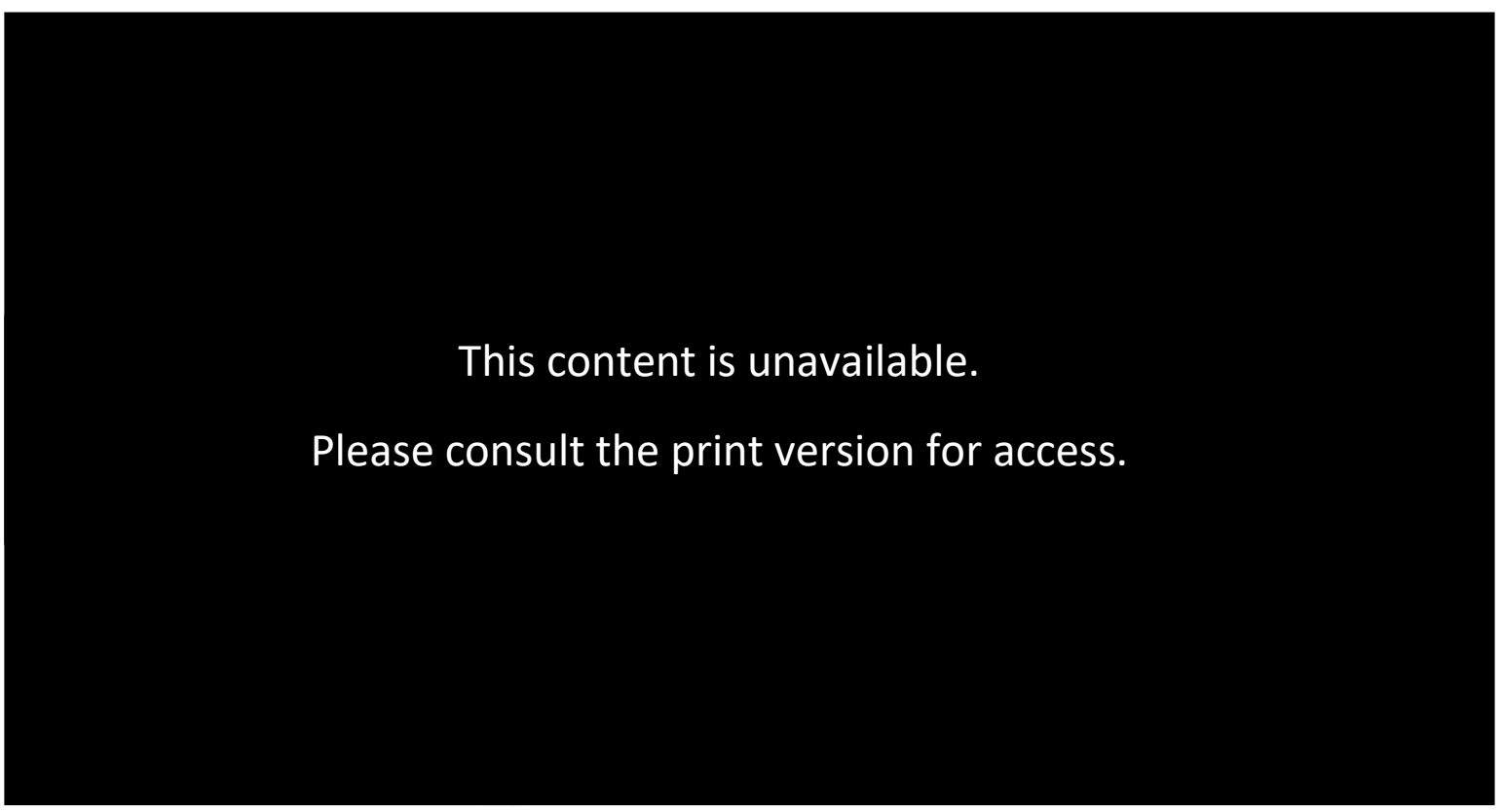

Figure 6.2: Tarikaka Street original plan (Leah, 2015)

\subsubsection{Green Home}

The Green Home was a $128 \mathrm{~m}^{2}$, detached double story home, built in the 1990s in Melbourne, Australia (Figure 6.3). The house was made of timber frame brick-veneer external walls and timber frame internal walls on a concrete slab. The first-floor was timber and the timberframed roof was covered with concrete tiles. Windows were timber frame with double glazed low-e glass (Fay et al., 2000; Petrović et al., 2017). Due to the insulation placement, the brick veneer has a tiny affect as thermal mass. 
This content is unavailable.

Please consult the print version for

access.

Figure 6.3: Green Home floor plan (Fay et al., 2000)

\subsubsection{Hockerton House}

The Hockerton House was a $167 \mathrm{~m}^{2}$ house that included a $47 \mathrm{~m}^{2}$ conservatory, constructed in 1995 in the village of Hockerton in Nottinghamshire, UK (Figure 6.4). The project, which originally consisted of five single-storey terraced, earth-sheltered houses, was designed to be zero emission and autonomous. Each house has only one exposed face to the south to make use of passive solar gains (Fay et al., 2000; Petrović et al., 2017). The Hockerton house was made of a $300 \mathrm{~mm}$ concrete slab with $200 \mathrm{~mm}$ dense concrete block internal walls and a concrete beam and block roof. The northern wall, which works as a retaining wall, was made of two masonry block walls filled with $300 \mathrm{~mm}$ reinforced concrete. The external walls, slab and roof were all insulated with $300 \mathrm{~mm}$ polystyrene and the concrete beam and block roof was further covered with a membrane and $400 \mathrm{~mm}$ of topsoil. The windows were timber framed triple glazed, with low-e glass, with argon fill (Fay et al., 2000; Petrović et al., 2017). 


\section{This content is unavailable.}

\section{Please consult the print version for access.}

Figure 6.4: Hockertoun House floor plan (Fay et al., 2000)

It is recognised these case studies are in different locations with different environmental conditions and use different construction systems and materials but the aim behind these designs makes the comparison useful. All designs try to reduce the life cycle energy of the house and its environmental impacts. Table 6.1 summarises the characteristics of each building. 
Table 6.1: Case study house characteristics

\begin{tabular}{|c|c|c|c|c|}
\hline & ADU & BIAC House & Green Home & Hockerton House \\
\hline Location/year & $\begin{array}{l}\text { Auckland, } \\
\text { NZ/2019 }\end{array}$ & $\begin{array}{l}\text { Auckland, } \\
\text { NZ/1970s-2019 }\end{array}$ & $\begin{array}{l}\text { Melbourne, } \\
\text { Australia/1990s }\end{array}$ & $\begin{array}{l}\text { Nottinghamshire, } \\
\text { UK/1995 }\end{array}$ \\
\hline Floor & $\begin{array}{l}150 \mathrm{~mm} \text { concrete } \\
\text { slab }\end{array}$ & $\begin{array}{l}\text { Concrete piles } \\
\text { and raised } \\
\text { timber floor with } \\
\text { particleboard }\end{array}$ & $\begin{array}{l}\text { Concrete slab and } \\
\text { timber floor for } \\
\text { the second storey }\end{array}$ & $\begin{array}{l}\text { 300mm concrete } \\
\text { slab }\end{array}$ \\
\hline External walls & $165 \mathrm{~mm}$ SIPs panel & $\begin{array}{l}\text { Softwood timber } \\
\text { frame }\end{array}$ & $\begin{array}{l}\text { Timber frame } \\
\text { with brick veneer }\end{array}$ & $\begin{array}{l}\text { Earth sheltered on } \\
300 \mathrm{~mm} \text { concrete } \\
\text { core with a glazed } \\
\text { south face }\end{array}$ \\
\hline Internal walls & Timber frame & Timber frame & Timber frame & $200 \mathrm{~mm}$ concrete \\
\hline Roof & $\begin{array}{l}215 \mathrm{~mm} \text { SIPs panel } \\
\text { ceiling and timber } \\
\text { trussed rafter roof } \\
\text { covered in } \\
\text { corrugated steel } \\
\text { and SIPs panel } \\
\text { ceiling }\end{array}$ & $\begin{array}{l}\text { Timber trussed } \\
\text { rafter roof with } \\
\text { corrugated steel } \\
\text { cladding and } \\
\text { insulated ceiling }\end{array}$ & $\begin{array}{l}\text { Timber roof with } \\
\text { concrete tile and } \\
\text { insulated ceiling }\end{array}$ & $\begin{array}{l}400 \mathrm{~mm} \text { earth on } \\
\text { concrete beam and } \\
\text { block with } \\
\text { insulation between }\end{array}$ \\
\hline Windows & $\begin{array}{l}\text { Timber } \\
\text { frame/double } \\
\text { glazed } \\
\end{array}$ & $\begin{array}{l}\text { Aluminium } \\
\text { frame/double } \\
\text { glazed }\end{array}$ & $\begin{array}{l}\text { Timber } \\
\text { frame/double } \\
\text { glazed }\end{array}$ & $\begin{array}{l}\text { Timber frame/triple } \\
\text { glazed }\end{array}$ \\
\hline Insulation & $\begin{array}{l}191 \mathrm{~mm} \\
\text { polystyrene in the } \\
\text { ceiling and } \\
151 \mathrm{~mm} \\
\text { polystyrene in } \\
\text { walls with } 150 \mathrm{~mm} \\
\text { polystyrene under } \\
\text { the slab }\end{array}$ & $\begin{array}{l}200 \mathrm{~mm} \text { glass } \\
\text { fibre in ceiling } \\
\text { and walls }\end{array}$ & $\begin{array}{l}\text { Air gap inside the } \\
\text { external walls and } \\
\text { foil plus R1 } \\
\text { beneath the roof } \\
\text { tiles }\end{array}$ & $\begin{array}{l}300 \mathrm{~mm} \text { polystyrene } \\
\text { to walls, slab and } \\
\text { roof }\end{array}$ \\
\hline
\end{tabular}

Table 6.1 shows all houses except the BIAC House used concrete floor to store heat and reduce the energy needed for keeping the house temperature stable, especially in colder periods. Moreover, all the designs, except for the Green Home, used a thick layer of insulation of different materials to reduce energy use and keep the interior space comfortable.

\subsection{Life Cycle Energy Calculations}

\subsubsection{Assumptions}

As previously mentioned in Section 3.7.3, any LCEA calculation includes assumptions that are based on the specifications of the study. The assumptions for this study are outlined below. First, the energy involved in constructing the ADU, both in the factory and on-site, that used for the transportation of the components to the site, and for the final demolition of the ADU were ignored in this research as, usually, together these amount to approximately $1 \%$ of a building's LCE (Ramesh, 2010). 
The EE coefficients of materials in this research are extracted from Table 3.3 and if any New Zealand coefficient was not available the coefficient for same material is used. The only exception to this method of determining the EE coefficient is adhesives, as each SIPs factory uses its own special glue for attaching the OSB sheets to the insulation core, and most appear to be polyurethane-based (Apollo Adhesive Solutions, 2014). After an extensive online and store base search, no reliable data was found for the EE of polyurethane adhesive or PVA, which potentially could also be used. To see how big the effect of using different adhesives could be, Table 6.2 shows the EE of different types of adhesives.

Table 6.2: Embodied energy of different types of adhesive

\begin{tabular}{|l|l|l|l|}
\hline Adhesive & Unit & Embodied energy & Source \\
\hline Epoxide Resin & $\mathrm{MJ} / \mathrm{kg}$ & 137 & Hammond and Jones, 2011 \\
\hline Mastic Sealant & $\mathrm{MJ} / \mathrm{kg}$ & $62-200$ & Hammond and Jones, 2011 \\
\hline Melamine Resin & $\mathrm{MJ} / \mathrm{kg}$ & 97 & Hammond and Jones, 2011 \\
\hline Phenol Formaldehyde & $\mathrm{MJ} / \mathrm{kg}$ & 87 & Alcorn and Wood, 1998 \\
\hline Urea Formaldehyde & $\mathrm{MJ} / \mathrm{kg}$ & 78 & Alcorn and Wood, 1998 \\
\hline Adhesives, cold & $\mathrm{MJ} / \mathrm{m}^{2}$ & $7-14$ & Ashby, 2013 \\
\hline Adhesives, heat-curing & $\mathrm{MJ} / \mathrm{m}^{2}$ & $18-40$ & Ashby, 2013 \\
\hline
\end{tabular}

The amount of adhesive for $1 \mathrm{~m}^{2}$ of SIPs panel depends on factors such as the type of adhesive, the material of the finish, and the function of the glued elements (County Construction Chemicals, 2007; Bekhta and Marutzky, 2007). However, 250gm-500gm adhesive is acceptable for attaching $1 \mathrm{~m}^{2}$ of OSB to polystyrene (Bunnings, 2019). As over $160 \mathrm{~m}^{2}$ SIPs panels are used in the ADU, which is equal to over $320 \mathrm{~m}^{2}$ of glued area, using different types of glue leads to an EE from 2,240MJ (the minimum of $7 \mathrm{MJ} / \mathrm{m}^{2}$ using cold adhesive) to $16,000 \mathrm{MJ}$ (the maximum of $50 \mathrm{MJ} / \mathrm{m}^{2}$ using mastic sealant). The big difference between the minimum and maximum value shows how important the selection of adhesive is. As a result, it was decided to use the average of the cold adhesive value range, as this was the closest material to PVA given the available data.

The OE in LCEA calculations is normally the energy used by the occupants and includes heating, cooling, and lighting as well as electrical devices (Mithraratne et al., 2007). However, in this research, it stands for just the heating energy knowing that New Zealand houses usually do not need cooling, and whenever a comparison has been made with other studies only heating energy is compared. This is due to the fact that space conditioning energy is the aspect most affected by design and construction, while others like appliance energy 
consumption are more affected by the users. The space heating energy by itself accounts for approximately 33\% of a household energy consumption in New Zealand (Energy Consult, 2015), although this would be $40 \%$ in Australia and would be different again in other countries (Energy Consult, 2015).

Regarding the life expectancy of materials and building elements, two assumptions have been made. The manufacturer of SIPs panels warrant their panels for 50 years as this is the structural life required by the NZBC and standards such as CertMark. However, they expect their panels to last for longer, but the use of SIPs panels in New Zealand is new with no experience of using them for a long time (NZSIPs, 2019). Given that the SIPs panels in the ADU are clad externally with a membrane as well as having an air gap between them and the cladding, they should last for the life of the building (100 years). Consequently the life span of the SIPs panels in this research is assumed to be 100 years. Table 3.4 gives the life span of the roof trusses as 90 years, but they would not be replaced if the ADU is thought to have a life of 100 year, so here it is assumed that they can stand for another 10 years, to reach year 100 , with some maintenance. Consequently, the trussed rafter roof is not replaced in year 90 . More data about what is included and what is excluded in calculations is mentioned in the relative sections.

\subsubsection{Initial results}

The first calculation gave an initial EE of $1,508 \mathrm{GJ}$ or slightly less than $22.0 \mathrm{GJ} / \mathrm{m}^{2}$. This is 7 times higher than the findings of Baird et al. (1984), and 9 times higher than Mithraratne et al. (2007) and Leah (2015) (Table 6.3).

Table 6.3: ADU initial embodied energy comparison

\begin{tabular}{|l|c|c|}
\hline Building & Embodied energy (GJ) & Embodied energy (GJ/m $\mathbf{m}^{\mathbf{}}$ ) \\
\hline ADU & 1,508 & 22.00 \\
\hline BIAC (Baird et al., 1984) & 298 & 3.17 \\
\hline BIAC (Mithraratne et al., 2007) & 217 & 2.30 \\
\hline $\begin{array}{l}\text { Tarikaka Settlement (Leah, } \\
\text { 2015) }\end{array}$ & 202 & 2.33 \\
\hline
\end{tabular}

The much higher EE of the ADU could be due to the quantity of polyurethane insulation used in the SIPs panels or to a mistake in the calculations. At this stage, it was decided to recheck all calculations and EE coefficients. Checking showed the polyurethane was responsible for over $78 \%$ of the initial EE of the ADU, which seemed high. Making sure the volume was calculated correctly, it was decided to compare the EE of polyurethane extracted from the 
Alcorn and Wood (1998) report, which is now 21 years old, with other studies. Hammond and Jones (2011) and Deshmukh and More (2014) both calculated the EE of polyurethane rigid foams as $101.5 \mathrm{MJ} / \mathrm{kg}$ or approximately $3045 \mathrm{MJ} / \mathrm{m}^{3}$. The World Bank Group (2016) gives the EE of rigid polyurethane foam as $123 \mathrm{MJ} / \mathrm{kg}$ or $3963 \mathrm{MJ} / \mathrm{m}^{3}$, although these studies used a different density for polyurethane rigid foam. However, Alcorn and Wood (1998) stated the EE of polyurethane is $44,400 \mathrm{MJ} / \mathrm{m}^{3}$ which is far higher than in these other studies. The problem seems to be that Alcorn and Wood (1998) failed to clarify the type of polyurethane they were considering, and this figure seems to be for solid polyurethane (used for example for trolley wheels) rather than foamed polyurethane. As a result, it was decided to use $101.5 \mathrm{MJ} / \mathrm{kg}$ as the EE of polyurethane in this research. The density for polyurethane rigid foam of $44 \mathrm{~kg} / \mathrm{m}^{3}$ was extracted from the SIPs manufacturer's data sheet (NZSIP, 2017). As a result, the EE of polyurethane rigid foam in this study was changed to $101.5 \mathrm{MJ} / \mathrm{kg}$ or $4,466 \mathrm{MJ} / \mathrm{m}^{3}$ and the initial LCE was recalculated.

It is also worth noting there was no data for the EE of OSB in New Zealand, so the EE of plywood was used instead. As a result, there was a need to see how big the differences are between the embodied energies of OSB and plywood. Based on Hammond and Jones (2011) UK study the EE of both was equal to $15 \mathrm{MJ} / \mathrm{kg}$. However, the density of these two materials can differ slightly, but these differences are small. As a result, the EE of plywood has been assumed in this research to be equal to OSB.

\subsubsection{Final results}

The final calculation gave the initial EE of the ADU of $281.5 \mathrm{GJ}$ or approximately $4,022 \mathrm{MJ} / \mathrm{m}^{2}$. This includes the structure, claddings, and fittings but excludes drainage, light bulbs and furniture. Looking at Table 6.3, the EE of the ADU is still higher than the others, but the differences are considerably smaller. This small difference can be due to use of different insulation materials and also different construction approach, especially the use of concrete in the floor of the ADU. The detailed reason behind the difference will be discussed later in this chapter. The EE of the ADU was then broken down into an elemental base and material base, although due to rounding off, the total values of the two categories may differ slightly. 


\subsubsection{Initial Embodied Energy Based on ADU Elements}

In this approach, the initial EE of the ADU is classified based on the elements of the gable roof, SIPs ceiling, SIPs walls, internal walls, doors and windows, plumbing and electrical, and foundations (excluding drainage connections). This approach can help in understanding which elements embody the most energy (Figure 6.5).

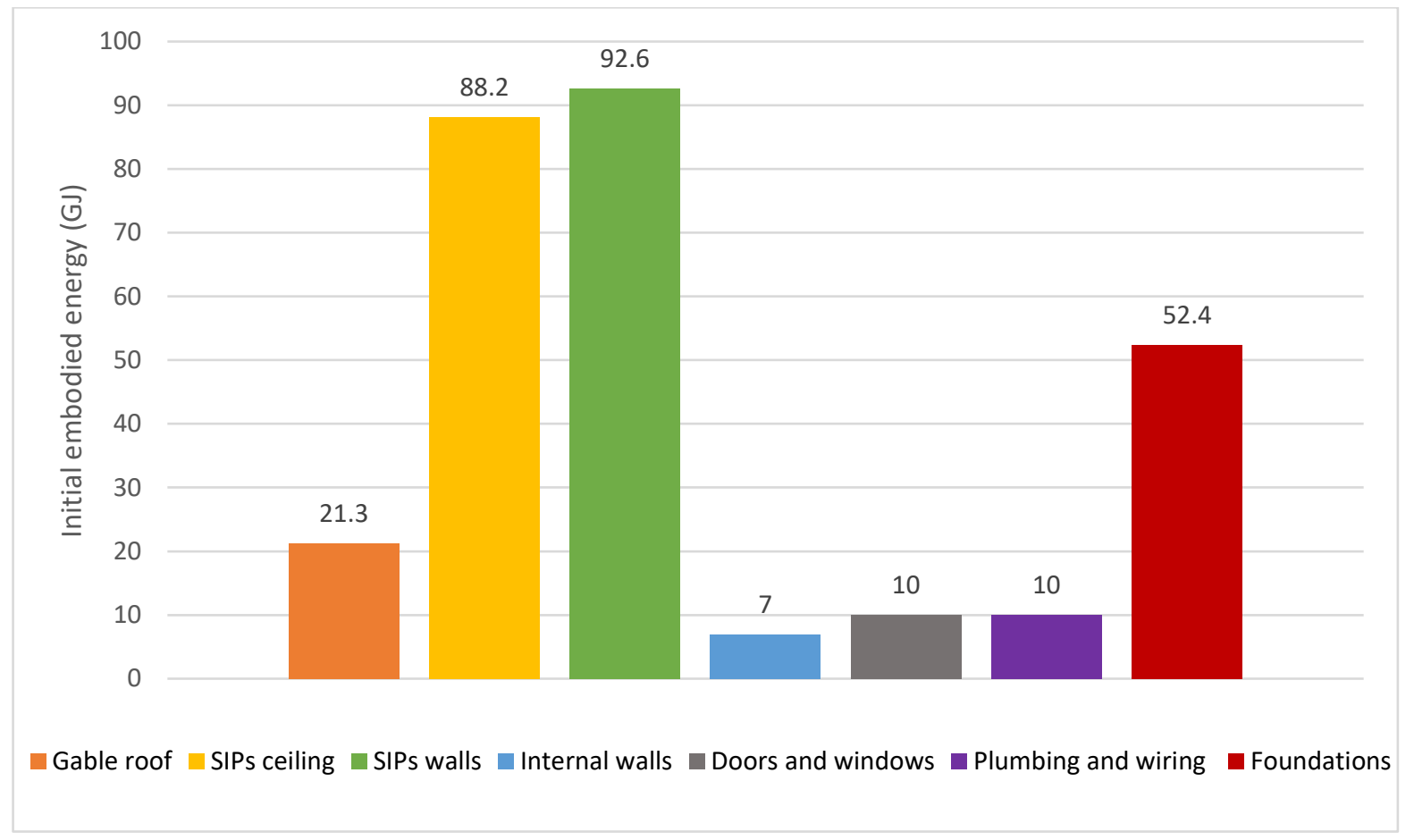

Figure 6.5: Initial embodied energy of building elements (GJ)

Figure 6.5 shows that SIPs walls and ceiling are the two largest elements when it comes to initial EE, accounting for $33 \%$ and $31 \%$ of the total respectively. This is due to the large amount of polyurethane used in the panels ( $63 \%$ and $66 \%$ of the EE of SIPs walls and ceiling) in order to increase their thermal efficiency. The foundations, including the under-slab insulation and DPM, have the next highest level of EE at $19 \%$. This mainly comes from the concrete and polystyrene used for insulating the slab, as having an insulated concrete slab is essential for the design of a near-zero energy ADU. The gable roof at $8 \%$ and doors and windows, internal walls, and plumbing and wiring at $2 \%$ or less form a small proportion of the total. The biggest share (over 64\%) of the gable roof comes from the corrugated steel roofing.

\subsubsection{Initial Embodied Energy Based on Materials}

In addition to the elemental analysis of $\mathrm{EE}$, having an idea of the amount of energy used by each material for building the ADU could be informative. (Figure 6.6). All ADU materials were 
classified into five groups: timber, metal, plastics, concrete, and ceramics and glass. Ceramics and glass include tiles and sanitary fittings as well as window glass and the shower enclosure.

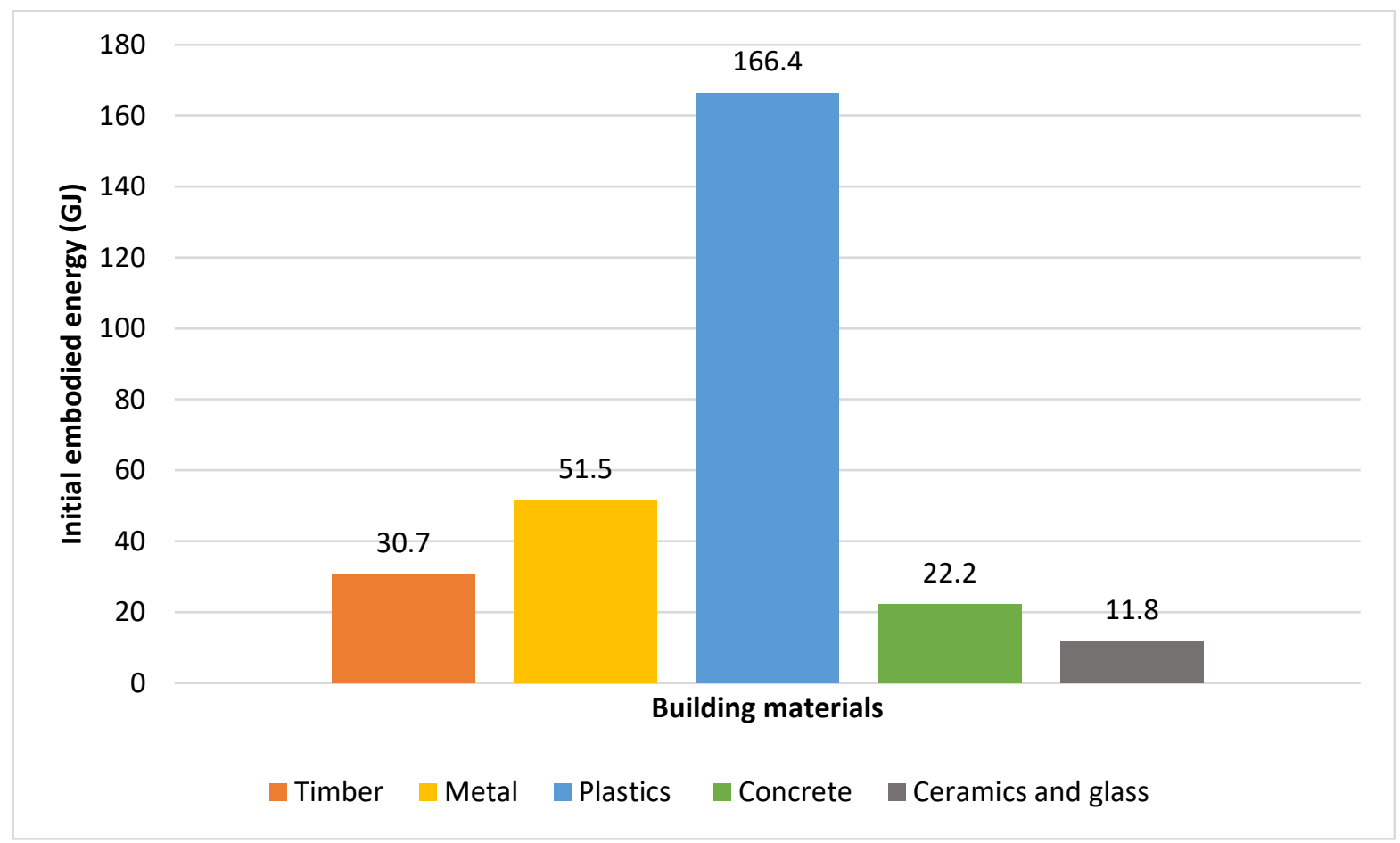

Figure 6.6: Initial embodied energy of ADU materials (GJ)

Figure 6.6 shows that plastics account for $59 \%$ of the initial energy embodied in ADU materials. Metal and timber form the next highest groups at $18 \%$ and $11 \%$ respectively, followed by concrete at $8 \%$ and ceramics and glass at $4 \%$. The biggest users of energy in the metal and timber groups are respectively the roof steel covering and the OSB used for the SIPs panels, accounting for $26 \%$ and $64 \%$ of their respective groups.

The results show that the a lower overall EE can come from making much use of a material with a low EE coefficient, such as timber, or relatively low use of a high embodied energy material, such as the corrugated steel roofing. Sometimes the EE can be high for both reasons, such as the use of plastics in the ADU, and it thus worth looking at these in more detail (Figure 6.7). 


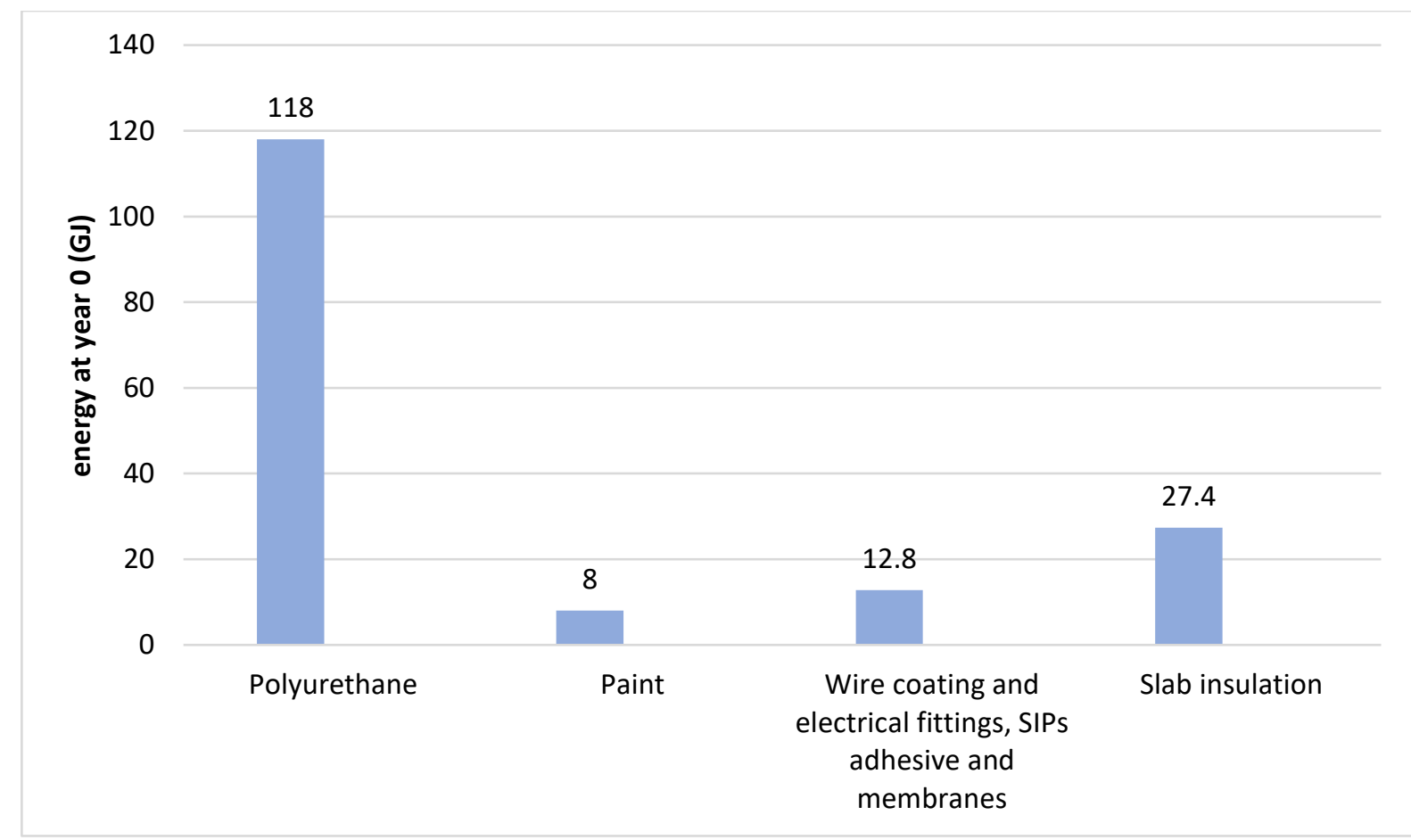

Figure 6.7: Break down of EE of plastics group at year 0 (GJ)

Figure 6.7 shows the energy embodied in foamed polyurethane is 118GJ making approximately $71 \%$ of the EE of the plastics group. Being responsible for over over $40 \%$ of the total initial EE of the ADU, the use of foam polyurethane should be considered in more detail to see if using SIPs panels of this type have benefits over the use of conventional timber frame methods or SIPs panels with other insulating materials (see Section 6.3.3.3). The polystyrene, used for insulating the slab embodied the highest energy after the polyurethane, accounting for $16 \%$ of the plastics group. Polyurethane and polystyrene make up half of the initial EE of the ADU. This offers the possibility of reducing the initial EE of the ADU by reducing the level of insulating materials, especially in SIPs panels. However, this would increase the OE of the ADU. One other point worth noting is the high dependence of the design on oil-based plastics. Should this level of the use of plastics in buildings be encouraged? As plastics are mainly made of oil and considering the fact peak oil has been passed, it is impossible to guarantee there would be enough oil for plastics production in the future (Vale, p.93 in Petrovic et al. 2017). Building houses with this level of dependency on oil would seem to be against the concept of sustainable development. 


\subsubsection{Embodied Energy of the ADU During its Lifetime}

This section looks at the changes in the EE of the ADU over its life span. The life span of the ADU is taken as 100 years and is analysed in five 25 year stages (Figure 6.8). The calculation of the lifetime EE is based on the lifetime of each element (Table 3.4).

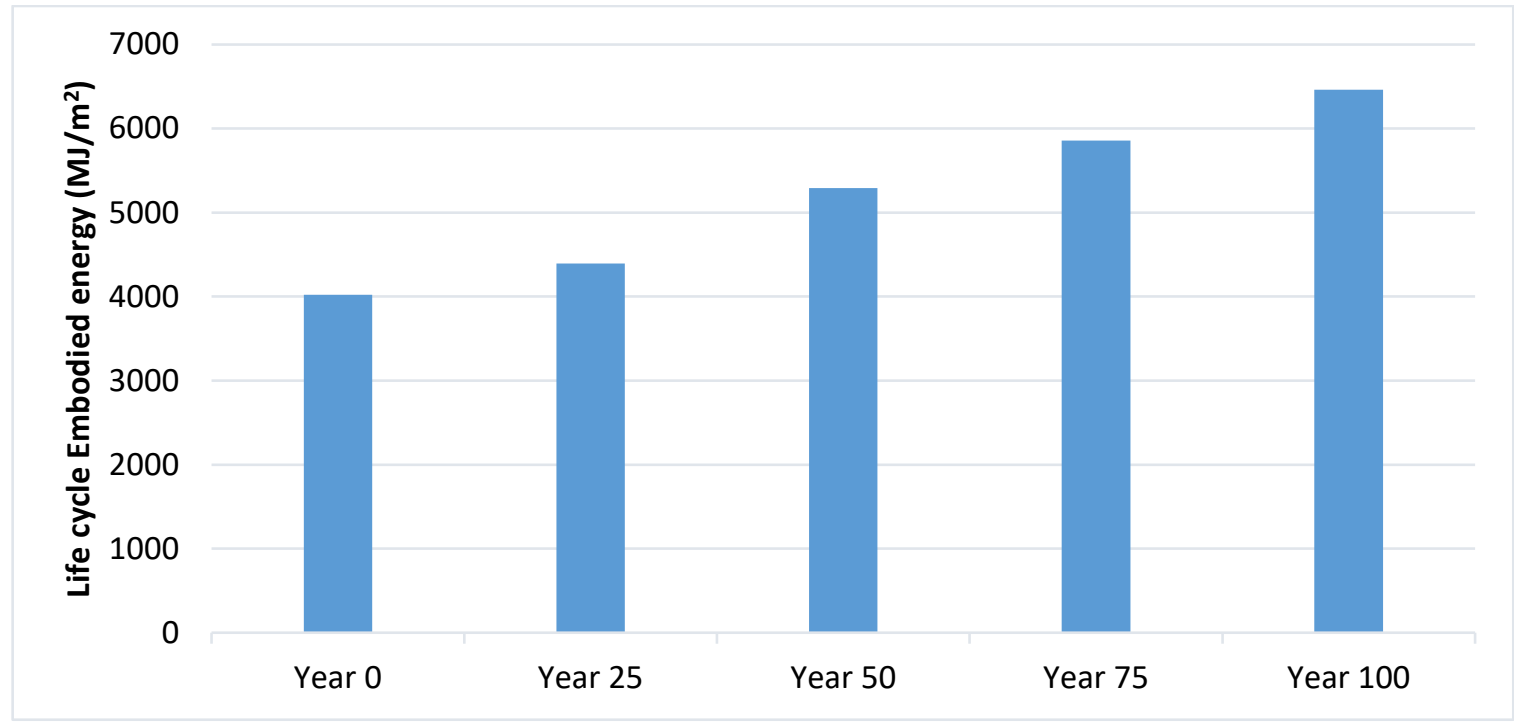

Figure 6.8: Life cycle embodied energy of the ADU $\left(\mathrm{MJ} / \mathrm{m}^{2}\right)$

Figure 6.8 shows $68 \%$ of the total EE of the ADU occurred in the first 25 years. If the SIPS panels were to be replaced in year 50 , the EE of the ADU would reach to $7,713 \mathrm{MJ} / \mathrm{m}^{2}$ in that year, which would be a growth of $46 \%$ in the EE. This suggests an ADU, or any building, should be designed to be used as long as possible, as maintaining a house and replacing its different elements, needs less energy than building a new one. However, over time the energy efficiency of the house may fall as its materials and elements no longer perform as well as originally. Figure 6.9 and Figure 6.10 break down the life cycle EE of the ADU into its elements and materials based on replacement and maintenance as necessary. 


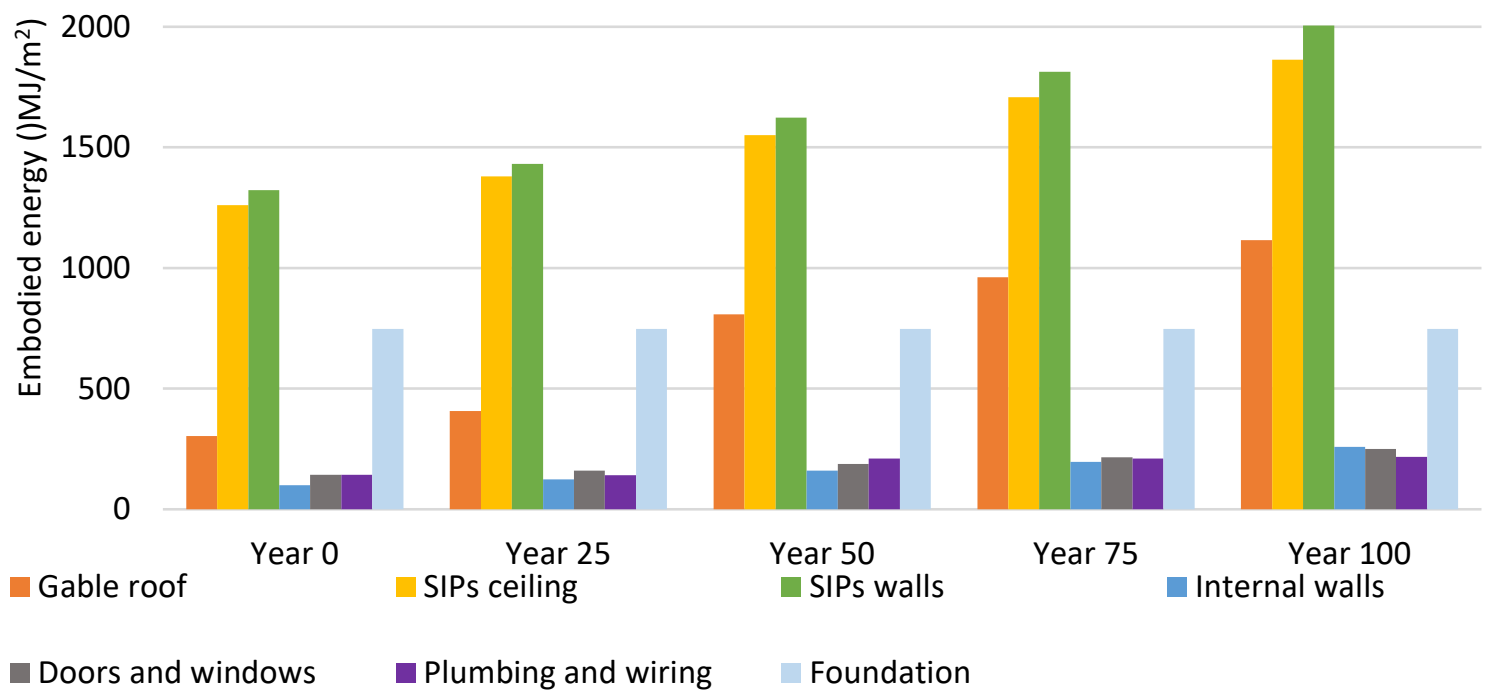

Figure 6.9: Breakdown of life cycle embodied energy for initial construction, repair and maintenance (building elements) $\left(\mathrm{MJ} / \mathrm{m}^{2}\right)$

Figure 6.9 shows the SIPs walls and ceiling have the greatest EE at all stages of the life of the ADU except for years 50, where the gable roof embodied the highest energy as the corrugated steel covering is replaced in that year. The embodied energy of the SIPs walls, ceiling and the foundations are significantly higher than the other categories in year 0 , together being $83 \%$ of total. Additional increments in years $25,50,75$ and 100 are mainly because of repainting of the SIPs walls, ceiling, and corrugated steel. As the area of walls is more than that of the ceiling and corrugated steel roof, the level of increase is more for the walls in these years. External doors and windows are maintained and repaired in year 90. Pipes and some bathroom fittings, mostly made of steel, are replaced in year 50 . The concrete slab is the only element with no need for any maintenance or replacement. This durability and low maintenance requirement should be considered as one of the main benefits of using concrete slabs as well as their high thermal efficiency if correctly detailed. 


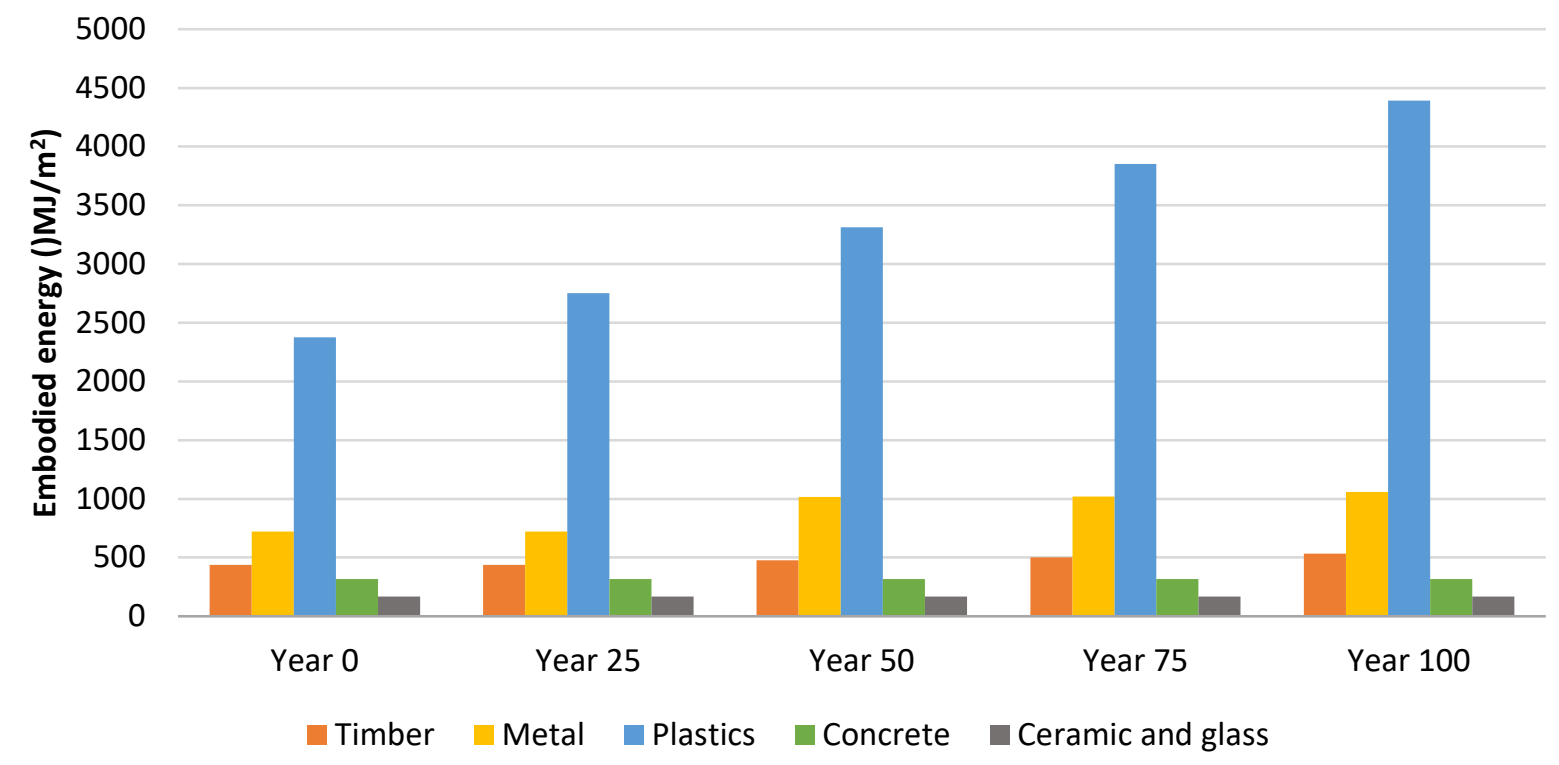

Figure 6.10: Breakdown of life cycle embodied energy for initial construction, repair and maintenance (materials) $\left(\mathrm{MJ} / \mathrm{m}^{2}\right)$

Figure 6.10 explores the distribution of the EE based on materials, showing that plastics accounted for $68 \%$ of the total, this being the highest materials-based EE over the lifetime of the ADU. However, there is a difference between the types of plastics used in year 0 with those in years $25,50,75$ and 100 . In year 0 , over $71 \%$ of the plastics $E E$ is from the polyurethane. The story is different in years $25,50,75$ and 100, where paint has the highest EE in the plastics category, being responsible for close to $90 \%$ of the maintenance and repair EE of the ADU in those years. The lifespan of paint depends on how it applied to the elements. Table 3.4 shows that a factory applied paint can last for 15 years, while normal paint is expected to last for just 8 years. Prefabricating the ADU modules in the factory means that all initial paint lasts for 15 years. After that, repainting is needed every 8 years. This is one of the advantages of prefabrication over traditional methods, as the number of times of repainting is reduced by one, which is equal to an energy saving of over $10.8 \mathrm{GJ}$ or $154.2 \mathrm{MJ} / \mathrm{m}^{2}$. The small metal-based EE in years 50, 75 and 100 mainly comes from joinery fittings, especially in year 50 when the roof covering needs to be replaced.

The finding that the SIPs panels (walls and ceiling) have the highest EE when it comes to building elements shows the importance of choosing the best materials for the design. SIPS panels were chosen for the ADU because of their high R-value and structural characteristics, 
as being close to zero operating energy was the primary goal of this research. This means it is necessary to look at the life cycle energy of the ADU based on both OE and EE. This can help in understanding if it is more efficient to use highly insulated elements, despite their high EE.

\subsubsection{Life Cycle Energy Analysis of the ADU}

Figure 6.11 illustrates the embodied, operating and life cycle energy of the ADU. This can provide a context for comparing the life cycle energy of the ADU with other studies. The ADU location, heating schedule and level were changed from Wellington, 24-hour heating and $16^{\circ} \mathrm{C}$ to Auckland, all day heating ( $7 \mathrm{am}$ to $23 \mathrm{pm}$ ) and $18^{\circ} \mathrm{C}$, as these are the specifications used for the OE calculations of the BIAC house. The aim was to achieve the highest level of similarity between the ADU and the BIAC house in order to increase the validity of comparison. The changes only affect the $\mathrm{OE}$ of the ADU and there was no change in EE. Because the EE coefficients are given in primary energy terms the calculated OE was multiplied by 1.1 to convert it to primary energy (Ministry of Business Innovation and Employment, 2018).

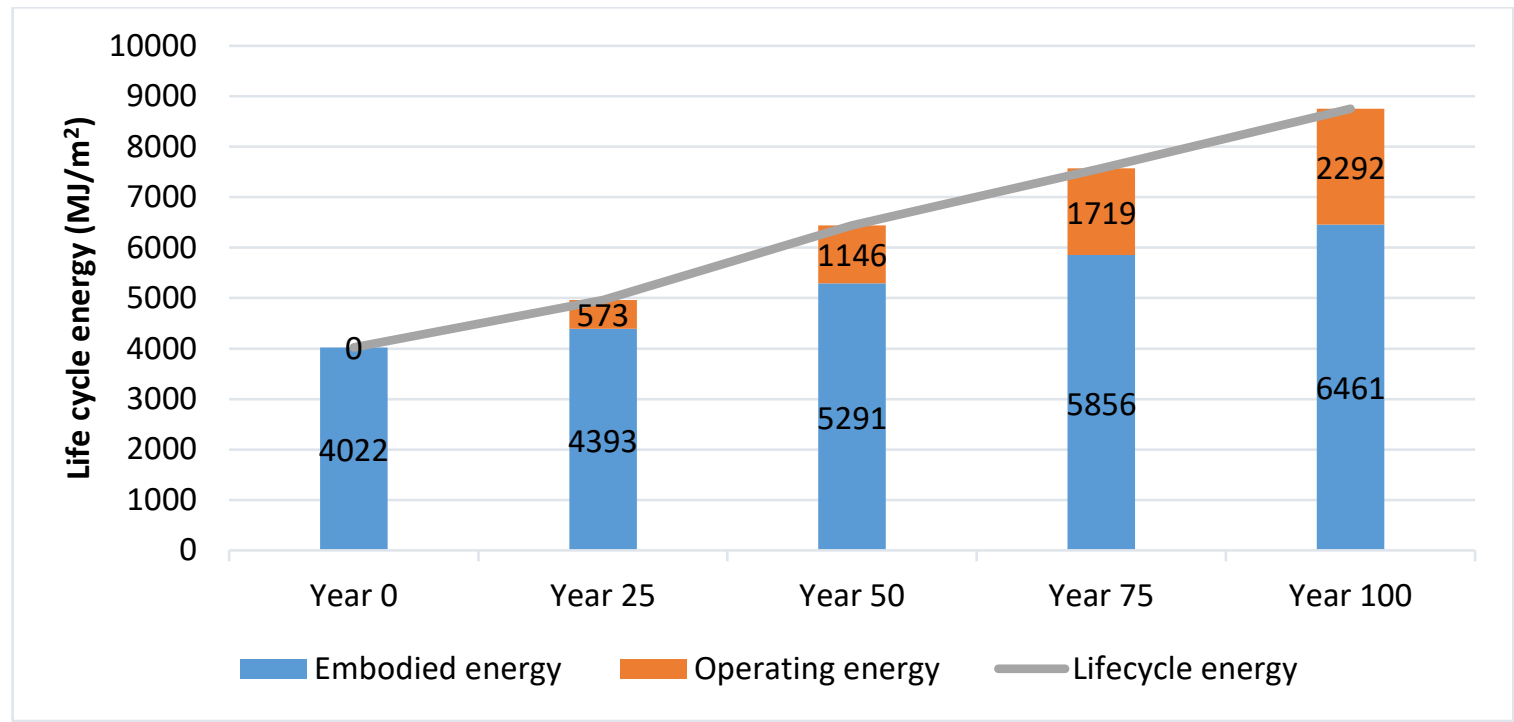

Figure 6.11: ADU life cycle energy $\left(\mathrm{MJ} / \mathrm{m}^{2}\right)$

Figure 6.11 shows that the life cycle energy of the ADU, which is all EE in year 0, went from $4,022 \mathrm{MJ} / \mathrm{m}^{2}$ to $8,753 \mathrm{MJ} / \mathrm{m}^{2}$ in year 100 . Close to $74 \%$ of the total life cycle energy of the ADU occurred in the first 50 years, with $46 \%$ in the initial construction and $18 \%$ being operational energy in the first 50 years. Overall, $74 \%$ of the total lifecycle energy of the ADU is embodied and the OE is just $26 \%$. The difference between the share of EE and OE in LCE of the ADU with conventional houses (see Section 7.3.2) is the fact that the ADU is designed to be zero energy. 


\subsubsection{Life Cycle Energy of the ADU Made of Different Insulating Materials}

Polyurethane foam insulation alone accounted for over a quarter (26\%) of the total life cycle embodied energy of the ADU. This would be even higher if SIPs panels were to be replaced in year 50 when it would form $38 \%$ of the ADU LCE. Knowing this and also looking at the reverse relationship of EE and $\mathrm{OE}$ compared to a conventional building, it was decided to test the effect of using other insulation materials with a lower R-value but also lower EE to see the effect on the total life-cycle energy of the ADU. Potentially there could be an increase in the $\mathrm{OE}$, but a reduction in the life-cycle $\mathrm{EE}$. The two alternative materials of polystyrene, which is a common material for use in SIPs panels (Formance, 2019), and glass fibre, which was used in the super insulated scenario of the BIAC house, were selected for further investigation. Using glass fibre meant the SIPs panels had to be replaced with double stud work, and this has been accounted for in the results (see Appendix D). This is important as $83 \%$ of the ADU initial energy was embodied in the structural elements, so any changes in structure could have a considerable effect (see Section 6.3.3.3). Table 6.4 shows the characteristics of these materials.

Table 6.4: Characteristics of alternative insulation materials

\begin{tabular}{|c|c|c|c|c|c|c|c|}
\hline \multirow[t]{2}{*}{ Material } & \multirow[t]{2}{*}{$\begin{array}{l}\text { R-value }\left(\mathrm{m}^{2}\right. \\
\mathrm{K} / \mathrm{W})\end{array}$} & \multirow[t]{2}{*}{ Source } & \multirow{2}{*}{$\begin{array}{l}\text { Embodied } \\
\text { energy } \\
\left(\mathrm{MJ} / \mathrm{m}^{3}\right) \\
(\text { Table } 3.3)\end{array}$} & \multicolumn{4}{|c|}{$\begin{array}{l}\text { Initial embodied energy of } 1 \mathrm{~m}^{2} \\
\text { wall/roof (MJ) }\end{array}$} \\
\hline & & & & Insulation & $\begin{array}{l}\text { Timber } \\
\text { and nails }\end{array}$ & $\begin{array}{l}\text { Adhe } \\
\text { sive }\end{array}$ & total \\
\hline \multirow[t]{2}{*}{$\begin{array}{l}\text { Polyurethan } \\
\text { e }\end{array}$} & $\begin{array}{l}5.3(165 \mathrm{~mm} \\
\text { wall panel) }\end{array}$ & \multirow[t]{2}{*}{$\begin{array}{l}\text { NZSIPs, } \\
2018\end{array}$} & \multirow[t]{2}{*}{4,466} & 669.9 & 124.8 & 10.5 & 805.2 \\
\hline & $\begin{array}{l}6.9(215 \mathrm{~mm} \\
\text { roof panel) }\end{array}$ & & & 853 & 124.8 & 10.5 & 988.3 \\
\hline \multirow[t]{2}{*}{ Polystyrene } & $\begin{array}{l}4.3(165 \mathrm{~mm} \\
\text { wall panel) }\end{array}$ & \multirow[t]{2}{*}{$\begin{array}{l}\text { Forman } \\
\text { ce, } 2019\end{array}$} & \multirow[t]{2}{*}{1,401} & 210 & 124.8 & 10.5 & 345.3 \\
\hline & $\begin{array}{l}5.7(215 \mathrm{~mm} \\
\text { roof panel) }\end{array}$ & & & 280.2 & 124.8 & 10.5 & 415.5 \\
\hline \multirow[t]{2}{*}{ Glass fibre } & $\begin{array}{l}2.85 \\
(165 \mathrm{~mm} \\
\text { wall) } \\
\end{array}$ & \multirow[t]{2}{*}{$\begin{array}{l}\text { BRANZ, } \\
2019\end{array}$} & \multirow[t]{2}{*}{1,026} & 153.9 & 565.4 & - & 719.3 \\
\hline & $\begin{array}{l}3.8(215 \mathrm{~mm} \\
\text { roof })^{*}\end{array}$ & & & 205.2 & 565.4 & - & 770.6 \\
\hline
\end{tabular}

*It was assumed that the $215 \mathrm{~mm}$ ceiling with the glass fibre insulation uses the same structure as the double stud wall

Table 6.4 shows the R-value of insulation materials has a direct relationship with their $\mathrm{EE}$ as the higher R-value is equal to a higher EE. However, the story is different, by looking at EE of $1 \mathrm{~m}^{2}$ of SIPs panels with a polyurethane core (scenario 1), SIPs panels with a polystyrene core 
(scenario 2), and a double stud frame wall with glass fibre insulation (scenario 3). Despite glass fibre having the lowest EE of all insulation materials in Table 6.4, the energy embodied for $1 \mathrm{~m}^{2}$ of scenario 3 is higher than for scenario 2 , and a little less than for scenario 1 with a polyurethane core. This is due to the higher amount of timber being used in scenario 3 as well as more steel in the form of nails. Moreover, in SIPs panels the OSB sheets work as both structure and interior cladding, as the exterior surface still needs another layer of cladding to protect the OSB sheets from the external environment. However, in scenario 3 structure and cladding are two separate elements, which means the use of more timber. To see the effects of using each insulation material in the prefabricated SIPs made wall and ceiling the EE of the ADU was recalculated allowing for the effect of changing the panel structure when using glass fibre insulation. The $\mathrm{OE}$ of the ADU with the new insulation materials was also recalculated using ALF3.2 (Figure 6.12) and converted to primary energy. The life span of double frame walls with glass fibre insulation is assumed to be 100 years.

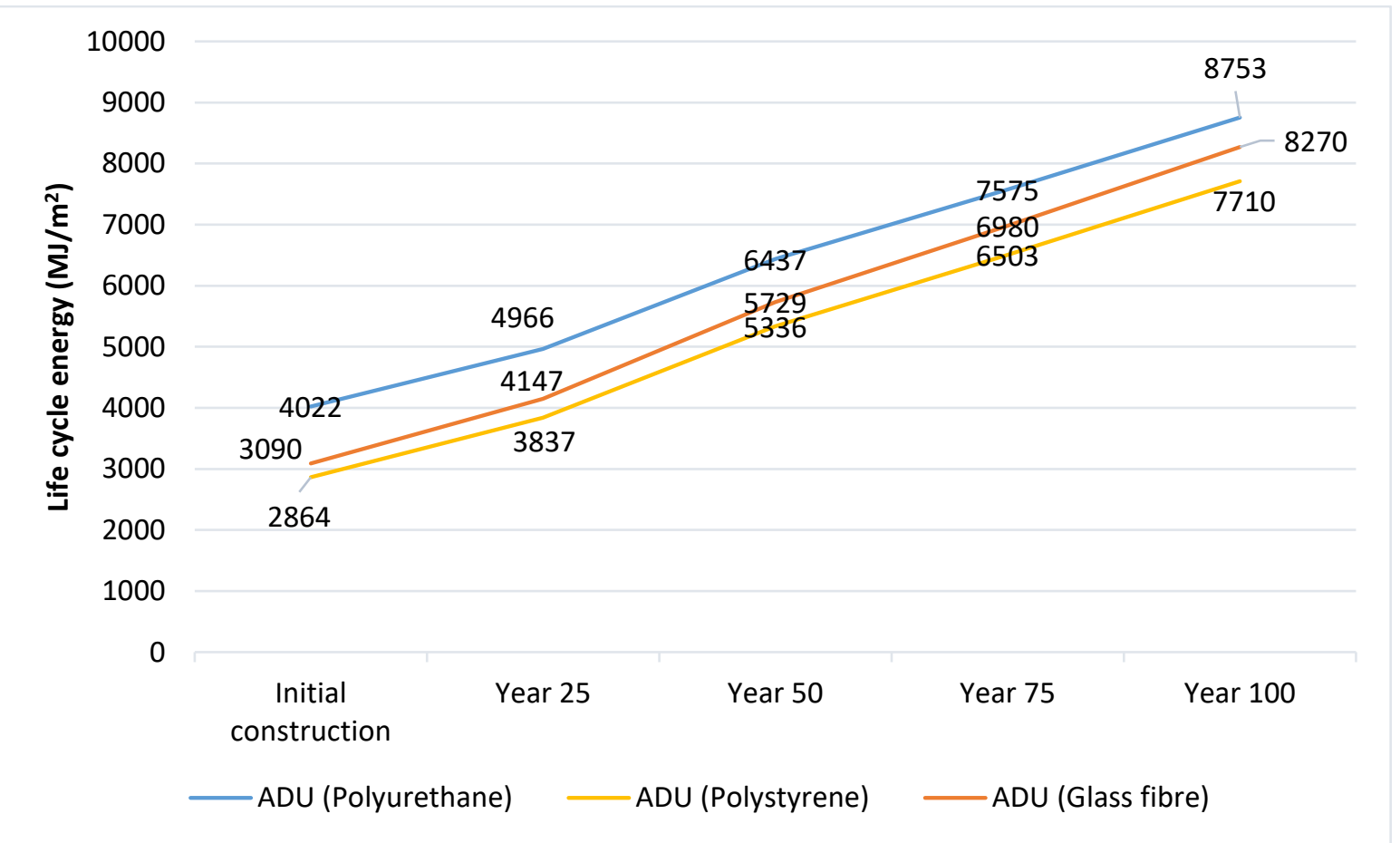

Figure 6.12: Life cycle energy of the ADU using different insulation materials $\left(\mathrm{MJ} / \mathrm{m}^{2}\right)$

Figure 6.12 shows compared to polyurethane made SIPs, either polystyrene (Scenario 2) or glass fibre (Scenario 3) can decrease the initial EE of the ADU, by $29 \%$ and $23 \%$ respectively. As expected, the annual OE of the ADU increased by approximately $5 \%$ in scenario 2 and over $19 \%$ scenario 3. Comparing scenario 2 with scenario 3, the first has a lower initial EE of $126 \mathrm{MJ} / \mathrm{m}^{2}$ and lower total life-cycle energy of $560 \mathrm{MJ} / \mathrm{m}^{2}$. However, after year 25 the lifecycle 
energy of scenario 3 grows a little faster than others due to the higher OE. Looking at scenarios 2 and 3, the majority of their LCE is still EE (69\% and 67\%), compared with 74\% in scenario 1 . This is due to the use of insulation with a lower EE per unit in scenarios 2 and 3.

Scenarios 1 and 2 are similar except for the type of insulation material. This change led to a $29 \%$ reduction in initial EE and a $26 \%$ reduction in the LCE for scenario 2, despite a $5 \%$ increase in life cycle OE. This is a big change, partly due to the high volume of insulation in the ADU, but still shows how a change in just one material can affect the balance of energy and the LCE of a building.

In order to extend the comparison to see how efficient the ADU is, it was decided to compare its life-cycle energy with other similar studies. Following the insulation material analysis, the ADU is now assumed to be made of SIPs panels with a polystyrene core, as this seems to offer the best potential for the lowest LCE.

\subsubsection{Comparing LCEA Results}

Figure 6.13 compares the lifecycle energy of the ADU with that of the three case studies. The LCE of both the Hockerton House and the Green Home are from Fay et al. (2000) while data for BIAC House is derived from Mithraratne et al. (2007). The Hockerton House and the Green Home were analysed in their climates of Nottinghamshire and Melbourne respectively, while the ADU and BIAC house were assumed to be in Auckland (Table 6.5). 


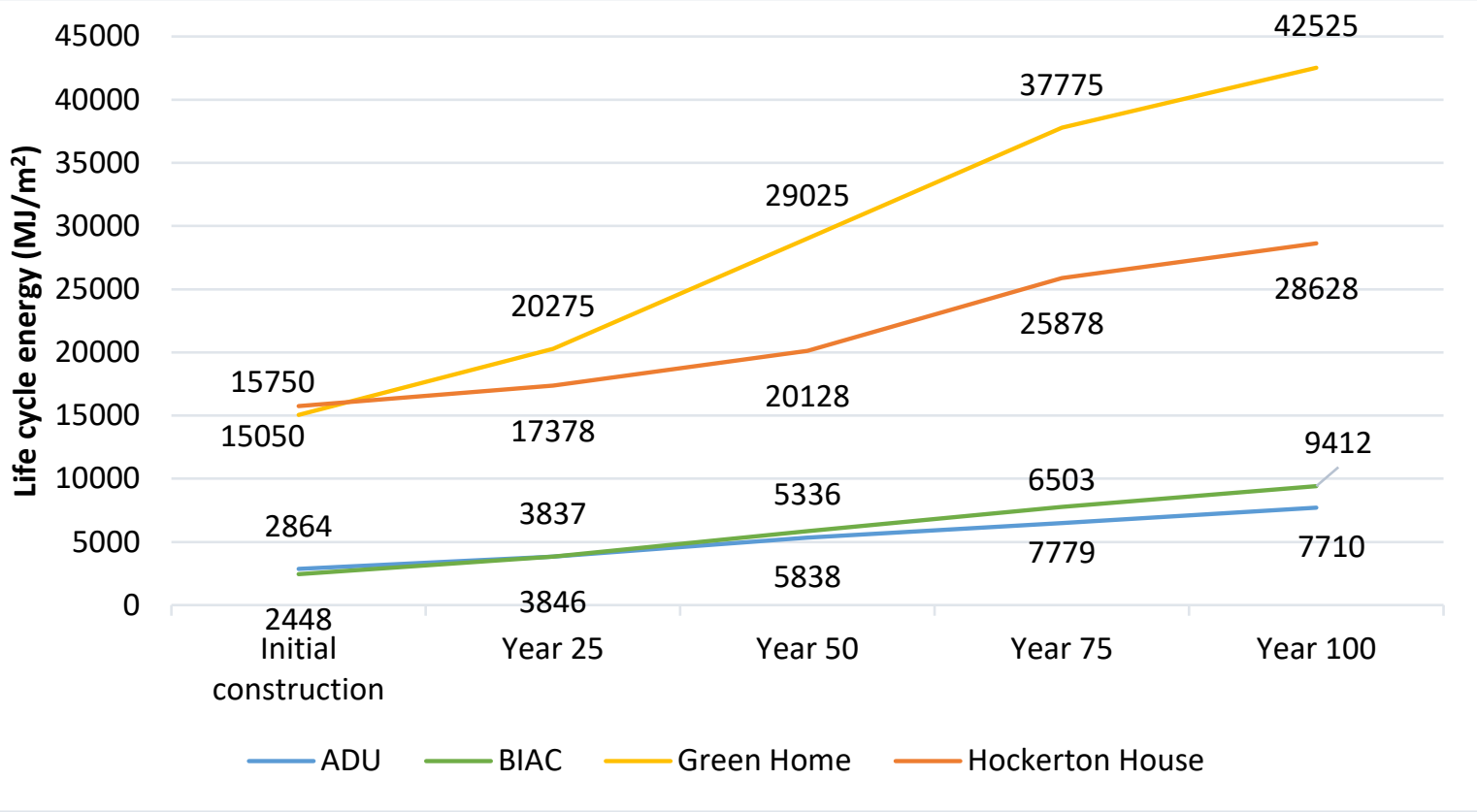

Figure 6.13: Case study lifecycle energy comparisons $\left(\mathrm{MJ} / \mathrm{m}^{2}\right)$

Figure 6.13 shows the Hockerton House, which has the highest use of concrete (239 tons) and thickest insulation, also has the highest initial EE of $15,750 \mathrm{MJ} / \mathrm{m}^{2}$. However, this use of concrete was part of making a zero energy house in a much colder climate than that of Melbourne or Auckland (the BIAC and ADU are modelled for Auckland (see Section 6.3.4)). Table 6.5 shows that Auckland and Melbourne have a very similar climate. However, the table shows that the Hockerton House is located in a considerably colder climate. Annual heating degree days in Nottinghamshire are far higher than in the other two cities, while the annual sunshine hours are approximately half. These data suggest there is less available natural energy and more demand for heating energy in the Hockerton House. In fact, the Hockerton House was designed to make use of the maximum amount of sunshine through correct window direction and size, and the layers of insulation and use of thermal mass.

Table 6.5: Case studies climate data

\begin{tabular}{|l|l|l|l|l|}
\hline Latitude & Latitude & $\begin{array}{l}\text { Annual heating } \\
\text { degree days to } \mathbf{1 8}^{\circ} \mathbf{C}\end{array}$ & $\begin{array}{l}\text { Annual sunshine } \\
\text { hours }\end{array}$ & Source \\
\hline Nottinghamshire, UK & $53^{\circ} 0^{\prime} \mathrm{N}$ & 3,344 & 1,296 & Fay et al.,2000 \\
\hline Melbourne, Australia & $37^{\circ} 49^{\prime} \mathrm{S}$ & 1,377 & 2,080 & Fay et al.,2000 \\
\hline Auckland New Zealand & $36^{\circ} 50^{\prime} \mathrm{S}$ & $1,213^{*}$ & 2,050 & Chappell, 2014 \\
\hline
\end{tabular}

*This number is the average of five different stations in the Auckland region.

Comparing the change between the initial EE and total lifecycle energy the Hockerton House, which is the only case study that has been monitored as being zero heating energy, showed the least amount of change in LCE over its life with a growth of $82 \%$ compared with the BIAC 
House with the biggest growth of $284 \%$. The growth is $169 \%$ and $1,863 \%$ for the ADU and the Green Home. This shows, again, using materials with high thermal mass (concrete) and those with high R-value increases the initial EE of the building while reducing the lifecycle energy of building by reducing the OE. Given this, the ADU seems to have a low LCE if SIPs with a polystyrene core are used. Figure 6.13 shows despite the initial lifecycle energy of the ADU being $416 \mathrm{MJ} / \mathrm{m}^{2}$ higher than the BIAC House, the LCE of the BIAC house exceeds that of the ADU just before year 25 due to its higher OE. At year 100 the total life-cycle energy of the $\mathrm{ADU}$ is $1,702 \mathrm{MJ} / \mathrm{m}^{2}$ lower than the BIAC House.

In Figure 6.13 the BIAC house is the only example with no considerable thermal mass. This can be one of the reasons for it having the lowest initial EE of all the case studies. However, when it comes to the life cycle $\mathrm{OE}$, the energy the BIAC House consumes for heating is $4,264 \mathrm{MJ} / \mathrm{m}^{2}$, which is approximately twice that of the ADU, and much higher than that of the Hockerton House. The life cycle heating energy of the Green Home is $10,000 \mathrm{MJ} / \mathrm{m}^{2}$. However, in comparing the life cycle energy of these case studies, it should be noted that the temperature was set at $18^{\circ} \mathrm{C}$ in both the $\mathrm{ADU}$ and the BIAC house, while in Green Home it was set at $21^{\circ} \mathrm{C}$ in winter and $26^{\circ} \mathrm{C}$ in summer, although no account was taken of its cooling energy in the comparison.

The other point to be considered is the volume of insulation, as although layers of insulation can improve the total R-value of the house this will also increase the EE. From the case studies in Figure 6.13, the Green Home has an air gap inside the external walls, with a very low Rvalue, and foil beneath the roof for insulation. Aside from the differences in the set temperature between the Green Home and the other houses and considering the substantial amount of concrete used in it (Table 6.1), this lack of proper insulation could be the reason behind its higher lifecycle OE. The Hockerton House has the highest amount of insulation with $300 \mathrm{~mm}$ polystyrene. This can explain why it is zero energy and also its high initial EE. The ADU and BIAC house have similar levels of insulation in walls and ceiling, while the type of insulation they use is different. The BIAC house was insulated by glass fibre with an R-value of $1.9 \mathrm{~m}^{2} \mathrm{~K} / \mathrm{W}\left(100 \mathrm{~mm}\right.$ thick) with initial EE of $1,026 \mathrm{MJ} / \mathrm{m}^{3}$ (Table 3.3). The ADU is made of SIPs panel with a polystyrene core with an R-value of over $2.4 \mathrm{~m}^{2} \mathrm{~K} / \mathrm{W}$, giving an initial $\mathrm{EE}$ of $1,401 \mathrm{MJ} / \mathrm{m}^{3}$ but resulting in a lower life-cycle OE. 


\subsubsection{Adjustment}

During the ADU design, the primary focus was on using materials with the highest R-value to reduce the $\mathrm{OE}$, which was successful. However, this chapter has shown the importance of having a balance between EE and OE during design. It also reveals the importance of looking at the LCE rather than focusing just on EE or OE. This reveals the need for reconsidering the criteria used for selecting the most efficient ADU design. The energy simulations and LCEA were conducted based on the polyurethane made SIPs panels and only a selected scenario was re-simulated based on the use of polystyrene (Table 6.6).

Selecting polystyrene made SIPs panels for the final design of the ADU needs to be considered further. Table 6.6 shows the changes in EE, OE, and LCE of the ADU in year 100 assuming the panels last this long without replacement, while comparing the effects of any change in thickness of the ceiling SIPs panels, as the thickest available option with the higher R-value was selected. This change affects both the amount of polystyrene used (EE) and the panel Rvalue (OE). The R-values of $165 \mathrm{~mm}$ and $215 \mathrm{~mm}$ polystyrene SIPs panels are $4.3 \mathrm{~m}^{2 \circ} \mathrm{C} / \mathrm{W}$ and $5.7 \mathrm{~m}^{2 \circ} \mathrm{C} / \mathrm{W}$ respectively (Formance, 2019).

Table 6.6: Life cycle energy of different polystyrene core ADUs (100 years) using ALF 4

\begin{tabular}{|l|l|l|l|l|l|}
\hline Scenario & $\begin{array}{l}\text { Wall panel } \\
\text { thickness }(\mathbf{m m})\end{array}$ & $\begin{array}{l}\text { Roof panel } \\
\text { thickness }(\mathbf{m m})\end{array}$ & OE $\left(\mathbf{M J} / \mathbf{m}^{\mathbf{2}}\right)$ & $\mathrm{EE}\left(\mathbf{M J} / \mathbf{m}^{\mathbf{2}}\right)$ & $\mathrm{LCE}\left(\mathbf{M J} / \mathbf{m}^{\mathbf{2}}\right)$ \\
\hline $\mathrm{A}$ & 165 & 215 & 3,208 & 5,304 & 8,512 \\
\hline B & 165 & 165 & 3,306 & 5,195 & 8,501 \\
\hline
\end{tabular}

The difference in values of scenario A (Table 6.6) compared with the number in Figure 6.13 is due to the changes in the ALF software and the ADU design. At the time this new calculation was done a new version of ALF, version 4, was released with some changes and new options, and this led to a different output than was achieved for ALF 3.2. In the new version, there is an option of choosing the soil conductivity of between $1.2 \mathrm{~W} / \mathrm{m}^{\circ} \mathrm{C}$ for dry sandy loam soil, $1.0 \mathrm{~W} / \mathrm{m}^{\circ} \mathrm{C}$ for normal soil and $0.8 \mathrm{~W} / \mathrm{m}^{\circ} \mathrm{C}$ for wet or saturated clay soil or where there is a high water table. In previous calculations, there was no such option, and the conductivity was taken as $1.2 \mathrm{~W} / \mathrm{m}^{\circ} \mathrm{C}$, but in the new calculations, it was changed to $1.0 \mathrm{~W} / \mathrm{m}^{\circ} \mathrm{C}$. Also, there is no longer a heating level of $16^{\circ} \mathrm{C}$ in the new version. Considering that scenario $B$ (Table 6.6) was simulated for the first time using ALF 4 and to maximise the comparability, scenario $A$ was recalculated using ALF 4 and with the same assumptions. 
Table 6.6 shows scenario A has lower OE but higher EE than scenario B due to having the highest level of polystyrene. Table 6.6 suggests scenario $B$ is the most energy efficient scenario to be selected as the final design. However, considering the small differences between scenario $A$ and $B$ a cost analysis could further help in the selection of the best scenario.

\subsubsection{SUNREL Simulation}

As mentioned earlier (see Section 5.6) the ALF outputs are not detailed and do not give a picture of the internal temperature of the ADU on specific days and hours. Having this data is important as due to the size of windows and being highly insulated there is a chance of overheating during summer. This is the reason for re-simulating the conditioning energy of the ADU but using SuNREL, which gives more extensive and detailed outputs. SUNREL is a software that simulates the energy behaviour of small buildings by considering the interactions between the site and the building. The software can produce outputs annually, monthly, or even hourly (Deru, 2002). This feature gives a precise idea about the internal environment of the ADU, including internal and external temperatures for a specific time on a specific day of the year.

SuNREL was first released in the early 1980s by the Solar Energy Research Institute (SERI) and then developed by NREL, which is the national laboratory of the U.S. Department of Energy (U.S. Department of Energy, 2018). This section on the SUNREL simulations is in the two parts of before and after the design modification. The first part was conducted before the LCEA as a complementary section to the ALF simulations, to see if there was any summer overheating. At this point, the ADU was made of polyurethane filled SIPs panels of $165 \mathrm{~mm}$ the walls and $215 \mathrm{~mm}$ for ceiling, on a $150 \mathrm{~mm}$ insulated concrete slab. However, the LCEA shows using $165 \mathrm{~mm}$ ceiling panels and changing the insulation core to polystyrene, gives a better LCEA in year 100. The second part, which investigates the efficiency of the ADU in different cities and directions, uses the modified design based on the LCEA results. This led to a slight change in the required heating in these two parts. All SUNREL heating outputs were also converted to primary energy. 


\subsubsection{Part One: Overheating}

Based on the ALF outputs, an ADU of $165 \mathrm{~mm}$ polyurethane SIPs panel for the walls, $215 \mathrm{~mm}$ SIPs panels for the roof and a $150 \mathrm{~mm}$ insulated concrete slab delivers the best result, being very close to zero energy use for space conditioning. However, to have a better understanding of how this and other scenarios might work, four scenarios were simulated with SUNREL (Table 6.7). As in the ALF modelling, the heating level was set to $16^{\circ} \mathrm{C}$, with no mechanical cooling or ventilation system. Variable items in each scenario include the type of floor and level of mass. The aim here is to monitor the internal temperature of the ADU over a smaller period of time to see if there is any overheating, as well as studying the required heating of the ADU.

Table 6.7: Specifications of different scenarios in SUNREL simulations

\begin{tabular}{|l|l|l|}
\hline Scenario & Type of floor & Level of mass \\
\hline 1 & Suspended floor made of $165 \mathrm{~mm}$ SIPs panel & No mass \\
\hline 2 & Suspended floor made of $165 \mathrm{~mm}$ SIPs panel & $50 \mathrm{~mm}$ concrete blocks on the floor \\
\hline 3 & $150 \mathrm{~mm}$ insulated concrete slab & $150 \mathrm{~mm}$ slab \\
\hline 4 & $150 \mathrm{~mm}$ insulated concrete slab & $\begin{array}{l}150 \mathrm{~mm} \text { slab and } 50 \mathrm{~mm} \text { concrete block } \\
\text { lining to the internal face of external } \\
\text { walls }\end{array}$ \\
\hline
\end{tabular}

The SUNREL simulations used natural ventilation. The set point for opening the windows was $23^{\circ} \mathrm{C}$ and $25 \%$ of each window was allowed to open for the outside air to enter. However, due to the limited window area, the internal temperature might exceed $23^{\circ} \mathrm{C}$ even with natural ventilation so the maximum internal temperatures of the ADU are also important factors to consider.

As a first step, monthly simulations were run to compare the internal temperature of different scenarios with the ambient temperature of Wellington over the year and also to calculate the annual energy each scenario would need for heating. Each month is also divided into four weeks and the average temperature of each week is calculated. Figure 6.14 compares the internal temperature of the ADU for the four scenarios with the ambient temperature where " $w 1$ " is the first week of January. 

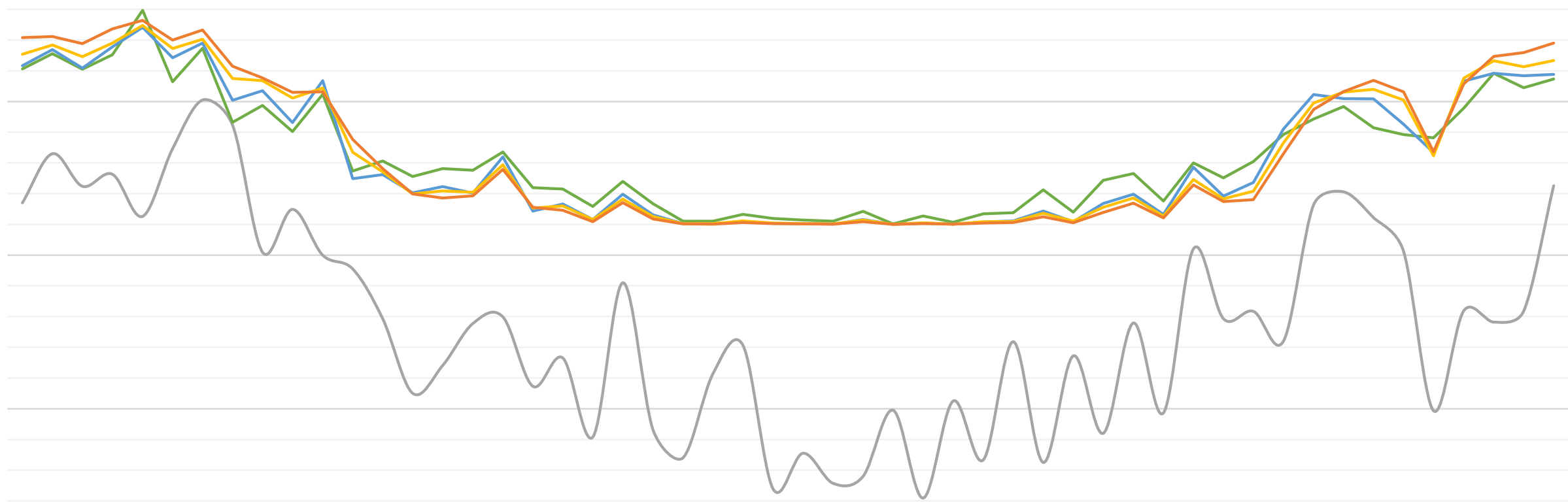

5

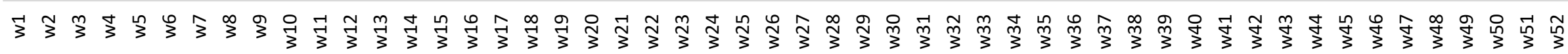

$$
\text { Ambient Temperature } \longrightarrow \text { Scenario one } \longrightarrow \text { Scenario two Scenario three — Scenario four }
$$

Figure 6.14: Differences between ambient temperature and internal temperature for the four scenarios $\left({ }^{\circ} \mathrm{C}\right)$ 
Figure 6.14 shows that annual Wellington temperatures fluctuate between $7.7^{\circ} \mathrm{C}$ (first week of July) and $19.1^{\circ} \mathrm{C}$ (first week of February). Because of the heating set point, no scenario had an internal temperature lower than $16^{\circ} \mathrm{C}$ and heating was required in the winter months. The weekly maximum temperature in all scenarios is recorded for the first week of February (w5), when the ambient temperature is also at its maximum. Scenario 1 has the highest weekly maximum temperature of $23^{\circ} \mathrm{C}$ in $w 5$, with scenarios 4,3 , and 2 having internal temperatures of $22.6^{\circ} \mathrm{C}, 22.5^{\circ} \mathrm{C}$ and $22.4^{\circ} \mathrm{C}$ respectively in $w 5$. None of these temperatures are very high. Figure 6.14 shows that the average ambient temperature is $12.8^{\circ} \mathrm{C}$ and the annual average internal temperatures in the four scenarios are very similar, being $18.3^{\circ} \mathrm{C}, 18.2^{\circ} \mathrm{C}, 18.3^{\circ} \mathrm{C}$ and $18.3^{\circ} \mathrm{C}$ for scenarios $1-4$ respectively. Figure 6.15 shows the average temperatures in each season.

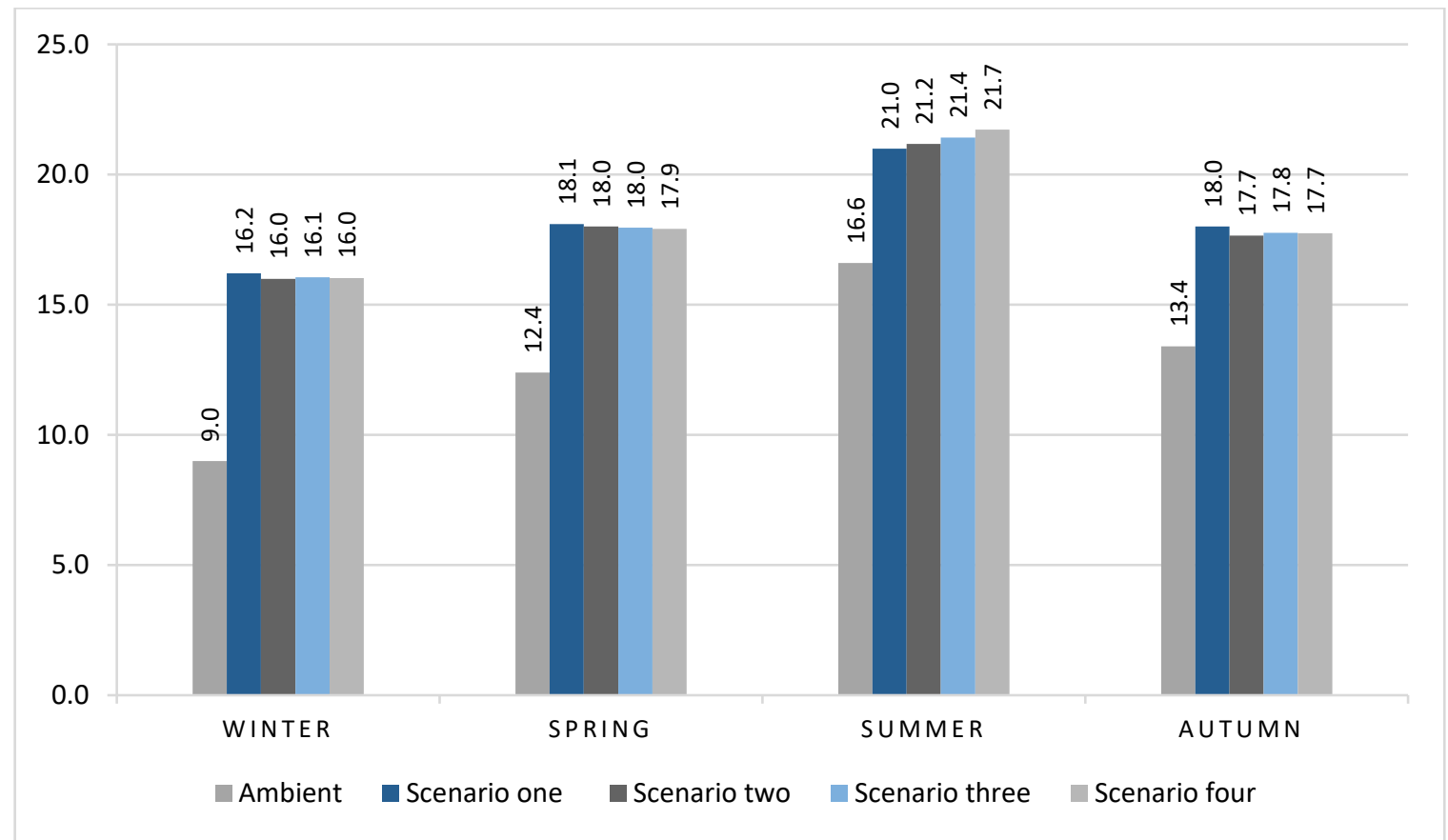

Figure 6.15: Average temperature in different seasons $\left({ }^{\circ} \mathrm{C}\right)$

Based on Figure 6.15 , despite the fact that the differences are minimal (only $0.7^{\circ} \mathrm{C}$ in summer), scenario 1 is the warmest in winter and coolest in summer while scenario 4 is the reverse. Scenarios two and three are in between and are very similar. This suggests scenario 1 would be the best option. However, the two important factors of energy consumption and daily maximum internal temperature need more investigation, and here is where SUNREL can help over ALF due to its detailed outputs. 


\subsubsection{Energy Consumption}

The energy each scenario consumes to keep the internal temperature of the ADU in the comfort zone is the first factor that needs to be investigated. This is followed by studying the thermal behaviour of the scenarios during summer as there is no mechanical cooling or ventilation system in the ADU, this being common practice in New Zealand houses. The only mechanism for controlling the internal temperature during summer is natural ventilation, while the ability of natural ventilation to lower the internal temperature is limited and highly affected by the size of the windows. This requires the internal temperature of the ADU in the different scenarios during summer to be investigated carefully to make sure that the ADU is liveable in all seasons (see Section 6.3.8.3). Before this, the energy the ADU needs for heating the internal spaces to at least $16^{\circ} \mathrm{C}$ during winter and possibly at night time in the other seasons is illustrated in Figure 6.16.

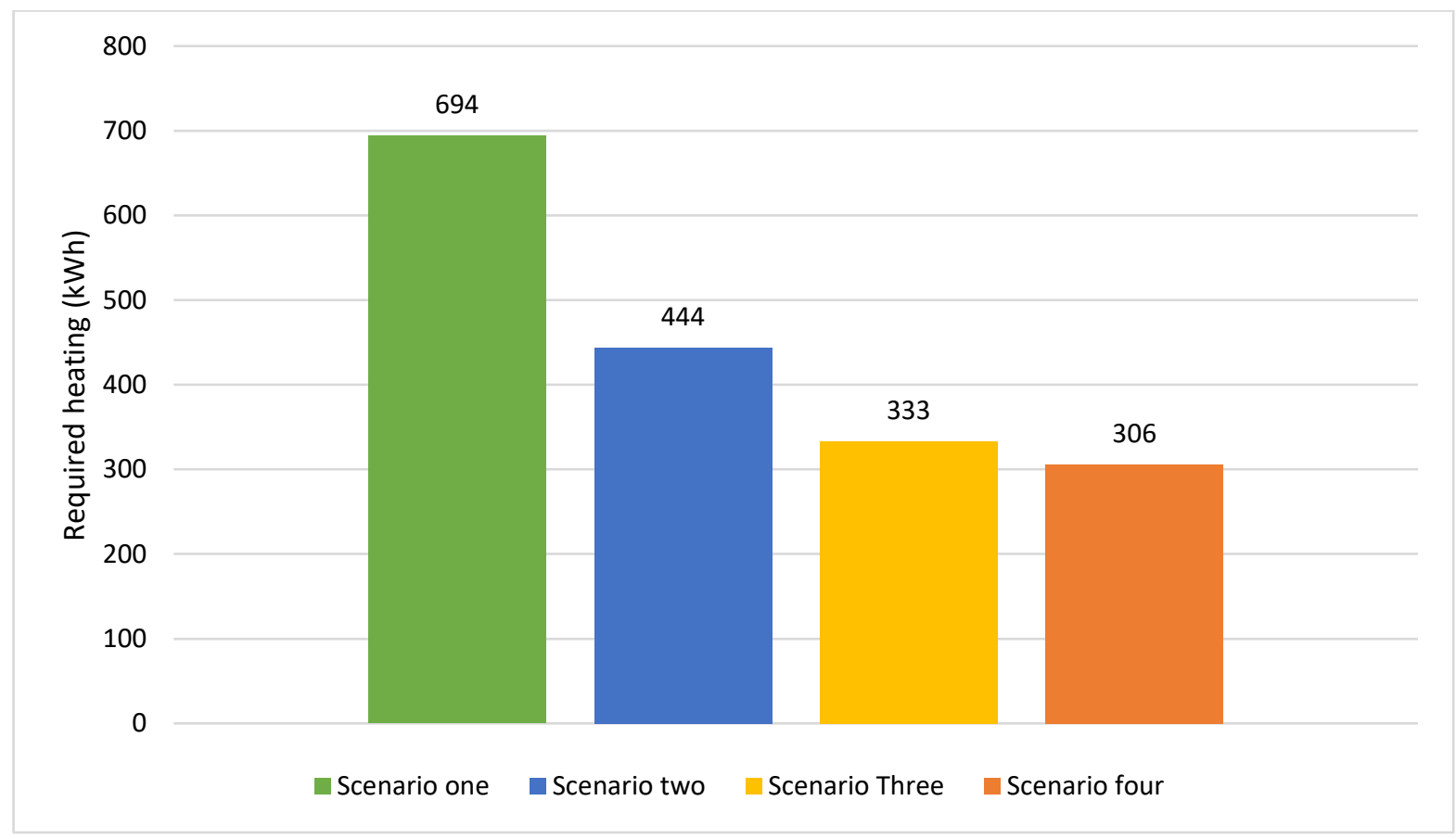

Figure 6.16: Annual energy consumption of the ADU (kWh)

Figure 6.16 shows the energy consumption in scenario 1 of $694 \mathrm{kWh}$ is considerably more than for the other scenarios, being more than $100 \%$ higher than scenarios 3 and 4 , and $56 \%$ more than scenario 2 . The latter is the second biggest user of energy at $444 \mathrm{kWh}$ annually, while the use of energy in scenarios 3 and 4 is approximately $30 \%$ less than that of scenario 2 . Looking at Figure 6.16 and Table 6.7 together shows the relationship between the volume of mass and the required heating of the $A D U$, where the higher mass in conjunction with the thermal 
insulation leads to less heating and more stable internal temperatures. Figure 6.17 breaks the energy use down on a monthly basis to investigate this further.

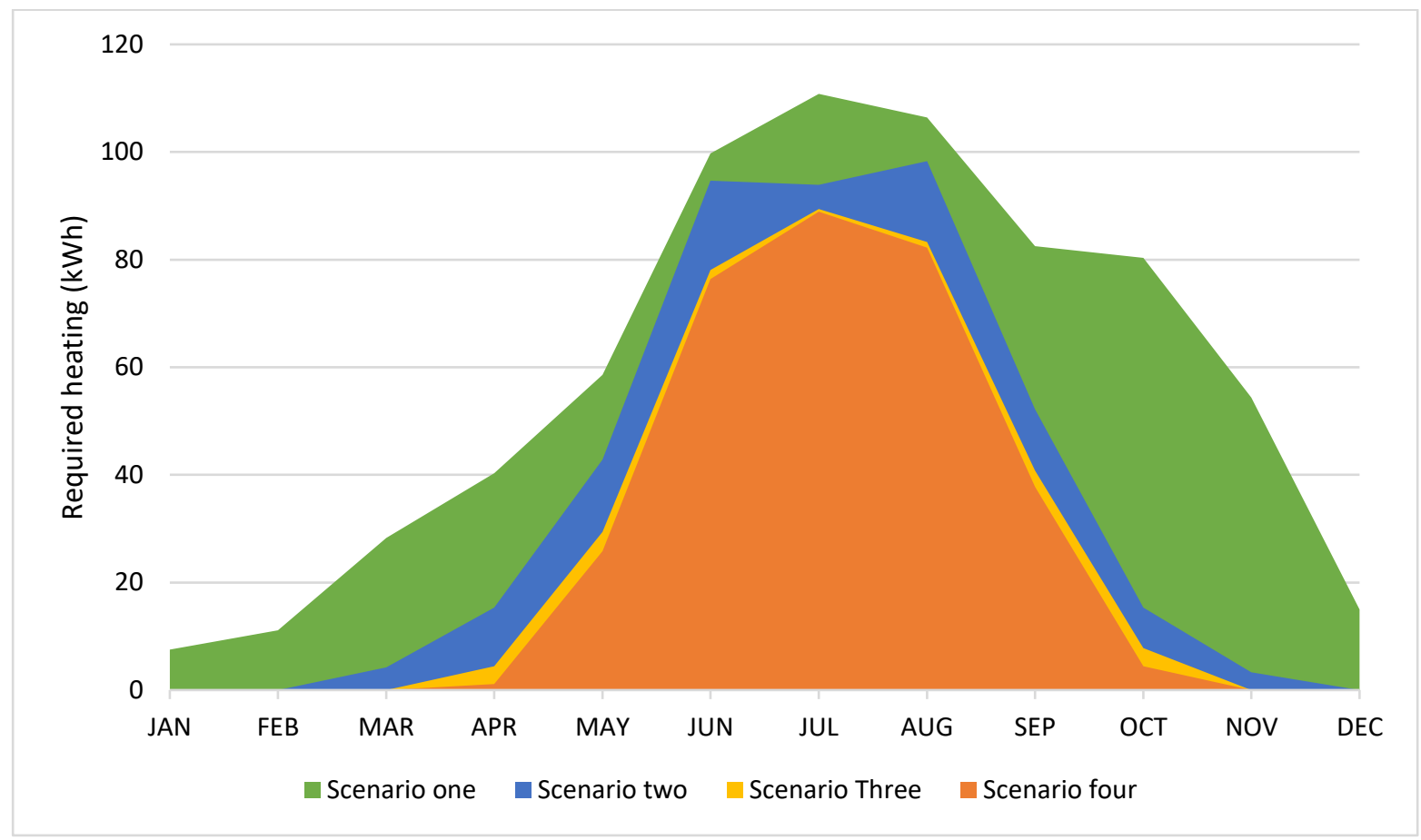

Figure 6.17: Monthly energy consumption of the ADU (kWh).

Figure 6.17 shows that differences in the energy consumption of the scenarios are more visible during spring and summer. The amount of energy scenarios 2,3 , and 4 use during these seasons is low or zero while scenario 1 still consumes energy. Studying Figure 6.17 more in detail shows scenarios 3 and 4 use no energy for heating during five months of the year (November-March), while in scenario 2 the ADU uses no energy during summer. This use of energy in scenario 1 is due the fact that even during summer there are some days or hours, mostly during the nights, when the ambient temperature falls below $16^{\circ} \mathrm{C}$ (Figure 6.20 ), and as there was no mass to store the surplus of the heat during the day the heating system will be on. At this stage it was decided to leave scenario 1 out of the available options due to the greater heating required, especially in summer.

\subsubsection{Internal Temperatures}

In order to evaluate the internal temperature of the ADU in more detail, especially during summer, it was decided to narrow the simulation down to an hourly basis to see how the internal temperatures change over a day. Figure 6.18-Figure 6.24 are the results of the daily simulations from January $30^{\text {th }}$ until February $5^{\text {th }}$, which is the warmest week of the year in Wellington. 


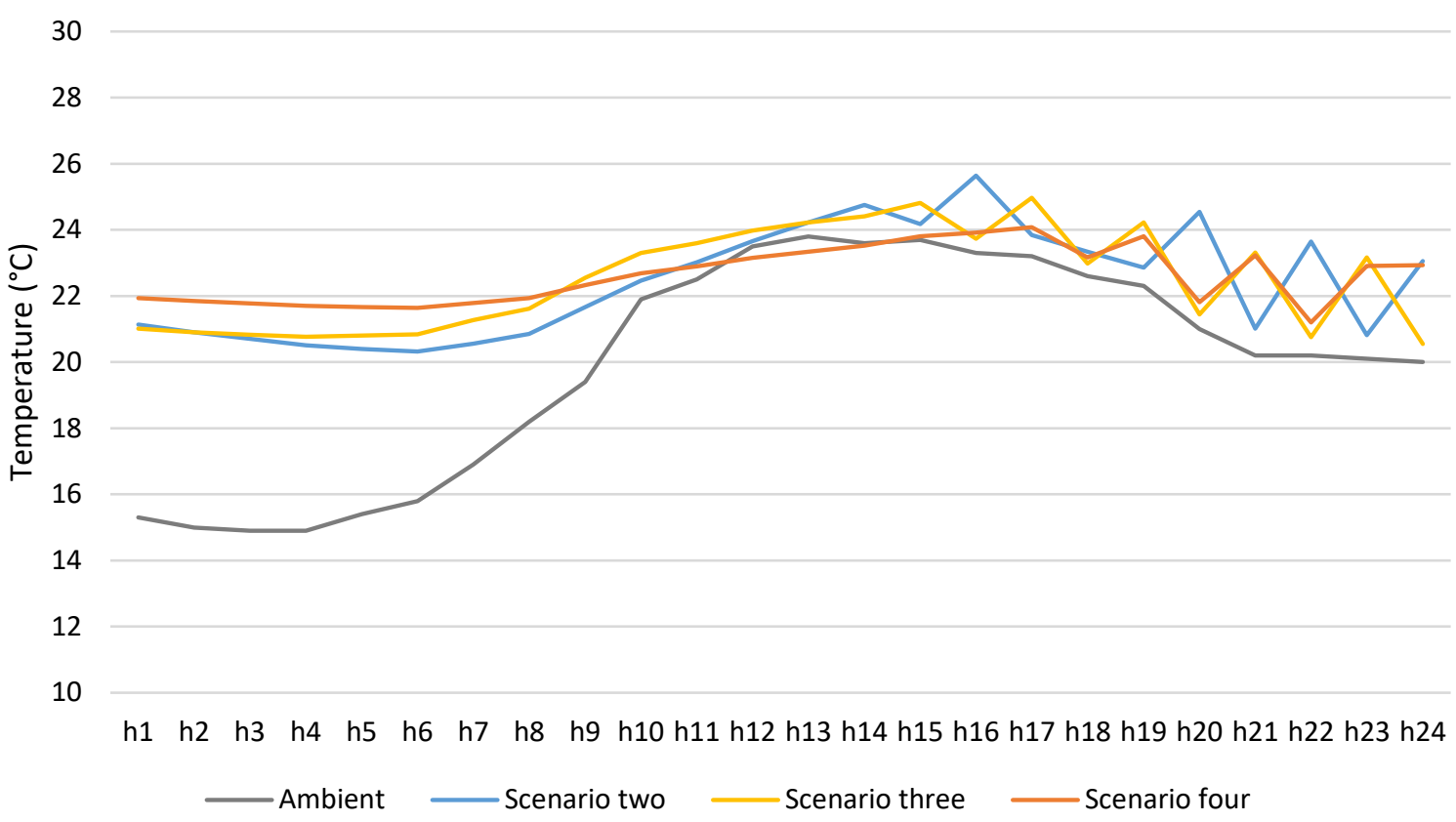

Figure 6.18: Differences between ambient temperature and internal temperature in different scenarios $\left({ }^{\circ} \mathrm{C}\right)$ January $30^{\text {th }}$

*scenario one is removed from available options (see Section 6.3.8.2), but the label (number) of other scenarios had no change to ease the flow.

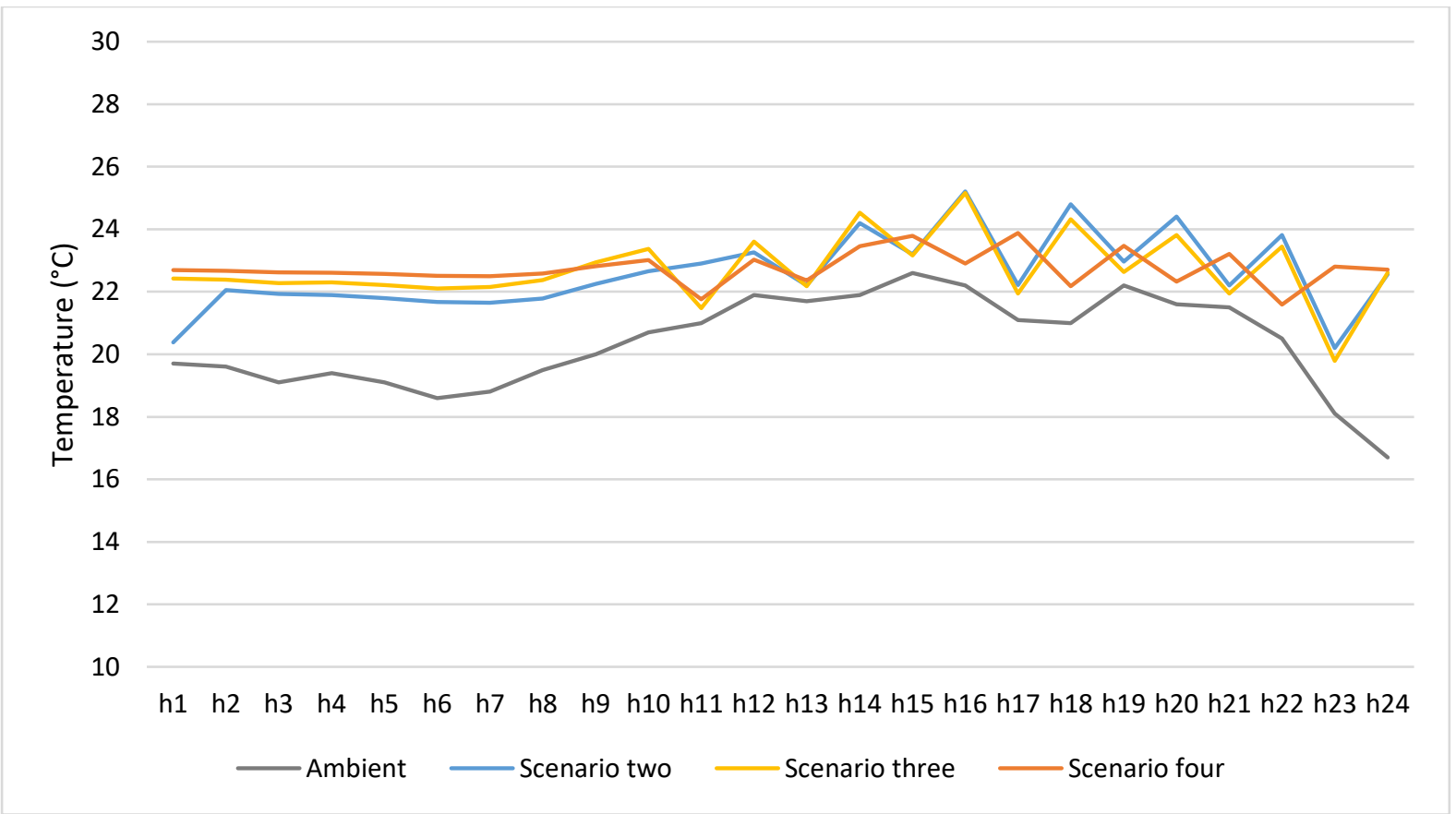

Figure 6.19: Differences between ambient temperature and internal temperature in different scenarios $\left({ }^{\circ} \mathrm{C}\right)$ January $31^{\text {th }}$ 


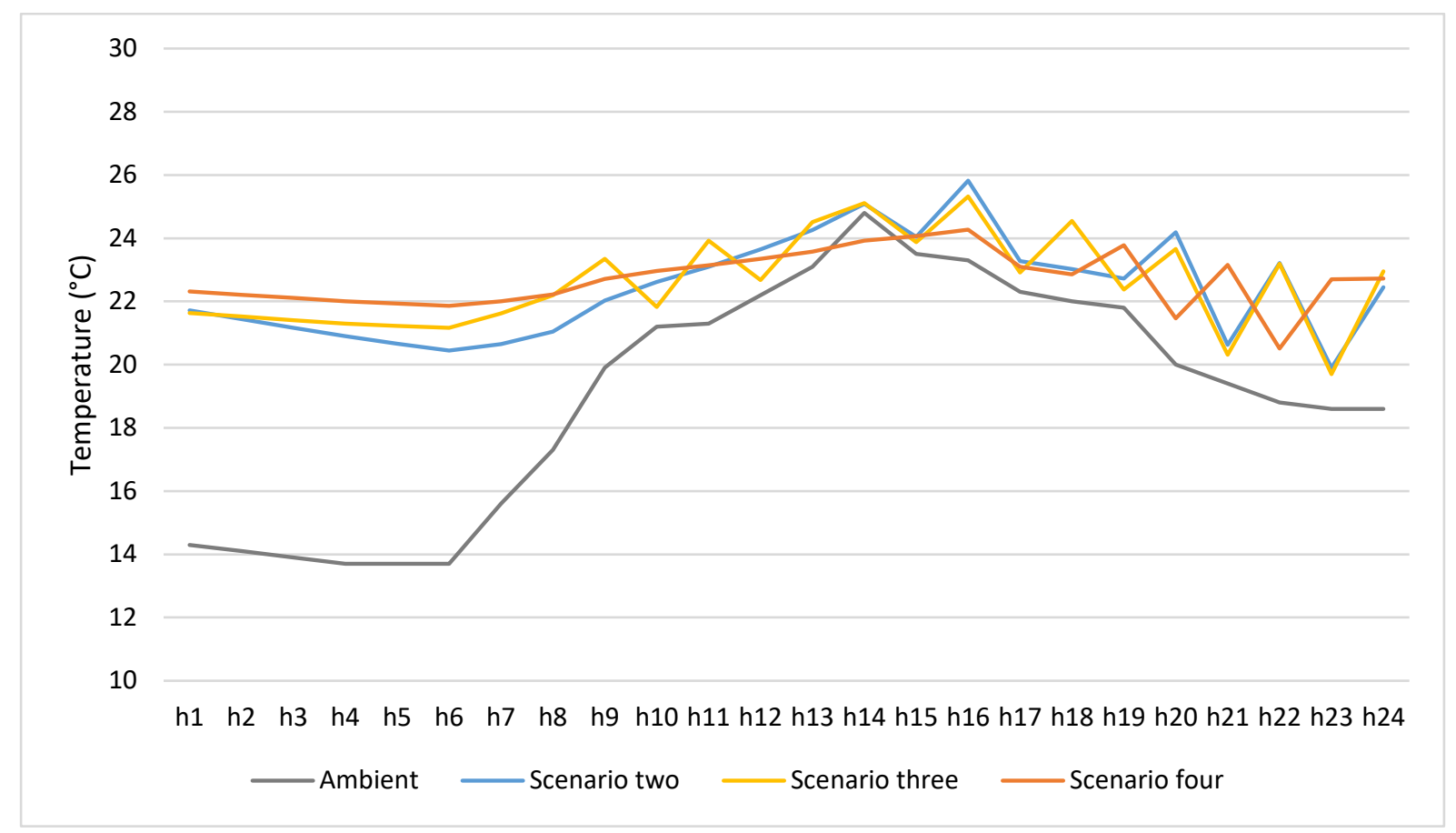

Figure 6.20: Differences between ambient temperature and internal temperature in different scenarios $\left({ }^{\circ} \mathrm{C}\right)$ February $1^{\text {st }}$

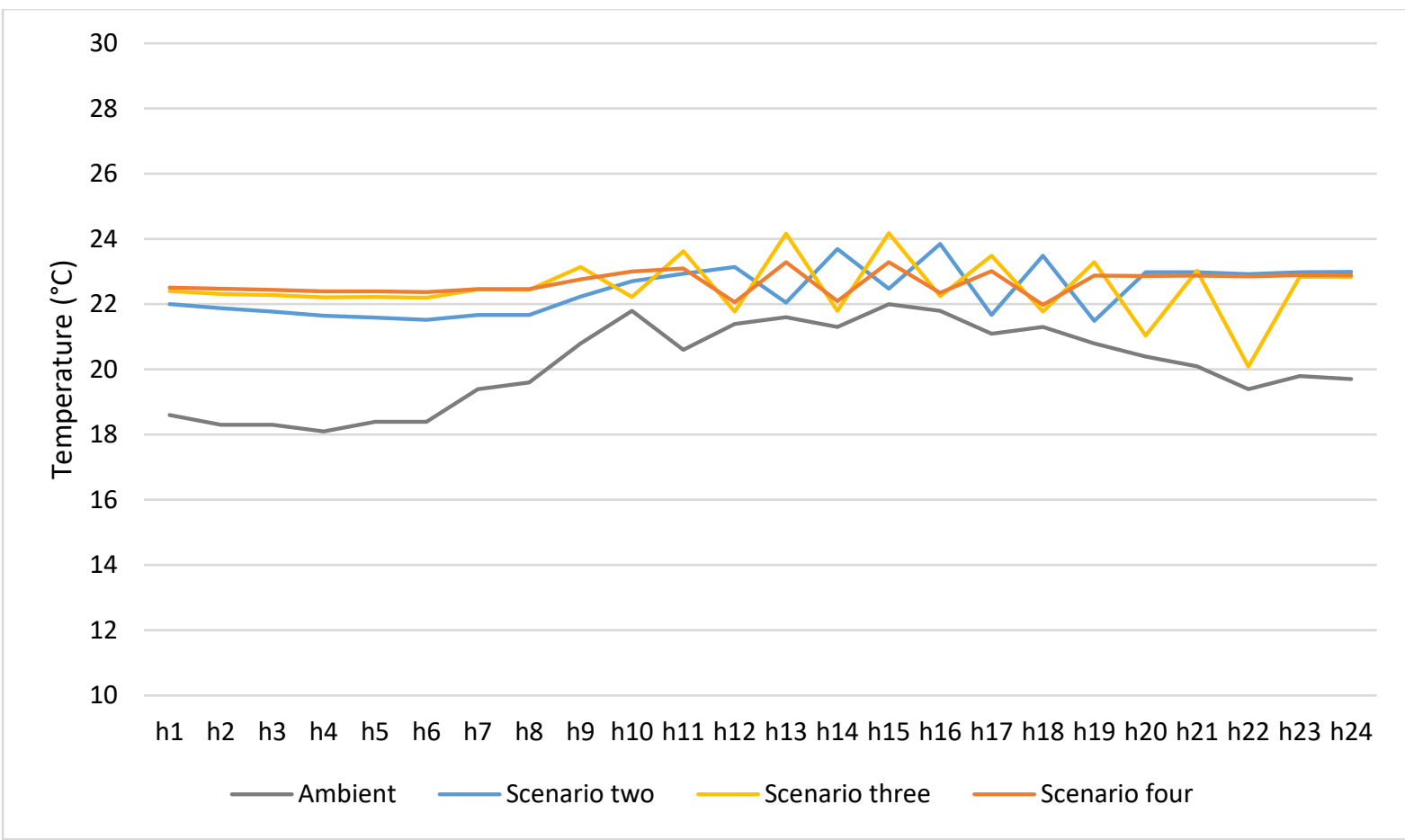

Figure 6.21: Differences between ambient temperature and internal temperature in different scenarios $\left({ }^{\circ} \mathrm{C}\right)$ February $2^{\text {nd }}$ 


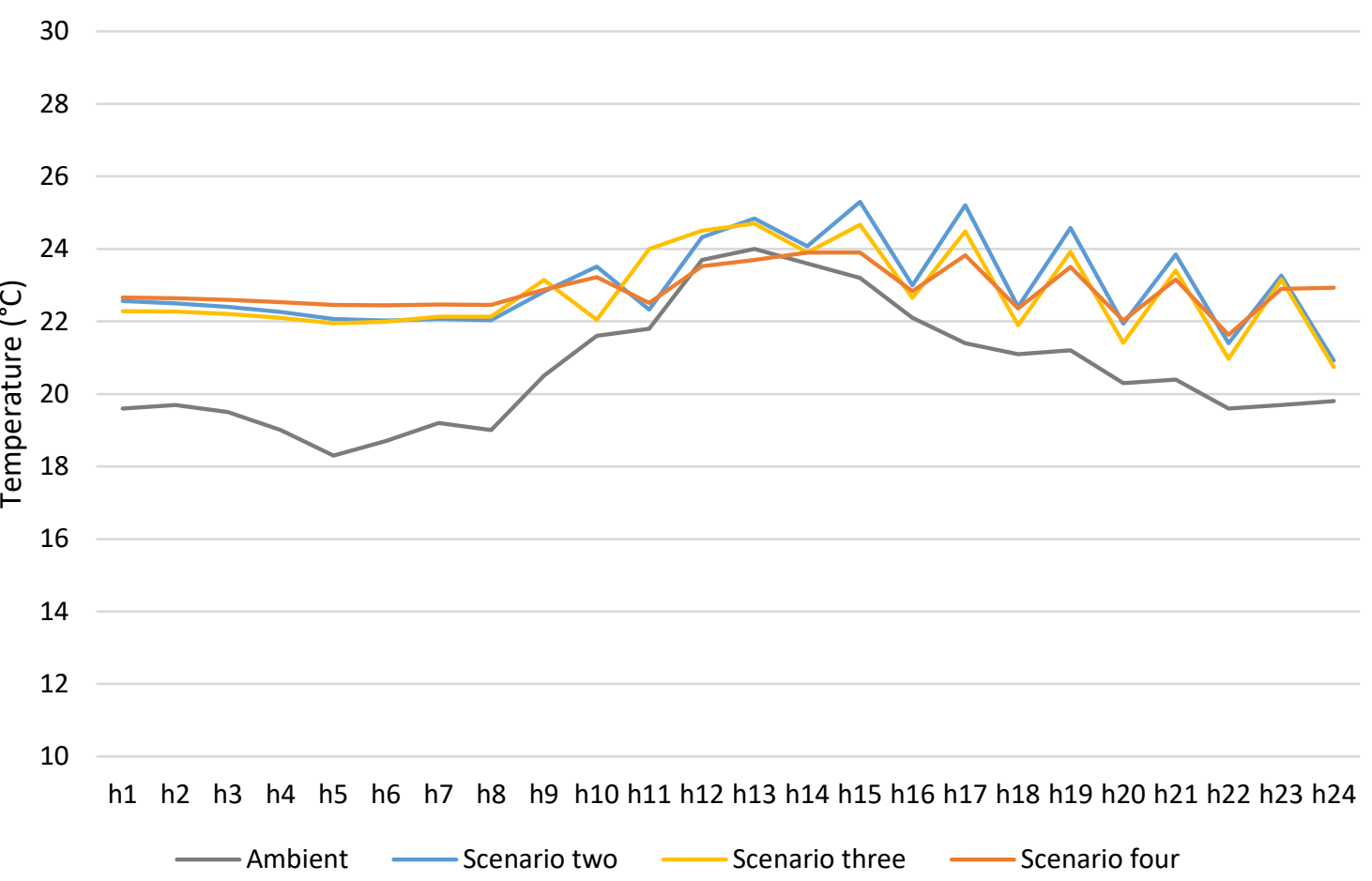

Figure 6.22: Differences between ambient temperature and internal temperature in different scenarios $\left({ }^{\circ} \mathrm{C}\right)$ February $3^{\text {rd }}$

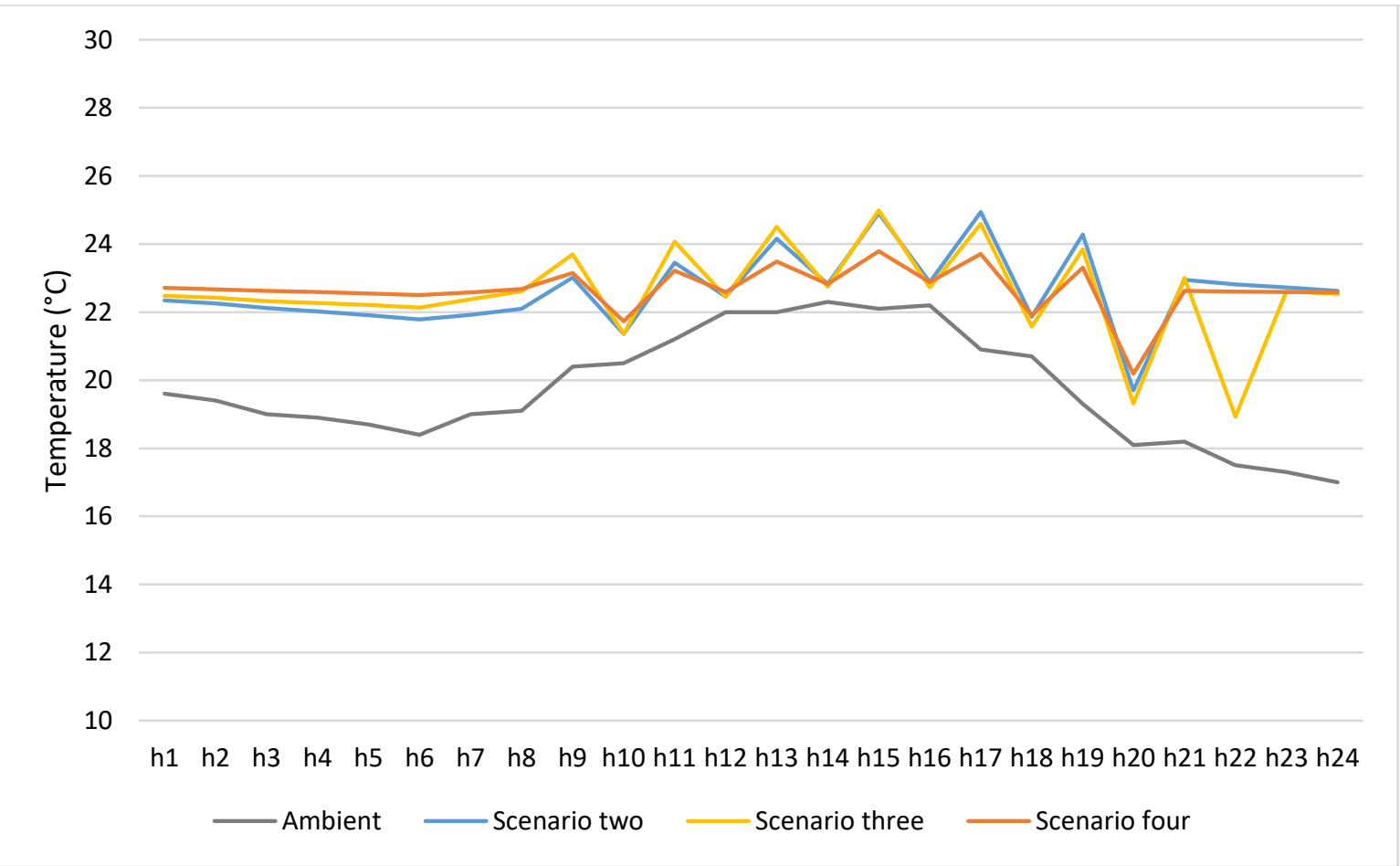

Figure 6.23: Differences between ambient temperature and internal temperature in different scenarios $\left({ }^{\circ} \mathrm{C}\right)$ February $4^{\text {th }}$ 


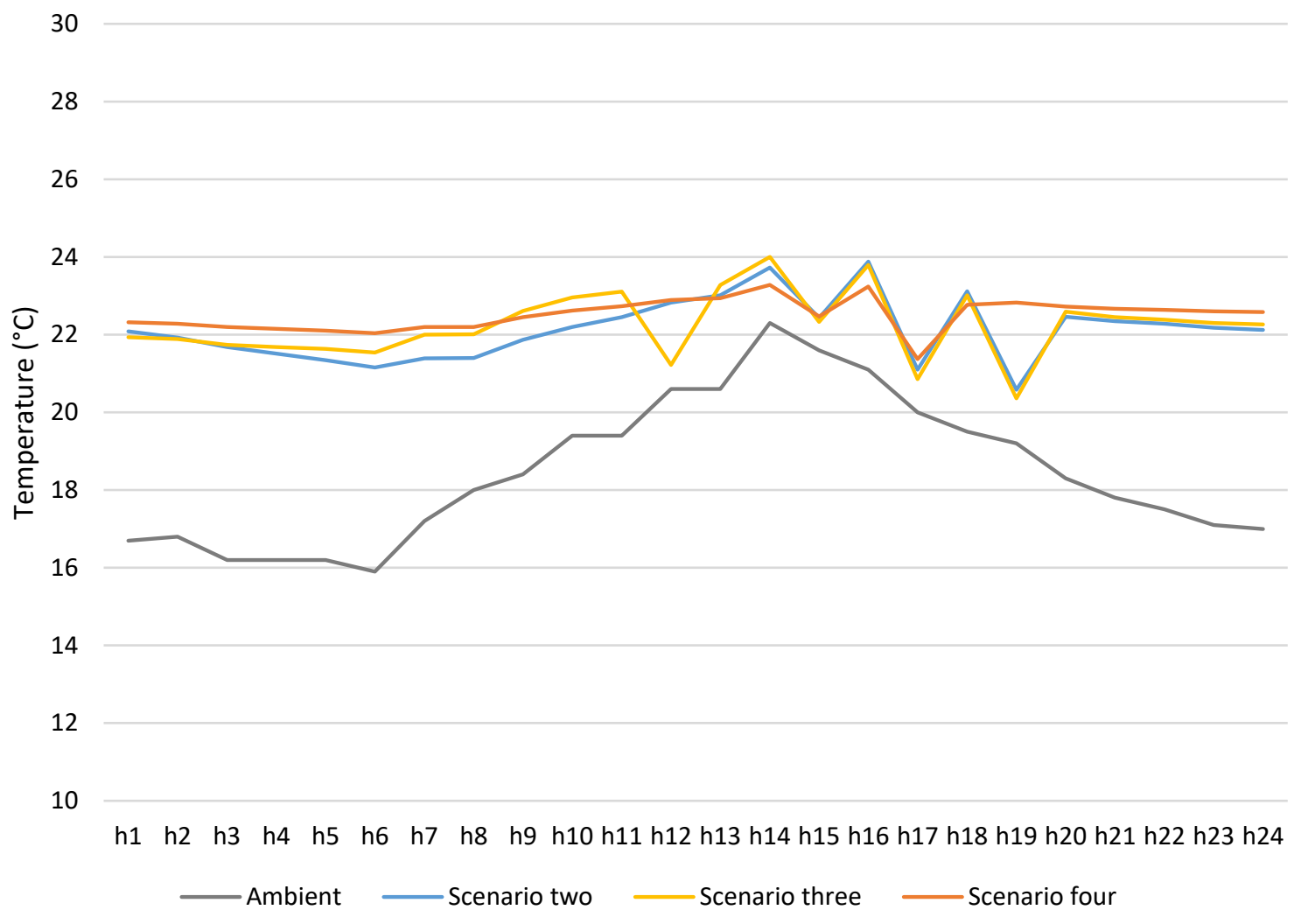

Figure 6.24: Differences between ambient temperature and internal temperature in different scenarios $\left({ }^{\circ} \mathrm{C}\right)$ February $5^{\text {th }}$

These figures show that even on the warmest days of the year there are some hours where the temperature goes below $16^{\circ} \mathrm{C}$, such as the first hours of January $30^{\text {th }}$ and February $1^{\text {st }}$. In scenarios 3 and 4 and to an extent in scenario 2 , the internal temperature stays above $16^{\circ} \mathrm{C}$ during these hours because of the heat stored in the ADU mass during the day.

The other points needing consideration are the maximum internal temperature of the ADU during this week and the amplitude of the internal temperatures over a day. The maximum temperatures being approximately $25^{\circ} \mathrm{C}$ for scenarios 2 and 3 and less than $24^{\circ} \mathrm{C}$ in scenario 4. Table 6.8 tabulates the minimum and maximum and amplitude of internal temperatures for the three scenarios from $31^{\text {st }}$ January to $5^{\text {th }}$ February. 
Table 6.8: Differences in internal temperature of the four scenarios

\begin{tabular}{|c|c|c|c|c|}
\hline & & Scenario two & Scenario three & Scenario four \\
\hline \multirow[t]{3}{*}{30 January } & Max & 25.64 & 24.97 & 24.08 \\
\hline & Min & 20.56 & 20.55 & 21.20 \\
\hline & Difference & 5.08 & 4.42 & 2.88 \\
\hline \multirow[t]{3}{*}{31 January } & Max & 25.21 & 25.16 & 23.88 \\
\hline & Min & 20.20 & 19.79 & 21.59 \\
\hline & Difference & 5.01 & 5.37 & 2.29 \\
\hline \multirow[t]{3}{*}{ February 1} & Max & 25.82 & 25.32 & 24.27 \\
\hline & Min & 19.90 & 19.70 & 20.51 \\
\hline & Difference & 5.92 & 5.62 & 3.76 \\
\hline \multirow[t]{3}{*}{ February 2} & Max & 23.85 & 24.18 & 23.28 \\
\hline & Min & 21.49 & 20.09 & 21.98 \\
\hline & Difference & 2.36 & 4.09 & 1.30 \\
\hline \multirow[t]{3}{*}{ February 3} & Max & 25.30 & 24.70 & 23.90 \\
\hline & Min & 20.92 & 20.74 & 21.63 \\
\hline & Difference & 5.38 & 3.96 & 2.27 \\
\hline \multirow[t]{3}{*}{ February 4} & Max & 24.94 & 24.99 & 23.79 \\
\hline & Min & 19.70 & 18.93 & 20.19 \\
\hline & Difference & 5.24 & 6.06 & 3.60 \\
\hline \multirow[t]{3}{*}{ February 5} & Max & 23.88 & 24.00 & 23.28 \\
\hline & Min & 20.58 & 20.36 & 21.37 \\
\hline & Difference & 3.30 & 3.64 & 1.91 \\
\hline \multicolumn{2}{|c|}{ Average differences } & 4.61 & 4.73 & 2.57 \\
\hline
\end{tabular}

Table 6.8 shows the internal temperature in scenarios 2 and 3 are similar, with differences between minimum and maximum in the range of $5-6^{\circ} \mathrm{C}$ and an average change of less than $5^{\circ} \mathrm{C}$. Scenario 4 shows the most stable behaviour, where the highest difference between minimum and maximum is less than $4^{\circ} \mathrm{C}$ and the average change is under $3^{\circ} \mathrm{C}$. Table 6.8 shows scenarios 2-4 are fairly comfortable, with scenario 4 as the best option. Again, the only differences are the volume of mass in each scenario (Table 6.7).

\subsubsection{The Best Scenario}

Considering Figure 6.18-Figure 6.24, scenario 4 is the best in energy and comfort terms. This scenario has an insulated $150 \mathrm{~mm}$ concrete slab working as thermal mass, as in scenario 3 , and an additional $50 \mathrm{~mm}$ of concrete blocks lining the internal face of external walls adding more mass to the ADU. Despite the slight improvement in energy use and comfort adding concrete blocks to the walls could have potentially negative effects on the construction and transportation of the ADU. Adding the blocks at the factory increases the weight of the ADU prefabricated units and their craning, whereas building them in on the site would add to the on-site work and the time taken for erection. Another problem is the fact that having these 
blocks would add $100 \mathrm{~mm}$ in each direction to each module. This addition will either make the modules bigger to keep the internal space unchanged or reduce the internal spaces. For the bigger modules, the length is not a problem as the loads can be over $20 \mathrm{~m}$ while the length of each module is just over $5 \mathrm{~m}$. However, the width would be a problem as the width of each module is $2.55 \mathrm{~m}$ which is the maximum allowed load width. Adding $100 \mathrm{~mm}$ to this width means seeking permission for transporting an oversized load (see Section 4.4). Adding mass to the inside is equally problematic as the ADU was designed based on Lifemark standards, and this change could substantially affect the usability of the ADU for disabled people. Contrasting the small benefits of having $50 \mathrm{~mm}$ concert blocks lining the walls with the huge problems this will cause, means this scenario has been dismissed.

Putting scenarios 4 aside, the simulated differences between scenarios 2 and 3 are slight when it comes to internal temperatures. However, scenario 3 needs approximately $30 \%$ less energy to keep the ADU in the comfort zone. Given being zero energy is one of the main goals of this research scenario 3 emerged as the best scenario, which was what the ALF results showed.

\subsubsection{Part two: Simulating the Energy Efficiency of the ADU in Different Cities and Directions}

This part investigates the effects of different environmental conditions (the climates of Auckland, Christchurch) and orientations in the climate of Wellington on the internal temperature and required heating of the ADU. The aim is to see if the existing design of the ADU is still energy efficient in different situations, or if the differences are too big and there is a need for different designs for each city and orientation. This is important as having no control over the orientation due to the position of the existing house and the lot boundaries would appear to be a potential weakness of prefabricated ADUs. It is worth noting that the ADU in this part has a $165 \mathrm{~mm}$ SIPs ceiling, and all SIPs panels are made with a polystyrene core.

\subsubsection{ADU in Different Cities}

The climates of Auckland and Christchurch in the Canterbury region were selected to be used in this series of simulations. In 2018, 31\% of New Zealand households were in Auckland, followed by $17 \%$ in the Canterbury region, and $10 \%$ in each of the Waikato and Wellington regions (Statistics NZ, 2015). Moreover, the Auckland and Canterbury regions were predicted 
to have the highest average annual growth rate from 2013 to 2038 in terms of the number of households, this being $1.7 \%$ and $1.1 \%$ respectively (Statistics NZ, 2015). This shows the need for more houses is higher in Auckland, Canterbury, and Wellington than in other regions. Also, the projections show by 2033 the number of those aged $65+$ in the population could double or triple in various local areas of Auckland, which means more houses are needed for this group of New Zealanders (Statistics New Zealand, 2013b). Moreover, these houses need to be easy to heat and maintain and ideally should enable people to age in their existing communities (Yavari et al., 2018).

The other reason for selecting Auckland and Christchurch is their environmental conditions which are different from both Wellington and each other. While Wellington is located at the southern edge of the North Island, Auckland is towards its northern end, and Christchurch is in the middle of the South Island. This distribution, which covers from far north to mid-south of the country represents the different environmental conditions of New Zealand. Table 6.9 shows annual heating degree days and sunshine hours of these cities and shows the annual heating degree days (base $18^{\circ} \mathrm{C}$ ) in Christchurch are 2,370, which is 465 and 1,157 more than Wellington and Auckland respectively. This suggests the ADU will need more energy to keep the internal temperature at an acceptable level.

Table 6.9: Environmental data of the case study cities

\begin{tabular}{|l|l|l|l|l|}
\hline Latitude & Latitude & $\begin{array}{l}\text { Annual heating } \\
\text { degree days to } 18^{\circ} \mathbf{C}\end{array}$ & $\begin{array}{l}\text { Annual } \\
\text { sunshine } \\
\text { hours }\end{array}$ & Source \\
\hline Auckland, New Zealand & $36^{\circ} 50^{\prime}$ S & 1,213 & 2,050 & Chappell, 2014 \\
\hline Wellington, New Zealand & $41^{\circ} 2^{\prime}$ S & 1,905 & 2,000 & Macara, 2018 \\
\hline Christchurch, New Zealand & $43^{\circ} 53^{\prime} \mathrm{S}$ & 2,370 & 1,950 & Macara, 2018 \\
\hline
\end{tabular}

Before comparing the ADU (scenario 3) in different cities it should be noted that replacing the polyurethane in the SIPs panels with polystyrene with a lower R-value, and changing the thickness of the ceiling panels from $215 \mathrm{~mm}$ to $165 \mathrm{~mm}$, increased the required heating in terms of delivered energy from 1.2GJ (333kWh/year) to 1.7GJ (472kWh/year) in Wellington. Figure 6.25 shows the monthly average internal temperature fluctuations in the three New Zealand cities with the heating set to come on at $16^{\circ} \mathrm{C}$. 


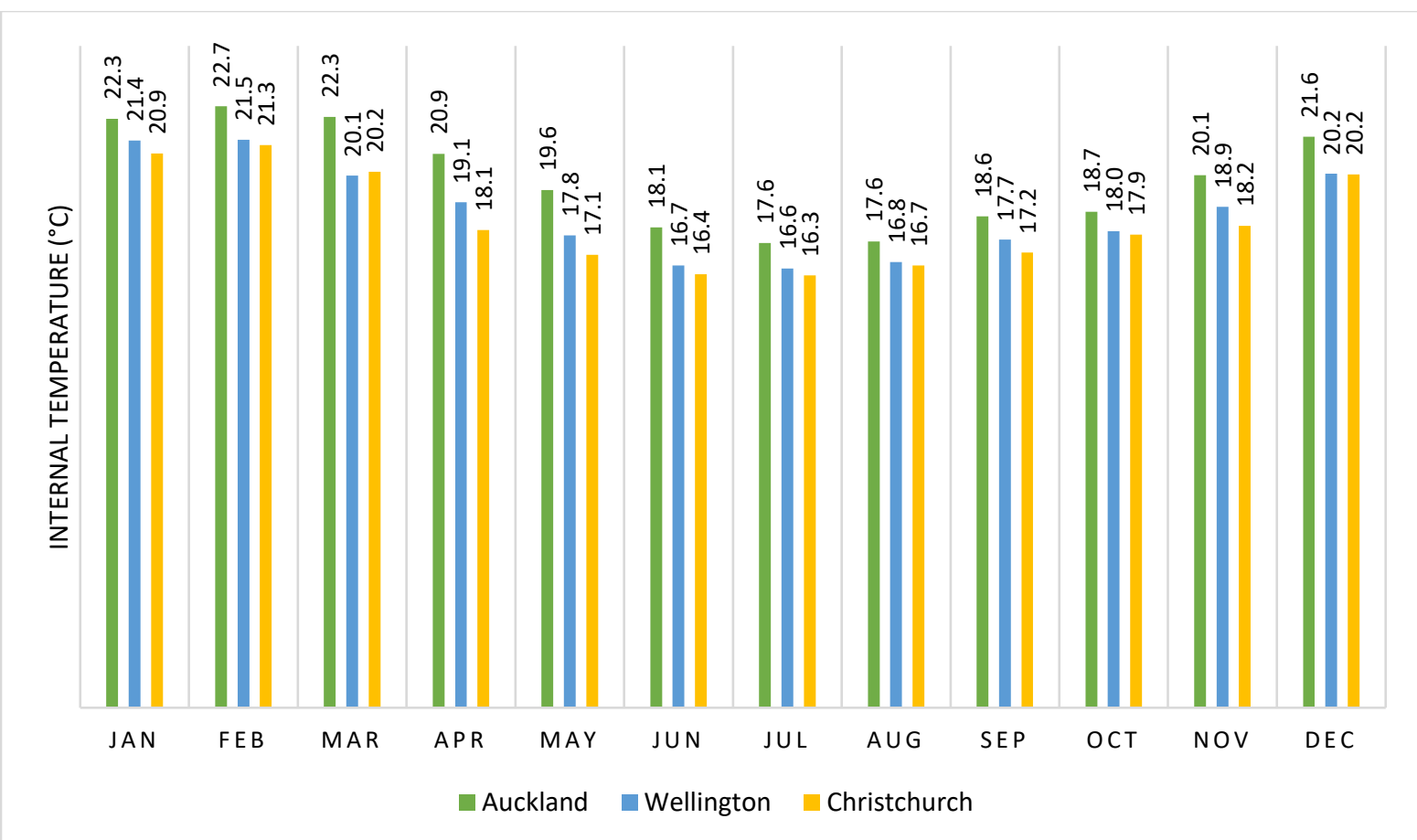

Figure 6.25: ADU internal monthly average temperatures in three New Zealand cities $\left({ }^{\circ} \mathrm{C}\right)$

Figure 6.25 shows the internal temperature of the ADU in Auckland is higher than in Wellington and Christchurch due to the higher annual sunshine hours in Auckland. While the monthly average temperature in Wellington and Christchurch never reached $22^{\circ} \mathrm{C}$, in Auckland, it was over $22^{\circ} \mathrm{C}$ in three consecutive months from January, with a maximum of $22.7^{\circ} \mathrm{C}$ in February. The energy for heating differed widely in the selected cities (Figure 6.26).

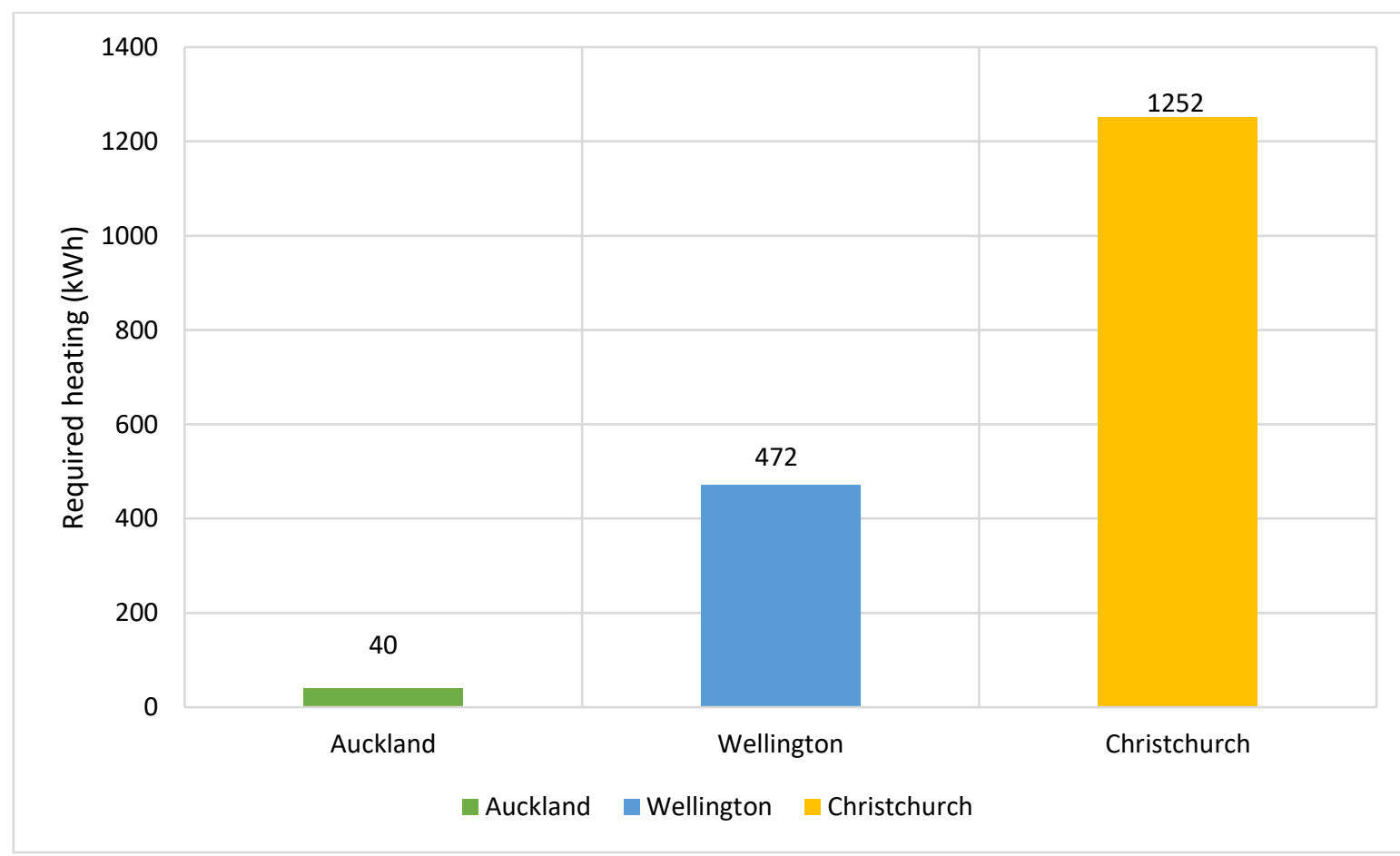

Figure 6.26: ADU required heating in three New Zealand cities (kWh) 
Figure 6.26 shows the energy required to keep the internal temperature of the ADU above $16^{\circ} \mathrm{C}$ in Christchurch is $780 \mathrm{kWh} /$ year and $1,112 \mathrm{kWh} /$ year more than needed in Wellington and Auckland respectively, this being predictable based on the environmental differences between these cities (Figure 6.27). Adding more thermal mass or more insulation could be a solution in Christchurch, but this could affect the portability of the prefabricated ADU. Figure 6.27 and Figure 6.28 show the monthly average external temperature and the required heating in each city.

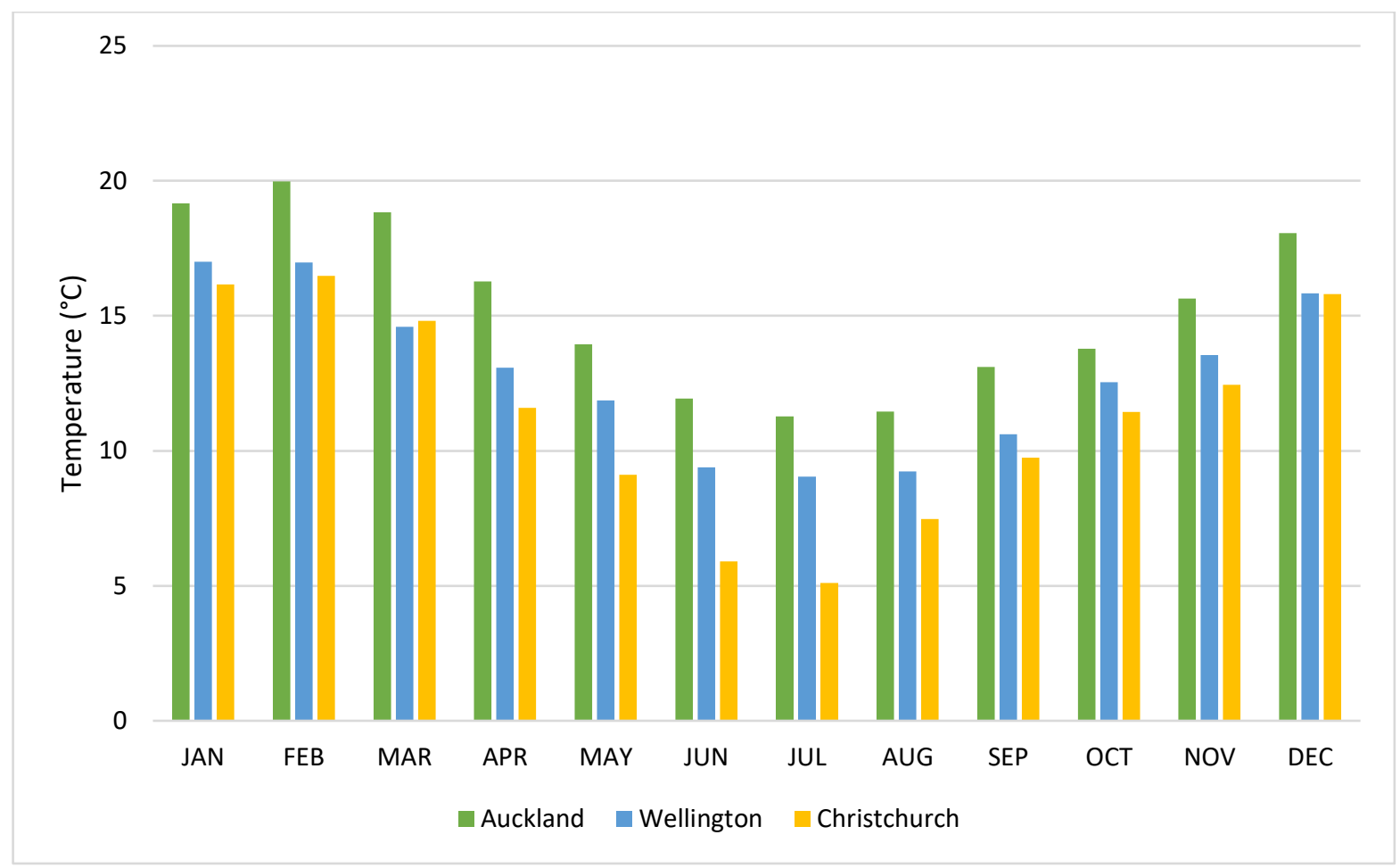

Figure 6.27: Average monthly ambient temperature $\left({ }^{\circ} \mathrm{C}\right)$ 


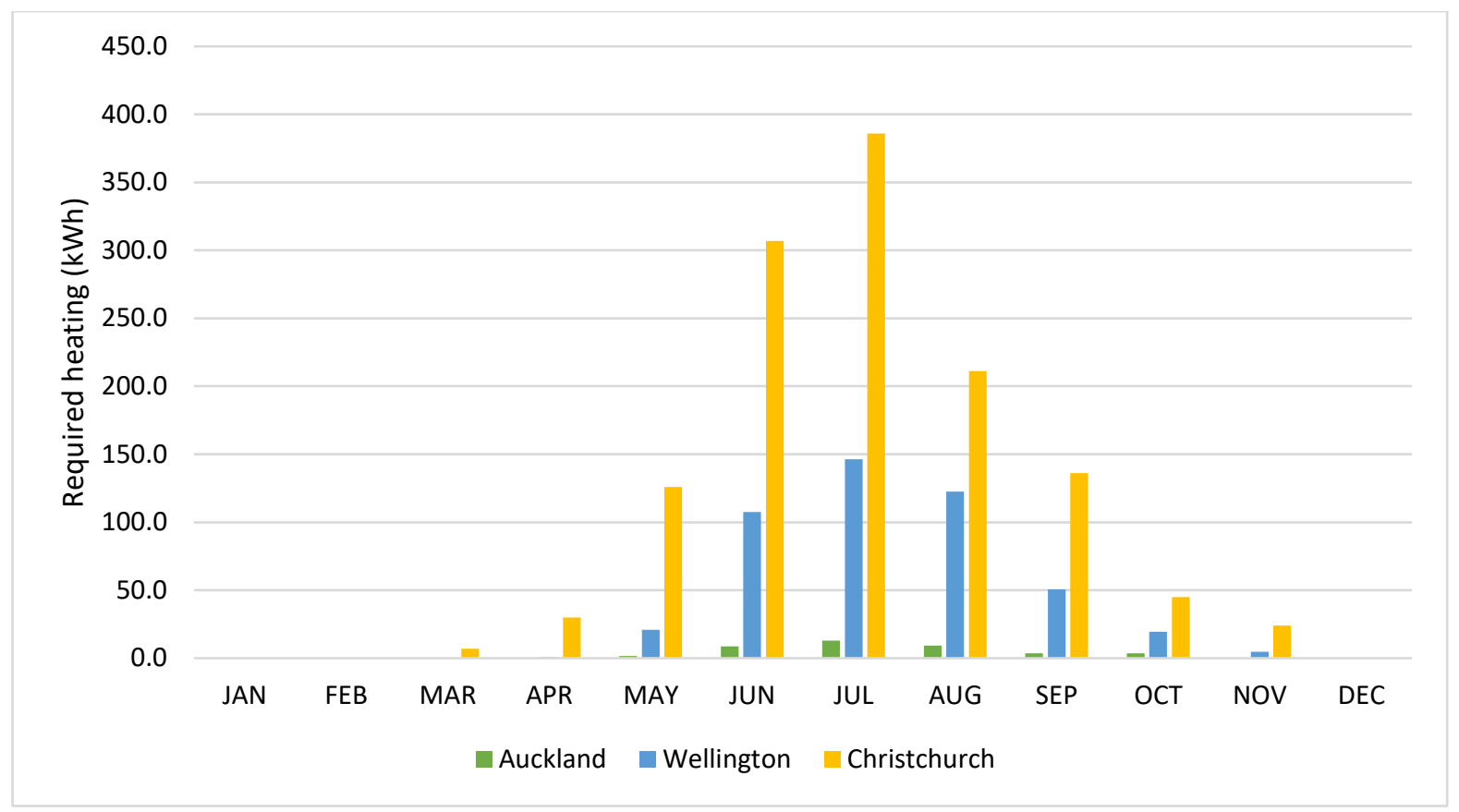

Figure 6.28: Required heating on a monthly basis (kWh)

Figure 6.27 shows the monthly average ambient temperature in Auckland is always higher than in the other cities and only falls below $16^{\circ} \mathrm{C}$ from May to November, having a minimum in July of $11.3^{\circ} \mathrm{C}$. Wellington and Christchurch also have monthly average temperatures below $16^{\circ} \mathrm{C}$ from March to November with respective minimums of $9.1^{\circ} \mathrm{C}$ and $5.1^{\circ} \mathrm{C}$. From December to March, the monthly average external temperature is very similar in Wellington and Christchurch, with a maximum difference of $1^{\circ} \mathrm{C}$, but this difference rises in the colder months reaching approximately $4^{\circ} \mathrm{C}$ in July, so more heating is required in the Christchurch winter. This means the prefabricated ADU design would be near zero energy in both Wellington and Auckland, but that it might be better to seek a different design for Christchurch.

\subsubsection{ADU in Different Orientations}

The orientation of the prefabricated ADU on the site will affect its performance, having been designed assuming the majority of the windows face north. However, other placements will be necessary to meet conditions such as required distance from the boundaries, and the shape of the available site. There is less control over the direction of the ADU on a site that has already been developed than if building in a conventional way, where each design can maximise the potential of each site. This limitation is one of the main potential weaknesses of prefabricated ADUs. This section, therefore, simulates the energy consumption and the internal temperatures of the ADU for the other orientations to see how big the differences are. In this series of simulations, the first simulation direction is shown in Figure 6.29 is 
labelled as $0^{\circ}$. The ADU is then rotated clockwise by $90^{\circ}, 180^{\circ}$ and $270^{\circ}$ for the next three rounds of simulations. The heating is set to come on at $16^{\circ} \mathrm{C}$ and results are only presented in terms of delivered energy.

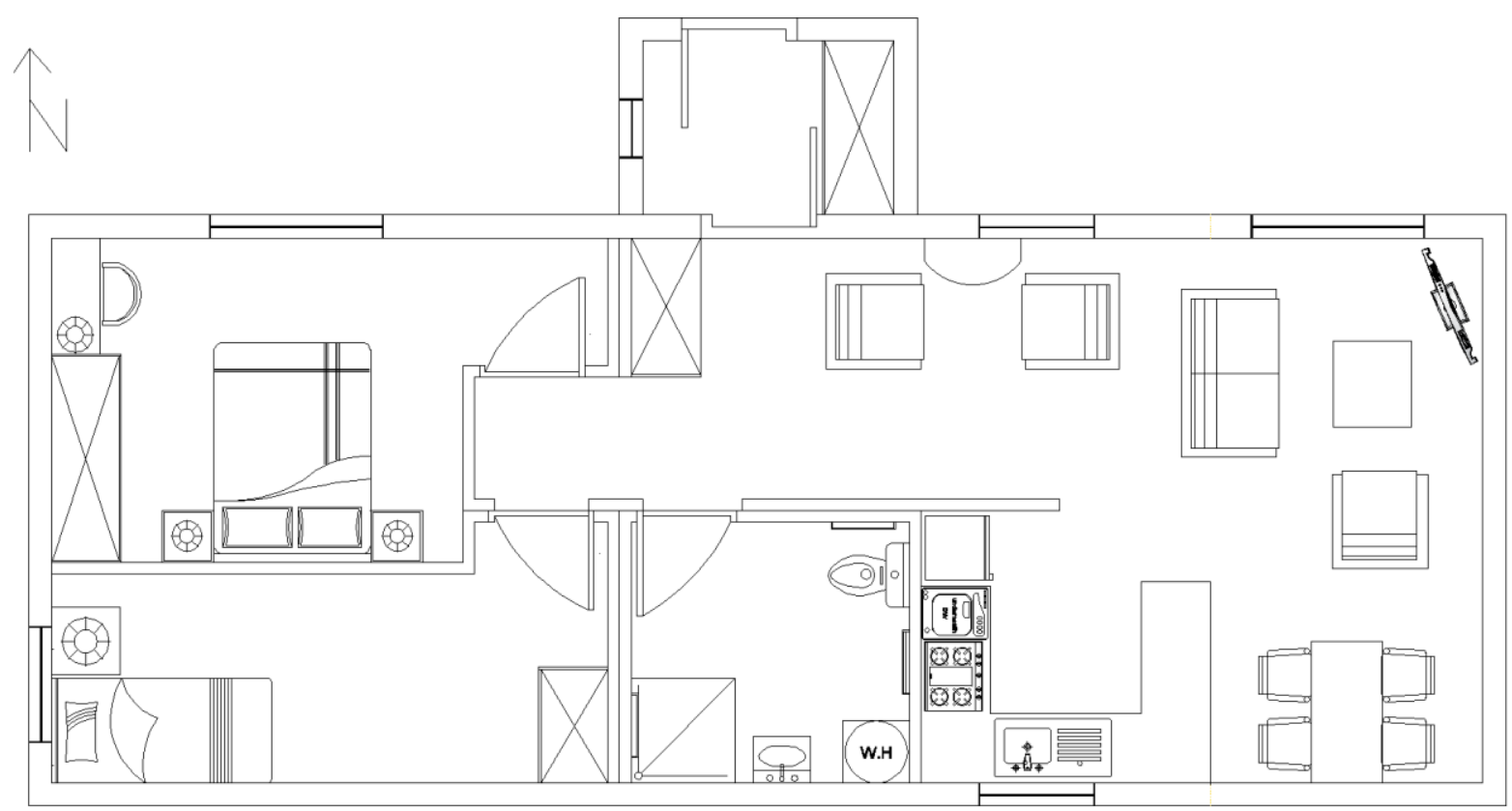

Figure 6.29: The ADU plan

Comparing the required annual heating of the different orientations shows, as expected the first scenario consumes energy less than any other (472 kWh/year) (Figure 6.30).

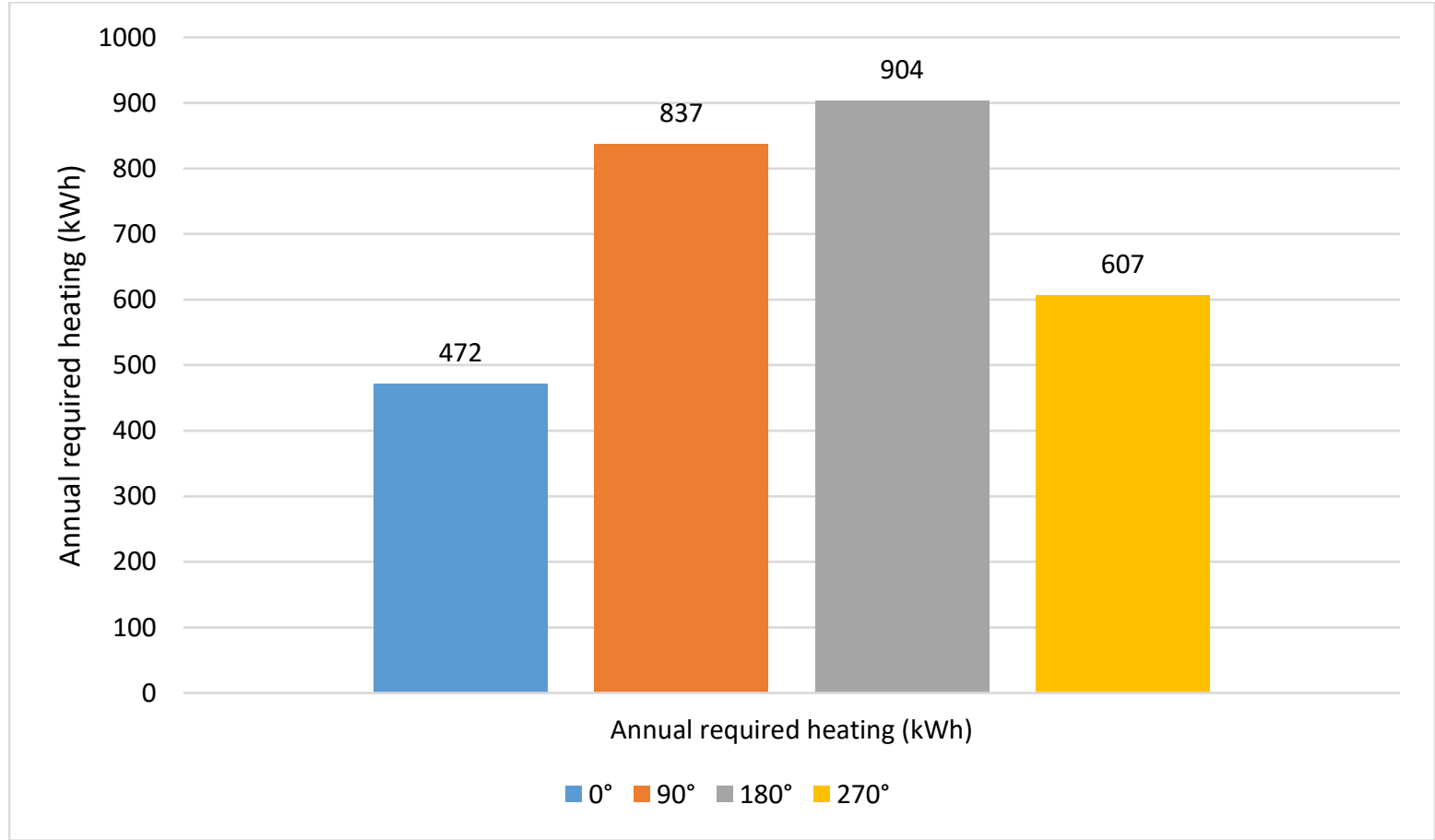

Figure 6.30: Annual required heating of different scenarios (kWh) 
As expected, scenario $180^{\circ}$, where the majority of windows facing south, is the least energy efficient, using a little less than twice the energy of scenario $0^{\circ}$. Scenarios $90^{\circ}$ and $270^{\circ}$ are better as they get the sun in the evening and early morning respectively. Figure 6.31 shows how the internal temperature of the ADU fluctuates for each orientation with the temperature never falling below $16^{\circ} \mathrm{C}$ in winter because of the heating set point.

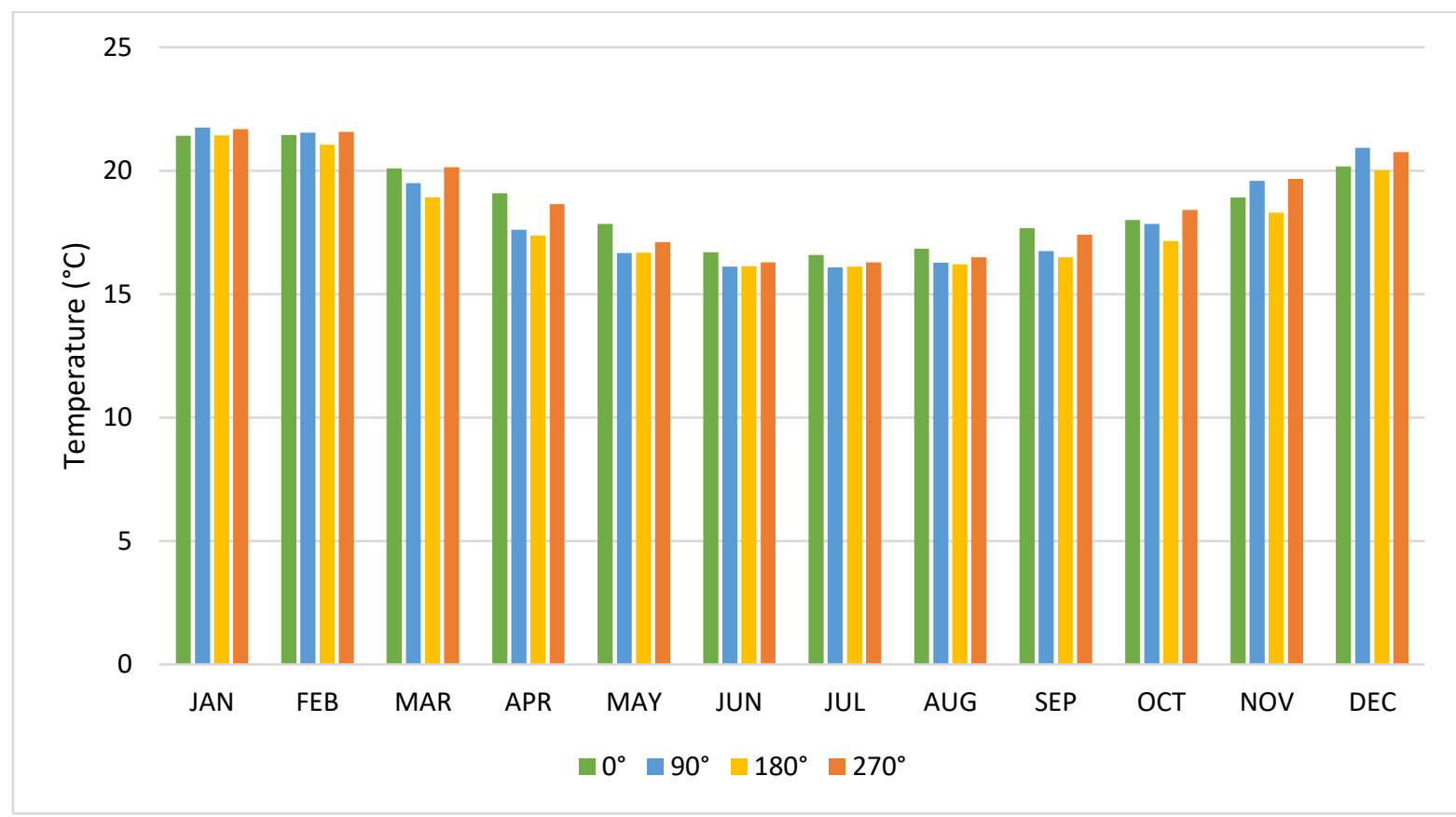

Figure 6.31: Internal temperatures $\left({ }^{\circ} \mathrm{C}\right)$ of the four scenarios

Figure 6.31 shows the internal temperatures of all scenarios are similar but scenarios $90^{\circ}$ and $270^{\circ}$ get a little warmer from November to April than scenarios $0^{\circ}$ and $180^{\circ}$. Figure 6.32 shows the monthly energy needed to keep the internal temperature of the $A D U$ over $16^{\circ} \mathrm{C}$. No heating is required in December, January and February for all scenarios $0^{\circ}$ and $90^{\circ}$ and $180^{\circ}$ do not need heating in March. Looking at Figure 6.31 shows there could potentially be no overheating in any scenario, but this needs more investigation. 


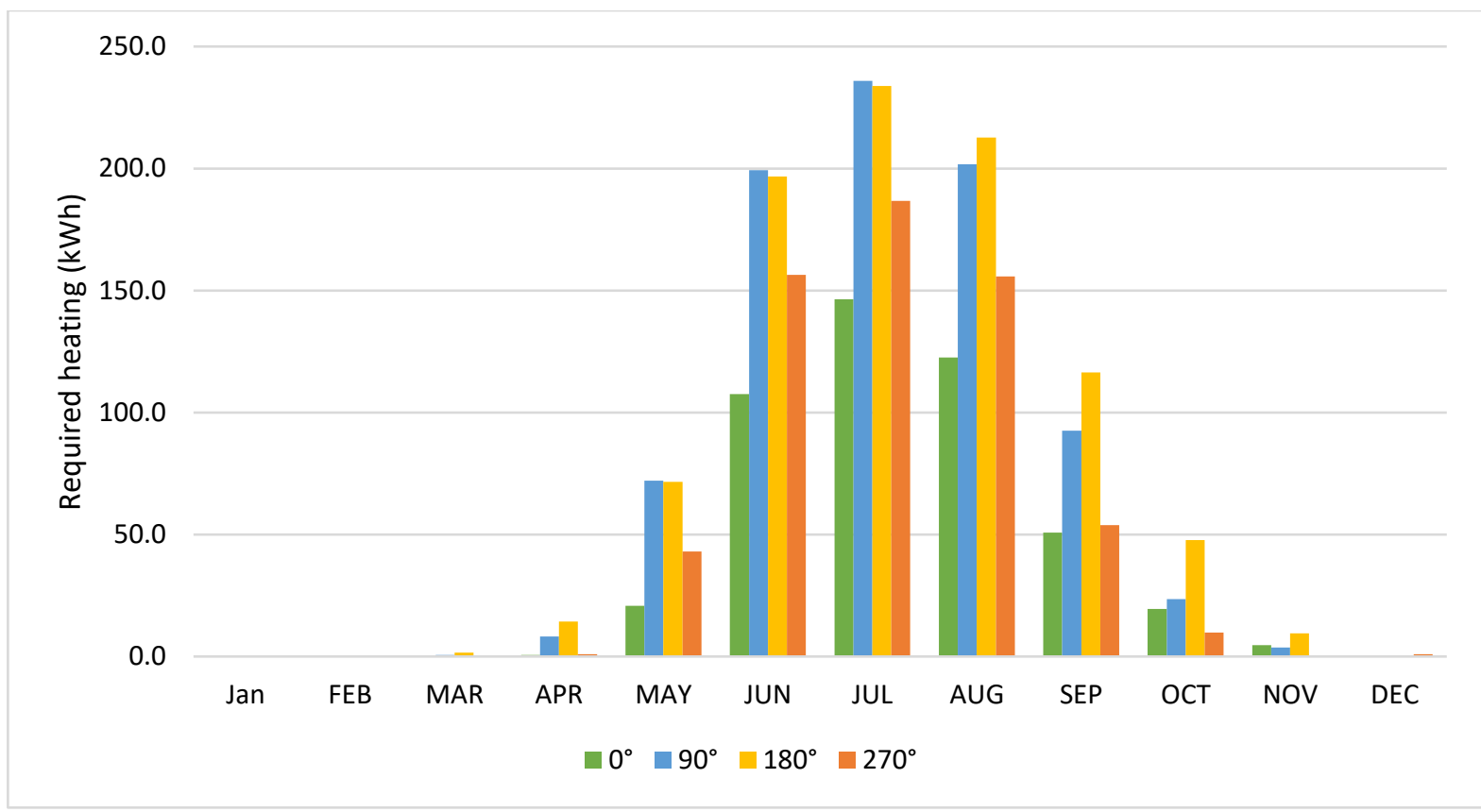

Figure 6.32: Monthly required heating of different scenarios (kWh)

At this stage it is worth looking at the required heating of the different scenarios in smaller periods to look at the reason behind the lower energy consumption of scenario $0^{\circ}$. For this purpose, the energy consumption and internal temperature of the ADU were investigated for the $23^{\text {rd }}$ of August and February $3^{\text {rd }}$, as the coldest and warmest days of the year, having daily average ambient temperatures of $6.1^{\circ} \mathrm{C}$ and $20.7^{\circ} \mathrm{C}$ respectively. Figure 6.33 and Figure 6.34 show the ambient temperature and the internal temperature for February $3^{\text {rd }}$ and $23^{\text {rd }}$ of August for the four scenarios.

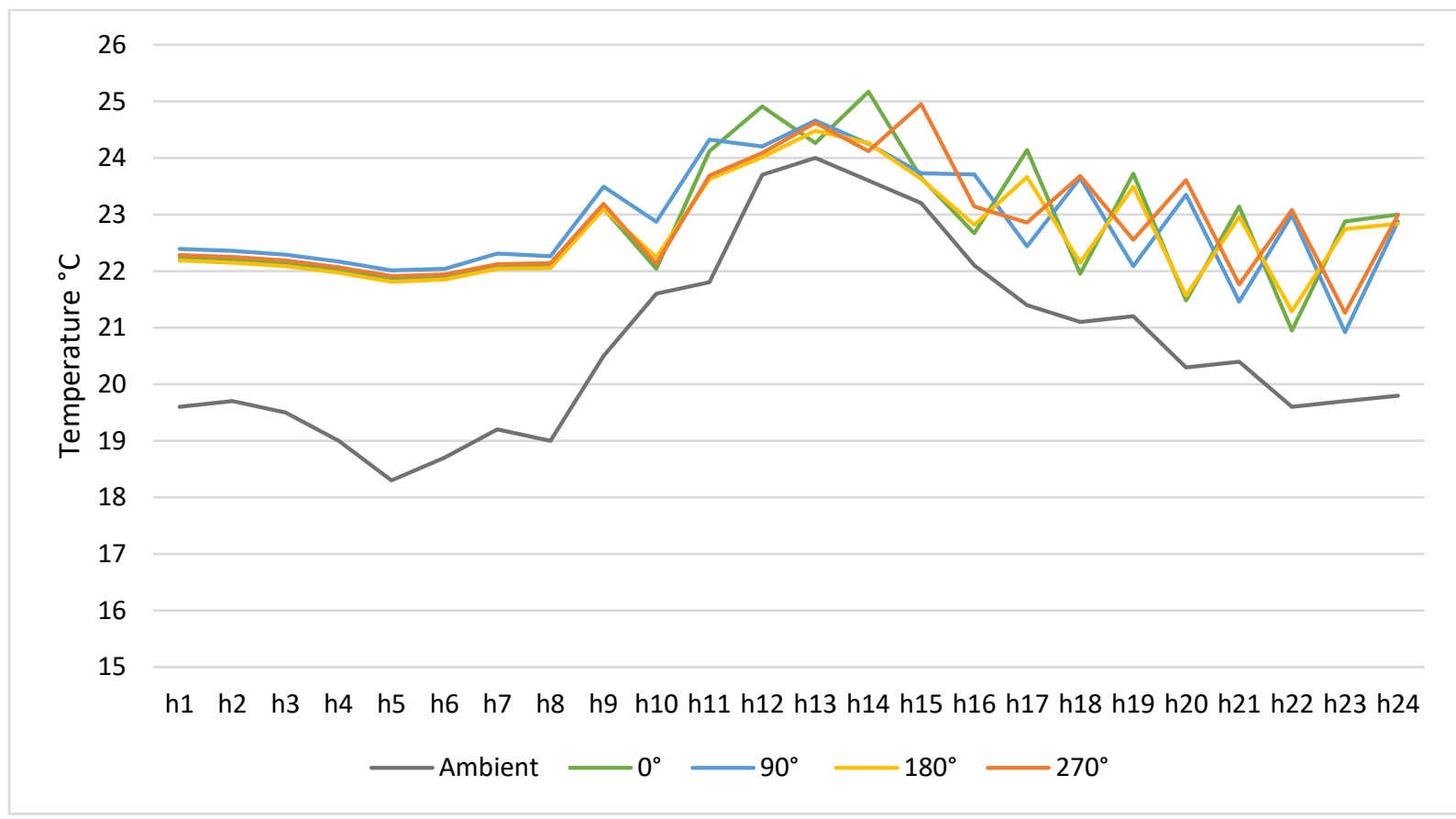

Figure 6.33: Temperatures on February $3^{\text {rd }}$ for the four scenarios $\left({ }^{\circ} \mathrm{C}\right)$ 
Figure 6.33 shows there is no sizable difference in the internal temperatures of the different scenarios on February $3^{\text {rd }}$. The internal temperature of the ADU follows the ambient temperature, with the fluctuations after 09.00 due to the ventilation, which was set to come on at $23^{\circ} \mathrm{CSUNREL}$. This means as soon as the temperature reaches $23^{\circ} \mathrm{C}$ the windows would be open to reduce the internal temperature naturally.

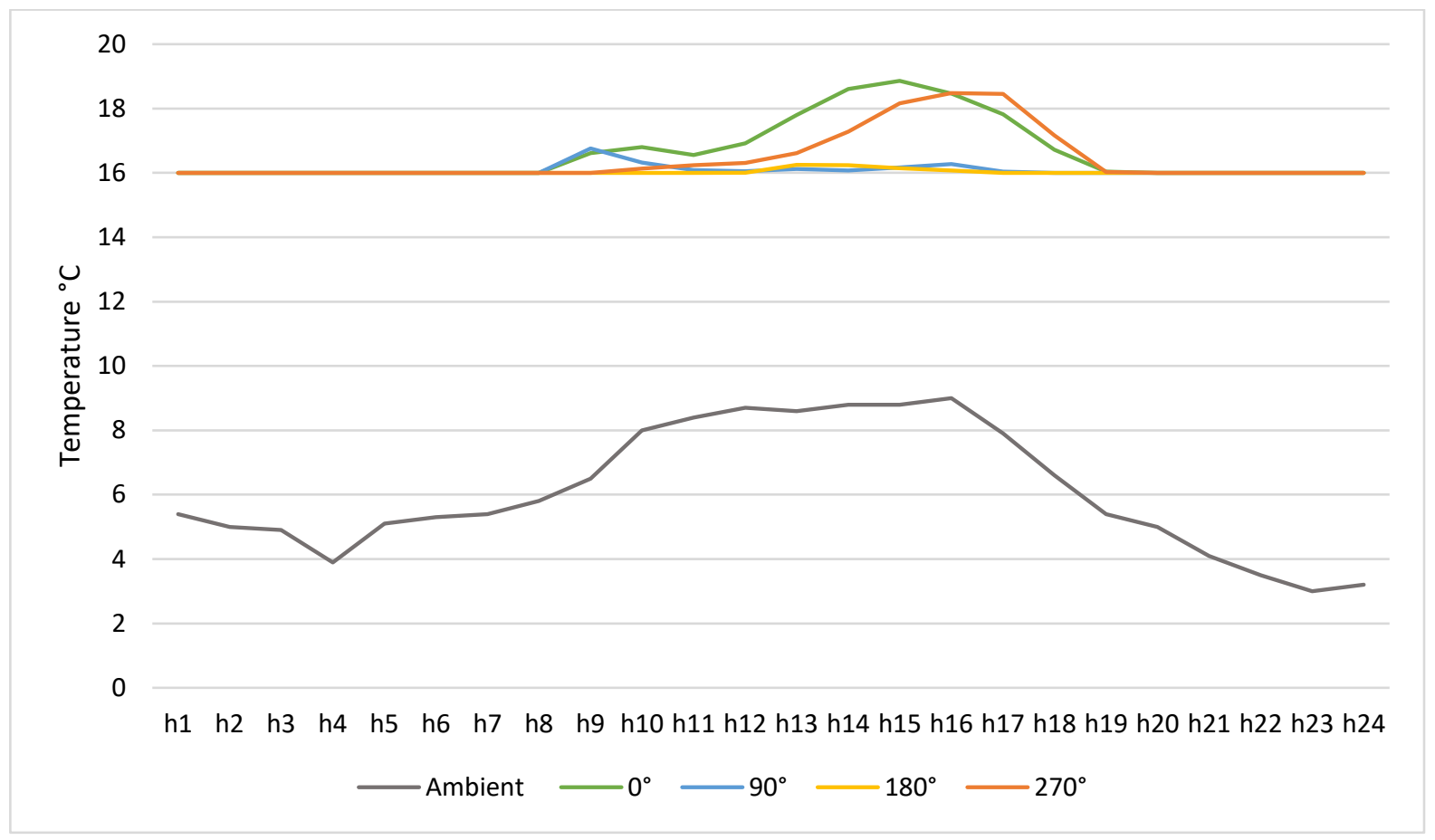

Figure 6.34: Temperature in August $23 \mathrm{rd}\left({ }^{\circ} \mathrm{C}\right)$

In winter the need for maximum heating would be in the early evening, where the temperature starts dropping more sharply and the least need for heating would be during the afternoon. The internal temperature of scenario $90^{\circ}$ with its $4.8 \mathrm{~m}^{2}$ windows facing east is the first to exceed $16^{\circ} \mathrm{C}$ in the morning. The internal temperature of this scenario drops back to $16^{\circ} \mathrm{C}$, which means there is a need for heating after II hours when the sun moves away from the east side of the ADU. The same pattern happens for scenario $0^{\circ}$, which also benefits from both morning sun and sun during the rest of the day with its north facing windows. The internal temperature of scenario $270^{\circ}$ with the majority of its windows facing west, keeps the internal temperature above $16^{\circ} \mathrm{C}$ later than the other scenarios by benefitting from the evening sun. The differences in the ADU energy consumption from the different orientations is not considerable, and the ADU behaves efficiently in all orientations, especially given the fact the majority of the life cycle energy of nearly zero-energy buildings, such as the ADU, is embodied energy (see Section 6.3.4). 


\subsection{Life $\mathrm{Cycle} \mathrm{CO}_{2}$ Emissions Calculations}

Following the LCE calculations, this section analyses the life cycle $\mathrm{CO}_{2}$ emissions of the ADU I the two categories of materials and operational heating energy. Calculating the life cycle $\mathrm{CO}_{2}$ emissions of the ADU is the second step in the LCA and includes comparison of the ADU with conventionally made houses.

\subsubsection{Initial Results}

While the life cycle embodied $\mathrm{CO}_{2}$ emissions of the $\mathrm{BIAC}$ house were $257 \mathrm{~kg} \mathrm{CO}_{2} \mathrm{e} / \mathrm{m}^{2}$, the first calculation showed the emissions of the ADU were only $71 \mathrm{~kg} \mathrm{CO}_{2} \mathrm{e} / \mathrm{m}^{2}$, which is approximately three times less than those of the BIAC house. This is a big difference for a one storey houses with some differences in the foundations, claddings and window frames. The investigation to find the reason for this difference showed the low emissions of the ADU were mainly due to both the high volume of timber used in the $\mathrm{ADU}$ and also the high negative $\mathrm{CO}_{2}$ coefficient of the timber elements (Table 3.5). This comes from the biogenic carbon stored in timber when it is growing. This effect known, as "carbon sequestration", means the carbon is locked up in the timber during its life although the same carbon would be released if the timber is burnt or decays (Gustavsson, et al., 2006; Van der Lugt et al., 2014; Bergman et al., 2014; Ratnasingam et al., 2015). Recycling or reusing the timber after it removed from a building, keeps the carbon inside the timber for a longer time. However, eventually, the stored carbon in the timber will find its way back in the atmosphere. This means how much carbon is sequestered in each life cycle calculation needs to be clarified, although the literature shows there is no clear instruction on how it should be considered. There is a need to make assumptions about what happens to the timber elements after their useful life is finished in the building (Symons et al., 2013; Clark, 2013; Lockie and Berebecki, 2014; Martínez-Alonso and Berdasco, 2015). There is no indication of what has been considered regarding this for the BIAC calculations (Mithraratne et al, 2007).

In the primary calculation of the life cycle embodied $\mathrm{CO}_{2}$ emissions of the $\mathrm{ADU}$ the negative $\mathrm{CO}_{2}$ coefficient of timber elements were included at the start, and also added when an element was replaced, which means the assumption was all timber elements were $100 \%$ recycled or preserved from decay after their useful life in the ADU was over. This led to emissions of approximately $-219 \mathrm{~kg} \mathrm{CO}_{2} \mathrm{e} / \mathrm{m}^{2}$ during the life span of the ADU. However, looking at the big differences in $\mathrm{CO}_{2}$ emissions between the $\mathrm{ADU}$ and the BIAC house, it was decided 
to use a different approach. In this new approach, it was assumed that the locked up carbon in the timber elements was only included once, regardless of how many time the elements were replaced during the life of the ADU. This idea was based on the assumption that any timber elements replaced before year 100, would release their locked up carbon back into the atmosphere. As a result, the life cycle embodied $\mathrm{CO}_{2}$ emissions of the ADU were recalculated based on this assumption.

\subsubsection{Final Results}

Re-calculating life-cycle $\mathrm{CO}_{2}$ emissions of the $\mathrm{ADU}$, this time by considering carbon sequestration, led to the total life cycle embodied $\mathrm{CO}_{2}$ emissions of the $\mathrm{ADU}$ increasing from $71 \mathrm{~kg} \mathrm{CO} 2 \mathrm{e} / \mathrm{m}^{2}$ to over $124 \mathrm{~kg} \mathrm{CO} 2 \mathrm{e} / \mathrm{m}^{2}$. The scale of change shows how important it is to have a clear assumption about carbon sequestration. Figure 6.35 breaks the emissions of the ADU and the BIAC house down by building element for comparison.

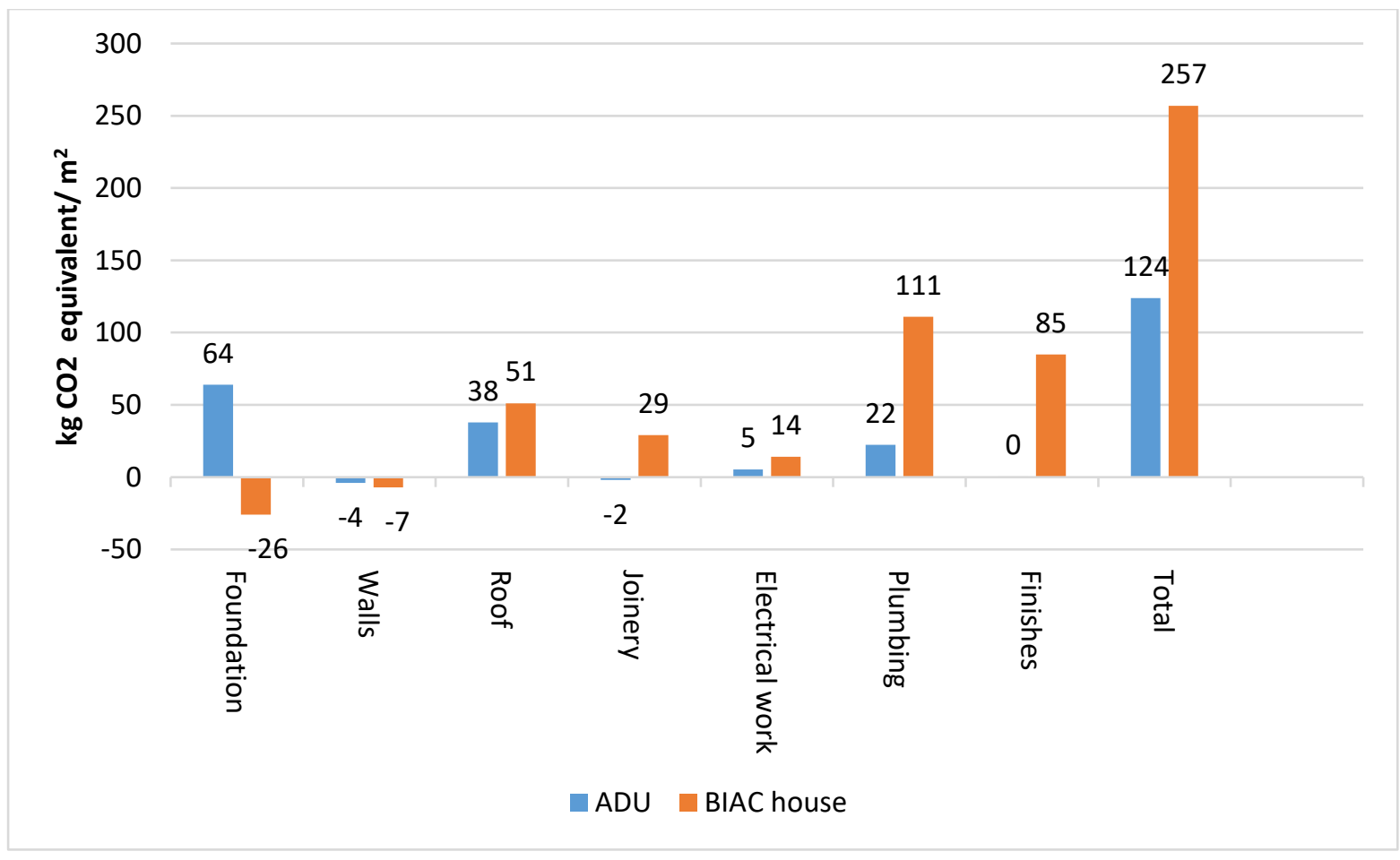

Figure 6.35: Elemental life cycle $\mathrm{CO}_{2}$ emissions of the $\mathrm{ADU}$ compared to the BIAC House

\subsubsection{Foundation}

Figure 6.35 shows the concrete slab, which works as both foundation and floor, has the highest elemental $\mathrm{CO}_{2}$ emissions of $64 \mathrm{~kg} / \mathrm{m}^{2}$. This is far higher than the emissions of the BIAC house foundation due to the different type of materials used. While the ADU is on a concrete slab, the BIAC house has a suspended timber frame floor. However, the ADU figure is close to 
the $\mathrm{CO}_{2}$ emissions of the heavy construction $\mathrm{BIAC}$ house of $67 \mathrm{~kg} \mathrm{CO}_{2} \mathrm{e} / \mathrm{m}^{2}$ (floor and foundation), which is made on a $150 \mathrm{~mm}$ concrete slab with $25 \mathrm{~mm}$ perimeter polystyrene to a depth of $500 \mathrm{~mm}$. Having the highest $\mathrm{CO}_{2}$ emissions, the use of concrete should be considered carefully in relation to the usefulness of acting as thermal mass (see Section 5.6.2). While the concrete slab was a good choice from an energy point of view, due to relatively low $\mathrm{EE}$, durability and the mass effect, Figure 6.35 shows it is not the best option if only $\mathrm{CO}_{2}$ emissions are considered. This again indicates the need to find a balance as each material has both benefits and disadvantages, and this is where LCA can be helpful.

\subsubsection{Walls}

The $\mathrm{CO}_{2}$ emissions of the walls of the ADU are $-4 \mathrm{~kg} / \mathrm{m}^{2}$, compared with $-7 \mathrm{~kg} / \mathrm{m}^{2}$ for the BIAC house. Despite the high volume of polystyrene in SIPs panels, which creates emissions of nearly $20 \mathrm{~kg} \mathrm{CO} 2 \mathrm{e} / \mathrm{m}^{2}$ for the $\mathrm{ADU}$, the $\mathrm{BIAC}$ house has a higher volume of glass fibre insulation being $200 \mathrm{~mm}$ thick compared with $151 \mathrm{~mm}$ for the expanded polystyrene in the ADU. However, looking at Table 3.5 shows the emissions factor of polystyrene is approximately $300 \%$ more than glass fibre, leading to the higher life cycle emissions of the walls of the ADU compared to the BIAC house. Moreover, this thicker insulation means a double stud frame is needed for the BIAC house which means the use of more timber with a negative emissions factor. However, the ADU is externally clad with timber board and batten, compared to fibre cement for the BIAC house. The $\mathrm{CO}_{2}$ coefficient of timber is $-2,115 \mathrm{~kg} / \mathrm{kg}$, compared with 0.955 $\mathrm{kg} / \mathrm{kg}$ for fibre cement board (Mithraratne et al, 2007, pp221-224; Hammond and Jones, 2011). Despite these considerable differences in design, the walls of both houses had very similar $\mathrm{CO}_{2}$ emissions.

\subsubsection{Roof}

The roof of the $\mathrm{ADU}$ emits $38 \mathrm{~kg} \mathrm{CO} \mathrm{CO}_{2} \mathrm{e} / \mathrm{m}^{2}$ during its life, which is less than the roof of the BIAC house at $51 \mathrm{~kg} \mathrm{CO}{ }_{2} \mathrm{e} / \mathrm{m}^{2}$. The differences in the roof emissions come from the use of different types and thicknesses of insulation, as discussed above.

\subsubsection{Joinery}

The emissions of the ADU joinery equate to $-2 \mathrm{~kg} \mathrm{CO}{ }_{2} \mathrm{e} / \mathrm{m}^{2}$, which is lower than the $\mathrm{BIAC}$ house of $29 \mathrm{~kg} \mathrm{CO} 2 \mathrm{e} / \mathrm{m}^{2}$. This difference comes from having fewer windows in the ADU and the fact the window frames are timber and lock up carbon compared to the aluminium frame 
windows of the $\mathrm{BIAC}$ house. The embodied $\mathrm{CO}_{2}$ emissions coefficient of recycled aluminium is $2,862 \mathrm{~kg} / \mathrm{m}^{3}$, which is substantially higher than that of timber at $-695 \mathrm{~kg} / \mathrm{m}^{3}$.

\subsubsection{Electrical work}

The $\mathrm{CO}_{2}$ emissions of electrical work in the ADU are $5 \mathrm{~kg} \mathrm{CO} 2 \mathrm{e} / \mathrm{m}^{2}$ and thus approximately $60 \%$ less than the BIAC house. The main reason here is the fact that the BIAC house has more spaces than the ADU, as it has one more bedroom and also a separate toilet, bathroom and laundry, while all of these functions are collected together in one space in the ADU. This led to an increase in the length of power cables.

\subsubsection{Plumbing}

The other considerable difference is the $\mathrm{CO}_{2}$ emissions of plumbing, which are just $22 \mathrm{Kg}$ $\mathrm{CO}_{2} \mathrm{e} / \mathrm{m}^{2}$ for the $\mathrm{ADU}$ compared with $111 \mathrm{~kg} \mathrm{CO} \mathrm{CO}_{2} \mathrm{e} / \mathrm{m}^{2}$ for the BIAC house. While plumbing has the highest emissions at the BIAC house, it has the fourth highest emissions at the ADU after the foundation, walls and roof. Some of the differences are due to the shorter length of pipes in the ADU as well as the use of multi-functional spaces. At the early design stages of the ADU, the idea was to have a service module containing all the wet areas. This was done for simplifying the manufacturing process, and ease of insulating the service module, and reducing the length of pipes. The other reason for the lower $\mathrm{CO}_{2}$ emissions of the ADU is the different assumptions made during the calculations. As an example, the life span of the hot water service was assumed to be 16 years at the BIAC house. This means the hot water cylinder would be replaced four times more than in the ADU, which assumes a life span of 40 years for the hot water service (Smart homes, 2019). This change in the life span of just one element is equal to releasing approximately $8 \mathrm{~kg} \mathrm{CO} \mathrm{CO}_{2} \mathrm{e} / \mathrm{m}^{2}$ over the life span of the house. A detailed comparison of plumbing elements is not possible due to the lack of detailed data about the BIAC house.

\subsubsection{Finishes}

After plumbing, finishes are the second highest producer of $\mathrm{CO}_{2}$ for the BIAC house. However, there are no substantial emissions for the finishes of the ADU. This is due to the fact that most of its structural elements are exposed with no extra finishes, apart from paint on the walls and ceiling, and sealer on the floor. Floors in the BIAC house are covered by vinyl, parquet, wool carpet. To have a better idea of the impact of this decision, over $6 \mathrm{~kg}$ of $\mathrm{CO}_{2}$ is released for producing $1 \mathrm{~kg}$ of wool carpet. This is close to the $\mathrm{CO}_{2}$ emissions factor of ABS plastic or 
expanded polystyrene (Mithraratne et al, 2007, 221). The effect on overall emissions becomes more critical as the carpet in the BIAC house was replaced every 12 years (Mithraratne et al, $2007,134)$.

\subsubsection{Materials and $\mathrm{CO}_{2}$ Emissions}

Knowing how the choice of material can affect the emissions of the ADU, it worth looking at the life cycle embodied $\mathrm{CO}_{2}$ emissions of the ADU based on different types of material (Table 6.10).

Table 6.10: Life cycle embodied $\mathrm{CO}_{2}$ emissions of the ADU based on the types of materials

\begin{tabular}{|c|c|c|c|}
\hline \multicolumn{2}{|c|}{ Building materials } & \multirow{2}{*}{$\begin{array}{c}\mathrm{kg} \mathrm{CO} 2 \mathrm{e} / \mathrm{m}^{2} \\
-19\end{array}$} & \multirow{2}{*}{$\begin{array}{l}\text { Total } \mathrm{kg} \mathrm{CO} 2 \mathrm{e} / \mathrm{m}^{2} \\
-116\end{array}$} \\
\hline \multirow[t]{3}{*}{ Timber } & External cladding (board and batten) & & \\
\hline & Plywood in SIPs panel & -33 & \\
\hline & $\begin{array}{l}\text { Other (trussed rafters, joinery, top and bottom } \\
\text { plates etc.) }\end{array}$ & -64 & \\
\hline \multirow[t]{3}{*}{ Metal } & Screws and Cam lock joints for SIPs & 17 & \multirow[t]{3}{*}{68} \\
\hline & Corrugated roofing and flashings & 21 & \\
\hline & Other (nails, fittings etc.) & 30 & \\
\hline \multirow[t]{3}{*}{ Plastics } & Polystyrene (SIPs panels and slab insulation) & 37 & \multirow[t]{3}{*}{111} \\
\hline & Paint & 47 & \\
\hline & $\begin{array}{l}\text { Wire coating and electrical fittings, SIPs adhesive } \\
\text { and membranes }\end{array}$ & 27 & \\
\hline \multicolumn{2}{|c|}{ Concrete } & 44 & 44 \\
\hline \multicolumn{2}{|c|}{ Sanitary fittings, tiles and glass } & 17 & 17 \\
\hline \multicolumn{2}{|l|}{ Total } & 124 & 124 \\
\hline
\end{tabular}

Table 6.10 shows plastics are responsible for the biggest portion of $\mathrm{CO}_{2}$ emissions of the ADU at $111 \mathrm{~kg} \mathrm{CO} \mathrm{CO}_{2} \mathrm{e} / \mathrm{m}^{2}$. This echoes Chapter 6 findings as plastics also embodied the highest amount of energy during the life of the ADU (see Section 6.3.3.2). These show special attention is needed when using plastics-based materials. The majority of $\mathrm{CO}_{2}$ emissions from plastics comes from paint, being responsible for $42 \%$ of plastics-related $\mathrm{CO}_{2}$ emission, mainly due to short replacement cycle of paint, being 8 years (except for the factory applied coat which should last 15 years). Polystyrene used in the SIPs panels and slab insulation accounts for $33 \%$ of the plastics emissions. 
Some $31 \%$ and $25 \%$ of the $\mathrm{CO}_{2}$ emissions of the metals, which is the second highest category in the ADU, come from the roof cladding, and the SIPs screws and camlock joints respectively. This is first due to the quantity of these elements and also the high $\mathrm{CO}_{2}$ coefficient of steel. To have a better idea, based on its location, each 1,220mm x 2,440mm SIPs ceiling panel needs 14-23 screws in addition to 45-90 annular grooved nails at the panel edges. Two wall panels of the same size need five camlock joints, one for each panel in addition to 24 nails at the top and bottom edges (see Appendix D).

In the end, the high negative $\mathrm{CO}_{2}$ coefficient of timber of $-116 \mathrm{Kg} \mathrm{CO}_{2} \mathrm{e} / \mathrm{m}^{2}$, led to total life cycle embodied $\mathrm{CO}_{2}$ emissions of $124 \mathrm{Kg} \mathrm{CO} \mathrm{CO}_{2} \mathrm{e} / \mathrm{m}^{2}$. Close to $45 \%$ of this $\mathrm{CO}_{2}$ lock up is due to the plywood in the SIPs panels and external cladding of the ADU at $29 \%$ and $16 \%$ respectively. Given the comparison between the ADU and the BIAC house, the three factors affecting the life cycle embodied $\mathrm{CO}_{2}$ emissions of a house are the $\mathrm{CO}_{2}$ coefficient, replacement cycle, and quantity of materials. While the $\mathrm{CO}_{2}$ coefficient and replacement cycle depend on the choice of materials, the quantity is more affected by the design. Figure 6.36 shows the time breakdown of the life cycle embodied $\mathrm{CO}_{2}$ emissions of the $\mathrm{ADU}$.

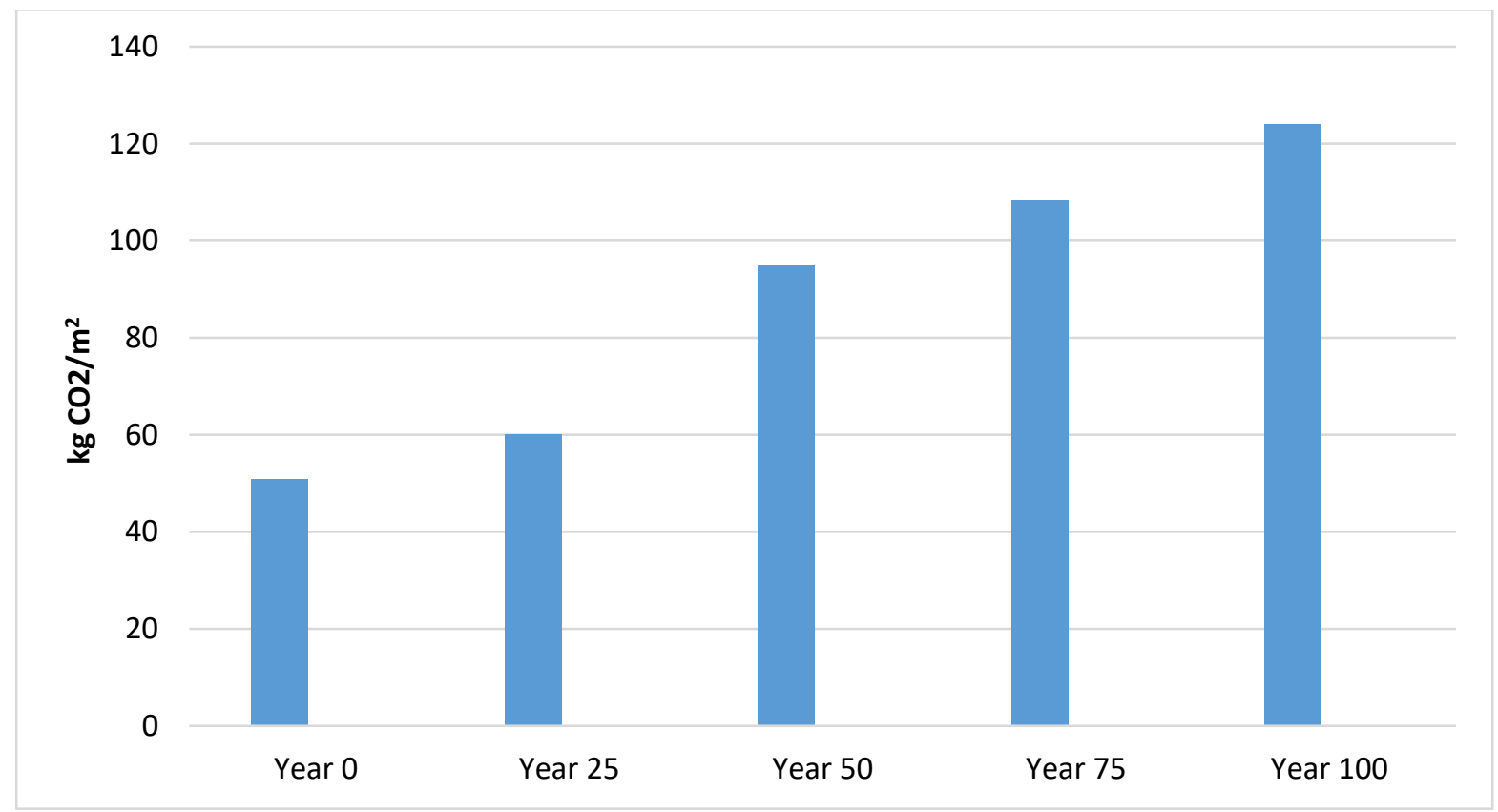

Figure 6.36: Breakdown of life cycle embodied $\mathrm{CO}_{2}$ emissions of the ADU

The highest proportions of the initial $\mathrm{CO}_{2}$ emissions of the ADU come from painting, the concrete slab and the polystyrene in the SIPs panels and underneath the slab, these being $47 \mathrm{~kg} \mathrm{CO} \mathrm{CO}_{2} \mathrm{e} / \mathrm{m}^{2}, 44 \mathrm{~kg} \mathrm{CO} \mathrm{CO}_{2} \mathrm{e} / \mathrm{m}^{2}$ and $37 \mathrm{~kg} \mathrm{CO}_{2} \mathrm{e} / \mathrm{m}^{2}$ respectively. The majority of the ADU emissions at years 25 and 75 come from the repainting of different elements. 


\subsection{Life Cycle $\mathrm{CO}_{2}$ Emissions of the ADU}

Despite the fact the ADU is near zero energy for heating it is worth analysing the life cycle $\mathrm{CO}_{2}$ emissions of space conditioning to compare this with the BIAC house and also with the materials $\mathrm{CO}_{2}$ emissions of the ADU (Table 6.11).

Table 6.11: Life cycle operational $\mathrm{CO}_{2}$ emissions of the ADU and BIAC house

\begin{tabular}{|c|c|c|c|c|c|c|c|}
\hline & \multirow{2}{*}{$\begin{array}{l}\text { Annual heating } \\
\text { energy (kWh) }\end{array}$} & \multicolumn{5}{|c|}{$\mathrm{kg} \mathrm{CO} 2 \mathrm{e} / \mathrm{m}^{2}$} \\
\hline House & & & & & & & \\
\hline \multicolumn{2}{|l|}{ ADU } & & 8 & 27 & 96 & 98 & ר \\
\hline \multirow[t]{3}{*}{$\mathrm{BIAC}$} & Light & 2,123 & 0 & 56 & 112 & 168 & 224 \\
\hline & Heavy & 2,019 & 0 & 54 & 108 & 162 & 216 \\
\hline & Super insulated & 1,115 & 0 & 30 & 60 & 90 & 120 \\
\hline
\end{tabular}

As expected, the life cycle operational $\mathrm{CO}_{2}$ emissions of the $\mathrm{ADU}$ are $59 \%, 57 \%$, and $23 \%$ less than those of the light, heavy and super insulated construction versions of the BIAC house (see Section 6.2.1). Figure 6.37 shows the embodied, operational and life $\mathrm{cycle}^{\mathrm{CO}} \mathrm{CO}_{2}$ emissions of the ADU made of $165 \mathrm{~mm}$ SIPs walls and ceiling with polystyrene core.

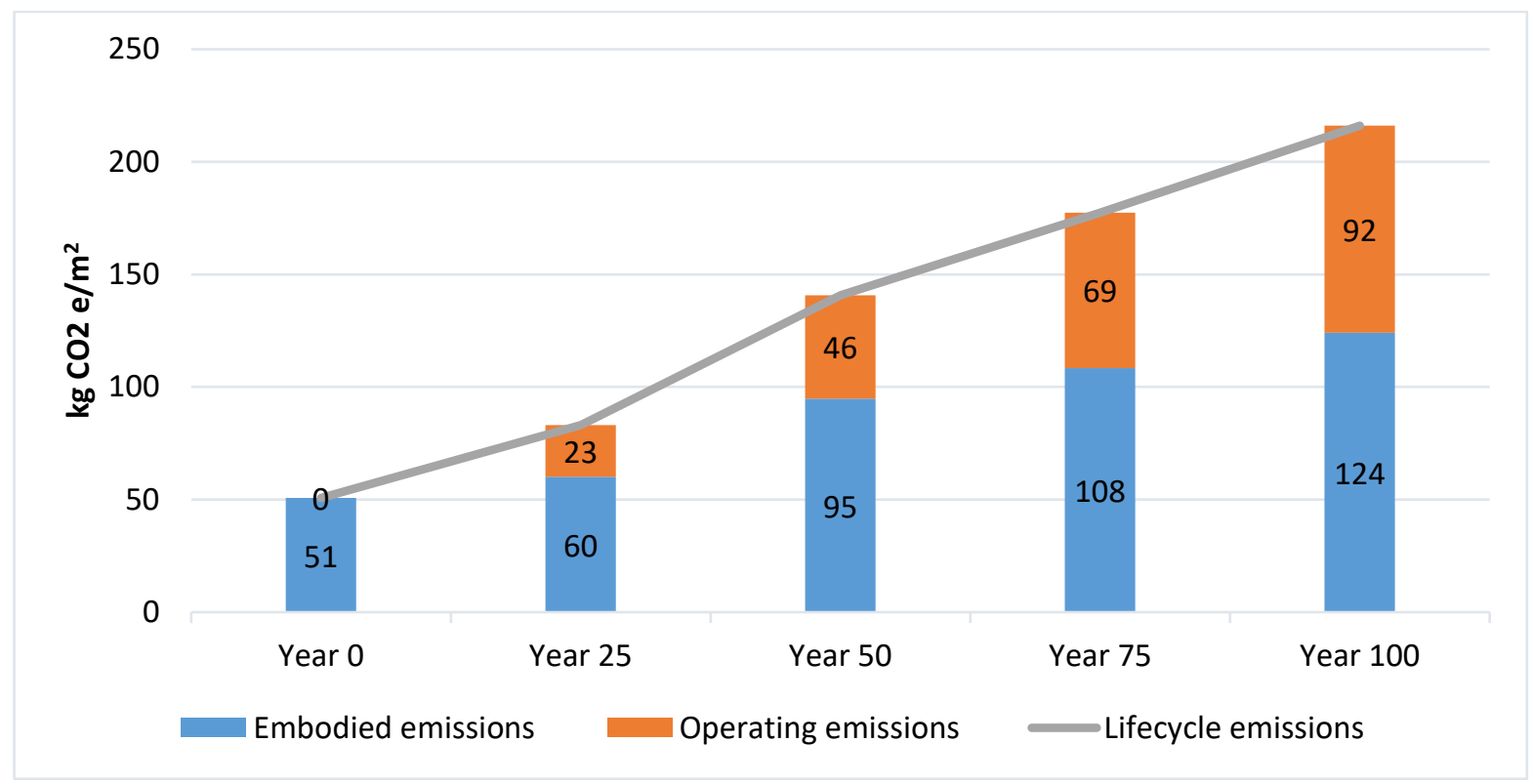

Figure 6.37: Embodied and operational $\mathrm{CO}_{2}$ emissions of the $\mathrm{ADU}$

Figure 6.37 shows that the life cycle embodied $\mathrm{CO}_{2}$ emissions is accounts for $57 \%$ of total life cycle $\mathrm{CO}_{2}$ emissions of the ADU. This shows, even in a near zero energy house, like the ADU, the operational energy $\mathrm{CO}_{2}$ emissions can be significant over the full lifetime. 


\subsection{Life Cycle Cost Calculations}

Cost is one of the most important factors affecting the willingness of consumers to buy a product (Sandu, 2014). Kupke (2008) did a survey in Australia with over 250 responses, asking first time home buyers to rate the most important factors affecting the timing of their decision to purchase. Affordable house prices were the most important factor, mentioned by over $60 \%$ on respondents. Gathering together a deposit, the financial climate of low-interest rates, flexible lending arrangements, which included a mix of variable and fixed rates, and a low inflation rate were the next top five factors. Abdullah et al. (2015) talked to 67 people in Malaysia looking to buy a new house for the first time, to discover the factors affecting their decision. After location, economic factors, including price, ability to obtain finance and payment terms, deposit requirement, and interest rate, as a group formed the second most important factor. Cost is also an important factor when it comes to the selection of building materials and construction systems. This includes the thickness of SIPs panels in this research since the cost of the thicker and more insulating panels has to be set against the cost of the energy saved over the life of the ADU.

The final cost of a house is affected by different factors such as floor area, structural system, design approach, and quality of fittings. There are also different types of cost, which form the final cost of a house when added together. The main costs are initial construction cost, maintenance and replacement cost, demolition cost and operating cost, the latter being the heating cost in this thesis. These different types of cost are highly affected by each other, and these mutual effects should be considered at the early design stage (Stone, 1980; Flanagan, 1989). For example, using highly insulating materials can decrease the operating energy cost considerably, but will increases the initial cost. The same holds true for the use of high-quality materials, as their use can decrease the cost of maintenance and replacement but will increase the initial cost of a building. Here is where the consumers should decide if they prefer to pay more money at the beginning, to win a lower life-cycle cost, or vice versa, based on the plans they have for the house. Homeowners in New Zealand mostly change their house every seven years, which is the reason why most of New Zealanders prefer to decrease the initial costs, even if it leads to higher life-cycle costs (Haberecht and Bennett, 1999; Donn, et al., 1995). 


\subsubsection{Results}

The ADU construction costs are discussed in the two categories of those extracted from Rawlinsons and Bunnings Warehouse, and the quote for the SIPs panels. While the first group of costs is fixed, the SIPs panels have the two options of $215 \mathrm{~mm}$ and $165 \mathrm{~mm}$ ceiling panels, with the thickness of the SIPs walls being $165 \mathrm{~mm}$. Table 6.12 shows the cost for each category as well as the total cost for each scenario.

Table 6.12: ADU construction cost breakdown

\begin{tabular}{|l|l|l|l|l|}
\hline Scenario & Fixed costs & SIPs panel costs & Total cost & Cost per $\mathbf{~}^{\mathbf{2}}$ \\
\hline $215 \mathrm{~mm}$ SIPs ceiling & $\$ 72,764$ & $\$ 22,700$ & $\$ 95,464$ & $\$ 1,364$ \\
\hline $165 \mathrm{~mm}$ SIPs ceiling & $\$ 72,764$ & $\$ 21,000$ & $\$ 93,764$ & $\$ 1,339$ \\
\hline
\end{tabular}

Table 6.12 shows using $165 \mathrm{~mm}$ SIP panels for the ceiling instead of $215 \mathrm{~mm}$ panels would save $\$ 1,700$ or $\$ 25 / \mathrm{m}^{2}$. As with the LCEA, the use of $165 \mathrm{~mm}$ SIP panels for the ceiling is more efficient. Despite the small differences between the two scenarios of Table 1, given the LCEA (see Section 6.3.3) and cost results, the differences could be substantial when looking at the ADU as an idea for mass production. However, these differences should be evaluated by adding in the operational cost, as using $165 \mathrm{~mm}$ panels for the walls and ceiling was found to use approximately $100 \mathrm{MJ} / \mathrm{m}^{2}$ or $27.8 \mathrm{kWh} / \mathrm{m}^{2}$ more operational energy than the other scenario during the life of the ADU. Given the fact that using $215 \mathrm{~mm}$ SIPs ceiling panel is $\$ 25 / \mathrm{m}^{2}$ more expensive than $165 \mathrm{~mm}$ wall panels, the scenario of $165 \mathrm{~mm}$ wall and ceiling panels would be $\$ 25 / \mathrm{m}^{2}$ or $\$ 1,750$ cheaper than the scenario of $165 \mathrm{~mm}$ wall panels and $215 \mathrm{~mm}$ ceiling panels, where all costs are discounted real costs (see Section 6.6.2). However, saving $27.8 \mathrm{kWh} / \mathrm{m}^{2}$ in the $215 \mathrm{~mm}$ ceiling panel scenario, and by considering $1 \mathrm{kWh}$ electricity to cost 29.03 cents (March 2018) (Ministry of Business Innovation \& Employment, 2018) also means a $\$ 2$ saving during the life of the ADU. Putting these numbers together, the ADU made of $165 \mathrm{~mm}$ SIPs panels for walls and ceiling would be $\$ 1,748$ cheaper than the other scenario, although this does not allow for inflation in the cost of delivered energy over the life of the ADU (see Section 6.6.2). As a result, this scenario, at an initial cost of $\$ 93,764$ or $\$ 1339 / \mathrm{m}^{2}$, is selected as the final design.

\subsubsection{Comparison of the Cost of the ADU with Conventional Houses}

To see if the ADU is a viable proposition economically, and ignoring energy efficiency at this stage, there is a need to compare its cost with that of conventionally made houses in New 
Zealand. For this purpose, the cost of housing from Rawlinsons (Rawlinsons Media Limited, 2011) was used as this has also formed the basis for the ADU cost calculations, together with Wilson (2006). There are different price ranges available for residential buildings in Rawlinsons, classified based on the number of storeys, plan area, type of cladding, number of bedrooms, and even their potential users, such as retirement village units. In order to find the closest option to the ADU, those of more than one storey were removed from the available options as well as those classified as large houses $\left(200 \mathrm{~m}^{2}-600 \mathrm{~m}^{2}\right)$. Table 6.13 shows the remaining options, their characteristics, and cost range for Wellington. The costs in Table 2 have been adjusted to 2018 costs using the $1.72 \%$ inflation rate.

Table 6.13: Cost of options (Rawlinsons Media Limited, 2011)

\begin{tabular}{|c|c|c|c|c|c|}
\hline \multicolumn{2}{|c|}{ Option } & $\begin{array}{l}\text { Area } \\
\left(\mathrm{m}^{2}\right)\end{array}$ & \multicolumn{2}{|l|}{ Characteristics } & $\begin{array}{l}\text { Cost } \$ / m^{2} \\
\text { Wellington }\end{array}$ \\
\hline \multicolumn{2}{|l|}{1} & $90-130$ & \multicolumn{2}{|c|}{$\begin{array}{l}\text { Pile foundations, particle board floor, kitchen, bathroom, WC. } \\
\text { Fibre-cement weatherboards, galvanised steel roof, standard } \\
\text { quality fittings. }\end{array}$} & $1,935-2,279$ \\
\hline \multirow[t]{4}{*}{2} & 1 & \multirow[t]{4}{*}{$\begin{array}{l}100- \\
250\end{array}$} & \multirow{4}{*}{$\begin{array}{l}\text { Concrete floor slab, } \\
\text { kitchen, bathroom, WC, } \\
\text { ensuite, Colorsteel }{ }^{\circledR} \text { roof, } \\
\text { medium quality fittings }\end{array}$} & $\begin{array}{l}\text { Weatherboard cladding, cedar or } \\
\text { pine. }\end{array}$ & $2,537-2,881$ \\
\hline & 2 & & & $\begin{array}{l}\text { Polystyrene or fibre cement } \\
\text { cladding, textured plaster or acrylic } \\
\text { coatings. }\end{array}$ & $2,537-2,881$ \\
\hline & 3 & & & Brick veneer, concrete tile roof. & $2,666-3,010$ \\
\hline & 4 & & & Insulated concrete block, tile roof. & $2,666-3,010$ \\
\hline \multicolumn{2}{|l|}{3} & NA & \multicolumn{2}{|c|}{$\begin{array}{l}\text { Concrete floor slab, concrete tile roof, kitchen, bathroom, } \\
\text { lounge, one to two bedrooms, medium quality fittings. } \\
\text { Community facilities, covered carparks. }\end{array}$} & $3,748-4,300$ \\
\hline
\end{tabular}

From these options in Table 6.13, option 1 is the closest to the ADU in terms of floor area, noting there is no area specified for option 3 . However, option 1 is on pile foundations, while the ADU is on a concrete slab as for options 3 and 2 (2-1 also has similar cladding). However, Table 6.12 shows the ADU is considerably cheaper than all options in Table 6.13. The ADU is over $30 \%$ cheaper than the average cost of option 1, which is the cheapest in Table 6.13. Wilson (2006) gave $\$ 1,908 / \mathrm{m}^{2}, \$ 2,341 / \mathrm{m}^{2}$ and $\$ 2,820 / \mathrm{m}^{2}-\$ 5,640 / \mathrm{m}^{2}$ as the average cost of construction in Wellington for respectively a standard design, executive house, and individual 
architect designed house ${ }^{2}$ (all costs are converted from the first quarter of 2006 to the third quarter of 2018 using a rate of $1.88 \%$ (Reserve Bank of New Zealand, 2019)). Wilson's (2006) findings are close to those of Rawlinsons and show that the ADU is still $30 \%$ cheaper than a conventional house in Wellington.

The main reason for the cost differences between the ADU and a conventional house is the structure. As an example, the external walls of a conventional residential building would cost approximately $\$ 196 / \mathrm{m}^{2}$ (Rawlinsons Media Limited, 2011). However, the external SIPs wall costs approximately $\$ 130 / \mathrm{m}^{2}$ (Formance, 2019). Over the $87 \mathrm{~m}^{2}$ of ADU external walls using SIPs means a saving of over $\$ 5,781$ or over $\$ 83 / \mathrm{m}^{2}$. The same is true for the ceiling.

The other factor affecting the lower cost of the ADU is the fact that the OSB used in the SIPS panels forms the internal cladding once painted, while in a conventional stud wall there is a need for cladding additional to the structure. Figure 6.38 shows the elemental cost of the ADU.

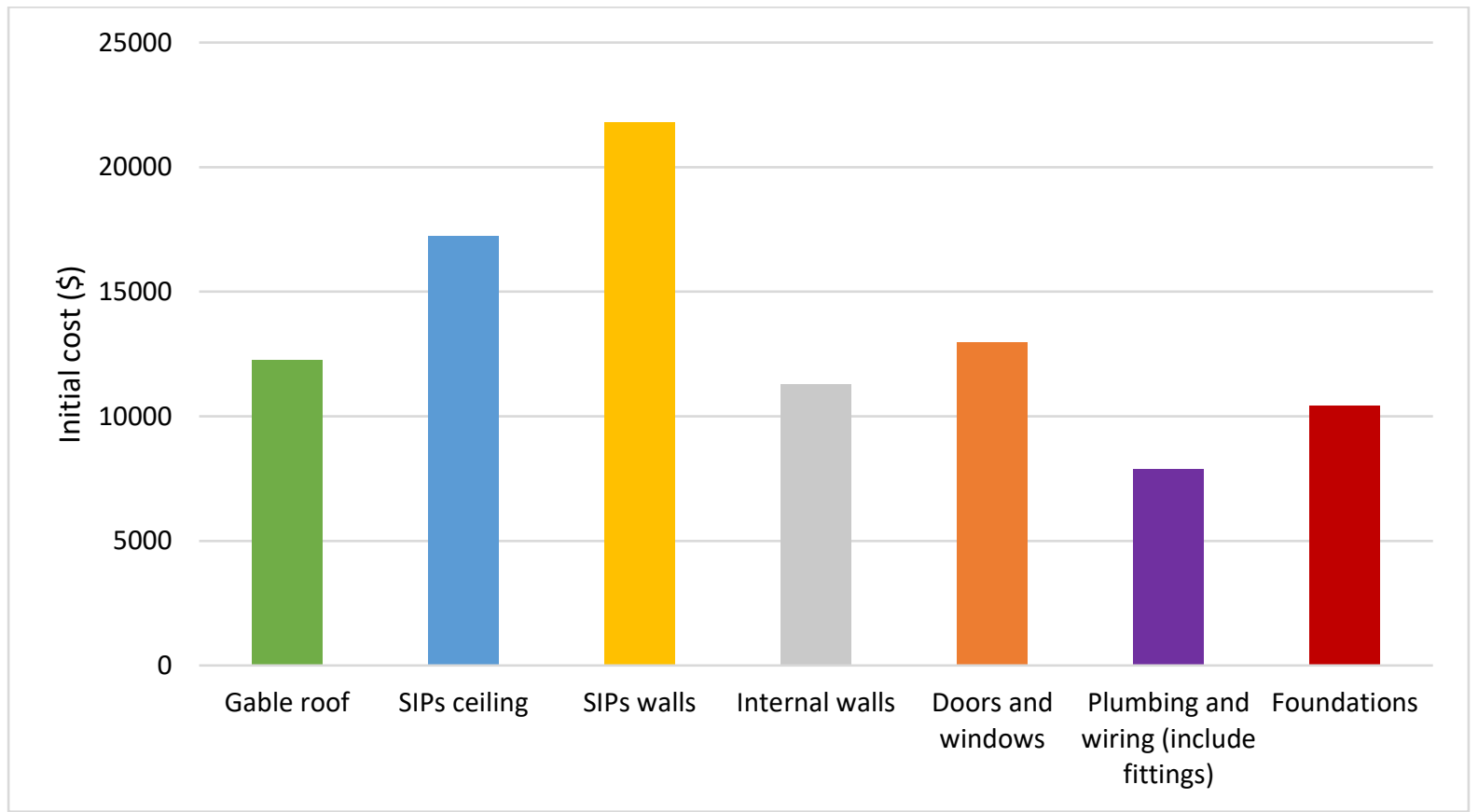

Figure 6.38: Elemental cost breakdown of the ADU

Figure 6.38 shows that SIPs walls and ceiling are the most expensive elements of the ADU, accounting for $41 \%$ of the total. From this $41 \%$, approximately $54 \%$ of the wall and ceiling cost

\footnotetext{
${ }^{2}$ The standard design is a $94 \mathrm{~m}^{2}$ house of three bedrooms made on timber piles with R2.2 batts in the wall, clad by fibre cement weatherboards, and having a Zincalume trussed rafter roof. The executive house is a two storey, two bedroom house with a double garage. The floor is concrete and the walls have a brick veneer with a metal tile roof and R2.2 batts in the wall.
} 
comes from the SIPs panels, while the rest is for joinery, paint, and external cladding. After the gable roof, doors and windows form the fourth most expensive element of the ADU. The high cost of doors and windows in New Zealand can be another reason why the ADU is cheaper than conventional houses, as the number and area of windows were reduced to improve the energy efficiency. The same story is true for the plumbing and wiring group, as the ADU was designed to minimise the length of pipes and wires, while there was no considerable difference in the number of lights, switches and power points, and sanitary fittings per square metre between the ADU and conventional houses.

\subsubsection{Life Cycle Cost Analysis of the ADU}

LCCA is a method of determining all the costs of a building during its life, beginning from the construction stage, and includes the operational cost (Kale, et al., 2016). Given the predictions need to be made regarding the future cost of energy and materials, the LCCA can never be $100 \%$ accurate, but it is a way of providing the general trend regarding what might happen in the future based on the decisions made in the present. However, to make this process as precise as possible economists consider different values to explore the sensitivity of the analysis to the many assumptions. In this thesis, due to its practicality, the method used for the LCC calculation is a discounted real cost method (Mithraratne et al., 2007).

- Real cost: In a real cost calculation the cost of materials and services in the future is predicted based on their present cost, with no inflation included. On the other side is the nominal cost, which is the real cost, while the general price inflation and the cost growth between calculation time and the predicted time for future expenditure are applied (Mithraratne et al., 2007, p.73).

- Discounted cost: "Discounted costs are future cost discounted using an appropriate discount rate, in order to convert expenses occurring at various points in time to a common basis."(Mithraratne et al., 2007, p.74).

As a result, real costs in the future can be converted to discounted real cost by applying Equation 6-1.

$$
f=\frac{1}{(1+d r)^{y}}
$$

Equation 6-1: Discounted cost factor (Mithraratne et al., 2007, p 74) 
$f:$ discounted real cost factor,

$\mathrm{dr}$ : annual real discount rate, and

$y:$ number of years between the base date and the date the cost occurs.

The life of the ADU is assumed to be 100 years, as for conventional houses in New Zealand (Mithraratne et al., 2007, p. 177). The costs over the life of the ADU are analysed in the two groups of initial construction and replacement (EE), and space heating energy (OE) (Figure 6.39). All costs are based on 2019 real costs, and a discount rate of $6 \%$ is applied to all the costs (The Treasury, ND). The cost of electricity for space heating for residential buildings is taken as 29.03 cents/kWh (March 2018) (Ministry of Business Innovation \& Employment, 2018).

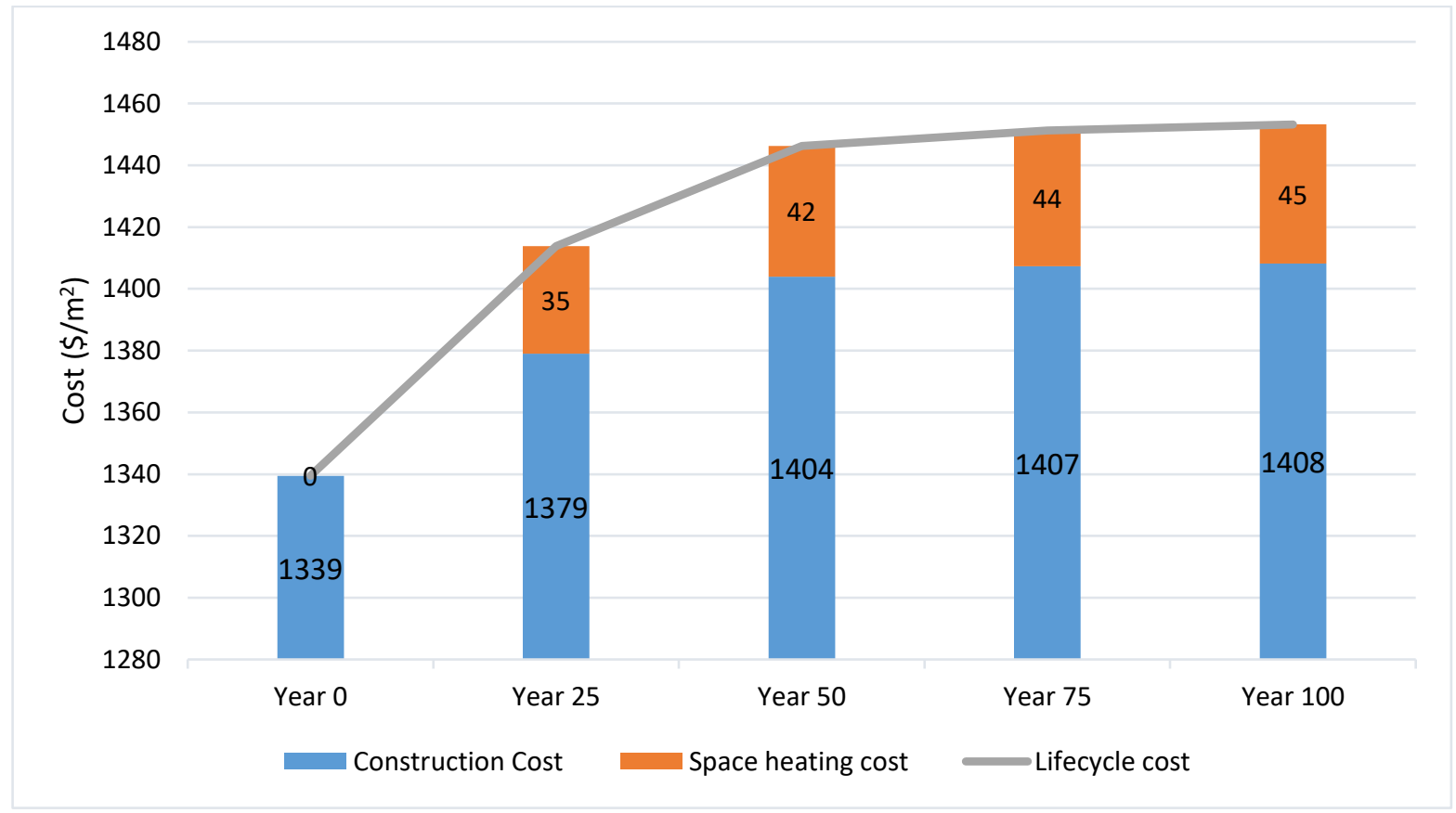

Figure 6.39: Life Cycle Cost Analysis (LCCA) of the ADU

Figure 6.39 shows the space heating energy cost is negligible compared with the construction and replacement costs as the ADU is nearly zero energy (being just 3\%). Finally, it appears that during the life of the ADU approximately $95 \%$ of costs are initial and $5 \%$ are for replacements.

\subsubsection{Sensitivity Analysis}

Sensitivity analysis of cost is one of the most important components of any LCCA. The importance of sensitivity analysis comes from the fact that there are assumptions regarding future costs in any LCCA project. Sensitivity analysis is a technique for evaluating the effect of 
any change in any assumption to see how big the change might be (Yeo, 1991). In this thesis, the major assumption was the discount rate, as no inflation was included. While Mithraratne et al. (2007, p177) used a 5\% discount rate, based on Australia/New Zealand Standards, and they also mentioned $3 \%-4 \%$ as the discount rate in international studies. In this thesis a discount rate of $6 \%$ is used follow the The Treasury (ND). There are also assumptions made around the life span of SIPs panels, which here are assumed to last much longer than the 50 years for which they are guaranteed. It was therefore thought useful to look at the LCC of the ADU over a series of possible lifespans (50,75, and 100 years). Table 6.14 shows the results of the sensitivity analysis of the ADU.

Table 6.14: Sensitivity analysis results

\begin{tabular}{|l|l|l|l|l|}
\hline Parameter & Estimate & Variation $\mathbf{( \% )}$ & $\mathbf{L C C}\left(\mathbf{\$} / \mathbf{m}^{\mathbf{2}}\right)$ & Change in cost $\mathbf{( \% )}$ \\
\hline \multirow{3}{*}{$\begin{array}{l}\text { Discount rate } \\
(100 \text { years) }\end{array}$} & $3 \%$ & -50 & 1670 & 15 \\
\cline { 2 - 5 } & $4 \%$ & -33 & 1564 & 8 \\
\cline { 2 - 5 } & $5 \%$ & -16 & 1491 & 3 \\
\cline { 2 - 5 } & $6 \%$ & 0.0 & 1453 & 0 \\
\hline \multirow{2}{*}{$\begin{array}{l}\text { Life span of ADU } \\
\text { (Discount rate of }\end{array}$} & 50 years & -50 & 1414 & -3 \\
\cline { 2 - 5 } & 75 years & -25 & 1446 & 0 \\
\cline { 2 - 5 } & 100 years & 0.0 & 1453 & 0 \\
\hline
\end{tabular}

Table 6.14 shows changing the discount rate does affect the final cost of the ADU as halving the discount rate gives rise to a growth in the LCC of over $15 \%$. On the other hand, the LCC of the ADU for different life spans shows that the changes in costs are not substantial. Reducing the life span of the ADU to 50 years only produces a $3 \%$ reduction in LCC while using the ADU for 75 years leads to a reduction of less than $1 \%(0.48 \%)$. This clearly shows that once the house is made it is better to use it for a longer time, even if there is a need for replacing some elements.

\subsubsection{Comparison with the BIAC House}

In order to have a more tangible idea about the cost efficiency of the ADU, it would be useful to compare it with the BIAC House. The costs of the BIAC House have been extracted from Mithraratne et al. (2007). All discounted real costs are converted from 2007 (Q1) values to 2018 (Q3) by using the conversion factor of 1.68\% (Reserve Bank of New Zealand, 2019). However, the BIAC house discount rate was $5 \%$ and aside from initial construction with no GST included, all other replacement elements and materials included $12.5 \%$ GST. In order to increase the comparability of the ADU with the BIAC House, the discounted rate of the ADU 
is set at $5 \%$ in this comparison, and GST at $12.5 \%$ is added to any replacement work (Table $6.15)$.

Table 6.15: ADU cost comparison

\begin{tabular}{|l|l|l|l|l|l|l|}
\hline \multirow{2}{*}{} & \multicolumn{2}{|l|}{ Construction cost $\left(\mathbf{\$} / \mathbf{m}^{\mathbf{2}}\right)$} & \multicolumn{2}{l|}{ Operational cost $\mathbf{( \$ / \mathbf { m } ^ { \mathbf { 2 } } )}$} & \multicolumn{2}{l|}{ LCC $\left(\mathbf{\$} / \mathbf{m}^{\mathbf{2}}\right)$} \\
\cline { 2 - 7 } & ADU & BIAC & ADU & BIAC & ADU & BIAC \\
\hline Year 0 & 1339.5 & 1950.5 & 0.0 & 0.0 & 1339.5 & 1950.4 \\
\hline Year 25 & 1395.5 & 2207.5 & 38.4 & 50.4 & 1434.0 & 2257.9 \\
\hline Year 50 & 1440.4 & 2341.9 & 48.5 & 65.5 & 1489.0 & 2407.4 \\
\hline Year 75 & 1448.1 & 2385.6 & 51.5 & 68.9 & 1499.6 & 2454.4 \\
\hline Year 100 & 1451.5 & 2392.3 & 52.3 & 70.6 & 1503.9 & 2462.9 \\
\hline
\end{tabular}

Based on construction cost the ADU is 39\% cheaper while for operating (heating) cost it is over $26 \%$ cheaper at year 100 . Considering LCC, the ADU is approximately $39 \%$ cheaper at year 100 . This comes from using less material and also less need for heating.

\subsection{Summary}

The first section of this chapter showed the key factors affecting the lifecycle energy (LCE) of a house, especially when the goal is being close to zero energy, could be classified into the two groups of those affecting the EE and those affecting the OE. However, the analysis also showed the EE and OE have a direct relationship and changing one soon affects the other. Factors in the first group are volume, energy coefficient, and replacement cycle of materials, while the second group consists of the volume of thermal mass, size and placement of windows, and the R-value of insulation materials.

The LCE calculation led to some changes in the design. The first was replacing the polyurethane core of the SIPs panels with polystyrene. Using polystyrene decreased the EE of the ADU but had a reverse effect on the OE as polyurethane has higher R-value. Taking a 100year perspective showed over 5\% lower LCE using panels made with a polystyrene core. The other change as a result of the LCEA was to use $165 \mathrm{~mm}$ SIPs panels for the ceiling instead of $215 \mathrm{~mm}$ panels as this increased the OE and decreased the EE, leading to a slightly lower LCE.

Before accepting these changes, the ADU with different layers of thermal mass was simulated in SUNREL to look for any overheating. The results showed having less mass led to higher energy consumption and also decreased the level of stability of the internal temperature. Because the ADU is a super insulated box with small windows without mass, the internal temperature could reach uncomfortable heights. 
The ADU was also simulated in different climates in New Zealand, as well as different orientations in Wellington. The result showed the ADU could still be practical in Auckland but a different design might be required for Christchurch to be near zero heating energy. More importantly, the prefabricated ADU showed an acceptable efficiency in different orientations in the Wellington climate.

The second section of this chapter investigated life cycle $\mathrm{CO}_{2}$ emissions of the $A D U$, which included the embodied $\mathrm{CO}_{2}$ emissions of materials and also the $\mathrm{CO}_{2}$ emissions of the energy (electricity) used for heating. Looking at the first group, as for the LCEA, the total $\mathrm{CO}_{2}$ emissions were affected by the quantity, $\mathrm{CO}_{2}$ coefficient and replacement cycle of materials. This result needs to be seen alongside the result for the LCE, as the comparison can give a better understanding of which materials give the best result. Moreover, if the building being studied includes considerable timber, as in the ADU, the assumptions about the carbon sequestration of timber should be clear as its effect can be huge. Looking at the operational $\mathrm{CO}_{2}$ emissions showed, despite the ADU being designed to be nearly zero energy, the operating $\mathrm{CO}_{2}$ emissions were considerable, accounting for $43 \%$ of the total.

The last section of this chapter showed the ADU is cheaper than a conventional house in New Zealand due to use of SIPs panels as these are both cheaper than timber frame structures and lead to lower energy consumption. A sensitivity analysis was conducted for the cost section. As LCA works based on assumptions, sensitivity analysis helps to understand what may happen if any of these assumptions change in the future. 


\section{Chapter 7 Conclusion}

\subsection{Introduction}

This chapter concludes the research and answers the research questions and the factors discussed in Table 3.1, after a brief review of the research problem. This chapter also discusses the contribution of this research to knowledge, examines its limitations and discussing areas for future research.

\subsection{Housing Needs in New Zealand}

The housing industry in New Zealand is facing a crisis, a situation also found in some other developing and developed countries. The housing needs in New Zealand can be seen from number of aspects, the first being the population growth that began mid-20th century. The literature review showed the population grew faster than the housing industry and infrastructure expansion, and that this led to a considerable shortage of dwellings. This shortage of dwellings had other causes such as inefficient urban development, which led the country to have one of the lowest urban densities in the world (see Section 1.1.3). This also means the lack of enough land close to existing urban areas for further expansion, which pushes up the price of land and consequently that of houses. As the scale of house price growth is more than that of income growth, the number of people who can afford to buy a house has also decreased. Finally, another housing-related issue in New Zealand, which is the focus of this research, is the age of New Zealanders, as the population is rapidly getting older. This is important as the housing needs of this group of older people are different from those of other age groups, who might prefer to live in a smaller, accessible houses which are easier to heat, clean, and maintain, but that are also located within their existing social context. So, staying in their neighbourhood should be one of the main considerations for housing this group.

The housing needs in New Zealand can be tackled in different ways, such as extending the existing urban boundaries to build more houses on newly developed land. However, this new land needs the installation of new infrastructure, which is both time consuming and costly. As a result of these considerations, this research designed a prefabricated age-friendly house in the form of an Accessory Dwelling Unit (ADU) that could be positioned on already developed land in order to add to the housing stock using existing infrastructure. 


\subsection{Answers to the Research Questions}

Nominating the prefabricated ADU as a potential contribution to the housing needs of New Zealand led to some questions. This section recalls the questions and answers them based on the results.

The main research question was:

How could an age-friendly zero energy prefabricated ADU be developed as a contribution to contemporary housing needs in New Zealand?

To answer the main question, required answering the following sub-questions:

How could a zero energy ADU be made in a factory, and transported to site and erected on site while abiding by the existing rules?

How would such an ADU compare with conventional houses in terms of energy consumption, cost, and environmental impacts?

In this section, firstly these two sub-questions are discussed and then the main one with regards to factors discussed earlier in Chapter 3 (Table 3.1).

\subsubsection{Factory Built, Transportable ADU}

In order to see how is it possible to build the ADU in a factory, transport it, and put it on site by abiding with the existing transportation rules, a four step systematic approach was used. First, the dispersion of each type of prefabrication manufacturer was investigated. This showed that the majority (68\%) of house prefabrication manufacturers are located in the North Island, where $75 \%$ of the households are. Regarding the type of prefabrication, the lack of manufacturers of higher degrees of prefabrication in terms of factory-built modules and whole buildings became clear, especially in the South Island. In all New Zealand there were only three manufacturers of completed buildings, all in the North Island.

There are just four modular manufacturers, the system used in this research, with only one in the South Island. This means prefabricated houses may need to travel long distances. This is a problem of prefabrication as the cost of setting up a factory depends on having a market, but it is hard to create a market unless people see the benefits of having a prefabricated ADU 
as a means of increasing density in urban areas. However, the fact that there are four module manufacturers means it would be possible to start producing the ADU, with the hope that demand for such buildings would lead to an expansion of the industry.

Looking at the transportation rules a prefabricated module should be smaller than $20 \mathrm{~m}$, $2.55 \mathrm{~m}$ and $4.3 \mathrm{~m}$ in length, width and height respectively. The weight also should be less than 50 tonnes. If any of these values is exceeded, the load would be classified as an over dimension load, and must apply for extra permissions based on the category in which it has been placed in (see Section 4.4). A design has been developed which shows it is possible using the modular approach to produce an ADU that could be carried within these dimensions. The two bedroom Type B1 layout is perhaps weakest in terms of furnishing the L-shaped living/dining room but a number of layouts were produced to see what might be possible (see Section 5.7.9.1).

It has been shown that the needs of the ageing New Zealand population are for smaller houses. This led to a need to investigate requirements specified by 55 New Zealand councils for ADUs. The aim here was to find a size for the prefabricated ADU that would be acceptable. Most important limitations were found to be Maximum Site Coverage (MSC), Maximum Gross Plan Area (MGPA) and Minimum Net Site Area Required (MNSA) in residential areas, and that these should be in the ranges of $30-50 \%, 50 m^{2}-70 m^{2}$ and $325 m^{2}-800 m^{2}$ respectively to get consented by the majority of councils. These figures, as well as the transportation limitations, set area and dimensional boundaries for the design of the prefabricated ADU.

The last factor, which was investigated to answer the first sub-question, was the accessibility of the ADU for older people, with the aim of achieving at least three Lifemark stars (see Section 4.5). The most important factors were designing the ADU to have a level entry, and a level entry shower, and with enough space for wheelchair access.

Given all these factors, a compliant ADU was designed using a prefabricated modular system, consisting of five main modules each of $2.55 \mathrm{~m}$ by $5.1 \mathrm{~m}$ and an entrance module, which is approximately one-third of the size of the main modules. The modules can be placed together in different ways to make different layouts and also ADUs with different plan areas. Each module is accessible for older people, achieving three Lifemark stars, and is transportable 
around New Zealand with no need for over-dimension load considerations. The short answer to this research sub-question would be 'yes' as the designed ADU can meet all requirements.

However, there are some important points to be considered. The most important one is the relationship between size limitations due to the transportation rules and the minimum size requirement of Lifemark, where the first pushes modules to be smaller, especially in width, but the second asks for wide internal spaces. The design proved that it is possible to meet both requirements simultaneously, but doing this has affected the internal layout and this could affect the market appeal.

\subsubsection{Is the Prefabricated ADU More Efficient than a Conventional House?}

To answer the second sub-question and see if the designed ADU is more efficient compared with a conventional house in terms of energy consumption, cost, and environmental impacts, a three-step analysis was conducted.

The first step, showed the 100 year LCE of the ADU was just over $8,753 \mathrm{MJ} / \mathrm{m}^{2}$, while modifying the design and changing the type and thickness of the insulating material decreased the 100 year LCE to $8,501 \mathrm{MJ} / \mathrm{m}^{2}$. This was approximately $911 \mathrm{MJ} / \mathrm{m}^{2}$ and $34,024 \mathrm{MJ} / \mathrm{m}^{2}$ less than the conventional BIAC (NZ) House, and the Melbourne (Australia) Green Home energy efficient case studies. However, close to $59 \%$ of the initial embodied energy of the ADU comes from oil-based plastics, which are not the most environmentally friendly materials.

Looking at environmental impacts as the second step, the ADU releases over $50 \%$ less $\mathrm{CO}_{2}$ than the BIAC house during the 100 year lifetime. The last step was calculating the LCC of the ADU, and finding it was approximately $39 \%$ cheaper than the BIAC house. So it can be said that the prefabricated ADU is more efficient compared with a conventional house in terms of energy consumption, cost, and environmental impacts. However, there needs to be discussion of the reasons behind this excellence.

While the ADU was found to be more efficient than conventional houses over a 100 -year period, this efficiency is more due to design decisions and choice of materials than being prefabricated or being an ADU. This research showed that there is not enough reliable support for prefabrication being considerably more efficient than conventional methods. 


\subsubsection{An Age-Friendly, Zero Energy Prefabricated ADU}

Given the answers to the sub-questions, the short answer to the main research question is 'yes' it is possible to design an age-friendly, very near zero energy, prefabricated ADU to contribute to housing needs in New Zealand. The ADU as designed is accessible, transportable, and would be acceptable under the current district plans of the majority of New Zealand councils.

The ADU uses existing infrastructure and developed land to increase the urban density and provide more living options for older people in their existing social contexts. The ADU is more energy and cost efficient than conventional hoses with less environmental impact. However, there are considerations to take into account before accepting the prefabricated ADU as a useful answer to housing needs in New Zealand. These considerations are discussed in the following sections on limitations and further research (see Section 7.5).

\subsection{Contribution to Knowledge}

This research set out to test the potential of using prefabricated ADUs to contribute to New Zealand housing needs (see Section 1.2). The contribution of this research to existing knowledge can be discussed from different points of view, first in terms of who is going to benefit from the result and then how this research differs from previous studies.

\subsubsection{Research Implication}

This research investigated the use of ADUs as a type of dwelling that could add to the housing options in New Zealand. The feasibility of this idea as demonstrated in this thesis could be used by the government and local authorities when it comes to decisions about creating more housing. This research has shown that an age-friendly, environmental and energy efficient ADU could be placed on developed land and add to housing stock using existing infrastructure. The prefabrication of such ADU would only use a small fraction of the manpower devoted to making houses in the traditional way for assembly on site, so would be a way of giving employment in the factory. At a time when there is a shortage of construction workers this could be an additional benefit (see Section 2.2.4.1).

In terms of users, the prefabricated ADU could provide housing for ageing in place at a lower cost than conventional housing. Existing house owners could also use the concept to make 
some extra money by renting the ADU or by providing a suitable living option for older members of their family.

\subsubsection{Research Novelty}

This research uses design to evaluate the potential of using prefabricated ADUs in New Zealand. Existing research has looked at prefabrication as a method of construction or at ADUs as a type of construction, but the two have not been combined before. Bringing both method and type of construction together as a contribution to housing needs in New Zealand is new.

\subsection{Limitations and Further Research}

There were some limitations in this research that could lead to future research.

\subsubsection{Life Cycle Assessment}

Operating energy in this research was limited to space conditioning energy, which is just heating in New Zealand, although this is an important user of energy in many houses. In order to have a more realistic view it would be worth including other types of operational energy in LCEA, LCC and life cycle $\mathrm{CO}_{2}$ emissions calculations. Moreover, the EE and $\mathrm{CO}_{2}$ coefficients, which were used in the research were mainly extracted from the Alcorn (2010) report, which is 9 years old and specific to New Zealand. These coefficients are highly dependent on production technologies, which can differ considerably from country to country, and over time. So, the LCEA, LCC and life cycle $\mathrm{CO}_{2}$ emissions calculated in this study are comparable, but are not generalizable. Recalculating them using the coefficients from other countries would make a useful study.

\subsubsection{Comparisons}

As mentioned in Section 7.4.2 this research is relatively new, which means there was no comparable, New Zealand building, and the comparison with both the BIAC house and buildings in other climates was not ideal. However, this is not an avenue for further research until the experience and understanding is available from increased construction of very low energy and zero energy houses.

\subsubsection{Talking to Experts}

One of the main aims of this thesis was to give a realistic view of the efficiency of prefabricated ADUs. The next step could be presenting the results of the theoretical study to prefabrication 
manufacturers and transport and housing experts to see how they evaluate these, as there maybe issues in manufacturing and transportation that have been overlooked.

\subsubsection{Potential Benefits of Prefabrication}

At the beginning of this research, prefabrication was selected as the method of construction due to its potential benefits. However, this research raises some arguments about this. The claimed benefits are not clear as to whether they happen during construction or the operational phases of the building. Moreover, this research has showed that the efficiency of a house is more related to the design decisions and choice of materials. So the next step could be investigating and comparing, probably using case studies rather than simulations, the energy consumption of a prefabricated building with a conventional made house in different stages of the building life cycle. This would give a reliable idea as to whether prefabrication is more efficient than conventional methods during the life of a building.

\subsubsection{The Users}

Finally it would be good to present the results to older groups of people to see what they think of the idea of ADUs in general and the designs for the prefabricated ADU in particular. Unless there is a market for the idea it will remain just that. 


\section{Bibliography}

Abdullah, L., Mohd Nor, M. N., Jumadi, N., Arshad, H. (2015). "First-time Home Buyers: Factors Influencing Decision Making", International Conference on Innovation and Technology for Sustainable Built Environment. Perak, Malaysia, 27-28 March 2012, 173-179.

Abosaad. H., Underwood, J., Boreny, S. (2009). "Towards an Information System Representation of OSM in Facilitating the Virtual Prototyping of Housing Design", 9th International Postgraduate Research Conference (IPGRC). Salford, United Kingdom, 29-30 January 2009, 509-520.

Abrantes, V., Rangel, B., Amorim Faria, J. M. (2017). "The Pre-Fabrication of Building Facades", edited by Vitor Abrantes, Bárbara Rangel, José Manuel Amorim Faria, Cham: Springer International Publishing.

Accessory Dwellings (2018). "Accessory Dwellings Plan", Retrieved 01/07/2018, from https://accessorydwellings.org/.

Adams, M. and R. Chapman (2016). "Do Denser Urban Areas Save on Infrastructure? Evidence from New Zealand territorial authorities", Policy Quarterly 12(4): 63-70.

AIGA (the professional association for design), (2011). "Case Study: Living Light Home / Solar Decathlon", New York: The Professional Association for Design, Retrieved 11/06/2018 from https://www.aiga.org/case-study-living-light-home.

Airstream (2019). "Heritage", $\quad$ Retrieved 05/05/2019 from https://www.airstream.com/heritage/.

Alcorn, A. (2003). "Embodied Energy and $\mathrm{CO}_{2}$ Coefficients for NZ Building Materials", Wellington, New Zealand, The Centre for Building Performance Research, Victoria University of Wellington, New Zealand.

Alcorn, A. (2010). "Global Sustainability and the New Zealand House", Architecture. Wellington, New Zealand, Victoria University of Wellington. PhD thesis.

Alcorn, A. (1996). "Embodied Energy Coefficients of Building Materials", Wellington: Centre for Building Performance Research, Victoria University of Wellington.

Alcorn, A. and P. Wood (1998). "New Zealand Building Materials Embodied Energy Coefficients Database", Volume II - Coefficients. Wellington, New Zealand: Centre for Building Performance Research, Victoria University of Wellington.

Anderson, S. (2017) "Rational Reconstructions and Architectural Knowledge", Plenum, 161173, Retrieved 05/05/2019 from https://e-pub.uniweimar.de/opus4/frontdoor/deliver/index/docld/3053/file/12.+Anderson_pdfa.pdf

Antoninetti, M. (2008). "The Difficult History of Ancillary Units: The Obstacles and Potential Opportunities to Increase the Heterogeneity of Neighborhoods and the Flexibility of Households in the United States." Journal of Housing for the Elderly 22(4): 348-375. 
Arena, A. P. and C. de Rosa (2003). "Life Cycle Assessment of Energy and Environmental Implications of the Implementation of Conservation Technologies in School Buildings in Mendoza-Argentina", Building and Environment 38(2): 359-368.

Arieff, A, and Burkhart, B. (2002). "Prefab", Layton, Utah: Gibbs Smith.

Ashby, M. F. (2013). "Materials and the Environment: Eco-informed Material Choice", Amsterdam; Boston: Elsevier/Butterworth-Heinemann.

Atombo, C., Dzantor, J. C. K., Agbo, A. A. (2015). "Integration of Sustainable Construction in Project Management: A Case Study in Ghana", International Journal of Construction Engineering and Management 4(1): 13-25

Auckland Design Manual (2018). “Living Spaces Make Smiling Faces”, Auckland, New Zealand: Auckland design manual. Retrieved 23/01/2019 from http://www.aucklanddesignmanual.co.nz/.

Baghchesaraei, A., Kaptan, M. V., Baghchesaraei, O. R. (2015). "Using Prefabrication Systems in Building Construction", International Journal of Applied Engineering Research 10(24): 44258-44262.

Bahho, M. (2017). "A Demonstration Sustainable Building: A Tool for Investigating Environmental Values", School of Architecture. Wellington, New Zealand, Victoria University of Wellington. PhD thesis.

Baird, G., Donn, M., Pool, F., Brander, W. D. S., Aun, C. S. (1984). "Energy Performance Buildings", Florida, United States of America: CRC Press.

Bardhan, S. (2011). "Assessment of Water Resource Consumption in Building Construction in India", WIT Transactions on Ecology and the Environment 144: 93-101.

Barnes, K., Morgan, J., C. Roberge, M., Lowe, S. (2012). "Sprawl Development: its Patterns, Consequences, and Measurement", Technical Report, University of Maryland, Department of Geography and Environmental Planning.

Bassett, M. and L. Malpass (2013). "Priced Out, How New Zealand Lost its Housing Affordability", Wellington, New Zealand: The New Zealand Initiative.

Bathsystem (2017). "Technical Guida”, Bathsystem. Italy, Bathsystem, Retrieved 05/01/2019 from https://www.bathsystem.com/en/.

Begum, R. A., Satari, S. K., Pereira, J. J. (2010). "Waste Generation and Recycling: Comparison of Conventional and Industrialized Building Systems", American Journal of Environmental Sciences 6(4): 383-388.

Bekhta, P. and R. Marutzky (2007). "Reduction of Glue Consumption in the Plywood Production by Using Previously Compressed Veneer", HolzalsRoh- und Werkstoff 65(1): 87-88. 
Bell, P. (2009). "Kiwi prefab: Prefabricated Housing in New Zealand: an Historical and Contemporary Overview with Recommendations for the Future Architecture and Design", Victoria University of Wellington, Master of Architecture.

Bell, P. (2011). "Demystifying Prefabrication", Retrieved 23/08/2018, from https://www.eboss.co.nz/detailed/pamela-bell/demystifying-prefab.

Bell, P. (2012). "Prefab + Green: Past, Present and Future", Wellington, New Zealand, prefab NZ. $\quad$ Retrieved 15/03/2018, from https://www.constructing.co.nz/uploads/events/3/3.pdf

Bell, P. and Southcombe, M. (2012). "Kiwi prefab: Cottage to Cutting Edge: Prefabricated Housing in New Zealand". Auckland, New Zealand: Balasoglou Books.

Bergdoll, B., Christensen, B., Christensen, P. H., Oshima, K (2008). "Home Delivery: Fabricating the Modern Dwelling", New York: Museum of Modern Art.

Bergman, R., Puettmann, M., Taylor, A., Skog, K. E. (2014). "The Carbon Impacts of Wood Products", LaGrange, United States of America: Forest Products Society.

Bernard, M. (2011). "2011 Solar Decathlon: Tidewater Virginia's Unit 6 Unplugged", Retrieved 05/05/2018 from http://buildipedia.com/aec-pros/design-news/2011-solardecathlon-tidewater-virginias-unit-6-unplugged?print=1\&tmpl=component.

Boafo, F. E., Kim, J. H., Kim, J. T. (2016). "Performance of Modular Prefabricated Architecture: Case Study-based Review and Future Pathways", Sustainability 8(6): 558-574.

Bock, T., Linner, T., Mayr, G., M., Andreaus, J. M. (2012). "Innovation Deployment Strategies in Construction", Creative Construction Conference, Budapest, Hungary. June 30 - July 3, 2012:105-119.

Bokkerink, M. (2018). “Re: Question About Modules". Matrix Homes, New Zealand, Personal Communication, 03/05/2018.

Botes, A. W. (2013). "A Feasibility Study of Utilising Shipping Containers to Address the Housing Backlog in South Africa", (Masters), Stellenbosch University, South Africa.

Bourdeau, L., Huovila, P., Lanting, R. (1998). "Sustainable Development and the Future of Construction, a CIB W82 Project", World Building Congress. Gavle; Sweden. 7 - 12 June 1998:1187-1196.

BRANZ (2018). "Life Cycle Assessment (LCA)", Retrieved 25/12/2018 from https://www.branz.co.nz/cms display.php?sn=308\&st=1\&pg=16913.

Britto, J., Dejonghe, N., Dubuisson, M., Schmandt, K. (2008). "Business Plan for Green Modular Housing", University of California, School of Environmental Science \& Management. Master of Environmental Science and Management.

Broad Sustainable Building (2013). "T30A Tower Hotel Technical briefing", Broad Sustainable Building (BSB), $\quad$ Retrieved 25/03/2018 from 
http://www.greenindustryplatform.org/wp-content/uploads/2013/07/Broad-GroupBSB-T30-Tower-Hotel Technical-Briefing.pdf .

Brookes, B. (2000). "At Home in New Zealand: Houses, History, People", Wellington, New Zealand, Bridget Williams Books.

Brown, M. J. and Palmeri, J. (2014). "Accessory dDwelling Units in Portland, Oregon: Evaluation and Interpretation of a Survey of ADU owners", Technical Report, Oregon, United States of America, Oregon Department of Environmental.

Brown, M. J. W., Taylor (2012). "Understanding and Appraising Properties with Accessory Dwelling Units", The Appraisal Journal 80(4): 297-309.

Bunnings (2019) "Material Costs", Bunnings. Wellington, New Zealand, Personal communication 12/02/2019.

Burgess, J., C, Buckett, N., R, Page, I. C. (2013). "Prefabrication Impacts in the New Zealand Construction Industry”, Study Report (SR279), Wellington, New Zealand: BRANZ.

Business New Zealand Energy Council (2015). “New Zealand Energy Scenarios, Navigating Energy Futures to 2050", Technical Report, Wellington, New Zealand: BusinessNZ Energy Council.

Buyle, M., Braet, J., Audenaert, A. (2013). "Life Cycle Assessment in the Construction Sector: A Review", Renewable and Sustainable Energy Reviews 26, October 2013: 379-388.

Carswell, A. T. (2012). "The Encyclopedia of Housing", Second Edition, Los Angeles, United States of America: SAGE Publications.

Chalmers, L. and Hails, G. B. (1991). "Granny Flats as Housing for the Elderly: International Perspectives", Journal of Housing for the Elderly 7(2): 17-28.

Chappell, N., Dlitt, B, Hollander, M., Miller, J. A., McWilliam, C. (2004). "Comparative Costs of Home Care and Residential Care", The Gerontologist 44(2): 389-400.

Chappell, P. R. (2014). "The Climate and Weather of Auckland", New Zealand: National Institute of Water and Atmospheric Research (NIWA), Retrieved 21/11/2018 from https://www.niwa.co.nz/static/Auckland\%20ClimateWEB.pdf.

Chen, Y., Okudan, G. E., Riley, D. R. (2010). "Sustainable Performance Criteria for Construction Method Selection in Concrete Buildings", Automation in Construction 19(2): 235-244.

Chisholm, D. H. (2004). "Tilt-up Technical Manual”, Wellington, New Zealand: Cement and Concrete Association of New Zealand, Retrieved 10/10/2017 fromhttps://www.ccanz.org.nz/files/documents/8c207b7c-d442-4ab8-b8f43c28e4b2c94f/TM\%2034.pdf

Chiu, S. T.-L. (2012). "An Analysis on the Potential of Prefabricated Construction Industry Forestry", Faculty of Forestry, University of British Columbia, Bachelor of Science in wood products processing. 
Chong, T. T. (2014). "Prefabricated Bathroom Unit (PBU) a Good Industry Practice CONQUAS Enhancement", Building and Construction Authority, Retrieved 10/01/2018 fromhttps://www.bca.gov.sg/Publications/EnhancementSeries/pbu.html.

Cilento, K. (2011). "Team New Jersey eNJoy House / NJIT + Rutgers University", Retrieved 10/03/2018 from https://www.archdaily.com/124105/team-new-jersey-enjoyhouse-njit-rutgers-university.

Clark, D. H. (2013). "What Colour is Your Building? Measuring and Reducing the Energy and Carbon Footprint of Buildings", London: RIBA Publishing.

Clawson, M. (1962). "Urban Sprawl and Speculation in Urban", Land Economics 38(2): 99-111.

Cobb, R. L. and S. Dvorak (2000). "Accessory Dwelling Units: Model State Act and Local Ordinance", United States of America: Public Policy Institute.

County Construction Chemicals (2007). "Universal PVA Adhesive and Sealer-Prime, Seals and Bonds", $\quad$ Retrieved 21/02/2019 from http://www.countyconchem.co.uk/products/technicaldata/geocel/universalpvadata sheet.pdf.

Cuff, D. and J. Blumenfeld (2017). "Build an ADU, Guidebook to Accessory Dwelling Units in the City of Los Angeles", United States of America: cityLAB, Retrieved 21/02/2019 from

https://static1.squarespace.com/static/58e4e9705016e194dd5cdc43/t/59b33bc749 fc2b50d07ec8ed/1504918476849/09-05+ +ADU+Booklet.pdf

Culvahouse, T. (2007). "The Tennessee Valley Authority: Design and Persuasion", New York: Princeton Architectural Press.

Davey, J. A., de Joux, V., Nana, G., Arcus, M. (2004). “Accommodation Options for Older People in Aotearoa/New Zealand", Report prepared for the Centre for Housing Research, Aotearoa/New Zealand (CHRANZ). Wellington, New Zealand.

Davies, A. (2018). "Modern Methods of Construction: A Forward-thinking Solution to the Housing Crisis?", Technical Report, London, UK: Royal Institution of Chartered Surveyors (RICS).

De Jonge, D., Ainsworth, E., Tanner, B. (2006). "Promoting Independence for Older Persons with Disabilities", International Conference on Aging, Disability and Independence. M. A. Helal. St Petersburg, FL, United States of America. 2-4 February 2006, 155-168.

Chiei, C., and Decker, J. (2005). "Quonset Hut: Metal Living for a Modern Age", Hudson, United States of America: Princeton Architectural Press.

Department of Building and Housing (2010). "New Zealand Housing Report 2009/2010: Structure, Pressures and Issues", Technical Report, Auckland, New Zealand: Ministry of Business, Innovation and Employment, Retrieved 13/10/2018 fromhttp://knowledgeauckland.org.nz/publication/?mid=812. 
Deshmukh, R. and More, A. (2014). "Low Energy Green Materials by Embodied Energy Analysis", International Journal of Civil and Structural Engineering Research 2(1): 5865.

Dieleman, F. and M. Wegener (2005). "Compact City and Urban Sprawl", Built Environment 30(4): 308-323.

Dixit, M. K., Culp, C. H., Fernandez-Solis, J. L. (2015). "Embodied Energy of Construction Materials: Integrating Human and Capital Energy into an IO-based Hybrid Model", Environmental Science \& Technology 49(3): 1936-1945.

Donn, M., Lee, J., Isaacs, N., Bannister, P. (1995). “Decision Support Tools for Building Code Energy Efficiency Compliance", International Building Performance Simulation Association, Fourth International Conference. Madison, Wisconsin, 14-16 August 284292.

Edhouse, T (2014)“Bracing Using NZS 3604:2011”, Build 131, August/September 2012: 29-30.

Eglinton, A. (2014). “Complete Buildings”, Build 139, December 2013/January 2014: 80-82.

El-Abidi, K. M. A. and Ghazali, F. (2015). "Motivations and Limitations of Prefabricated Building: An Overview", Applied Mechanics and Materials 802: 668-675.

Elitzer, J. (2015). "Do You Know The Difference Between Prefab And Manufactured Homes?", Retrieved 05/05/2018 from http://modularhomeowners.com/do-you-know-thedifference-between-prefab-and-manufactured-homes/.

Elrich, M. (2019). "County Executive Marc Elrich is Wrong to Oppose Accessory Dwelling Units", $\quad$ Retrieved 05/05/2019 from https://commonwealthmoco.com/2019/03/06/county-executive-marc-elrich-iswrong-to-oppose-accessory-dwelling-units/.

Energy Consult (2015a). "Residential Energy Baseline Study: New Zealand”, Technical Report, Victoria, Australia: Department of Industry and Science.

Historic England (2011). "Domestic 4: Modern Houses and Housing", London, UK: English Heritage.

Enshassi, A., Kochendoerfer, B., Ghoul, H. A. (2016). "Factors Affecting Sustainable Performance of Construction Projects during Project Life Cycle Phases", International Journal of Sustainable Construction Engineering and Technology 7(1): 50-68.

European Association for Architectural Education (EAAE) (2012). "EAAE Charter on Architectural Research", Retrieved 15/05/2019 from http://www.eaae.be/about/statutes-and-charter/eaae-charter-architecturalresearch/.

Evans, B. (2012). "Goodbye Urban Sprawl, Hello Apartments", Build 130, June-July 2012: 3031. 
Ewing, R. (1997). "Is Los Angeles-Style Sprawl Desirable?", Journal of the American Planning Association 63(1): 107-126.

Ewing, R. and Cervero, R. (2010). "Travel and the Built Environment." Journal of the American Planning Association 76(3): 265-294.

Family home plans (2018). "Home Plans", Retrieved 12/07/2018 from https://www.familyhomeplans.com.

Fay, R. (1999). "Comparative Life Cycle Energy Studies of Typical Australian Suburban Dwellings", Faculty of Architecture, Building and Planning, The University of Melbourne. PhD thesis.

Fay, R., Vale, B., Vale, R. (2000). "Assessing the Importance of Design Decisions on Life Cycle Energy and Environmental Impacts", 17th International PLEA Conference, K. Steemers and S. Yannas. Cambridge, England, 2-5 July 2000, 164-169.

Fendik, E. S. (2011). "AS-BUILT Drawing set", USA, Middlebury College, Retrieved 15/05/2018 from https://www.solardecathlon.gov/past/2013/pdfs/midd cd.pdf.

Fenner, A. E., Razkenari, M. A., Hakim, H., Kibert, C. J. (2017). "A Review of Prefabrication Benefits for Sustainable and Resilient Coastal Areas", 6th International Network of Tropical Architecture Conference: Tropical Storms as a Setting for Adaptive Development and Architecture, University of Florida, United States of America, 1-3 December 2017, 316-327.

Fenwick, B. (2011). "Living light, US Solar Decathlon House Team Tennessee: Proposal to the National Renewable Energy Laboratory and U.S. Department of Energy", Tennessee, The University of Tennessee, Retrieved 15/05/2018 from file://C:/Users/Milad/Downloads/Documents/SD FinalProposal.pdf.

Finnimore, B. (1989). "Houses From the Factory: System Building and the Welfare State 194274", London: Rivers Oram Press.

First Light (2011a). "The Meridian First Light House", Retrieved 06/05/2018 from http://www.firstlightstudio.co.nz/the-meridian-first-light-house/\#top.

Flanagan, R. (1989). "Life Cycle Costing: Theory and Practice", Oxford: BSP Professional Books.

Florian, U. (2013). "The Hut on the Garden Plot Informal Architecture in Twentieth-Century Berlin", Journal of the Society of Architectural Historians 72(2): 221-249.

Formance (2019). "What are SIPs?" , New Zealand, Formance, Retrieved 06/02/2019 from https://www.formance.co.nz/why-sips/.

Frame and Truss Manufacturers' Association of New Zealand. (2016). "Corporate Members (Cat D)", New Zealand, FTMA, Retrieved 03/03/2018 from http://www.ftma.co.nz/meet-our-members.html. 
French, L., Camilleri, M., Isaacs, N. (2006). "Winter Temperatures in New Zealand Houses", Comfort and Energy Use in Buildings - Getting them Right conference, Cumberland Lodge, Windsor, UK, 27-30th April 2006, NP.

Frey, H. (1999). "Designing the City: Towards a More Sustainable Urban Form”, New York: Taylor \& Francis.

Garne, J. S. (1993). "World War II Temporary Military Buildings: A Brief History of the Architecture and Planning of Cantonments and Training Stations in the United States", United States of America: US Army Corps of Engineers.

Garton, S. (2018). "Question Regarding Panels", Durapanel. New Zealand, Personal communication, 06/01/2018.

Gavilan, R.M., and Bernold, L.E. (1994). "Source Evaluation of Solid Waste in Building Construction", Journal of Construction Engineering and Management, 120(3):536-552.

Gellen, M. (1985). "Accessory Apartments in Single-Family Housing", New York, USA: Transaction Publishers.

Generalova, E. M., Generalov, V. P., \& Kuznetsova, A. A. (2016). "Modular Buildings in Modern Construction", Procedia Engineering 153: 167-172.

George, A. F. C. (1937). “George A. Fuller Company, General Contractors, 1882-1937”, New York; Washington: George A. Fuller Company.

Gibb, A. and Pendlebury, M. (2005). "Glossary of Terms". London, UK, Build offsite, Retrieved 03/03/2018 from https://offsite.lboro.ac.uk/docs/Buildoffsite glossary V1.6b 2006.pdf

Gibb, A. G. F. (1999). “Off-site Fabrication: Prefabrication, Pre-assembly and Modularisation”, New York: John Wiley \& Sons.

Gibb, A. G. F. and Isack, F (2003). "Re-engineering Through Pre-assembly: Client Expectations and Drivers", Building Research \& Information 31(2): 146-160.

Giedion, S. (1967). "Space, Time and Architecture; the Growth of a New Tradition", Cambridge, UK: Harvard University Press.

Giller, J. (2012). "Reinventing the Tent: An Exploration of Fabric Construction. School of Architecture", Wellington, New Zealand, Victoria University of Wellington. Master of Architecture.

Gillham, O. and A. S. MacLean. (2002). "The Limitless City: A Primer on the Urban Sprawl Debate", Washington, United States of America: Island Press.

Giovannoni, E. and G. Fabietti. (2013). "What Is Sustainability? A Review of the Concept and Its Applications". Busco, C., Frigo, M., Riccaboni, A., and Quattrone, P (Eds.), Integrated Reporting, Switzerland: Springer. 
Global Energy Assessment. (2012). "Global Energy Assessment-Toward a Sustainable Future”, Cambridge University Press, Cambridge, UK and New York, the International Institute for Applied Systems Analysis, Luxemburg, Austria.

Global Footprint Network. (2016). "What_we_do", Retrieved 12/12/2018 from http://www.footprintnetwork.org/en/index.php/GFN/page/what we do/.

Gordon, P. and H. W. Richardson. (1997). "Are Compact Cities a Desirable Planning Goal?", Journal of the American Planning Association 63(1): 95-106.

Gorgolewski, M. T. (2005). "The Potential for Prefabrication in United Kingdom Housing to Improve Sustainability", Yang, J., Brandon, P.S., and Sidewell, A.C. (Ed.) Smart and Sustainable Built Environments, Oxford: Blackwell Publishing.

Granny flat Australia. (2013). "The Granny Flat Bible: Everything you Need to Know", Australia: Granny flat Australia, Retrieved 25/10/2018 from https://grannyflatsaustralia.com.au/wp-content/uploads/2018/05/GFA-BIBLEVersion1-Aug2013.pdf

Greenbrook, S. R. (2005). "Village People: the Changing Role of Retirement Villages in New Zealand's Ageing Society", Auckland, New Zealand, The University of Auckland, Master of Art.

Groat, L. N. and Wang, D (2013). "Architectural Research Methods", Hoboken, New Jersey: John Wiley \& Sons Inc.

Gustavsson, L., Pingoud, K., Sathre, R. (2006). "Carbon Dioxide Balance of Wood Substitution: Comparing Concrete- and Wood-Framed Buildings", Mitigation and Adaptation Strategies for Global Change 11(3): 667-691.

Guy, O. (1987). "Prefab: A study in Policy-making", Public Administration 16(4): 407-422.

Haberecht, P. W. and Bennett, A. F. (1999). "Experience with Durability Assessment and Performance-based Building Codes", First Asia Pacific Conference on Harmonisation of Durability Standards and Performance Tests for Components in Buildings and Infrastructure, Bangkok, Thailand, 8-10 September, 1999.

Hamdy, A., Abdelkader, M., Stait, M., Samy, S. (2018). "Defining the Characteristics of Prefabricated Architecture as an Alternative Sustainable Construction Approach", International Conference for Sustainable Design of the Built Environment SDBE London, UK, 12-13 September 2018, 635-643.

Hamilton, C. K. G. (2017). "The Benefits of Incorporating Shipping Containers into Climate Change Adaption Plans at NASA Wallops flight facility", (Masters), University of Florida, Florida, United States of America.

Hammond, G. P. and Jones, C.I. (2011). "Inventory of Carbon \& Energy (ICE), Version 2.0 UK" University of Bath, Retrieved 03/10/2018 from https://www.carbonsolutions.com/Resources/ICE\%20V2.0\%20-\%20Jan\%202011.xls. 
Hampson, K. and Brandon, P. (2004). "Construction 2020: a Vision for Australia's Property and Construction Industry", Brisbane, Australia: Cooperative Research Centre for Construction Innovation.

Hargreaves, R. (2003). "Mitigating the Impacts of Climate Change on the Built Environment", Study Report, Wellington, New Zealand, BRANZ.

Harrison, H., Mullin, S., Reeves, B., and Stevens, A. (2012). "Non-traditional Houses: Identifying Non-traditional Houses in the UK 1918-75", UK: Building Research Establishment.

Hashemi, A. (2013). "Review of the UK Housing History in Relation to System Building", Alam Cipta 6(1): 47-58.

Hauberg, J. (2011). "Research by Design-A Research Strategy", Architecture \& Education Journal (5): 46-56.

Hawaii Appleseed. (2016). “Accessory Dwelling Unit, Homeowners' Handbook: A Guide for Homeowners on Oahu Interested in Building an Accessory Dwelling Unit", Hawaii, Retrieved 05/02/2018 from http://hawaiiadu.org/wpcontent/uploads/2016/03/HawaiiADU-Handbook.pdf.

Hayes, N. (1999). "Making Homes by Machine: Images, Ideas and Myths in the Diffusion of Non-Traditional Housing in Britain 1942-54", Twentieth Century British History 10 (3): 282-309.

HDW Builders (2016). "Tilt-Slab eco building", Retrieved 3/04/2018 from https://www.hdwbuilders.nz/portfolio/tilt-slab-eco-building/\#prettyPhoto.

Health and Safety Executive (2012). "Manual Handling at Work: A Brief Guide", United Kingdom, Health and Safety Executive, Retrieved 05/02/2018 from http://www.hse.gov.uk/pubns/indg143.htm.

Heim, C. E. (2001). "Leapfrogging, Urban Sprawl, and Growth Management: Phoenix, 19502000", The American Journal of Economics and Sociology 60(1): 245-283.

Henilane, I. (2016). "Housing Concept and Analysis of Housing Classification", Baltic Journal of Real Estate Economics and Construction Management 4(1): 168-179.

Herbers, J. (2004). "Prefab Modern” New York: Harper Design International.

Herbert, G. (1984). "The Dream of the Factory-made House: Walter Gropius and Konrad Wachsmann", Cambridge: MIT Press.

Hernandez, P. and Kenny, P. (2010). "From Net energy to Zero Energy Buildings: Defining Life Cycle Zero Energy Buildings (LC-ZEB)", Energy and Buildings 42(6): 815-821.

Hickey, B. (2014). "Could History be About to Repeat?", Retrieved 26/04/2019 from https://www.interest.co.nz/opinion/70389/bernard-hickey-harks-back-2003-timewhen-auckland-house-prices-were-rising-15. 
Holden, E. (2004). "Ecological Footprints and Sustainable Urban Form", Journal of Housing and the Built Environment 19(1): 91-109.

Homes, G. (2018). "Genius Homes", Retrieved 10/02/2018 from https://www.geniushomes.co.nz/.

Hong Kong Observatory (2016). "Hong Kong in a Warming World", Hong Kong, Hong Kong Observatory, Retrieved 27/02/2018 from https://www.hko.gov.hk/climate change/climate_change_e.pdf.

House plans (2018). "House Plans", Retrieved 06/08/2018 from https://www.houseplans.com.

HousePlans.pro (2018). "HousePlans", Retrieved 03/07/2018 from https://www.houseplans.pro/.

Howard, F. (2002). "Urban Sprawl and Public Health", Public Health Reports 117(3): 201-217.

Hulse, T. M. (2015). "Use of Accessory Dwelling Units as a Housing Strategy: A Case Study of Lawrence, Kansas”, USA, University of Nebraska-Lincoln. Master of Planning.

Hunt, G. (2016). "Valuing the Role of Construction in the New Zealand Economy", Study Report: PricewaterhouseCoopers, Retrieved 12/05/2018 from https://infrastructure.org.nz/resources/Documents/Reports/CSG\%20PwC\%20Value \%20of\%20Construction\%20Sector final\%20report 201610 16.pdf.

Hutt City Council. (2018). "Maps", Retrieved 18/07/2018 from http://www.huttcity.govt.nz/Services/maps/.

Huxley, J. (1943). "TVA (Tennessee Valley Authority) Adventure in Planning", New York: The Architectural Press.

Inhabitat (2011). "Ghent University Students Develop DIY Zero Energy E-Cube Building Kit for Solar Decathlon", Retrieved 12/09/2018 from https://inhabitat.com/ghent-universitystudents-develop-diy-zero-energy-e-cube-building-kit-for-solar-decathlon/e-cubeghent-university-solar-decathlon-10/.

International Energy Agency (2018). "Key World Energy Statistics 2018" Paris, France: International Energy Agency.

Isaacs, N. (2008). "House Assembly - Prefabrication and Factory Manufacture", Build October/November 2008: 94-95.

Jabar, I. I., Ismail, F., Aziz, A. R. A. (2015). "Public Participation: Enhancing Public Perception Towards IBS Implementation", Procedia - Social and Behavioral Sciences 168: 61-69.

Jackson, K. T. (1985). "Crabgrass Frontier the Suburbanization of the United States", USA: Oxford University Press. 
Jaillon, L. and Poon, C.N. (2008). "Sustainable Construction Aspects of Using Prefabrication in Dense Urban Environment: a Hong Kong Case Study." Construction Management and Economics 26(9): 953-966.

Jaillon, L., Poon, C. S. (2009). "Quantifying the Waste Reduction Potential of Using Prefabrication in Building Construction in Hong Kong." Waste management 29(1): 309320.

Jaques, R. (2013). The Heart of Zero-energy Buildings", Build 139, December 2013/January 2014: 74-75.

Jara, C. (1996). "Prefabrication in the Design of Housing at Forest Hills Gardens in New York, 1909-19", ACSA European Conference, Copenhagen, Denmark, 25-29 May 1996, 282289.

Javanifard, N., Markert, D., Strobel, K., Yap, J. (2013). “Modular Prefabricated Residential Construction Constraints and Opportunities", PNCCRE Technical Report, Washington University of Washington.

Jiang, H., Jia, S., Huang, Y. (2013). "The Study of the Factors Affecting Urban Residential Land Price", Applied Mechanics and Materials (357-360): 2854-2858.

Johnstone, I. M. (2001). "Energy and Mass Flows of Housing: Estimating Mortality", Building and Environment 36(1): 43-51.

Kaatz, E., Root, D., Bowen, P. (2005). "Broadening Project Participation Through a Modified Building Sustainability Assessment", Building Research and Information 33(5): 441454.

Kale, N. N., Joshi, D., Menon, R. (2016). "Life Cycle Cost Analysis of Commercial Buildings with Energy Efficient Approach", Perspectives in Science 8: 452-454.

Karakayaci, Z. (2016). "The Concept of Urban Sprawl and its Causes", The Journal of International Social Research 9(45): 815-818.

Kellaway, T. (1994). "The Austrian State Houses, Titahi Bay", Porirua, New Zealand: Porirua Museum, Porirua City Council.

Kelly, B. (1951). "The Prefabrication of Houses", New York: The Technology Press of the Massachusetts Institute of Technology and John Wiley and Sons.

keywordbasket (2019). "Nissen Hut Plans", Retrieved 05/05/2019 from http://www.keywordbasket.com/.

Khajehzadeh, I. (2017). "An Investigation of the Effects of Large Houses on Occupant Behaviour and Resource-Use in New Zealand", Wellington, New Zealand, Victoria University of Wellington. PhD thesis.

Khasreen, M. M., Banfill, P. F. G., Menzies, G. F. (2009). "Life-Cycle Assessment and the Environmental Impact of Buildings: A Review", Sustainability 1: 674-701. 
Khatavkar, J. and Y. P. Joshi (2015). "Use of Partial Prefabrication and Non-traditional Technology in Construction of Structure in Disaster Prone Areas", International Journal of Civil Engineering and Technology (IJCIET) 6(4): 127-135

Khawaja, M. T., Nicholas. (2000). Population Ageing in New Zealand", Statistics New Zealand, Retrieved 21/09/2018 from http://archive.stats.govt.nz/browse for stats/people and communities/older peo ple/pop-ageing-in-nz.aspx.

Kibert, C. J. (2016). "Sustainable Construction: Green Building Design and Delivery", Hoboken, New Jersey: John Wiley and Sons, Inc.

King, J. L. (2012). "Accessory Dwelling Units: an Infill Opportunity for Denton, Texas. Community and Regional Planning", University of Texas, Master of Planning.

Kingspan (2018). "Insulated Roof \& Wall Panels, KS1000 AWP Data Sheet", New Zealand: Kingspan, $\quad$ Retrieved 16/11/2018 from file://C:/Users/Milad/Downloads/57992 Kingspan Architectural\%20Wall\%20Panels \%20KS1000\%20AWP Datasheet 042019v3 NZ EN LR\%20(2).pdf.

Kinsella, F. (2012). "50 Years of Construction Camps and Single Purpose Towns in the South", Victoria University of Wellington, Master of Architecture.

Kosmatka, S. H. and Wilson, M.H. (2016). "Design and Control of Concrete Mixtures", Illinois, United States of America: Portland Cement Association.

Kosny, J., Desjarlais, A., Christian, J. (1999). "Whole Wall Rating/Label for Structural Insulated Panels Steady-state Thermal Analysis", Oak Ridge National Laboratory, and Buildings Technology Center, Retrieved 12/06/2018 from http://www.lamitindustries.com/literature/WholeWallR-ValueStudy.pdf.

Krass, C. (2013). "Factors Associated with Accessory Dwelling Unit Density", University of Washington. Master of Urban Planning.

Kryzhanovsky, I. (2012). "Pre-assembled Bathrooms and Sanitary Rooms Made of GRP: an international Experience", FRP Consultant, Retrieved 16/11/2018 from http://www.frp-consulting.com/d/349239/d/article pre-assembled-bathroomsmade-of-grp by-ilya-kryzhanovsky may-2012 .pdf.

Kupke, V. (2008). "Factors Important in the Decision to Buy a First Home", Fourteenth Pacific Rim Real Estate Society Conference, Kuala Lumpur, Malaysia, 20-23 January, 2008.

Landman, M. (1999). "Breaking Through the Barriers to Sustainable Building: Insights from Building Professionals on Government Initiatives to Promote Environmentally Sound Practices", Tufts University, PhD thesis.

Lang Lasalle, J. (2017). "New Zealand Retirement Village Database (NZRVD) ", Retrieved 01/02/2018 from http://www.jll.nz/new-zealand/en-gb/research/400/ill-nzretirement-villagewhitepaper-2017. 
Lapointe, M., Beauregard, R., D'Amours, S. (2006). “An Exploration of Design Systems for Mass Customization of Factory-built Timber Frame Homes", Working Paper, Network Organization Technology Research Centre, Université Laval, Québec, Canada.

Lausten, J. (2008). "Energy Efficiency Requirements in Building Codes, Energy Efficiency Policies for New Buildings", Information Paper, France: International Energy Agency.

Leah, A, L. (2015). "Lifestyle and Embodied Energy: A Proposed Hybrid Analysis Method for Housing", Victoria University of Wellington. PhD thesis.

Lee, H. (2018). "Re: Question About Panels", Easy Build, New Zealand, Personal Communication, 30/05/2018.

Legmpelos, N. (2013). “On-site Construction Versus Prefabrication”. Department of Civil and Environmental Engineering, Massachusetts Institute of Technology. Master of Civil Engineering.

Lenzholzer, S., Duchhart, I., Koh, J. (2013). "'Research Through Designing in Landscape Architecture", Landscape and Urban Planning 113: 120-127.

Levering, A. P. (2017). "An Investigation of Community Policies and Attitudes towards Accessory Dwelling Units in Greater Boston". Urban and Environmental Policy and Planning", TUFTS University. Master of Urban Planning.

Li, J. (2014). "Recent Trends on Housing Affordability Research: Where Are We up to?", Working Paper: Urban Research Group, Retrieved 10/10/2018 from https://www.ssrn.com/abstract=2555439.

Lifetime Design Limited. (2016). "Lifemark Design Standards Handbook", Version 2. Auckland, New Zealand: Lifetime Design Limited.

Litman, T. (2017). "Understanding Smart Growth Savings: Evaluating Economic Savings and Benefits of Compact Development, and How They Are Misrepresented by Critics", Working Report, Canada: Victoria Transport Policy Institute.

Lockwood (2017). "Lockwood", Retrieved 10/12/2017 from https://www.lockwood.co.nz/?gclid=Cj0KCQjw1q3VBRCFARIsAPHJXrGq5yNc34p7Rh 9dFn9keen5oGZI8ab2350D4JHtxJSKq1SrDKcsTuwaAt4kEALw wcB.

Love, S. (2010). "Carbon Footprint of New Zealand Laminated Veneer Lumber New Zealand", Study Report, SCION, Retrieved 11/06/2018 from http://www.nelsonpine.co.nz/wpcontent/uploads/Carbon-Footprint-of-NZ-LVL-Dec10-FINAL.pdf.

Lu, N. (2007). "Investigation of the Designers' and General Contractors' Perceptions of Offsite Construction Techniques in the United States Construction Industry", Graduate School of Clemson University, PhD thesis. 
Lu, W. and Yuan, H. (2013). "Investigating Waste Reduction Potential in the Upstream Processes of Offshore Prefabrication Construction." Renewable and Sustainable Energy Reviews 28: 804-811.

Macara, G. R. (2018). "The Climate and Weather of New Zealand", New Zealand, National Institute of Water and Atmospheric Research (NIWA), Retrieved 12/01/2019 from https://www.niwa.co.nz/static/web/NZ Climate-NIWA.pdf.

Majzub (1977). "Modular Housing Systems Used Around the World", International Journal of Housing Science 1, 73-84.

Mallory, K. and Ottar, A. (1973). "The Architecture of War", New York, United States of America: Pantheon.

Manning, J. (1947). "Building the Navy's Bases in World War II", Washington, United States Government Printing Office 1, Retrieved 12/04/2018 from https://www.history.navy.mil/research/library/online-reading-room/title-listalphabetically/b/building-the-navys-bases/building-the-navys-bases-vol-1.html

Markelj, J., KitekKuzman, M., Grošelj, P., Zbašnik-Senegačnik, M. (2014). "A Simplified Method for Evaluating Building Sustainability in the Early Design Phase for Architects", Sustainability 6(6): 8775-8795.

Marriage, G. (2018). "First Light House", Wellington, New Zealand, Personal Communication $12 / 06 / 2018$.

Marshall, D., Worthing, D., Dann, N. (2014). "Understanding Housing Defects", London, United Kingdom: Taylor \& Francis Ltd.

Marszal, A. J., Heiselberg, P., Bourrelle, J. S., Musall, E., Voss, K., Sartori, I., Napolitano, A. (2011). "Zero Energy Building - A Review of Definitions and Calculation Methodologies", Energy and Buildings 43(4): 971-979.

Martínez-Alonso, C. and L. Berdasco (2015). "Carbon Footprint of Sawn Timber Products of Castaneasativa Mill in the North of Spain", Journal of Cleaner Production 102: 127-135.

McIntyre, I. S. and Stevens, A.J. (2010). "Timber Frame Housing Systems Built in the UK 19201965”, Garston: Building Research Establishment.

McKean, C. (1995). "A Scottish Modernism, 1933-1939", History Workshop Journal (40): 165172.

McNab, D. J., Lynch, M., Young, P. (2011). "Auditing of Water Use on Construction Sites Phase I", Working Report, UK: Mabbett \& Associates.

Meis, A. (2015). "The True Cost of SIPs: A Comprehensive Tool for Comparing the Price of Residential Structural Insulated Panel and Stick Frame Construction", University of Colorado Boulder, Bachelors of Environmental Design. 
Mendoza, C. D. (2018). "Prefabrication: a Solution for a NZ Housing Shortage? Literature Review". Wellington, New Zealand, Victoria University of Wellington, Retrieved $12 / 11 / 2018$

from http://www.prefabnz.com/Downloads/Assets/Download/9728/1/PrefabNZ\%20CnC \%20Lit\%20Review\%20FINAL\%20180302.pdf.

Mertz, G. A., Raffio, G. S., Kissock, K. (2007). "Cost Optimization of Net-Zero Energy House” ASME 2007 Energy Sustainability Conference, Long Beach, California, 27-30 July, 2007: 477-487.

Miller, C. (2017). "MBIE Figures Show Nationwide Housing Shortage of 71,000", NZ Herald, Retrieved $12 / 10 / 2018$ from https://www.nzherald.co.nz/business/news/article.cfm?c id=3\&objectid=11940328 g.

Ministry for the Environment (2016). “Guidance for Voluntary Greenhouse Gas Reporting 2016: Using Data and Methods from the 2014 Calendar Year", Working Report Wellington: Ministry for the Environment.

Ministry for the Environment and Statistics New Zealand (2015). "Environment Aotearoa 2015. New Zealand's Environmental Reporting", New Zealand: Ministry for the Environment \& Statistics New Zealand.

Ministry of Business Innovation and Employment (2013). "Productivity Improvement from Value Stream Mapping the NZ Small Builder - New House Segment", New Zealand: Productivity Partnership.

Ministry of Business Innovation and Employment (2017a). "Briefing for the Incoming Minister of Housing \& Urban Development", Wellington, New Zealand: Ministry of Business, Innovation and Employment.

Ministry of Business Innovation and Employment (2017b). "Housing, Delivery your Housing Program", Wellington, New Zealand: Ministry of Business, Innovation and Employment.

Ministry of Business Innovation and Employment (2017c). "House Insulation Requirements", Retrieved 16/9/2018 from https://www.building.govt.nz/about-buildingperformance/contact-us/.

Ministry of Business, Innovation and Employment (2018). "Using NZS 3604 Timber-framed buildings", Retrieved 06/12/2018 from https://www.building.govt.nz/building-codecompliance/how-the-building-code-works/using-nzs-3604-timber-framed-buildings/

Ministry of Works (1944). "Post-war Building Studies, Housing Construction", London, UK, H.M. Stationery Office.

Mithraratne, N., Vale, B., Vale, R. (2007). "Sustainable Living: the Role of Whole life Costs and Value", Oxford: Butterworth-Heinemann. 
Molavi, J. and D. L. Barral (2016). "A Construction Procurement Method to Achieve Sustainability in Modular Construction", Procedia Engineering 145: 1362-1369.

Moncaster, A., M. Symons, K. E. (2013). "A Method and Tool for 'Cradle to Grave' Embodied Carbon and Energy Impacts of UK Buildings in Compliance with the new TC350 Standards", Energy and Buildings 66: 514-523.

Moradibistouni, M, and Gjerde, M. (2017), "Potential for Prefabrication to Enhance the New Zealand Construction Industry", 51st International Conference of the Architectural Science Association (ANZASCA), Back to the future: The next 50 years, Victoria University of Wellington, New Zealand, 29 Nov - 2 Dec 2017, 427-435.

Moradibistouni, M, Vale, B and Isaacs, N (2018). Evaluating Sustainability of Prefabrication Methods in Comparison with Traditional Methods. Kaparaju, P. et al (Eds.), Sustainability in Energy and Buildings 2018 (Proceedings of the 10th International Conference in Sustainability on Energy and Buildings (SEB'18), Switzerland: Springer, 228-237.

Mostafa, S., Dumrak, J., Chileshe, N., Zuo, J. (2014). “Offsite Manufacturing in Developing Countries: Current Situation and Opportunities", 5th International Conference on Engineering, Project, and Production Management, Port Elizabeth, South Africa, 26-28 November 2014, 64-73.

Mrkonjic, K. (2007). "Environmental Aspects of Use of Aluminium for Prefabricated Lightweight Houses: Dymaxion House Case Study." Journal of Green Building 2(4): 130136.

Nana, G. (2003). "Assessment of the Economic Impact of Efficiency Improvements in Building and Construction", Wellington, New Zealand, BRANZ, Retrieved 19/06/2018 from http://www.branz.co.nz/cms show download.php?id=9355bd8b85c79bb5337bcfbe 26c9952ae9f5e95b.

Nash, P., Hird, D., Tonkin, P. S. (1954). "The Spread of Fire in USA Type Temporary Bungalows", Hertfordshire, London: Department of Scientific and Industrial Research and Fire Offices.

Navaratnam, S., Ngo, T., Gunawardena, T., Henderson, D. (2019). "Performance Review of Prefabricated Building Systems and Future Research in Australia", Buildings 9(38):.

Neelamkavil, J. (2009). "Automation in the Prefab and Modular Construction Industry", 26th International Symposium on Automation and Robotics in Construction (ISARC 2009) Texas, Unted States of America, 24-27 June: 299-306.

Nepomechie, M. (2011). "Project Manual", USA, University of South Florida, Retrieved 06/03/2018 from https://www.solardecathlon.gov/past/2011/pdfs/fiu manual.pdf. 
New Zealand Green Building Council (2009). "Green Star New Zealand - Office Interiors", Wellington, New Zealand: Green Building Council and BRANZ Retrieved 16/02/2018 from https://www.nzgbc.org.nz/Category?Action=View\&Category id=163.

New Zealand Green Building Council (2014)." Homestar Certified Manual”, Wellington, New Zealand: New Zealand Green Building Council and BRANZ, Retrieved 06/04/2018 from https://www.nzgbc.org.nz/Attachment?Action=Download\&Attachment id=1375

New Zealand Productivity Commission (2015). "Using Land for Housing", Wellington, New Zealand, New Zealand Productivity Commission, Retrieved 25/01/2018 from https://www.productivity.govt.nz/inquiry-content/2060?stage $=4$.

New Zealand Transport Agency (2017a). "Overdimension Vehicles and Loads: Factsheet 53a", New Zealand, NZ Transport agency, Retrieved 12/05/2018 from https://www.nzta.govt.nz/assets/resources/factsheets/53/docs/53overdimension.pdf.

New Zealand Transport Agency (2017b). "Heavy Rigid Vehicles: Factsheet 13a. New Zealand”, NZ Transport Agency, Retrieved 12/06/2018 from https://www.nzta.govt.nz/assets/resources/factsheets/13a/docs/13a-heavyrigid.pdf.

New Zealand Transport Agency (2017c). "Vehicle Dimensions and Mass Guide to Factsheet 13 series", New Zealand, New Zealand Transport Agency, Retrieved 10/09/2018 from https://www.nzta.govt.nz/resources/factsheets/13/.

New Zealand Transport Agency (2018). "Heavy Rigid Motor Vehicle Definitions and Specifications", New Zealand, NZ Transport Agency, Retrieved 13/05/2019 from https://www.nzta.govt.nz/resources/roadcode/heavy-vehicle-road-ode/informationfor-heavy-vehicle-drivers/heavy-rigid-vehicle-definitions-and-specifications/.

Ngoenchuklin, C. (2014). "Feasibility of Implementing Prefabricated U.S. Products and Methods for Residential Construction in Thailand“", Architecture, Georgia Institute of Technology, Master of Architecture.

Noor, N. M., Asmawi, M. Z., Rusni, N. A. (2013). "Measuring Urban Sprawl on Geospatial Indices Characterized by Leap Frog Development Using Remote Sensing and GIS Techniques", 8th International Symposium of the Digital Earth (ISDE8), Sarawak, Malaysia, 26-29 August 2013, 1021-1027.

NZSIP (2017). "Smart Structural Insulated Panels (NZSIP)", Retrieved 02/05/2018, from http://www.nzsip.co.nz/.

NZSIPs (2019). "SIPs Panels Lifespan" NZSIPs, New Zealand, Personal Communication, 05/06/2018.

O'Neill, D, Samantha, O. (2016). "A Literature Review of the Evolution of British prefabricated Low-Rise housing", Structural Survey 34(2): 191-214. 
Openscope studio (2015). "Sf-ADU, a Guide for Homeowners, Designers, and Contractors Considering Adding an Accessory Dwelling Unit to an Existing Residence in San Francisco", San Francisco: San Francisco planning department, Retrieved 20/06/2018 from https://archive.org/details/sfaduguideforhom2015sanf.

Osman, S., Nawawi, A., Jamalunlaili, A. (2008). "Urban Sprawl and Its Financial Cost: - A Conceptual Framework", Asian Social Science 4(10): 39-50.

Owen, E. V. (2007). "Intermarriage: its Role and Importance within Early New Zealand Shore Whaling Stations", Massey University. Master of Arts.

Owen, L. (2016). "Landlords Renting out 'Unsafe' Conversions", Retrieved 08/05/2019, from https://www.newshub.co.nz/home/new-zealand/2016/07/landlords-renting-outunsafe-conversions.html.

Panjehpour, M., Ali, A., Lei Voo, Y. (2013). "Structural Insulated Panels: Past, Present, and Future", Journal of Engineering, Project, and Production Management 3(1): 2-8.

Patel, R. and Sharma, M. (2016). "Study of prefabrication in India", International Journal of Advanced Research in Engineering, Science \& Management 2(4): 6.

Pearson, C. and Delatte, N. (2005). "Ronan Point Apartment Tower Collapse and its Effect on Building Codes", Journal of Performance Constructed Facilities 19(2): 172-177.

Pečur, I., Milovanović, B., Carević, I., Alagušić, M. (2014). “Precast Sandwich panel- Innovative Way of Construction", 10th Czech Concrete Congress. Liberec, Czech Republic, 1-2 October 2014, 12pp.

Pennoyer, P., Walker, A., Stern, R. A. M. (2009). "The Architecture of Grosvenor Atterbury", New York, United States of America: W. W. Norton \& Company.

Perez, C. (2011). "Perform [D]ance House: Construction drawings", USA, Florida International University, $\quad$ Retrieved 23/06/2018 from https://www.solardecathlon.gov/past/2011/pdfs/fiu cd.pdf.

Peterson, C. E. (1965). "Prefabs in the California Gold Rush, 1849", Journal of the Society of Architectural Historians 24(4): 318-324.

Petrović, E. K., Vale, B., Pedersen Zari, M. (2017). "Materials for a Healthy, Ecological and Sustainable Built Environment: Principles for Evaluation", UK: Woodhead Publishing.

Petterson, J. (2016). "Review of the Land Transport Rule: Vehicle Dimensions \& Mass 2002", Regulatory Impact Statement New Zealand, New Zealand Government.

Phillipson, M. (2001). "New and Improved Technologies and Techniques Defining the Sustainability of Prefabrication and Modular Process in Construction", Interim Report, Scotland: BRE Scotland. 
Piroozfar, P. and Farr, E. R. P. (2013). "Evolution of Nontraditional Methods of Construction: 21st Century Pragmatic Viewpoint." Journal of Architectural Engineering 19(2): 119133

Pollock Cranes (2015). "GMK6400 Hydraulic all Terrain Mobile 400-tonne", Retrieved 12/09/2018 from https://pollockcranes.co.nz/crane-hireage/.

Prasher, E. M., Shaluza (2016). "Prefabrication in Ancient Period", IOSR Journal of Mechanical and Civil Engineering 1(special): 34-39.

Prefab NZ (2015a). "Levers for PREFAB: How Offsite Construction Can Deliver Better Costeffective Housing to more New Zealanders", Wellington, New Zealand, Prefab NZ Incorporated, $\quad$ Retrieved 12/06/2018 from http://www.prefabnz.com/Downloads/Assets/7645/1/.

Prefab NZ (2015b). "Prefab NZ 5-Year Impact", Wellington, New Zealand, Prefab NZ Incorporated, $\quad$ Retrieved 21/09/2018 from http://www.prefabnz.com/Downloads/Assets/7635/1/.

Prefab NZ. (2016). "Prefab Roadmap a Way Forward for Prefabrication in New Zealand", Wellington, New Zealand, Prefab NZ Incorporated, Retrieved 02/10/2018 from http://www.prefabnz.com/Images/Assets/2740/1/Prefab.

Prefab NZ (2018a). "Capacity and Capability Report", Wellington, New Zealand, Prefab NZ Incorporated, $\quad$ Retrieved 12/11/2018 from http://www.prefabnz.com/Downloads/Assets/9759/1/.

Prefab NZ (2018b). "The Directory", Retrieved 02/03/2018 from http://www.prefabnz.com/Directory?member=all\&buildingType=\&typology=\&role= \&region $=$ \&newZealand $=1 \&$ all $=$.

Prefabs2009 (2009). "A Journey Around the United States", Retrieved 05/05/2019 from http://www.prefabs2009.org/casestudy/earlyprefabs/earlyprefabs.html.

PUDA (2017). "The Best Construction Solution", Retrieved 03/06/2018 from http://www.puda.com.tw/benefits-1.html.

Purvis, B., Mao, Y., Robinson, D. (2019). "Three Pillars of Sustainability: in Search of Conceptual Origins." Sustainability Science 14(3): 681-695.

Queensland Building Services Authority (2009). "Building or Renovating? Protect Your HardEarned Cash", Queensland, Australia: Queensland Building Services Authority.

de Queiroz Barbosa, E., DeMeulder, B., Gerrits, Y. (2014). "Design Studio as a Process of Inquiry: The case of Studio Sao Paulo", Architecture \& Education Journal 11: 241-254.

Rahman, A. B. A. and W. Omar (2006). "Issues and Challenges in the Implementation of IBS in Malaysia", 6th Asia-Pacific Structural Engineering and Construction Conference (ASPEC 2006), Kuala Lumpur, Malaysia, 5-6 September 2006, 45-53. 
Ramesh, T., Prakash, R., Shukla, K. K. (2010). "Life Cycle Energy Analysis of Buildings: An Overview." Energy and Buildings 42(10): 1592-1600.

Ramsey-Musolf, D. (2018). "Accessory Dwelling Units as Low-Income Housing: California's Faustian Bargain", Urban Science 2(3).

Ratnasingam, J., Ramasamy, G., Toong, W., loras, F., Canja, C. M., Lupu, M. I., Abrudan, I. V. (2015). "Carbon Stocking in the Natural Forests - The Case of Malaysia", Notulae Botanicae Horti Agrobotanici Cluj-Napoca 43(1): 278-286.

Rawlinsons Media Limited, Ed. (2011). "Rawlinson New Zealand Construction Handbook", Auckland, New Zealand: Rawlinsons Publishing.

Reserve Bank of New Zealand (2019). "Inflation Calculator", Retrieved 27/02/2019 from https://www.rbnz.govt.nz/monetary-policy/inflation-calculator.

Reston, V. (2008). "Accessory Dwelling Units: Case Study. United States of America", U.S. Department of Housing and Urban Development Office of Policy Development and Research, Retrieved 27/11/2018 from https://www.huduser.gov/portal/publications/adu.pdf.

Road transport forum New Zealand (2018). "New Zealand's Truck Fleet", Retrieved 02/06/2018 from https://www.rtfnz.co.nz/new-zealand-road-transport/newzealands-truck-fleet/.

Roggema, R. (2016). "Research by Design: Proposition for a Methodological Approach", Urban Science 1(1).

Rose, J. (2010). "Living Light: Construction Drawing", USA, The University of Tennessee, Retrieved 02/06/2018 from https://www.solardecathlon.gov/past/2011/pdfs/tenn cd.pdf.

Roskruge, A. (2011). "A Design System for Homes and Housing: a Rationalised Approach to Housing Supply for Auckland", Unitec Institute of Technology, Master of Architecture.

Ross, J. (2016). "Accessory Dwelling Units: A Smart Growth Tool for Providing Affordable Housing", Housing News Network 32: 17-19.

Royal Wolf (2019). "20ft Shipping Containers", Retrieved 06/06/2019, 2019, from https://www.royalwolf.co.nz/product/20ft-shipping-containers/.

Rowley, J. (2014). "Walter's Super-insulated House", Retrieved 16/05/2018 from http://www.hammondfh.ca/inspiration-3-walters-super-insulated-house/.

Lockie, S., and Berebecki, P. (2014). "Methodology to Calculate Embodied Carbon", Professional Guideline, UK: Royal Institution of Chartered Surveyors (RICS).

Russell, s. (2011). "Design Development Documents", Retrieved 12/06/2018 from https://www.solardecathlon.gov/past/2011/pdfs/fla cd.pdf. 
Salmond, J. (1986). “Old New Zealand Houses 1800-1940", Auckland New Zealand: Reed Methuen.

Sandu, M. C. (2014). "Important Elements in Consumer's Decision-making Process", Calitatea Vietii, 25(4) 365-373.

Sanna, F. (2018). "Timber Modern Methods of Monstruction: a Comparative Study", Scotland, Edinburgh Napier University. PhD thesis.

Saville-Smith, K., Saville-Smith, N., Fraser, R. (2017). “ADU Potential: Have we the Potential to Use our Existing Housing Stock of Homes to Create a Bigger Stock of Affordable, Fit for Purpose Homes?" New Zealand: Centre for Research, Evaluation and Social Assessment (CRESA).

Schnyder, M. (2016). "National History Museum Showcases Little-known Wichita Artifact", Retrieved 09/04/2018 from http://www.kansas.com/living/travel/article121807393.html.

Schoenwitz, M. (2014). "Aligning Product and Processes to Customer Needs in Prefabricated House Building", Cardiff University, PhD thesis.

Schofield, J. (1991). "The Construction of Medieval and Tudor Houses in London", Construction History 7: 3-28.

Schrader, B. (2005). "We Call it Home: a History of State Housing in New Zealand", Auckland New Zealand: Reed.

Schwartz, D. (2015). "The Importance of Affordable Housing to Economic Competitiveness", Economic Development Journal 15(1): 40-46.

Serrats, M. (2014). "Prefab Houses Design Source", New York, United States of America: Harper Design.

Shahzad, W., Mbachu, J., Domingo, N. (2014). "Prefab Content Versus Cost and Time savings in Construction Projects: A Regression Analysis", 4th New Zealand Built Environment Research Symposium (NZBERS). Auckland, New Zealand, 14 November 2014.

Sharlot (2011, 05/05/2018). "Gentse E-cube Dingt Mee Naar Hoofdprijs in Internationale Wedstrijd", $\quad$ Retrieved 02/10/2018 from http://www.standaard.be/cnt/dmf20110928 080.

Siegel, B. A. (2011). "Solyndra Technology Powers" Washington, United States of America, Huffington Post, Retrieved 13/09/2018 from https://www.huffpost.com/entry/solyndra-technology-power b 976715.

Simafranca, C. (2017). “Decision Support System for Development of Current and Future Accessory Dwelling Units: A Bottom-up Approach to Affordable Housing", University of Hawaii at Manoa. PhD thesis. 
Simpson, R. W., Petroeschevsky, A., Lowe, I. (2000). "An Ecological Footprint Analysis for Australia", Australasian Journal of Environmental Management 7(1): 11-18.

Smarter Homes (2018). "Smart Guide: Construction Systems", Retrieved 16/05/2018 from https://www.smarterhomes.org.nz/smart-guides/construction-andmaterials/construction-systems/.

Smarter Homes (2019). "Smart Guide: Hot Water Cylinders and Pipes ", Retrieved 19/04/2019 from https://www.smarterhomes.org.nz/about/contact-us/.

Smith, P. F. (2005). "Architecture in a Climate of Change: A Guide to Sustainable Design", Oxford: Architectural Press/ Elsevier.

Smith, R. (2010). "Prefab Architecture: A Guide to Modular Design and Construction", New Jersey: John Wiley \& Sons.

Smith, R, (2016) "Off-Site and Modular Construction Explained", Retrieved 23/01/2019, from https://www.wbdg.org/resources/site-and-modular-construction-explained.

Smith, R. E. (2009). "History of Prefabrication: A Cultural Survey", Third International Congress on Construction History, Cottbus, Germany, 20-24 May 2009, 267-274.

Standards New Zealand (2001). "Design for Access and Mobility: Buildings and Associated Facilities: Superseding NZS 4121:1985 and NZMP 4121:1989", Wellington, New Zealand, Standards New Zealand, Retrieved 13/06/2018 from https://shop.standards.govt.nz/catalog/4121:2001(NZS)/scope.

Standards New Zealand. (2009). "NZS 4218:2009 Thermal insulation - Housing and Small Buildings. Compliance Methods", New Zealand, Ministry of Business Innovation and Employment, $\quad$ Retrieved 12/01/2018 from https://shop.standards.govt.nz/catalog/4218:2009(NZS)/scope.

Statistics New Zealand (2004). "New Zealand: An Urban/Rural Profile", Wellington, New Zealand, Statistics New Zealand, Retrieved 24/03/2018 from http://archive.stats.govt.nz/browse for stats/Maps and geography/Geographicareas/urban-rural-profile-update.aspx.

Statistics New Zealand (2010). “New Zealand's International Migration Statistics: 1922-2009. International Travel and Migration Articles", Wellington, New Zealand, Statistics New Zealand, Retrieved 16/02/2018 from http://archive.stats.govt.nz/browse for stats/population/Migration/internationaltravel-and-migration-articles/nz-international-migration-stats-1922-2009.aspx.

Statistics New Zealand (2013a). "2013 Census Usually Resident Population Counts", Wellington, New Zealand, Statistics New Zealand, Retrieved 10/03/2018 from http://archive.stats.govt.nz/browse for stats/population/census counts/2013Cens usUsuallyResidentPopulationCounts HOTP2013Census.aspx. 
Statistics New Zealand (2013b). "How Will New Zealand's AgeingP Affect the Property Market?", Wellington, New Zealand, Statistics New Zealand Retrieved 09/04/2018 from

http://archive.stats.govt.nz/browse for stats/population/estimates and projection s/ageing-population-property-market.aspx.

Statistics New Zealand (2015a). "Subnational Family and Household Projections: 2013 (base)2038", Wellington, New Zealand, Statistics New Zealand, Retrieved 01/06/2018 from https://www.stats.govt.nz/information-releases/subnational-family-and-householdprojections-2013base2038.

Statistics New Zealand (2015b). "Historical Context", Wellington, New Zealand, Statistics New Zealand, Retrieved 02/07/2017 from http://archive.stats.govt.nz/browse for stats/Maps and geography/Geographicareas/urban-rural-profile/historical-context.aspx.

Statistics New Zealand (2016). "National Population Projections: 2016 (base)-2068", Wellington, New Zealand, Statistics New Zealand, Retrieved 01/06/2017 from http://archive.stats.govt.nz/browse for stats/population/estimates and projection s/NationalPopulationProjections HOTP2016.aspx.

Statistics New Zealand (2017a). "Population Growth Fastest in Northland, Auckland, and Waikato", Wellington, New Zealand, Statistics New Zealand, Retrieved 26/11/2018 from https://www.stats.govt.nz/news/population-growth-fastest-in-northlandauckland-and-waikato.

Statistics New Zealand (2017b). "Three in Four New Zealanders Live in the North Island", Wellington, New Zealand, Statistics New Zealand, Retrieved 10/12/2017 from https://www.stats.govt.nz/news/three-in-four-new-zealanders-live-in-the-northisland.

Statistics New Zealand (2017c). "Trending Topics - Housing", Wellington, New Zealand, Statistics New Zealand, Retrieved 12/03/2018 from https://www.stats.govt.nz/reports/trending-topics-housing.

Statistic New Zealand (2017d). "New Zealand Business Demography Statistics”, Wellington, New Zealand, Statistics New Zealand, Retrieved 16/05/2018 from https://www.stats.govt.nz/information-releases/new-zealand-businessdemography-statistics-at-february-2017.

Statistics New Zealand (2018). "Annual Net Migration Down 7,400 from Peak in 2017", Retrieved 26/04/2019 from https://www.stats.govt.nz/news/annual-net-migrationdown-7400-from-peak-in-2017.

Statistics New Zealand (2019). "Population - Concepts", Wellington, New Zealand, Statistics New Zealand, Retrieved 24/04/2019 from http://datainfoplus.stats.govt.nz/Item/nz.govt.stats/583ca9da-d6d2-41e0-b6265743c14deaf5\#/nz.govt.stats/6d72597f-1600-4dda-974e-4468071c8aff\#. 
Stege, E. H. (2009). "What Next for Accessory Dwellings? Getting from Bylaws to Buildings", Massachusetts Institute of Technology, Master of Urban Planning.

Stein, A. (2016). "Disruptive Development: Modular Manufacturing in Multifamily Housing", University of California. Master of City Planning.

Steinhardt, D. A., Manley, K., Miller, W. (2013a). "Reshaping Housing - the Role of Prefabricated Systems", Working Project, School of Civil Engineering and Built Environment, Science and Engineering Faculty Queensland University of Technology.

Steinhardt, D. A., Manley, K., Miller, W. (2013b). "Profiling the Nature and Context of the Australian Prefabricated Housing Industry", Working Project, Queensland University of Technology, School of Civil Engineering and Built Environment.

Stevens, P. N. (2011). "Empower House", Retrieved 13/06/2018 from https://www.solardecathlon.gov/past/2011/pdfs/pars cd.pdf.

Sto Panel Technology, S. C. (2016). "Which System is Right for you", Retrieved 02/06/2018 from https://www.stopanel.com/panel-systems/\#1475691648-1-23.

Stockdale, M. (2016). "Review of the Vehicle Dimensions \& Mass Rule", New Zealand, The New Zealand Automobile Association, Retrieved 21/06/2018 from https://www.aa.co.nz/assets/about/events/government-submissions/2016/Reviewof-Vehicle-Dimensions-Mass-17-02-2016.pdf.

Stone, P. A. (1980). “Building Design Evaluation: Costs-in-use”, New York: E. \& F.N. Spon Ltd.

Strange, T. and Bayley, A. (2008). "Sustainable Development: Linking Economy, Society, Environment", Paris, France: OCDE.

Tam, V. W. Y. and Hao, J. J. L. (2014). "Prefabrication as a Mean of Minimizing Construction Waste on Site", International Journal of Construction Management 14(2): 113-121.

Tam, V. W. Y., Tam, C. M., Chan, J. K. W., Ng, W. C. Y. (2006). "Cutting Construction Wastes by Prefabrication", International Journal of Construction Management 6(1): 15-25.

Taware, A. K. and Taware, A.A. (2017). "Prefabrication, Sustainable Technique in Building Construction", International Journal of Science \& Engineering 1(2): 44-50.

Taylor, R., Smith, I (1997). “The State of New Zealand's Environment 1997", Wellington, New Zealand: The Ministry for the Environment.

Team New York (2011). "Team New York Solar Roof Pod", Retrieved 15/06/2018 from https://www.solardecathlon.gov/past/2011/pdfs/ny cd.pdf.

TechLaw (2011). "Abandoned Mobile Homes Toolkit, Best Management Practices Resource Guide", United States of America, U.S. Environmental Protection Agency, Retrieved 12/08/2018 from https://www.epa.gov/sites/production/files/201706/documents/best practices.pdf. 
The Authority on Sustainable Building (2013). "Construction Systems", Retrieved 12/04/2018 from http://www.level.org.nz/material-use/construction-systems/.

The house designers (2018). "Plan Style", Retrieved 22/07/2018 from https://www.thehousedesigners.com/house-plans/architectural-styles/.

The Treasury (ND). "Discount Rates", Retrieved 02/03/2019 from https://treasury.govt.nz/information-and-services/state-sector-

leadership/guidance/financial-reporting-policies-and-guidance/discount-rates.

The University of Waikato (2015). "Working Safely: Guideline for Lifting Safety", Retrieved 02/06/2018

from

https://www.waikato.ac.nz/pod/induction/manualhandling/unit4c.html

Tidewater, V. (2011). "Tidewater Virginia", Retrieved 02/06/2018 from https://www.solardecathlon.gov/past/2011/pdfs/va cd.pdf.

Tilt Wall (2017). "The Insulation Process of Concrete Wall Panels Explained", Retrieved 18/05/2018 from https://tiltwall.ca/blog/the-insulation-process-of-concrete-wallpanels-explained/.

Tongji University (2011). "Construction and Transportation: Y Container", Retrieved 03/06/2018 from https://www.solardecathlon.gov/past/2011/pdfs/china cd.pdf.

Toomath, W. (1996). "Built in New Zealand: the Houses we Live in", Auckland, New Zealand: Harper Collins.

Torcellini, P. A. (2006). "Zero energy Buildings: a Critical Look at the Definition" USA, National Renewable Energy Laboratory, Retrieved 03/05/2018 from https://www.nrel.gov/docs/fy06osti/39833.pdf.

Turner, C. and R. Partington (2015). "Homes Through the Decades", UK, NHBC Foundation, retrieved 12/08/2018 from http://www.nhbc.co.uk/cms/publish/consumer/NewsandComment/HomesThrough TheDecades.pdf.

Tyre, P. t. (2008). "Accessory Dwelling Units as Affordable Housing and Smart Growth: Case Studies of Winter Park and Orlando, Florida" United States of America, University of Florida. Master of Arts.

U.S. Department of Energy (2018). "SUNREL Energy Simulation Software", Retrieved 24/09/2018 from https://www.nrel.gov/buildings/sunrel.html.

U.S. Department of Energy Solar Decathlon (2011). "Team New York's Solar Decathlon 2011 Video Walkthrough", Retrieved 03/05/2018 from https://www.youtube.com/watch?time continue=58\&v=B3GtEqlpcJU.

U.S. Department of Energy Solar Decathlon (2018). "Solar Decathlon 2011", Retrieved 02/05/2018, from https://www.solardecathlon.gov. 
United Nations (1991). "General Comment No. 4: The Right to Adequate Housing United States of America", United States of America: UN Committee on Economic, Social and Cultural Rights (CESCR).

United Nations (2016). "Policy Paper 10: Housing Policies", Retrieved 16/02/2018, from http://habitat3.org/wpcontent/uploads/Habitat\%20II\%20Policy\%20Paper\%2010.pdf

United Nations (2018). "World Urbanization Prospects: The 2018 Revision", United States of America: Department of Economic and Social Affairs.

United Nations Human Settlements Programme (2016). "World Cities Report 2016: Urbanization and Development: Emerging Future", United Nations Human Settlements Programme. Nairobi, Kenya: United Nations Human Settlements Programme (UN-Habitat)

Vale, B. (1995). "Prefabs: The History of the UK Temporary Housing Programme" London: Routledge.

Vale, B., and Vale, R. (2013). "Architecture on the Carpet: the Curious Tale of Construction toys and the Genesis of Modern Buildings", New York: Thames \& Hudson.

Vale, B. and Pooley, B. (2002). "The English at Point England", Construction History, 18: 99110.

Vale, B. and Vale, R. (2000). "The New Autonomous House: Design and Planning for Sustainability", London: Thames \& Hudson.

Vale, V. and Skinner, R. (2018). "Beatson: From Student Work to Auckland Houses. Historiographies of Technology and Architecture". The 35th Annual Conference of the Society of Architectural Historians, Australia and New Zealand Wellington, New Zealand, 4-7 July 2018, 519-534.

Villaitramani, K. R. and Hirani, D. P. (2014). "Prefabricated Construction for Mass Housing in Mumbai", International Journal of Innovative Research in Advanced Engineering 1(9): 134-138.

Vogtlander, J., van der Velden, N. M., \& Lugt, P. (2014). "Carbon Sequestration in LCA, a Proposal for a New Approach Based on the Global Carbon Cycle; Cases on Wood and on Bamboo", The International Journal of Life Cycle Assessment 19(1): 13-23.

Waidyasekara, K. G. A. S. (2016). "Sustainable Use of Water in Construction Projects: the Case of Sri Lanka", Sri Lanka, University of Moratuwa. PhD thesis.

Warszawski, A. (1999). "Industrialized and Automated Building System", London, UK, Technion-Israel Institute of Technology.

Waskett, P. (2001). "Current Practice and Potential Uses of Prefabrication", Watford, UK: Building Research Establishment and Department of Trade and Industry. 
WaterShed (2011a). "Inspired Innovation, WaterShed at the University of Maryland", Maryland: University of Maryland.

WaterShed (2011b). AS-Built Drawing Set", Retrieved 21/06/2018 from https://www.solardecathlon.gov/past/2011/pdfs/umd cd.pdf.

WaterShed (2011c). "Construction", Retrieved 02/05/2018 from http://2011.solarteam.org/design/process/construction.

Waylen, C., Thornback, J., and Garrett, J. (2011). “An Action Plan for Reducing Water Usage on Construction Sites", Working Report, UK: Strategic Forum for Construction

Wellington City Council (2019). "Housing Choice \& Town Centre Planning", Retrieved 21/04/2019 from https://wellington.govt.nz/your-council/projects/housing-choiceand-supply.

Wetzstein, S. (2017). "The Global Urban Housing Affordability Crisis." Urban Studies 54(14): 3159-3177.

White, V. and M. Jones (2017). Warm, Dry, Healthy? Insights from 2015 House Condition Survey on Insulation, Ventilation, Heating and Mould in New Zealand Houses", SR372, New Zealand, BRANZ, Retrieved 12/11/2018 from https://www.branz.co.nz/cms show download.php?id=50335e67bb00f3e0464097b e1d4d71ac8a85f6bf.

Whitehouse, D. (2013). "The Global Warming Standstill”, Working Report, London: The Global Warming Policy Foundation.

Wilden, R. W. (2002). "Manufactured Housing and Its Impact on Seniors", Oklahoma, United States of America: Wilden and Associates, LLC, Retrieved 12/09/2018 from file://C:/Users/Milad/Downloads/Documents/g5.pdf.

Wiles, J. L., Leibing, A., Guberman, N., Reeve, J., Allen, R. E. (2011). "The Meaning of "Aging in Place" to Older People." Gerontologist 52(3): 357-366.

Williamson, P. (2014). "Sustainability in Action", Cambridge, UK: University of Cambridge.

World Bank (2018). "Urban Population (New Zealand)", Retrieved 20/04/2019 from https://data.worldbank.org/indicator/SP.URB.TOTL.IN.ZS?end=2017\&locations=NZ\& start=1960.

World Bank Group (2016). "EDGE Materials Embodied Energy, Methodology \& Results", Washington, United States of America, World Bank Group, Retrieved 27/06/2018 from https://www.edgebuildings.com/wp-content/uploads/2016/11/20161102-EDGEMaterials-methodology-report-v2.2.pdf

Wright, G. (1983). "Building the Dream”, Cambridge, Massachusetts: MIT Press. 
Xu, X. and Zhao, Y. (2010). "Some Economic Facts of the Prefabricated Housing", Department of Supply Chain Management and Marketing Sciences Retrieved 12/07/2018 from https://www.researchgate.net/publication/267262813 Some Economic Facts of $t$ he Prefabricated Housing/download.

Yavari, F. (2019). "House Conversions and Sharing for an Ageing Population in New Zealand", School of Architecture, Wellington, New Zealand, Victoria University of Wellington. PhD thesis.

Yavari, F., Khajehzadeh, I., Vale, B. (2018). "Design Options for an Ageing New Zealand Population: A life cycle energy (LCE) analysis." Energy and Buildings, 166: 1-22.

Yeo, K. T. (1991). "Project Cost Sensitivity and Variability Analysis", International Journal of Project Management 9(2): 111-116.

Young, P. (2017). "Toward a 2050 Pathway for New Zealand" Wellington, New Zealand: GLOBE-NZ, $\quad$ Retrieved 16/05/2018 from https://www.parliament.nz/media/4449/towards-a-2050-pathway-for-new-zealandyoung.pdf.

Yu, C. W. F. and Kim, J. T. (2011). "Building Environmental Assessment Schemes for Rating of IAQ in Sustainable Buildings", Indoor and Built Environment 20(1): 5-15.

Zeng, S. X., Tam, C. M., Deng, Z. M., Tam, V. W. Y. (2003). "ISO 14000 and the Construction Industry: Survey in China", Journal of Management in Engineering 19(3): 107-115.

Zucker, S. (2017). "Durham Cathedral, Pier and Columns", Retrieved 03/01/2019from https://www.flickr.com/photos/profzucker/35638347420/in/photostream/. 
Appendix A: District Plan Provisions Specific to ADUs

This appendix presents the district plan provisions specific to ADUs extracted from Saville-Smith et al. (2017). The following table shows the symbols used in the table.

\begin{tabular}{|l|l|}
\hline Type of permission & Abbreviation \\
\hline Permitted & $\mathrm{P}$ \\
\hline Discretionary & $\mathrm{D}$ \\
\hline Restricted Discretionary & RD \\
\hline Controlled Activity & CA \\
\hline
\end{tabular}

- District plan provisions specific to ADUs

\begin{tabular}{|c|c|c|c|c|c|c|c|c|c|c|}
\hline \multirow[t]{2}{*}{ Council } & \multirow[t]{2}{*}{ Zone } & \multirow[t]{2}{*}{ Type of ADU } & \multicolumn{4}{|c|}{ Type of permission } & \multicolumn{3}{|l|}{ Limitation } & \multirow[t]{2}{*}{ Comments } \\
\hline & & & $\mathrm{P}$ & $\mathrm{D}$ & RD & CA & MSCA & $\begin{array}{l}\text { MGPA } \\
\left(m^{2}\right)\end{array}$ & $\begin{array}{l}\text { MNSA } \\
\left(\mathrm{m}^{2}\right)\end{array}$ & \\
\hline \multirow[t]{3}{*}{ Far North } & Residential & Alteration/addition & & $\mathrm{v}$ & & & $\begin{array}{l}55 \% \text { or } 550 \\
\mathrm{~m}^{2}\end{array}$ & & & \\
\hline & Rural & Alteration/addition & $\mathrm{v}$ & & & & $\begin{array}{l}10 \% \text { or } \\
2400 \mathrm{~m}^{2}\end{array}$ & & & \\
\hline & Coopers Beachfront Estate & One detached ADU & $\mathrm{v}$ & & & & & 45 & & \\
\hline Kaipara & Residential & Detached & $\mathrm{v}$ & & & & & & $600-1000$ & MNSA is $3000 \mathrm{~m}^{2}$ for un-serviced sites. \\
\hline \multirow[t]{4}{*}{ Whangarei } & Living Environments1 & Construction or alteration & $\mathrm{v}$ & & & & & \multirow[t]{3}{*}{70} & 500 & \\
\hline & Living Environments2 & Construction or alteration & $\mathrm{v}$ & & & & & & 350 & \\
\hline & Living Environments3 & Construction or alteration & $\mathrm{v}$ & & & & & & 2000 & \\
\hline & & & $\mathrm{v}$ & & & & & 70 & & \\
\hline \multirow[t]{14}{*}{ Auckland Unitary } & Single House & $\begin{array}{l}\text { Conversion Into a maximum of two } \\
\text { dwellings }\end{array}$ & $\mathrm{v}$ & & & & & & & \multirow[t]{10}{*}{ Building consent and resource consent is likely to be required. } \\
\hline & \multirow[t]{4}{*}{ Mixed Housing Suburban and urban } & 2 dwellings per site & $\mathrm{V}$ & & & & & & & \\
\hline & & 3 or more dwellings per site & & & $\mathrm{v}$ & & & & & \\
\hline & & $\begin{array}{l}\text { Conversion into a maximum of two } \\
\text { dwellings }\end{array}$ & $\mathrm{v}$ & & & & & & & \\
\hline & & ADUs & $\mathrm{v}$ & & & & & & & \\
\hline & \multirow[t]{3}{*}{ Residential Large Lot } & Minor dwelling & & & $\mathrm{v}$ & & & & & \\
\hline & & More than one dwelling per site & & & & & & & & \\
\hline & & Accessory buildings & & & & & & & & \\
\hline & \multirow[t]{3}{*}{ Residential - Rural and Coastal settlement } & $\begin{array}{l}\text { Conversion into a maximum of two } \\
\text { dwellings }\end{array}$ & & $\mathrm{v}$ & & & & & & \\
\hline & & Minor dwellings & & & $\mathrm{v}$ & & & & & \\
\hline & & $\begin{array}{l}\text { More than one dwelling rather than } \\
\text { aforementioned }\end{array}$ & & & & & & & & Non-complying \\
\hline & \multirow[t]{2}{*}{ Residential - Terrace Housing and Apartment } & Accessory buildings & $\mathrm{v}$ & & & & & & & \\
\hline & & Conversion of principal dwelling & $\mathrm{v}$ & & & & & & & \\
\hline & Future Urban & Minor dwellings & & & v & & & & & \\
\hline \multirow{6}{*}{$\begin{array}{l}\text { Thames- } \\
\text { Coromandel }\end{array}$} & & One minor Unit & $\mathrm{V}$ & & & & & & & Permitted under Rule 14 providing they meet standards. \\
\hline & Coastal & & & & & & $30 \%$ & \multirow{5}{*}{$50-60$} & & \multirow{5}{*}{$\begin{array}{l}\text { MGPA: } 60 \mathrm{~m}^{2} \text { if Lifemark certified or has another certification of } \\
\text { functionality for the elderly or disabled. Otherwise } 50 \mathrm{~m}^{2} \text {. Both } \\
\text { exclude garage } \\
\text { MSCA } 35 \% \text { or } 40 \% \text { if Lifemark or accessible design certified }\end{array}$} \\
\hline & Residential Zone & & & & & & $35 \%-40 \%$ & & & \\
\hline & Extra Density Residential & & & & & & $45 \%$ & & & \\
\hline & Low-Density Residential & & & & & & $15 \%$ & & & \\
\hline & Rural Lifestyle & & & & & & $10 \%$ & & & \\
\hline
\end{tabular}




\begin{tabular}{|c|c|c|c|c|c|c|c|c|c|c|}
\hline & Village & & & & & & $35 \%$ & & & \\
\hline & Waterfront & & & & & & $50 \%$ & & & \\
\hline \multirow[t]{8}{*}{ Waikato District } & & Dependent Persons Dwelling (DPD) & $\mathrm{v}$ & & & & & & & $\begin{array}{l}\text { Subsidiary dwellings permitted on some sites with resource } \\
\text { consent. }\end{array}$ \\
\hline & \multirow[t]{2}{*}{ Living Zone } & One DPD per site & $\mathrm{v}$ & & & & & & & \\
\hline & & Subsequent dwellings and DPDs & & $\mathrm{v}$ & & & & & & \\
\hline & Coastal Zone & & & & & & & & & $\begin{array}{l}\text { One dwelling per certificate of title as a controlled activity or two if } \\
\text { the title contains at least } 40 \text { ha. }\end{array}$ \\
\hline & Country Living Zone & Construction or alteration & $v$ & & & & & 80 & & $\begin{array}{l}\text { If total building coverage does not exceed } 10 \% \text { and gross floor } \\
\text { area of all accessory buildings (excluding garage) does not exceed } \\
80 \mathrm{~m}^{2} \text {.MGPA: excluding garage }\end{array}$ \\
\hline & & Dependent person's dwelling & & & & & & 70 & & Must be built for relative \\
\hline & & Second subsequent & & & & & & 70 & & Can be used by unrelated individuals \\
\hline & & Subsidiary dwelling & & & & & & $\begin{array}{l}65 \\
120\end{array}$ & & $\begin{array}{l}\text { MGPA: } 65 \mathrm{~m}^{2} \text { if used for housing relatives or } 120 \mathrm{~m}^{2} \text { if used by } \\
\text { seasonal, farming or horticultural workers }\end{array}$ \\
\hline \multirow[t]{3}{*}{ Hamilton } & General Residential & One ancillary residential unit & $\mathrm{v}$ & & & & $600 \mathrm{~m}^{2}$ & 60 & & \multirow[t]{3}{*}{ MSCA includes both ADU and the primary house } \\
\hline & Large Lot Residential & One ancillary residential unit & $\mathrm{v}$ & & & & $3500 \mathrm{~m}^{2}$ & 60 & & \\
\hline & Medium density residential & One ancillary unit for change of use & $\mathrm{v}$ & $\mathrm{v}$ & & & & 60 & & \\
\hline Otorohanga & & $\begin{array}{l}\text { Small, habitable buildings with plumbing } \\
\text { and drainage, additions and alterations }\end{array}$ & $\mathrm{v}$ & & & & & 30 & & \\
\hline Waipa & Residential & One secondary dwelling & $\mathrm{v}$ & & & & & 70 & 850 & Must be encompassed within the bulk of the principal dwelling \\
\hline South Waikato & $\begin{array}{l}\text { Tokoroa, Putāruru, Tirau Residential and } \\
\text { Arapuni Village }\end{array}$ & Accessory buildings & $\mathrm{v}$ & & & & & & & Maximum two buildings on a site \\
\hline \multirow{8}{*}{ Tauranga } & Suburban Residential & Secondary independent dwelling & $\mathrm{v}$ & & & & & & 325 & \multirow{8}{*}{$\begin{array}{l}\text { Maximum of } 2 \text { bedrooms (or } 2 \text { rooms other than the main living } \\
\text { area capable of being used as bedrooms). } \\
\text { Subject to compliance with height, noise, light, character and } \\
\text { environmental requirements. } \\
\text { Without negatively impacting on neighbourhood character, } \\
\text { amenities and environmental characteristics. }\end{array}$} \\
\hline & Large Lot Residential & Secondary independent dwelling & $\mathrm{v}$ & & & & & & 1,000 & \\
\hline & City Living Residential & Secondary independent dwelling & $\mathrm{v}$ & & & & & & 200 & \\
\hline & City Living Mixed Use & Secondary independent dwelling & $\mathrm{v}$ & & & & & & & \\
\hline & Urban Marae Community 1 & & $\mathrm{v}$ & & & & & & 325 & \\
\hline & $\begin{array}{l}\text { Ngati Kahu Sub-Zone A and Commercial } \\
\text { (Waewae) }\end{array}$ & & $\mathrm{v}$ & & & & & & & \\
\hline & Wairakei Residential & & & & $\mathrm{v}$ & & & & 500 & \\
\hline & $\begin{array}{l}\text { Papamoa Medium Rise Plan Area - Inland and } \\
\text { Beachside Neighbourhoods }\end{array}$ & & $\mathrm{v}$ & & & & & & & \\
\hline \multirow[t]{6}{*}{$\begin{array}{l}\text { Western Bay of } \\
\text { Plenty }\end{array}$} & $\begin{array}{l}\text { Residential areas, Future Urban, Rural } \\
\text { Residential and Lifestyle. }\end{array}$ & One minor dwelling & & & & $\mathrm{v}$ & & 60 & & \\
\hline & $\begin{array}{l}\text { Katikati, Te Puke, Waihi Beach (including } \\
\text { Athenree, Bowentown and Pios Beach) }\end{array}$ & & & & & & & 60 & 350 & \\
\hline & Omokoroa Stage 1 & & & & & & & 60 & $400-800$ & $400 \mathrm{~m}^{2}$ per dwelling with a maximum average of $800 \mathrm{~m}^{2}$. \\
\hline & Omokoroa Stage 2 & & & & & & & 60 & $350-650$ & $350 \mathrm{~m}^{2}$ per dwelling with a maximum average of $650 \mathrm{~m}^{2}$. \\
\hline & Omokoroa Existing Village & & & & & & & 60 & 600 & \\
\hline & Other areas & & & & & & & 60 & 800 & \\
\hline \multirow[t]{5}{*}{ Rotorua District } & Residential Zone 1 & $\begin{array}{l}\text { Buildings and alterations } \\
\text { One additional household unit }\end{array}$ & $\mathrm{v}$ & & & & $40 \%$ & 72 & 600 & \\
\hline & Residential Zone 2 & Buildings and alterations & $\mathrm{v}$ & & & & & & & \\
\hline & Residential Zone 3 & Buildings and alterations & $\mathrm{v}$ & & & & $50 \%$ & & & \\
\hline & Residential Zone 4 & Buildings and alterations & $\mathrm{v}$ & & & & $40 \%$ & & & \\
\hline & Residential Zone 5 & Buildings and alterations & $\mathrm{v}$ & & & & $25 \%$ & & & \\
\hline Whakatane & $\begin{array}{l}\text { Deferred Residential, Mixed Use, Commercial, } \\
\text { Rural Plains, Rural Foothills and Community } \\
\text { and Culture }\end{array}$ & One accessory building & $\mathrm{v}$ & & & & & 65 & & \\
\hline
\end{tabular}




\begin{tabular}{|c|c|c|c|c|c|c|c|c|c|}
\hline & Residential Zone & One accessory building & $\mathrm{v}$ & & & & 65 & $\begin{array}{l}350 \text { or } \\
1,200\end{array}$ & $\begin{array}{l}\text { MNSA: } 1,200 \mathrm{~m}^{2} \text { of lot area if an on-site effluent treatment system } \\
\text { is required. }\end{array}$ \\
\hline & Urban Living & One accessory building & $v$ & & & & 65 & $\begin{array}{l}200 \text { or } \\
250\end{array}$ & MNSA: $200 \mathrm{~m}^{2}$ if attached and $250 \mathrm{~m}^{2}$ if detached \\
\hline & Rural Coastal & One accessory building & & & $\mathrm{v}$ & & 65 & & \\
\hline & Rural Ōwhiwa & One accessory building & $\mathrm{v}$ & $\mathrm{v}$ & $\mathrm{v}$ & & 65 & & $\begin{array}{l}\text { Depending on location, height/impact on ridgeline and compliance } \\
\text { with other rules. }\end{array}$ \\
\hline Opotiki & & Accessory dwellings & v & & & $40 \%$ & & & $\begin{array}{l}\text { That part of the building encroaching on the yard does not exceed } \\
\text { either } 30 \% \text { of the length of the nearest boundary to the yard or } \\
10 \mathrm{~m} \text {, whichever is the smaller. } \\
\text { Outside pedestrian access is available to the rear of the dwelling. } \\
\text { Vehicle access must be possible for septic tank maintenance }\end{array}$ \\
\hline \multirow[t]{3}{*}{ Gisborne } & Residential & Minor dwelling & $\mathrm{v}$ & & & & & & \\
\hline & Residential Lifestyle & Minor dwelling & & $\mathrm{v}$ & & & & & \\
\hline & & & & & & $35 \%$ & 60 & & \\
\hline \multirow[t]{2}{*}{ New Plymouth } & Residential A\&C & 1 habitable & $\mathrm{v}$ & & & $35 \%$. & & & \multirow{2}{*}{$\begin{array}{l}\begin{array}{l}\text { Permission dependent on ability to accommodate traffic and noise } \\
\text { controls. }\end{array} \\
\end{array}$} \\
\hline & Residential B & 1 habitable & $\mathrm{v}$ & & & $50 \%$ & & & \\
\hline Stratford & Residential & Accessory buildings & $\mathrm{v}$ & & & & & & \\
\hline \multirow[t]{3}{*}{ South Taranaki } & Residential & Minor dwellings & $\mathrm{v}$ & & & & & & \\
\hline & & Restricted Discretionary & & & & & & & $\begin{array}{l}\text { When a new dwelling unit is on a site with a net site area between } \\
1,000 \mathrm{~m}^{2} \text { and } 4,000 \mathrm{~m}^{2} \text {. }\end{array}$ \\
\hline & & & & & & $40 \%$ & 60 & 400 & Maximum two dwellings per site. \\
\hline Whanganui & & One minor dwelling/granny flat & & & & & 60 & & \begin{tabular}{|l} 
Must share access-way with principal dwelling. \\
\end{tabular} \\
\hline \multirow[t]{2}{*}{ Manawatu } & Residential & Family flats & & & & $35 \%$ & 70 & 350 & \multirow[t]{2}{*}{ Must be in the same ownership as the main dwelling unit. } \\
\hline & Rural & Family flats & & & & & 70 & & \\
\hline Wairoa & Residential (Mahia) & One dwelling (see net area) & & & & & & 800 & $\begin{array}{l}\text { For areas of land of less than } 800 \mathrm{~m}^{2} \text { held in one certificate of title } \\
\text { first registered before } 19 \text { December } 2006 \text {, one dwelling unit is } \\
\text { permitted. } \\
\text { MNSA is } 1,000 \mathrm{~m}^{2} \text { for un-serviced lots. }\end{array}$ \\
\hline Napier & Main residential & $\begin{array}{l}\text { Development of a supplementary unit } \\
\text { (only one) }\end{array}$ & $\mathrm{v}$ & & & $50 \%$ & 80 & & The unit must consist of a single bedroomed dwelling unit. \\
\hline \multirow[t]{7}{*}{ Hastings } & Most residential & One supplementary residential building & $v$ & & & & 80 & & \multirow[t]{7}{*}{$\begin{array}{l}\text { In most zones supplementary dwelling units exceeding } 80 \mathrm{~m}^{2} \text { are } \\
\text { restricted discretionary. }\end{array}$} \\
\hline & General Residential Zone & $\begin{array}{l}\text { One residential building and one } \\
\text { supplementary dwelling }\end{array}$ & & & & $45 \%$ & & 350 & \\
\hline & Rural Residential, & & & & & $20 \%$ & 100 & & \\
\hline & Nature Preservation & & & & & & 100 & & \\
\hline & Tuki Tuki Special Character & & & & & $20 \%$ & 100 & & \\
\hline & City Living & & & & & $45 \%$ & & & \\
\hline & Character Residential & & & & & $35 \%$ & & & \\
\hline $\begin{array}{l}\text { Central Hawke's } \\
\text { Bay }\end{array}$ & Residential and Township Zones & Max two residential units on any site. & & & & & & & $\begin{array}{l}\text { Minimum net area for any site shall be } 350 \mathrm{~m}^{2} \text { for each residential } \\
\text { unit contained within the site provided that it is connected to a } \\
\text { reticulated sewerage system, except that for each residential unit } \\
\text { with a gross floor area less than } 60 \mathrm{~m}^{2} \text { the minimum net area for } \\
\text { any site shall be } 150 \mathrm{~m}^{2} \text {. }\end{array}$ \\
\hline Tararua & & Accessory buildings & $\mathrm{v}$ & & & & & & \\
\hline Palmerston North & & Minor dwellings & $\mathrm{v}$ & & & \begin{tabular}{|l|}
$40 \%$ \\
$200 \mathrm{~m}^{2}$ \\
$35 \%$ \\
\end{tabular} & 80 & & $\begin{array}{l}\text { Maximum one dwelling unit and one minor unit; or one dwelling } \\
\text { unit and one sleep-out. } \\
\text { MSCA: } 40 \% \text { on sites of less than } 500 \mathrm{~m}^{2}, 200 \mathrm{~m}^{2} \text { on sites } 500 \mathrm{~m}^{2} \text { to } \\
572 \mathrm{~m}^{2}, 35 \% \text { on sites over } 572 \mathrm{~m}^{2} \text {. }\end{array}$ \\
\hline
\end{tabular}




\begin{tabular}{|c|c|c|c|c|c|c|c|c|c|c|}
\hline & & One dependent dwelling & & & & $\mathrm{v}$ & & 100 & & $\begin{array}{l}\text { A dependent dwelling unit must be removed or integrated into the } \\
\text { main building within six months of occupation by the dependent } \\
\text { person leaving. } \\
\text { Dependent Dwelling Units may have a condition of consent } \\
\text { imposed pertaining to a financial contribution or bond to, for } \\
\text { example, ensure that any exterior works are completed to an } \\
\text { appropriate standard. }\end{array}$ \\
\hline \multirow[t]{4}{*}{ Horowhenua } & Residential & Family flats & 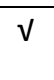 & & & & \multirow[t]{2}{*}{$35 \%-40 \%$} & 50 & & \multirow{2}{*}{$\begin{array}{l}\text { MSCA: } 35 \% \text { for sites greater than } 500 \mathrm{~m}^{2} ; 40 \% \text { for sites } 500 \mathrm{~m}^{2} \text { or } \\
\text { less }\end{array}$} \\
\hline & & Detached Residential units & & & & & & & & \\
\hline & & $\begin{array}{l}\text { Two or more residential dwelling } \\
\text { units/family flats per site }\end{array}$ & & $\mathrm{v}$ & & & & & & \\
\hline & Rural & & & & & & & & & $\begin{array}{l}\text { One residential dwelling unit and one family flat per site on sites } \\
\text { up to } 40 \text { hectares. } \\
\text { Two residential dwelling units and one family flat per site on sites } \\
\text { between } 40-100 \text { hectares. } \\
\text { Three residential dwelling units and one family flat per site on sites } \\
100 \text { hectares and over. }\end{array}$ \\
\hline \multirow[t]{2}{*}{ Kapiti Coast } & \begin{tabular}{|l|l|} 
Residential \\
\end{tabular} & One dwelling and one family flat & $\mathrm{v}$ & & & & & & & \\
\hline & Rural & Family flats & $\mathrm{v}$ & & & & $40 \%$. & 50 & & $\begin{array}{l}\text { With the exception of the Tourist Activity Precinct. } \\
\text { Must be relocatable. Cannot be sold or disposed of except in } \\
\text { conjunction with the dwelling. } \\
\text { May only be occupied by a socially dependent relative or close } \\
\text { family associate of the occupants of the main dwelling. }\end{array}$ \\
\hline \multirow{4}{*}{$\begin{array}{l}\text { Masterton \& } \\
\text { Carterton \& South } \\
\text { Wairarapa }\end{array}$} & & Subdivision & & & & $\mathrm{v}$ & & & & Permission subject to minimum lot size \\
\hline & Rural Zone & One minor dwelling & $\mathrm{v}$ & & & & & 60 & & $\begin{array}{l}\text { Maximum of } 5 \mathrm{~m} \text { high and no further than } 30 \mathrm{~m} \text { away from the } \\
\text { main dwelling at the minor dwelling's most distant point. }\end{array}$ \\
\hline & & Dwellings for farm workers & & & & & & & & \\
\hline & & One dwelling for farm workers & & & & & & & & Per 500 hectares. \\
\hline Porirua & & $\begin{array}{l}\text { Second or any subsequent detached } \\
\text { dwelling }\end{array}$ & $\mathrm{v}$ & & & & $35 \%$ & & & $\begin{array}{l}\text { Minimum of one car park per dwelling of up to } 75 \mathrm{~m}^{2} \mathrm{GFA} \text { and two } \\
\text { car parks per dwelling of greater than } 75 \mathrm{~m}^{2} \text {. } \\
\text { In the Medium Density Residential Policy Area two car parks are } \\
\text { required for any dwelling unit. }\end{array}$ \\
\hline \multirow[t]{7}{*}{ Upper Hutt City } & Residential Zones & & & & & & $35 \%$ & & $\begin{array}{l}400 \text { or } \\
450\end{array}$ & MNSA: $400 \mathrm{~m}^{2}$ front and rear lots, $450 \mathrm{~m}^{2}$ corner lots. \\
\hline & Residential A (Centres Overlay) & & & & & & & & $\begin{array}{l}300 \text { or } \\
350\end{array}$ & MNSA: $300 \mathrm{~m}^{2}$ front and back lots, $350 \mathrm{~m}^{2}$ corner lots \\
\hline & Conservation and Hills & & & & & & & & $\begin{array}{l}750 \text { or } \\
900\end{array}$ & MNSA: $750 \mathrm{~m}^{2}$ front and corner lots $900 \mathrm{~m} 2$ rear lots. \\
\hline & Residential Conservation and Residential Hill & & & & & & $30 \%$ & & & \multirow{3}{*}{$\begin{array}{l}\text { For all zones: } \\
\text { Permit one family flat in conjunction with a dwelling on any site or } \\
\text { two or more dwellings per site when in residential zones } \\
\text { compliant with net size standards. } \\
\text { Permit two or more dwellings on a site within a Residential } \\
\text { (Centres Overlay) area except on land identified as Pt Section } 618 \\
\text { Hutt District. }\end{array}$} \\
\hline & & Family flats & & & & & & 55 & & \\
\hline & & & & & & & & & & \\
\hline & Rural Zones & Family flats & $\mathrm{v}$ & & & & & & & \begin{tabular}{|l} 
Permitted in conjunction with a dwelling. \\
\end{tabular} \\
\hline \multirow[t]{3}{*}{ Wellington } & Residential & Accessory buildings and home conversions & $\mathrm{v}$ & & & & & & & \multirow{3}{*}{$\begin{array}{l}\text { In all zones Accessory buildings maximum } 1 \text { storey. } \\
\text { Assess less typical development on a case by case basis. Accessory } \\
\text { buildings in front yards are permitted. }\end{array}$} \\
\hline & Air noise Boundary & $\begin{array}{l}\text { Construction, alteration, and addition to } \\
\text { residential buildings, resulting in } 2 \\
\text { household units. }\end{array}$ & & $\mathrm{v}$ & & & & & & \\
\hline & Thorndon and Mt Victoria North & $\begin{array}{l}\text { Construction, alteration of, and addition to } \\
\text { residential buildings, accessory buildings } \\
\text { and residential structures }\end{array}$ & & & $\mathrm{v}$ & & & & & \\
\hline
\end{tabular}




\begin{tabular}{|c|c|c|c|c|c|c|c|c|c|}
\hline & Outer residential & Detached dwellings & $\mathrm{v}$ & & & & & & \\
\hline & Medium Density Residential Area 1 & & & & & & & & \\
\hline & Medium Density Residential Area 2 & & & & & & & & $\begin{array}{l}\text { Requires minimum lot dimensions, front yard and provision of } \\
\text { ground level open space. }\end{array}$ \\
\hline & Inner \& Outer Residential Areas & & & & & & & & \\
\hline & Inner Residential areas & & & & & & & & $\begin{array}{l}\text { Waived car parking requirements for conversions of single family } \\
\text { dwellings into two units }\end{array}$ \\
\hline \multirow[t]{3}{*}{ Hutt City } & Landscape Protection Residential Area & Dwelling Houses & $\mathrm{v}$ & & & $15 \%$ & & 2,000 & \\
\hline & Special Residential Activity Area & Dwelling Houses & $\mathrm{v}$ & & & $30 \%$ & & 700 & \\
\hline & Hill Residential Activity Area & Dwelling Houses & $\mathrm{v}$ & & & $30 \%$ & & 1,000 & \\
\hline \multirow[t]{5}{*}{ Nelson } & & $\begin{array}{l}\text { Extensions which increase the ground floor } \\
\text { area by not more than } 20 \%\end{array}$ & $\mathrm{v}$ & & & & & & \\
\hline & Some zones & Secondary residential dwellings & & & & & & & \\
\hline & & Conversion & & & & & & & $\begin{array}{l}\text { Resource consent is needed to ensure that the building will not be } \\
\text { adversely affected by inundation. }\end{array}$ \\
\hline & In certain areas - e.g. in Inundation Overlays. & Conversion & $x$ & & & & & & \\
\hline & Standard residential zone & & & & & & & & $\begin{array}{l}400 m^{2} \text { must be allocated to each residential unit. Parking and } \\
\text { vehicle manoeuvring requirements must be met for each unit. }\end{array}$ \\
\hline \multirow[t]{9}{*}{ Tasman } & Residential Zone & $\begin{array}{l}\text { Minor dwellings and } \\
\text { construction or alteration }\end{array}$ & $v$ & & & & $\begin{array}{l}80 \\
120\end{array}$ & & $\begin{array}{l}\text { May be undertaken without resource consent in the Residential } \\
\text { Zone provided they comply with standards. MGPA: } 120 \mathrm{~m}^{2} \text { if garage } \\
\text { is included }\end{array}$ \\
\hline & Residential Zone & Subdivision & & & $\mathrm{v}$ & & & & \\
\hline & Rural 1, 2 \& 3 Zones & Second dwelling & & & $\mathrm{v}$ & & & & \\
\hline & Rural 1, & Workers' accommodation & & & $\mathrm{v}$ & & & 120,000 & Must be relocatable \\
\hline & Rural 2 & Workers' accommodation & & & $\mathrm{v}$ & & & 500,000 & Must be relocatable \\
\hline & Rural 3 & Workers' accommodation & & & $\mathrm{v}$ & & & 500,000 & Must be relocatable \\
\hline & Rural 1, 2, 3 and Rural Residential & Conversion & $\mathrm{v}$ & & & & & & \\
\hline & Rural 1, 2, 3 and Rural Residential Zones & Construction/alteration & & & $\mathrm{v}$ & & & & $\begin{array}{l}\text { If it contains no more than two self-contained housing units within } \\
\text { the same building and: both are contained in the same building; } \\
\text { one unit is clearly subsidiary; the connecting rooms/passages have } \\
\text { a continuous roof; the walls are enclosed. }\end{array}$ \\
\hline & Rural $1 \& 2$ and Rural Residential Zones & Co-operative living & & $\mathrm{v}$ & & & & & \\
\hline $\begin{array}{l}\text { Marlborough } \\
\text { Wairau/Awatere }\end{array}$ & & Accessory dwelling & $v$ & & & & & & \multirow[b]{2}{*}{$\begin{array}{l}\text { Where a building is intended for the care of a relative and site } \\
\text { coverage has already been reached a building of } 65 \mathrm{~m}^{2} \text { maximum } \\
\text { will be permitted subject to the building being relocatable. } \\
\text { The landowner shall enter into a bond with the Council to ensure } \\
\text { that the building is removed when no longer required for the } \\
\text { dependent relative. } \\
\text { The bond will be registered under the Land Transfer Act } 1952 \\
\text { against the Certificate of Title to the land and shall be of a } \\
\text { covenant running with the land which binds all subsequent owners } \\
\text { of the land. }\end{array}$} \\
\hline $\begin{array}{l}\text { Marlborough } \\
\text { Marlborough } \\
\text { Sounds }\end{array}$ & Urban Residential and Sounds Residential & Family flats (up to two family members) & & & & & 80 & & \\
\hline Kaikoura & Port, Marina and Coastal Marine & Additions and minor extension & $\mathrm{v}$ & & & & & & $\begin{array}{l}\text { The extension or alteration is contained within the form of the } \\
\text { existing structures, or adds no more than } 5 \% \text { to the plan or cross- } \\
\text { sectional area of the structure within any } 24 \text { month period; there } \\
\text { will be no significant change to the external appearance of the } \\
\text { structure; the maintenance or repair does not result in any } \\
\text { increase in the area of coastal marine area occupied by the } \\
\text { structure; The activity does not result in any discharge or } \\
\text { deposition of contaminants into the coastal marine area. }\end{array}$ \\
\hline Buller & Residential & $\begin{array}{l}\text { Two habitable dwellings (including granny } \\
\text { flats and sleep-outs) }\end{array}$ & $\mathrm{v}$ & & & & & & \\
\hline
\end{tabular}




\begin{tabular}{|c|c|c|c|c|c|c|c|c|c|}
\hline Grey & & Family flats & $v$ & & & & 65 & & $\begin{array}{l}\text { Must be occupied by a dependent relative of the household in the } \\
\text { main dwelling. }\end{array}$ \\
\hline Hurunui & & Internal subdivision and change of use. & $v$ & & & & & & \\
\hline Waimakiriri & & $\begin{array}{l}\text { One additional physically separated } \\
\text { dwelling-house }\end{array}$ & $v$ & & & & 75 & & $\begin{array}{l}\text { Should be located within } 30 \text { metres of the primary dwelling-house. } \\
\text { Only one kitchen facility under any individual roof structure. } \\
\text { A building consent is required to build a sleep-out with a floor area } \\
\text { exceeding } 10 \mathrm{~m}^{2} \text { or containing sanitary fixtures, cooking facilities, } \\
\text { or potable water. }\end{array}$ \\
\hline Selwyn & & Family flats & $\mathrm{v}$ & & & & 70 & & $\begin{array}{l}\text { Must comply with bulk, location and relocation requirements. } \\
\text { Can only be lived in by someone of the same immediate family as } \\
\text { someone residing in the main dwelling. }\end{array}$ \\
\hline \multirow[t]{5}{*}{ Christchurch } & $\begin{array}{l}\text { Residential: Suburban, Suburban Density } \\
\text { Transition, Banks Peninsula, New } \\
\text { Neighbourhood. }\end{array}$ & Minor residential & $\mathrm{v}$ & & & & \multirow[t]{4}{*}{80} & 450 & \multirow{5}{*}{$\begin{array}{l}\text { Must be detached from primary dwelling } \\
\text { In a Character Area overlay, additional rules apply. A resource } \\
\text { consent will be required if the minor residential unit is: visible } \\
\text { from the street or located in that part of the site between the road } \\
\text { boundary and the main residential unit on the site. } \\
\text { Family flats must be occupied by family members in some way } \\
\text { dependent on a member in the main dwelling. } \\
\text { When no longer required by family member a family flat must be } \\
\text { removed, have its kitchen removed or comply with requirements } \\
\text { for a residential unit }\end{array}$} \\
\hline & Residential Hills, & Minor residential & $\mathrm{v}$ & & & & & 650 & \\
\hline & Residential Large Lot, & Minor residential & $v$ & & & & & $\begin{array}{l}1,500- \\
2,000\end{array}$ & \\
\hline & Residential Small Settlement & Minor residential & $v$ & & & & & 1,000 & \\
\hline & All residential zones & Family flats & & & & & & & \\
\hline \multirow[t]{2}{*}{ Westland } & Residential and Residential Mixed & Accessory dwellings & $\mathrm{v}$ & & & & & & \\
\hline & Coastal & Accessory dwellings & $\mathrm{v}$ & & & & & & As long as they are relocatable. \\
\hline \multirow[t]{3}{*}{ Timaru } & Residential $1,2,3,5$ and 6 . & Residential accessory buildings & $\mathrm{v}$ & & & & & & \\
\hline & Residential 4 & Residential accessory buildings & $\mathrm{v}$ & & $\mathrm{v}$ & & & & Depending on potential environmental impacts. \\
\hline & Residential 4 & Alterations, additions and modifications & & $\mathrm{v}$ & & & & & \\
\hline \multirow[t]{7}{*}{ Mackenzie } & Residential 1 & Minor units & $\mathrm{v}$ & & & $40 \%$ & 50 & & \\
\hline & Residential 2 & Minor units & & & & $85 \%$ & 50 & 250 & MNSA excludes access for each dwelling. \\
\hline & Residential 3 & & & & & $20 \%$ & & & \\
\hline & Residential 4 & Minor units & & & & $10 \%$ & 250 & & \\
\hline & Rural Residential Zone - Manuka Terrace & One residential and one minor unit per lot. & & & & & & & \\
\hline & \begin{tabular}{|l|} 
Rural-Residential Zone1 \\
\end{tabular} & $\begin{array}{l}\text { One dwelling and one minor dwelling per } \\
\text { lot. }\end{array}$ & & & & & & 10,000 & \\
\hline & \begin{tabular}{|l} 
Rural-Residential Zone2 \\
\end{tabular} & $\begin{array}{l}\text { One dwelling and one minor dwelling per } \\
\text { lot. }\end{array}$ & & & & & & 40,000 & \\
\hline Waitaki & & \begin{tabular}{|l} 
Family flats \\
\end{tabular} & v & & & & & & $\begin{array}{l}\text { Where a family flat does not comply with the residential density, } \\
\text { outdoor living space, and parking standards for residential units it } \\
\text { must be relocatable; and the landowner must enter into a bond } \\
\text { with the Council to ensure that the family flat is removed, when it } \\
\text { is no longer required for the housing of a dependent relative. } \\
\text { Controls imposed to prevent family flats being used as rental } \\
\text { accommodation. }\end{array}$ \\
\hline Waimate & & Family flats & $\mathrm{v}$ & & & & & & $\begin{array}{l}\text { Should be relocated, when no longer required by a dependent } \\
\text { relative. } \\
\text { Additional parking spaces and outdoor living areas are not } \\
\text { required for the family flat as the relative occupying the family flat } \\
\text { is considered to be a part of the family on the site. }\end{array}$ \\
\hline Queenstown & Low Density and High-Density Residential & Residential flats & $v$ & & & & 70 & & $\begin{array}{l}\text { Contains only one kitchen facility; } \\
\text { Limited to one residential flat per residential unit; } \\
\text { Is situated on the same site and held in the same ownership as the } \\
\text { residential unit, but may be leased to another party. MGPA } \\
\text { excludes garage }\end{array}$ \\
\hline
\end{tabular}




\begin{tabular}{|c|c|c|c|c|c|c|c|c|c|}
\hline & Mount Cardrona Station Special Zone & Secondary units & $\mathrm{v}$ & & & & 60 & & $\begin{array}{l}\text { Consists of no more than one unit in the same ownership as the } \\
\text { residential unit; } \\
\text { Contains no more than one kitchen and one laundry; } \\
\text { Is within the same certificate of title as the residential unit }\end{array}$ \\
\hline & High-Density Residential Sub-Zones & Construction of, alteration to, or addition & & & & & & & $\begin{array}{l}\text { If exceeds the maximum building footprint sizes specified is a } \\
\text { restricted discretionary activity in Residential areas. } \\
\text { Maximum building footprint: } \\
\text { High-Density Residential Sub-Zone A } 500 \mathrm{~m}^{2} \text {; } \\
\text { High-Density Residential Sub-Zone B } 400 \mathrm{~m}^{2} \text {; } \\
\text { High-Density Residential Sub-Zone C } 300 \mathrm{~m}^{2}\end{array}$ \\
\hline & Rural Zones & $\begin{array}{l}\text { The addition, alteration or construction of } \\
\text { buildings, including Residential Units, } \\
\text { added to, altered or constructed within } \\
\text { Residential Building Platforms }\end{array}$ & & & $\mathrm{v}$ & $15 \%$ & & & $\begin{array}{l}\text { In the Rural Lifestyle Zone and Ferry Hill Rural Residential Sub- } \\
\text { zone, any Residential Unit not contained within a Residential } \\
\text { Building Platform is non-complying. }\end{array}$ \\
\hline Central Otago & $\begin{array}{l}\text { Residential Resource } \\
\text { Rural Settlements }\end{array}$ & Family flat & & $\mathrm{v}$ & & & & & Temporary duration. \\
\hline Dunedin & All zones except medium density & Family flats & $\mathrm{v}$ & & & & & & $\begin{array}{l}\text { Do not require consent so long as performance standards are met. } \\
\text { In rural zones "family flats" can be used to house a person or } \\
\text { persons employed by a member of the primary household. }\end{array}$ \\
\hline Clutha & & Detached dwellings & $\mathrm{v}$ & & & & & 100 & $\begin{array}{l}\text { Use is customary in connection with the principle building or } \\
\text { permitted use of the land. } \\
\text { An additional dwelling for the purposes of accommodating the } \\
\text { staff of any property owner is permitted in the Rural Resource } \\
\text { Area providing it remains on the same certificate of title and } \\
\text { shares the same access road as the main dwelling. }\end{array}$ \\
\hline
\end{tabular}


- Manufacturers of components

\begin{tabular}{|c|c|c|c|c|c|c|c|c|c|c|c|c|}
\hline \multirow[t]{3}{*}{ Name } & \multirow[t]{3}{*}{ Location } & \multirow[t]{3}{*}{ Installation service } & \multirow{3}{*}{$\begin{array}{l}\text { Supply without } \\
\text { installation (DIY) }\end{array}$} & \multirow[t]{3}{*}{ Guarantee } & \multicolumn{4}{|c|}{ Flexibility } & \multirow[t]{3}{*}{ Area of service limitation } & \multirow[t]{3}{*}{ Ready plan } & \multirow{2}{*}{\multicolumn{2}{|c|}{\begin{tabular}{|l|} 
Design \\
services
\end{tabular}}} \\
\hline & & & & & Colour & Size & Plan & \multirow[t]{2}{*}{ Material } & & & & \\
\hline & & & & & & & Design & & & & In & Out \\
\hline Carters & Wellington & $x$ & $\mathrm{x}$ & & & & & & & & & \\
\hline $\begin{array}{l}\text { Northern Timber } \\
\text { Manufacturing Ltd(ITM) }\end{array}$ & Whangarei & & $\mathrm{x}$ & & & $x$ & $x$ & & North Island & & $x$ & \\
\hline Dysart Timbers Ltd ()ITM & Auckland & & $x$ & & & & & & & & & \\
\hline Wiri Timber Ltd & Auckland & & $\mathrm{x}$ & & & & & & & & & \\
\hline VIP Frames \& Trusses & Christchurch & & $x$ & & & $x$ & & & South Island & & $\mathrm{x}$ & $\mathrm{x}$ \\
\hline Kopu Road Manufacturing & Kopu & & $x$ & & & & & & $\begin{array}{l}\text { Thames, Coromandel and Hauraki } \\
\text { areas. }\end{array}$ & & & \\
\hline $\begin{array}{l}\text { Tauranga Truss \& Frame } \\
\text { Ltd }\end{array}$ & Tauranga & & $\mathrm{x}$ & & & & & & & & & \\
\hline $\begin{array}{l}\text { Place Makers Frame \& } \\
\text { Truss }\end{array}$ & Manukau & & $\mathrm{x}$ & & & & & & & & $x$ & $x$ \\
\hline $\begin{array}{l}\text { Capital Pre-cut Solutions } \\
\text { Ltd }\end{array}$ & Masterton & $x$ & $\mathrm{x}$ & & & $x$ & & & & $x$ & & \\
\hline Champion Construction Ltd & Wellington & & $x$ & & & & & & & & & \\
\hline Paraparaumu Pre-nail Ltd & Wellington & & $x$ & & & & & & Wellington region & & & \\
\hline $\begin{array}{l}\text { Pre-nail Frames \& Trusses } \\
\text { Ltd }\end{array}$ & Wellington & $x$ & $\mathrm{x}$ & & & & & & & & $\mathrm{x}$ & \\
\hline Aoraki Frame \& Truss Ltd & Timaru & & $x$ & & & & $x$ & & & & $\mathrm{x}$ & \\
\hline $\begin{array}{lll}\text { Canterbury } & \text { Frames } & \& \\
\text { Trusses Ltd } & & \end{array}$ & Christchurch & & $x$ & & & & & & & & $x$ & \\
\hline Westimber Ltd & Christchurch & & $\mathrm{x}$ & & & & & & & & & \\
\hline Westlake Timber Ltd & Christchurch & & $\mathrm{x}$ & & & & & & South Island & & & \\
\hline TimberCo (1999) Ltd & New Plymouth & & $\mathrm{x}$ & & & & & & Taranaki region & & & \\
\hline Henderson Timbers & Auckland & & $\mathrm{x}$ & & & & & & $\begin{array}{l}\text { North Island and the Pacific Islands } \\
\text { including Hawaii }\end{array}$ & $\mathrm{x}$ & & \\
\hline Pre-nail Systems Ltd & Levin & $x$ & $x$ & & & & & & Lower half of the North Island & $x$ & $x$ & $x$ \\
\hline $\begin{array}{l}\text { Red Stag Wood Solutions } \\
\text { Ltd. }\end{array}$ & Hamilton & & $\mathrm{x}$ & & & & & & & & $x$ & \\
\hline Frametek steel framing & Auckland & $\mathrm{x}$ & & & & & & & & & $\mathrm{x}$ & \\
\hline FrameCAD/Steel & Auckland & & $\mathrm{x}$ & & & & $\mathrm{x}$ & & & $\mathrm{x}$ & $\mathrm{x}$ & \\
\hline
\end{tabular}


- Manufacturers of panels

\begin{tabular}{|c|c|c|c|c|c|c|c|c|c|c|c|c|}
\hline \multirow[t]{3}{*}{ Name } & \multirow[t]{3}{*}{ Location } & \multirow[t]{3}{*}{ Installation service } & \multirow{3}{*}{$\begin{array}{l}\text { Supply without } \\
\text { installation (DIY) }\end{array}$} & \multirow[t]{3}{*}{ Guarantee } & \multicolumn{4}{|c|}{ Flexibility } & \multirow[t]{3}{*}{ Area of service limitation } & \multirow[t]{3}{*}{ Ready plan } & \multirow{2}{*}{\multicolumn{2}{|c|}{$\begin{array}{l}\text { Design } \\
\text { services }\end{array}$}} \\
\hline & & & & & \multirow[t]{2}{*}{ Colour } & \multirow[t]{2}{*}{ Size } & \multirow{2}{*}{\begin{tabular}{|l|} 
Plan \\
Design
\end{tabular}} & \multirow[t]{2}{*}{ Material } & & & & \\
\hline & & & & & & & & & & & $\ln$ & Out \\
\hline Spanbild Projects & Christchurch & $x$ & & & & & $x$ & & & & $\mathrm{x}$ & \\
\hline Grey stoke & Wairau Valley & & & & & $x$ & & & & & & \\
\hline Concision & Christchurch & $x$ & & & & $x$ & $x$ & $x$ & & & $\mathrm{x}$ & $x$ \\
\hline Metrapanel & Tregoweth & $x$ & & & & & $x$ & & & $x$ & & \\
\hline Welhaus & Christchurch & $x$ & & & $x$ & & $x$ & & Export worldwide & & $x$ & $x$ \\
\hline Versatile & Wellington & & & $\mathrm{x}$ & & & $\mathrm{x}$ & & & $\mathrm{x}$ & $\mathrm{x}$ & \\
\hline $\begin{array}{l}\text { Value Building } \\
\text { Supplies }\end{array}$ & New Plymouth & & $x$ & & & & & & & $x$ & & $x$ \\
\hline $\begin{array}{l}\text { Manawatu ITM Pre- } \\
\text { nailed Plant }\end{array}$ & Manawatu & & & & & & & & & & & \\
\hline Laminata & Kerikeri & & & & & & & & Northland & $x$ & & \\
\hline Dura panel systems & Awanui & & & & & & & & & $x$ & $\mathrm{x}$ & $x$ \\
\hline Easy build Homes & Masterton & & $x$ & $\mathrm{x}$ & $x$ & & $x$ & $x$ & & $\mathrm{x}$ & & \\
\hline $\begin{array}{l}\text { ModuleNZ Canterbury } \\
\text { Ltd }\end{array}$ & Canterbury & & & & & $x$ & & & & $x$ & & \\
\hline
\end{tabular}

- Manufacturers of modules

\begin{tabular}{|c|c|c|c|c|c|c|c|c|c|c|c|c|}
\hline \multirow[t]{3}{*}{ Name } & \multirow[t]{3}{*}{ Location } & \multirow[t]{3}{*}{ Installation service } & \multirow{3}{*}{$\begin{array}{l}\text { Supply without } \\
\text { installation (DIY) }\end{array}$} & \multirow[t]{3}{*}{ Guarantee } & \multicolumn{4}{|c|}{ Flexibility } & \multirow[t]{3}{*}{ Area of service limitation } & \multirow[t]{3}{*}{ Ready plan } & \multicolumn{2}{|c|}{ Design services } \\
\hline & & & & & Colour & Size & Plan & Material & & & & \\
\hline & & & & & & & Design & & & & IN & OUT \\
\hline ZCAP Ltd & Auckland & $\mathrm{x}$ & $\mathrm{x}$ & & & & $\mathrm{x}$ & & & & $x$ & $\mathrm{x}$ \\
\hline $\begin{array}{l}\text { Stanley } \\
\text { (house and class room) }\end{array}$ & Matamata & $x$ & $x$ & $x$ & $x$ & $x$ & $x$ & $x$ & North Island & & & \\
\hline Matrix homes & Wellington & $x$ & & $\mathrm{x}$ & $\mathrm{x}$ & $\mathrm{x}$ & $\mathrm{x}$ & $\mathrm{x}$ & North Island/ some South Island & $x$ & & \\
\hline
\end{tabular}

- Manufacturers of containers

\begin{tabular}{|c|c|c|c|c|c|c|c|c|c|c|c|c|}
\hline \multirow[t]{3}{*}{ Name } & \multirow[t]{3}{*}{ location } & \multirow[t]{3}{*}{ Installation service } & \multirow{3}{*}{$\begin{array}{l}\text { Supply without } \\
\text { installation (DIY) }\end{array}$} & \multirow[t]{3}{*}{ Guarantee } & \multicolumn{4}{|c|}{ Flexibility } & \multirow[t]{3}{*}{ Area of service limitation } & \multirow[t]{3}{*}{ Ready plan } & \multicolumn{2}{|c|}{ Design services } \\
\hline & & & & & Colour & Size & Plan & Material & & & & \\
\hline & & & & & & & Design & & & & IN & OUT \\
\hline 1. Shape Construction & Christchurch & $\mathrm{x}$ & & & $\mathrm{x}$ & & & & & $x$ & $\mathrm{x}$ & \\
\hline 2. Container homes & Auckland & & & & & & & & & $x$ & & \\
\hline 3. Ecotech (Imported) & Lower North Island & $\mathrm{x}$ & & & & & & & & $x$ & & \\
\hline
\end{tabular}


- Manufacturers of completed buildings

\begin{tabular}{|c|c|c|c|c|c|c|c|c|c|c|c|c|}
\hline \multirow[t]{3}{*}{ Name } & \multirow[t]{3}{*}{\begin{tabular}{|l|} 
Location \\
\end{tabular}} & \multirow[t]{3}{*}{ Installation service } & \multirow{3}{*}{$\begin{array}{l}\text { Supply without } \\
\text { installation (DIY) }\end{array}$} & \multirow[t]{3}{*}{ Guarantee } & \multicolumn{4}{|c|}{ Flexibility } & \multirow[t]{3}{*}{ Area of service limitation } & \multirow[t]{3}{*}{ Ready plan } & \multicolumn{2}{|c|}{ Design services } \\
\hline & & & & & Colour & Size & Plan & Material & & & & \\
\hline & & & & & & & Design & & & & IN & OUT \\
\hline Genius Homes & Timaru & $\mathrm{x}$ & & $\mathrm{x}$ & $\mathrm{x}$ & $\mathrm{x}$ & $\mathrm{x}$ & $\mathrm{x}$ & South Island & $x$ & $x$ & \\
\hline Ezy line Homes & \begin{tabular}{|l} 
Mount Maunganui \\
\end{tabular} & $\mathrm{x}$ & & & $\mathrm{x}$ & & $\mathrm{x}$ & & & $x$ & $x$ & \\
\hline Keith hay Homes & Auckland & $\mathrm{x}$ & & $\mathrm{x}$ & & & $\mathrm{x}$ & & & $x$ & $\mathrm{x}$ & \\
\hline Panel wood Homes & Auckland & $x$ & & & $x$ & $x$ & $x$ & $x$ & & $x$ & $\mathrm{x}$ & \\
\hline
\end{tabular}

- Kitchens

\begin{tabular}{|c|c|c|c|c|c|c|c|c|c|c|c|c|}
\hline \multirow[t]{3}{*}{ Name } & \multirow[t]{3}{*}{ Location } & \multirow[t]{3}{*}{ Installation service } & \multirow{3}{*}{$\begin{array}{l}\text { Supply without } \\
\text { installation (DIY) }\end{array}$} & \multirow[t]{3}{*}{ Guarantee } & \multicolumn{4}{|c|}{ Flexibility } & \multirow[t]{3}{*}{ Area of service limitation } & \multirow[t]{3}{*}{ Ready plan } & \multicolumn{2}{|c|}{ Design services } \\
\hline & & & & & Colour & Size & \begin{tabular}{|l} 
Plan Design \\
\end{tabular} & Material & & & & \\
\hline & & & & & & & & & & & IN & OUT \\
\hline 1. Place Makers & Wellington & & $x$ & & & & & & & & & \\
\hline 2. ITM & Auckland & & $\mathrm{x}$ & $x$ & & & $\mathrm{x}$ & & & & $x$ & \\
\hline 3. Neo design & Auckland & $\mathrm{x}$ & $\mathrm{x}$ & $x$ & $x$ & $\mathrm{x}$ & $x$ & & & & $\mathrm{x}$ & \\
\hline
\end{tabular}

- Bathrooms

\begin{tabular}{|c|c|c|c|c|c|c|c|c|c|c|c|c|}
\hline \multirow[t]{3}{*}{ Name } & \multirow[t]{3}{*}{ Location } & \multirow[t]{3}{*}{ Installation service } & \multirow{3}{*}{\begin{tabular}{|l|} 
Supply without \\
installation (DIY)
\end{tabular}} & \multirow[t]{3}{*}{ Guarantee } & \multicolumn{4}{|c|}{ Flexibility } & \multirow[t]{3}{*}{ Area of service limitation } & \multirow[t]{3}{*}{ Ready plan } & \multicolumn{2}{|c|}{ Design services } \\
\hline & & & & & Colour & Size & Plan Design & Material & & & & \\
\hline & & & & & & & & & & & IN & OUT \\
\hline Sapone & Christchurch & $x$ & & & $\mathrm{x}$ & & $x$ & $\mathrm{x}$ & & & $\mathrm{x}$ & $x$ \\
\hline Degeest & Oamaru & $\mathrm{x}$ & & & & & $x$ & & & & & $x$ \\
\hline JBL group & Oamaru & & & & & & & & & & & \\
\hline Neo design & Auckland & $x$ & $x$ & $x$ & & & & & & & $\mathrm{x}$ & \\
\hline
\end{tabular}

- Other

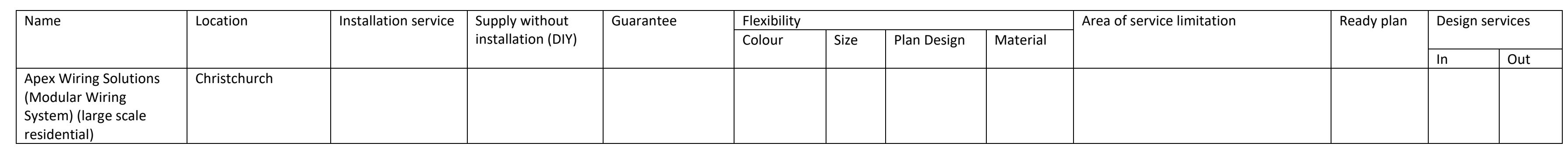


Appendix C: Plan Analysis

This appendix presents the table of data extracted from each plan and the plans for each of the GPA groups. The following table shows the symbols used in the main tables.

\begin{tabular}{|l|l|}
\hline Symbol & Meaning \\
\hline NB & Number of bedroom/s \\
\hline NW & Number of wardrobe/s \\
\hline ND & Number of deck/s \\
\hline$X$ & Not mentioned \\
\hline
\end{tabular}


- GPA rage of $50 m^{2}-55 m^{2}$

\begin{tabular}{|c|c|c|c|c|c|c|c|c|c|c|c|c|c|c|c|c|c|c|}
\hline \multirow{2}{*}{$\begin{array}{l}\text { Pla } \\
\text { n }\end{array}$} & \multirow{2}{*}{$\begin{array}{l}\text { GPA } \\
\left(m^{2}\right)\end{array}$} & \multirow[t]{2}{*}{ NB } & \multicolumn{4}{|c|}{ Sanitation space } & \multicolumn{3}{|c|}{$\begin{array}{l}\text { Kitchen } \\
\text { form }\end{array}$} & \multirow{2}{*}{$\begin{array}{l}\mathbf{N} \\
\mathbf{W}\end{array}$} & \multicolumn{2}{|c|}{ Laundry space } & \multirow[t]{2}{*}{ ND } & \multicolumn{4}{|c|}{ Plan shape } & \multirow{2}{*}{$\begin{array}{l}\text { Wet } \\
\text { zone }\end{array}$} \\
\hline & & & $\begin{array}{l}\text { Ensuite } \\
\mathrm{s}\end{array}$ & $\begin{array}{l}\text { Jack \& } \\
\text { Jill }\end{array}$ & $\begin{array}{l}\text { Bathroo } \\
\mathrm{m}\end{array}$ & $\begin{array}{l}\text { Shower } \\
\text { room }\end{array}$ & $\begin{array}{l}\text { Lin } \\
\mathrm{e}\end{array}$ & $\mathrm{L}$ & $U$ & & $\begin{array}{l}\text { Separate } \\
\text { d }\end{array}$ & $\begin{array}{l}\text { Shar } \\
\mathrm{e}\end{array}$ & & $\begin{array}{l}\text { Squar } \\
\mathrm{e}\end{array}$ & $\begin{array}{l}\text { Rectangl } \\
\mathrm{e}\end{array}$ & $\mathrm{L}$ & $\begin{array}{l}\text { Irregula } \\
r\end{array}$ & \\
\hline 1 & 54.81 & 1 & & & & $\mathrm{~V}$ & & $\mathrm{v}$ & & 1 & $\sqrt{ }$ & & & & & & $\mathrm{V}$ & $\sqrt{ }$ \\
\hline 2 & 51.09 & 1 & & & & $\mathrm{v}$ & & $\mathrm{v}$ & & 2 & & $\mathrm{~V}$ & & & & & $\mathrm{v}$ & $x$ \\
\hline 3 & 50.53 & 2 & & & $\mathrm{~V}$ & & $\mathrm{~V}$ & & & 2 & $\mathrm{~V}$ & & 2 & & $\mathrm{~V}$ & & & $\mathrm{~V}$ \\
\hline 4 & 52.86 & 1 & & $\mathrm{~V}$ & & & & $\mathrm{v}$ & & 2 & $\mathrm{~V}$ & & 1 & & & & $\mathrm{~V}$ & $\mathrm{~V}$ \\
\hline 5 & 53.51 & 1 & & & $\mathrm{v}$ & & $\mathrm{V}$ & & & 2 & & $\mathrm{~V}$ & 2 & & $\mathrm{~V}$ & & & $\mathrm{~V}$ \\
\hline 6 & 50.44 & 2 & & & & $\mathrm{~V}$ & & $\mathrm{v}$ & & 2 & & $x$ & 1 & & $\mathrm{~V}$ & & & $x$ \\
\hline 7 & 51.74 & 2 & & & $\mathrm{~V}$ & & & & $\mathrm{v}$ & 4 & & $x$ & 1 & & & & $\mathrm{~V}$ & $\mathrm{~V}$ \\
\hline 8 & 50.53 & 1 & $\mathrm{~V}$ & & & & $\mathrm{~V}$ & & & 2 & $\mathrm{~V}$ & & 1 & & & & $\mathrm{~V}$ & $\mathrm{~V}$ \\
\hline 9 & 52.58 & 2 & & & & & & $\mathrm{v}$ & & 2 & & $x$ & & & & & $\mathrm{v}$ & $x$ \\
\hline 10 & 51.09 & 1 & $\mathrm{~V}$ & & & $\mathrm{~V}$ & & $\mathrm{~V}$ & & 1 & & $\mathrm{~V}$ & 2 & & & $\mathrm{v}$ & & $x$ \\
\hline 11 & 59.45 & 2 & $\mathrm{~V}$ & & $\mathrm{~V}$ & & & $\mathrm{v}$ & & $x$ & & $x$ & & & $\mathrm{~V}$ & & & $x$ \\
\hline 12 & 50.16 & 2 & & & & $\mathrm{~V}$ & & $\mathrm{v}$ & & $x$ & & $x$ & 1 & & $\mathrm{~V}$ & & & $\mathrm{~V}$ \\
\hline 13 & 53.51 & 1 & & & & $\mathrm{~V}$ & $\mathrm{~V}$ & & & $x$ & & $x$ & 1 & $\mathrm{~V}$ & & & & $\mathrm{~V}$ \\
\hline 14 & 53.14 & 2 & & & & $\mathrm{v}$ & & $\mathrm{v}$ & & 3 & & $x$ & 1 & & $\mathrm{~V}$ & & & $x$ \\
\hline 15 & 53.51 & 2 & & & $\mathrm{~V}$ & & & $\mathrm{v}$ & & 2 & $\mathrm{~V}$ & & 1 & $\mathrm{~V}$ & & & & $\mathrm{~V}$ \\
\hline 16 & 53.51 & 1 & & $\mathrm{~V}$ & & & $\mathrm{v}$ & & & 2 & $\mathrm{v}$ & & 1 & & & & $\mathrm{~V}$ & $x$ \\
\hline 17 & 52.11 & 1 & & & & V & & $\mathrm{v}$ & & 1 & $\mathrm{~V}$ & & 1 & & $\mathrm{~V}$ & & & $x$ \\
\hline 18 & 53.32 & 1 & & & & $\mathrm{~V}$ & $\mathrm{~V}$ & & & 1 & $\mathrm{~V}$ & & $x$ & & & & $\mathrm{v}$ & $x$ \\
\hline
\end{tabular}


This content is unavailable.

Please consult the print version for access.

Plan \#1

Source: https://accessorydwellings.org/category/projects/floor-plan/

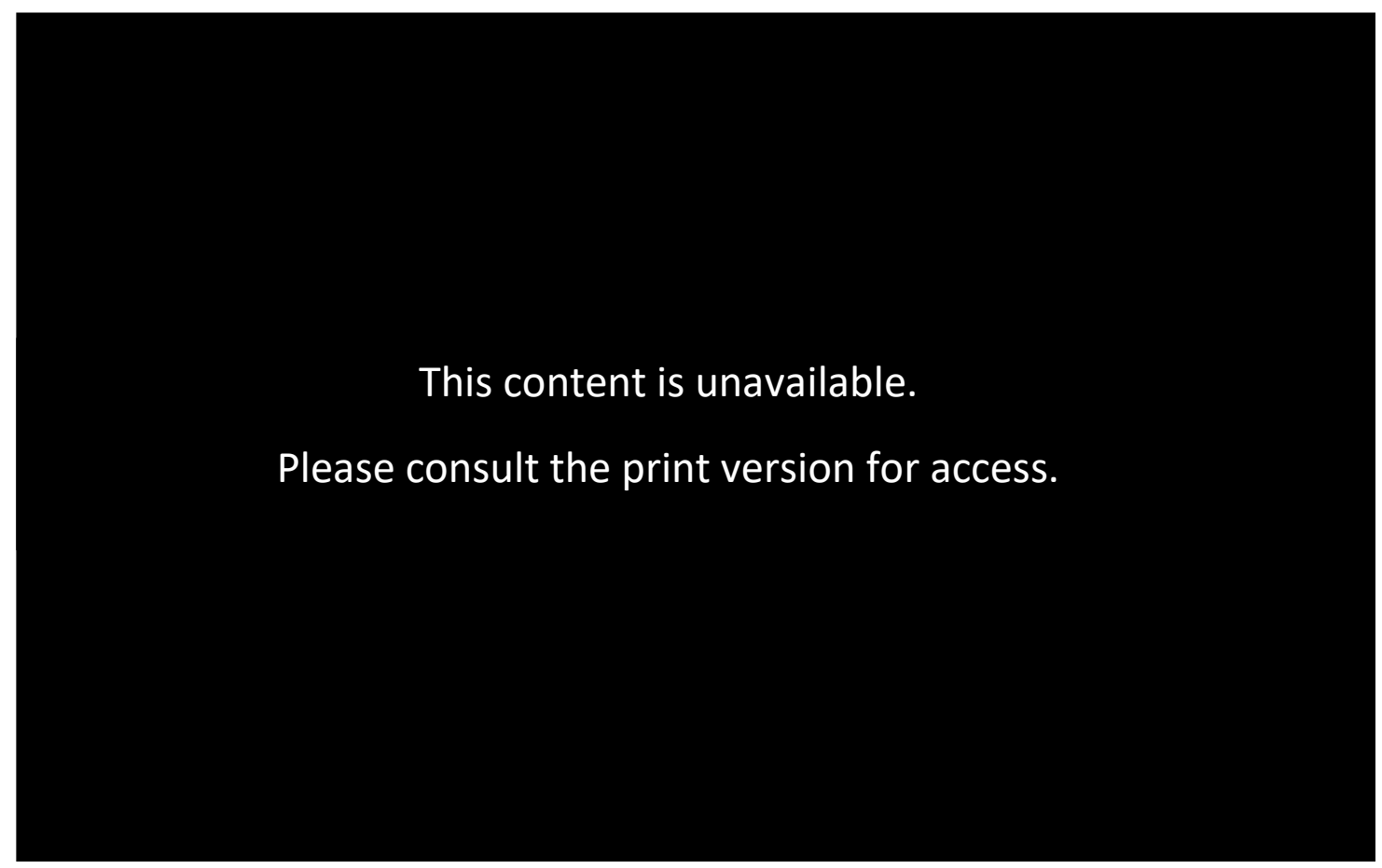

Plan \#2

Source: https://accessorydwellings.org/2014/01/10/susan-morays-adu-updating-history-inladds/ 
This content is unavailable.

Please consult the print version for access.

Plan \#3

Source: https://www.houseplans.com/plan/544-square-feet-2-bedrooms-1-bathroomcottage-house-plans-0-garage-36521

This content is unavailable.

Please consult the print version for access.

Plan \#4

Source: https://www.houseplans.com/plan/569-square-feet-1-bedrooms-1-bathroomcountry-house-plans-0-garage-32067 
This content is unavailable.

Please consult the print version for access.

Plan \#5

Source: https://www.houseplans.com/plan/576-square-feet-1-bedrooms-0-bathroomcottage-house-plans-0-garage-36522

This content is unavailable.

Please consult the print version for access.

Plan \#6

Source: https://www.houseplans.com/plan/543-square-feet-2-bedrooms-1-bathroomcontemporary-house-plans-1-garage-37073 
This content is unavailable.

Please consult the print version for access.

Plan \#7

Source: https://www.houseplans.com/plan/557-square-feet-2-bedroom-1-bathroom-0garage-cottage-39331

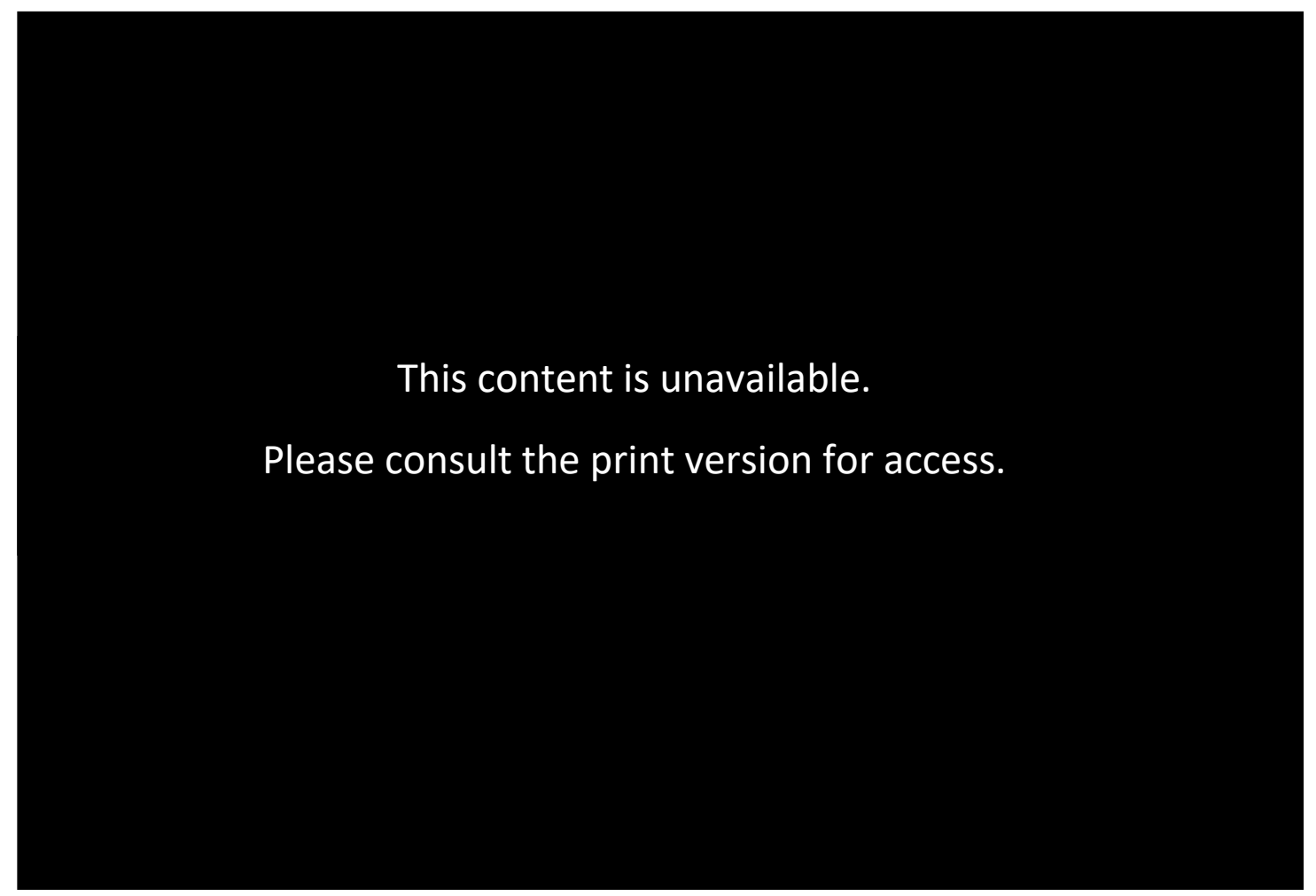

Plan \#8

Source: https://www.houseplans.com/plan/544-square-feet-1-bedroom-1-bathroom-0garage-cottage-39166 
This content is unavailable.

Please consult the print version for access.

Plan \#9

Source: https://www.houseplans.com/plan/566-square-feet-2-bedrooms-1-bathroomtraditional-house-plans-1-garage-37072

This content is unavailable.

Please consult the print version for access.

Plan \#10

Source: https://www.houseplans.com/plan/550-square-feet-1-bedroom-1-bathroom-0garage-cottage-ranch-craftsman-country-sp125062 
This content is unavailable.

Please consult the print version for access.

Plan \#11

Source: https://www.houseplans.com/plan/640-square-feet-2-bedroom-2-bathroom-0garage-craftsman-cabin-country-cottage-58477

This content is unavailable.

Please consult the print version for access.

Plan \#12

Source: https://www.houseplans.com/plan/540-square-feet-2-bedrooms-1-bathroombeach-home-plans-0-garage-32888 
This content is unavailable.

Please consult the print version for access.

Source: https://www.houseplans.com/plan/576-square-feet-1-bedroom-1-bathroom-0garage-craftsman-39858

This content is unavailable.

Please consult the print version for access.

Plan \#14

Source: https://www.houseplans.com/plan/572-square-feet-2-bedroom-1-bathroom-0garage-contemporary-40019 
This content is unavailable.

Please consult the print version for access.

Plan \#15

Source: https://www.houseplans.com/plan/576-square-feet-2-bedrooms-1-bathroomcountry-house-plans-0-garage-32623

This content is unavailable.

Please consult the print version for access.

Plan \#16

Source: https://www.houseplans.com/plan/576-square-feet-1-bedrooms-1-bathroomranch-house-plans-0-garage-35 
This content is unavailable.

Please consult the print version for access.

Source: https://www.familyhomeplans.com/house-plan-51458

This content is unavailable.

Please consult the print version for access.

Plan \#18

Source: https://www.familyhomeplans.com/house-plan-5851 
- GPA rage of $55.01 \mathrm{~m}^{2}-60 \mathrm{~m}^{2}$

\begin{tabular}{|c|c|c|c|c|c|c|c|c|c|c|c|c|c|c|c|c|c|c|}
\hline \multirow{2}{*}{$\begin{array}{l}\text { Pla } \\
n\end{array}$} & \multirow{2}{*}{$\begin{array}{l}\text { GPA } \\
\left(\mathrm{m}^{2}\right)\end{array}$} & \multirow[t]{2}{*}{ NB } & \multicolumn{4}{|c|}{ Sanitation space } & \multicolumn{3}{|c|}{$\begin{array}{l}\text { Kitchen } \\
\text { form }\end{array}$} & \multirow[t]{2}{*}{ NW } & \multicolumn{2}{|c|}{ Laundry space } & \multirow[t]{2}{*}{ ND } & \multicolumn{4}{|c|}{ Plan shape } & \multirow{2}{*}{$\begin{array}{l}\text { Wet } \\
\text { zone }\end{array}$} \\
\hline & & & Ensuites & Jack \&jill & Bathroom & $\begin{array}{l}\text { Shower } \\
\text { room }\end{array}$ & $\begin{array}{l}\text { Lin } \\
\mathrm{e}\end{array}$ & $\mathrm{L}$ & $U$ & & Separated & $\begin{array}{l}\text { Shar } \\
\mathrm{e}\end{array}$ & & Square & Rectangle & $\mathrm{L}$ & Irregular & \\
\hline 19 & 55.80 & 1 & & & & $\mathrm{~V}$ & & & $\mathrm{~V}$ & 1 & & $\mathrm{~V}$ & $x$ & & $\mathrm{~V}$ & & & $x$ \\
\hline 20 & 57.00 & 1 & & & & $\mathrm{~V}$ & & $\mathrm{~V}$ & & 1 & & $\mathrm{~V}$ & $x$ & & & $\mathrm{v}$ & & $\mathrm{V}$ \\
\hline 21 & 59.90 & 2 & & & & $\mathrm{~V}$ & & $\mathrm{~V}$ & & 2 & $\sqrt{ }$ & & $x$ & & & & $\mathrm{~V}$ & $x$ \\
\hline 22 & 60.00 & 2 & & & & $\mathrm{~V}$ & & $\mathrm{~V}$ & & 2 & & $\mathrm{~V}$ & $x$ & & & $\mathrm{~V}$ & & $x$ \\
\hline 23 & 60.00 & 2 & & & & $\mathrm{~V}$ & $\mathrm{~V}$ & & & 2 & & $\mathrm{~V}$ & $x$ & & $\mathrm{~V}$ & & & $\mathrm{~V}$ \\
\hline 24 & 59.80 & 2 & & & & $\mathrm{~V}$ & $\mathrm{~V}$ & & & 2 & $\mathrm{~V}$ & & $x$ & & & $\mathrm{~V}$ & & $\mathrm{~V}$ \\
\hline 25 & 60.00 & 2 & & & & $\mathrm{~V}$ & & & $\mathrm{~V}$ & 2 & $\mathrm{~V}$ & & $x$ & & $\mathrm{~V}$ & & & $\mathrm{~V}$ \\
\hline 26 & 60.00 & 2 & & & & $\mathrm{~V}$ & & $\mathrm{~V}$ & & 2 & $\mathrm{~V}$ & & $x$ & & & & $\mathrm{~V}$ & $\mathrm{~V}$ \\
\hline 27 & 60.00 & 2 & & & & $\mathrm{~V}$ & & & $\mathrm{~V}$ & 2 & $V$ & & $x$ & & & $\mathrm{v}$ & & $\mathrm{V}$ \\
\hline 28 & 60.00 & 2 & & & & $\mathrm{~V}$ & & & $\mathrm{~V}$ & 2 & $\mathrm{~V}$ & & $x$ & & $\mathrm{~V}$ & & & $x$ \\
\hline 29 & 60.00 & 2 & & & & $\mathrm{~V}$ & & & $\mathrm{~V}$ & 2 & & $\mathrm{~V}$ & $x$ & & $\mathrm{~V}$ & & & $\mathrm{~V}$ \\
\hline 30 & 60.00 & 2 & & & & $\mathrm{~V}$ & & $\mathrm{~V}$ & & 2 & $\mathrm{~V}$ & & $x$ & & & & $\mathrm{~V}$ & $\mathrm{~V}$ \\
\hline 31 & 60.00 & 2 & & & & $\mathrm{~V}$ & & $\mathrm{~V}$ & & 2 & & $\mathrm{~V}$ & $x$ & & $\mathrm{~V}$ & & & $\mathrm{~V}$ \\
\hline 32 & 60.00 & 2 & & & & $\mathrm{~V}$ & & $\mathrm{~V}$ & & 2 & $\sqrt{ }$ & & $x$ & & & $\mathrm{v}$ & & $x$ \\
\hline 33 & 60.00 & 2 & & & $\mathrm{~V}$ & & & $\mathrm{~V}$ & & 2 & & $X$ & $X$ & & & $\mathrm{~V}$ & & $x$ \\
\hline 34 & 60.00 & 3 & & & & $\mathrm{~V}$ & $\mathrm{~V}$ & & & 2 & & $\mathrm{~V}$ & $x$ & & $\mathrm{~V}$ & & & $x$ \\
\hline 35 & 60.00 & 3 & & & & $\mathrm{~V}$ & $\mathrm{~V}$ & & & 3 & & $\mathrm{~V}$ & $x$ & & & & $\mathrm{~V}$ & $\mathrm{~V}$ \\
\hline 36 & 55.74 & 1 & & $\mathrm{~V}$ & & & $\mathrm{~V}$ & & & 1 & & $x$ & 3 & & $\mathrm{~V}$ & & & $\mathrm{~V}$ \\
\hline 37 & 59.45 & 1 & & & $\mathrm{~V}$ & & & $\mathrm{~V}$ & & 2 & & $x$ & 2 & & & & $\mathrm{~V}$ & $x$ \\
\hline 38 & 59.45 & 2 & & & $\mathrm{~V}$ & & $\mathrm{~V}$ & & & 2 & $\mathrm{~V}$ & & 1 & & $\mathrm{~V}$ & & & $\mathrm{~V}$ \\
\hline 39 & 55.55 & 1 & & & $\mathrm{~V}$ & & & & $\mathrm{~V}$ & 1 & & $\mathrm{~V}$ & 1 & & $\mathrm{~V}$ & & & $\mathrm{~V}$ \\
\hline 40 & 55.74 & 1 & & & & $\mathrm{~V}$ & $\mathrm{~V}$ & & & 2 & $\mathrm{~V}$ & & $x$ & & $\mathrm{~V}$ & & & $\mathrm{~V}$ \\
\hline 41 & 58.43 & 2 & & $\mathrm{~V}$ & & & & $\mathrm{~V}$ & & 2 & $V$ & & 1 & & & $\mathrm{v}$ & & $x$ \\
\hline 42 & 55.74 & 2 & & & & $\mathrm{~V}$ & $\mathrm{~V}$ & & & 2 & $x$ & & 1 & & $\mathrm{~V}$ & & & $x$ \\
\hline 43 & 59.45 & 1 & & & $\mathrm{~V}$ & & $\mathrm{~V}$ & & & 1 & $\mathrm{~V}$ & & 2 & & $\mathrm{~V}$ & & & $x$ \\
\hline 44 & 57.97 & 1 & & & $\mathrm{~V}$ & & & $\mathrm{~V}$ & & 2 & & $\mathrm{~V}$ & $x$ & & $\mathrm{~V}$ & & & $\mathrm{~V}$ \\
\hline 45 & 55.74 & 1 & & & & $\mathrm{~V}$ & & $\mathrm{~V}$ & & 1 & $\mathrm{~V}$ & & $x$ & & & $\mathrm{v}$ & & $\mathrm{V}$ \\
\hline 46 & 58.62 & 2 & & & & $V$ & $\mathrm{~V}$ & & & 2 & $V$ & & 2 & & & & $\mathrm{~V}$ & $x$ \\
\hline
\end{tabular}


This content is unavailable.

Please consult the print version for access.

Plan \#19

Source: Granny flat Australia

This content is unavailable.

Please consult the print version for access.

Plan \#20

Source: Granny flat Australia 
This content is unavailable.

Please consult the print version for access.

Plan \#21

Source: Granny flat Australia

This content is unavailable.

Please consult the print version for access.

Plan \#22

Source: Granny flat Australia 
This content is unavailable.

Please consult the print version for access.

Plan \#23

Source: Granny flat Australia

This content is unavailable.

Please consult the print version for access.

Plan \#24

Source: Granny flat Australia 
This content is unavailable.

Please consult the print version for access.

Plan \#25

Source: Granny flat Australia

This content is unavailable.

Please consult the print version for access.

Plan \#26

Source: Granny flat Australia 
This content is unavailable.

Please consult the print version for access.

Plan \#27

Source: Granny flat Australia

This content is unavailable.

Please consult the print version for access.

Plan \#28

Source: Granny flat Australia 
This content is unavailable.

Please consult the print version for access.

Plan \#29

Source: Granny flat Australia

This content is unavailable.

Please consult the print version for access.

Plan \#30

Source: Granny flat Australia 
This content is unavailable.

Please consult the print version for access.

Plan \#31

Source: Granny flat Australia

This content is unavailable.

Please consult the print version for access.

Plan \#32

Source: Granny flat Australia 
This content is unavailable.

Please consult the print version for access.

Plan \#33

Source: Granny flat Australia

This content is unavailable.

Please consult the print version for access.

Plan \#34

Source: Granny flat Australia 
This content is unavailable.

Please consult the print version for access.

Plan \#35

Source: Granny flat Australia

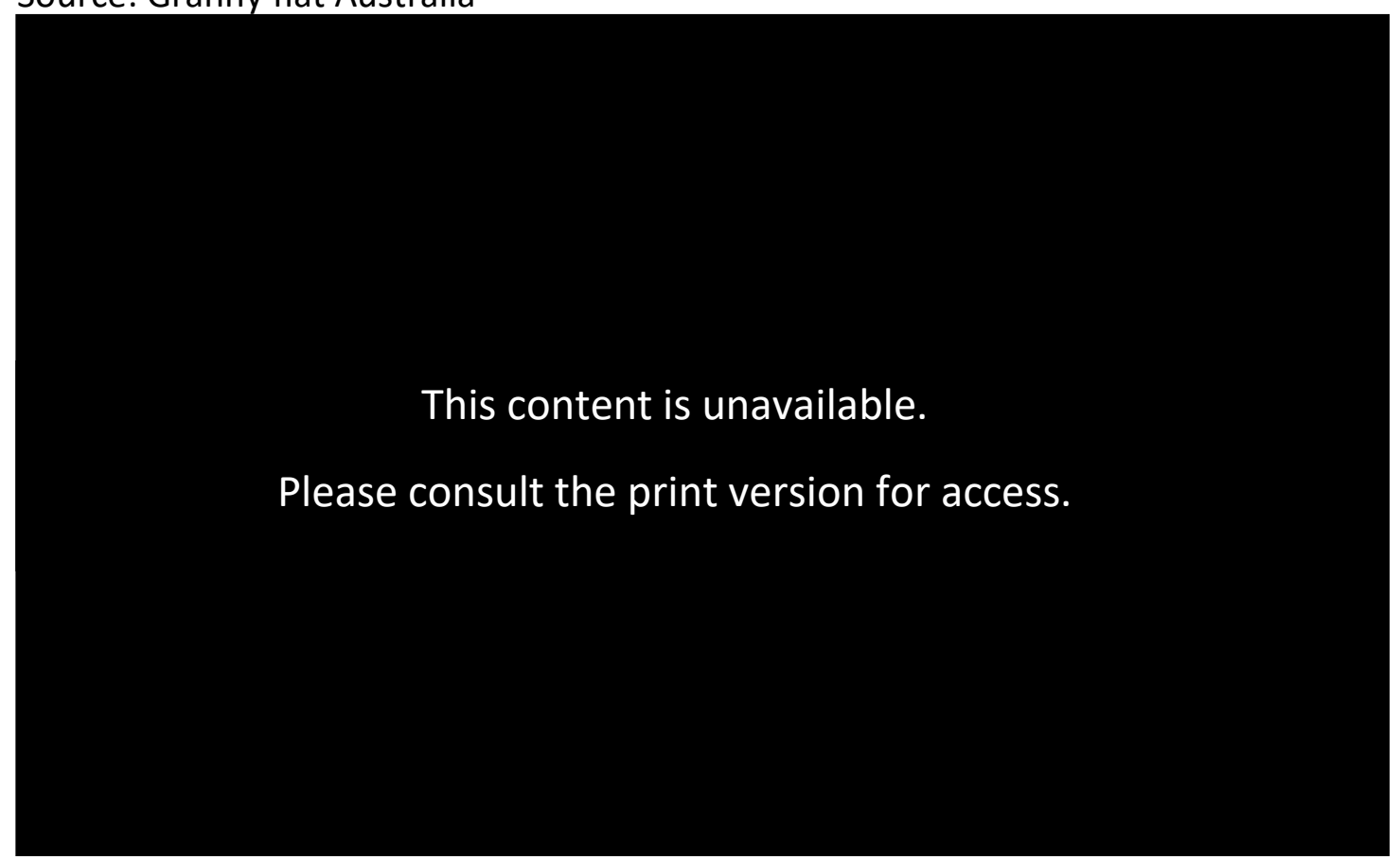

Plan \#36

Source: https://www.houseplans.com/plan/600-square-feet-1-bedrooms-1-bathroomcottage-house-plans-0-garage-25908 
This content is unavailable.

Please consult the print version for access.

Plan \#37

Source: https://www.houseplans.com/plan/640-square-feet-1-bedrooms-1-bathroomcontemporary-house-plans-0-garage-35272

This content is unavailable.

Please consult the print version for access.

\section{Plan \#38}

Source: https://www.houseplans.com/plan/640-square-feet-1-bedrooms-1-bathroomcontemporary-house-plans-0-garage-36684 
This content is unavailable.

Please consult the print version for access.

Plan \#39

Source: https://www.houseplans.com/plan/598-square-feet-1-bedrooms-1-bathroombeach-home-plans-0-garage-33160

This content is unavailable.

Please consult the print version for access.

Plan \#40

Source: https://www.houseplans.com/plan/600-square-feet-1-bedrooms-1-bathroomcontemporary-house-plans-0-garage-35282 
This content is unavailable.

Please consult the print version for access.

Plan \#41

Source: https://www.houseplans.com/plan/629-square-feet-2-bedroom-1-bathroom-0garage-cottage-craftsman-40874

This content is unavailable.

Please consult the print version for access.

Plan \#42

Source:https://www.google.co.nz/search?q=sq+ft+to+sq+m\&rlz=1C1CHBD enNZ756NZ756 \&oq=sq+ft+to+sq+m\&aqs=chrome.0.69i59j6j69i59j013.6359j0j7\&sourceid=chrome\&ie=UTF$\underline{8}$ 
This content is unavailable.

Please consult the print version for access.

Plan \#43

Source: https://www.houseplans.com/plan/640-square-feet-1-bedrooms-1-bathroombungalow-house-plans-0-garage-36563

This content is unavailable.

Please consult the print version for access.

Plan \#44

Source: https://www.houseplans.com/plan/624-square-feet-1-bedrooms-1-bathroomtraditional-house-plans-0-garage-30360 
This content is unavailable.

Please consult the print version for access.

Plan \#45

Source: https://www.houseplans.com/plan/600-square-feet-1-bedrooms-1-bathroomsouthwest-contemporary-plans-0-garage-13068

This content is unavailable.

Please consult the print version for access.

Plan \#46

Source: https://www.familyhomeplans.com/house-plan-76460 
- GPA rage of $60.01 m^{2}-65 m^{2}$

\begin{tabular}{|c|c|c|c|c|c|c|c|c|c|c|c|c|c|c|c|c|c|c|}
\hline \multirow{2}{*}{$\begin{array}{l}\text { Pla } \\
n\end{array}$} & \multirow{2}{*}{$\begin{array}{l}\text { GPA } \\
\left(\mathrm{m}^{2}\right)\end{array}$} & \multirow[t]{2}{*}{ NB } & \multicolumn{4}{|c|}{ Sanitation space } & \multicolumn{3}{|c|}{$\begin{array}{l}\text { Kitchen } \\
\text { form }\end{array}$} & \multirow[t]{2}{*}{ NW } & \multicolumn{2}{|c|}{ Laundry space } & \multirow[t]{2}{*}{ ND } & \multicolumn{4}{|c|}{ Plan shape } & \multirow{2}{*}{$\begin{array}{l}\text { Wet } \\
\text { zone }\end{array}$} \\
\hline & & & Ensuites & $\begin{array}{l}\text { Jack \& } \\
\text { Jill }\end{array}$ & Bathroom & $\begin{array}{l}\text { Shower } \\
\text { room }\end{array}$ & $\begin{array}{l}\text { Lin } \\
\mathrm{e}\end{array}$ & $\mathrm{L}$ & $U$ & & Separated & $\begin{array}{l}\text { Shar } \\
\mathrm{e}\end{array}$ & & Square & Rectangle & $\mathrm{L}$ & Irregular & \\
\hline 47 & 62.43 & 2 & & & $\mathrm{~V}$ & & & $\mathrm{~V}$ & & 1 & $\sqrt{ }$ & & 2 & & $\sqrt{ }$ & & & $\mathrm{V}$ \\
\hline 48 & 62.43 & 1 & & & & $\mathrm{~V}$ & $\mathrm{~V}$ & & & 3 & & $\mathrm{~V}$ & 2 & & & & $\mathrm{~V}$ & $x$ \\
\hline 49 & 64.75 & 1 & & & $\mathrm{~V}$ & & & $\mathrm{~V}$ & & 4 & $\sqrt{ }$ & & 2 & & & & $\mathrm{~V}$ & $x$ \\
\hline 50 & 64.00 & 1 & & & & $\mathrm{~V}$ & & & $\mathrm{~V}$ & 1 & & $\mathrm{~V}$ & 1 & & & & $\mathrm{~V}$ & $\mathrm{~V}$ \\
\hline 51 & 64.19 & 2 & & & & $\mathrm{~V}$ & & $\mathrm{~V}$ & & 2 & $\mathrm{~V}$ & & 1 & & & & $\mathrm{~V}$ & $\mathrm{~V}$ \\
\hline 52 & 62.80 & 1 & & & $\mathrm{~V}$ & & $\mathrm{~V}$ & & & 1 & V & & 1 & $\mathrm{~V}$ & & & & $\mathrm{~V}$ \\
\hline 53 & 64.66 & 2 & & & & $\mathrm{~V}$ & & $\mathrm{~V}$ & & 2 & $x$ & & 1 & & & & $\mathrm{~V}$ & $\mathrm{~V}$ \\
\hline 54 & 63.17 & 1 & & & $\mathrm{~V}$ & & & & $\mathrm{~V}$ & 1 & $x$ & & 1 & & & $\mathrm{v}$ & & $x$ \\
\hline 55 & 61.31 & 3 & & & & $\mathrm{~V}$ & $\mathrm{~V}$ & & & 3 & $x$ & & 1 & & $\mathrm{~V}$ & & & $\mathrm{~V}$ \\
\hline 56 & 64.56 & 1 & & $\mathrm{~V}$ & & & & $\mathrm{~V}$ & & 2 & $\mathrm{~V}$ & & 1 & & & & $\mathrm{~V}$ & $\mathrm{~V}$ \\
\hline 57 & 63.26 & 2 & & & & $\mathrm{~V}$ & & $\mathrm{~V}$ & & $x$ & & $x$ & 1 & & & $\mathrm{v}$ & & $\mathrm{V}$ \\
\hline 58 & 63.54 & 2 & & & $\mathrm{~V}$ & & $\mathrm{~V}$ & & & 3 & & $x$ & 1 & & & $\mathrm{v}$ & & $\mathrm{V}$ \\
\hline 59 & 60.94 & 1 & & $\mathrm{~V}$ & & & $\mathrm{~V}$ & & & $x$ & & $x$ & 1 & & & $\mathrm{v}$ & & $\mathrm{V}$ \\
\hline 60 & 62.43 & 1 & & & & $\mathrm{~V}$ & & $\mathrm{~V}$ & & 1 & $V$ & & 1 & & & $\mathrm{v}$ & & $\mathrm{V}$ \\
\hline 61 & 63.91 & 2 & & $\mathrm{~V}$ & & & $\mathrm{~V}$ & & & $x$ & $\mathrm{~V}$ & & 1 & & $\mathrm{~V}$ & & & $\mathrm{~V}$ \\
\hline 62 & 62.89 & 2 & & & $\mathrm{~V}$ & & $\mathrm{~V}$ & & & 2 & $\mathrm{~V}$ & & 1 & & & $\mathrm{v}$ & & $x$ \\
\hline
\end{tabular}


This content is unavailable.

Please consult the print version for access.

Plan \#47

Source: https://www.houseplans.com/plan/672-square-feet-2-bedrooms-1-bathroomcountry-house-plans-0-garage-36985

This content is unavailable.

Please consult the print version for access.

Plan \#48

Source: https://www.houseplans.com/plan/672-square-feet-1-bedrooms-1-bathroomvacation-house-plan-0-garage-37403 
This content is unavailable.

Please consult the print version for access.

Plan \#49

Source: https://www.houseplans.com/plan/697-square-feet-1-bedrooms-1-bathroomcraftsman-home-plans-0-garage-33439

This content is unavailable.

Please consult the print version for access.

Plan \#50

Source: http://content.aucklanddesignmanual.co.nz/resources/case-

studies/living places dandenong/Documents/Case\%20study\%20 Living\%20Places.pdf 
This content is unavailable.

Please consult the print version for access.

Plan \#51

Source: https://www.houseplans.com/plan/691-square-feet-2-bedroom-1-bathroom-0garage-country-bungalow-craftsman-41321

This content is unavailable.

Please consult the print version for access.

Plan \#52

Source: https://www.houseplans.com/plan/676-square-feet-1-bedrooms-1-bathroom-farmhouse-plans-0-garage-1257 
This content is unavailable.

Please consult the print version for access.

Plan \#53

Source: https://www.houseplans.com/plan/696-square-feet-2-bedrooms-1-bathroomcontemporary-house-plans-0-garage-7083

This content is unavailable.

Please consult the print version for access.

Plan \#54

Source: https://www.houseplans.com/plan/680-square-feet-1-bedrooms-1-bathroom-

sunbelt-home-plans-1-garage-16404 
This content is unavailable.

Please consult the print version for access.

Plan \#55

Source: https://www.houseplans.com/plan/660-square-feet-3-bedroom-1-bathroom-0garage-country-39832

This content is unavailable.

Please consult the print version for access.

Plan \#56

Source: https://www.houseplans.com/plan/695-square-feet-1-bedrooms-1-bathroomcontemporary-house-plans-0-garage-1034 
This content is unavailable.

Please consult the print version for access.

Plan \#57

Source: https://www.familyhomeplans.com/house-plan-43204

This content is unavailable.

Please consult the print version for access.

Plan \#58

Source: https://www.familyhomeplans.com/house-plan-54745 
This content is unavailable.

Please consult the print version for access.

Plan \#59

Source: https://www.familyhomeplans.com/house-plan-73894

This content is unavailable.

Please consult the print version for access.

Plan \#60

Source: https://www.familyhomeplans.com/house-plan-56580 
This content is unavailable.

Please consult the print version for access.

Plan \#61

Source: https://www.familyhomeplans.com/house-plan-67583

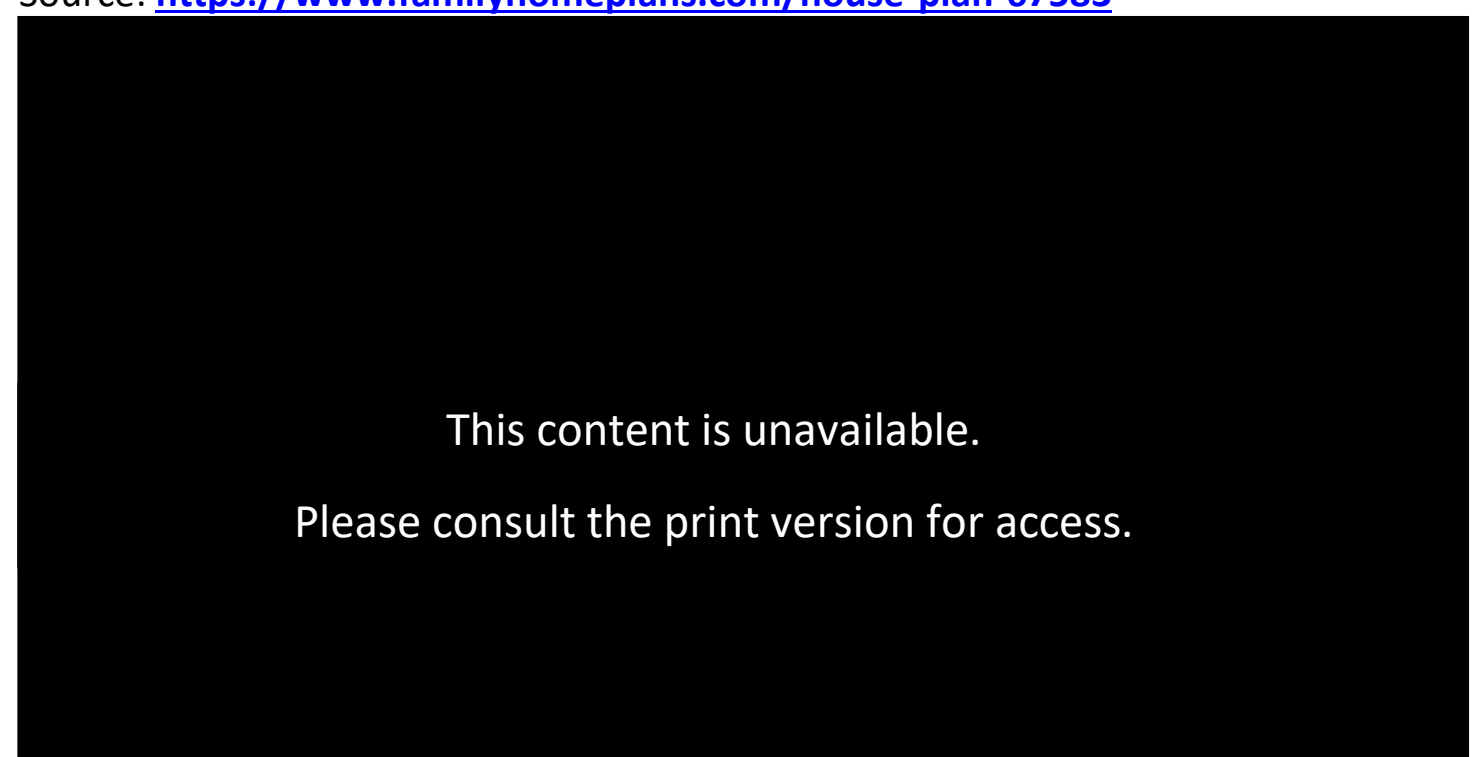

Plan \#62

Source: http://www.cityhomeconstructions.com/house-2/exploiting-the-help-of-tinyhouse-plans-free/attachment/tiny-home-plans-free/ 
- GPA rage of $65.01 \mathrm{~m}^{2}-70 \mathrm{~m}^{2}$

\begin{tabular}{|c|c|c|c|c|c|c|c|c|c|c|c|c|c|c|c|c|c|c|}
\hline \multirow{2}{*}{$\begin{array}{l}\text { Pla } \\
\text { n }\end{array}$} & \multirow{2}{*}{$\begin{array}{l}\text { GPA } \\
\left(\mathrm{m}^{2}\right)\end{array}$} & \multirow[t]{2}{*}{ NB } & \multicolumn{4}{|c|}{ Sanitation space } & \multicolumn{3}{|c|}{$\begin{array}{l}\text { Kitchen } \\
\text { form }\end{array}$} & \multirow[t]{2}{*}{ NW } & \multicolumn{2}{|c|}{ Laundry space } & \multirow[t]{2}{*}{ ND } & \multicolumn{4}{|c|}{ Plan shape } & \multirow{2}{*}{$\begin{array}{l}\text { Wet } \\
\text { zone }\end{array}$} \\
\hline & & & Ensuites & $\begin{array}{l}\text { Jack \& } \\
\text { Jill }\end{array}$ & Bathroom & $\begin{array}{l}\text { Shower } \\
\text { room }\end{array}$ & $\begin{array}{l}\text { Lin } \\
\mathrm{e}\end{array}$ & $\mathrm{L}$ & $U$ & & Separated & $\begin{array}{l}\text { Shar } \\
\mathrm{e}\end{array}$ & & Square & Rectangle & $\mathrm{L}$ & Irregular & \\
\hline 63 & 65.03 & 2 & $\mathrm{VV}^{3}$ & & & & & $\mathrm{v}$ & & 2 & & $x$ & 2 & & & & $\mathrm{~V}$ & $\mathrm{~V}$ \\
\hline 64 & 66.98 & 2 & & & $\mathrm{~V}$ & & $\mathrm{~V}$ & & & $x$ & & $\mathrm{~V}$ & 1 & & & $\mathrm{v}$ & & $x$ \\
\hline 65 & 97.81 & 2 & & & $\mathrm{~V}$ & & & $\mathrm{~V}$ & & 4 & $\mathrm{~V}$ & & 2 & & & & $\mathrm{~V}$ & $x$ \\
\hline 66 & 65.40 & 1 & & & & $\mathrm{~V}$ & & $\mathrm{v}$ & & 2 & $\mathrm{~V}$ & & 1 & & $\mathrm{~V}$ & & & $x$ \\
\hline 67 & 67.63 & 2 & & & $\mathrm{~V}$ & & & $\mathrm{v}$ & & $x$ & $\mathrm{~V}$ & & 1 & & & & $\mathrm{~V}$ & $\mathrm{~V}$ \\
\hline 68 & 68.09 & 2 & & & $\mathrm{~V}$ & & & $\mathrm{~V}$ & & 2 & $\mathrm{~V}$ & & 1 & & & $\mathrm{~V}$ & & $\mathrm{~V}$ \\
\hline 69 & 65.40 & 2 & & & $\mathrm{~V}$ & & $\mathrm{~V}$ & & & 2 & $\mathrm{~V}$ & & 1 & & $\mathrm{v}$ & & & $\mathrm{V}$ \\
\hline 70 & 66.23 & 2 & & & & $\mathrm{~V}$ & & $\mathrm{~V}$ & & 3 & $\mathrm{~V}$ & & 1 & & & $\mathrm{v}$ & & $x$ \\
\hline 71 & 68.37 & 2 & & & $\mathrm{~V}$ & & & $\mathrm{~V}$ & & 2 & $\mathrm{~V}$ & & 2 & & & $\mathrm{v}$ & & $x$ \\
\hline 72 & 69.77 & 2 & & & $\mathrm{~V}$ & & & $\mathrm{~V}$ & & 3 & $\mathrm{~V}$ & & 1 & & & & $\mathrm{~V}$ & $x$ \\
\hline 73 & 65.03 & 2 & & & $\mathrm{~V}$ & & & $\mathrm{~V}$ & & 3 & $\mathrm{~V}$ & & 1 & & & & $\mathrm{~V}$ & $x$ \\
\hline 74 & 67.81 & 1 & $\mathrm{~V}$ & & & & & & $\mathrm{~V}$ & 1 & $\mathrm{~V}$ & & 1 & & & $\mathrm{v}$ & & $x$ \\
\hline 75 & 67.16 & 1 & $\mathrm{~V}^{4}$ & & & & & $\mathrm{~V}$ & & 1 & & $x$ & 1 & & & & $\mathrm{~V}$ & $x$ \\
\hline 76 & 65.03 & 2 & & & & $\mathrm{~V}$ & $\mathrm{~V}$ & & & 1 & $\mathrm{~V}$ & & 1 & & & $\mathrm{v}$ & & $\mathrm{V}$ \\
\hline 77 & 65.03 & 2 & & & $\mathrm{~V}$ & & & $\mathrm{~V}$ & & 3 & $\mathrm{~V}$ & & 1 & & & & $\mathrm{~V}$ & $x$ \\
\hline 78 & 66.61 & 1 & & & & $\mathrm{~V}$ & & & $\mathrm{~V}$ & 1 & & $x$ & 1 & & & $\mathrm{v}$ & & $\mathrm{V}$ \\
\hline 79 & 66.89 & 2 & & & $\mathrm{~V}$ & & & & $\mathrm{~V}$ & 1 & $\mathrm{~V}$ & & 1 & & & & $\mathrm{~V}$ & $\mathrm{~V}$ \\
\hline 80 & 67.63 & 2 & & & $\mathrm{~V}$ & & & $\mathrm{~V}$ & & 3 & $\mathrm{~V}$ & & 1 & & & & $\mathrm{~V}$ & $\mathrm{~V}$ \\
\hline 81 & 69.67 & 2 & & & & $\mathrm{~V}$ & $\mathrm{~V}$ & & & 1 & $\mathrm{~V}$ & & 1 & & & $\mathrm{v}$ & & $x$ \\
\hline 82 & 69.77 & 2 & & & $\mathrm{~V}$ & & & $\mathrm{v}$ & & 3 & $\mathrm{~V}$ & & 1 & & & & $\mathrm{~V}$ & $x$ \\
\hline 83 & 65.49 & 2 & & & $\mathrm{~V}$ & & $\mathrm{~V}$ & & & 2 & $\mathrm{~V}$ & & 1 & & & $\mathrm{v}$ & & $x$ \\
\hline 84 & 66.89 & 1 & & & $\mathrm{~V}$ & & $\mathrm{~V}$ & & & 3 & $\mathrm{~V}$ & & $x$ & & $\mathrm{~V}$ & & & $x$ \\
\hline 85 & 66.89 & 1 & & & $\mathrm{~V}$ & & & $\mathrm{~V}$ & & 2 & $\mathrm{~V}$ & & 1 & & $\mathrm{~V}$ & & & $\mathrm{~V}$ \\
\hline
\end{tabular}

${ }^{3}$ There are two ensuites

${ }^{4}$ This plan has a WC in addition to ensuite 
This content is unavailable.

Please consult the print version for access.

Plan \#63

Source: https://www.ladbs.org/docs/default-source/publications/misc-publications/aduguidebook.pdf?sfvrsn=12

This content is unavailable.

Please consult the print version for access.

Plan \#64

Source: https://accessorydwellings.org/category/projects/floor-plan/ 
This content is unavailable.

Please consult the print version for access.

Plan \#65

Source: https://www.houseplans.com/plan/730-square-feet-2-bedrooms-1-bathroommodern-house-plan-0-garage-36127

This content is unavailable.

Please consult the print version for access.

Plan \#66

Source: https://www.houseplans.com/plan/704-square-feet-1-bedrooms-1-bathroomcountry-house-plans-0-garage-36033 
This content is unavailable.

Please consult the print version for access.

Plan \#67

Source: https://www.houseplans.com/plan/728-square-feet-2-bedrooms-1-bathroomcountry-house-plans-0-garage-1018

This content is unavailable.

Please consult the print version for access.

Plan \#68

Source: https://www.houseplans.com/plan/733-square-feet-2-bedrooms-1-bathroomranch-house-plans-0-garage-35770 
This content is unavailable.

Please consult the print version for access.

Source: https://www.houseplans.com/plan/704-square-feet-2-bedrooms-1-bathroomcraftsman-home-plans-0-garage-10714

This content is unavailable.

Please consult the print version for access.

Plan \#70

Source: https://www.houseplans.com/plan/713-square-feet-2-bedroom-1-bathroom-0garage-contemporary-european-sp124495 
This content is unavailable.

Please consult the print version for access.

Plan \#71

Source: https://www.houseplans.com/plan/736-square-feet-2-bedrooms-1-bathroomcottage-house-plans-0-garage-30980

This content is unavailable.

Please consult the print version for access.

Plan \#72

Source: https://www.houseplans.com/plan/751-square-feet-2-bedrooms-1-bathroomranch-house-plans-0-garage-25863 
This content is unavailable.

Please consult the print version for access.

Plan \#73

Source: https://www.houseplans.com/plan/700-square-feet-2-bedrooms-1-bathroomcountry-house-plans-0-garage-15329

This content is unavailable.

Please consult the print version for access.

Plan \#74

Source: https://www.houseplans.com/plan/730-square-feet-1-bedrooms-1-bathroomtraditional-house-plans-0-garage-15494 
This content is unavailable.

Please consult the print version for access.

Plan \#75

Source: https://www.houseplans.com/plan/723-square-feet-1-bedroom-1-bathroom-0garage-southern-38308

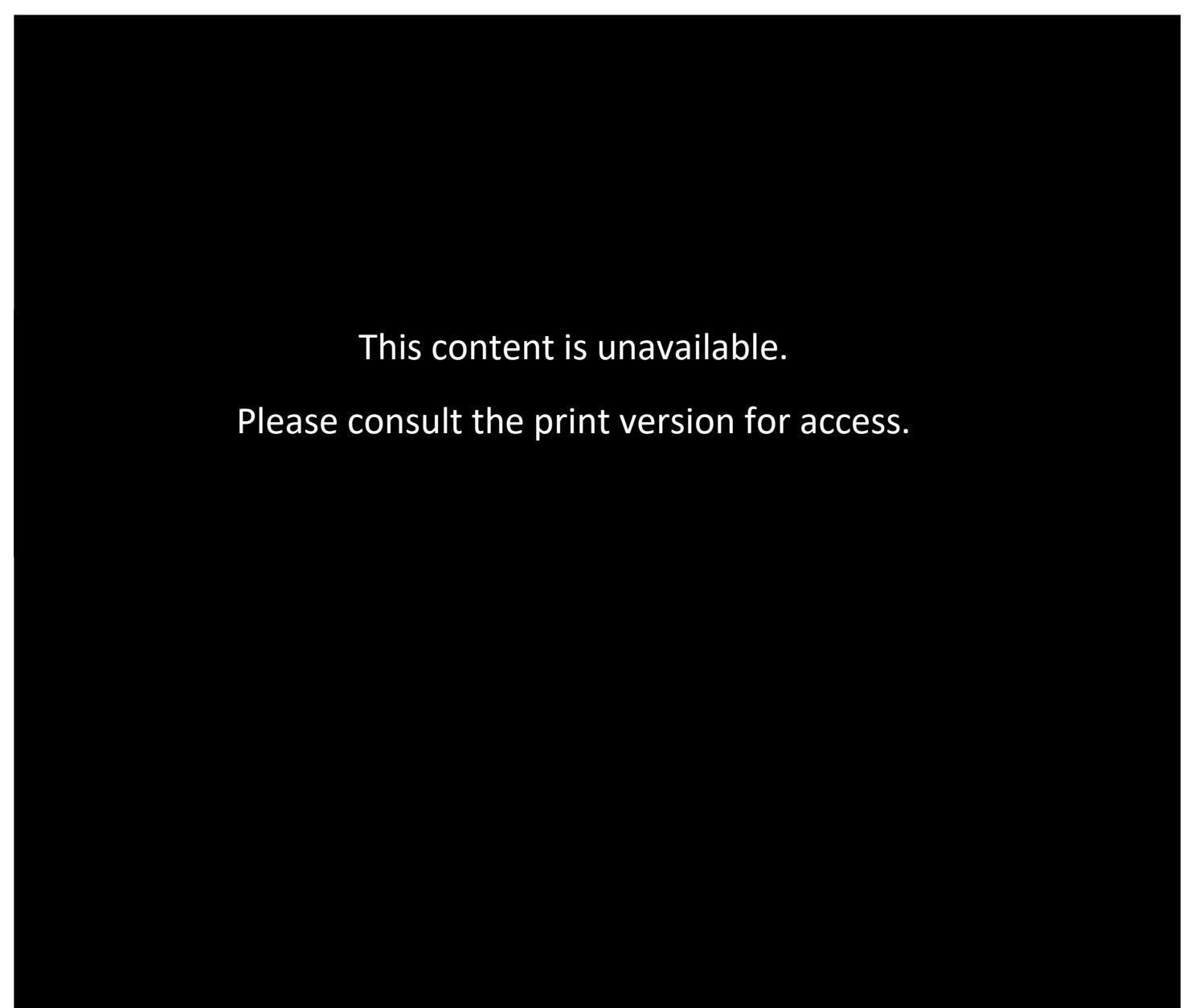

Plan \#76

Source: https://www.familyhomeplans.com/house-plan-76459 
This content is unavailable.

Please consult the print version for access.

Source: https://www.familyhomeplans.com/house-plan-94331

This content is unavailable.

Please consult the print version for access.

Plan \#78

Source: https://www.familyhomeplans.com/house-plan-60564 
This content is unavailable.

Please consult the print version for access.

Source: https://www.familyhomeplans.com/house-plan-58509

This content is unavailable.

Please consult the print version for access.

Plan \#80

Source: https://www.familyhomeplans.com/house-plan-58504 
This content is unavailable.

Please consult the print version for access.

Plan \#81

Source: https://www.familyhomeplans.com/house-plan-70849

This content is unavailable.

Please consult the print version for access.

Plan \#82

Source: https://www.familyhomeplans.com/house-plan-49097 
This content is unavailable.

Please consult the print version for access.

Plan \#83

Source: https://sites.google.com/site/excellentfloorplans/house-plans/16x30h4f

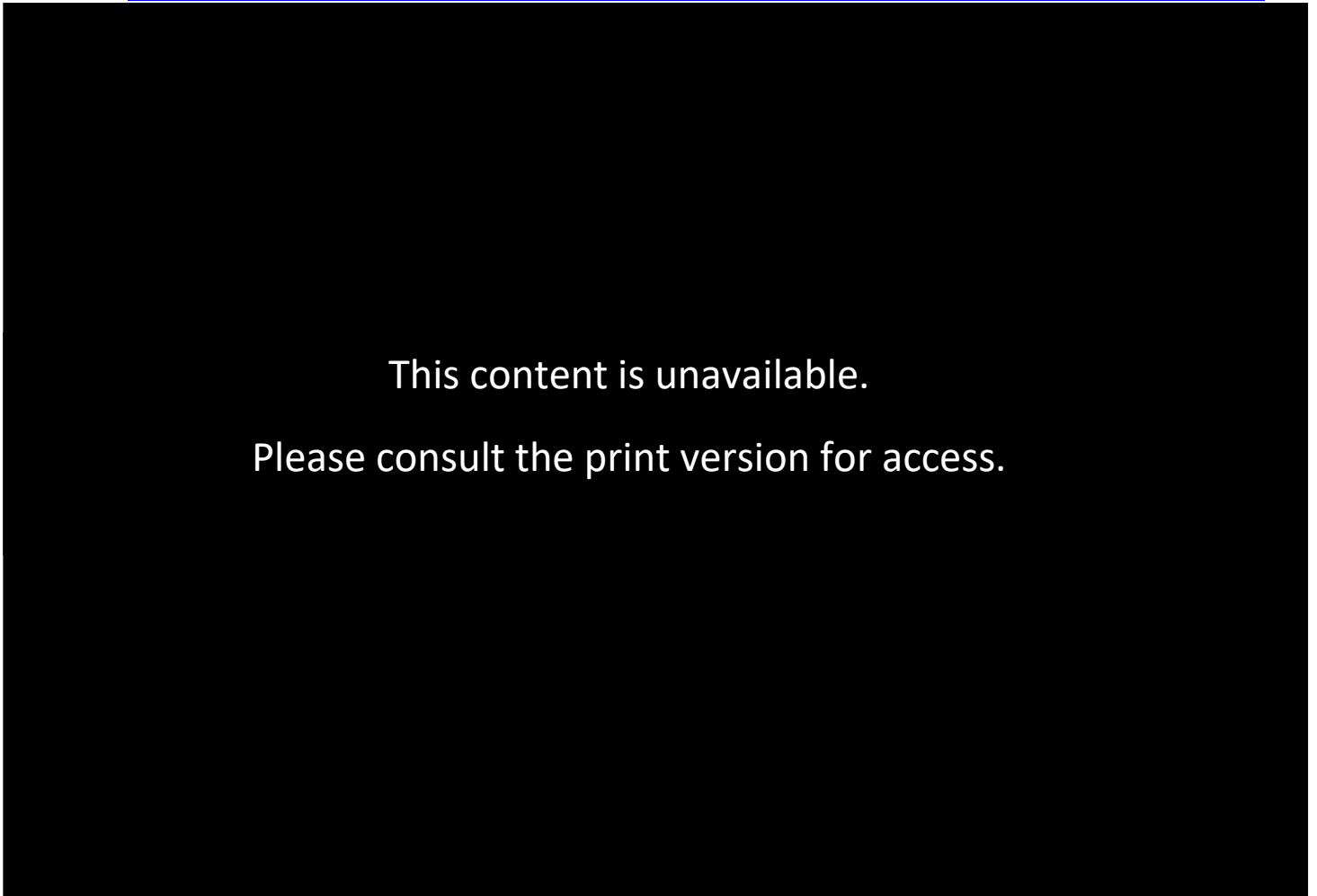

Plan \#84

Source: https://sites.google.com/site/excellentfloorplans/house-plans/30x24h2b 
This content is unavailable.

Please consult the print version for access.

Plan \#85

Source: https://sites.google.com/site/excellentfloorplans/house-plans/24x30h2e 


\section{Appendix D: Construction Details}

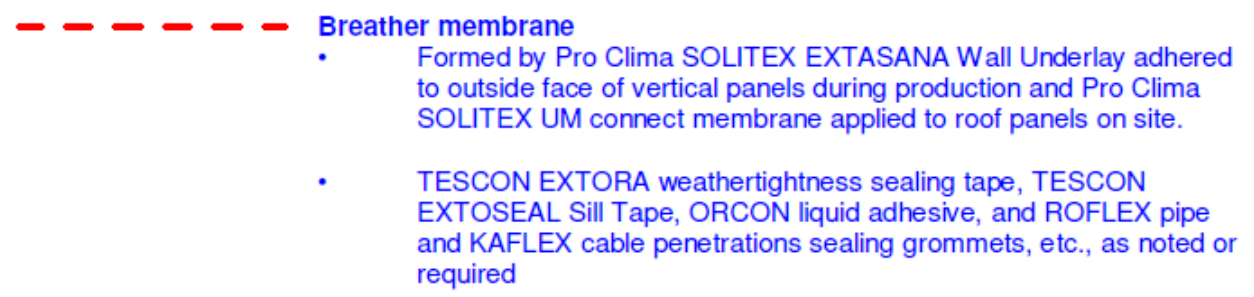
--- - Vapour control layer
- $\quad$ Formed by Inside OSB face of SIP panels. Seal joints, junctions and large penetrations with TESCON Vana and Profil tapes. Seal services penetrations with Kaflex or Roflex grommets
- $\quad$ Target air infiltration rate to be confirmed at the pre-lining stage with a blower door test Targets as follows
- Passive House Standard $\leq 0.6$ ach-1 @50Pa (Mandatory)
- Projects with mechanical ventilation $\leq 1.5$ ach-1@50Pa (recommended)
- Projects with passive ventilation $\leq 3.0$ ach-1 @50Pa (recommended)

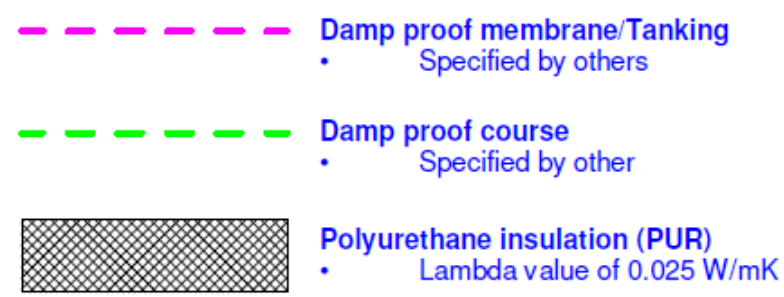

- Lambda value of $0.025 \mathrm{~W} / \mathrm{mK}$

Orlented Strand Board (OSB)

- Lambda value of $0.13 \mathrm{~W} / \mathrm{mK}$

- $\quad$ OSB/3 grade - Load-bearing boards for use in humid conditions

\section{$\checkmark$ General TImber framing}

- Lambda value of $0.13 \mathrm{~W} / \mathrm{mK}$

- $\quad$ SG8/LVL8 grade

- H1.2 treatment unless otherwise noted

镐高 Speclflc TImber framing elements

- Lambda value of $0.13 \mathrm{~W} / \mathrm{mK}$

- $\quad$ Structural grade as noted.

- $\quad \mathrm{H} 1.2$ treatment unless otherwise noted

Foam Sealant

- applied onsite to junctions as indicated. 


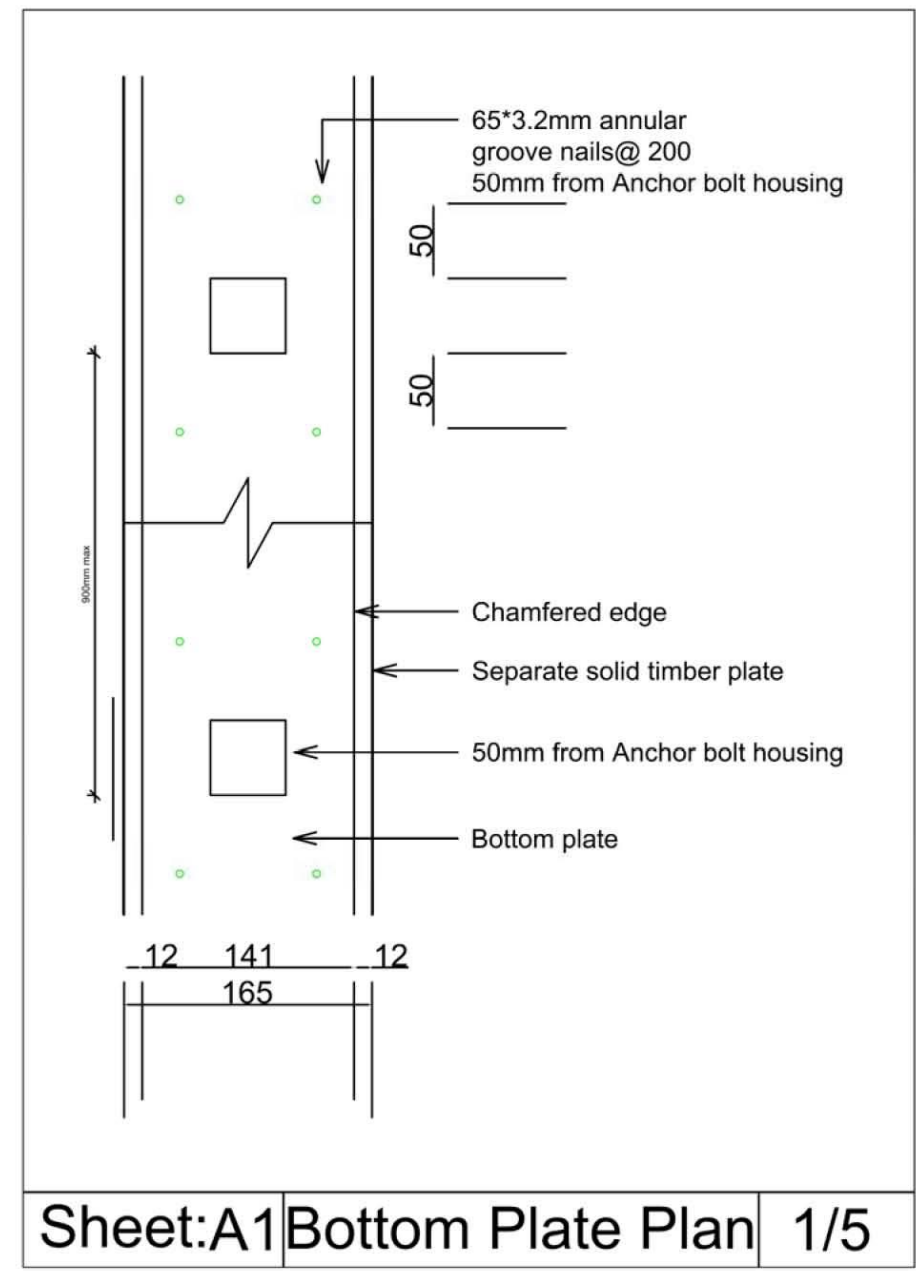




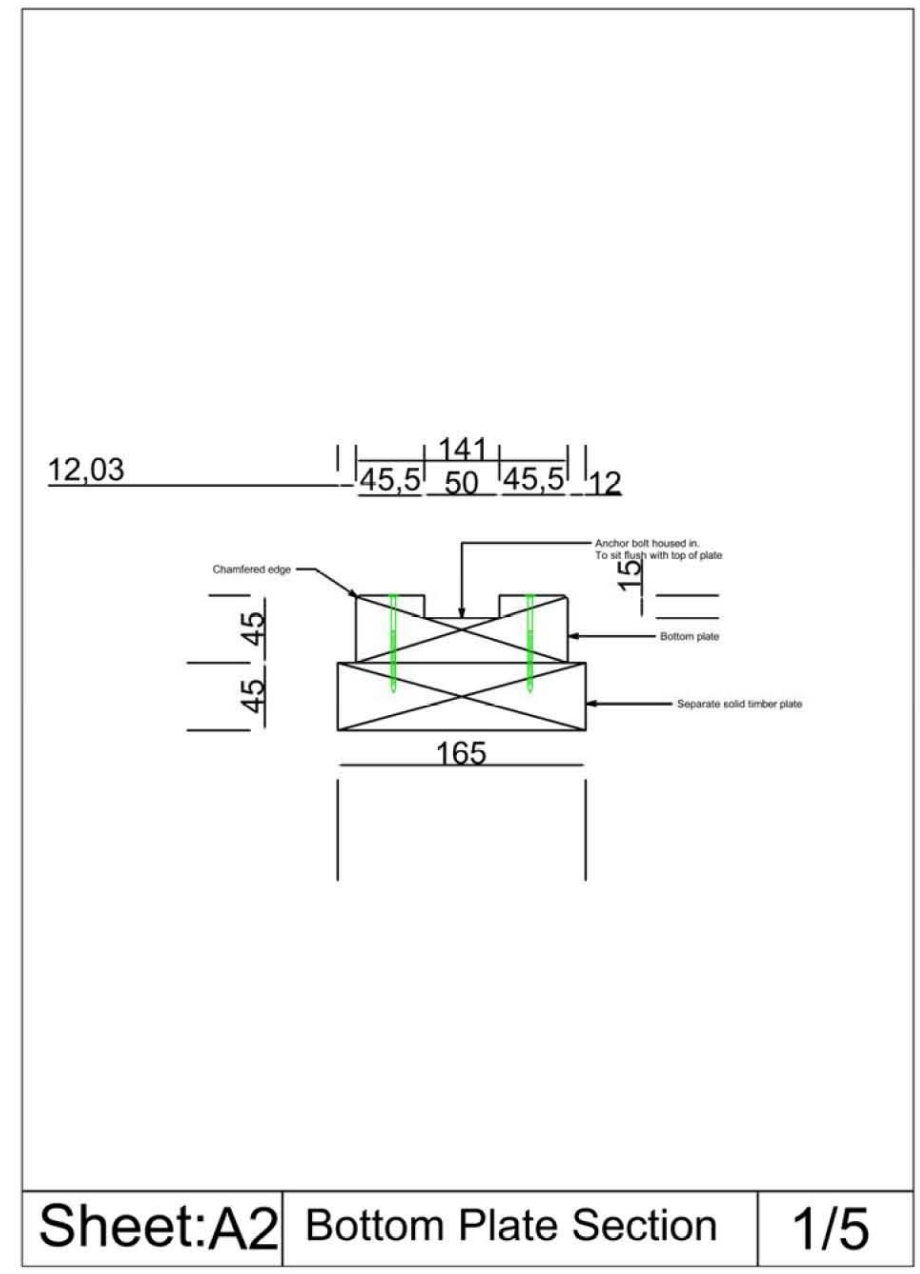




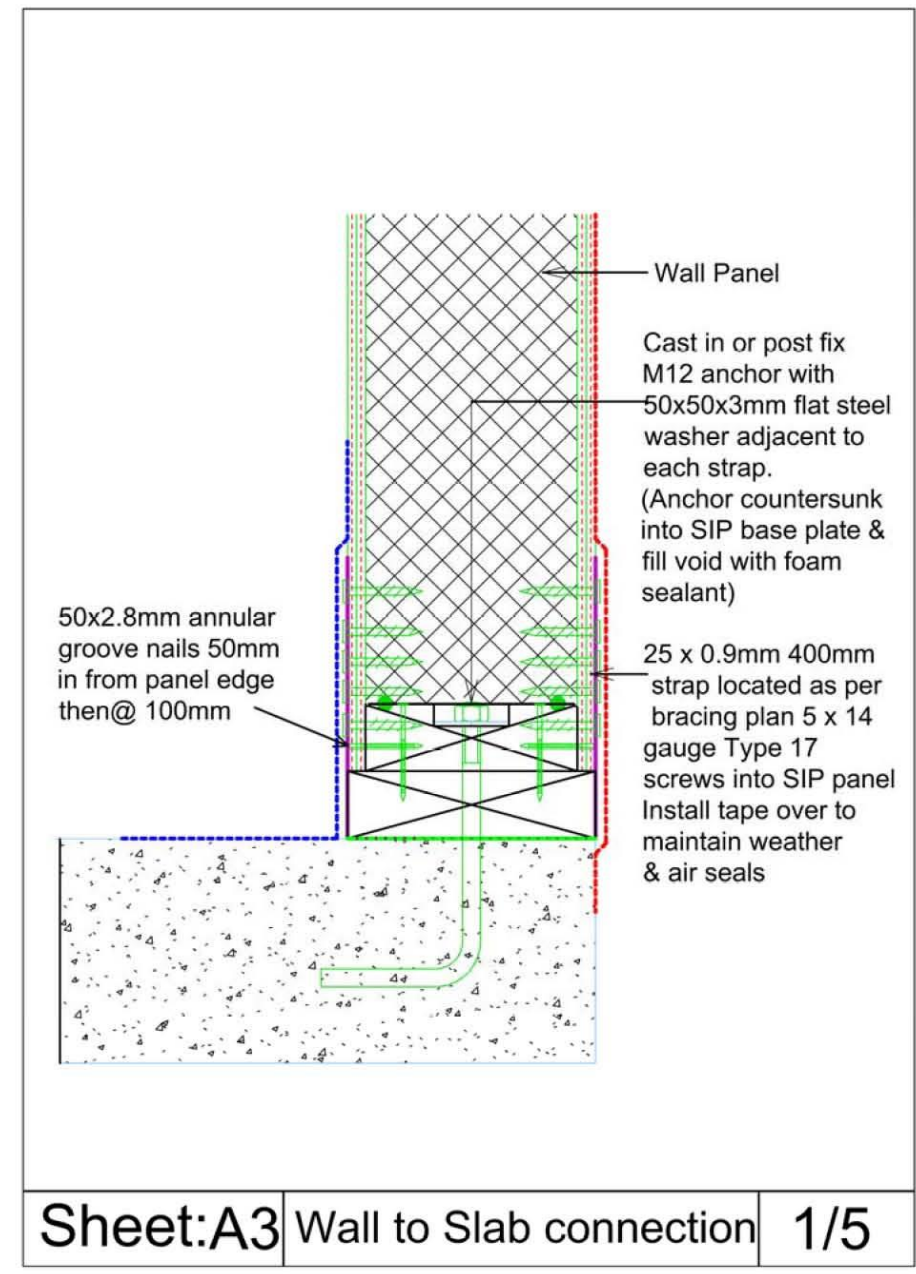




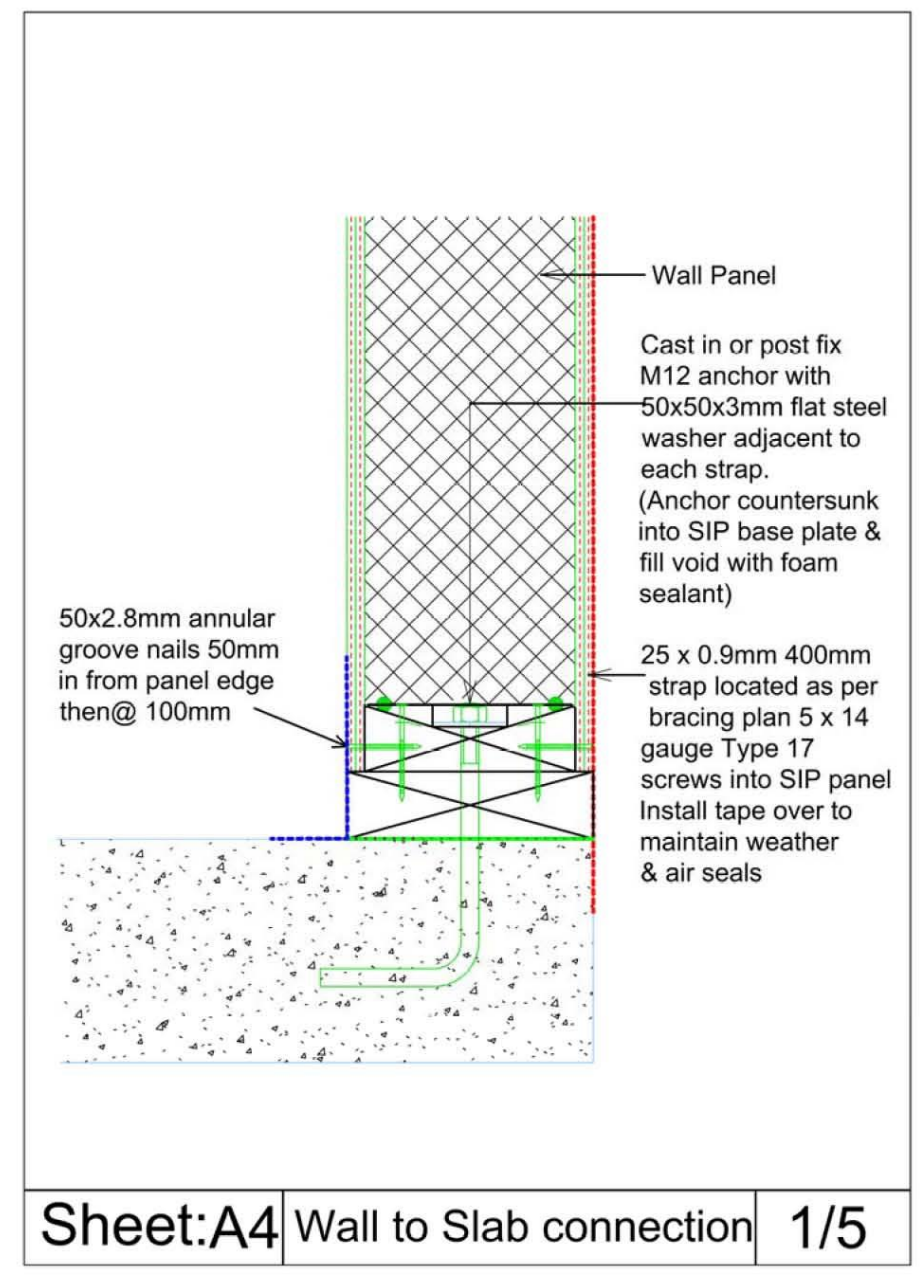




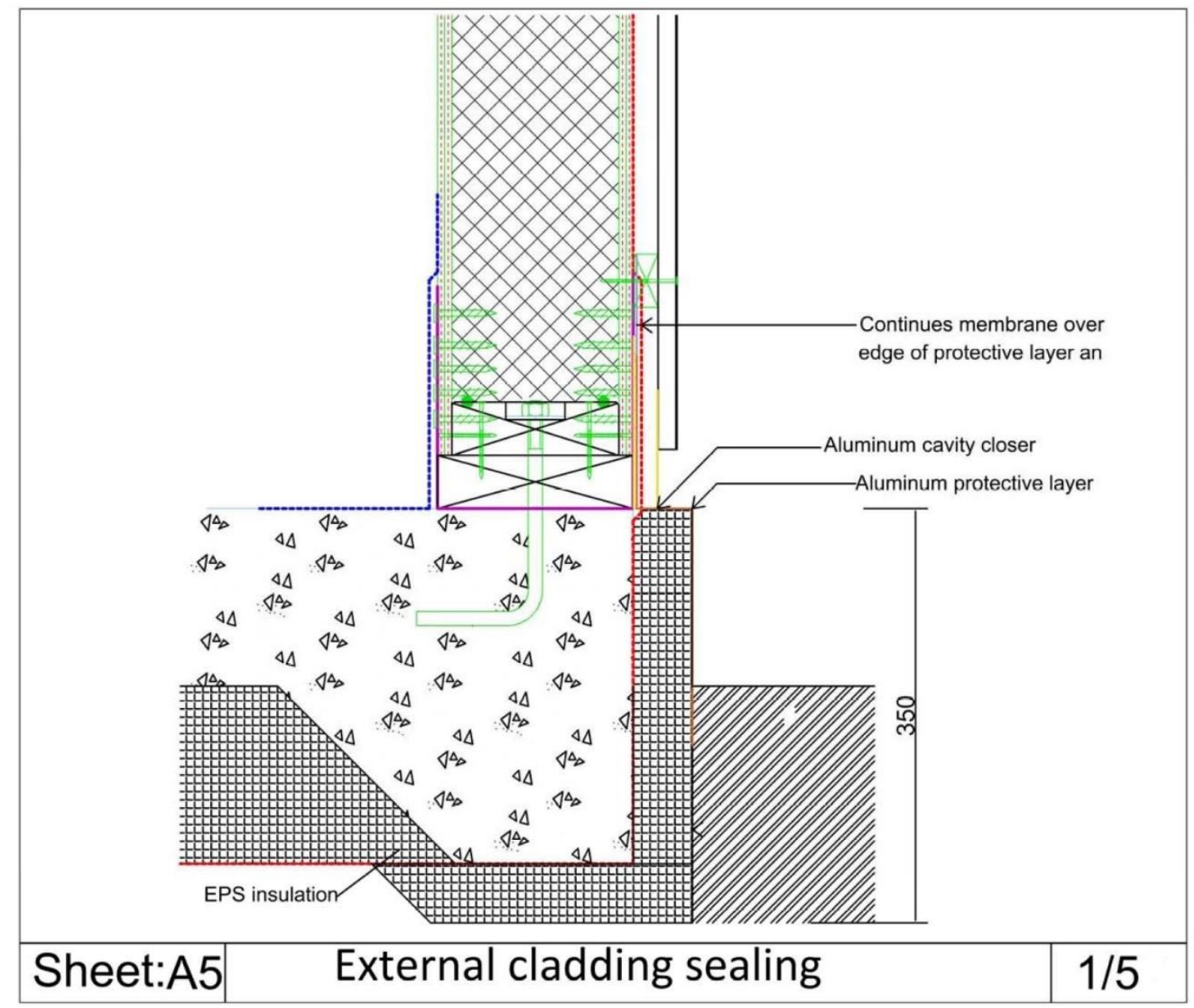




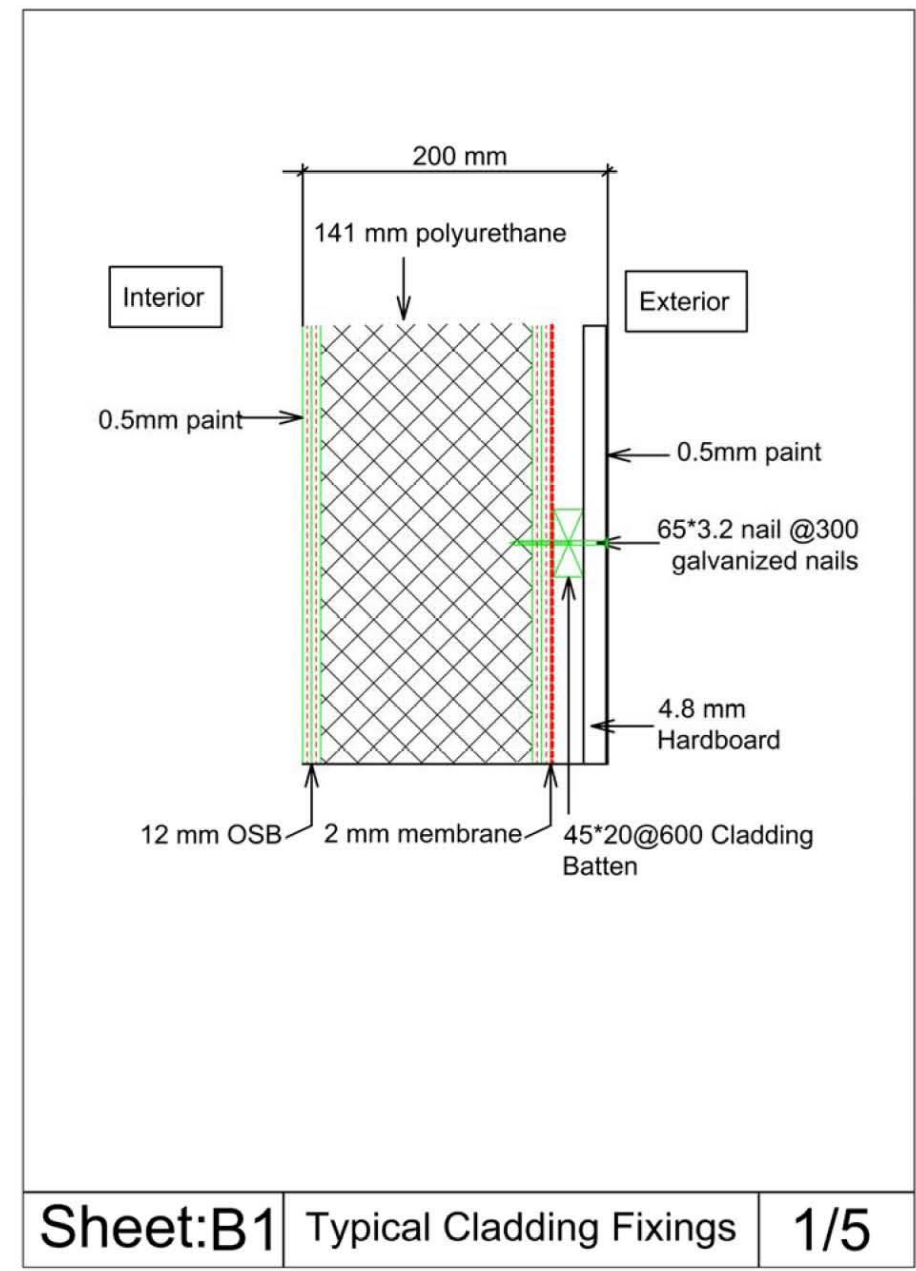




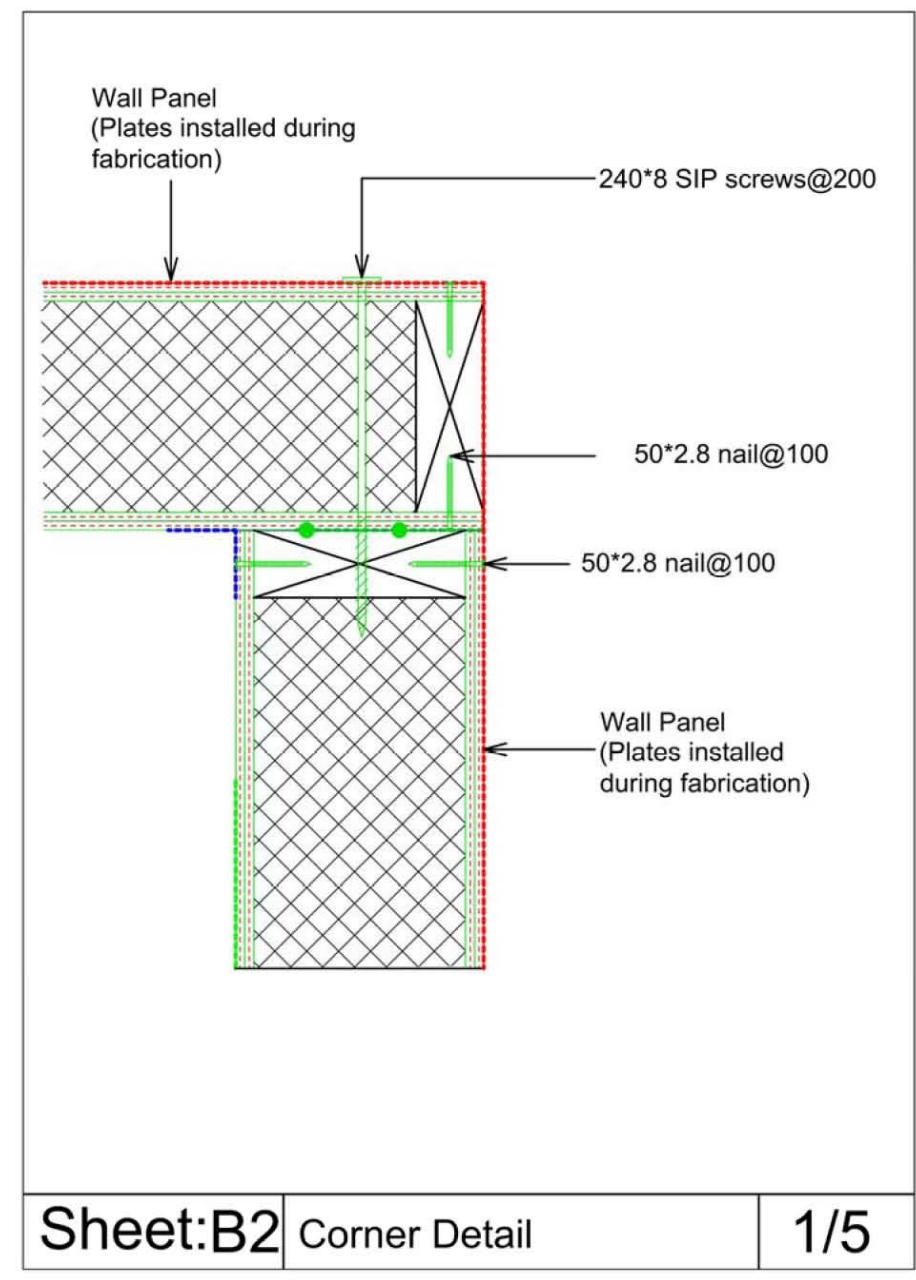




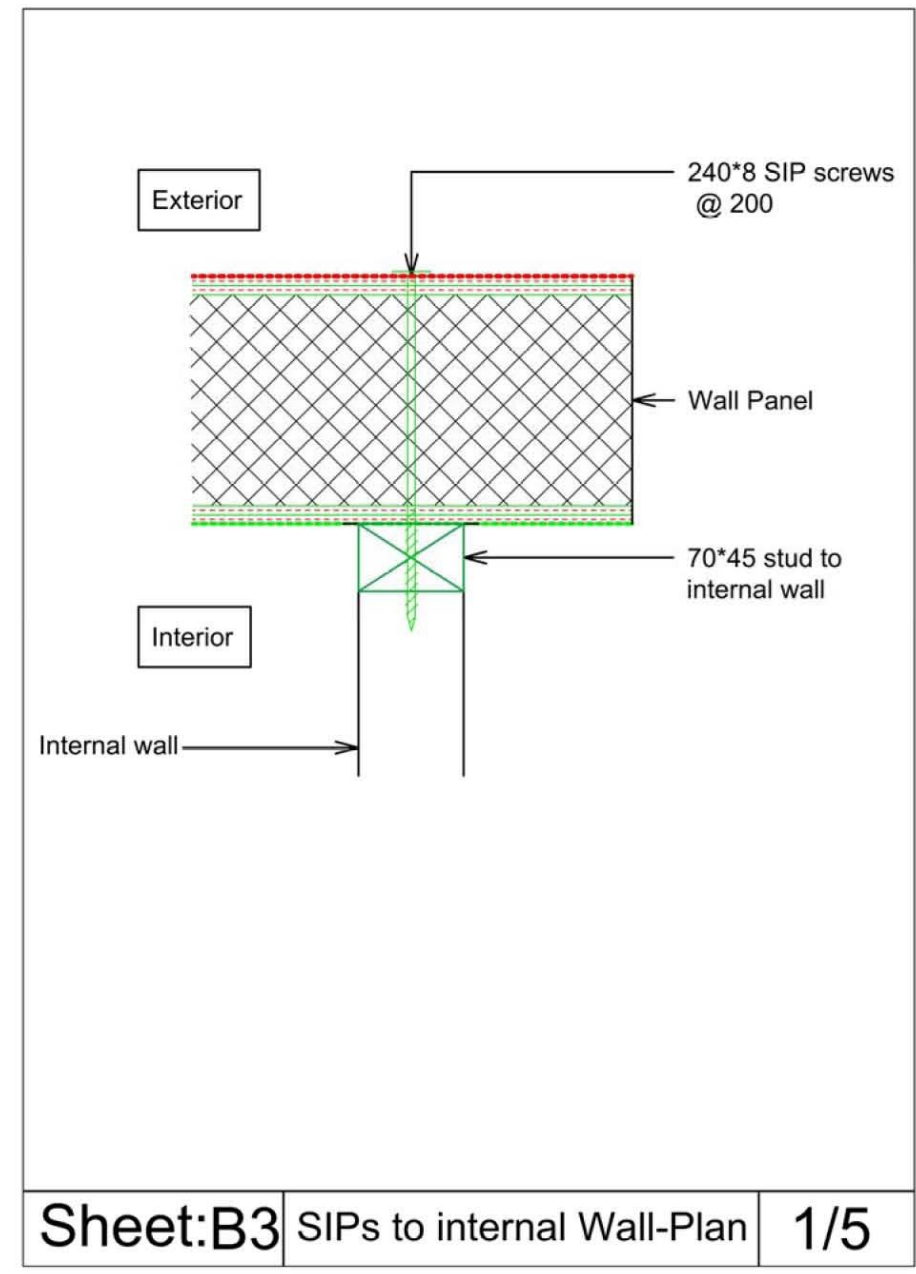




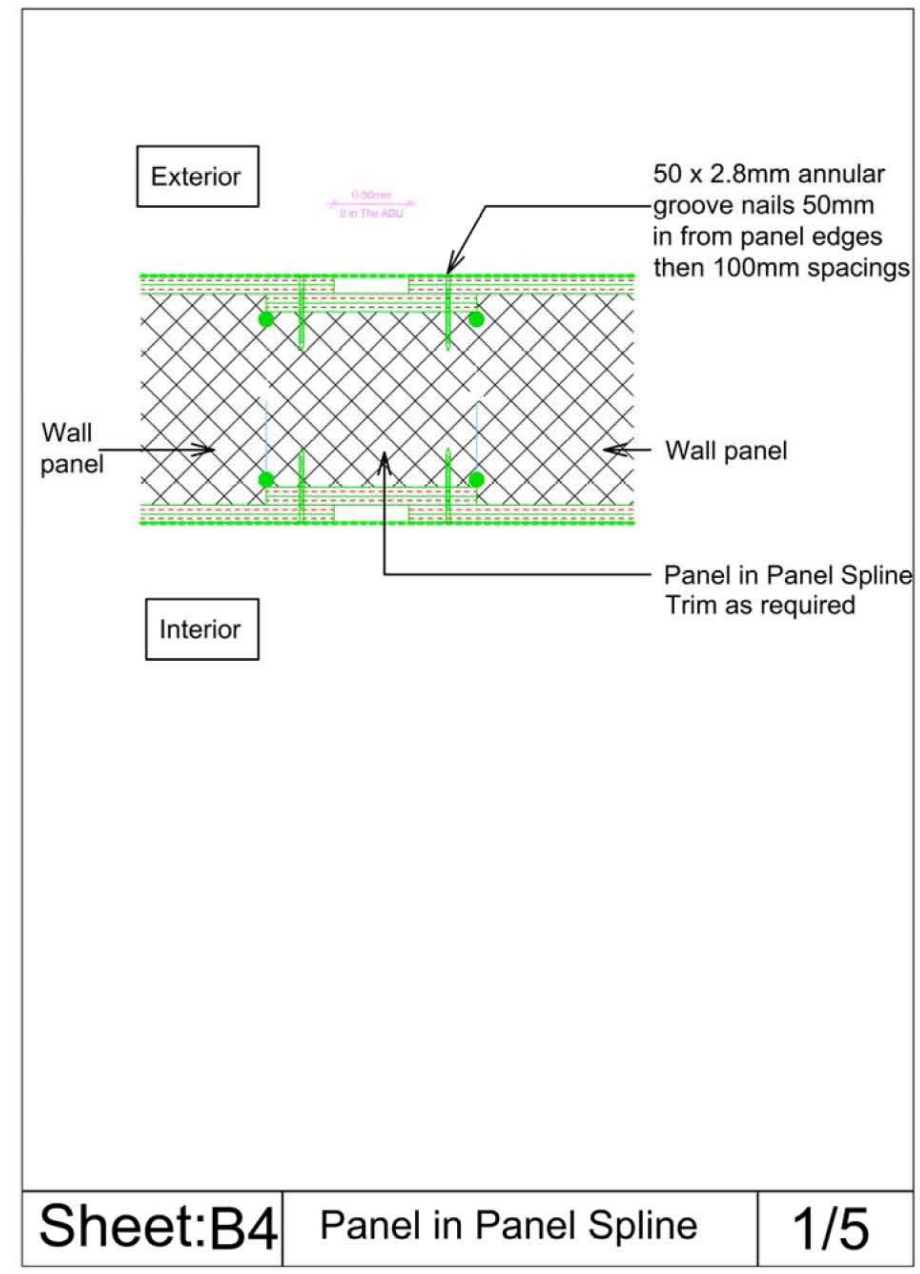




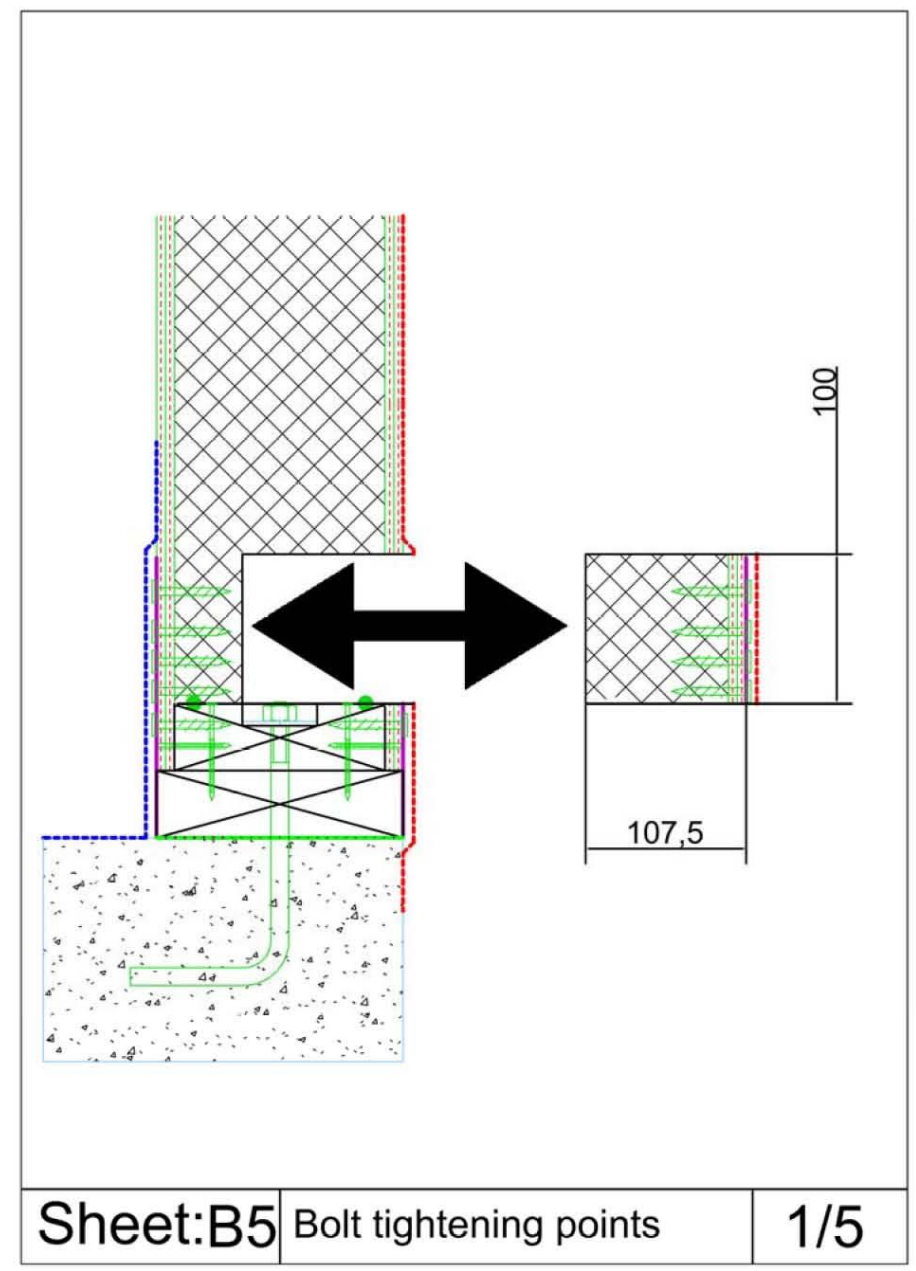




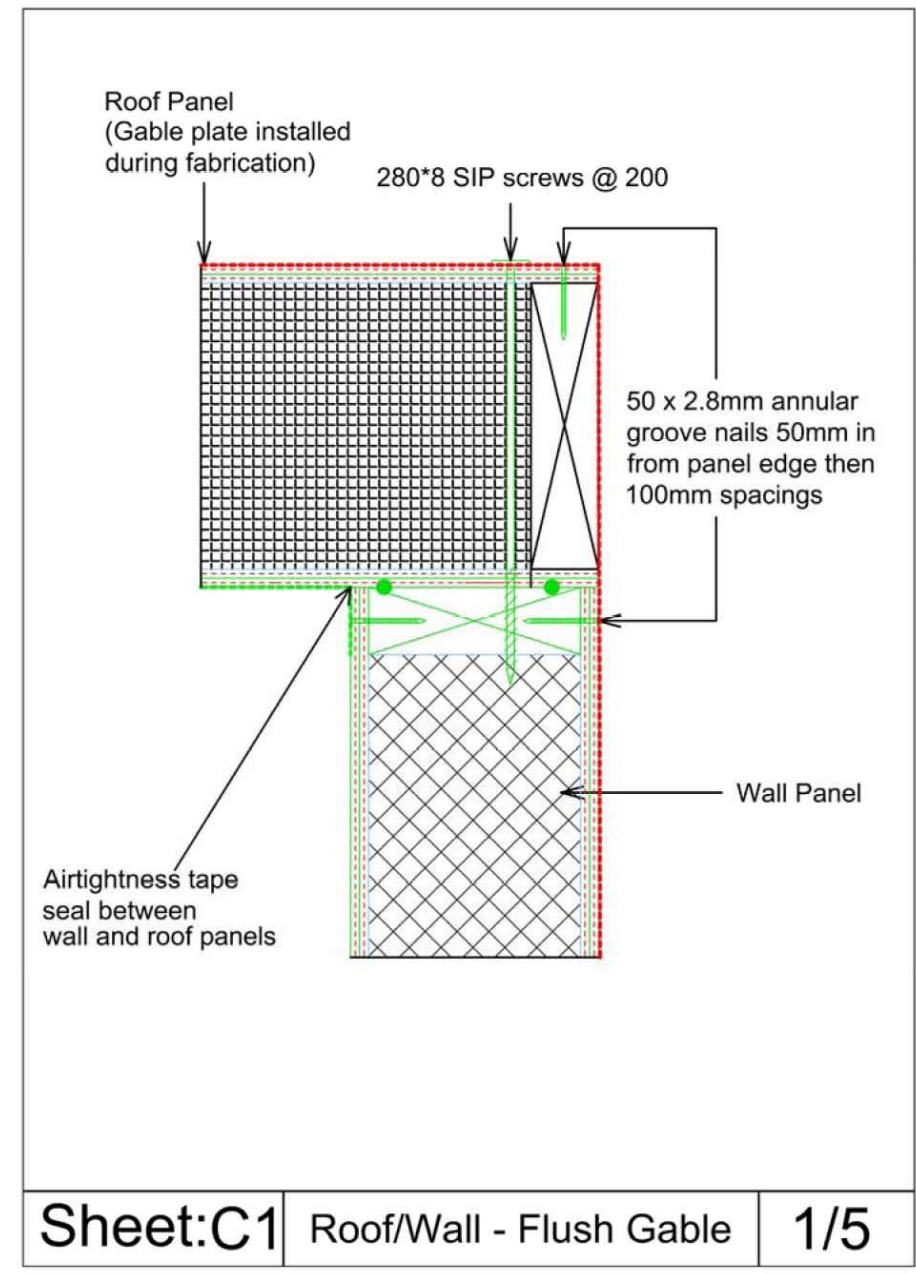




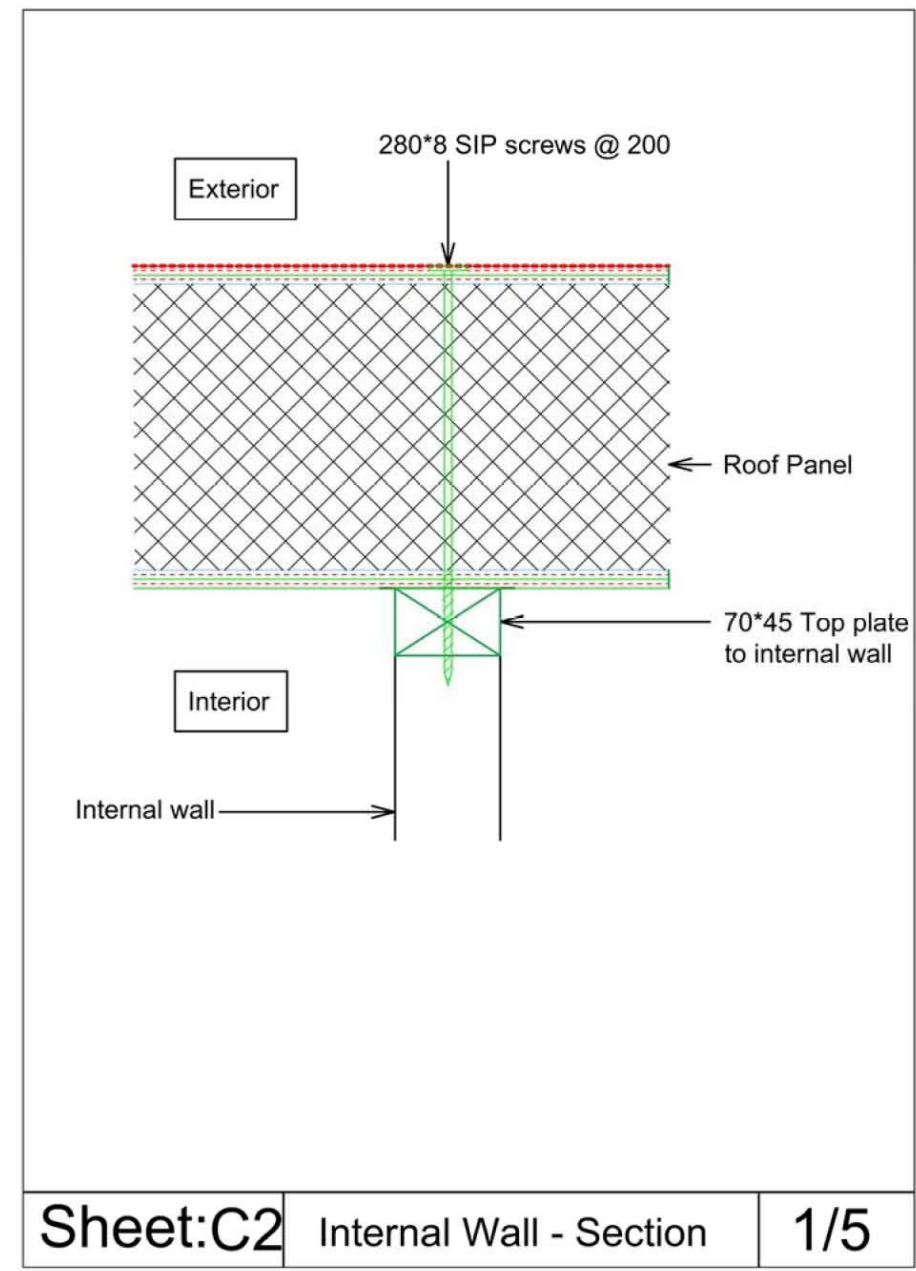




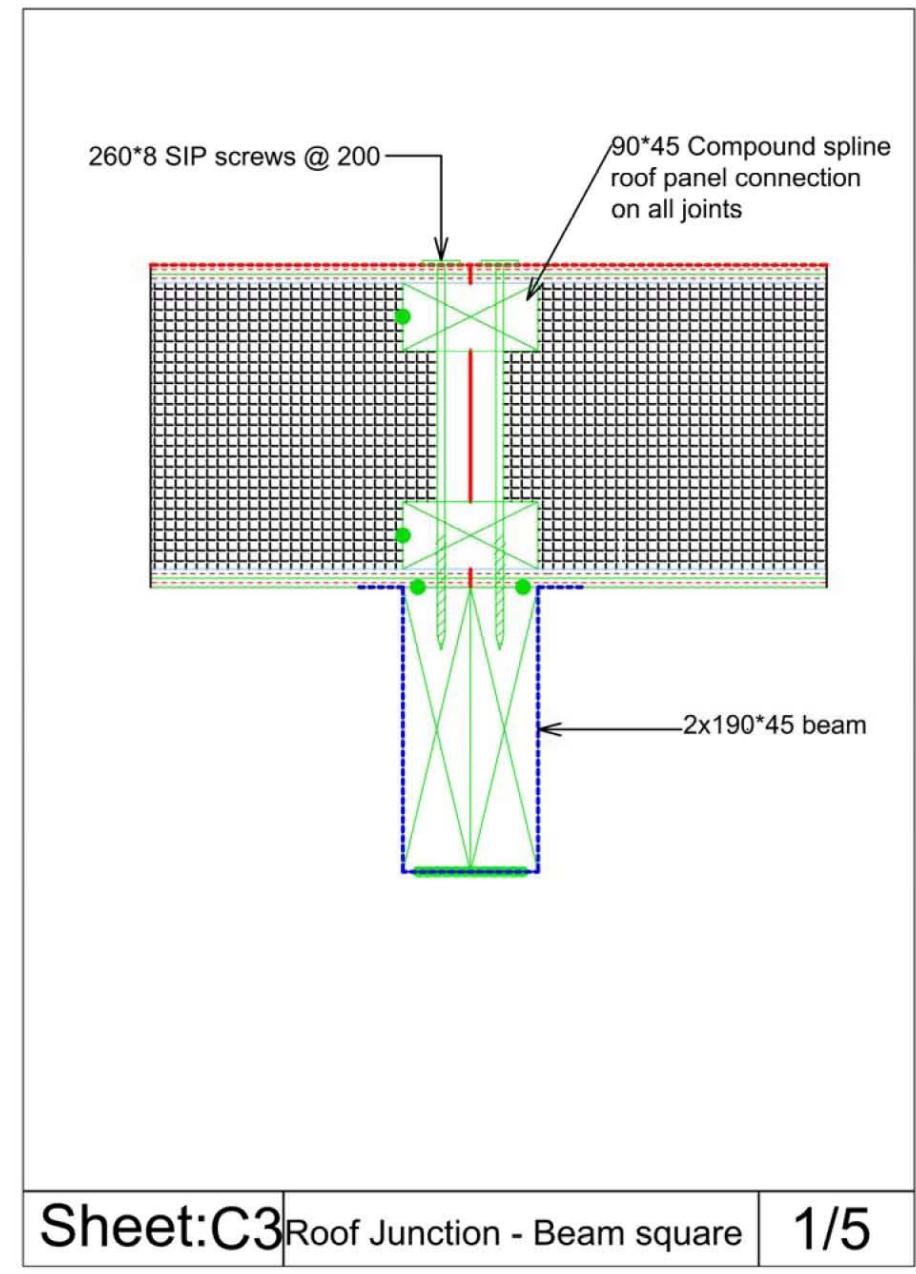




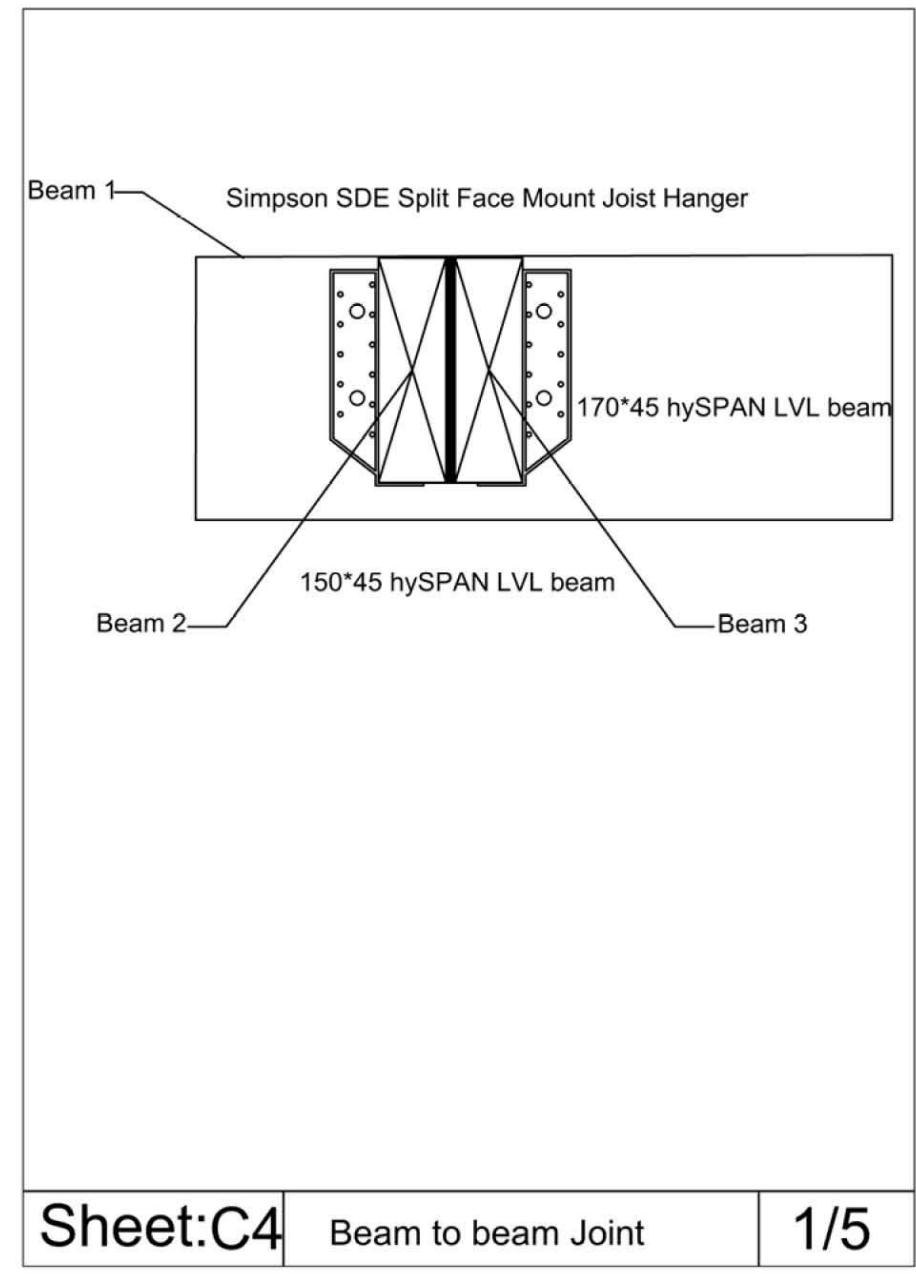




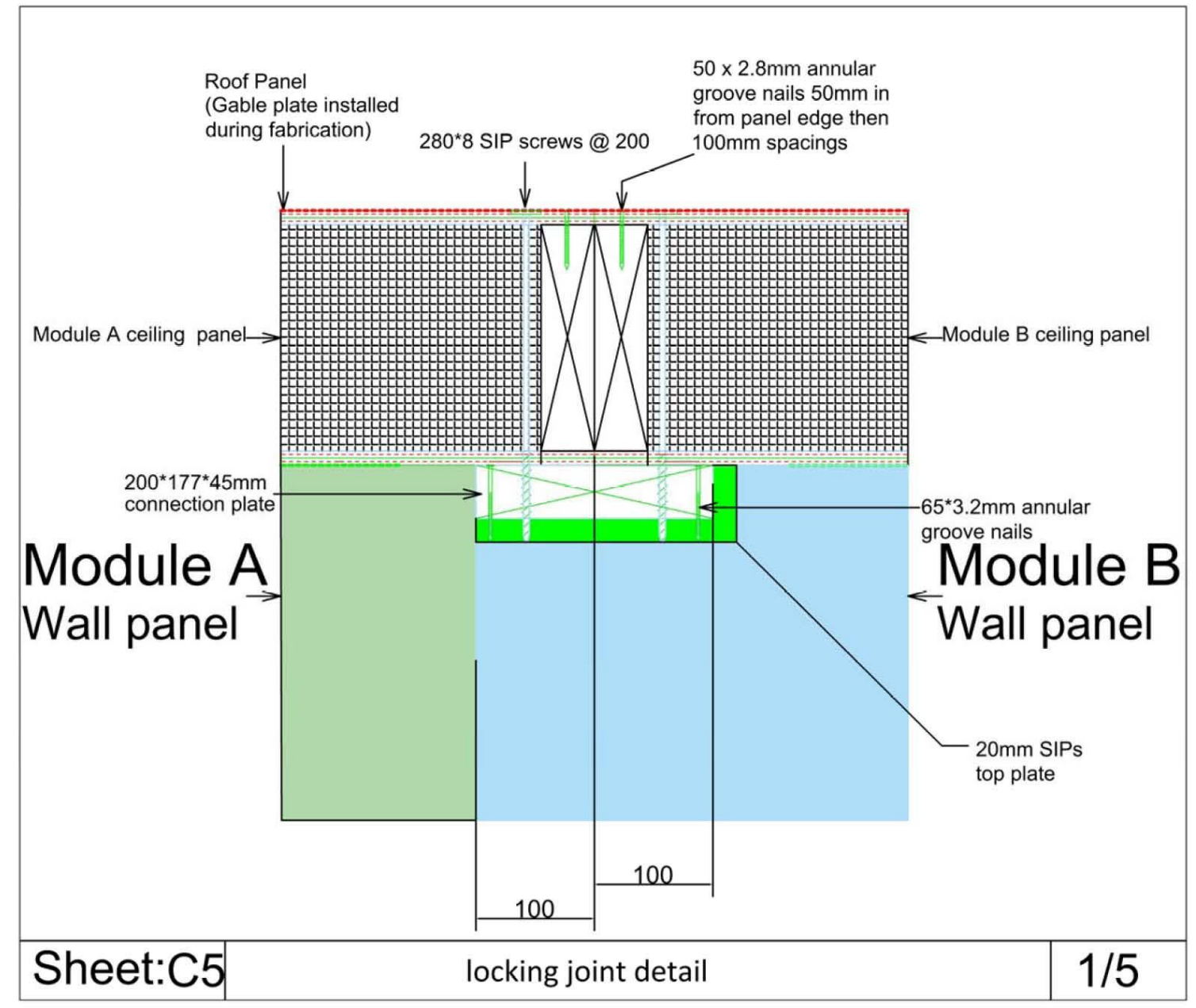




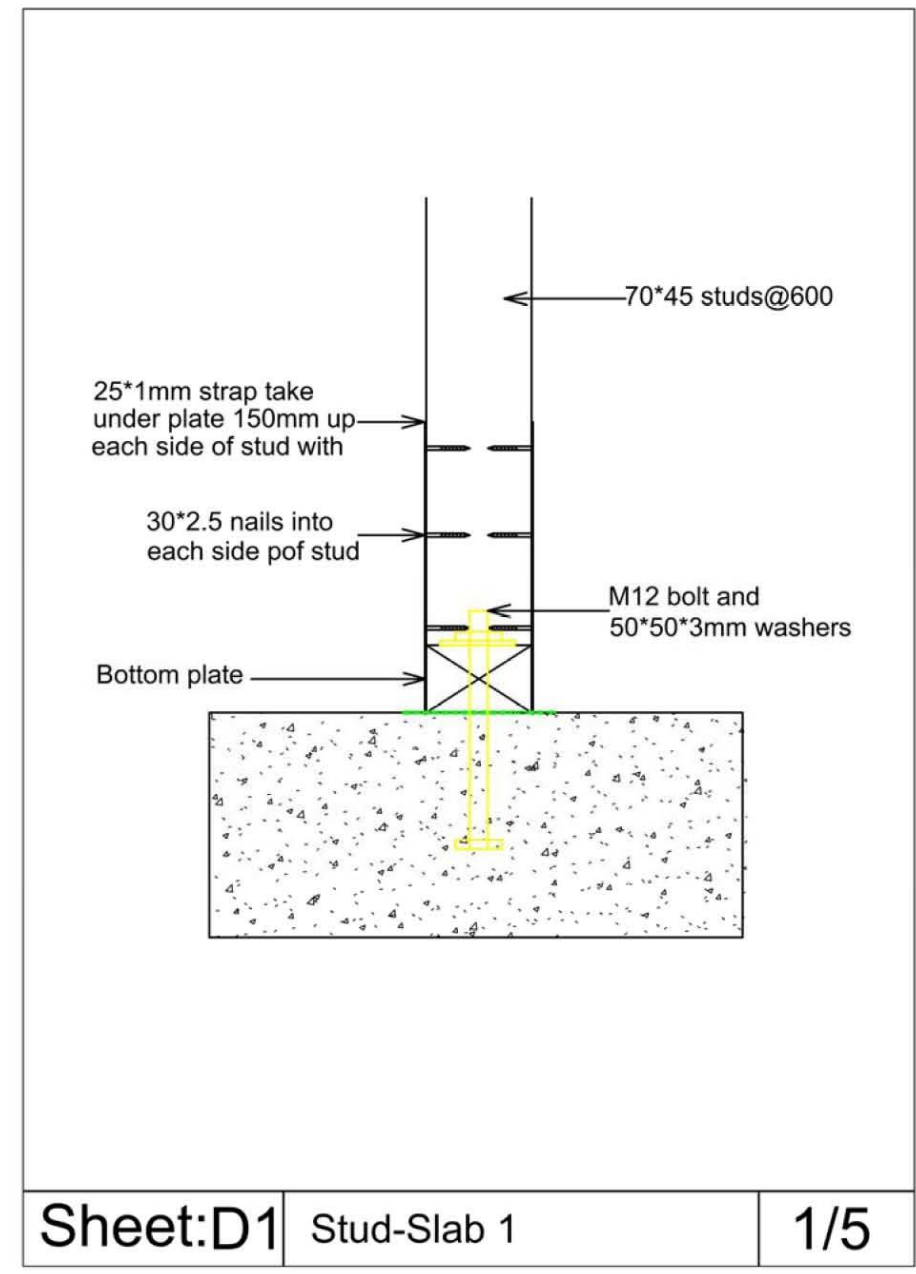




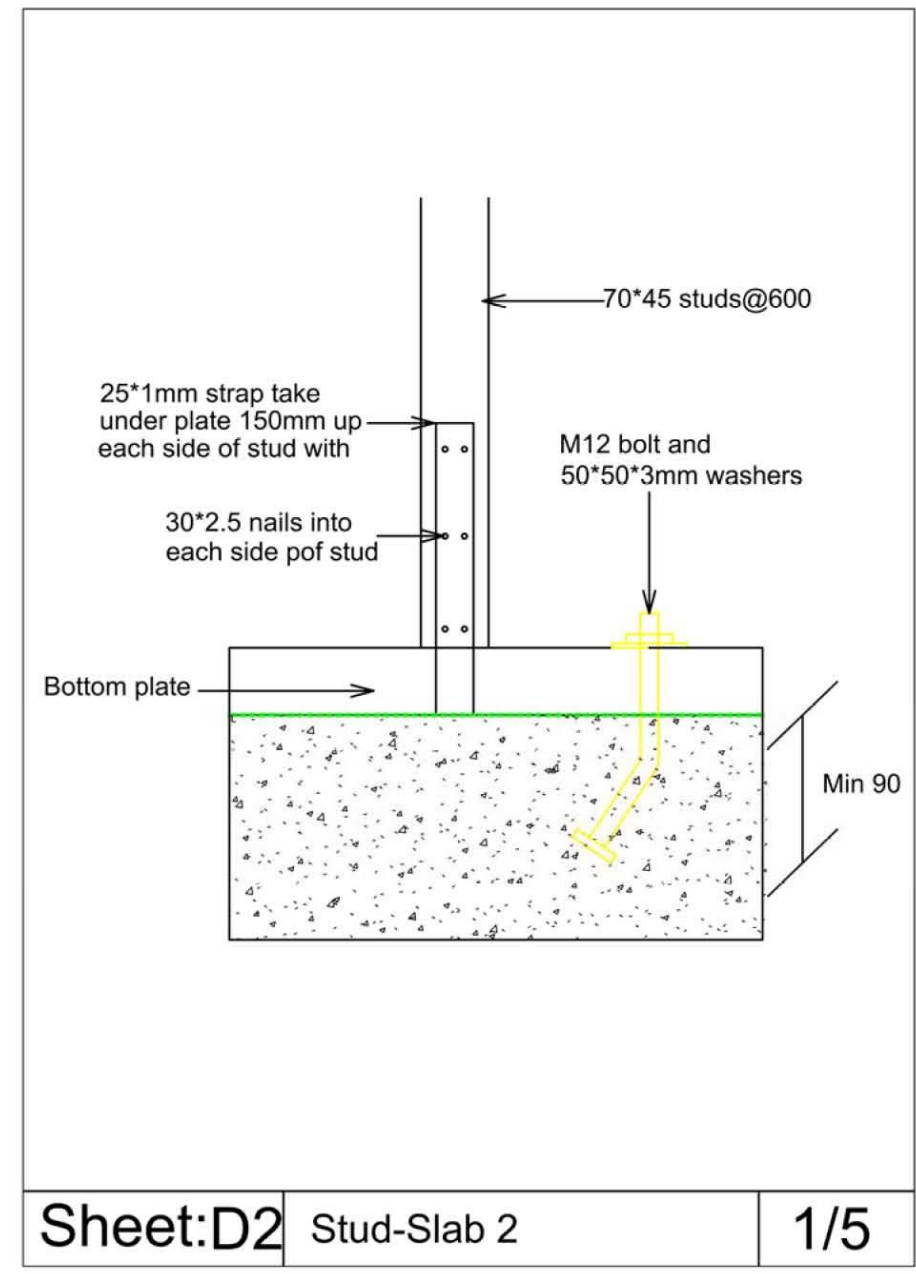




\section{Section}

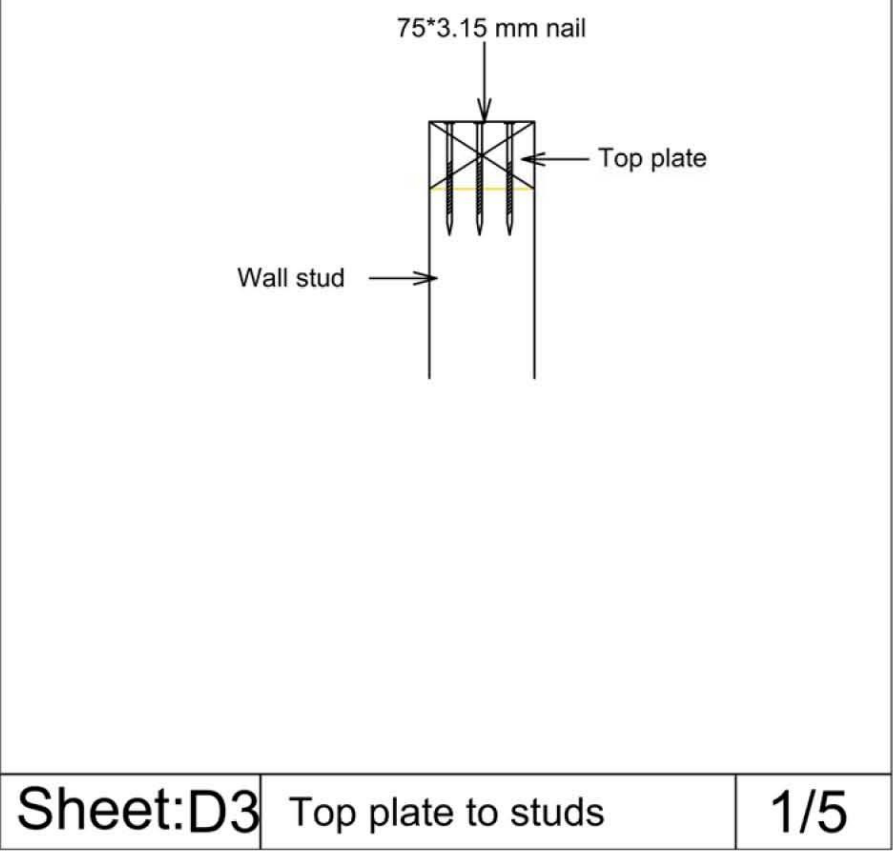




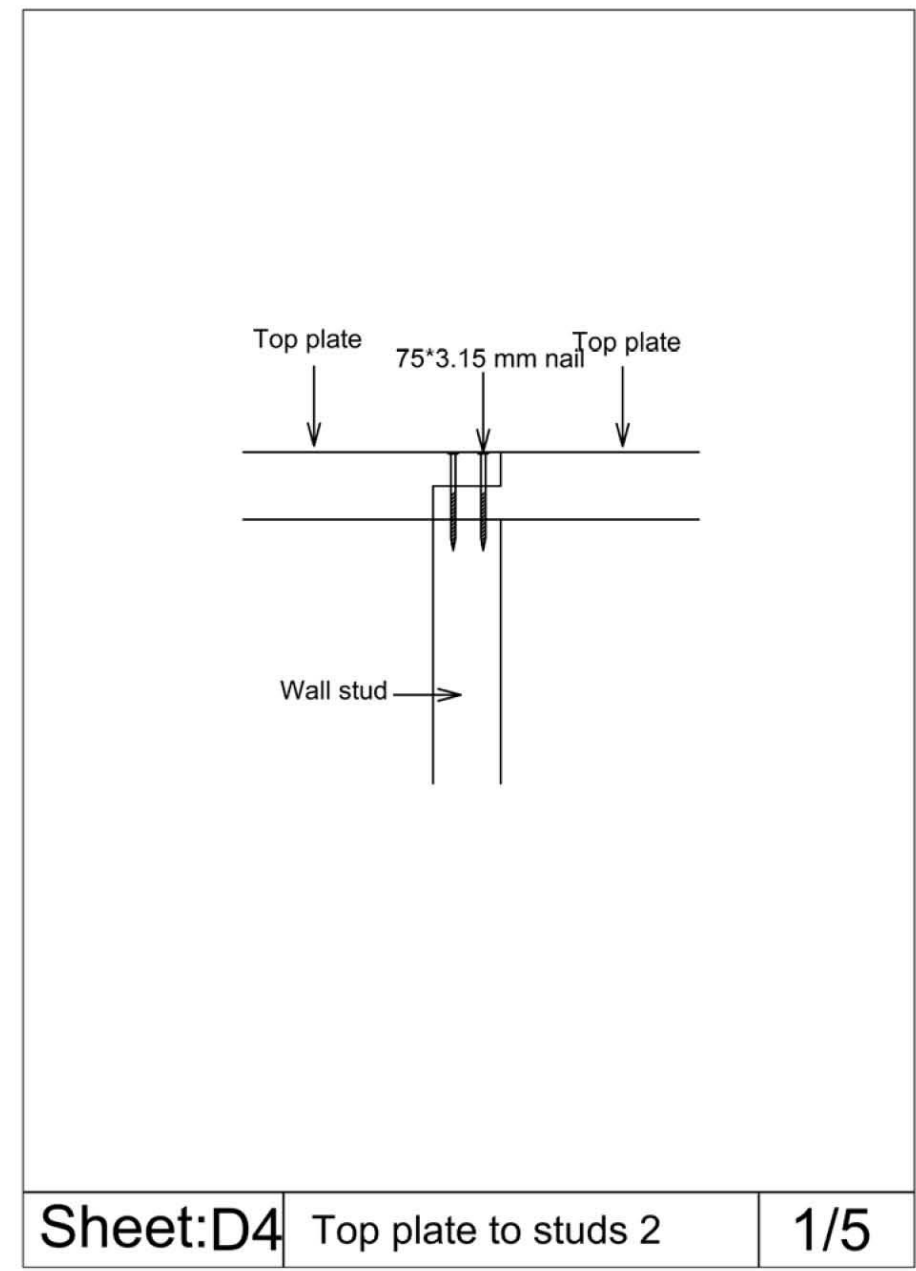




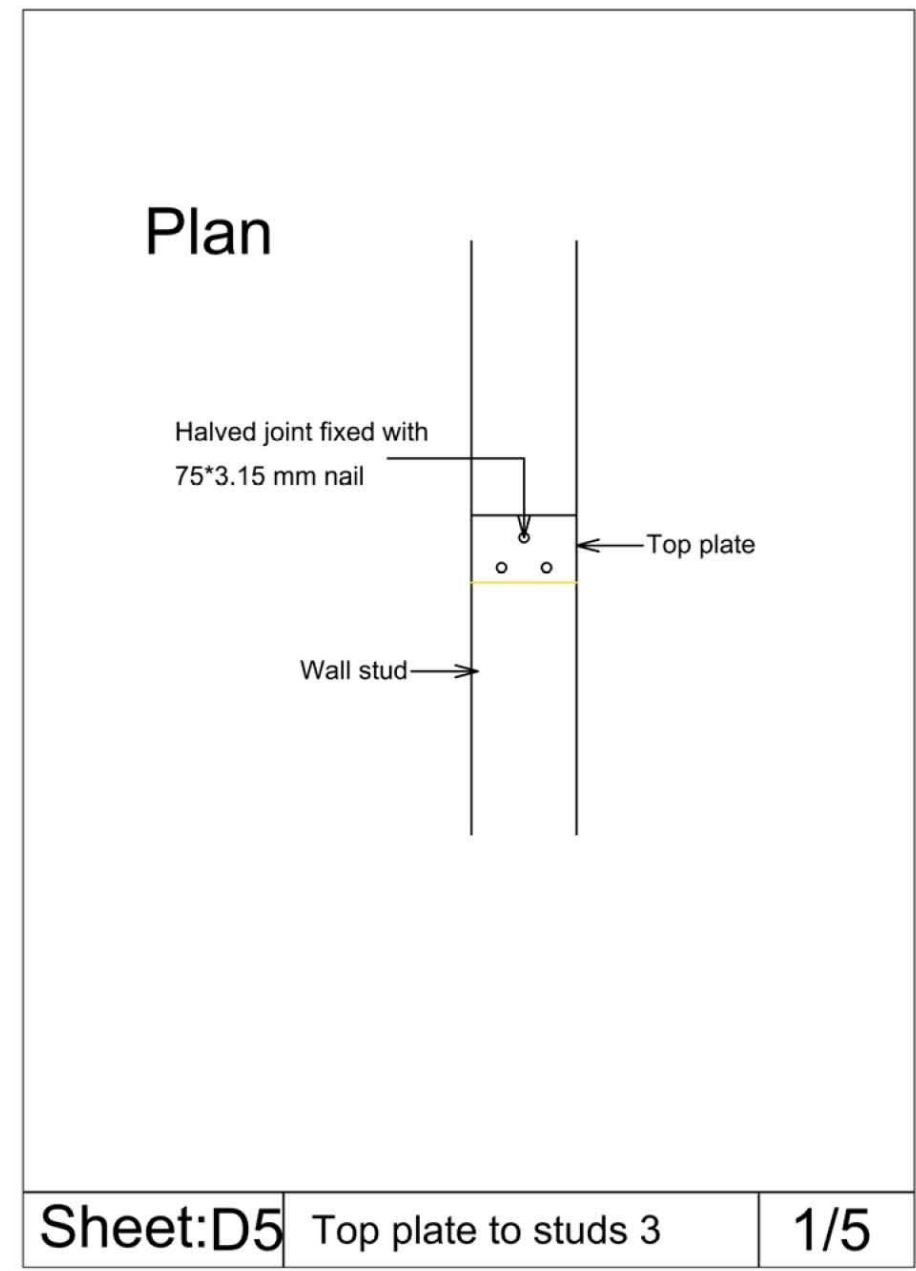




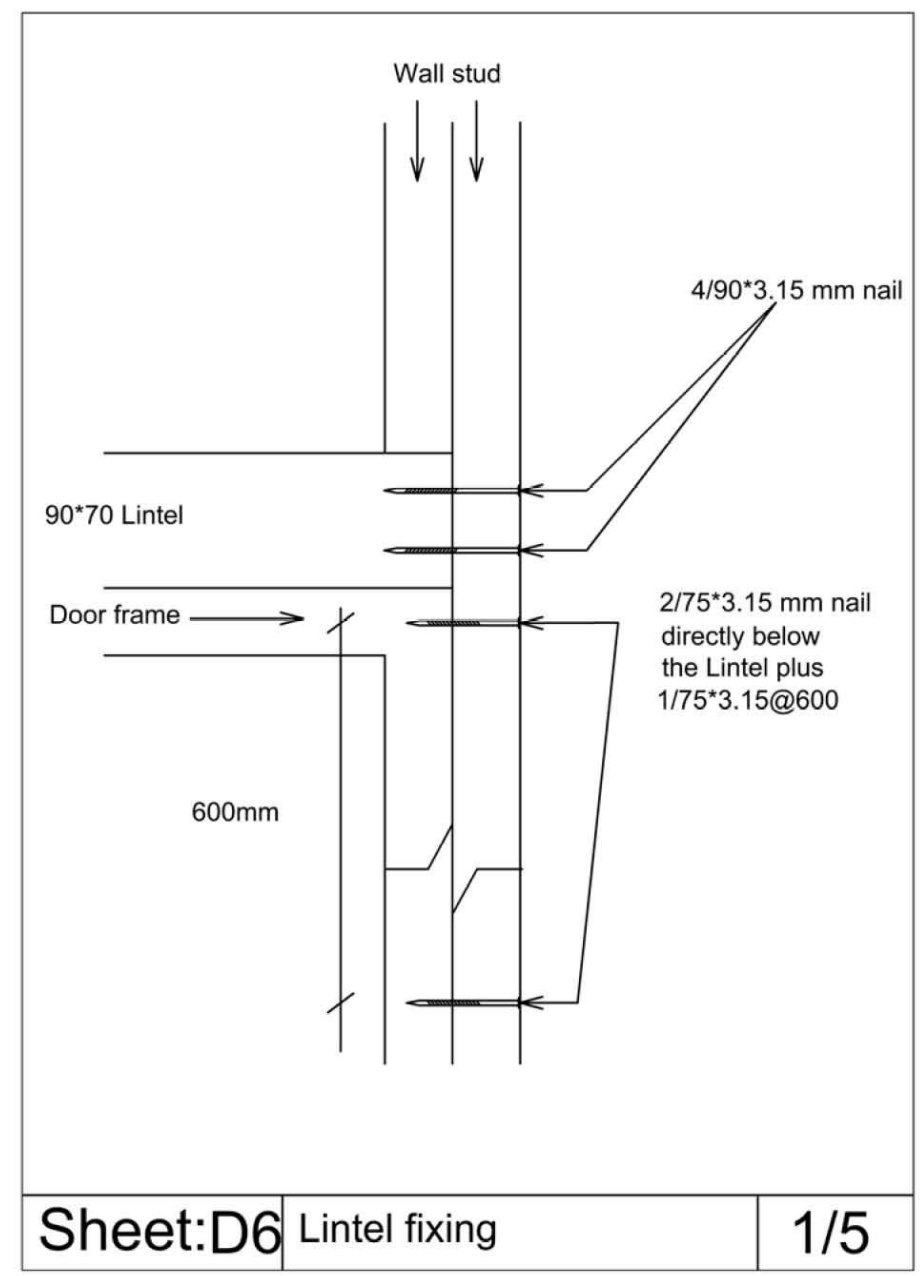




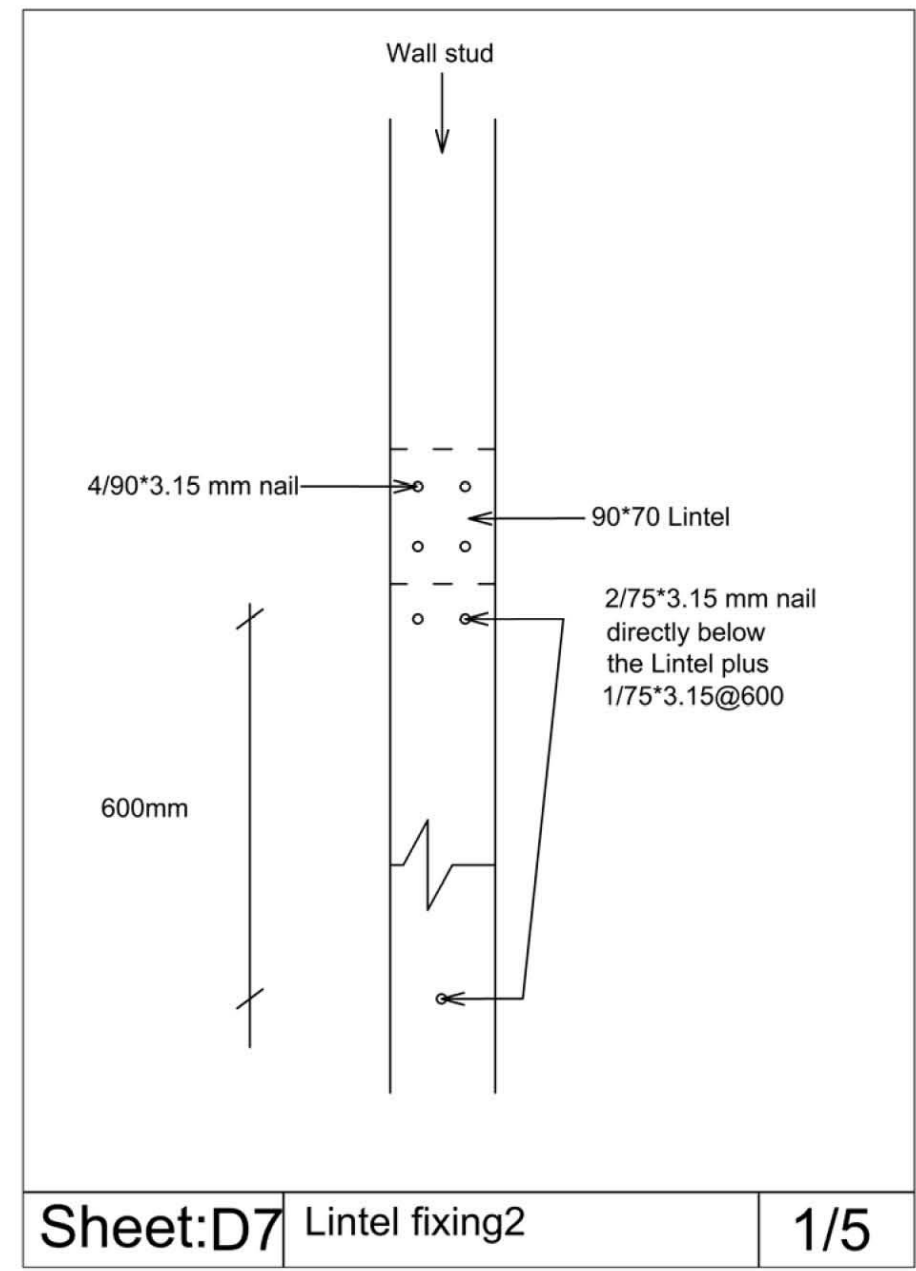




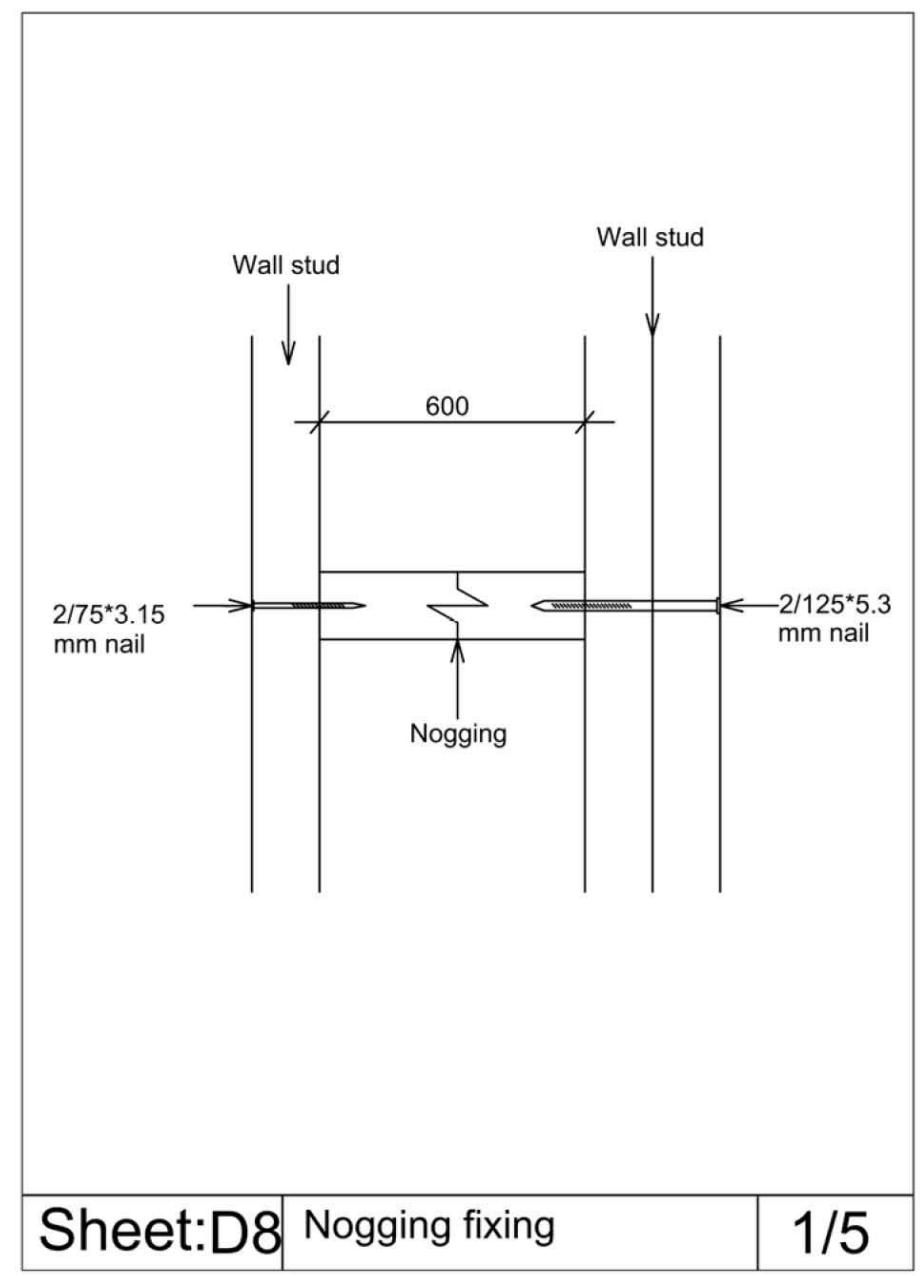




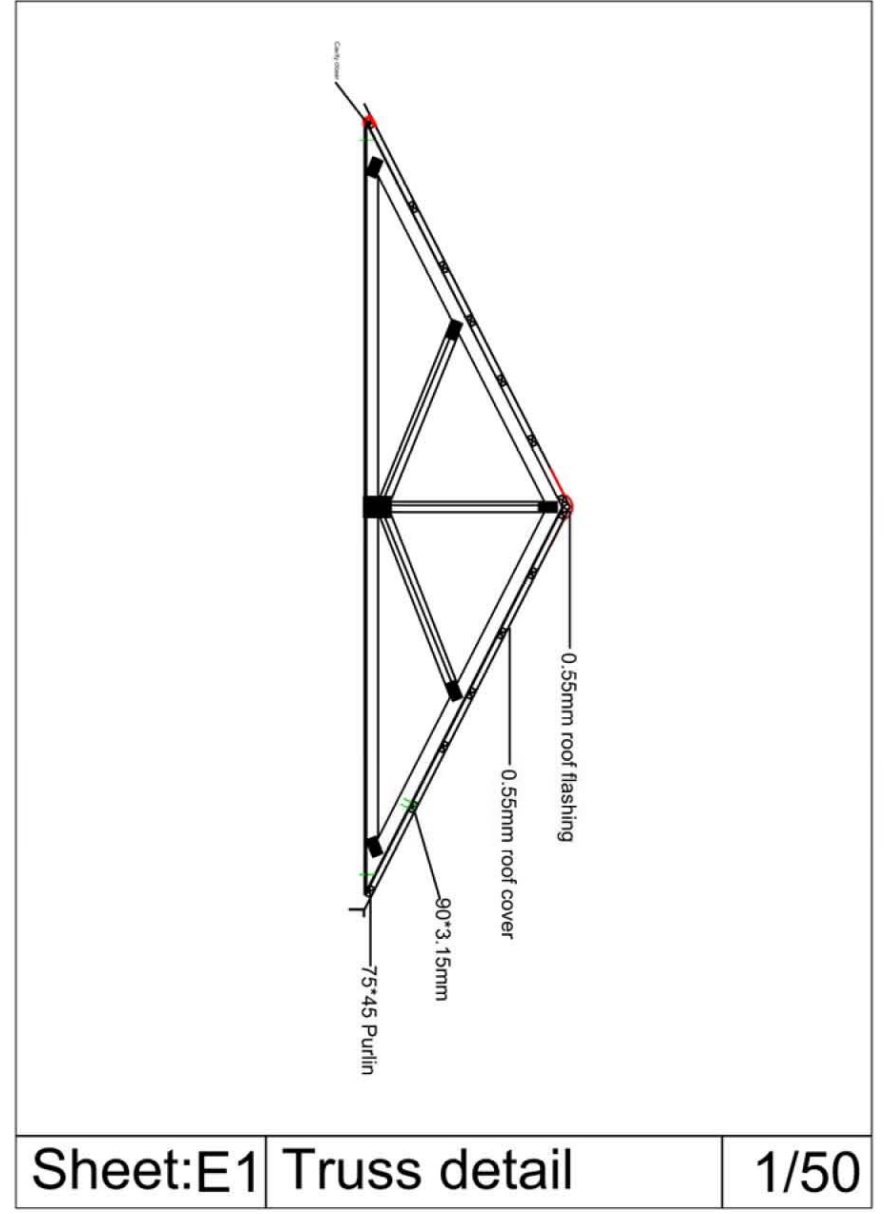




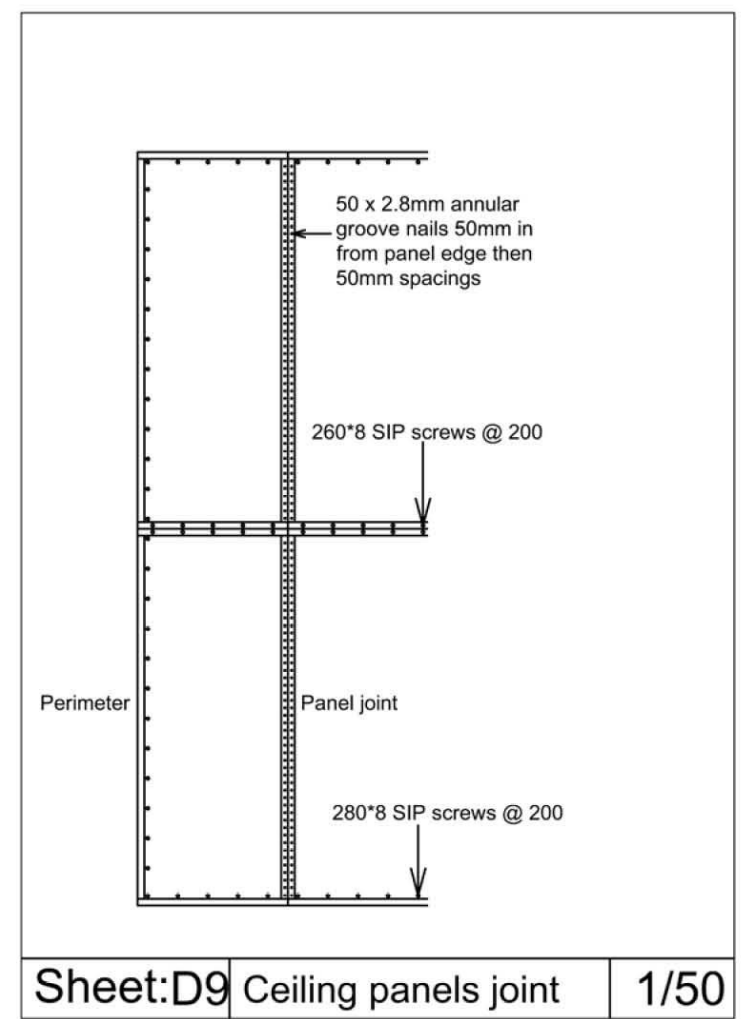


